NUREG/CR-6508

ORNL-6909

\title{
Component Unavailability Versus
}

\section{Inservice Test (IST)}

\section{Interval: Evaluations of}

Component Aging Effects With

\section{Applications to Check Valves}

Manuscript Completed: June 1997

Date Published: July 1997

Prepared by

W. E. Vesely*, A. B. Poole

Oak Ridge National Laboratory

Managed by Lockheed Martin Energy Research Corporation

Oak Ridge, TN 37831-8038

*Consultant

655 Metro Place South, Suite 745, Dublin, OH 43017

J. Jackson, NRC Project Manager

Prepared for

Division of Engineering Technology

Office of Nuclear Regulatory Research

U.S. Nuclear Regulatory Commission

Washington, DC 20555-0001

NRC Job Code W6324

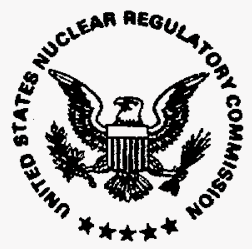



DISCLAIMER

Portions of this document may be illegible in electronic image products. Images are produced from the best available original document. 



\section{DISCLAIMER}

This report was prepared as an account of work sponsored by an agency of the United States Government. Neither the United States Government nor any agency thereof, nor any of their employees, make any warranty, express or implied, or assumes any legal liability or responsibility for the accuracy, completeness, or usefulness of any information, apparatus, product, or process disclosed, or represents that its use would not infringe privately owned rights. Reference herein to any specific commercial product, process, or service by trade name, trademark, manufacturer, or otherwise does not necessarily constitute or imply its endorsement, recommendation, or favoring by the United States Government or any agency thereof. The views and opinions of authors expressed herein do not necessarily state or reflect those of the United States Government or any agency thereof. 



\begin{abstract}
Methods are presented for calculating component unavailabilities when Inservice Test (IST) intervals are changed and when component aging is explicitly included. The methods extend usual approaches for calculating unavailability and risk effects of changing IST intervals which utilize Probabilistic Risk Assessment (PRA) methods that do not explicitly include component aging. Different IST characteristics are handled including ISTs which are followed by corrective maintenances which completely renew or partially renew the component. ISTs which are not followed by maintenance activities needed to renew the component are also handled. Any downtime associated with the IST, including the test downtime and the following maintenance downtime, is included in the unavailability evaluations. A range of component aging behaviors is studied including both linear and nonlinear aging behaviors. Based upon evaluations completed to date, pooled failure data on check valves show relatively small aging (e.g., less than $7 \%$ per year). However, data from some plant systems could be evidence for larger aging rates occurring in time periods less than 5 years. The methods are utilized in this report to carry out a range of sensitivity evaluations to evaluate aging effects for different possible applications. Based on the sensitivity evaluations, summary tables are constructed showing how optimal IST interval ranges for check valves can vary relative to different aging behaviors which might exist. The evaluations are also used to identify IST intervals for check valves which are robust to component aging effects. General insights on aging effects are also extracted. These sensitivity studies and extracted results provide useful information which can be supplemented or be updated with plant specific information. The models and results can also be input to PRAs to determine associated risk implications.
\end{abstract}





\section{Contents}

Abstract

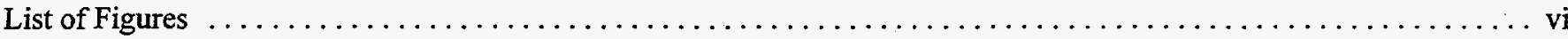

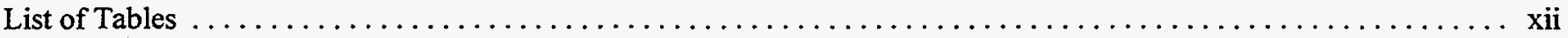

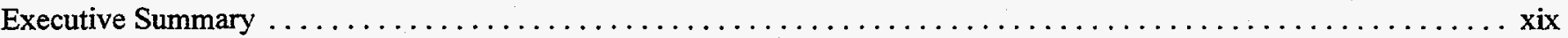

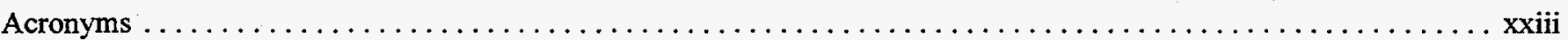

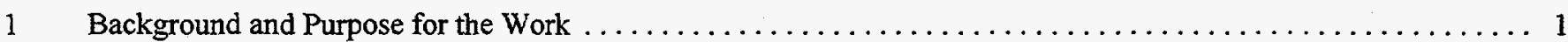

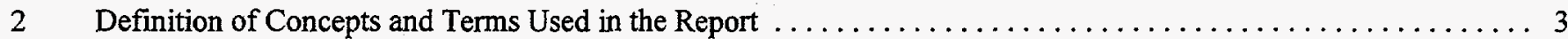

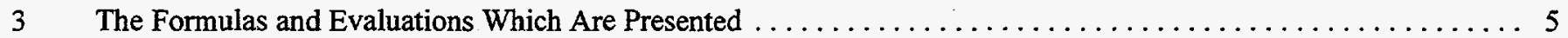

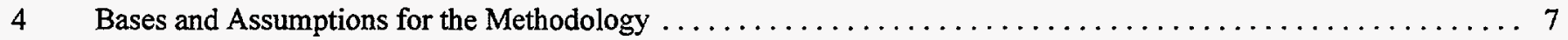

$5 \quad$ Guidelines for Using the Results of the Report $\ldots \ldots \ldots \ldots \ldots \ldots \ldots \ldots \ldots \ldots \ldots \ldots \ldots \ldots \ldots \ldots$

6 Identification of Responses to Questions Which Resulted From Reviews of the Report $\ldots \ldots \ldots \ldots \ldots \ldots$

$7 \quad$ Formulas for the Component Unavailability When Aging is Described by the Linear Aging Model $\ldots \ldots \ldots \ldots$

7.1 Formulas When the Component is in a Renewed State After the IST With Follow-up

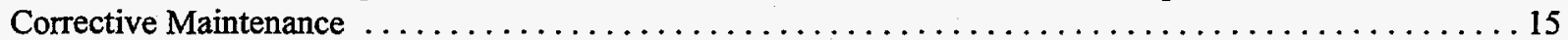

7.2 Formulas When the Component is Not Renewed as a Result of the IST $\ldots \ldots \ldots \ldots \ldots \ldots \ldots \ldots \ldots$

7.3 Formulas When the Component is in a Partially Renewed State After the IST With

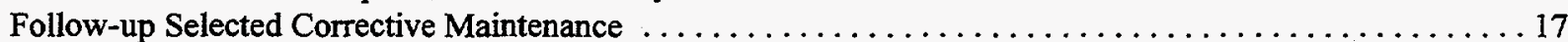

8 Formulas for the Component Unavailability When Aging is Described by the Nonlinear Weibull

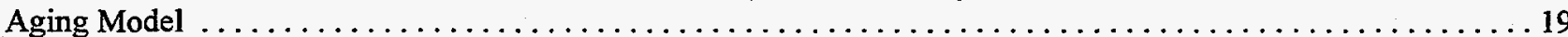

8.1 Formulas When the Component is in a Renewed State After the IST With Follow-up

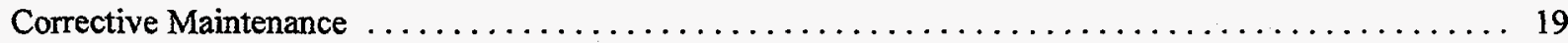

8.2 Formula When the Component is Not Renewed as a Result of the IST $\ldots \ldots \ldots \ldots \ldots \ldots \ldots \ldots \ldots \ldots$

8.3 Formula When the Component is in a Partially Renewed State After the IST With

Follow-up Selected Corrective Maintenance $\ldots \ldots \ldots \ldots \ldots \ldots \ldots \ldots \ldots \ldots \ldots \ldots \ldots \ldots \ldots \ldots \ldots \ldots \ldots \ldots$

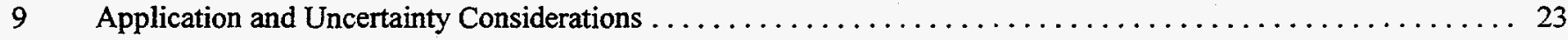

10 Evaluations of Component Unavailability Versus IST Interval for Check Valves With Linear Aging ....... 25

11 Evaluations of Component Unavailability Versus IST Interval for Check Valves with Nonlinear Aging $\ldots \ldots \ldots 65$

12 Conclusions from the Check Valve Sensitivity Studies on Optimal IST Interval Regions and Effects

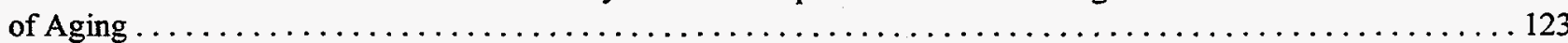

12.1 Conclusions on IST Intervals When the IST is Followed by Total Renewal $\ldots \ldots \ldots \ldots \ldots \ldots \ldots \ldots \ldots$

12.2 Conclusions on IST Intervals When the IST Has No Follow-up Renewal $\ldots \ldots \ldots \ldots \ldots \ldots \ldots \ldots \ldots \ldots$

12.3 Conclusions on the IST Intervals When the IST is Followed by Partial Renewal $\ldots \ldots \ldots \ldots \ldots \ldots \ldots$ 


\section{Contents (continued)}

References

Appendix A: DERIVATION OF THE COMPONENT UNAVAILABILITY FORMULAS

Appendix B:

EVALUATIONS OF COMPONENT UNAVAILABILITY VERSUS IST INTERVAL FOR CHECK VALVES WITH LINEAR AGING: ASSOCIATED TABLES

Appendix C:

EVALUATIONS OF COMPONENT UNAVAILABILITY VERSUS IST INTERVAL FOR CHECK VALVES WITH NONLINEAR AGING: ASSOCIATED TABLES

Appendix D: CHECK VALVE INSERVICE TEST REQUIREMENTS AND IMPLEMENTATION

RESULTS

Appendix E:

CHECK VALVE TYPES AND FAILURE RATES AND TRENDS FROM FAILURE

DATA

Appendix F

RESPONSES TO QUESTIONS FROM REVIEWS OF THE DRAFT VERSION OF THE REPORT

\section{List of Figures}

ES.1 Check Valve Unavailability Versus IST Interval For Different Valve Aging Rates: Total Renewal, No Intermediate operational testing, Baseline Failure Rate $\lambda_{0}=1 \times 10^{-7} \mathrm{hr}^{-1}$, Inservice Test Downtime

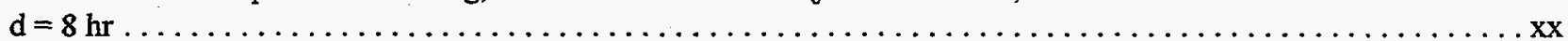

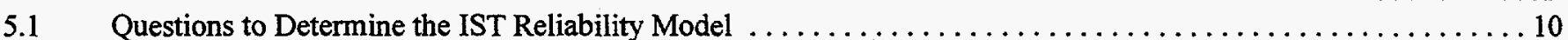

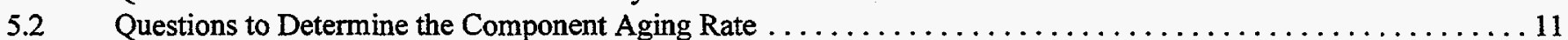

10.1 Check Valve Unavailability Versus IST Interval For Different Valve Aging Rates: Total Renewal, No Intermediate Operational Testing, Baseline Failure Rate $\lambda_{0}=1 \times 10^{-6} \mathrm{hr}^{-1}$, Inservice Test Downtime

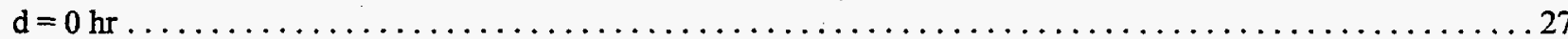

10.2 Check Valve Unavailability Versus IST Interval For Different Valve Aging Rates: Total Renewal, No Intermediate Operational Testing, Baseline Failure Rate $\lambda_{0}=1 \times 10^{-6} \mathrm{hr}^{-1}$, Inservice Test Downtime $\mathrm{d}=8 \mathrm{hr} \ldots \ldots \ldots \ldots \ldots \ldots \ldots \ldots \ldots \ldots \ldots \ldots \ldots \ldots \ldots \ldots \ldots \ldots \ldots \ldots \ldots \ldots \ldots \ldots \ldots \ldots$ Total Renewal,

10.3 Check Valve Unavailability Versus IST Interval For Different Valve Aging Rates: Total Renewal,
No Intermediate Operational Testing, Baseline Failure Rate $\lambda_{0}=1 \times 10^{-6} \mathrm{hr}^{-1}$, Inservice Test Downtime

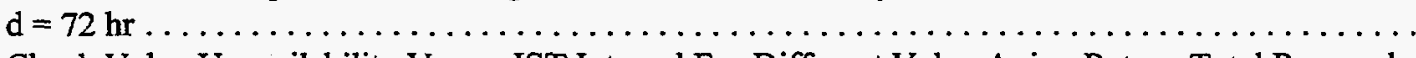

10.4 Check Valve Unavailability Versus IST Interval For Different Valve Aging Rates: Total Renewal, No Intermediate Operational Testing, Baseline Failure Rate $\lambda_{0}=1 \times 10^{-7} \mathrm{hr}^{-1}$, Inservice Test Downtime

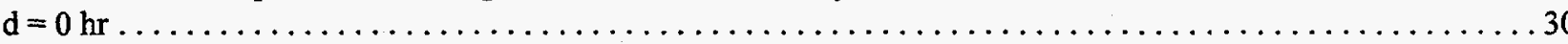

10.5 Check Valve Unavailability Versus IST Interval For Different Valve Aging Rates: Total Renewal, No Intermediate Operational Testing, Baseline Failure Rate $\lambda_{o}=1 \times 10^{-7} \mathrm{hr}^{-1}$, Inservice Test Downtime

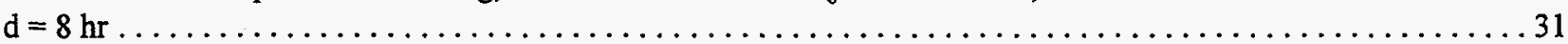

10.6 Check Valve Unavailability Versus IST Interval For Different Valve Aging Rates: Total Renewal, No Intermediate Operational Testing, Baseline Failure Rate $\lambda_{\mathrm{o}}=1 \times 10^{-7} \mathrm{hr}^{-1}$, Inservice Test Downtime

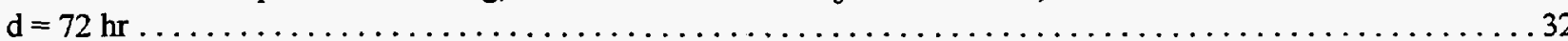

10.7 Check Valve Unavailability Versus IST Interval For Different Valve Aging Rates: Total Renewal, Baseline Failure Rate $\lambda_{o}=1 \times 10^{-6} \mathrm{hr}^{-1}$, Operational test interval $\mathrm{T}=1 \mathrm{mo}$, Inservice Test Downtime $\mathrm{d}=0 \mathrm{hr}$ 


\section{List of Figures (Continued)}

10.8 Check Valve Unavailability Versus IST Interval For Different Valve Aging Rates: Total Renewal, Baseline Failure Rate $\lambda_{0}=1 \times 10^{-6} \mathrm{hr}^{-1}$, Operational test interval $\mathrm{T}=1 \mathrm{mo}$, Inservice Test Downtime

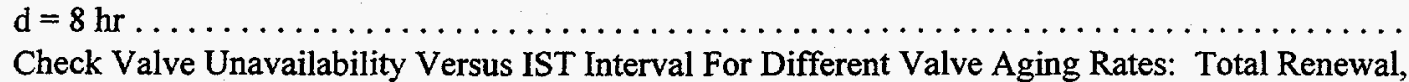

10.9 Check Valve Unavailability Versus IST Interval For Different Valve Aging Rates: Total Renewal,
Baseline Failure Rate $\lambda_{0}=1 \times 10^{-6} \mathrm{hr}^{-1}$, Operational test interval $\mathrm{T}=1 \mathrm{mo}$, Inservice Test Downtime

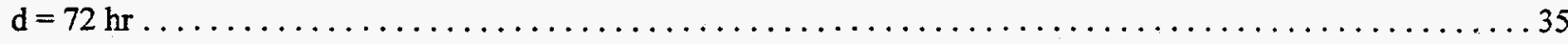

10.10 Check Valve Unavailability Versus IST Interval For Different Valve Aging Rates: Total Renewal, Baseline Failure Rate $\lambda_{o}=1 \times 10^{-6} \mathrm{hr}^{-1}$, Operational test interval $\mathrm{T}=12 \mathrm{mo}$, Inservice Test Downtime $\mathrm{d}=0 \mathrm{hr}$.

10.11 Check Valve Unavailability Versus IST Interval For Different Valve Aging Rates: Total Renewal, Baseline Failure Rate $\lambda_{o}=1 \times 10^{-6} \mathrm{hr}^{-1}$, Operational test interval $\mathrm{T}=12 \mathrm{mo}$, Inservice Test Downtime $\mathrm{d}=8 \mathrm{hr}$

10.12 Check Valve Unavailability Versus IST Interval For Different Valve Aging Rates: Total Renewal, Baseline Failure Rate $\lambda_{\mathrm{o}}=1 \times 10^{-6} \mathrm{hr}^{-1}$, Operational test interval $\mathrm{T}=12 \mathrm{mo}$, Inservice Test Downtime

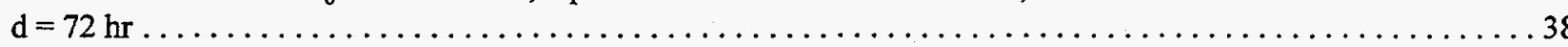

10.13 Check Valve Unavailability Versus IST Interval For Different Valve Aging Rates: Total Renewal, Baseline Failure Rate $\lambda_{o}=1 \times 10^{-7} \mathrm{hr}^{-1}$, Operational test interval $\mathrm{T}=1 \mathrm{mo}$, Inservice Test Downtime

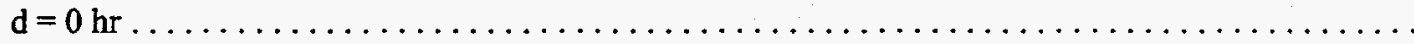

10.14 Check Valve Unavailability Versus IST Interval For Different Valve Aging Rates: Total Renewal, Baseline Failure Rate $\lambda_{0}=1 \times 10^{-7} \mathrm{hr}^{-1}$, Operational test interval $\mathrm{T}=1 \mathrm{mo}$, Inservice Test Downtime $\mathrm{d}=\mathbf{8} \mathrm{hr}$

10.15 Check Valve Unavailability Versus IST Interval For Different Valve Aging Rates: Total Renewal, Baseline Failure Rate $\lambda_{0}=1 \times 10^{-7} \mathrm{hr}^{-1}$, Operational test interval $\mathrm{T}=1 \mathrm{mo}$, Inservice Test Downtime

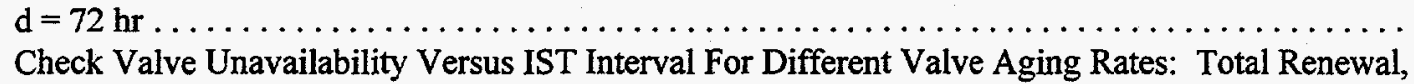

10.16 Check Valve Unavailability Versus IST Interval For Different Valve Aging Rates: Total Renewal,
Baseline Failure Rate $\lambda_{\mathrm{o}}=1 \times 10^{-7} \mathrm{hr}^{-1}$, Operational test interval $\mathrm{T}=12 \mathrm{mo}$, Inservice Test Downtime

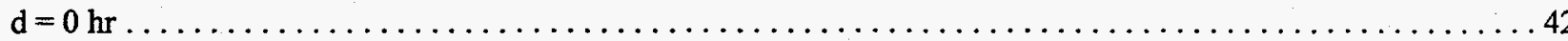

10.17 Check Valve Unavailability Versus IST Interval For Different Valve Aging Rates: Total Renewal, Baseline Failure Rate $\lambda_{\mathrm{o}}=1 \times 10^{-7} \mathrm{hr}^{-1}$, Operational test interval $\mathrm{T}=12 \mathrm{mo}$, Inservice Test Downtime $\mathrm{d}=8 \mathrm{hr}$

10.18 Check Valve Unavailability Versus IST Interval For Different Valve Aging Rates: Total Renewal, Baseline Failure Rate $\lambda_{o}=1 \times 10^{-7} \mathrm{hr}^{-1}$, Operational test interval $\mathrm{T}=12 \mathrm{mo}$, Inservice Test Downtime

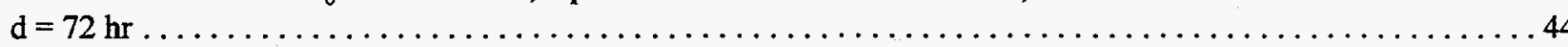

10.19 Check Valve Unavailability Versus IST Interval For Different Valve Aging Rates: Nonrenewal, No Intermediate Testing, Baseline Failure Rate $\lambda_{o}=1 \times 10^{-6} \mathrm{hr}^{-1}$, Inservice Test Downtime $\mathrm{d}=0 \mathrm{hr}$, Remaining Life $\mathrm{s}=40 \mathrm{yr}$

10.20 Check Valve Unavailability Versus IST Interval For Different Valve Aging Rates: Nonrenewal, No Intermediate Testing, Baseline Failure Rate $\lambda_{o}=1 \times 10^{-6} \mathrm{hr}^{-1}$, Inservice Test Downtime $\mathrm{d}=8 \mathrm{hr}$, Remaining Life $s=40$ yr $\ldots \ldots \ldots \ldots \ldots \ldots \ldots \ldots \ldots \ldots \ldots \ldots \ldots \ldots \ldots \ldots \ldots \ldots \ldots \ldots \ldots \ldots$
Check Valve Unavailability Versus IST Interval For Different Valve Aging Rates: Nonrenewal,

10.21 Check Valve Unavailability Versus IST Interval For Different Valve Aging Rates: Nonrenewal,
No Intermediate Testing, Baseline Failure Rate $\lambda_{o}=1 \times 10^{-6} \mathrm{hr}^{-1}$, Inservice Test Downtime $\mathrm{d}=72 \mathrm{hr}$,

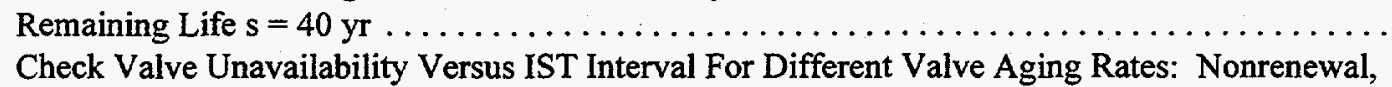

10.22 Check Valve Unavailability Versus IST Interval For Different Valve Aging Rates: Nonrenewal,
No Intermediate Testing, Baseline Failure Rate $\lambda_{o}=1 \times 10^{-7} \mathrm{hr}^{-1}$, Inservice Test Downtime $\mathrm{d}=0 \mathrm{hr}$, Remaining Life $s=40 \mathrm{yr} \ldots \ldots \ldots \ldots \ldots \ldots \ldots \ldots \ldots \ldots \ldots \ldots \ldots \ldots \ldots \ldots \ldots \ldots \ldots \ldots \ldots \ldots$
Check Valve Unavailability Versus IST Interval For Different Valve Aging Rates: Nonrenewal,

10.23 Check Valve Unavailability Versus IST Interval For Different Valve Aging Rates: Nonrenewal,
No Intermediate Testing, Baseline Failure Rate $\lambda_{o}=1 \times 10^{-7} \mathrm{hr}^{-1}$, Inservice Test Downtime $\mathrm{d}=8 \mathrm{hr}$,

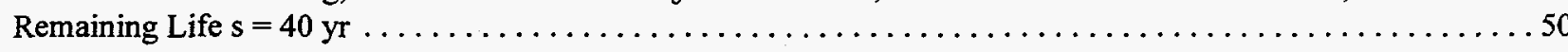




\section{List of Figures (Continued)}

10.24 Check Valve Unavailability Versus IST Interval For Different Valve Aging Rates: Nonrenewal, No Intermediate Testing, Baseline Failure Rate $\lambda_{o}=1 \times 10^{-7} \mathrm{hr}^{-1}$, Inservice Test Downtime $\mathrm{d}=72 \mathrm{hr}$,

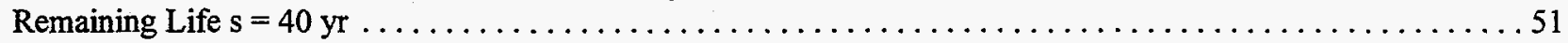

10.25 Check Valve Unavailability Versus IST Interval For Different Valve Aging Rates: Partial Renewal, No Intermediate Testing, Baseline Failure Rate $\lambda_{0}=1 \times 10^{-6} \mathrm{hr}^{-1}$, Inservice Test Downtime $\mathrm{d}=0 \mathrm{hr}$,

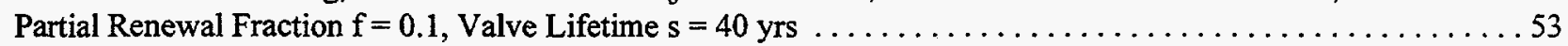

10.26 Check Valve Unavailability Versus IST Interval For Different Valve Aging Rates: Partial Renewal, No Intermediate Testing, Baseline Failure Rate $\lambda_{o}=1 \times 10^{-6} \mathrm{hr}^{-1}$, Inservice Test Downtime $\mathrm{d}=8 \mathrm{hr}$,

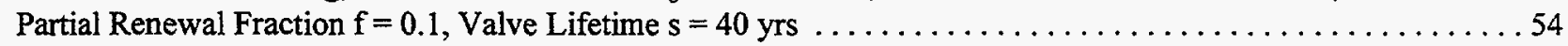

10.27 Check Valve Unavailability Versus IST Interval For Different Valve Aging Rates: Partial Renewal, No Intermediate Testing, Baseline Failure Rate $\lambda_{o}=1 \times 10^{-6} \mathrm{hr}^{-1}$, Inservice Test Downtime $\mathrm{d}=72 \mathrm{hr}$,

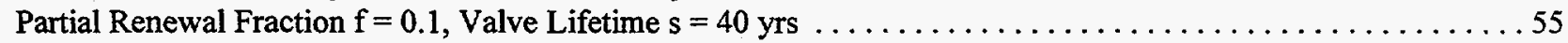

10.28 Check Valve Unavailability Versus IST Interval For Different Valve Aging Rates: Partial Renewal, No Intermediate Testing, Baseline Failure Rate $\lambda_{0}=1 \times 10^{-7} \mathrm{hr}^{-1}$, Inservice Test Downtime $\mathrm{d}=0 \mathrm{hr}$,

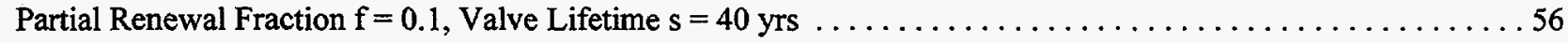

10.29 Check Valve Unavailability Versus IST Interval For Different Valve Aging Rates: Partial Renewal, No Intermediate Testing, Baseline Failure Rate $\lambda_{0}=1 \times 10^{-7} \mathrm{hr}^{-1}$, Inservice Test Downtime $\mathrm{d}=8 \mathrm{hr}$,

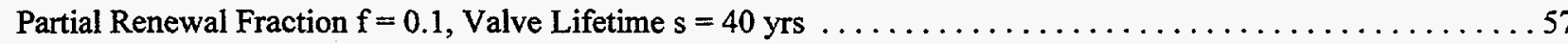

10.30 Check Valve Unavailability Versus IST Interval For Different Valve Aging Rates: Partial Renewal, No Intermediate Testing, Baseline Failure Rate $\lambda_{o}=1 \times 10^{-7} \mathrm{hr}^{-1}$, Inservice Test Downtime $\mathrm{d}=72 \mathrm{hr}$,

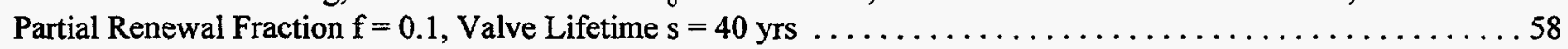

10.31 Check Valve Unavailability Versus IST Interval For Different Valve Aging Rates: Partial Renewal, No Intermediate Testing, Baseline Failure Rate $\lambda_{0}=1 \times 10^{-6} \mathrm{hr}^{-1}$, Inservice Test Downtime $\mathrm{d}=0 \mathrm{hr}$,

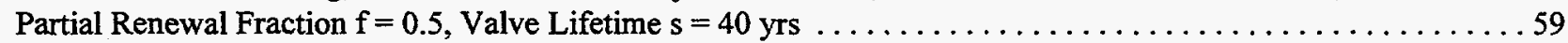

10.32 Check Valve Unavailability Versus IST Interval For Different Valve Aging Rates: Partial Renewal, No Intermediate Testing, Baseline Failure Rate $\lambda_{0}=1 \times 10^{-6} \mathrm{hr}^{-1}$, Inservice Test Downtime $\mathrm{d}=8 \mathrm{hr}$,

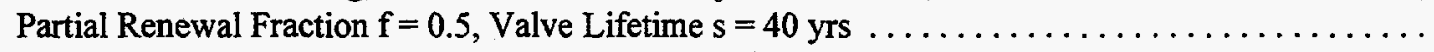

10.33 Check Valve Unavailability Versus IST Interval For Different Valve Aging Rates: Partial Renewal, No Intermediate Testing, Baseline Failure Rate $\lambda_{o}=1 \times 10^{-6} \mathrm{hr}^{-1}$, Inservice Test Downtime $\mathrm{d}=72 \mathrm{hr}$,

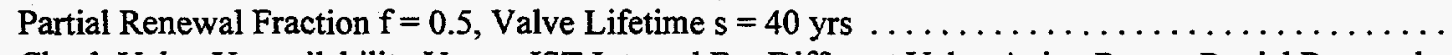

10.34 Check Valve Unavailability Versus IST Interval For Different Valve Aging Rates: Partial Renewal, No Intermediate Testing, Baseline Failure Rate $\lambda_{0}=1 \times 10^{-7} \mathrm{hr}^{-1}$, Inservice Test Downtime $\mathrm{d}=0 \mathrm{hr}$, Partial Renewal Fraction $f=0.5$, Valve Lifetime $s=40$ yrs $\ldots \ldots \ldots \ldots \ldots \ldots \ldots \ldots \ldots \ldots \ldots \ldots$.
Check Valve Unavailability Versus IST Interval For Different Valve Aging Rates: Partial Renewal,

10.35 Check Valve Unavailability Versus IST Interval For Different Valve Aging Rates: Partial Renewal,
No Intermediate Testing, Baseline Failure Rate $\lambda_{\mathrm{o}}=1 \times 10^{-7} \mathrm{hr}^{-1}$, Inservice Test Downtime $\mathrm{d}=8 \mathrm{hr}$,

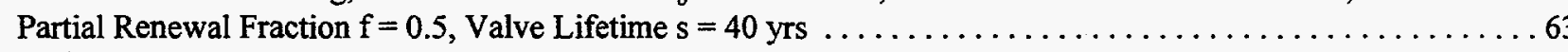

10.36 Check Valve Unavailability Versus IST Interval For Different Valve Aging Rates: Partial Renewal, No Intermediate Testing, Baseline Failure Rate $\lambda_{0}=1 \times 10^{-7} \mathrm{hr}^{-1}$, Inservice Test Downtime $\mathrm{d}=72 \mathrm{hr}$,

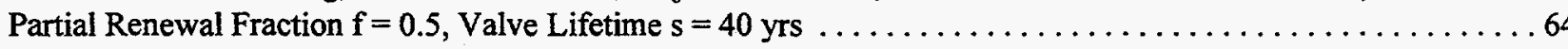

10.37 Check Valve Unavailability Versus IST Interval For Different Valve Aging Rates: Total Renewal, Weibull Aging Model $\mathrm{c}=2$, No Intermediate Testing, Baseline Failure Rate $\lambda_{o}=1 \times 10^{-6} \mathrm{hr}^{-1}$, Inservice

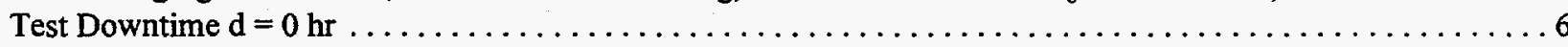

10.38 Check Valve Unavailability Versus IST Interval For Different Valve Aging Rates: Total Renewal, Weibull Aging Model $\mathrm{c}=2$, No Intermediate Testing, Baseline Failure Rate $\lambda_{\mathrm{o}}=1 \times 10^{-6} \mathrm{hr}^{-1}$, Inservice

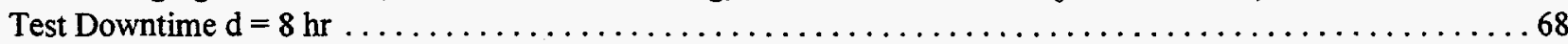

10.39 Check Valve Unavailability Versus IST Interval For Different Valve Aging Rates: Total Renewal, Weibull Aging Model $\mathrm{c}=2$, No Intermediate Testing, Baseline Failure Rate $\lambda_{\mathrm{o}}=1 \times 10^{-6} \mathrm{hr}^{-1}$, Inservice Test Downtime $\mathrm{d}=72 \mathrm{hr}$ 


\section{List of Figures (Continued)}

10.40 Check Valve Unavailability Versus IST Interval For Different Valve Aging Rates: Total Renewal, Weibull Aging Model c $=2$, No Intermediate Testing, Baseline Failure Rate $\lambda_{0}=1 \times 10^{-7} \mathrm{hr}^{-1}$, Inservice

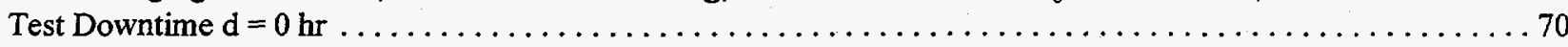

10.41 Check Valve Unavailability Versus IST Interval For Different Valve Aging Rates: Total Renewal, Weibull Aging Model $c=2$, No Intermediate Testing, Baseline Failure Rate $\lambda_{o}=1 \times 10^{-7} \mathrm{hr}^{-1}$, Inservice

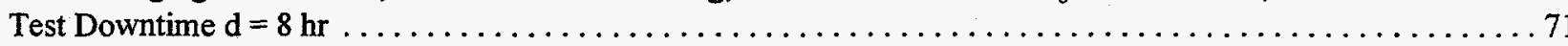

10.42 Check Valve Unavailability Versus IST Interval For Different Valve Aging Rates: Total Renewal, Weibull Aging Model $\mathrm{c}=2$, No Intermediate Testing, Baseline Failure Rate $\lambda_{o}=1 \times 10^{-7} \mathrm{hr}^{-1}$, Inservice

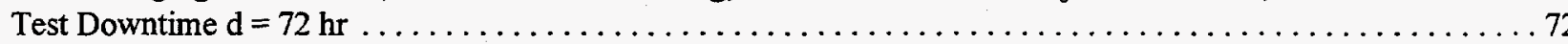

10.43 Check Valve Unavailability Versus IST Interval For Different Valve Aging Rates: Total Renewal, Weibull Aging Model $\mathrm{c}=2$, Baseline Failure Rate $\lambda_{\mathrm{o}}=1 \times 10^{-6} \mathrm{hr}^{-1}$, Operational test interval $\mathrm{T}=1 \mathrm{mo}$,

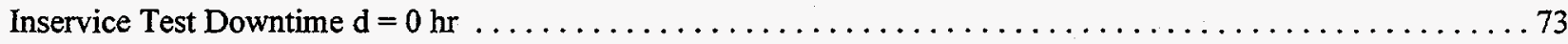

10.44 Check Valve Unavailability Versus IST Interval For Different Valve Aging Rates: Total Renewal, Weibull Aging Model $\mathrm{c}=2$, Baseline Failure Rate $\lambda_{o}=1 \times 10^{-6} \mathrm{hr}^{-1}$, Operational test interval $\mathrm{T}=1 \mathrm{mo}$,

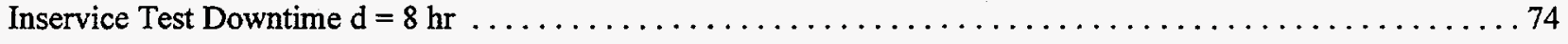

10.45 Check Valve Unavailability Versus IST Interval For Different Valve Aging Rates: Total Renewal, Weibull Aging Model $\mathrm{c}=2$, Baseline Failure Rate $\lambda_{o}=1 \times 10^{-6} \mathrm{hr}^{-1}$, Operational test interval $\mathrm{T}=1 \mathrm{mo}$,

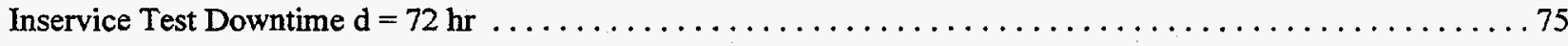

10.46 Check Valve Unavailability Versus IST Interval For Different Valve Aging Rates: Total Renewal, Weibull Aging Model c $=2$, Baseline Failure Rate $\lambda_{\mathrm{o}}=1 \times 10^{-6} \mathrm{hr}^{-1}$, Operational test interval $\mathrm{T}=12 \mathrm{mo}$,

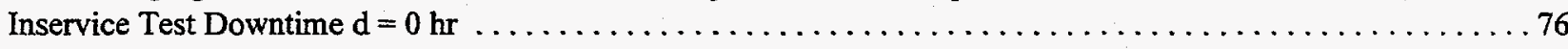

10.47 Check Valve Unavailability Versus IST Interval For Different Valve Aging Rates: Total Renewal, Weibull Aging Model $\mathrm{c}=2$, Baseline Failure Rate $\lambda_{\mathrm{o}}=1 \times 10^{-6} \mathrm{hr}^{-1}$, Operational test interval $\mathrm{T}=12 \mathrm{mo}$,

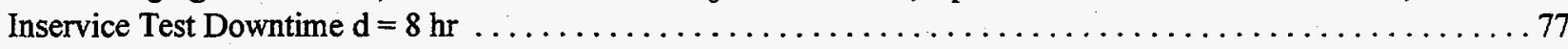

10.48 Check Valve Unavailability Versus IST Interval For Different Valve Aging Rates: Total Renewal, Weibull Aging Model $\mathrm{c}=2$, Baseline Failure Rate $\lambda_{\mathrm{o}}=1 \times 10^{-6} \mathrm{hr}^{-1}$, Operational test interval T $=12 \mathrm{mo}$,

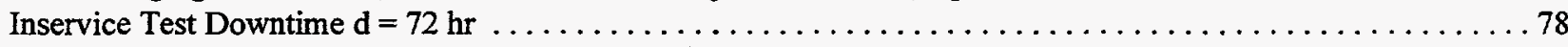

10.49 Check Valve Unavailability Versus IST Interval For Different Valve Aging Rates: Total Renewal, Weibull Aging Model $\mathrm{c}=2$, Baseline Failure Rate $\lambda_{\mathrm{o}}=1 \times 10^{-7} \mathrm{hr}^{-1}$, Operational test interval $\mathrm{T}=1 \mathrm{mo}$,

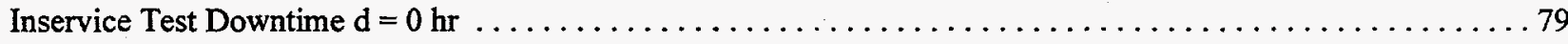

10.50 Check Valve Unavailability Versus IST Interval For Different Valve Aging Rates: Total Renewal, Weibull Aging Model $\mathrm{c}=2$, Baseline Failure Rate $\lambda_{\mathrm{o}}=1 \times 10^{-7} \mathrm{hr}^{-1}$, Operational test interval $\mathrm{T}=1 \mathrm{mo}$,

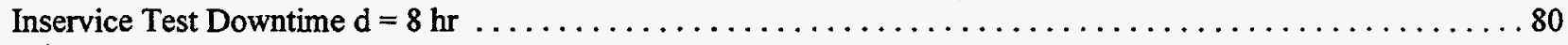

10.51 Check Valve Unavailability Versus IST Interval For Different Valve Aging Rates: Total Renewal, Weibull Aging Model c $=2$, Baseline Failure Rate $\lambda_{\circ}=1 \times 10^{-7} \mathrm{hr}^{-1}$, Operational test interval T $=1 \mathrm{mo}$,

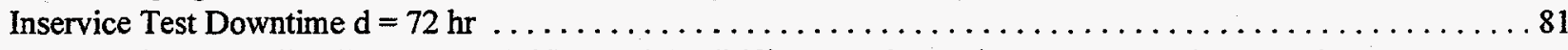

10.52 Check Valve Unavailability Versus IST Interval For Different Valve Aging Rates: Total Renewal, Weibull Aging Model c $=2$, Baseline Failure Rate $\lambda_{o}=1 \times 10^{-7} \mathrm{hr}^{-1}$, Operational test interval $\mathrm{T}=12 \mathrm{mo}$,

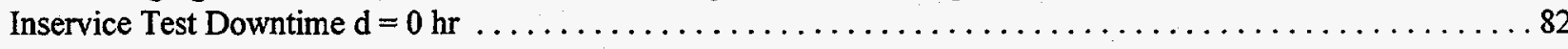

10.53 Check Valve Unavailability Versus IST Interval For Different Valve Aging Rates: Total Renewal, Weibull Aging Model $c=2$, Baseline Failure Rate $\lambda_{0}=1 \times 10^{-7} \mathrm{hr}^{-1}$, Operational test interval $\mathrm{T}=12 \mathrm{mo}$,

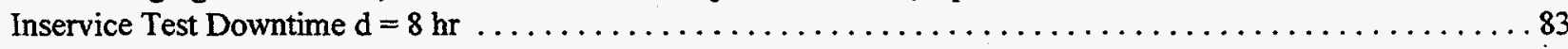

10.54 Check Valve Unavailability Versus IST Interval For Different Valve Aging Rates: Total Renewal, Weibull Aging Model $\mathrm{c}=2$, Baseline Failure Rate $\lambda_{\mathrm{o}}=1 \times 10^{-7} \mathrm{hr}^{-1}$, Operational test interval T $=12 \mathrm{mo}$, Inservice Test Downtime $\mathrm{d}=72 \mathrm{hr} \ldots \ldots \ldots \ldots \ldots \ldots \ldots \ldots \ldots \ldots \ldots \ldots \ldots \ldots \ldots \ldots \ldots \ldots \ldots \ldots \ldots$
Check Valve Unavailability Versus IST Interval For Different Valve Aging Rates: Nonrenewal,

10.55 Check Valve Unavailability Versus IST Interval For Different Valve Aging Rates: Nonrenewal,
No Intermediate Testing, Baseline Failure Rate $\lambda_{\mathrm{o}}=1 \times 10^{-6} \mathrm{hr}^{-1}$, Inservice Test Downtime $\mathrm{d}=0 \mathrm{hr}$,

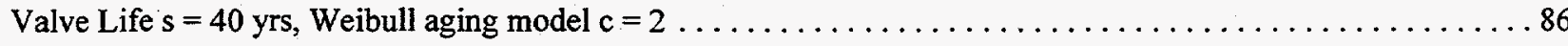




\section{List of Figures (Continued)}

10.56 Check Valve Unavailability Versus IST Interval For Different Valve Aging Rates: Nonrenewal, No Intermediate Testing, Baseline Failure Rate $\lambda_{o}=1 \times 10^{-6} \mathrm{hr}^{-1}$, Inservice Test Downtime $\mathrm{d}=8 \mathrm{hr}$,

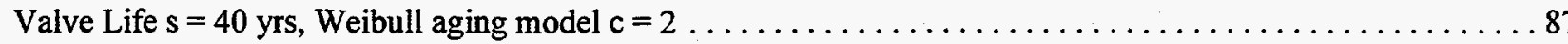

10.57 Check Valve Unavailability Versus IST Interval For Different Valve Aging Rates: Nonrenewal, No Intermediate Testing, Baseline Failure Rate $\lambda_{\mathrm{o}}=1 \times 10^{-6} \mathrm{hr}^{-1}$, Inservice Test Downtime $\mathrm{d}=72 \mathrm{hr}$,

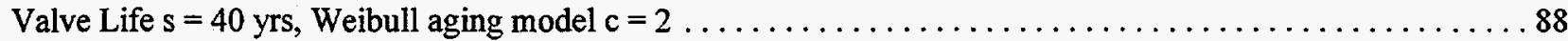

10.58 Check Valve Unavailability Versus IST Interval For Different Valve Aging Rates: Nonrenewal, No Intermediate Testing, Baseline Failure Rate $\lambda_{0}=1 \times 10^{-7} \mathrm{hr}^{-1}$, Inservice Test Downtime $\mathrm{d}=0 \mathrm{hr}$,

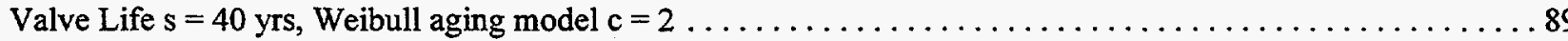

10.59 Check Valve Unavailability Versus IST Interval For Different Valve Aging Rates: Nonrenewal, No Intermediate Testing, Baseline Failure Rate $\lambda_{\mathrm{o}}=1 \times 10^{-7} \mathrm{hr}^{-1}$, Inservice Test Downtime $\mathrm{d}=8 \mathrm{hr}$,

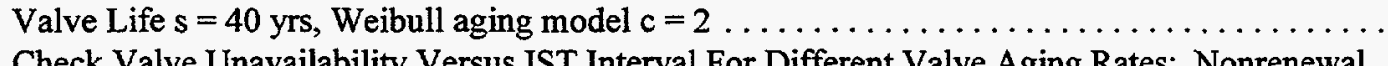

10.60 Check Valve Unavailability Versus IST Interval For Different Valve Aging Rates: Nonrenewal, No Intermediate Testing, Baseline Failure Rate $\lambda_{o}=1 \times 10^{-7} \mathrm{hr}^{-1}$, Inservice Test Downtime $\mathrm{d}=72 \mathrm{hr}$, Valve Life $s=40$ yrs, Weibull aging model $c=2$

10.61 Check Valve Unavailability Versus IST Interval For Different Valve Aging Rates: Nonrenewal, No Intermediate Testing, Baseline Failure Rate $\lambda_{0}=1 \times 10^{-6} \mathrm{hr}^{-1}$, Inservice Test Downtime $\mathrm{d}=0 \mathrm{hr}$, Valve Life $s=40$ yrs, Weibull aging model $c=3 \ldots \ldots \ldots \ldots \ldots \ldots \ldots \ldots \ldots \ldots \ldots \ldots \ldots \ldots \ldots \ldots$.

10.62 Check Valve Unavailability Versus IST Interval For Different Valve Aging Rates: Nonrenewal,
No Intermediate Testing, Baseline Failure Rate $\lambda_{0}=1 \times 10^{-6} \mathrm{hr}^{-1}$, Inservice Test Downtime $\mathrm{d}=8 \mathrm{hr}$ Valve Life $s=40$ yrs, Weibull aging model $c=3$.

10.63 Check Valve Unavailability Versus IST Interval For Different Valve Aging Rates: Nonrenewal, No Intermediate Testing, Baseline Failure Rate $\lambda_{0}=1 \times 10^{-6} \mathrm{hr}^{-1}$, Inservice Test Downtime $\mathrm{d}=0 \mathrm{hr}$, Valve Life $s=40$ yrs, Weibull aging model $c=3$.

10.64 Check Valve Unavailability Versus IST Interval For Different Valve Aging Rates: Nonrenewal, No Intermediate Testing, Baseline Failure Rate $\lambda_{0}=1 \times 10^{-7} \mathrm{hr}^{-1}$, Inservice Test Downtime $\mathrm{d}=0 \mathrm{hr}$,

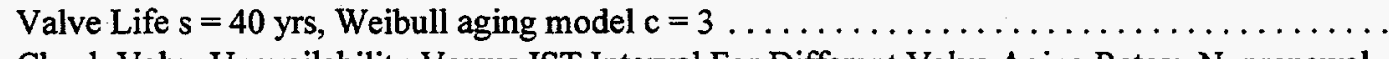

10.65 Check Valve Unavailability Versus IST Interval For Different Valve Aging Rates: Nonrenewal, No Intermediate Testing, Baseline Failure Rate $\lambda_{0}=1 \times 10^{-7} \mathrm{hr}^{-1}$, Inservice Test Downtime $\mathrm{d}=8 \mathrm{hr}$,

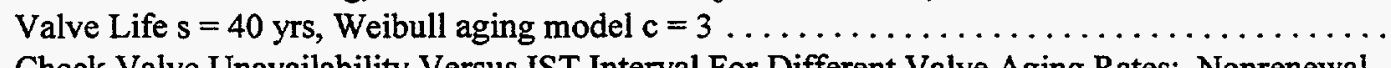

10.66 Check Valve Unavailability Versus IST Interval For Different Valve Aging Rates: Nonrenewal, No Intermediate Testing, Baseline Failure Rate $\lambda_{\mathrm{o}}=1 \times 10^{-7} \mathrm{hr}^{-1}$, Inservice Test Downtime $\mathrm{d}=72 \mathrm{hr}$,

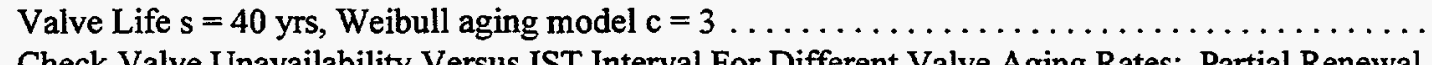

10.67 Check Valve Unavailability Versus IST Interval For Different Valve Aging Rates: Partial Renewal, No Intermediate Testing, Baseline Failure Rate $\lambda_{0}=1 \times 10^{-6} \mathrm{hr}^{-1}$, Inservice Test Downtime $\mathrm{d}=0 \mathrm{hr}$, Partial Renewal Fraction $\mathrm{f}=0.1$, Valve Life $\mathrm{s}=40$ yrs, Weibull aging model $\mathrm{c}=2$

10.68 Check Valve Unavailability Versus IST Interval For Different Valve Aging Rates: Partial Renewal, No Intermediate Testing, Baseline Failure Rate $\lambda_{0}=1 \times 10^{-6} \mathrm{hr}^{-1}$, Inservice Test Downtime $\mathrm{d}=8 \mathrm{hr}$, Partial Renewal Fraction $f=0.1$, Valve Life $s=40$ yrs, Weibull aging model $c=2$

10.69 Check Valve Unavailability Versus IST Interval For Different Valve Aging Rates: Partial Renewal, No Intermediate Testing, Baseline Failure Rate $\lambda_{0}=1 \times 10^{-6} \mathrm{hr}^{-1}$, Inservice Test Downtime $\mathrm{d}=72 \mathrm{hr}$, Partial Renewal Fraction $f=0.1$, Valve Life $s=40$ yrs, Weibull aging model $c=2 \ldots \ldots \ldots \ldots \ldots \ldots$

10.70 Check Valve Unavailability Versus IST Interval For Different Valve Aging Rates: Partial Renewal, No Intermediate Testing, Baseline Failure Rate $\lambda_{o}=1 \times 10^{-7} \mathrm{hr}^{-1}$, Inservice Test Downtime $\mathrm{d}=0 \mathrm{hr}$, Partial Renewal Fraction $f=0.1$, Valve Life $s=40$ yrs, Weibull aging model $c=2 \ldots \ldots \ldots \ldots \ldots \ldots \ldots \ldots$

10.71 Check Valve Unavailability Versus IST Interval For Different Valve Aging Rates: Partial Renewal, No Intermediate Testing, Baseline Failure Rate $\lambda_{\mathrm{o}}=1 \times 10^{-7} \mathrm{hr}{ }^{-1}$, Inservice Test Downtime $\mathrm{d}=8 \mathrm{hr}$, Partial Renewal Fraction $f=0.1$, Valve Life $s=40$ yrs, Weibull aging model $c=2$ 


\section{List of Figures (Continued)}

10.72 Check Valve Unavailability Versus IST Interval For Different Valve Aging Rates: Partial Renewal, No Intermediate Testing, Baseline Failure Rate $\lambda_{o}=1 \times 10^{-7} \mathrm{hr}^{-1}$, Inservice Test Downtime $\mathrm{d}=72 \mathrm{hr}$, Partial Renewal Fraction $f=0.1$, Valve Life $s=40$ yrs, Weibull aging model $c=2 \ldots \ldots \ldots \ldots \ldots$

10.73 Check Valve Unavailability Versus IST Interval For Different Valve Aging Rates: Partial Renewal, No Intermediate Testing, Baseline Failure Rate $\lambda_{0}=1 \times 10^{-6} \mathrm{hr}^{-1}$, Inservice Test Downtime $\mathrm{d}=0 \mathrm{hr}$, Partial Renewal Fraction $f=0.5$, Valve Life $s=40$ yrs, Weibull aging model $c=2 \ldots \ldots \ldots \ldots \ldots$

10.74 Check Valve Unavailability Versus IST Interval For Different Valve Aging Rates: Partial Renewal, No Intermediate Testing, Baseline Failure Rate $\lambda_{o}=1 \times 10^{-6} \mathrm{hr}^{-1}$, Inservice Test Downtime $\mathrm{d}=8 \mathrm{hr}$, Partial Renewal Fraction $f=0.5$, Valve Life $s=40$ yrs, Weibull aging model $c=2 \ldots \ldots \ldots \ldots \ldots \ldots$

10.75 Check Valve Unavailability Versus IST Interval For Different Valve Aging Rates: Partial Renewal, No Intermediate Testing, Baseline Failure Rate $\lambda_{o}=1 \times 10^{-6} \mathrm{hr}^{-1}$, Inservice Test Downtime $\mathrm{d}=72 \mathrm{hr}$, Partial Renewal Fraction $\mathrm{f}=0.5$, Valve Life $\mathrm{s}=40$ yrs, Weibull aging model $\mathrm{c}=2 \ldots \ldots \ldots \ldots$

10.76 Check Valve Unavailability Versus IST Interval For Different Valve Aging Rates: Partial Renewal, No Intermediate Testing, Baseline Failure Rate $\lambda_{o}=1 \times 10^{-7} \mathrm{hr}^{-1}$, Inservice Test Downtime $\mathrm{d}=0 \mathrm{hr}$, Partial Renewal Fraction $f=0.5$, Valve Life $s=40$ yrs, Weibull aging model $\mathrm{c}=2 \ldots \ldots \ldots \ldots \ldots \ldots$

10.77 Check Valve Unavailability Versus IST Interval For Different Valve Aging Rates: Partial Renewal, No Intermediate Testing, Baseline Failure Rate $\lambda_{\circ}=1 \times 10^{-7} \mathrm{hr}^{-1}$, Inservice Test Downtime $\mathrm{d}=8 \mathrm{hr}$, Partial Renewal Fraction $f=0.5$, Valve Life $s=40$ yrs, Weibull aging model $c=2 \ldots \ldots \ldots \ldots \ldots$

10.78 Check Valve Unavailability Versus IST Interval For Different Valve Aging Rates: Partial Renewal, No Intermediate Testing, Baseline Failure Rate $\lambda_{o}=1 \times 10^{-7} \mathrm{hr}^{-1}$, Inservice Test Downtime $\mathrm{d}=72 \mathrm{hr}$, Partial Renewal Fraction $f=0.5$, Valve Life $s=40$ yrs, Weibull aging model $c=2 \ldots \ldots \ldots \ldots \ldots \ldots 110$

10.79 Check Valve Unavailability Versus IST Interval For Different Valve Aging Rates: Partial Renewal, No Intermediate Testing, Baseline Failure Rate $\lambda_{0}=1 \times 10^{-6} \mathrm{hr}^{-1}$, Inservice Test Downtime $\mathrm{d}=0 \mathrm{hr}$, Partial Renewal Fraction $f=0.1$, Valve Life $s=40$ yrs, Weibull aging model $c=3 \ldots \ldots \ldots \ldots \ldots \ldots \ldots$

10.80 Check Valve Unavailability Versus IST Interval For Different Valve Aging Rates: Partial Renewal, No Intermediate Testing, Baseline Failure Rate $\lambda_{0}=1 \times 10^{-6} \mathrm{hr}^{-1}$, Inservice Test Downtime $\mathrm{d}=8 \mathrm{hr}$, Partial Renewal Fraction $\mathrm{f}=0.1$, Valve Life $\mathrm{s}=40 \mathrm{yrs}$, Weibull aging model $\mathrm{c}=3 \ldots \ldots \ldots \ldots \ldots \ldots \ldots \ldots$

10.81 Check Valve Unavailability Versus IST Interval For Different Valve Aging Rates: Partial Renewal, No Intermediate Testing, Baseline Failure Rate $\lambda_{o}=1 \times 10^{-6} \mathrm{hr}^{-1}$, Inservice Test Downtime $\mathrm{d}=72 \mathrm{hr}$, Partial Renewal Fraction $f=0.1$, Valve Life $s=40$ yrs, Weibull aging model $c=3 \ldots \ldots \ldots \ldots \ldots \ldots$

10.82 Check Valve Unavailability Versus IST Interval For Different Valve Aging Rates: Partial Renewal, No Intermediate Testing, Baseline Failure Rate $\lambda_{o}=1 \times 10^{-7} \mathrm{hr}^{-1}$, Inservice Test Downtime $\mathrm{d}=0 \mathrm{hr}$, Partial Renewal Fraction $\mathrm{f}=0.1$, Valve Life $\mathrm{s}=40$ yrs, Weibull aging model $\mathrm{c}=3 \ldots \ldots \ldots \ldots \ldots \ldots \ldots \ldots$

10.83 Check Valve Unavailability Versus IST Interval For Different Valve Aging Rates: Partial Renewal, No Intermediate Testing, Baseline Failure Rate $\lambda_{0}=1 \times 10^{-7} \mathrm{hr}^{-1}$, Inservice Test Downtime $\mathrm{d}=8 \mathrm{hr}$, Partial Renewal Fraction $f=0.1$, Valve Life $s=40$ yrs, Weibull aging model $c=3 \ldots \ldots \ldots \ldots \ldots \ldots$

10.84 Check Valve Unavailability Versus IST Interval For Different Valve Aging Rates: Partial Renewal, No Intermediate Testing, Baseline Failure Rate $\lambda_{0}=1 \times 10^{-7} \mathrm{hr}^{-1}$, Inservice Test Downtime $\mathrm{d}=72 \mathrm{hr}$, Partial Renewal Fraction $\mathrm{f}=0.1$, Valve Life $\mathrm{s}=40 \mathrm{yrs}$, Weibull aging model $\mathrm{c}=3 \ldots \ldots \ldots \ldots \ldots \ldots$

10.85 Check Valve Unavailability Versus IST Interval For Different Valve Aging Rates: Partial Renewal, No Intermediate Testing, Baseline Failure Rate $\lambda_{o}=1 \times 10^{-6} \mathrm{hr}^{-1}$, Inservice Test Downtime $\mathrm{d}=0 \mathrm{hr}$, Partial Renewal Fraction $f=0.5$, Valve Life $s=40$ yrs, Weibull aging model $c=3 \ldots \ldots \ldots \ldots \ldots$
Check Valve Unavailability Versus IST Interval For Different Valve Aging Rates: Partial Renewal, 10.86 Check Valve Unavailability Versus IST Interval For Different Valve Aging Rates: Partial Renewal,
No Intermediate Testing, Baseline Failure Rate $\lambda_{o}=1 \times 10^{-6} \mathrm{hr}^{-1}$, Inservice Test Downtime $\mathrm{d}=8 \mathrm{hr}$, Partial Renewal Fraction $f=0.5$, Valve Life $s=40$ yrs, Weibull aging model $c=3 \ldots \ldots \ldots \ldots$

10.87 Check Valve Unavailability Versus IST Interval For Different Valve Aging Rates: Partial Renewal, No Intermediate Testing, Baseline Failure Rate $\lambda_{o}=1 \times 10^{-6} \mathrm{hr}^{-1}$, Inservice Test Downtime $\mathrm{d}=72 \mathrm{hr}$, Partial Renewal Fraction $f=0.5$, Valve Life $s=40$ yrs, Weibull aging model $c=3$ 


\section{List of Figures (Continued)}

10.88 Check Valve Unavailability Versus IST Interval For Different Valve Aging Rates: Partial Renewal, No Intermediate Testing, Baseline Failure Rate $\lambda_{0}=1 \times 10^{-7} \mathrm{hr}^{-1}$, Inservice Test Downtime $\mathrm{d}=8 \mathrm{hr}$, Partial Renewal Fraction $f=0.5$, Valve Life $s=40$ yrs, Weibull aging model $c=3 \ldots \ldots \ldots \ldots \ldots \ldots$

10.89 Check Valve Unavailability Versus IST Interval For Different Valve Aging Rates: Partial Renewal, No Intermediate Testing, Baseline Failure Rate $\lambda_{0}=1 \times 10^{-7} \mathrm{hr}^{-1}$, Inservice Test Downtime $\mathrm{d}=8 \mathrm{hr}$, Partial Renewal Fraction $f=0.5$, Valve Life $s=40$ yrs, Weibull aging model $c=3 \ldots \ldots \ldots \ldots \ldots \ldots \ldots$

10.90 Check Valve Unavailability Versus IST Interval For Different Valve Aging Rates: Partial Renewal, No Intermediate Testing, Baseline Failure Rate $\lambda_{o}=1 \times 10^{-7} \mathrm{hr}^{-1}$, Inservice Test Downtime $\mathrm{d}=72 \mathrm{hr}$, Partial Renewal Fraction $f=0.5$, Valve Life $s=40$ yrs, Weibull aging model $c=3 \ldots \ldots \ldots \ldots \ldots \ldots \ldots \ldots \ldots$

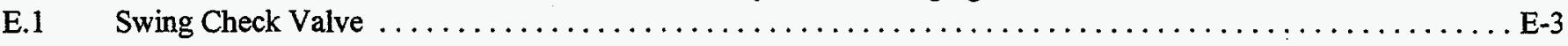

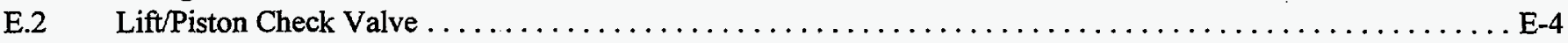

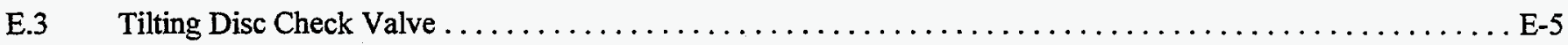

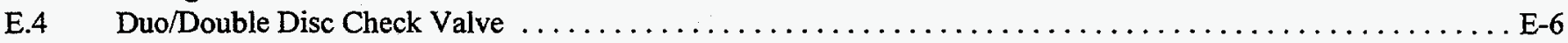

E.5 Failure Rate Data for Check Valves from ORNL/NRC/LTR-96/11 (1992 Data) for 22 Vendors . . . . . . . . E-9

\section{List of Tables}

ES.1 Results for Check Valve IST Intervals: No Follow-Up Renewal, Linear Aging $\ldots \ldots \ldots \ldots \ldots \ldots \ldots$

12.1 Results For Optimal Check Valve IST Intervals: Total Renewal, Low to Moderate Linear Aging,

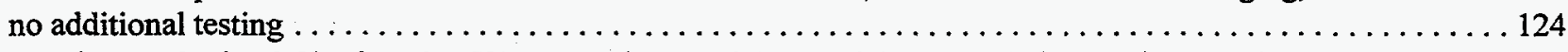

12.2 Results For Optimal Check Valve IST Intervals: Total Renewal, Low to Moderate Linear Aging,

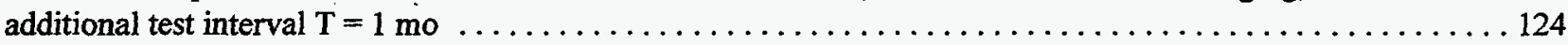

12.3 Results For Check Valve IST Intervals: Nonrenewal with Zero Downtime, Linear Aging . . . . . . . . . 126

12.4 Results For Check Valve IST Intervals: Nonrenewal with Nonzero Downtime, Linear Aging . . . . . . . . 126

B.1 Check Valve Unavailability Versus IST Interval for Different Valve Aging Rates: Total Renewal, No Intermediate Operational Testing, Baseline Failure Rate $\lambda_{0}=1 \times 10^{-6}$, Inservice Test Downtime

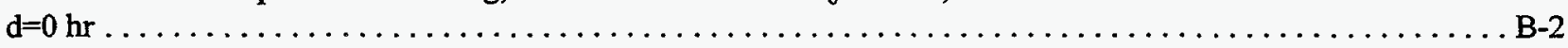

B.2 Check Valve Unavailability Versus IST Interval for Different Valve Aging Rates: Total Renewal, No Intermediate Operational Testing, Baseline Failure Rate $\lambda_{0}=1 \times 10^{-5}$, Inservice Test Downtime

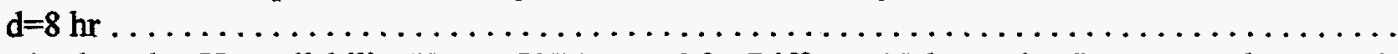

B.3 Check Valve Unavailability Versus IST Interval for Different Valve Aging Rates: Total Renewal, No Intermediate Operational Testing, Baseline Failure Rate $\lambda_{0}=1 \times 10^{-6}$, Inservice Test Downtime

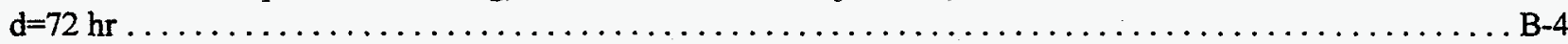

B.4 Check Valve Unavailability Versus IST Interval for Different Valve Aging Rates: Total Renewal, No Intermediate Operational Testing, Baseline Failure Rate $\lambda_{0}=1 \times 10^{-7}$, Inservice Test Downtime

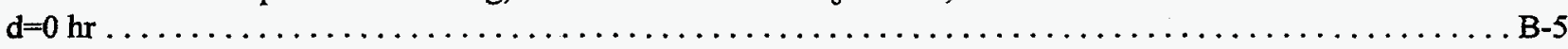

B.5 Check Valve Unavailability Versus IST Interval for Different Valve Aging Rates: Total Renewal, No Intermediate Operational Testing, Baseline Failure Rate $\lambda_{0}=1 \times 10^{-7}$, Inservice Test Downtime

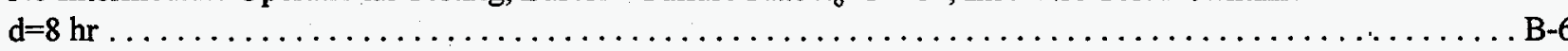

B.6 Check Valve Unavailability Versus IST Interval for Different Valve Aging Rates: Total Renewal, No Intermediate Operational Testing, Baseline Failure Rate $\lambda_{0}=1 \times 10^{-7}$, Inservice Test Downtime

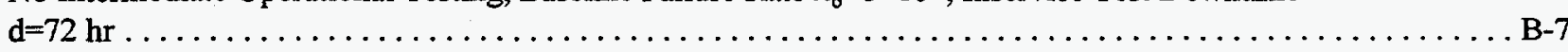

B.7 Check Valve Unavailability Versus IST Interval for Different Valve Aging Rates: Total Renewal, Baseline Failure Rate $\lambda_{0}=1 \times 10^{-6}$, Operational Test Interval $\mathrm{T}=1 \mathrm{mo}$, Inservice Test Downtime

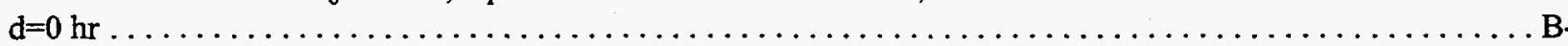




\section{List of Tables (Continued)}

B.8 Check Valve Unavailability Versus IST Interval for Different Valve Aging Rates: Total Renewal, Baseline Failure Rate $\lambda_{0}=1 \times 10^{-6}$, Operational Test Interval $\mathrm{T}=1 \mathrm{mo}$, Inservice Test Downtime

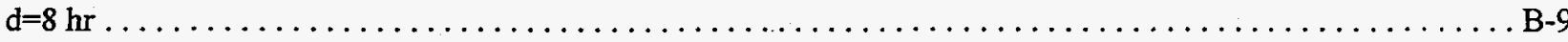

B.9 Check Valve Unavailability Versus IST Interval for Different Valve Aging Rates: Total Renewal, Baseline Failure Rate $\lambda_{0}=1 \times 10^{-6}$, Operational Test Interval $\mathrm{T}=1 \mathrm{mo}$, Inservice Test Downtime $\mathrm{d}=72 \mathrm{hr}$

B.10 Check Valve Unavailability Versus IST Interval for Different Valve Aging Rates: Total Renewal, Baseline Failure Rate $\lambda_{0}=1 \times 10^{-6}$, Operational Test Interval $\mathrm{T}=12 \mathrm{mo}$, Inservice Test Downtime $\mathrm{d}=0 \mathrm{hr}$

B.11 Check Valve Unavailability Versus IST Interval for Different Valve Aging Rates: Total Renewal, Baseline Failure Rate $\lambda_{0}=1 \times 10^{-6}$, Operational Test Interval $\mathrm{T}=12 \mathrm{mo}$, Inservice Test Downtime

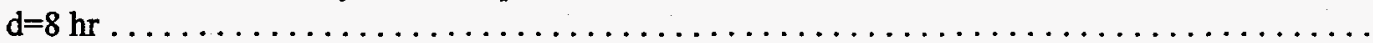

B.12 Check Valve Unavailability Versus IST Interval for Different Valve Aging Rates: Total Renewal, Baseline Failure Rate $\lambda_{0}=1 \times 10^{-6}$, Operational Test Interval $\mathrm{T}=12 \mathrm{mo}$, Inservice Test Downtime $\mathrm{d}=72 \mathrm{hr} \ldots \ldots \ldots \ldots \ldots \ldots \ldots \ldots \ldots \ldots \ldots \ldots \ldots \ldots \ldots \ldots \ldots \ldots \ldots \ldots \ldots \ldots \ldots \ldots \ldots \ldots$.

B.13 Check Valve Unavailability Versus IST Interval for Different Valve Aging Rates: Total Rene
Baseline Failure Rate $\lambda_{0}=1 \times 10^{-7}$, Operational Test Interval $\mathrm{T}=1 \mathrm{mo}$, Inservice Test Downtime

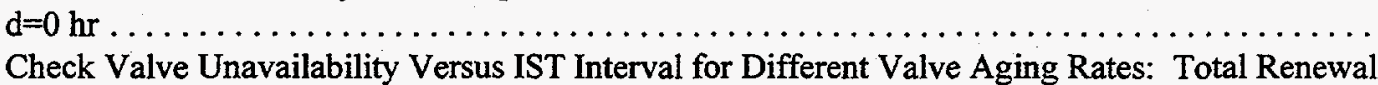

B.14 Check Valve Unavailability Versus IST Interval for Different Valve Aging Rates: Total Renewa
Baseline Failure Rate $\lambda_{0}=1 \times 10^{-7}$, Operational Test Interval $\mathrm{T}=1 \mathrm{mo}$, Inservice Test Downtime

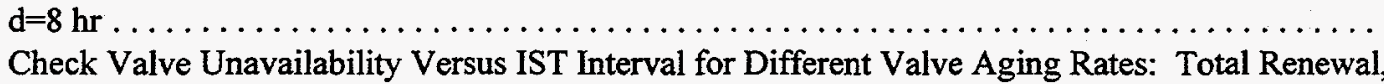

B.15 Check Valve Unavailability Versus IST Interval for Different Valve Aging Rates: Total Rene
Baseline Failure Rate $\lambda_{0}=1 \times 10^{-7}$, Operational Test Interval $T=1$ mo, Inservice Test Downtime

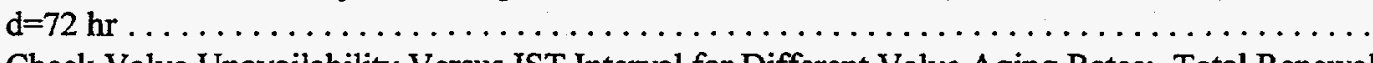

B.16 Check Valve Unavailability Versus IST Interval for Different Valve Aging Rates: Total Renewal, Baseline Failure Rate $\lambda_{0}=1 \times 10^{-7}$, Operational Test Interval $T=12 \mathrm{mo}$, Inservice Test Downtime $\mathrm{d}=0 \mathrm{hr}$.

B.17 Check Valve Unavailability Versus IST Interval for Different Valve Aging Rates: Total Renewal, Baseline Failure Rate $\lambda_{0}=1 \times 10^{-7}$, Operational Test Interval $T=12 \mathrm{mo}$, Inservice Test Downtime

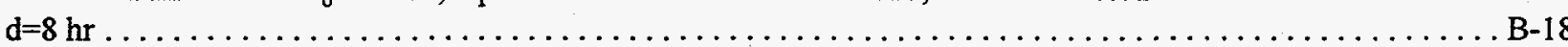

B.18 Check Valve Unavailability Versus IST Interval for Different Valve Aging Rates: Total Renewal, Baseline Failure Rate $\lambda_{0}=1 \times 10^{-7}$, Operational Test Interval $\mathrm{T}=12 \mathrm{mo}$, Inservice Test Downtime

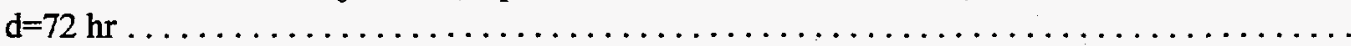

B.19 Check Valve Unavailability Versus IST Interval for Different Valve Aging Rates: Nonrenewal, No Intermediate Testing, Baseline Failure Rate $\lambda_{0}=1 \times 10^{-6}$, Inservice Test Downtime $d=0 \mathrm{hr}$,

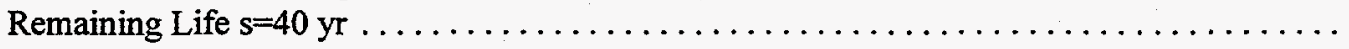

B.20 Check Valve Unavailability Versus IST Interval for Different Valve Aging Rates: Nonrenewal, No Intermediate Testing, Baseline Failure Rate $\lambda_{0}=1 \times 10^{-6}$, Inservice Test Downtime $d=8 \mathrm{hr}$, Remaining $L$ ife $s=40 \mathrm{yr} \ldots \ldots \ldots \ldots \ldots \ldots \ldots \ldots \ldots \ldots \ldots \ldots \ldots \ldots \ldots \ldots \ldots \ldots \ldots \ldots \ldots \ldots \ldots$
Check Valve Unavailability Versus IST Interval for Different Valve Aging Rates: Nonrenewal,

B.21 Check Valve Unavailability Versus IST Interval for Different Valve Aging Rates: Nonrenewa
No Intermediate Testing, Baseline Failure Rate $\lambda_{0}=1 \times 10^{-6}$, Inservice Test Downtime $d=72 \mathrm{hr}$,

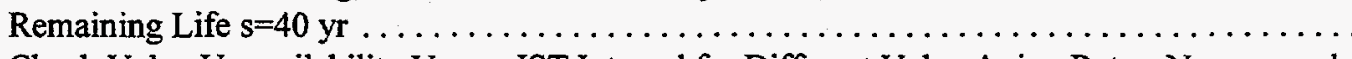

B.22 Check Valve Unavailability Versus IST Interval for Different Valve Aging Rates: Nonrenewal, No Intermediate Testing, Baseline Failure Rate $\lambda_{0}=1 \times 10^{-7}$, Inservice Test Downtime $d=0 \mathrm{hr}$, Remaining Life $s=40$ yr $\ldots \ldots \ldots \ldots \ldots \ldots \ldots \ldots \ldots \ldots \ldots \ldots \ldots \ldots \ldots \ldots \ldots \ldots \ldots$. $\ldots \ldots \ldots$. $\ldots \ldots$.

B.23 Check Valve Unavailability Versus IST Interval for Different Valve Aging Rates: Nonrenewal
No Intermediate Testing, Baseline Failure Rate $\lambda_{0}=1 \times 10^{-7}$, Inservice Test Downtime $d=8 \mathrm{hr}$,

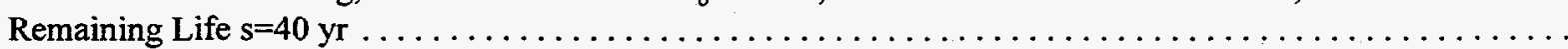




\section{List of Tables (Continued)}

B.24 Check Valve Unavailability Versus IST Interval for Different Valve Aging Rates: Nonrenewal, No Intermediate Testing, Baseline Failure Rate $\lambda_{0}=1 \times 10^{-7}$, Inservice Test Downtime $\mathrm{d}=72 \mathrm{hr}$,

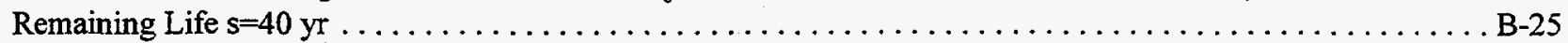

B.25 Check Valve Unavailability Versus IST Interval for Different Valve Aging Rates: Partial Renewal, No Intermediate Testing, Baseline Failure Rate $\lambda_{0}=1 \times 10^{-6}$, Inservice Test Downtime $\mathrm{d}=0 \mathrm{hr}$,

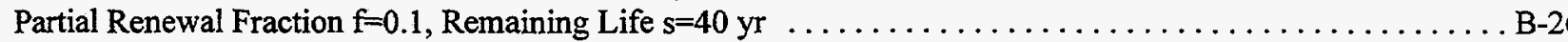

B.26 Check Valve Unavailability Versus IST Interval for Different Valve Aging Rates: Partial Renewal, No Intermediate Testing, Baseline Failure Rate $\lambda_{0}=1 \times 10^{-6}$, Inservice Test Downtime $\mathrm{d}=8 \mathrm{hr}$,

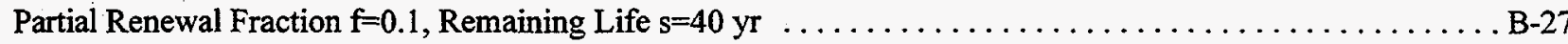

B.27 Check Valve Unavailability Versus IST Interval for Different Valve Aging Rates: Partial Renewal, No Intermediate Testing, Baseline Failure Rate $\lambda_{0}=1 \times 10^{-6}$, Inservice Test Downtime $\mathrm{d}=72 \mathrm{hr}$,

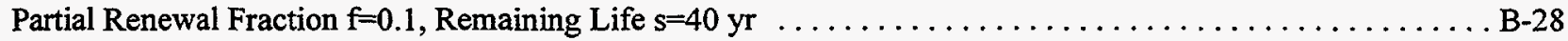

B.28 Check Valve Unavailability Versus IST Interval for Different Valve Aging Rates: Partial Renewal, No Intermediate Testing, Baseline Failure Rate $\lambda_{0}=1 \times 10^{-7}$, Inservice Test Downtime $d=0 \mathrm{hr}$,

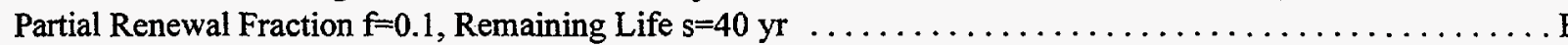

B.29 Check Valve Unavailability Versus IST Interval for Different Valve Aging Rates: Partial Renewal, No Intermediate Testing, Baseline Failure Rate $\lambda_{0}=1 \times 10^{-7}$, Inservice Test Downtime $\mathrm{d}=8 \mathrm{hr}$,

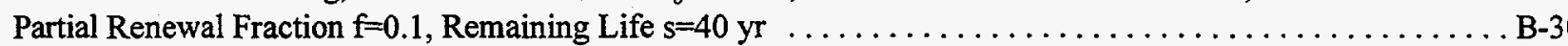

B.30 Check Valve Unavailability Versus IST Interval for Different Valve Aging Rates: Partial Renewal, No Intermediate Testing, Baseline Failure Rate $\lambda_{0}=1 \times 10^{-7}$, Inservice Test Downtime $d=72 \mathrm{hr}$,

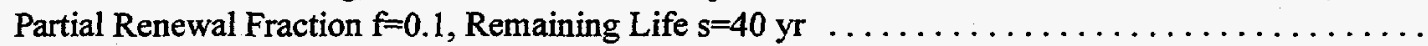

B.31 Check Valve Unavailability Versus IST Interval for Different Valve Aging Rates: Partial Renewal, No Intermediate Testing, Baseline Failure Rate $\lambda_{0}=1 \times 10^{-6}$, Inservice Test Downtime $d=0 \mathrm{hr}$, Partial Renewal Fraction $\mathrm{f}=0.5$, Remaining Life $\mathrm{s}=40 \mathrm{yr}$

B.32 Check Valve Unavailability Versus IST Interval for Different Valve Aging Rates: Partial Renewal, No Intermediate Testing, Baseline Failure Rate $\lambda_{0}=1 \times 10^{-6}$, Inservice Test Downtime $d=8 \mathrm{hr}$,

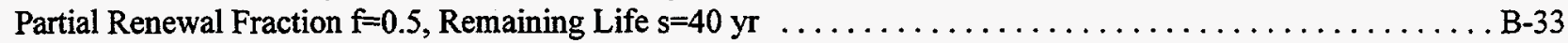

B.33 Check Valve Unavailability Versus IST Interval for Different Valve Aging Rates: Partial Renewal, No Intermediate Testing, Baseline Failure Rate $\lambda_{0}=1 \times 10^{-6}$, Inservice Test Downtime $d=72 \mathrm{hr}$,

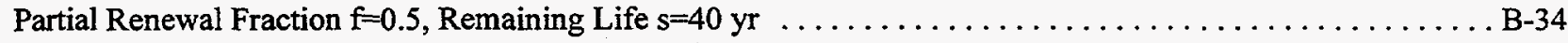

B.34 Check Valve Unavailability Versus IST Interval for Different Valve Aging Rates: Partial Renewal, No Intermediate Testing, Baseline Failure Rate $\lambda_{0}=1 \times 10^{-7}$, Inservice Test Downtime $d=0 \mathrm{hr}$,

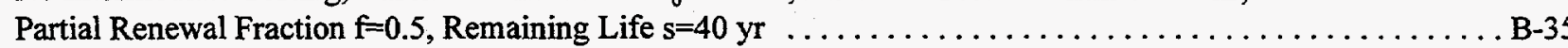

B.35 Check Valve Unavailability Versus IST Interval for Different Valve Aging Rates: Partial Renewal, No Intermediate Testing, Baseline Failure Rate $\lambda_{0}=1 \times 10^{-7}$, Inservice Test Downtime $\mathrm{d}=8 \mathrm{hr}$,

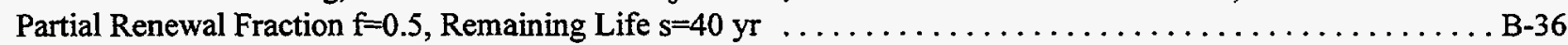

B.36 Check Valve Unavailability Versus IST Interval for Different Valve Aging Rates: Partial Renewal, No Intermediate Testing, Baseline Failure Rate $\lambda_{0}=1 \times 10^{-7}$, Inservice Test Downtime $\mathrm{d}=72 \mathrm{hr}$, Partial Renewal Fraction $\mathrm{f}=0.5$, Remaining Life $\mathrm{s}=40 \mathrm{yr}$...

C.1 Check Valve Unavailability Versus IST Interval for Different Valve Aging Rates: Total Renewal, Weibull Aging Model $c=2$, No Intermediate Operational Testing, Baseline Failure Rate $\lambda_{0}=1 \times 10^{-6}$, Inservice Test Downtime $\mathrm{d}=0 \mathrm{hr} \ldots \ldots \ldots \ldots \ldots \ldots \ldots \ldots \ldots \ldots \ldots \ldots \ldots \ldots \ldots \ldots \ldots \ldots \ldots \ldots \ldots$
Check Valve Unavailability Versus IST Interval for Different Valve Aging Rates: Total Renewal,

C.2 Check Valve Unavailability Versus IST Interval for Different Valve Aging Rates: Total Renewal,
Weibull Aging Model $c=2$, No Intermediate Operational Testing, Baseline Failure Rate $\lambda_{0}=1 \times 10^{-6}$,

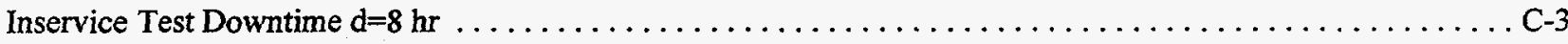

C.3 Check Valve Unavailability Versus IST Interval for Different Valve Aging Rates: Total Renewal, Weibull Aging Model $c=2$, No Intermediate Operational Testing, Baseline Failure Rate $\lambda_{0}=1 \times 10^{-6}$, Inservice Test Downtime $\mathrm{d}=72$ 


\section{List of Tables (Continued)}

C.4 Check Valve Unavailability Versus IST Interval for Different Valve Aging Rates: Total Renewal, Weibull Aging Model $c=2$, No Intermediate Operational Testing, Baseline Failure Rate $\lambda_{0}=1 \times 10^{-7}$,

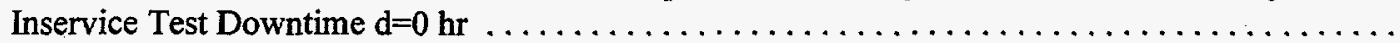

C.5 Check Valve Unavailability Versus IST Interval for Different Valve Aging Rates: Total Renewal, Weibull Aging Model $c=2$, No Intermediate Operational Testing, Baseline Failure Rate $\lambda_{0}=1 \times 10^{-7}$,

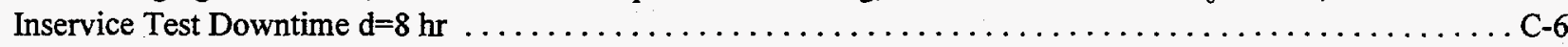

C.6 Check Valve Unavailability Versus IST Interval for Different Valve Aging Rates: Total Renewal, Weibull Aging Model $c=2$, No Intermediate Operational Testing, Baseline Failure Rate $\lambda_{0}=1 \times 10^{-7}$,

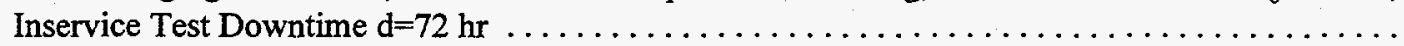

C.7 Check Valve Unavailability Versus IST Interval for Different Valve Aging Rates: Total Renewal, Weibull Aging Model $c=2$, Baseline Failure Rate $\lambda_{0}=1 \times 10^{-6}$, Operational Test Interval T=1 mo, Inservice Test Downtime $\mathrm{d}=0 \mathrm{hr}$

C.8 Check Valve Unavailability Versus IST Interval for Different Valve Aging Rates: Total Renewal, Weibull Aging Model $c=2$, Baseline Failure Rate $\lambda_{0}=1 \times 10^{-6}$, Operational Test Interval $T=1 \mathrm{mo}$,

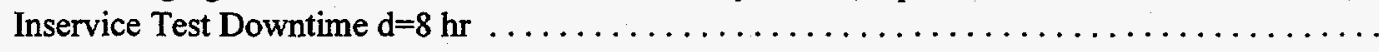

C.9 Check Valve Unavailability Versus IST Interval for Different Valve Aging Rates, Total Renewal, Weibull Aging Model $c=2$, Baseline Failure Rate $\lambda_{0}=1 \times 10^{-6}$, Operational Test Interval $\mathrm{T}=1 \mathrm{mo}$, Inservice Test Downtime $\mathrm{d}=72 \mathrm{hr} \ldots \ldots \ldots \ldots \ldots \ldots \ldots \ldots \ldots \ldots \ldots \ldots \ldots \ldots \ldots \ldots \ldots \ldots \ldots \ldots \ldots$
Check Valve Unavailability Versus IST Interval for Different Valve Aging Rates, Total Renewal, Weibull Aging Model $c=2$, Baseline Failure Rate $\lambda_{0}=1 \times 10^{-6}$, Operational Test Interval $\mathrm{T}=12 \mathrm{mo}$,

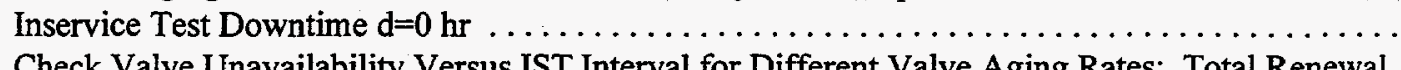

C.11 Check Valve Unavailability Versus IST Interval for Different Valve Aging Rates: Total Renewal, Weibull Aging Model $c=2$, Baseline Failure Rate $\lambda_{0}=1 \times 10^{-6}$, Operational Test Interval $\mathrm{T}=12 \mathrm{mo}$,

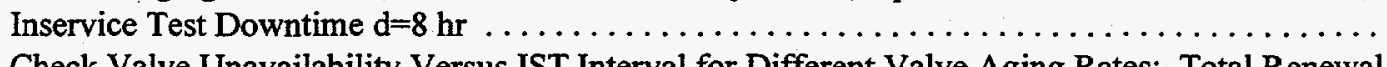

C.12 Check Valve Unavailability Versus IST Interval for Different Valve Aging Rates: Total Renewal, Weibull Aging Model $c=2$, Baseline Failure Rate $\lambda_{0}=1 \times 10^{-6}$, Operational Test Interval $\mathrm{T}=12 \mathrm{mo}$,

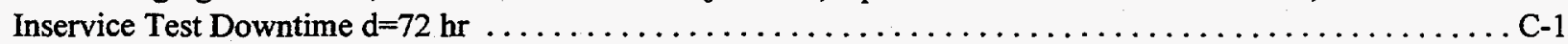

C.13 Check Valve Unavailability Versus IST Interval for Different Valve Aging Rates: Total Renewal, Weibull Aging Model $c=2$, Baseline Failure Rate $\lambda_{o}=1 \times 10^{-7}$, Operational Test Interval $T=1 \mathrm{mo}$, Inservice Test Downtime $\mathrm{d}=0 \mathrm{hr}$ Check Valve Unavailability Versus IST Interval for Different Valve Aging Rates: Total Renewal, Weibull Aging Model $c=2$, Baseline Failure Rate $\lambda_{0}=1 \times 10^{-7}$, Operational Test Interval $\mathrm{T}=1 \mathrm{mo}$, Inservice Test Downtime $\mathrm{d}=8 \mathrm{hr} \ldots \ldots \ldots \ldots \ldots \ldots \ldots \ldots \ldots \ldots \ldots \ldots \ldots \ldots \ldots \ldots \ldots \ldots \ldots \ldots$
Check Valve Unavailability Versus IST Interval for Different Valve Aging Rates: Total Renewal,

C.15 Check Valve Unavailability Versus IST Interval for Different Valve Aging Rates: Total Renew
Weibull Aging Model $c=2$, Baseline Failure Rate $\lambda_{0}=1 \times 10^{-7}$, Operational Test Interval $\mathrm{T}=1 \mathrm{mo}$,

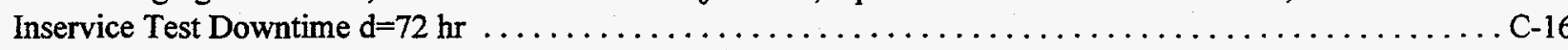

C.16 Check Valve Unavailability Versus IST Interval for Different Valve Aging Rates: Total Renewal, Weibull Aging Model $c=2$, Baseline Failure Rate $\lambda_{0}=1 \times 10^{-7}$, Operational Test Interval $T=12 \mathrm{mo}$,

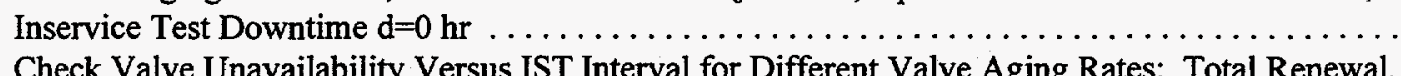

C.17 Check Valve Unavailability Versus IST Interval for Different Valve Aging Rates: Total Renewal, Weibull Aging Model $c=2$, Baseline Failure Rate $\lambda_{0}=1 \times 10^{-7}$, Operational Test Interval $\mathrm{T}=12 \mathrm{mo}$,

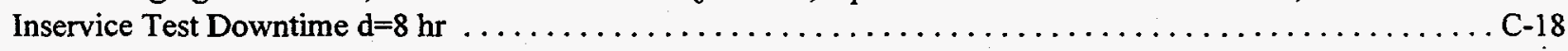

C.18 Check Valve Unavailability Versus IST Interval for Different Valve Aging Rates: Total Renewal, Weibull Aging Model $c=2$, Baseline Failure Rate $\lambda_{0}=1 \times 10^{-7}$, Operational Test Interval $\mathrm{T}=12 \mathrm{mo}$, Inservice Test Downtime $d=72 \mathrm{hr} \ldots \ldots \ldots \ldots \ldots \ldots \ldots \ldots \ldots \ldots \ldots \ldots \ldots \ldots \ldots \ldots \ldots \ldots$
Check Valve Unavailability Versus IST Interval for Different Valve Aging Rates: Nonrenewal, C.19 Check Valve Unavailability Versus IST Interval for Different Valve Aging Rates: Nonrenewal,
No Intermediate Testing, Baseline Failure Rate $\lambda_{0}=1 \times 10^{-6}$, Inservice Test Downtime $d=0 \mathrm{hr}$,
Valve Life $s=40$ yrs, Weibull Aging Model $c=2 \ldots \ldots \ldots$ No Intermediate Testing, Baseline Failure Rate $\lambda_{0}=1 \times 10^{-6}$, Inservice Test Downtime $\mathrm{d}=0 \mathrm{hr}$,
Valve Life $s=40$ yrs, Weibull Aging Model $c=2 \ldots \ldots \ldots \ldots \ldots \ldots \ldots \ldots \ldots \ldots \ldots \ldots \ldots \ldots \ldots$ 


\section{List of Tables (Continued)}

C.20 Check Valve Unavailability Versus IST Interval for Different Valve Aging Rates: Nonrenewal, No Intermediate Testing, Baseline Failure Rate $\lambda_{0}=1 \times 10^{-6}$, Inservice Test Downtime $d=8 \mathrm{hr}$, Valve Life $\mathrm{s}=40$ yrs, Weibull Aging Model $\mathrm{c}=2$.

C.21 Check Valve Unavailability Versus IST Interval for Different Valve Aging Rates: Nonrenewal, No Intermediate Testing, Baseline Failure Rate $\lambda_{0}=1 \times 10^{-6}$, Inservice Test Downtime $\mathrm{d}=72 \mathrm{hr}$, Valve Life $s=40$ yrs, Weibull Aging Model $c=2$

C.22 Check Valve Unavailability Versus IST Interval for Different Valve Aging Rates: Nonrenewal, No Intermediate Testing, Baseline Failure Rate $\lambda_{0}=1 \times 10^{-7}$, Inservice Test Downtime $\mathrm{d}=0 \mathrm{hr}$, Valve Life $\mathrm{s}=40$ yrs, Weibull Aging Model $\mathrm{c}=2$

C.23 Check Valve Unavailability Versus IST Interval for Different Valve Aging Rates: Nonrenewal, No Intermediate Testing, Baseline Failure Rate $\lambda_{0}=1 \times 10^{-7}$, Inservice Test Downtime $d=8 \mathrm{hr}$, Valve Life $\mathrm{s}=40$ yrs, Weibull Aging Model $\mathrm{c}=2$

C.24 Check Valve Unavailability Versus IST Interval for Different Valve Aging Rates: Nonrenewal, No Intermediate Testing, Baseline Failure Rate $\lambda_{0}=1 \times 10^{-7}$, Inservice Test Downtime $d=72 \mathrm{hr}$,

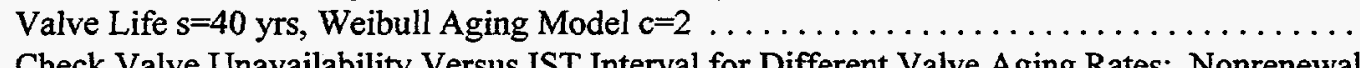

C.25 Check Valve Unavailability Versus IST Interval for Different Valve Aging Rates: Nonrenewal, No Intermediate Testing, Baseline Failure Rate $\lambda_{0}=1 \times 10^{-6}$, Inservice Test Downtime $d=0 \mathrm{hr}$, Valve Life $s=40$ yrs, Weibull Aging Model $c=3$

C.26 Check Valve Unavailability Versus IST Interval for Different Valve Aging Rates: Nonrenewal, No Intermediate Testing, Baseline Failure Rate $\lambda_{0}=1 \times 10^{-6}$, Inservice Test Downtime $d=8 \mathrm{hr}$, Valve Life $s=40$ yrs, Weibull Aging Model $c=3$

C.27 Check Valve Unavailability Versus IST Interval for Different Valve Aging Rates: Nonrenewal, No Intermediate Testing, Baseline Failure Rate $\lambda_{0}=1 \times 10^{-6}$, Inservice Test Downtime $d=72 \mathrm{hr}$,

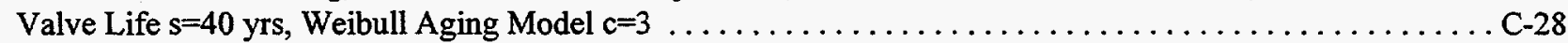

C.28 Check Valve Unavailability Versus IST Interval for Different Valve Aging Rates: Nonrenewal, No Intermediate Testing, Baseline Failure Rate $\lambda_{0}=1 \times 10^{-7}$, Inservice Test Downtime $\mathrm{d}=0 \mathrm{hr}$, Valve Life $s=40$ yrs, Weibull Aging Model $\mathrm{c}=3 \ldots \ldots \ldots \ldots \ldots \ldots \ldots \ldots \ldots \ldots \ldots \ldots \ldots \ldots \ldots \ldots$.
Check Valve Unavailability Versus IST Interval for Different Valve Aging Rates: Nonrenewal,

C.29 Check Valve Unavailability Versus IST Interval for Different Valve Aging Rates: Nonrenewal
No Intermediate Testing, Baseline Failure Rate $\lambda_{0}=1 \times 10^{-7}$, Inservice Test Downtime $d=8 \mathrm{hr}$, Valve Life $s=40$ yrs, Weibull Aging Model $c=3 \ldots \ldots \ldots \ldots \ldots \ldots \ldots \ldots \ldots \ldots \ldots \ldots \ldots \ldots \ldots$.
Check Valve Unavailability Versus IST Interval for Different Valve Aging Rates: Nonrenewal,

C.30 Check Valve Unavailability Versus IST Interval for Different Valve Aging Rates: Nonrenewal,
No Intermediate Testing, Baseline Failure Rate $\lambda_{0}=1 \times 10^{-7}$, Inservice Test Downtime $\mathrm{d}=72 \mathrm{hr}$,

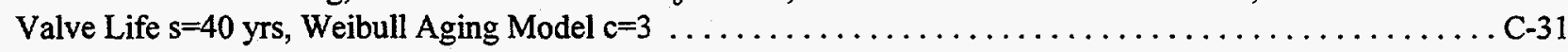

C.31 Check Valve Unavailability Versus IST Interval for Different Valve Aging Rates: Partial Renewal, No Intermediate Testing, Baseline Failure Rate $\lambda_{0}=1 \times 10^{-6}$, Inservice Test Downtime $d=0 \mathrm{hr}$, Partial Renewal Fraction $f=0.1$, Valve Lifetime $s=40$ yrs, Weibull Aging Model $c=2$

C.32 Check Valve Unavailability Versus IST Interval for Different Valve Aging Rates: Partial Renewal, No Intermediate Testing, Baseline Failure Rate $\lambda_{0}=1 \times 10^{-6}$, Inservice Test Downtime $\mathrm{d}=8 \mathrm{hr}$, Partial Renewal Fraction $\mathrm{f}=0.1$, Valve Lifetime $s=40 \mathrm{yrs}$, Weibull Aging Model $\mathrm{c}=2 \ldots \ldots \ldots \ldots \ldots \ldots$. 33

C.33 Check Valve Unavailability Versus IST Interval for Different Valve Aging Rates: Partial Renewal, No Intermediate Testing, Baseline Failure Rate $\lambda_{0}=1 \times 10^{-6}$, Inservice Test Downtime $d=72 \mathrm{hr}$, Partial Renewal Fraction $f=0.1$, Valve Lifetime $s=40$ yrs, Weibull Aging Model $c=2 \ldots \ldots \ldots \ldots \ldots \ldots .34$

C.34 Check Valve Unavailability Versus IST Interval for Different Valve Aging Rates: Partial Renewal, No Intermediate Testing, Baseline Failure Rate $\lambda_{0}=1 \times 10^{-7}$, Inservice Test Downtime $\mathrm{d}=0 \mathrm{hr}$, Partial Renewal Fraction $f=0.1$, Valve Lifetime $s=40$ yrs, Weibull Aging Model $c=2 \ldots \ldots \ldots \ldots \ldots \ldots$. 35

C.35 Check Valve Unavailability Versus IST Interval for Different Valve Aging Rates: Partial Renewal, No Intermediate Testing, Baseline Failure Rate $\lambda_{0}=1 \times 10^{-7}$, Inservice Test Downtime $\mathrm{d}=8 \mathrm{hr}$, Partial Renewal Fraction $f=0.1$, Valve Lifetime $s=40$ yrs, Weibull Aging Model $c=2$ 


\section{List of Tables (Continued)}

C.36 Check Valve Unavailability Versus IST Interval for Different Valve Aging Rates: Partial Renewal,

No Intermediate Testing, Baseline Failure Rate $\lambda_{0}=1 \times 10^{-7}$, Inservice Test Downtime $d=72 \mathrm{hr}$,

Partial Renewal Fraction $f=0.1$, Valve Lifetime $s=40 \mathrm{yrs}$, Weibull Aging Model $c=2 \ldots \ldots \ldots \ldots \ldots \ldots c-37$

C.37 Check Valve Unavailability Versus IST Interval for Different Valve Aging Rates: Partial Renewal,

No Intermediate Testing, Baseline Failure Rate $\lambda_{0}=1 \times 10^{-6}$, Inservice Test Downtime $d=0 \mathrm{hr}$,

Partial Renewal Fraction $\mathrm{f}=0.5$, Valve Lifetime $s=40 \mathrm{yrs}$, Weibull Aging Model $c=2 \ldots \ldots \ldots \ldots \ldots . .38$

C.38 Check Valve Unavailability Versus IST Interval for Different Valve Aging Rates: Partial Renewal,

No Intermediate Testing, Baseline Failure Rate $\lambda_{0}=1 \times 10^{-6}$, Inservice Test Downtime $d=8 \mathrm{hr}$,

Partial Renewal Fraction $\mathrm{f}=0.5$, Valve Lifetime $s=40$ yrs, Weibull Aging Model $\mathrm{c}=2 \ldots \ldots \ldots \ldots \ldots \ldots$. 39

C.39 Check Valve Unavailability Versus IST Interval for Different Valve Aging Rates: Partial Renewal,

No Intermediate Testing, Baseline Failure Rate $\lambda_{0}=1 \times 10^{-6}$, Inservice Test Downtime $d=72 \mathrm{hr}$,

Partial Renewal Fraction $f=0.5$, Valve Lifetime $s=40$ yrs, Weibull Aging Model $c=2 \ldots \ldots \ldots \ldots \ldots \ldots$. 40

C.40 Check Valve Unavailability Versus IST Interval for Different Valve Aging Rates: Partial Renewal,

No Intermediate Testing, Baseline Failure Rate $\lambda_{0}=1 \times 10^{-7}$, Inservice Test Downtime $d=0 \mathrm{hr}$,

Partial Renewal Fraction $\mathrm{f}=0.5$, Valve Lifetime $\mathrm{s}=40 \mathrm{yrs}$, Weibull Aging Model $\mathrm{c}=2 \ldots \ldots \ldots \ldots \ldots \ldots$. 41

C.41 Check Valve Unavailability Versus IST Interval for Different Valve Aging Rates: Partial Renewal,

No Intermediate Testing, Baseline Failure Rate $\lambda_{0}=1 \times 10^{-7}$, Inservice Test Downtime $\mathrm{d}=8 \mathrm{hr}$,

Partial Renewal Fraction $f=0.5$, Valve Lifetime $s=40$ yrs, Weibull Aging Model $c=2 \ldots \ldots \ldots \ldots \ldots \ldots c-42$

C.42 Check Valve Unavailability Versus IST Interval for Different Valve Aging Rates: Partial Renewal,

No Intermediate Testing, Baseline Failure Rate $\lambda_{0}=1 \times 10^{-7}$, Inservice Test Downtime $d=72 \mathrm{hr}$,

Partial Renewal Fraction $f=0.5$, Valve Lifetime $s=40$ yrs, Weibull Aging Model $c=2 \ldots \ldots \ldots \ldots \ldots \ldots$ C-43

C.43 Check Valve Unavailability Versus IST Interval for Different Valve Aging Rates: Partial Renewal,

No Intermediate Testing, Baseline Failure Rate $\lambda_{0}=1 \times 10^{-6}$, Inservice Test Downtime $\mathrm{d}=0 \mathrm{hr}$,

Partial Renewal Fraction $f=0.1$, Valve Lifetime $s=40$ yrs, Weibull Aging Model $c=3 \ldots \ldots \ldots \ldots \ldots \ldots c-44$

C.44 Check Valve Unavailability Versus IST Interval for Different Valve Aging Rates: Partial Renewal,

No Intermediate Testing, Baseline Failure Rate $\lambda_{o}=1 \times 10^{-6}$, Inservice Test Downtime $\mathrm{d}=\mathbf{8 h r}$,

Partial Renewal Fraction $f=0.1$, Valve Lifetime $s=40$ yrs, Weibull Aging Model $c=3 \ldots \ldots \ldots \ldots \ldots .45$

C.45 Check Valve Unavailability Versus IST Interval for Different Valve Aging Rates: Partial Renewal,

No Intermediate Testing, Baseline Failure Rate $\lambda_{0}=1 \times 10^{-6}$, Inservice Test Downtime $d=72 \mathrm{hr}$,

Partial Renewal Fraction $f=0.1$, Valve Lifetime $s=40$ yrs, Weibull Aging Model $c=3 \ldots \ldots \ldots \ldots \ldots \ldots$ C-46

C.46 Check Valve Unavailability Versus IST Interval for Different Valve Aging Rates: Partial Renewal,

No Intermediate Testing, Baseline Failure Rate $\lambda_{0}=1 \times 10^{-7}$, Inservice Test Downtime $d=0 \mathrm{hr}$,

Partial Renewal Fraction $f=0.1$, Valve Lifetime $s=40$ yrs, Weibull Aging Model $c=3 \ldots \ldots \ldots \ldots \ldots \ldots$.

C.47 Check Valve Unavailability Versus IST Interval for Different Valve Aging Rates: Partial Renewal,

No Intermediate Testing, Baseline Failure Rate $\lambda_{0}=1 \times 10^{-7}$, Inservice Test Downtime $\mathrm{d}=8 \mathrm{hr}$,

Partial Renewal Fraction $f=0.1$, Valve Lifetime $s=40$ yrs, Weibull Aging Model $c=3 \ldots \ldots \ldots \ldots \ldots \ldots$ C-48

C.48 Check Valve Unavailability Versus IST Interval for Different Valve Aging Rates: Partial Renewal,

No Intermediate Testing, Baseline Failure Rate $\lambda_{0}=1 \times 10^{-7}$, Inservice Test Downtime $d=72 \mathrm{hr}$,

Partial Renewal Fraction $f=0.1$, Valve Lifetime $s=40$ yrs, Weibull Aging Model $c=3 \ldots \ldots \ldots \ldots \ldots . C-49$

C.49 Check Valve Unavailability Versus IST Interval for Different Valve Aging Rates: Partial Renewal,

No Intermediate Testing, Baseline Failure Rate $\lambda_{o}=1 \times 10^{-6}$, Inservice Test Downtime $\mathrm{d}=0 \mathrm{hr}$,

Partial Renewal Fraction $\mathrm{f}=0.5$, Valve Lifetime $s=40$ yrs, Weibull Aging Model $c=3 \ldots \ldots \ldots \ldots \ldots .50$

C.50 Check Valve Unavailability Versus IST Interval for Different Valve Aging Rates: Partial Renewal,

No Intermediate Testing, Baseline Failure Rate $\lambda_{0}=1 \times 10^{-6}$, Inservice Test Downtime $d=8 \mathrm{hr}$,

Partial Renewal Fraction $\mathrm{f}=0.5$, Valve Lifetime $s=40$ yrs, Weibull Aging Model $c=3 \ldots \ldots \ldots \ldots \ldots . .51$

C.51 Check Valve Unavailability Versus IST Interval for Different Valve Aging Rates: Partial Renewal,

No Intermediate Testing, Baseline Failure Rate $\lambda_{o}=1 \times 10^{-6}$, Inservice Test Downtime $d=72 \mathrm{hr}$,

Partial Renewal Fraction $\mathrm{f}=0.5$, Valve Lifetime $s=40 \mathrm{yrs}$, Weibull Aging Model $\mathrm{c}=3$. . . 


\section{List of Tables (Continued)}

C.52 Check Valve Unavailability Versus IST Interval for Different Valve Aging Rates: Partial Renewal, No Intermediate Testing, Baseline Failure Rate $\lambda_{0}=1 \times 10^{-7}$, Inservice Test Downtime $d=0 \mathrm{hr}$, Partial Renewal Fraction $f=0.5$, Valve Lifetime $s=40$ yrs, Weibull Aging Model $c=3$

C.53 Check Valve Unavailability Versus IST Interval for Different Valve Aging Rates: Partial Renewal, No Intermediate Testing, Baseline Failure Rate $\lambda_{0}=1 \times 10^{-7}$, Inservice Test Downtime $\mathrm{d}=8 \mathrm{hr}$, Partial Renewal Fraction $\mathrm{f}=0.5$, Valve Lifetime $\mathrm{s}=40$ yrs, Weibull Aging Model $\mathrm{c}=3$

C.54 Check Valve Unavailability Versus IST Interval for Different Valve Aging Rates: Partial Renewal, No Intermediate Testing, Baseline Failure Rate $\lambda_{0}=1 \times 10^{-7}$, Inservice Test Downtime $d=72 \mathrm{hr}$, Partial Renewal Fraction $\mathrm{f}=0.5$, Valve Lifetime $\mathrm{s}=40$ yrs, Weibull Aging Model $\mathrm{c}=3 \ldots \ldots \ldots \ldots \ldots \ldots . .55$

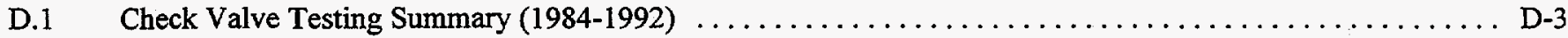

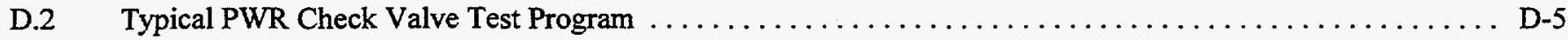

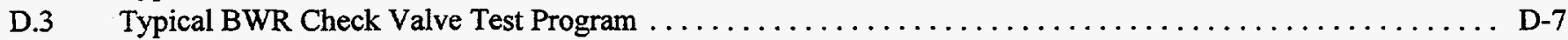

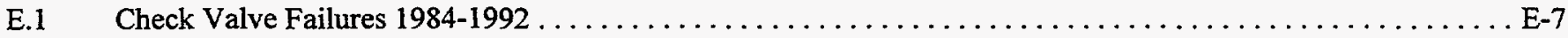

E.2 Check Valve Failure Rate by Type of Check Valve for 1991 and 1992 Failures . . . . . . . . . . . . . E-7 


\section{Executive Summary}

As part of risk-informed applications, test intervals for Inservice Tests (ISTs) are being evaluated for possible extension when the component unavailability or plant risk is decreased or is not significantly increased. If the IST interval is extended then in certain cases unmitigated component aging, if it is being experienced in the fluid system, could significantly increase the unavailability and risk due to the decreased testing. Evaluations of the impacts of IST changes using the usual Probabilistic Risk Assessments (PRAs) as currently evaluated in the industry do not explicitly include the time-dependent effects of component aging since constant component failure rates are used. This report provides methods for evaluating component unavailability changes when IST intervals are modified and when component aging is explicitly included in the evaluations. The results in the report focus on the component unavailability impacts of IST intervals." Sensitivity studies are carried out by evaluating the effects of aging on the component unavailability for different IST intervals for check valves. The resulting component unavailabilities with aging are compared to the values with no aging assumed.

In the report, the aging of a component is characterized by its relative aging rate which is the rate at which the baseline component failure rate is increasing per year. The baseline component failure rates used in this report are similar to those used in plant PRA evaluations and may be somewhat more conservative than specific plant data might predict. However, they allow for better assessments on how IST intervals and aging could impact PRA results. General guidelines are given for determining the level of the aging rate for a component based on the characteristics of the component's operating conditions. Because a component can experience different aging behaviors in different circumstances, formulas and evaluations are given for both linear and nonlinear aging behaviors. The sensitivity studies which are carried out for check valves indicate the types of evaluations which can be performed when component failure rates and aging rates are not precisely known. The aging rate values which are used, especially the lower values, are compatible with present data. For certain extended IST intervals, even the low component aging rate values result in significant unavailability increases as compared to the calculated unavailabilities which assume no aging.

For the methods and evaluations which are presented, the IST is categorized as to whether it is followed by necessary corrective maintenances which result in total renewal of the component or partial renewal of the component. ISTs with no follow-up renewal actions are also evaluated. For total renewal, major component pieceparts are replaced or otherwise refurbished when they are aged and deteriorated, before they fail. For partial renewal, only certain aged pieceparts are replaced or otherwise refurbished. Other aged pieceparts are not replaced until they fail. An IST with partial renewal is characterized by its renewal fraction, which is the fraction of failure modes replaced or refurbished. For an IST having no follow-up renewal, pieceparts are only replaced when they fail.

Significant differences in resulting unavailabilities occur for different types of ISTs. The Figure ES.1 below is illustrative of the results which are obtained from the methods and evaluations in the report. The figure shows the component unavailability versus IST interval for a check valve having a baseline (good as new) failure rate of $1 \times 10^{-7}$ per hour which is a value comparable to that currently used in PRAs. The results are for an IST having an associated test and corrective maintenance downtime of $\mathbf{8}$ hours with no additional testing performed besides the IST. The different curves are for different relative check valve aging rates ranging from a zero aging rate $(\alpha=0)$ to an aging rate of $100 \%$ per year $(\alpha=1.00)$. The usual PRA calculation assumes no aging, i.e. $\alpha=0$. The lower aging rates, e.g. $\alpha \leq 0.10$, are not inconsistent with present data for check valves experiencing low to moderate aging. As observed, for IST intervals greater than 5 years, the aging effects result in significantly higher unavailabilities compared to the no aging case. A range of results is presented for check valves using different IST associated downtimes and test characteristics and different baseline failure rates.

From the set of sensitivity evaluations which are performed for check valves, summary tables of results and general conclusions are presented in the report. Table ES.1 below is extracted from one of the various summary tables which are obtained from a sensitivity evaluation.

\footnotetext{
*The component unavailability is the probability that the component is down and not operational at a random point in time. The plant risk can be the calculated core damage frequency or other measure of risk.
} 


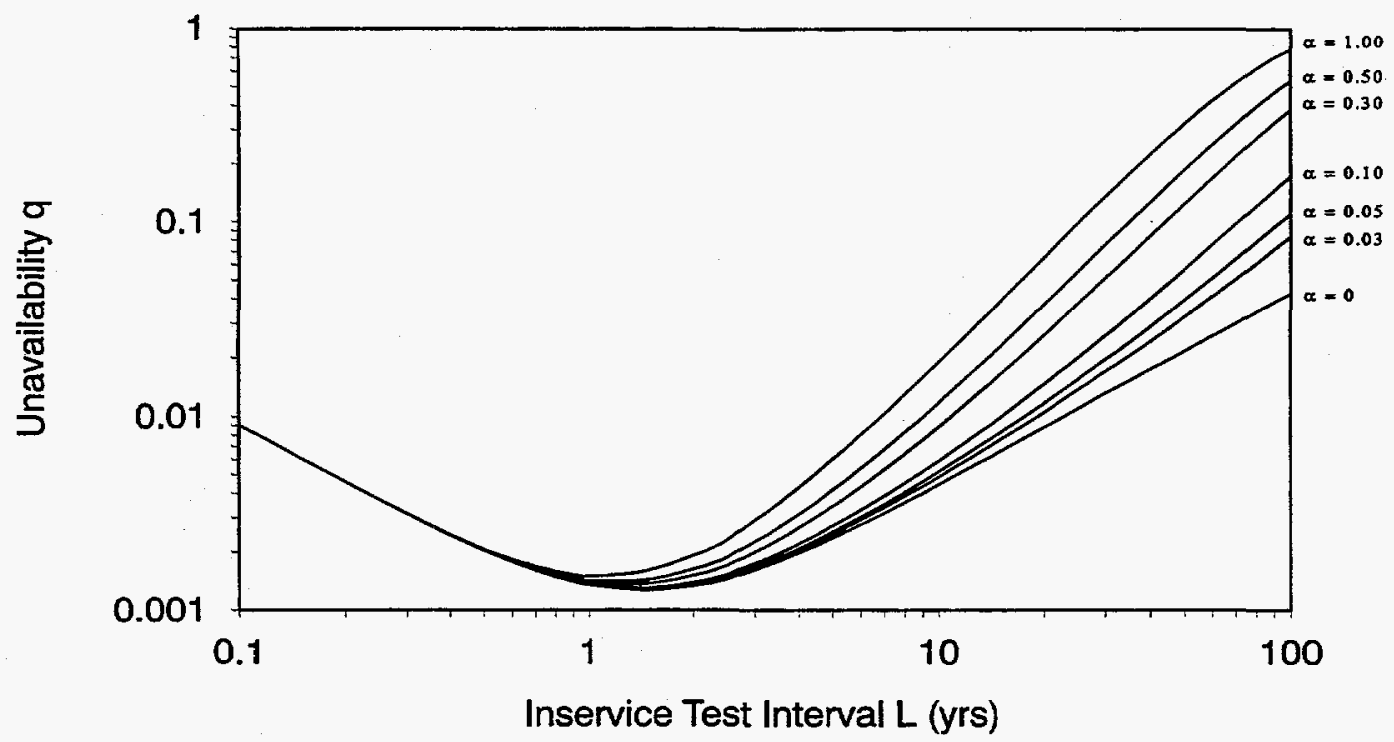

Figure ES.1 Check Valve Unavailability Versus IST Interval For Different Valve Aging Rates: Total Renewal, No Intermediate Operational Testing, Baseline Failure Rate $\lambda_{0}=1 \times 10^{-7} \mathrm{hr}^{-1}$, Inservice Test Downtime $\mathrm{d}=8 \mathrm{hr}$

The table shows an important aging effect; for a given IST interval, the unavailability increases by approximately a factor of 2 for each $10 \%$ aging rate increase. Thus, for any given IST interval a check valve with a $50 \%$ aging rate has an unavailability of approximately a factor of $10(=5 \times 2)$ higher than the value computed assuming no aging.

Table ES.1 Results for Check Valve IST Intervals: No Follow-Up Renewal, Linear Aging

\begin{tabular}{|c|c|c|c|c|c|}
\hline $\begin{array}{c}\text { baseline } \\
\text { failure rate } \\
\lambda_{0}\left(\mathbf{h r}^{-1}\right)\end{array}$ & $\begin{array}{c}\text { IST } \\
\text { downtime } \\
\text { d (hrs) }\end{array}$ & $\begin{array}{c}\text { relative } \\
\text { aging } \\
\text { rate } \alpha\left(y^{-1}\right)\end{array}$ & $\begin{array}{c}\text { IST } \\
\text { interval } \\
L^{*} \text { (yrs) }\end{array}$ & $\begin{array}{c}\text { associated } \\
\text { component } \\
\text { unavailability } q\end{array}$ & $\begin{array}{c}\text { Factor increase } \\
\text { in q compared } \\
\text { to } \alpha=0\end{array}$ \\
\hline \multirow[t]{8}{*}{$1 \times 10^{-6}$} & 8 & 0 & 0.5 & $4 \times 10^{-3}$ & - \\
\hline & & 0.1 & $"$ & $1 \times 10^{-2}$ & 2.5 \\
\hline & & 0.5 & $"$ & $3 \times 10^{-2}$ & 9 \\
\hline & & 1.0 & $"$ & $5 \times 10^{-2}$ & 14 \\
\hline & 72 & 0 & 1.5 & $1 \times 10^{-2}$ & - \\
\hline & & 0.1 & & $3 \times 10^{-2}$ & 3 \\
\hline & & 0.5 & $"$ & $8 \times 10^{-2}$ & 8 \\
\hline & & 1.0 & " & $2 \times 10^{-1}$ & 20 \\
\hline \multirow[t]{8}{*}{$1 \times 10^{-7}$} & 8 & 0 & 2 & $1 \times 10^{-3}$ & - \\
\hline & & 0.1 & $"$ & $3 \times 10^{-3}$ & 3 \\
\hline & & 0.5 & " & $1 \times 10^{-2}$ & 10 \\
\hline & & 1.0 & $“$ & $2 \times 10^{-2}$ & 20 \\
\hline & 72 & 0 & 5 & $4 \times 10^{-3}$ & - \\
\hline & & 0.1 & $"$ & $9 \times 10^{-3}$ & 2.5 \\
\hline & & 0.5 & $"$ & $3 \times 10^{-2}$ & 9 \\
\hline & & 1.0 & " & $6 \times 10^{-2}$ & 15 \\
\hline
\end{tabular}

*The given value of $L$ is the optimal IST interval for zero aging with $q$ the associated optimal unavailability. 
Finally, from the sensitivity studies which are performed and the summary tables which are prepared, conclusions and recommendations are presented:

1. ISTs should be treated as resulting in nonrenewal of the component unless there is justification that the IST is followed by corrective maintenances which significantly renew the component, i.e. refurbishes greater than $\mathbf{5 0 \%}$ of the failure modes. ISTs followed by selective corrective maintenances which refurbish less than $50 \%$ of the failure modes give basically the same unavailabilities as ISTs followed by no renewal.

2. For ISTs with no follow-up renewal, aging (if it is known to take place) has impacts on check valve unavailability at all IST intervals, with the unavailability increasing by a factor of approximately 2 for each $10 \%$ increase in the valve aging rate. Thus, if the usual PRA calculations are performed assuming no aging, sensitivity studies should at a minimum be carried out increasing the valve unavailability by a factor of at least 2 to evaluate aging effects. Unavailabilities of all valves susceptible to aging (especially in the same system and/or train) should be simultaneously increased by this factor to cover the simultaneous effects of aging.

3. An IST interval between 2 to 3 years is identified to be near optimal in providing minimal unavailabilities for the range of check valve aging rates and IST characteristics covered in the sensitivity studies. IST intervals which are robust to component aging are identified as being those which were less than or equal to 5 years since IST intervals greater than 5 years result in significant valve unavailability increases for even the lower valve aging rates.

4. To use the formulas in this report, component aging rates and IST downtimes are required. The discussions in Chapter $\mathbf{5}$ are useful in this regard. For initial evaluations, the IST can be treated as having no associated renewal. When the component is not subjected to harsh operating conditions, a low to moderate aging rate can be used (e.g. $\alpha=0.2$ ) to check the robustness of the IST interval to possible component aging effects.

5. If the valve is subjected to harsh operating conditions, such as being located in a sea water environment or being in a location which subjects the.valve to flutter or constant operation, then a higher aging rate (e.g. $\alpha=0.5)$ can be used to check the robustness of the IST interval. A nonlinear aging model can also be used to check for effects of aging nonlinearities.

6. Since plant specific considerations and plant specific data are always most valid, the results and general observations which are given in this report should be checked and modified where warranted using plant specific considerations and data.

7. Finally, to determine the risk implications of the IST intervals, the associated component unavailabilities can be input to the PRA, or the age-dependent component unavailability models can be used in place of the constant failure rate models. 



\section{List of Acronyms}

AFW Auxiliary Feedwater system

ASME American Society of Mechanical Engineers

BWR boiling water reactor

CCW Component Cooling Water system

CTMT Containment

CVCS Chemical Volume and Control system

ESW

Emergency/Essential Service Water system

HPCI High Pressure Coolant Injection system

HVAC Heating Ventilating Air Conditioning

LLRT local leak rate test

LPCI

LT

Low Pressure Core Injection system

LWR

MSIV

NPRDS

NRC

leak test

light water reactor

main steam isolation valve

ORNL Oak Ridge National Laboratory

PRA probabilistic risk assessments

IST inservice test

PWR pressurized-water reactor

RCIC Reactor Core Isolation Cooling system

RHR Residual Heat Removal system 



\section{Background and Purpose for the Work}

As part of risk-informed applications, Inservice Test (IST) intervals are being evaluated for their possible extension when the component unavailability or plant risk is decreased or is not significantly increased. If the IST interval is extended, then in certain cases, unmitigated component aging and deterioration can significantly increase the unavailability and risk due to decreased testing. Component failure data, such as the check valve failure data collected by Oak Ridge National Laboratory (ORNL) in NUREG/CR-5944, Volumes 1 and $2(1,2)$, generally do not indicate obvious aging behaviors in the components. However, aging can be occurring in the components and may not be detected because of the sparseness of the data and heterogeneity of the component population. The component aging rates which are used in this report, especially the lower aging rate values, are in general difficult to detect in these types of data analyses." However, as will be shown, even the lower aging rate values can cause the component unavailability to significantly increase for certain IST intervals. Furthermore, as plants continue to age, the incidences of component aging can be postulated to increase. Hence, it is important to consider component aging effects in evaluating IST intervals to assure that the intervals are robust to aging effects and control the unavailability when aging exists.

Usual Probabilistic Risk Assessment (PRA) calculations do not explicitly include the effects of component aging when using constant component failure rates to determine component unavailabilities and plant risk. The use of constant component failure rates in PRAs is sufficient for determining a snapshot of the component unavailabilities and plant risk at a given time. However, the usual PRA calculations can underestimate the unavailability and risk impacts of proposed extensions in IST intervals when component aging exists. This underestimation of the unavailability impacts and risk impacts can lead to an unfounded conclusion that the IST interval can be significantly extended with insignificant impacts on component unavailability and plant risk. To assure acceptable performance and acceptable risk, it is important to consider component aging effects to assure that the IST interval controls the component unavailability under component aging conditions.

The effect of component aging on the component unavailability for different IST intervals is specifically evaluated in this work. The resulting risk impacts due to the component unavailability effects are not evaluated. By focusing on the component unavailability, the component performance implications of the IST are thus the focus. If component aging does not cause a significant increase in the component unavailability then the risk will not be significantly increased. If component aging does cause a significant increase in the unavailability then component performance is affected though risk may not be affected if the component is not risk important. To determine the associated risk effects, the unavailability formulas and calculated unavailabilities can be used in the appropriate plant PRA.

This work was carried out to demonstrate a methodology for including component aging effects in IST evaluations and to evaluate the magnitudes of these aging effects for given cases. Determination of IST intervals which are robust to potential component aging effects was a particular focus of the evaluations. More specifically, this report has four purposes:

1. To document a methodology for calculating the component unavailability associated with different IST intervals when component aging is explicitly included in the evaluations.

2. To demonstrate the methodology by calculating the unavailability impacts of changes in IST intervals for check valves using a range of plausible check valve aging rates and IST characteristics as examples.

3. To extract insights and conclusions from the check valve evaluations on the effects of aging and the effects of modifying IST intervals.

4. To propose guidelines for using the methodology and the results of the sensitivity evaluations.

The first part of this report, Sections 1 through 6, presents the bases for the methodology and presents guidelines for using the results of the report. The second part of the report, Sections 7 and 8, presents the formulas for calculating the component unavailability for any IST interval, different IST characteristics, and different component aging behaviors. The third part of the report, Sections 9,10 and 11 , presents application considerations and presents sensitivity studies of check valve unavailability versus IST interval for a range of IST characteristics and check valve aging behaviors. Sections 12 and 13 present conclusions from the check valve sensitivity studies and give recommendations for implementations of the results

*More specifically, the hypothesis of component aging with a given aging rate cannot be rejected in statistical hypothesis tests of the data. 
and methodology. Appendix A presents derivations of the formulas and Appendices B and $C$ present the associated tables for the check valve figures in Sections 10 and 11. Appendix $D$ overviews check valve IST requirements and summarizes historical data on the fraction of failures detected by various check valve tests. Appendix E discusses check valve types and presents estimated failure rates and trends for different type check valves in different plant fluid systems. Finally, Appendix $F$ gives responses to questions from reviews of the report. 


\section{Definition of Concepts and Terms Used in the Report}

Reliability concepts and terms are used in the report to describe the unavailability impacts of ISTs. Engineering terms are also used to describe engineering features. These concepts and terms pertain either to the IST or to the component being tested. Because they are important for the understanding and application of the results of this report, these concepts and terms are given below for reference:

IST - an inservice test which is performed on the component, while the component is in service to assure the component is available. In certain cases the IST may also result in replacement or renewal of component pieceparts which are found to be deteriorated.

IST downtime - the period of time in the conduct of the IST during which the component is unavailable and could be called upon if an accident or incident were to occur.

IST with follow-up renewal actions - an IST which is followed by a corrective maintenance when needed to replace or otherwise refurbish aged or deteriorated component pieceparts which are detected by the IST.

IST with follow-up complete renewal - an IST with follow-up replacement and renewal actions of aged or deteriorated pieceparts which leave the total component in basically a new state ("good as new").

IST with non-renewal - an IST which checks component status and repairs detected failures, but which does not replace aged pieceparts until they fail.

IST with follow-up partial renewal - an IST with follow-up replacement and renewal actions on only a fixed portion of the pieceparts which leave the component in a partially renewed state after the IST.

Partial renewal fraction - The fraction of the component failure modes which are renewed or refurbished in the partial renewal maintenance actions.

IST with additional, operational testing - an IST for which there is additional testing of the component to assure its availability, where the additional test does not replace or renew aged pieceparts unless they are failed.

Component availability - the probability that the component is available if needed at any random time. The component unavailability is the probability that the component is unavailable at a random time.

Component failure rate - the probability per unit time that the component will suffer a failure. The component failure rate is generally a function of the component characteristics, service history, and service environment.

Component relative aging rate - the relative rate at which the design or baseline component failure rate ("good as new" component failure rate) is increasing. For example, a $10 \%$ relative aging rate per year describes an increase in the baseline failure rate of $10 \%$ per year. 



\section{The Formulas and Evaluations Which Are Presented}

The formulas and evaluations which are presented for the component unavailability versus IST interval have various parameters which can be varied to cover different applications and to study sensitivities. Under the assumption of no aging, the formulas simplify to the formulas used in the usual PRA allowing direct comparisons to be made with usual PRA results. The parameters which are varied for the evaluations are:

1. The baseline component failure rate (the "good as new" failure rate).

2. The component aging behavior - for no aging this element is zero. For cases where aging may be present it can be estimated to be linear, where the failure rate increases linearly with component age, or estimated to be nonlinear, where the failure rate increases according to some power of the component age.

3. The component aging rate value, which is the rate at which the component failure rate increases; a zero value corresponds to no aging.

4. The power of the component age at which the failure rate increases when the aging behavior is assumed to be nonlinear.

5. The renewal actions which follow the IST - whether corrective maintenance after the IST results in the component being in a renewed state, i.e. good as new, whether it is in a partially renewed state, or whether there is no associated corrective maintenance in which case the IST serves only to check the operational status of the component.

6. If the maintenance actions after the IST result in the component being in a partially renewed state then the renewal fraction which is the fraction of component failure modes (in general, this element is very difficult to determine) which are checked for aging and are renewed when necessary by replacing or otherwise refurbishing specific component pieceparts.

7. The downtime which is associated with the conduct of the IST and any following corrective maintenance during which the component is unavailable and could be called upon if an accident or incident were to occur.

8. The life of the component if the component is not renewed after the IST; this is generally taken to be 40 years in the examples, the assumed lifetime of the plant, but can be varied and should be determined by review of both plant and industry performance data.

and

9. Whether there is any additional operational testing performed on the component to check the component status and if so the interval at which the test is performed.

The formulas and evaluations for the check valves are organized according to the above different parameter options. 



\section{Bases and Assumptions for the Methodology}

Subsequent sections provide the detailed formulas for the component unavailability versus IST interval for different IST characteristics and different component aging behaviors. These formulas are applications of the general formulas given in Appendix B of NUREG/CR-5510 (3), and in references on component reliability evaluations (See, for example; References 4 and 5). It is important to highlight the bases and assumptions underlying the methodology to provide for meaningful implementations. The major modeling assumptions and bases are:

1. The IST does not have any deleterious effects on the component other than the downtime which may be associated with the IST during which the component is unavailable.

2. The IST assures the component is available; the unavailability of the component immediately after the test is conducted is essentially zero.

3. There is no burn-in associated with replacing the component or component pieceparts in any associated corrective maintenance.

4. For an IST with follow-up partial renewal if needed, only specific parts of the component are checked for wear and deterioration. These parts are replaced with essentially new parts ("good as new").

5. If intermediate testing of the component is also done in addition to the IST then the test is only an operational test, testing whether the component is available, with no renewal of aged component pieceparts.

6. Failures are repaired when detected by the IST or the additional operational test; the failed pieceparts are replaced with basically new pieceparts.

7. For a linear aging behavior of a component, the time-dependent component failure rate $\lambda(t)$ is given by

$$
\lambda(t)=\lambda_{0}+a t
$$

where

$\lambda_{0}=$ the baseline failure rate when the component is new (the "good as new failure rate")

$a=$ the linear aging rate of the component, which is the rate of change of the failure rate.

$t=$ the age of the component, i.e. the time since replacement or renewal of the component

The linear aging model is a first order aging model that is used in various applications including applications where the aging is not severe. (See references $(3,4,5)$ ).

When the component is renewed then it begins again at age $t=0$. When $a=0$ then there is no aging of the component and the failure rate becomes the constant failure rate $\lambda_{0}$. The linear aging rate a of the component may also be expressed in terms of a relative aging rate a

$$
\mathrm{a}=\alpha \lambda_{0}
$$

where

$a=$ the relative component aging rate, expressed as the fraction or percent which the failure

rate changes per year 
8. For a nonlinear aging behovior of a component, the time-dependent component failure rate $\lambda(t)$ may be modeled by the Weibull failure rate model:

$$
\lambda(t)=\lambda_{0}+b t^{e}
$$

where

$\lambda_{\mathrm{o}}=$ the baseline failure rate when the component is new ("good as new" failure rate).

$b=$ the aging rate of the component

$c=$ the trend factor, or shape factor, describing the trend in the aging behavior

and

$t=$ the age of the component, or the time since last replacement or renewal of the component.

The Weibull aging model is a general aging model used in various reliability applications. Note that for a trend factor of $c=1$ then the Weibull nonlinear model specializes to the linear aging model. When $b=0$ there is no aging and the failure rate specializes to the constant failure rate $\lambda_{\circ}$. The aging rate $b$ can again be expressed in terms of a relative aging rate factor

$$
b=\alpha \lambda_{0}
$$

where

$$
a=\text { the relative aging factor for the component. }
$$

It should be noted that no Weibull aging rates or trend factors have been established based upon an analysis of check valve failures. All numerical cases in this report are provided for example use only. 


\section{Guidelines for Using the Results of the Report}

The primary purpose of this report is to present a methodology that can be used to support risk-based extensions of testing intervals in a program that utilizes IST and aging analyses. Secondary goals of this study include performing the example calculations using the mathematical model and making those results available as examples and for potentially "practical" purposes. However, please note that rigorous analyses, plant-specific studies, or present-day, PRA-supporting studies demand more precision that can be obtained from the results tabulated in this report (in spite of the length or bulk of these results). As mentioned earlier, valve- and application-specific failure rates and rates of aging must be used in determining the appropriate parameters to use in the unavailability calculations. The degree of required precision can best be determined using sensitivity studies.

The formulas in the next section for the component unavailability versus IST interval and the subsequent check valve evaluations are given in terms of the component and IST parameters. To apply the appropriate formula or to use the appropriate evaluation, the user needs to select the appropriate formula and needs to select the appropriate parameter values. These choices can be divided into two steps:

Selecting the IST characteristics

Selecting the component characteristics.

Selecting the IST characteristics involves:

Selecting the renewal capability associated with follow-up actions after the IST

Selecting the IST associated test and maintenance downtime

Selecting the IST interval

Selecting whether additional testing is performed.

Selecting the component characteristics involves:

Selecting the baseline, good as new failure rate

Selecting the aging behavior, whether linear or nonlinear

Selecting the aging rate

If the aging is nonlinear, selecting the power for the age growth.

Where there are uncertainties, ranges for the parameters or conservative values can be selected. Also, parametric studies can be carried out in which the parameter or parameters are varied to determine their effects and sensitivities. The check valve evaluations which are carried out are examples of such parametric studies which show the effectiveness of particular IST intervals in controlling the component unavailability over ranges of aging behaviors and IST performance characteristics. Figures 5.1 and 5.2 on the following pages present proposed guidelines for determining the required IST parameters from the engineering description of the IST and for determining the component aging parameters from the component's operating characteristics. Proposed default values are also provided for bounding evaluations and screening evaluations. Appendix D gives example categorizations of ISTs for different types of check valve tests and plant systems. Appendix E gives example values for check valve rates and trends from plant failure data. The proposed values and example results should be checked and modified where necessary using plant specific considerations and data. 

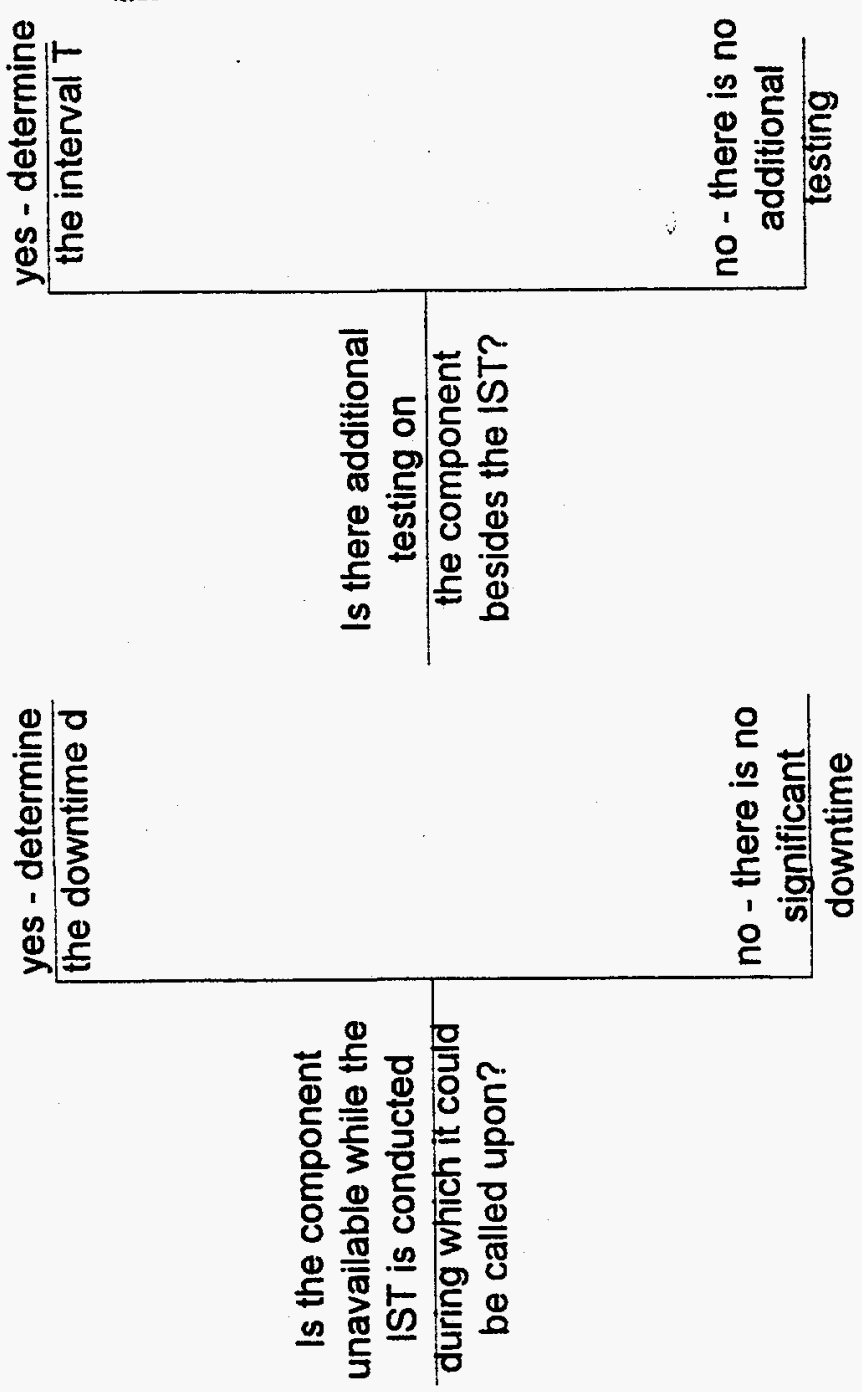



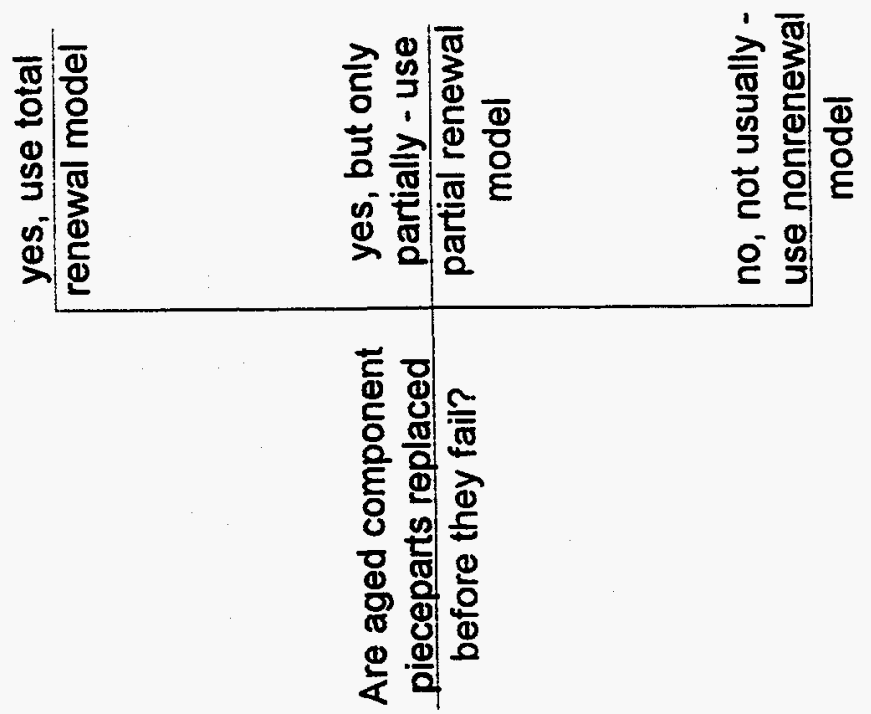




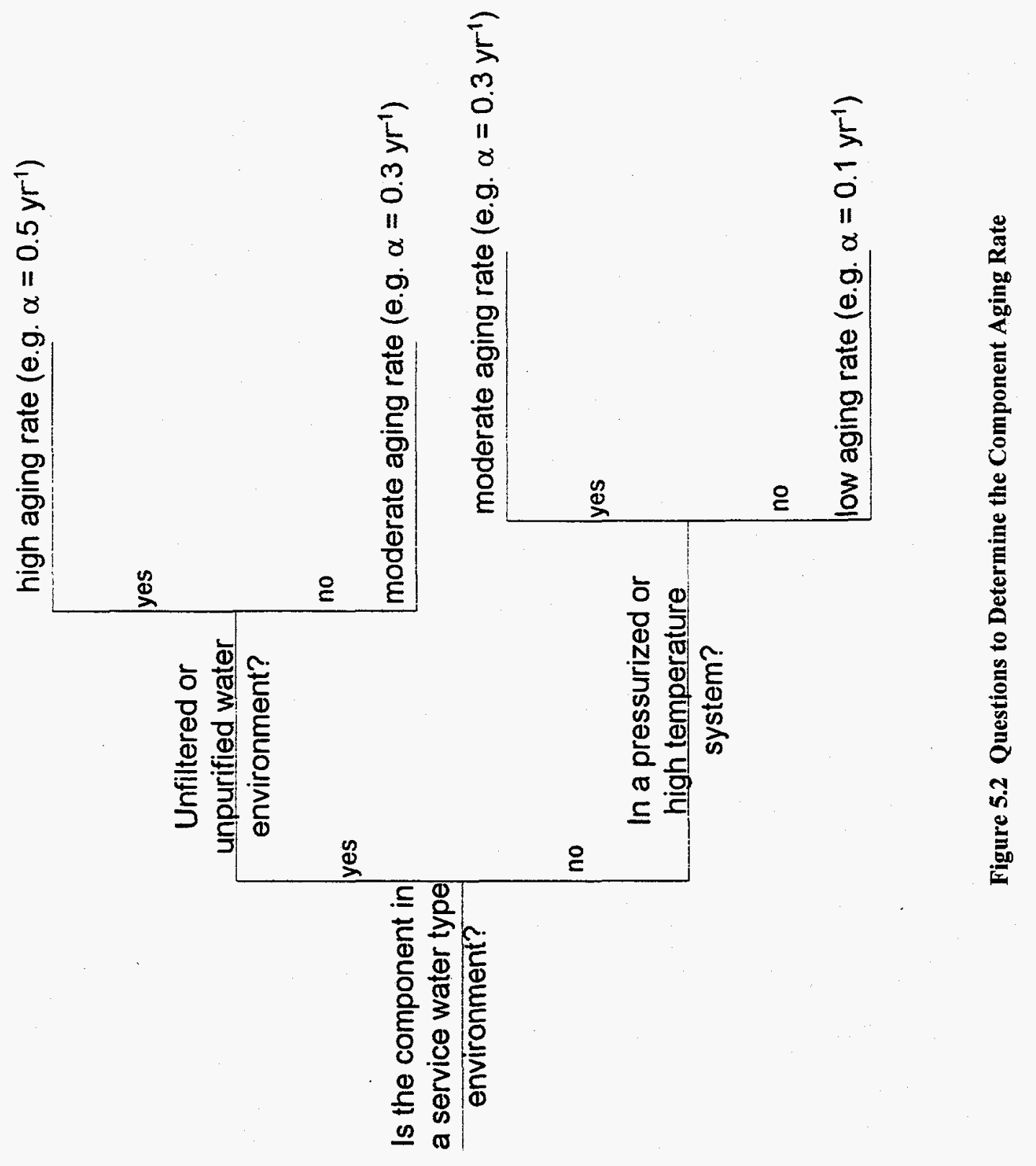




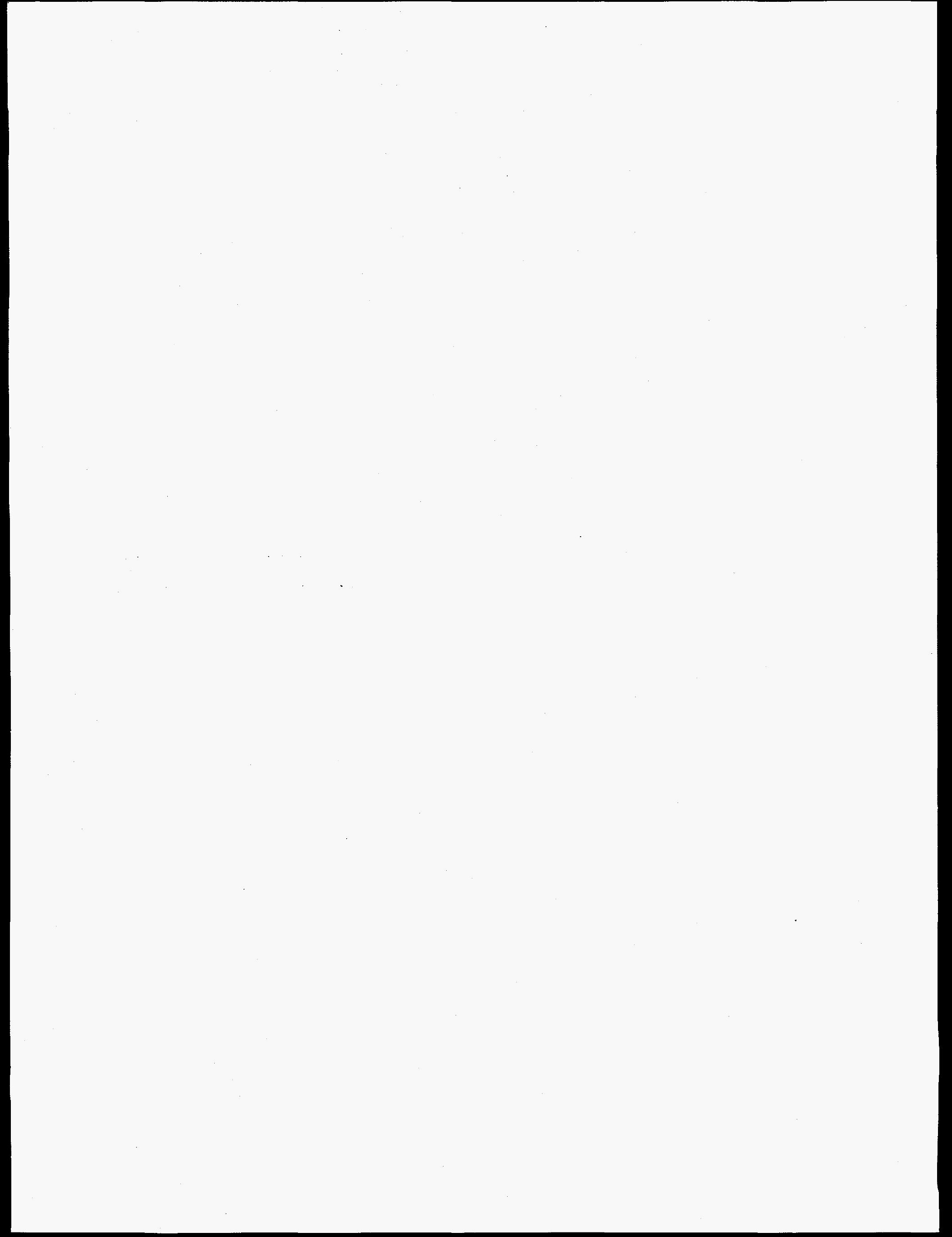




\title{
6 Identification of Responses to Questions Which Resulted From Reviews of the Report
}

\begin{abstract}
A number of questions were generated on the methodology and on the sensitivity studies when the draft version of this report was submitted for review. The report was modified to respond to the questions, however the questions are important in themselves with regard to the issues that arise in reviewing the bases for the methodology and in determining its applicability along with the applicability of the sensitivity studies. Therefore, the questions have been abstracted along with their responses and have been placed in Appendix F.
\end{abstract}





\section{Formulas for the Component Unavailability When Aging is Described by the Linear Aging Model}

The formulas for the component unavailability versus IST interval are presented here when the component aging is described by the linear aging model. The formulas are applications of the aging methodology which was developed in NUREG/CR5510 (3). The formulas are also applications of general, time-dependent unavailability formulas (See References 4 and 5). Only the formulas are given here; the derivations of the formulas are given in Appendix A.

\subsection{Formulas When the Component is in a Renewed State After the IST With Follow-up Corrective Maintenance}

When the component is completely renewed by follow-up corrective maintenance if any significant degradation is detected by the IST then the component is basically "good as new" after the IST and the needed maintenance is conducted. The appropriate unavailability formula depends upon whether there is additional, intermediate testing or no other testing besides the IST.

\section{Additional Intermediate Testing}

For intermediate operational testing performed in addition to the IST, the total component unavailability $q$ associated with the IST is calculated using the formula,

$$
q=1-\exp \left[-\lambda_{0} \frac{T^{2}}{2}-a \frac{T}{2} \frac{(L-T)}{2}\right]+\frac{d}{L+d}
$$

where

$$
\begin{aligned}
& \lambda_{0}=\text { the baseline component failure rate } \\
& a=\text { the component linear aging rate } \\
& T=\text { the additional operational test interval (if any); } T \leq L \\
& L=\text { the IST interval } \\
& d=\text { the average downtime associated with each IST during which the } \\
& \text { component is unavailable. }
\end{aligned}
$$

The average downtime $d$ is the sum of the test downtime $d_{1}$ plus the average downtime $d_{2}$ per test required for corrective maintenance. The average corrective maintenance downtime $d_{2}$ per test can be expressed as $f_{c m} d_{c m}$ where $f_{c m}$ is the fraction of tests requiring corrective maintenance and $d_{c m}$ is the average downtime for a corrective maintenance. If the corrective maintenance fraction $f_{c m}$ is small then $d_{2}$ can be negligible compared to $d_{1}$ but this needs to be checked.

For easier estimation and application, the component linear aging rate " $\mathrm{a}$ " can be expressed in terms of a relative aging rate multiplying the baseline failure rate, i.e.

$$
\mathrm{a}=\alpha \lambda_{0}
$$

where 
$\alpha=$ the component relative aging rate (expressed as the percent increase in $\lambda_{\circ}$ per year).

A calculational formula can then be obtained which express the parameters in commonly used units. For $\lambda_{0}$ in units of per hour, $\alpha$ in units of the fractional change per year, $T$ in months, $d$ in hours, $L$ in years, then

$$
\begin{aligned}
q= & 1-\exp \left[-\frac{1}{2} \lambda_{\mathrm{o}} 8760 \frac{\mathrm{T}}{12}-\frac{1}{6} \alpha \lambda_{\mathrm{o}} 8760\left(\frac{\mathrm{T}}{12}\right)^{2}\right. \\
& \left.-\frac{1}{4} \alpha \lambda_{\mathrm{o}} 8760 \frac{\mathrm{T}}{12}\left(\mathrm{~L}-\frac{\mathrm{T}}{12}\right)\right]+\frac{\mathrm{d} / 8760}{\mathrm{~L}+\mathrm{d} / 8760}
\end{aligned}
$$

In the above formulas, the total component unavailability q calculated is the total average component unavailability averaged over time. This is also the type of unavailability calculated in PRAs.

\section{No Additional Testing}

For no additional testing besides the IST, the total component unavailability $q$ associated with the IST is

$$
q=1-\exp \left[-\frac{1}{2} \lambda_{o} L-\frac{1}{6} \mathrm{aL}^{2}\right]+\frac{\mathrm{d}}{\mathrm{L}+\mathrm{d}}
$$

For $\lambda_{o}$ in units of per hour, $\alpha$ in units of the fractional change in failure rate per year, $d$ in hours, and $L$ in years, the corresponding calculational equation becomes

$$
q=1-\exp \left[-\frac{1}{2} \lambda_{0} 8760 L-\frac{1}{6} \alpha \lambda_{o} 8760 L^{2}\right]+\frac{d / 8760}{L+d / 8760}
$$

As described in Appendix A, the above formulas are first order formulas as used in PRAs. These formulas are obtained by averaging the time-dependent exponent in the unavailability expression which yields accurate values for unavailability less then 0.1 and is slightly conservative otherwise.

\subsection{Formulas When the Component is Not Renewed as a Result of the IST}

When there is minimal overhaul or correction of degradations as a follow-up to the IST then the IST serves only as an operational test, checking the availability of the component. The component is thus basically "good as old" after each IST. Since the IST is now an operational test, Equation (22) in Section 7.1 for an intermediate, operational test is applicable where the IST is now the operational test and the component is replaced or is renewed at the end of its lifetime. If the component is not replaced or renewed during the plant lifetime, then the component lifetime is equal to the plant lifetime, e.g. 40 years.

Thus, in the exponent in Equation (22), the IST interval $\mathrm{L}$ is substituted for the operational test interval $\mathrm{T}$ and the component lifetime $S$ is substituted for the renewal interval $L$. The last term on the right hand side of the equation is not changed since it is the downtime contribution associated with the IST interval L. Consequently, the equation for the total unavailability $q$ becomes

$$
q=1-\exp \left[-\lambda_{0} \frac{L}{2}-a \frac{L^{2}}{6}-a \frac{L}{2} \frac{S}{2}\right]+\frac{d}{L+d}
$$


In the above equation the factor $\frac{S}{2}$ is used instead of $(S-L) / 2$ where it is assumed that $S$ is significantly larger than the IST
interval L.*

The corresponding calculational formula is

$$
q=1-\exp \left[-\frac{1}{2} \lambda_{0} 8760 L-\frac{1}{6} \alpha \lambda_{0} 8760 L^{2}-\frac{1}{4} \alpha \lambda_{o} 8760 L S\right]+\frac{d / 8760}{L+d / 8760} \text {. }
$$

Since this is no corrective maintenance following the IST, the average downtime $d$ per IST is the test downtime $d_{1}$.

\subsection{Formulas When the Component is in a Partially Renewed State After the IST With Follow-up Selected Corrective Maintenance}

When the component is partially renewed as a result of corrective maintenance following the IST then only certain pieceparts are replaced or refurbished if they are degraded, which constitute a fraction of the component's failure modes. The fraction of failure modes that is renewed can be separately modeled by the IST renewal equation given previously, Equation (23). The fraction that is not renewed can be separately modeled by the previous IST non-renewal equation, Equation (25). For these evaluations, the case for no additional, operational testing will be used since the IST serves as the operational test on those failure modes not renewed.

Let

$$
\begin{aligned}
& \mathrm{f}=\text { the fraction of the failure modes renewed as the result of corrective maintenance } \\
& \text { following the IST } \\
& \mathrm{q}_{\mathrm{r}}=\text { the renewed component unavailability corresponding to the fraction } \mathrm{f} \text { of failure modes } \\
& \text { renewed } \\
& \mathrm{q}_{\mathrm{n}}=\text { the nonrenewal component unavailability corresponding to the fraction }(1-\mathrm{f}) \text { of failure } \\
& \text { modes non-renewed } \\
& \mathrm{q}=\text { the total component unavailability. }
\end{aligned}
$$

Then from Equation (23)

$$
q_{r}=1-\exp \left[-\frac{1}{2} f \lambda_{o} L-\frac{1}{6} f a L^{2}\right]+\frac{f d}{L+d}
$$

From Equation (25)

$$
q_{n}=1-\exp \left[-(1-f) \lambda_{0} \frac{L}{2}-(1-f) a \frac{L^{2}}{6}-(1-f) a \frac{L}{2} \frac{S}{2}\right]+(1-f) \frac{d}{L+d}
$$

The total unavailability $q$ is then

** The factor $(\mathrm{L}-\mathrm{T}) / 2$ in the original equation, instead of $\mathrm{L} / 2$, covered those cases when $\mathrm{T}$ was comparable or equal to $\mathrm{L}$. 


$$
\begin{aligned}
q= & 1-\left(1-q_{r}\right)\left(1-q_{n}\right) \\
& =q_{r}+q_{n}-q_{r} q_{n} .
\end{aligned}
$$

In Equations (31) and (32) the IST downtime contribution $d /(L+d)$ is allocated according to renewal fraction $f$. It could have as equally well been treated as a separate contributor. The total downtime contribution $d /(L+d)$ is what enters in $q$. The average downtime $d$ per IST is again the sum of the test downtime $d_{1}$ plus the maintenance downtime $d_{2}$ per IST.

The corresponding calculational equations are:

$$
q_{r}=1-\exp \left[-\frac{1}{2} f \lambda_{0} 8760 L-\frac{1}{6} f \alpha \lambda_{o} L^{2}\right]+f \frac{d / 8760}{L+d / 8760}
$$

and

$$
\begin{aligned}
\mathrm{q}_{\mathrm{n}}= & 1-\exp \left[-\frac{1}{2}(1-\mathrm{f}) \lambda_{\mathrm{o}} 8760 \mathrm{~L}-\frac{1}{6}(1-\mathrm{f}) \alpha \lambda_{\mathrm{o}} 8760 \mathrm{~L}^{2}-\frac{1}{4}(1-\mathrm{f}) \alpha \lambda_{\mathrm{o}} 8760 \mathrm{LS}\right] \\
& +(1-\mathrm{f}) \frac{\mathrm{d} / 8760}{\mathrm{~L}+\mathrm{d} / 8760}
\end{aligned}
$$




\section{Formulas for the Component Unavailability When Aging is Described by the Nonlinear Weibull Aging Model}

The formulas for the component unavailability versus IST are presented in this section when component aging is described by the nonlinear Weibull model defined in Section 4 . The formulas are generalizations of the linear aging formulas given in the previous section and are derived in Appendix A.

\subsection{Formulas When the Component is in a Renewed State After the IST With Follow-up Corrective Maintenance}

As previously indicted, for complete renewal as a follow-up to the IST when degradations are detected, the component is essentially "good as new" after each IST. For nonlinear aging behaviors, the appropriate formula again depends upon whether there is additional, operational testing of the component.

\section{Additional Intermediate Testing}

For nonlinear, Weibull aging and for intermediate operational testing conducted in addition to the IST, the total component unavailability is given by the formula,

$$
\begin{aligned}
\mathrm{q}= & 1-\exp \left[-\lambda_{0} \frac{\mathrm{T}}{2}-\frac{\mathrm{b}}{(\mathrm{c}+1)(\mathrm{c}+2)(\mathrm{c}+3)} \frac{(\mathrm{L}+\mathrm{T})^{\mathrm{c}+3}}{\mathrm{LT}}+\frac{\mathrm{b}}{(\mathrm{c}+1)(\mathrm{c}+2)(\mathrm{c}+3)} \frac{\mathrm{T}^{\mathrm{c}+2}}{\mathrm{~L}}\right. \\
& \left.+\frac{\mathrm{b}}{(\mathrm{c}+1)(\mathrm{c}+2)} \mathrm{L}^{\mathrm{c}+1}\right]+\frac{\mathrm{d}}{\mathrm{L}+\mathrm{d}}
\end{aligned}
$$

where

$$
\mathrm{b}=\text { the Weibull aging rate scale parameter }
$$

and

$$
\mathrm{c}=\text { the Weibull aging rate shape parameter }
$$

and where the other parameters are the same as defined for the linear aging formula.

The above formula is again a first order formula. For $b$ expressed in terms of a relative aging rate then $b$ in the above formula is given

$$
b=\alpha \lambda_{0}
$$

where

$$
\alpha=\text { the component relative aging rate (expressed as percent increase in } \lambda_{\mathrm{o}} \text { per year). }
$$

A calculational formula expressing the parameters in commonly used units can be obtained from the above formula. For $\lambda_{0}$ in units of per hour, $\alpha$ in units of fractional change per year, $T$ in months, $d$ in hours, $L$ in years, then for intermediate operational testing 


$$
\begin{aligned}
\mathrm{q}= & 1-\exp \left[-\frac{1}{2} \lambda_{\mathrm{o}} 8760 \frac{\mathrm{T}}{12}-\frac{\alpha \lambda_{\mathrm{o}} 8760}{(\mathrm{c}+1)(\mathrm{c}+2)(\mathrm{c}+3)} \frac{(\mathrm{L}+\mathrm{T} / 12)^{\mathrm{c}+3}}{\mathrm{LT} / 12}\right. \\
& +\frac{\alpha \lambda_{\mathrm{o}} 8760}{(\mathrm{c}+1)(\mathrm{c}+2)(\mathrm{c}+3)} \frac{\mathrm{L}^{\mathrm{c}+2}}{\mathrm{~T} / 12}+\frac{\alpha \lambda_{\mathrm{o}} 8760}{(\mathrm{c}+1)(\mathrm{c}+2)(\mathrm{c}+3)} \frac{(\mathrm{T} / 12)^{\mathrm{c}+2}}{\mathrm{~L}} \\
& \left.+\frac{\alpha \lambda_{\mathrm{o}} 8760}{(\mathrm{c}+1)(\mathrm{c}+2)} \mathrm{L}^{\mathrm{c}+1}\right]+\frac{\mathrm{d} / 8760}{\mathrm{~L}+\mathrm{d} / 8760} .
\end{aligned}
$$

\section{No Additional Testing}

For no intermediate operational testing in addition to the IST,

$$
q=1-\exp \left[-\frac{1}{2} \lambda_{0} L-\frac{b}{(c+1)(c+2)} L^{c+1}\right]+\frac{d}{L+d}
$$

The corresponding calculational formula is

$$
q=1-\exp \left[-\frac{1}{2} \lambda_{o} 8760 L-\frac{\alpha \lambda_{0} 8760}{(c+1)(c+2)} L^{c+1}\right]+\frac{d / 8760}{L+d / 8760}
$$

For the above nonlinear formulas, to obtain the most concise expression, the averaging of $q$ is carried out over the interval from 0 to $\mathrm{L}$ instead of from 0 to $\mathrm{L}-\mathrm{T}$ as done for the linear aging formula. Where desired $\mathrm{L}-\mathrm{T}$ can be substituted for $\mathrm{L}$ in the equations for direct analogy with the linear formula. The difference is insignificant for $L \gg T$.

\subsection{Formula When the Component is Not Renewed as a Result of the IST}

When there is no follow-up renewal or partial renewal following the IST, then the IST serves as an operational test only. The previous formula for additional, intermediate testing is applicable where the IST interval L is substituted for the operational test interval $T$ and the component lifetime $S$ is substituted for the renewal interval $L$. The downtime contribution $d /(L+d)$ remains unchanged since the downtime occurs at each IST. The formula for the total unavailability $q$ is then

$$
\begin{aligned}
\mathrm{q}= & 1-\exp \left[-\lambda_{0} \frac{\mathrm{L}}{2}-\frac{\mathrm{b}}{(\mathrm{c}+1)(\mathrm{c}+2)(\mathrm{c}+3)} \frac{(\mathrm{S}+\mathrm{L})^{\mathrm{c}+3}}{\mathrm{SL}}+\frac{\mathrm{b}}{(\mathrm{c}+1)(\mathrm{c}+2)(\mathrm{c}+3)} \frac{\mathrm{L}^{\mathrm{c}+2}}{\mathrm{~S}}\right. \\
& \left.+\frac{\mathrm{b}}{(\mathrm{c}+1)(\mathrm{c}+2)(\mathrm{c}+3)} \frac{\mathrm{S}^{\mathrm{c}+2}}{\mathrm{~L}}+\frac{\mathrm{b}}{(\mathrm{c}+1)(\mathrm{c}+2)} \mathrm{S}^{\mathrm{c}+1}\right]+\frac{\mathrm{d}}{\mathrm{L}+\mathrm{d}}
\end{aligned}
$$

The corresponding calculational formula is

$$
\begin{aligned}
q= & 1-\exp \left[-\frac{1}{2} \lambda_{0} 8760 L-\frac{\alpha \lambda_{0} 8760}{(c+1)(c+2)(c+3)} \frac{(S+L)^{c+3}}{S L}+\frac{\alpha \lambda_{o} 8760}{(c+1)(c+2)(c+3)} \frac{L^{c+2}}{S}\right. \\
& \left.+\frac{\alpha \lambda_{o} 8760}{(c+1)(c+2)(c+3)} \frac{S^{c+2}}{L}+\frac{\alpha \lambda_{0} 8760}{(c+1)(c+2)} S^{c+1}\right]+\frac{d / 8760}{L+d / 8760}
\end{aligned}
$$




\subsection{Formula When the Component is in a Partially Renewed State After the IST With Follow-up Selected Corrective Maintenance}

For partial renewal after the IST with selected corrective maintenance, again let $f$ be the fraction of failure modes renewed, $q_{r}$ be the renewed unavailability, $\mathrm{q}_{\mathrm{n}}$ the non-renewed unavailability and $\mathrm{q}$ the total unavailability. Then $\mathrm{q}_{\mathrm{r}}$ is given by Equation (43) for the fraction of failure modes renewed and $\mathrm{q}_{\mathrm{n}}$ is given by Equation (45) for the fraction of failure modes nonrenewed.

Hence

$$
q_{r}=1-\exp \left[-\frac{1}{2} f \lambda_{o} L-\frac{f b}{(c+1)(c+2)} L^{c+1}\right]+\frac{f d}{L+d}
$$

and

$$
\begin{aligned}
q_{n} & =1-\exp \left[-(1-f) \lambda_{\circ} \frac{L}{2}-\frac{(1-f) b}{(c+1)(c+2)(c+3)} \frac{(S+L)^{c+3}}{S L}+\frac{(1-f) b}{(c+1)(c+2)(c+3)} \frac{L^{c+2}}{S}\right. \\
& \left.+\frac{(1-f) b}{(c+1)(c+2)(c+3)} \frac{S^{c+2}}{L}+\frac{(1-f) b}{(c+1)(c+2)} S^{c+1}\right]+\frac{(1-f) d}{L+d}
\end{aligned}
$$

and

$$
\begin{gathered}
q=1-\left(1-q_{r}\right)\left(1-q_{n}\right) \\
=q_{r}+q_{n}-q_{r} q_{n} .
\end{gathered}
$$

The corresponding calculational formulas are

$$
q_{r}=1-\exp \left[-\frac{1}{2} f \lambda_{o} 8760 L-\frac{f \alpha \lambda_{o} 8760}{(c+1)(c+2)} L^{c+1}\right]+\frac{f d / 8760}{L+d / 8760}
$$

and

$$
\begin{aligned}
\mathrm{q}_{\mathrm{n}} & =1-\exp \left[-\frac{1}{2}(1-\mathrm{f}) \lambda_{\mathrm{o}} 8760 \mathrm{~L}-\frac{(1-\mathrm{f}) \alpha \lambda_{\mathrm{o}} 8760}{(\mathrm{c}+1)(\mathrm{c}+2)(\mathrm{c}+3)} \frac{(\mathrm{S}+\mathrm{L})^{\mathrm{c}+3}}{\mathrm{SL}}\right. \\
& +\frac{(1-\mathrm{f}) \alpha \lambda_{\mathrm{o}} 8760}{(\mathrm{c}+1)(\mathrm{c}+2)(\mathrm{c}+3)} \frac{\mathrm{L}^{\mathrm{c}+2}}{\mathrm{~S}}+\frac{(1-\mathrm{f}) \alpha \lambda_{\mathrm{o}} 8760}{(\mathrm{c}+1)(\mathrm{c}+2)(\mathrm{c}+3)} \frac{\mathrm{S}^{\mathrm{c}+2}}{\mathrm{~L}} \\
& \left.+\frac{(1-\mathrm{f}) \alpha \lambda_{\mathrm{o}} 8760}{(\mathrm{c}+1)(\mathrm{c}+2)} \mathrm{S}^{\mathrm{c}+1}\right]+\frac{(1-\mathrm{f}) \mathrm{d} / 8760}{\mathrm{~L}+\mathrm{d} / 8760}
\end{aligned}
$$





\section{Application and Uncertainty Considerations}

As presented in the previous section, the component aging models which are utilized are the linear aging model $\left(\lambda(t)=\lambda_{\circ}+\right.$ at) and the Weibull aging model $\left(\lambda(t)=\lambda_{o}+b t^{c}\right)$. Thus, if one desires to use a specific model and specific results from this report for a given application, the most appropriate aging model and most appropriate parameter values need to be selected for the application. If sufficient failure data exists for the component or for the group of similar components then the most appropriate model and associated parameter values can be identified. Engineering knowledge can also be importantly utilized in selecting the appropriate model and ranges on the parameters. Guidelines have been given for selecting appropriate parameter values and bounds.

When there is a lack of failure data and engineering knowledge then there will be uncertainties as to which aging model and parameters are appropriate. For these situations, sensitivity and parametric studies can be carried out over a range of plausible aging behaviors. The observations and conclusions that are drawn from these parametric studies can be used to gain insights on the robustness of various IST alternatives in controlling the possible aging effects. The parametric studies that are carried out in the next section illustrate the types of studies that can be carried out and the types of conclusions that can be obtained. 



\section{Evaluations of Component Unavailability Versus IST Interval for Check Valves With Linear Aging}

To study the effects of aging for different ISTs and IST intervals, parametric studies are carried out to determine the unavailabilities of check valves versus IST interval for different check valve characteristics and IST characteristics. This section presents results for the linear aging model. The next section, Section 11, presents results for nonlinear aging behavior. For the linear aging behavior evaluated in this section, a range of check valve aging rates is used. The different IST parameters that are evaluated include whether an additional operational test is performed and its interval, the average downtime duration associated with the IST, and the interval at which the IST is performed. In reviewing the results of the parametric studies the focus should be on the relative changes which occur in the unavailability due to aging as compared to the no aging case.

The check valve unavailability curves versus IST interval are presented on the following pages; the accompanying tables are reproduced in Appendix B. The curves of check valve unavailability versus IST interval are organized into blocks, or groups, for ease of presentation. The blocks are organized by the renewal capability following the IST, i.e. whether the IST is followed by complete renewal, no renewal, or partial renewal of the component.

Block 1 covers cases of complete renewal as a follow-up to the IST when degradations are detected. Block 1 is defined by:

Block 1: Complete Renewal as a Follow-up to the IST

No Additional Testing or Additional Testing at $1 \mathrm{mo}$ or $12 \mathrm{mo}$

Linear Aging Rates of $0 \%, 3 \%, 5 \%, 10 \%, 30 \%, 50 \%, 100 \%$ per year

Baseline Check Valve Failure Rate of $1 \times 10^{-6} \mathrm{hr}^{-1}$ or $1 \times 10^{-7} \mathrm{hr}^{-1}$

IST Downtime of $0 \mathrm{hrs}, 8 \mathrm{hrs}, 72 \mathrm{hrs}$

The baseline check valve failure rates of $1 \times 10^{-6}$ per hour and $1 \times 10^{-7}$ per hour are selected to represent examples of failure rates that are typical of values used in PRA analysis for check valves found in nuclear industry practice. The failure rate value of $1 \times 10^{-6}$ per hour is generally typical for modeling the check valve failure mode of failure to close and the value of $1 \times 10^{-7}$ per hour is typical for failure to open. These are the failure modes which are generally modeled in PRAs. It is understood that specific plant data or a rigorous review of data for components with a given set of parameters (e.g., lift check valves in a dirty system) may provide a basis for different failure rate values. As indicated at the beginning of this section, however, in reviewing the results of the parametric studies, the focus should be on the relative changes in unavailability due to aging compared to the no aging case which do not strongly depend on the reference check valve failure rate selected.

Block 2 covers cases of nonrenewal following the IST. Block 2 is defined by:

Block 2: No Renewal as Follow-up to the IST

No Additional Operational Testing

Linear Aging Rates of $0 \%, 10 \%, 50 \%, 100 \%$ per year

Baseline Check Valve Failure Rate of $1 \times 10^{-6} \mathrm{hr}^{-1}$ or $1 \times 10^{-7} \mathrm{hr}^{-1}$

IST Downtime of $0 \mathrm{hrs}, 8 \mathrm{hrs}, 72 \mathrm{hrs}$

Block 3 covers partial renewal associated with the IST. Block 3 is defined by:

Block 3: Partial Renewal as Follow-up to the IST

Renewal Fraction of 0.1 or 0.5

No Additional Operational Testing

Linear Aging Rates of $0 \%, 10 \%, 50 \%, 100 \%$ per year

Baseline Check Valve Failure Rate of $1 \times 10^{-5} \mathrm{hr}^{-1}$ or $1 \times 10^{-7} \mathrm{hr}^{-1}$

IST Downtime of $0 \mathrm{hrs}, 8 \mathrm{hrs}, 72 \mathrm{hrs}$ 


\section{BLOCK 1. CURVES OF CHECK VALVE UNAVAILABLITY VERSUS IST INTERVAL FOR LINEAR AGING AND TOTAL RENEWAL AFTER THE IST}

Total Renewal Following the IST

No Additional Testing or Additional Testing at $1 \mathrm{mo}$ or $12 \mathrm{mo}$

Linear Aging Rates of $0 \%, 3 \%, 5 \%, 10 \%, 30 \%, 50 \%, 100 \%$ per year

Baseline Check Valve Failure Rate of $1 \times 10^{-6} \mathrm{hr}^{-1}$ or $1 \times 10^{-7} \mathrm{hr}^{-1}$

IST Associated Downtime of $0 \mathrm{hrs}, 8 \mathrm{hrs}, 72 \mathrm{hrs}$ 


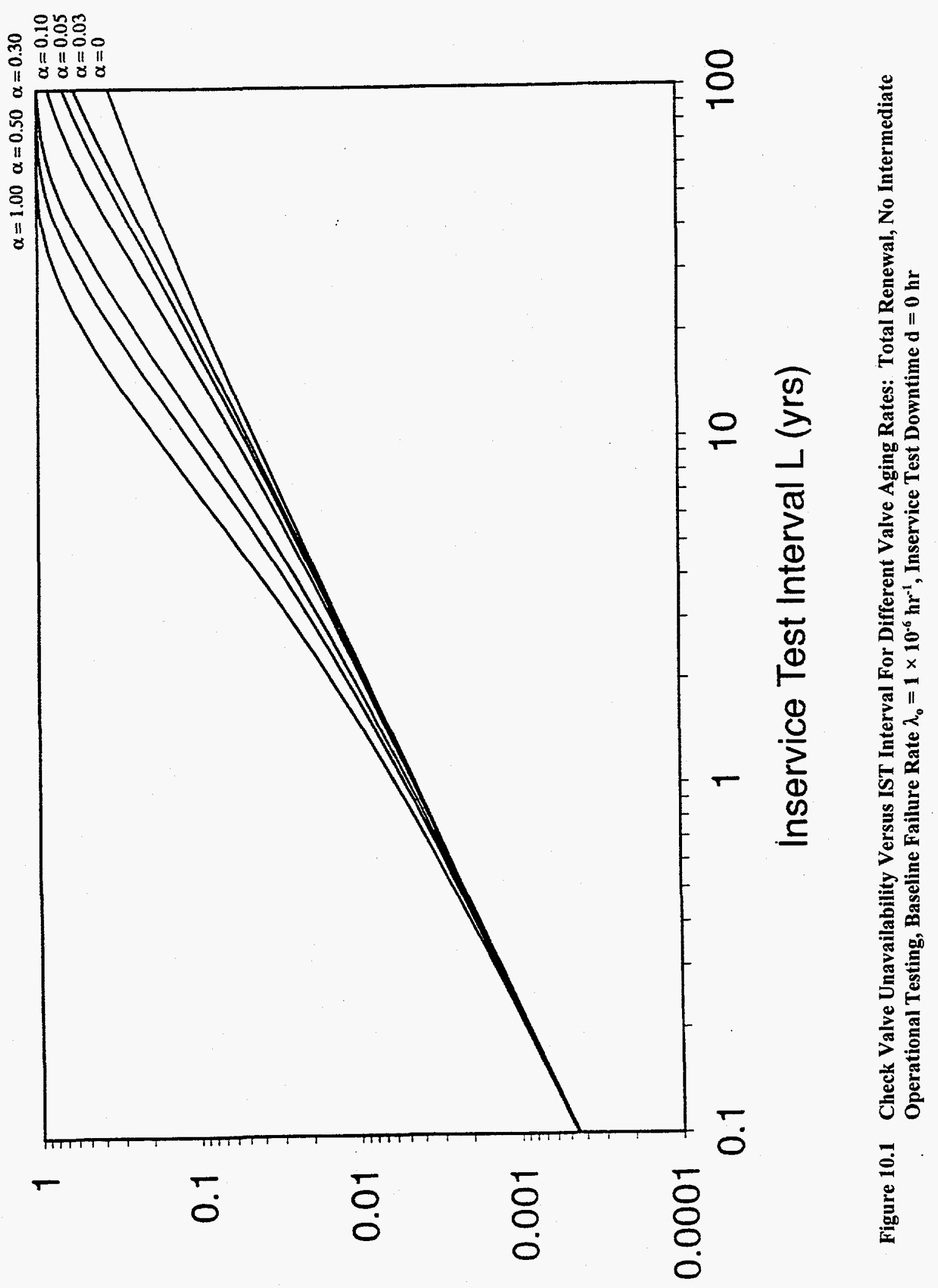

b אł!!!qe|!eseuก 


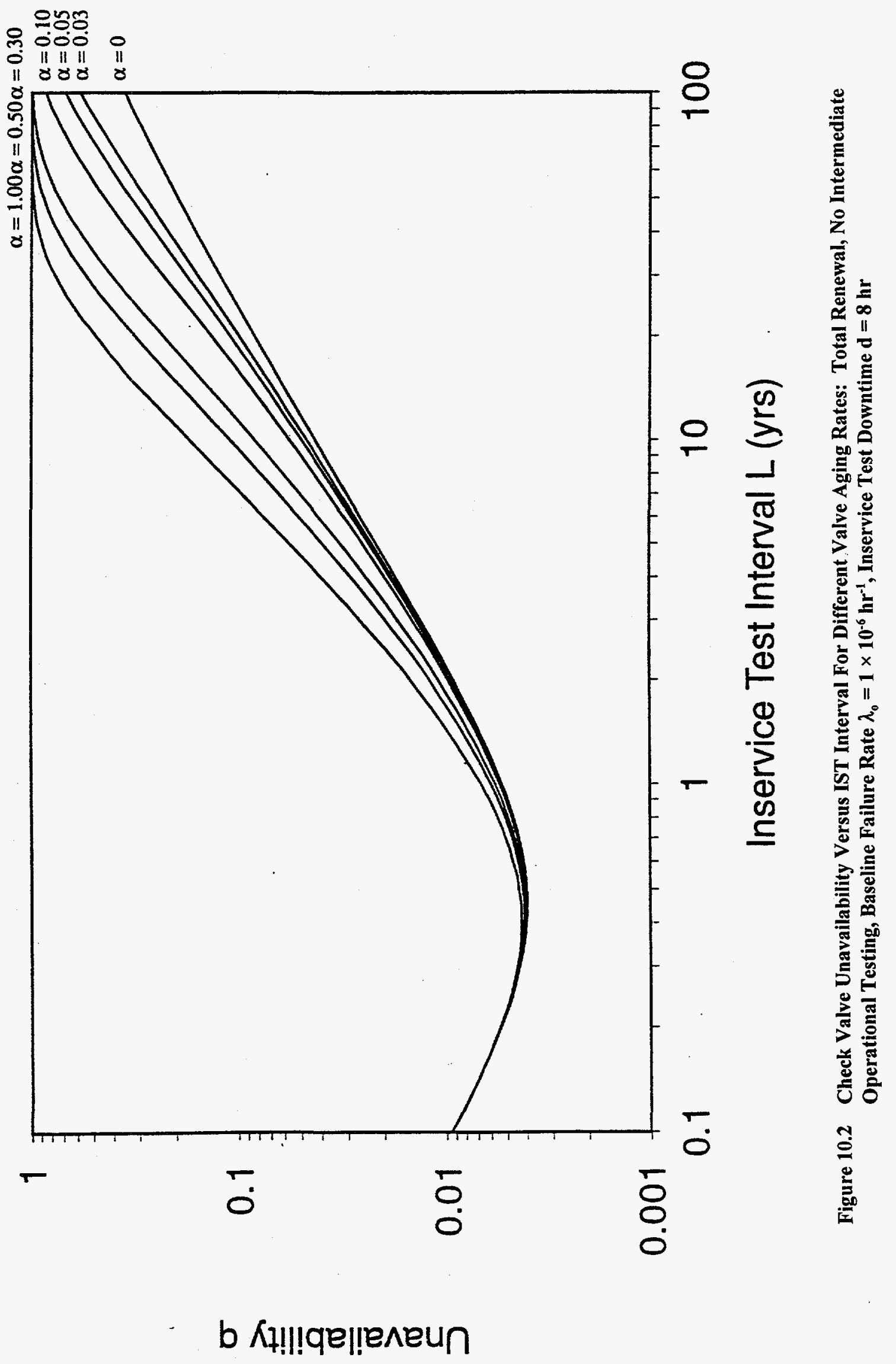




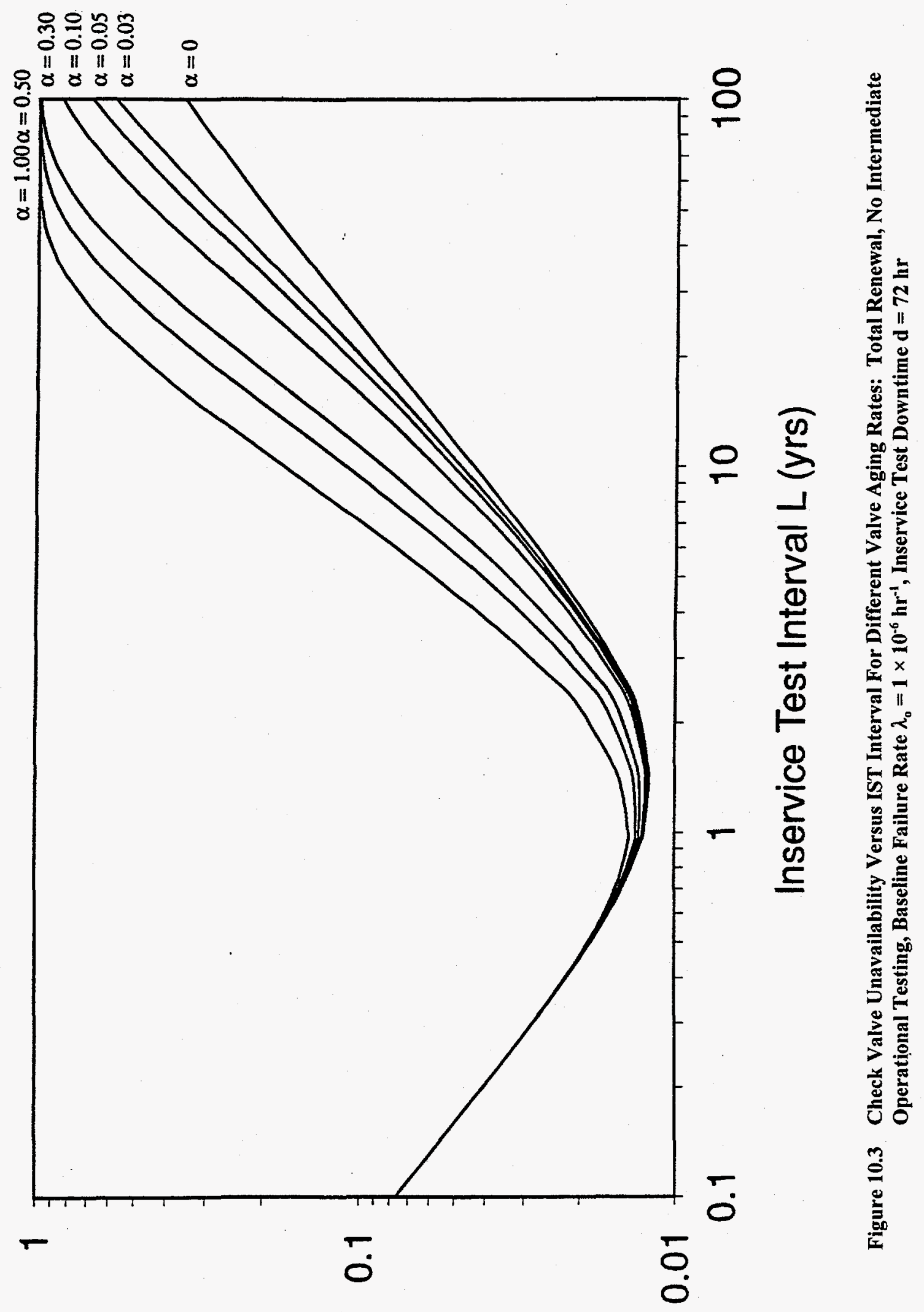

b א1!!!qe|!eseuก 


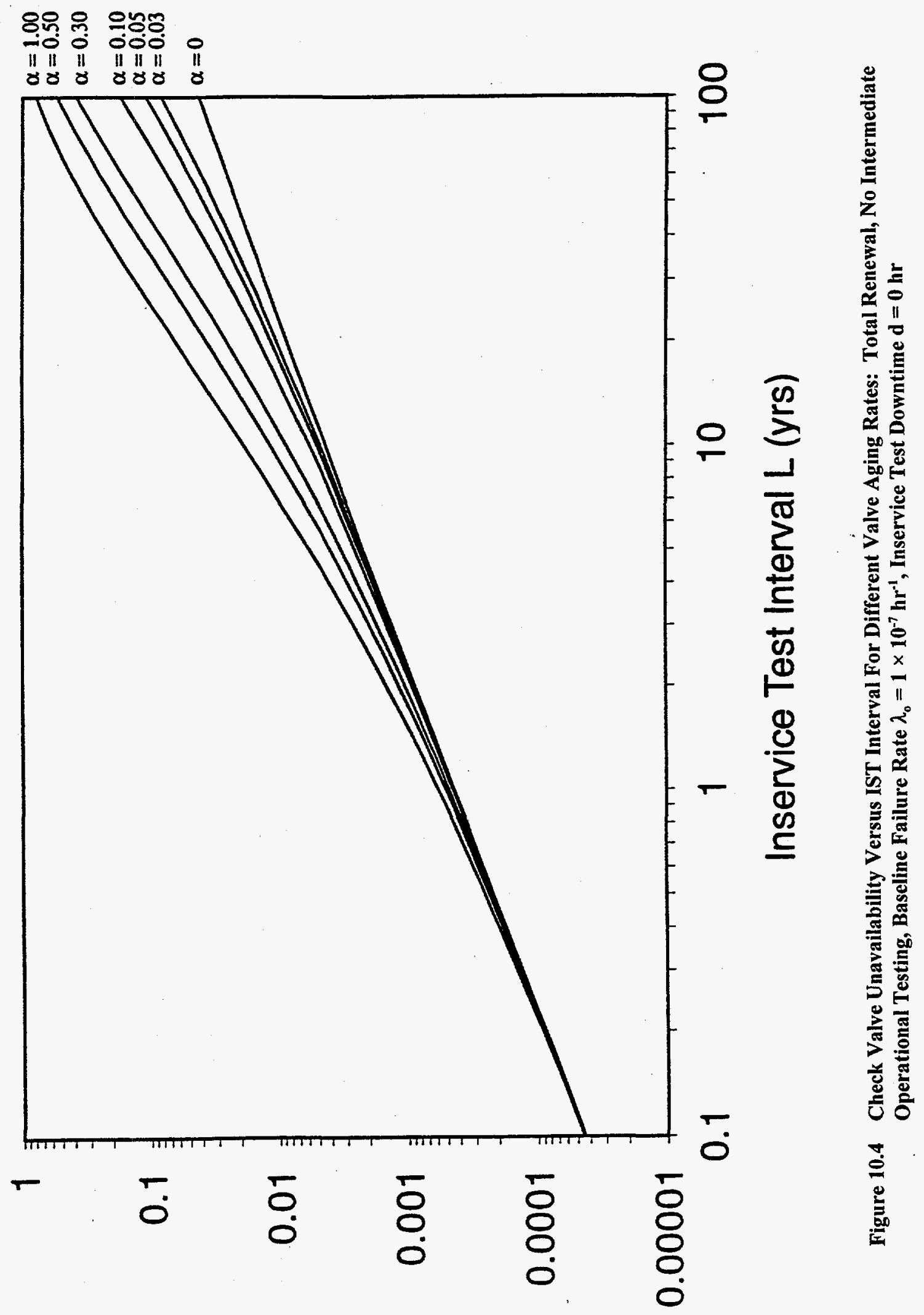

b א4!!!qe|!eлeuก 


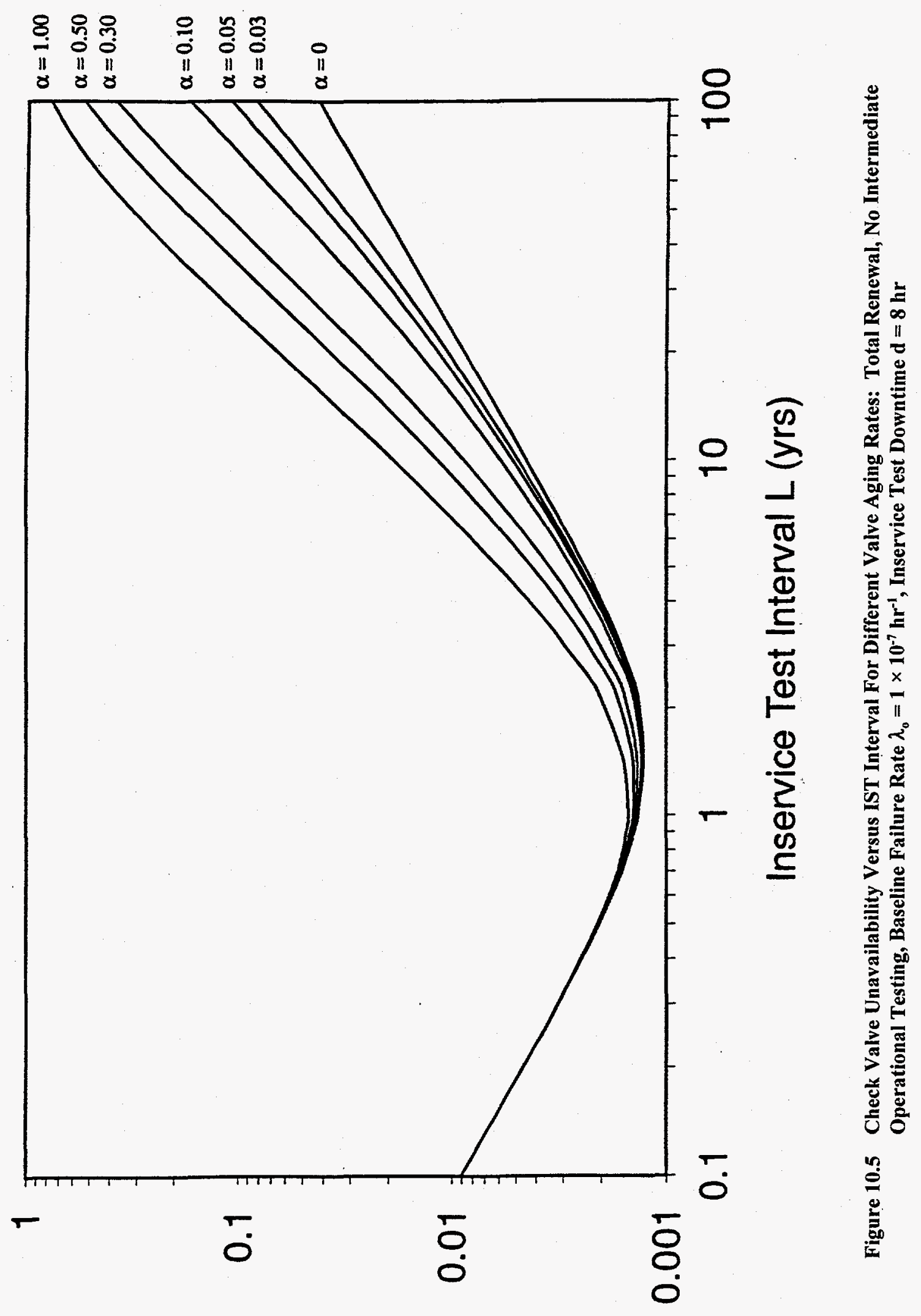

b אᄉ!!!qe|!eлеuก 


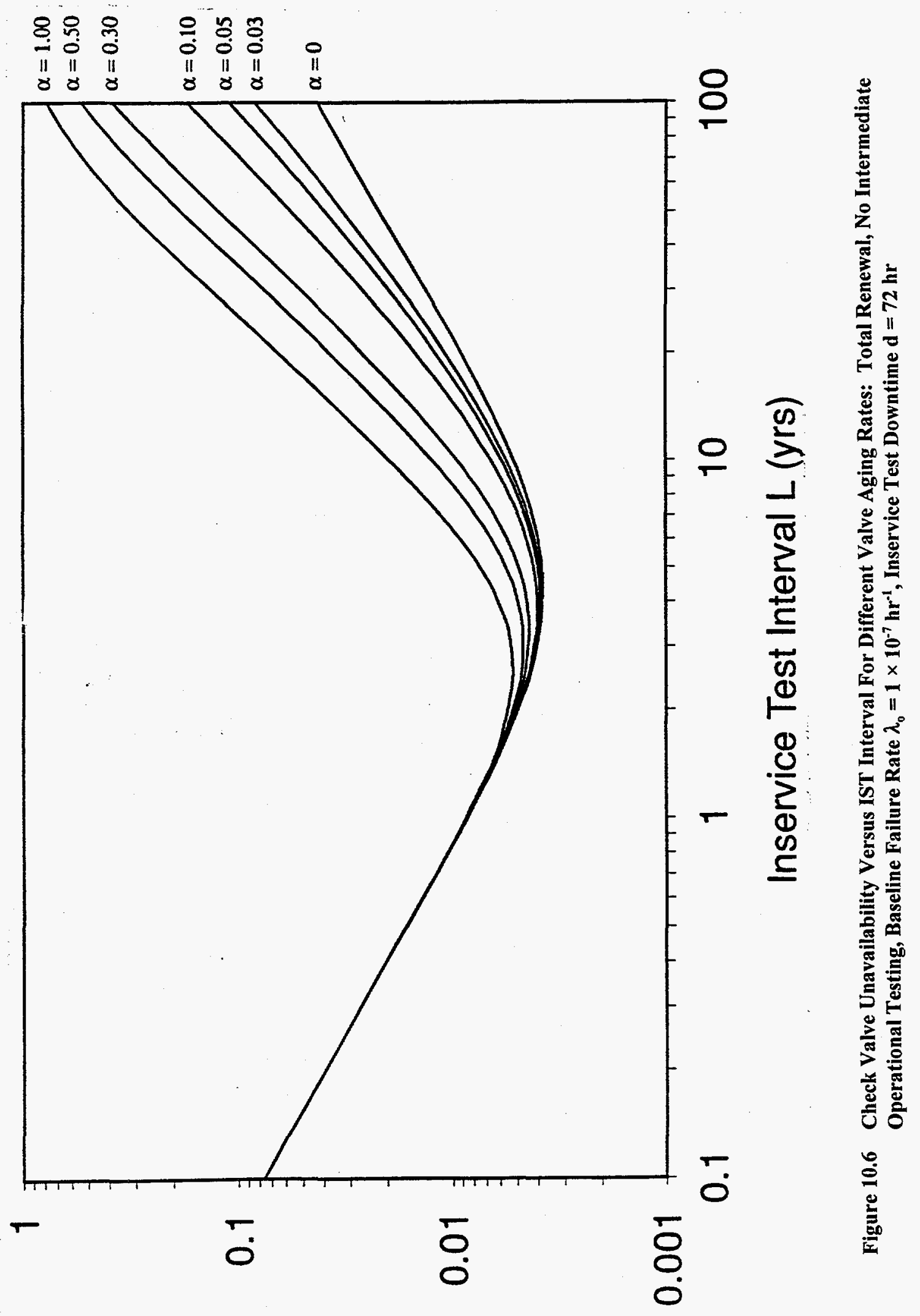

b אł!!!qej!eneuก 


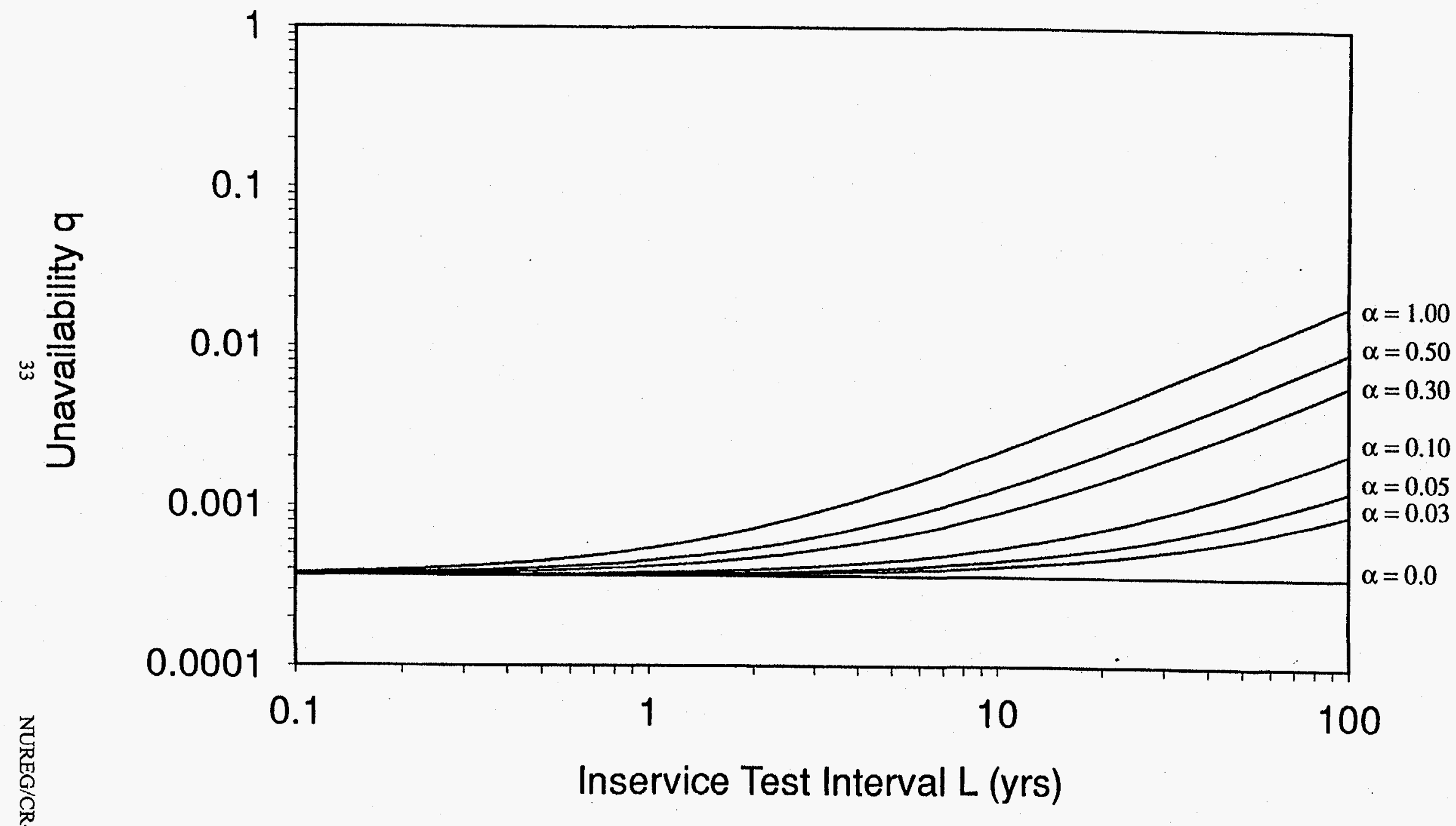

Figure 10.7 Check Valve Unavailability Versus IST Interval For Different Valve Aging Rates: Total Renewal, Baseline Failure Rate $\lambda_{0}=1 \times 10^{-6} \mathrm{hr}^{-1}$, Operational test interval T $=1 \mathrm{mo}$, Inservice Test Downtime $\mathrm{d}=0 \mathrm{hr}$ 


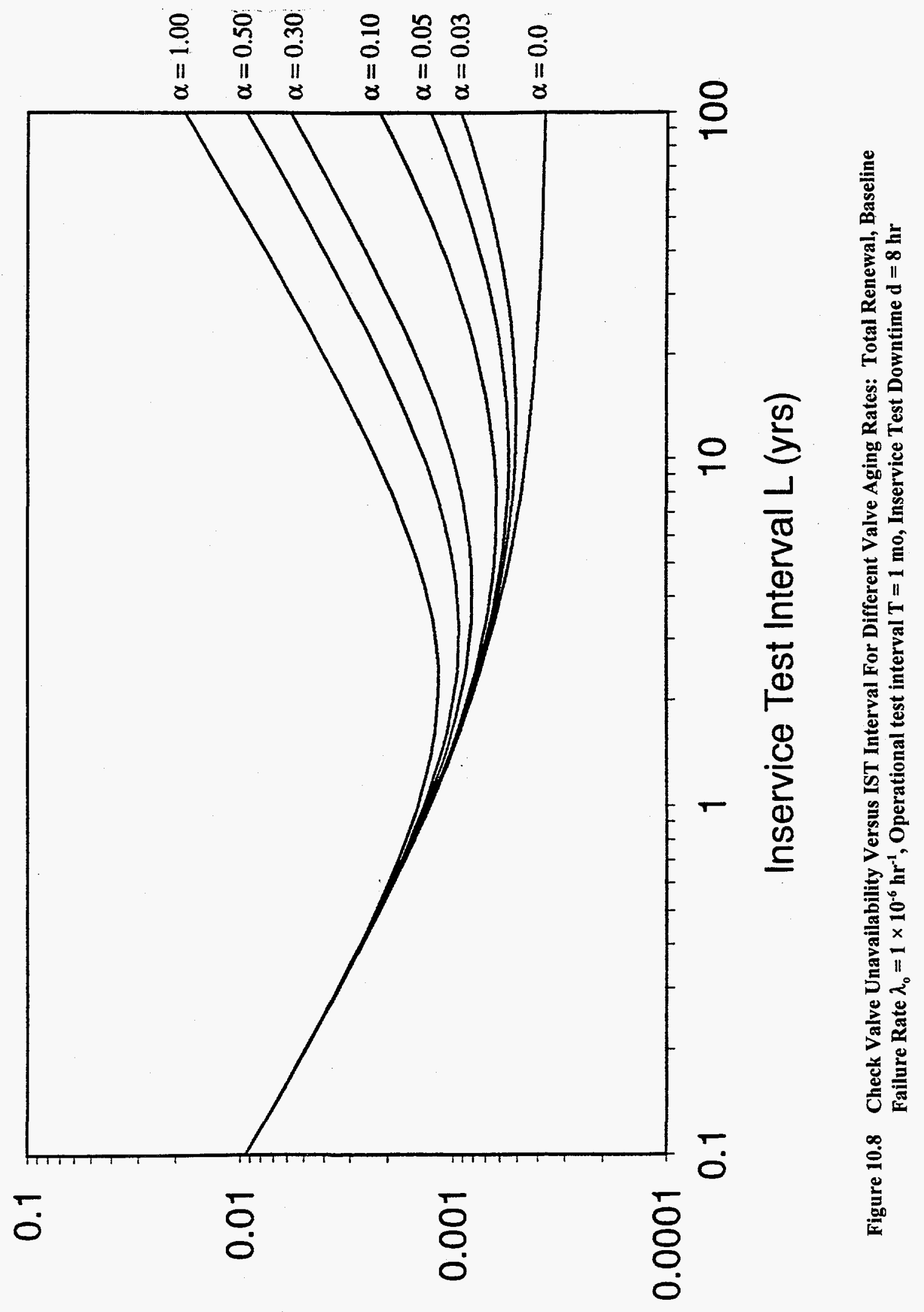

b Ri!!!qe|!eseun 


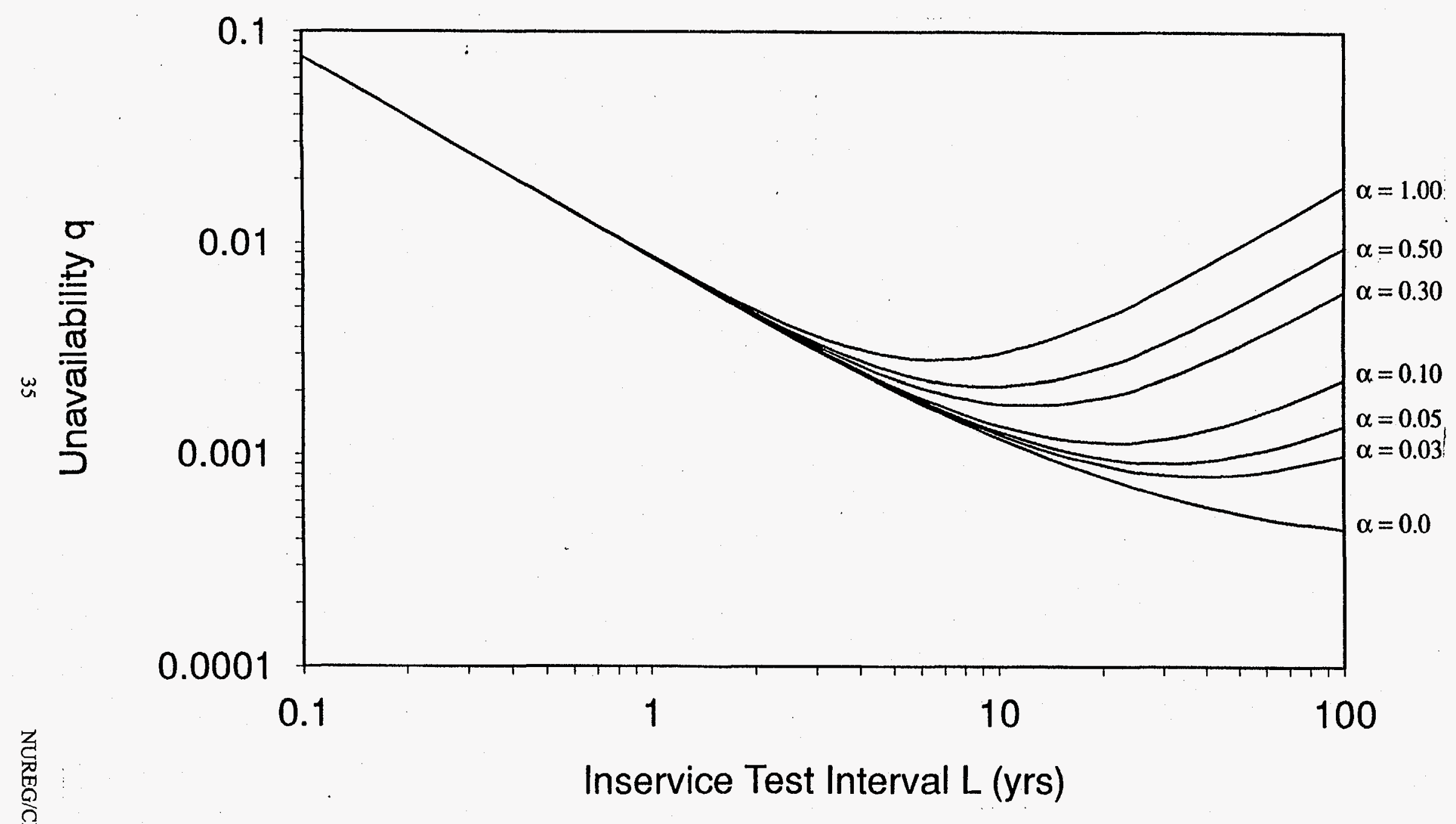

Figure 10.9 Check Valve Unavailability Versus IST Interval For Different Valve Aging Rates: Total Renewal, Baseline Failure Rate $\lambda_{0}=1 \times 10^{-6} \mathrm{hr}^{-1}$, Operational test interval $\mathrm{T}=1 \mathrm{mo}$, Inservice Test Downtime $\mathrm{d}=72 \mathrm{hr}$ 


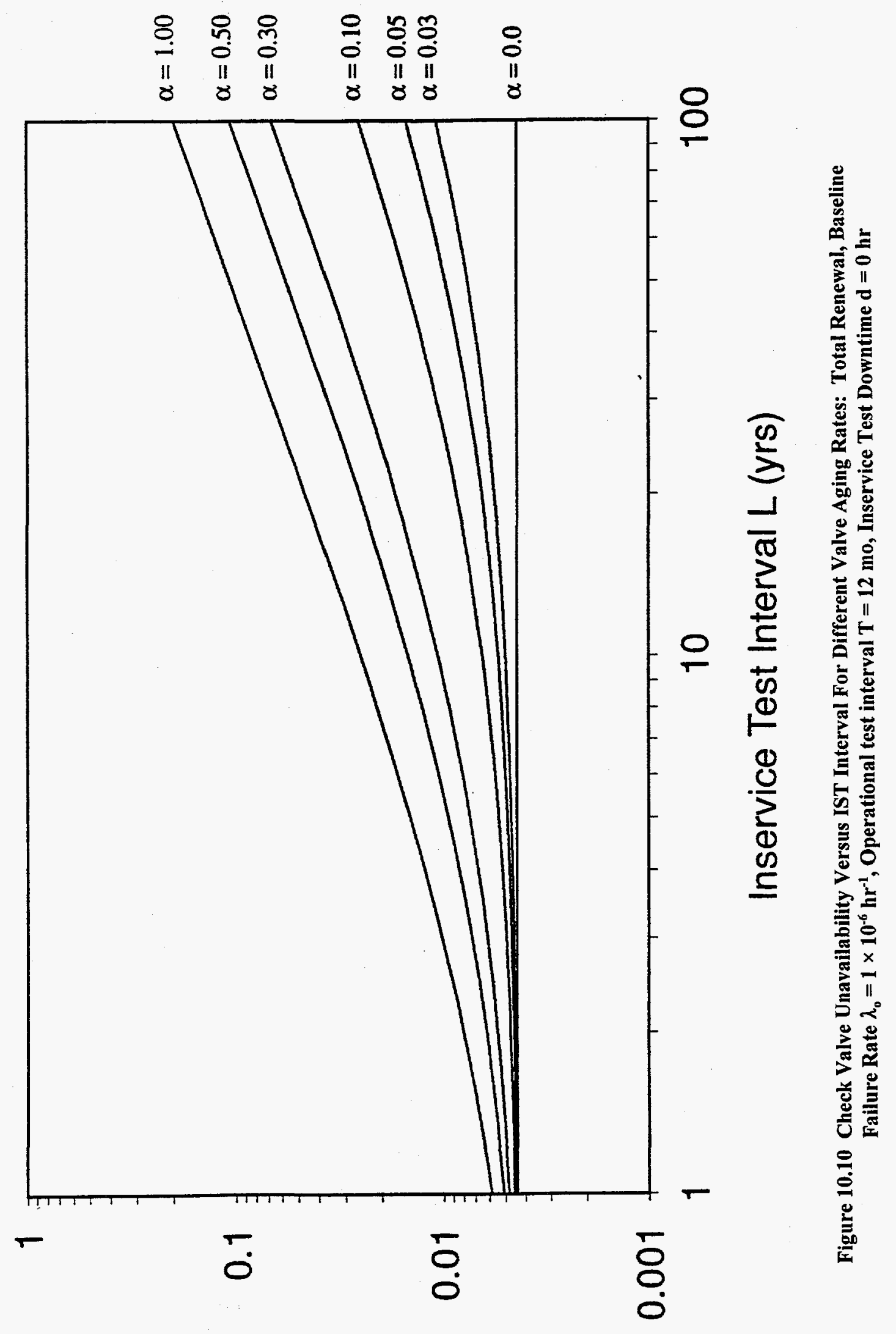

b אұ!!!qe|!eneuก 


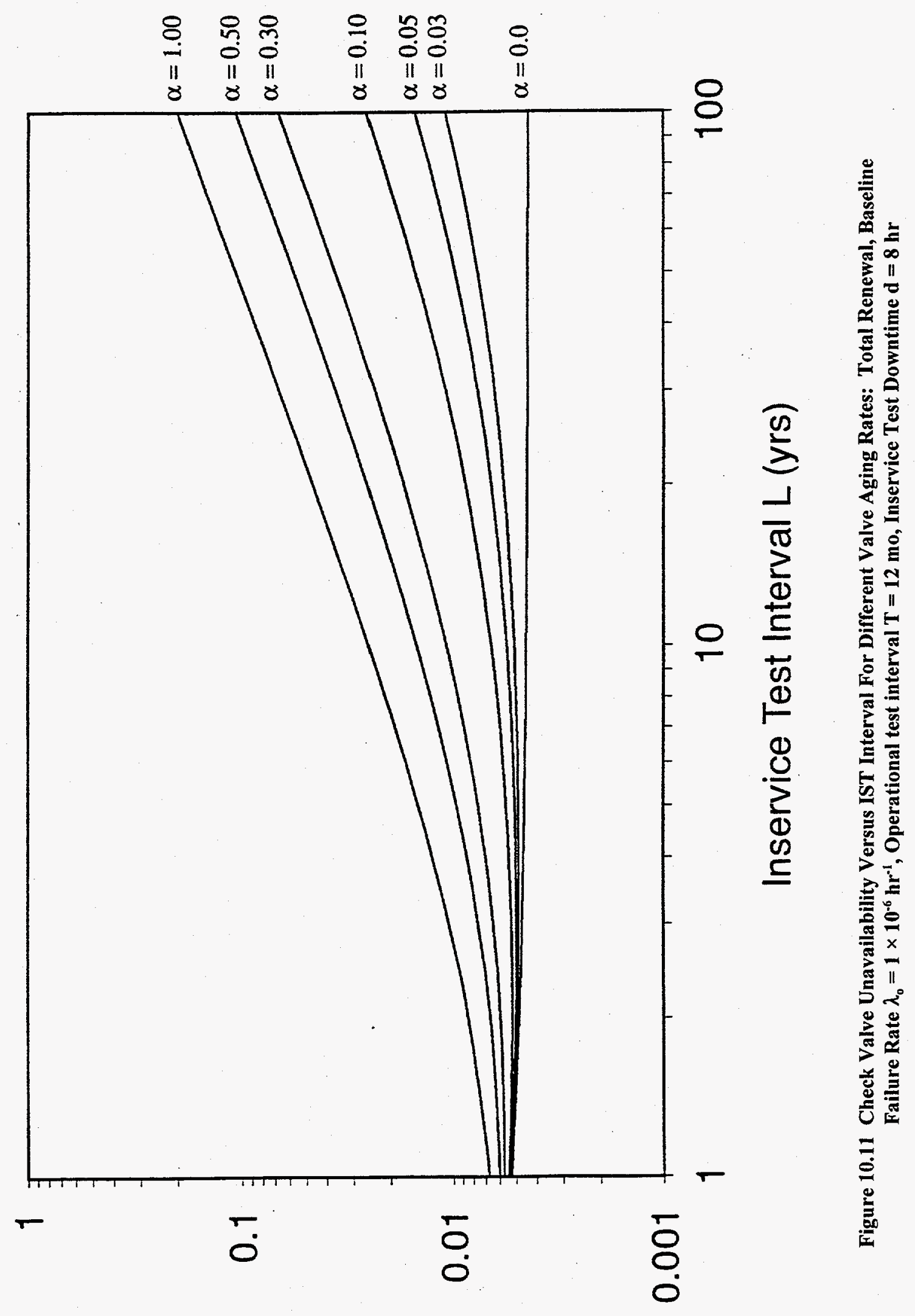

b K1!!!qe|!eseuก 


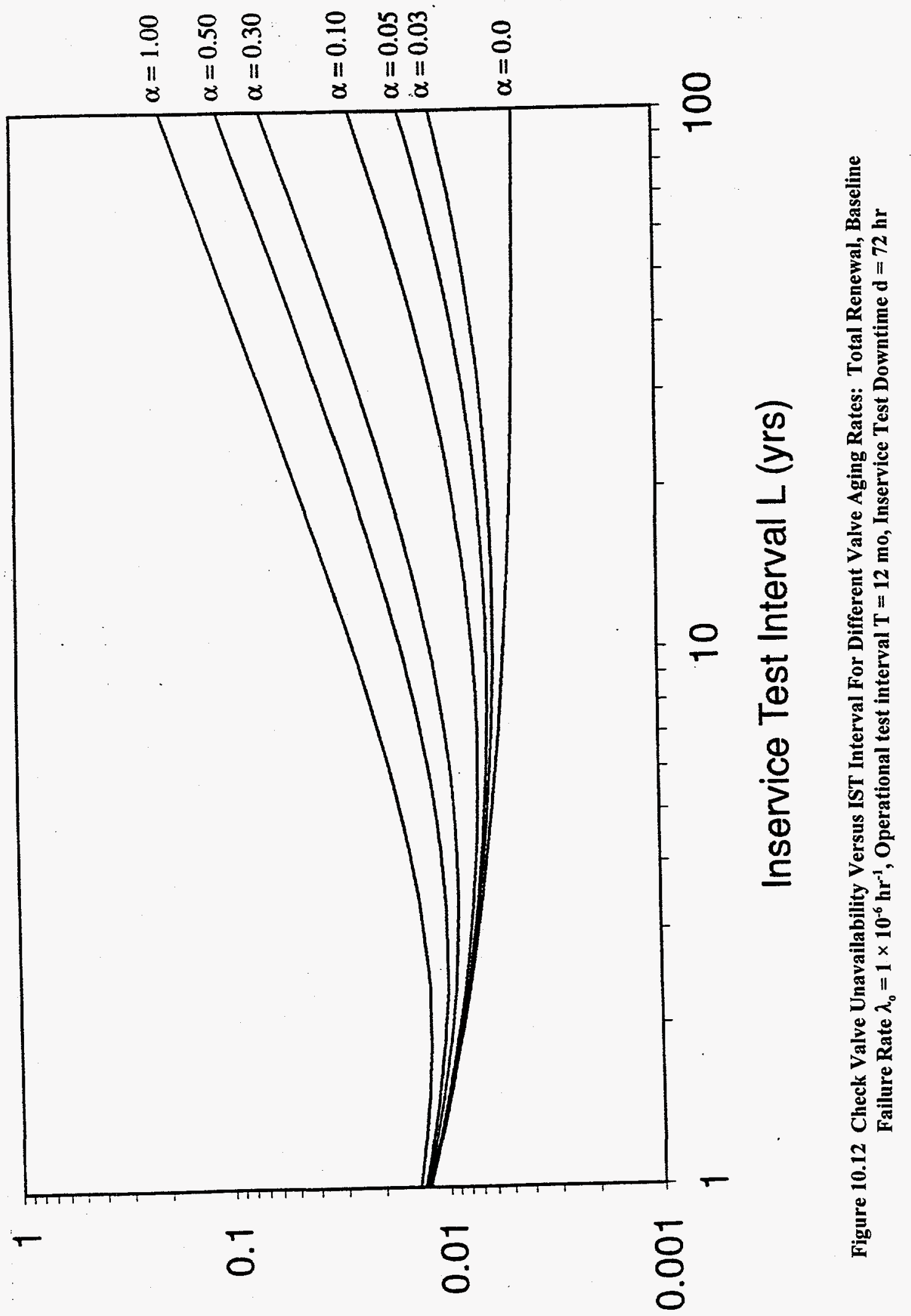

b Kł!!!qe|!eлеuก 


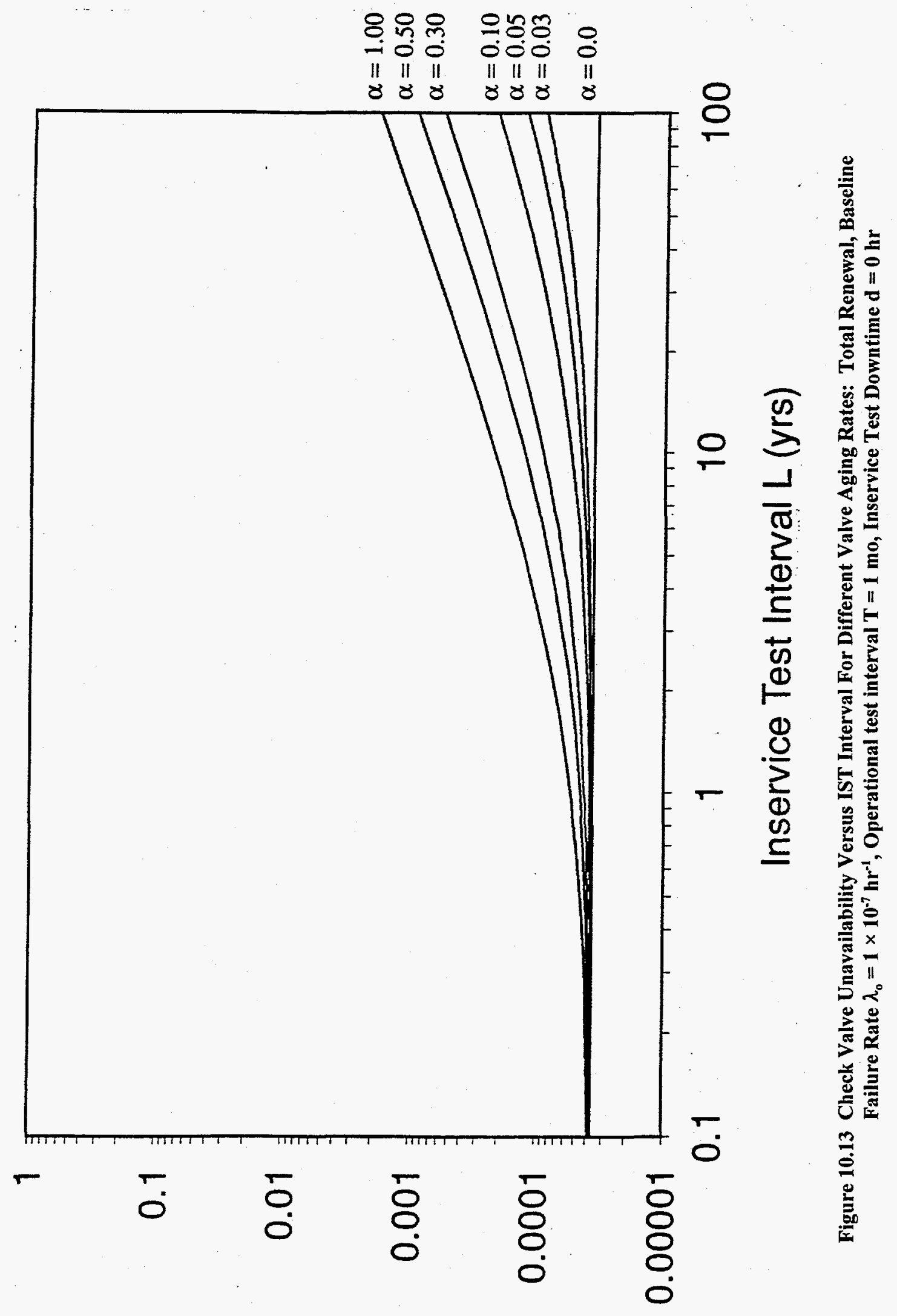

b אᄉ!!!qqe|!eseuก 


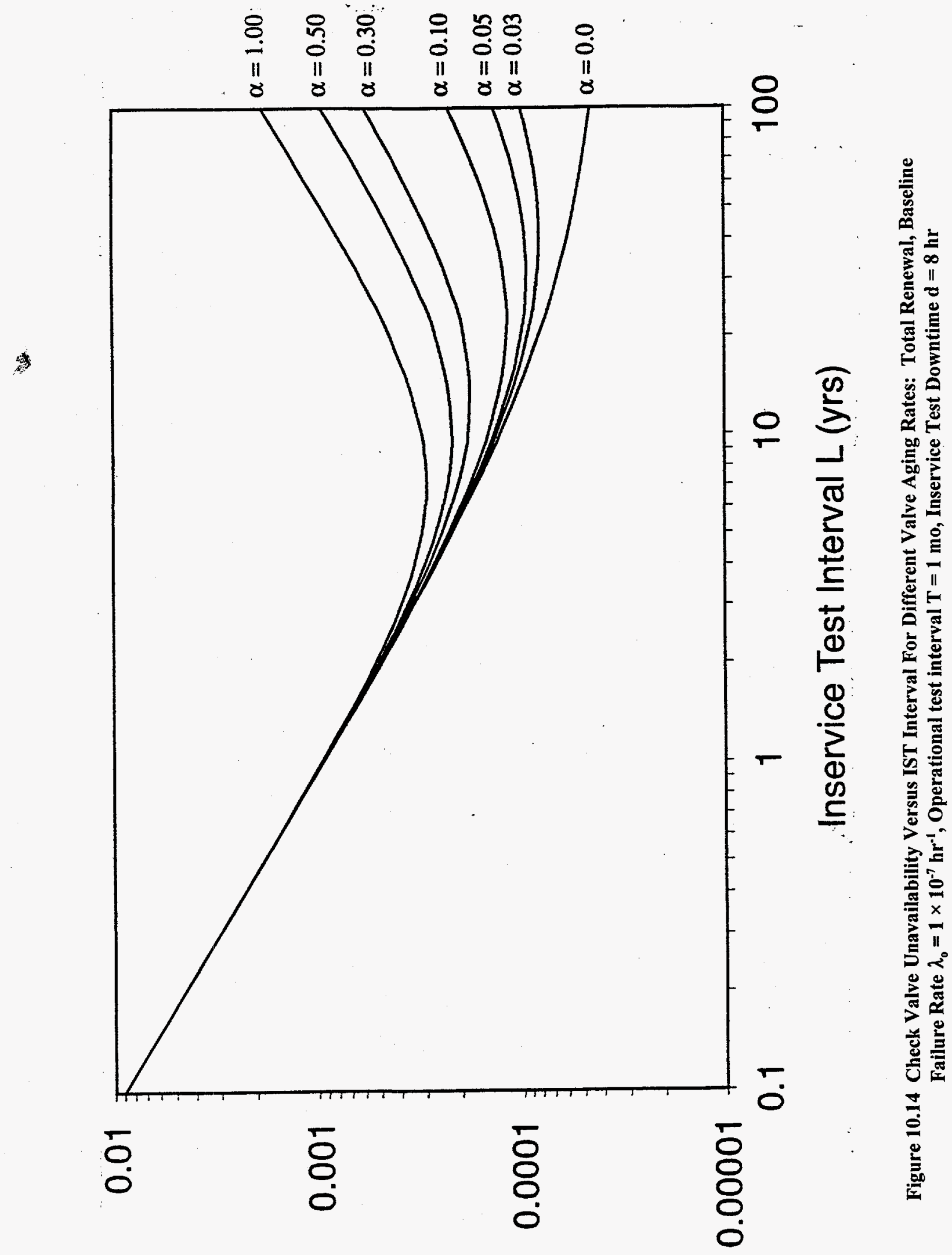

b אł!!!qe|!eseun 


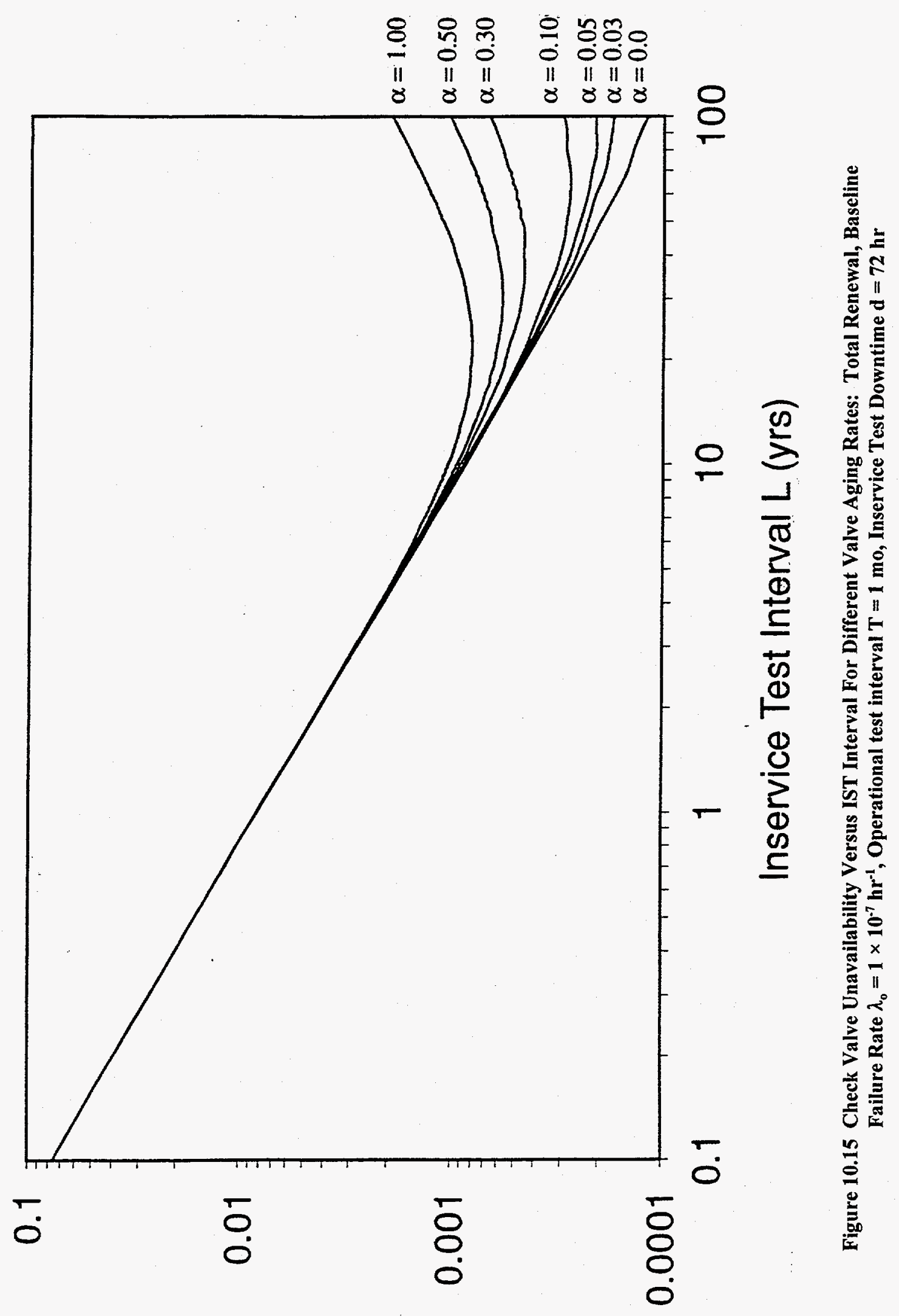

b Kł!!!qe!!e^euก 


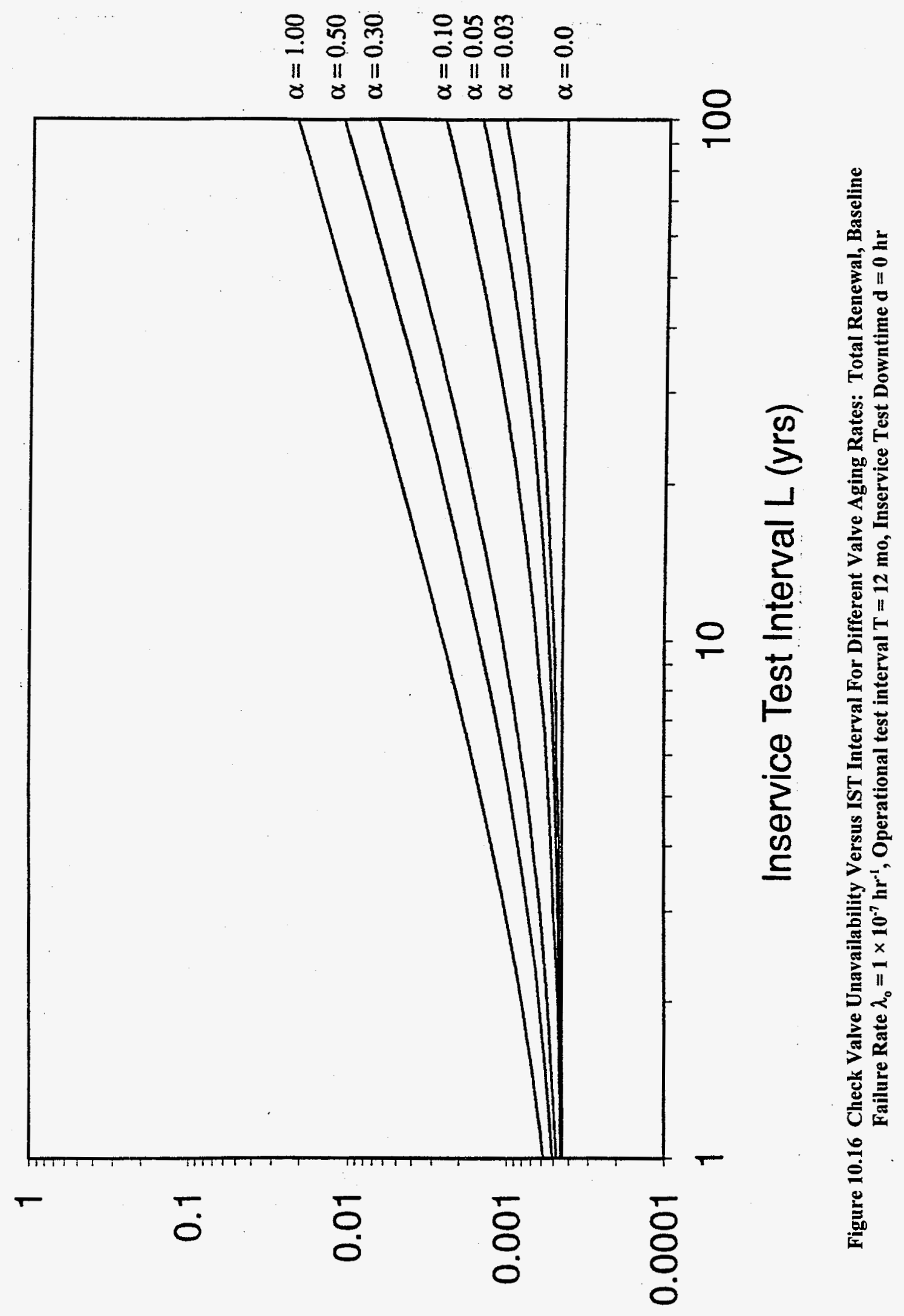

b K!!!!qe|!eneuก 


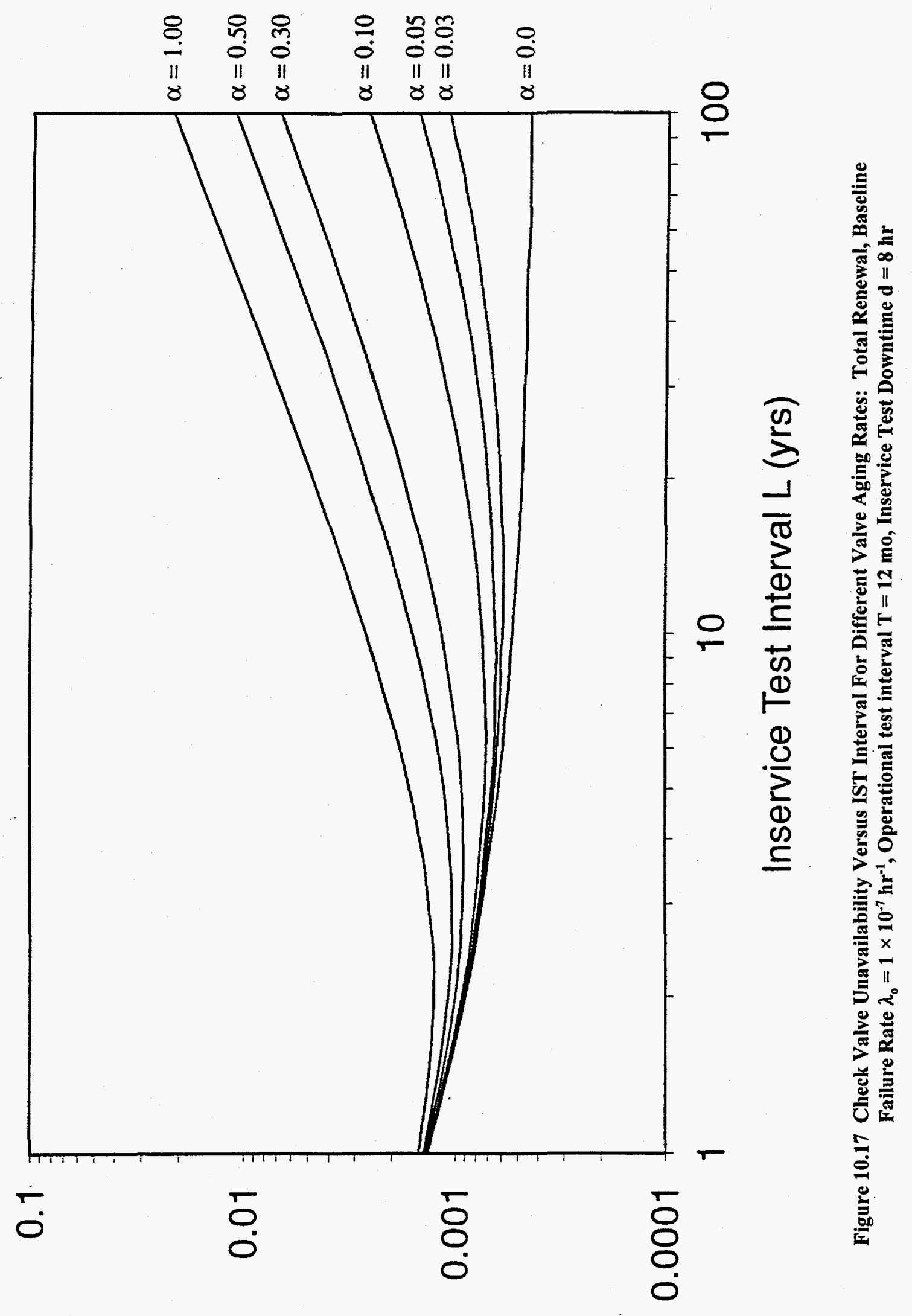

b אł!!!qe|!eseun 


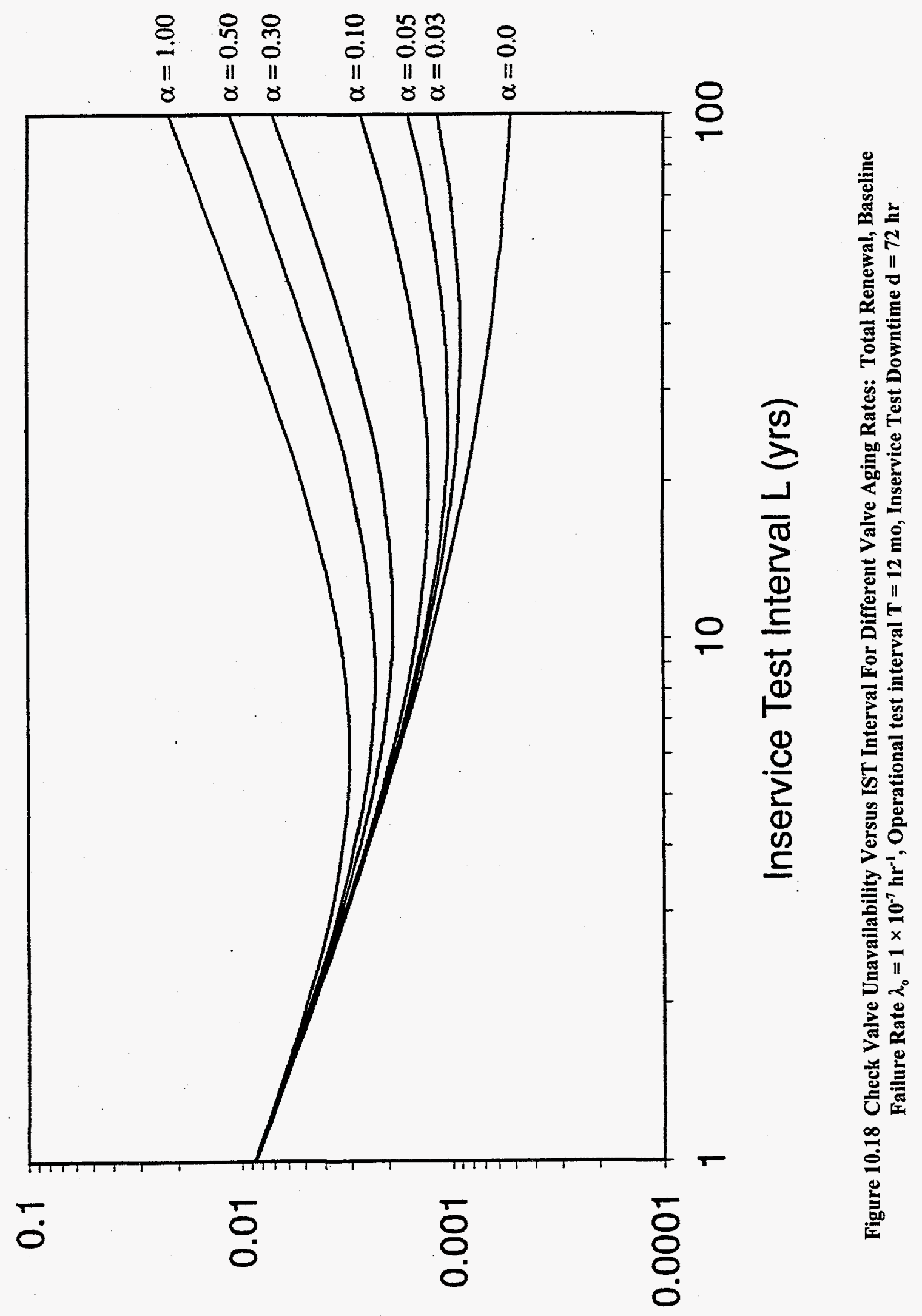

b אł!!!qe|!eseun 


\section{BLOCK 2. CURVES OF CHECK VALVE UNAVAILABILITY VERSUS IST INTERVAL FOR LINEAR AGING AND NO RENEWAL AFTER THE IST}

No Renewal Following the IST

No Additional Operational Testing

Linear Aging Rates of $0 \%, 10 \%, 50 \%, 100 \%$ per year

Baseline Check Valve Failure Rate of $1 \times 10^{-6} \mathrm{hr}^{-1}$ or $1 \times 10^{-7} \mathrm{hr}^{-1}$

IST Associated Downtime of $0 \mathrm{hrs}, 8 \mathrm{hrs}, 72 \mathrm{hrs}$ 


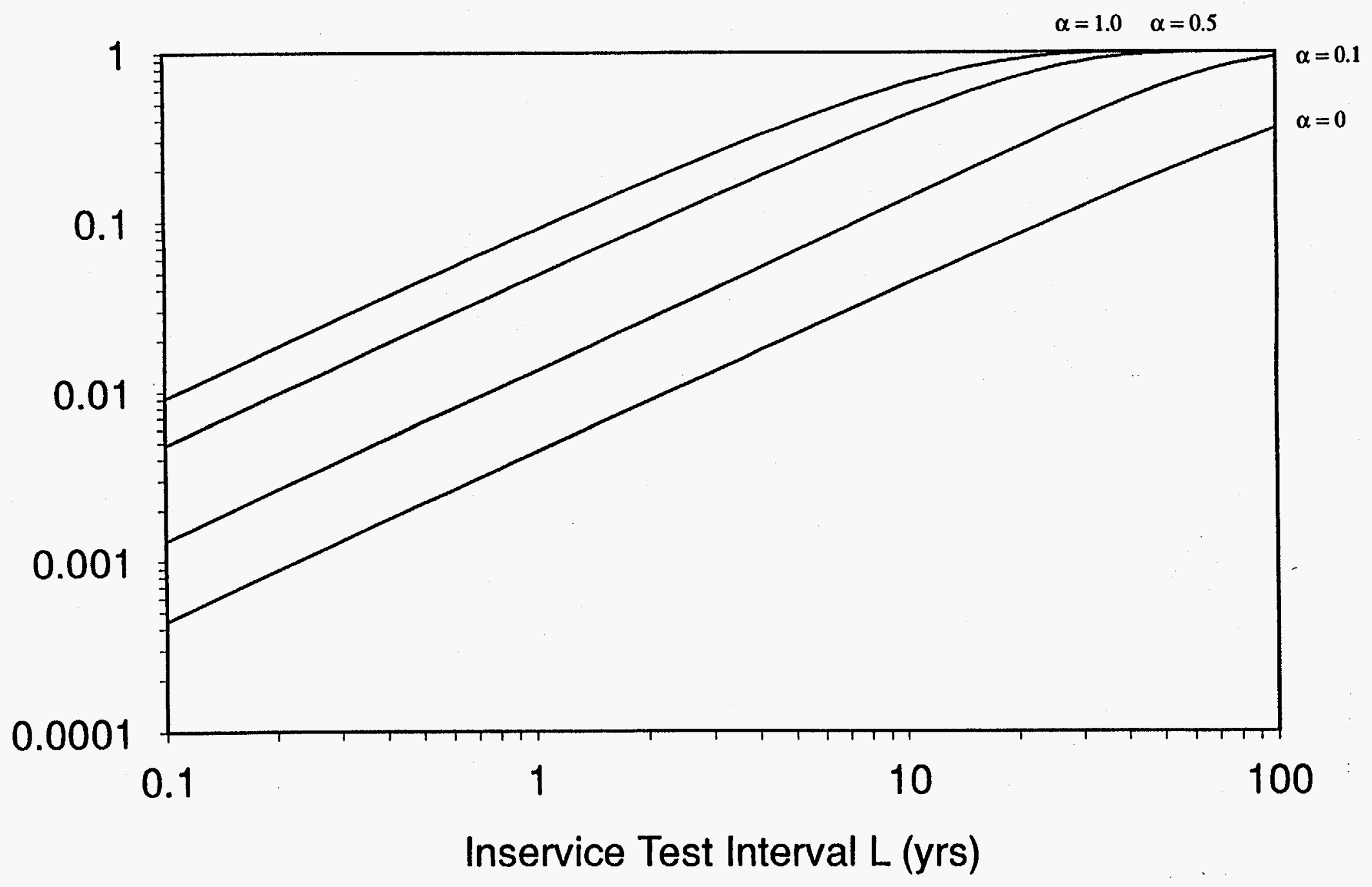

Figure 10.19 Check Valve Unavailability Versus IST Interval For Different Valve Aging Rates: Nonrenewal, No Intermediate Testing, Baseline Failure Rate $\lambda_{0}=1 \times 10^{-6} \mathrm{hr}^{-1}$, Inservice Test Downtime d $=0 \mathrm{hr}$,

Remaining Life $s=40 \mathrm{yr}$ 


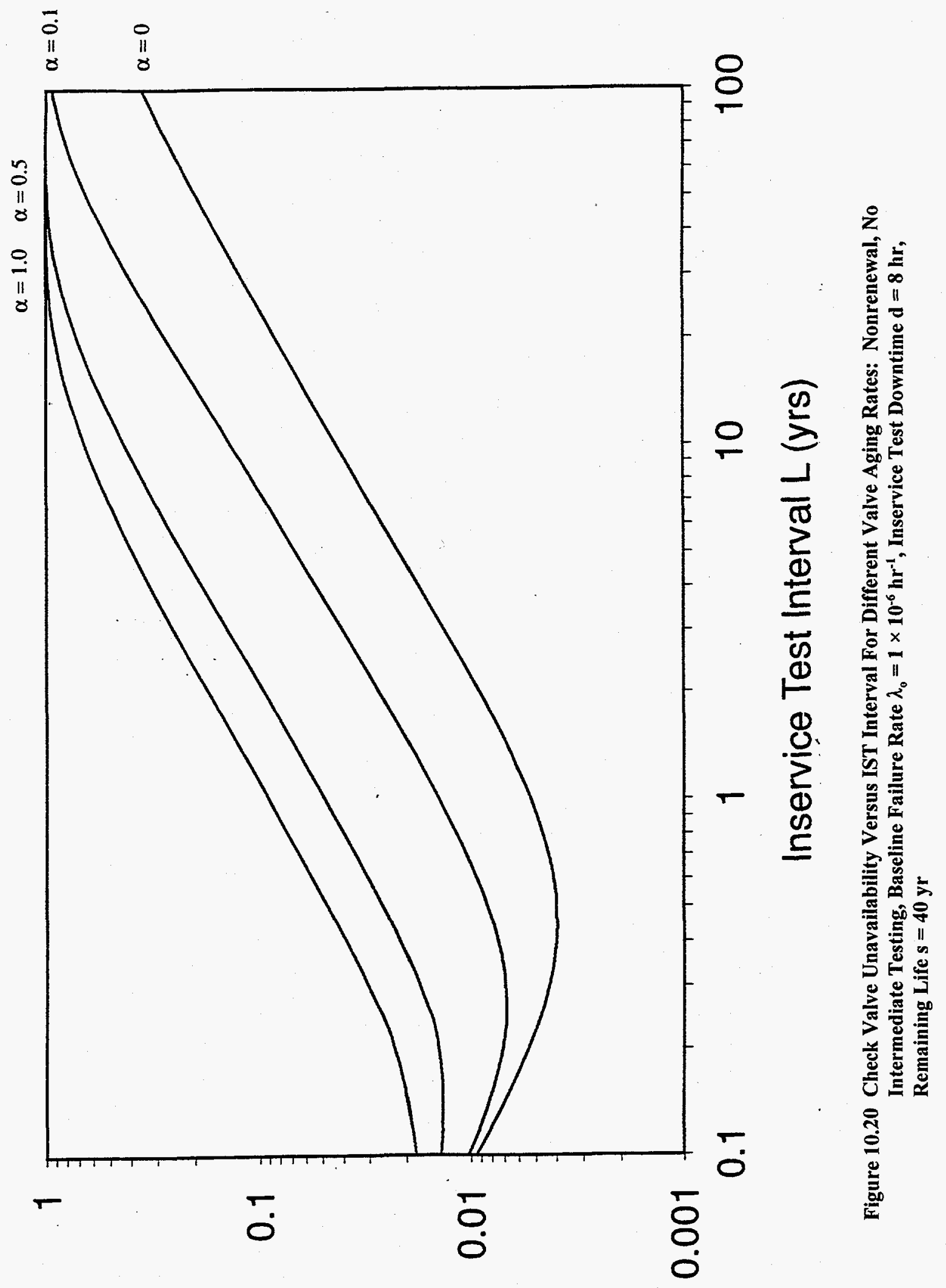

b אł!!!qe|!eneuก 


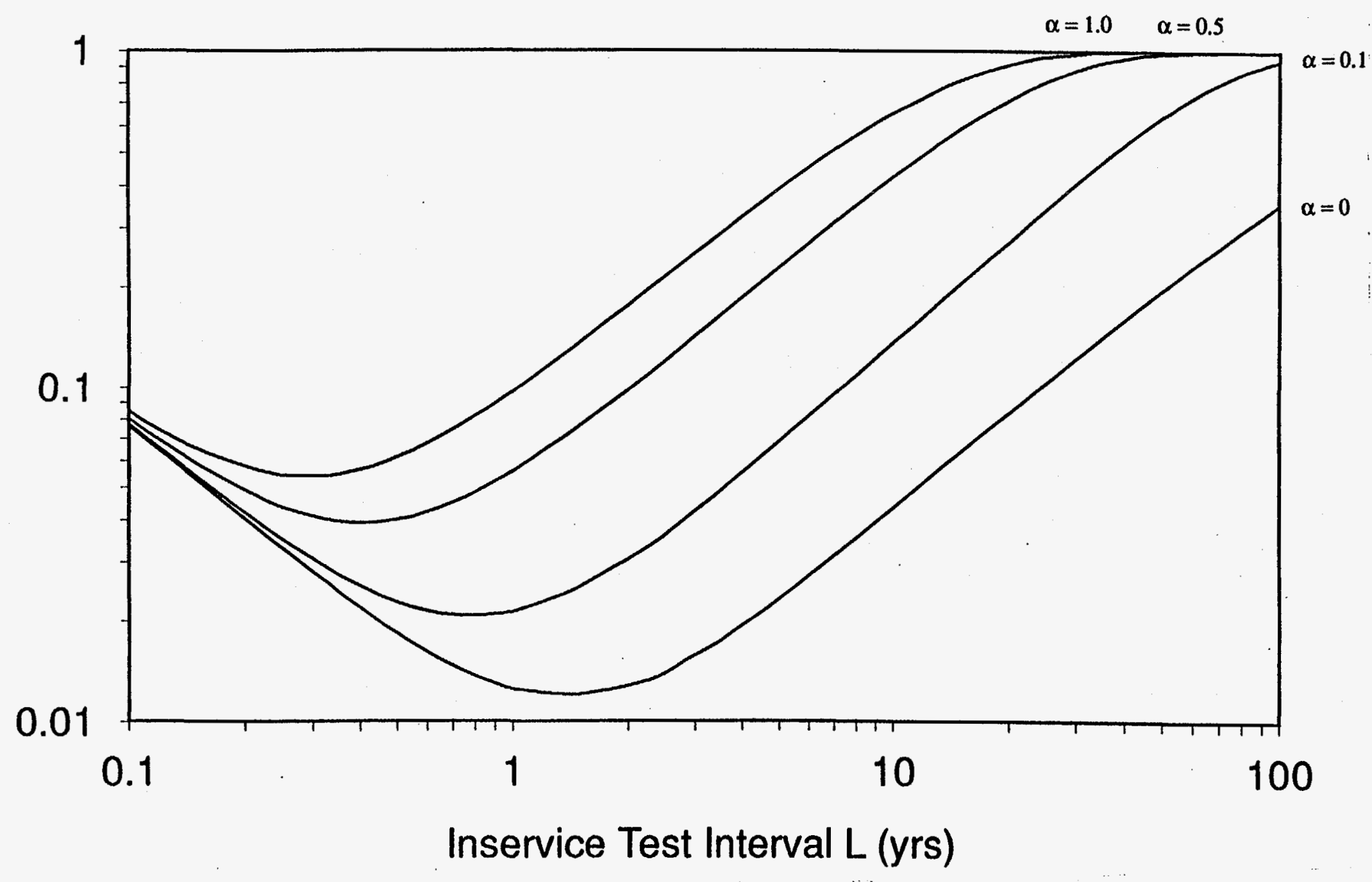

Figure 10.21 Check Valve Unavailability Versus IST Interval For Different Valve Aging Rates: Nonrenewal, No Intermediate Testing, Baseline Failure Rate $\lambda_{o}=1 \times 10^{-6} \mathrm{hr}^{-1}$, Inservice Test Downtime d $=72 \mathrm{hr}$, Remaining Life $s=40$ yr 


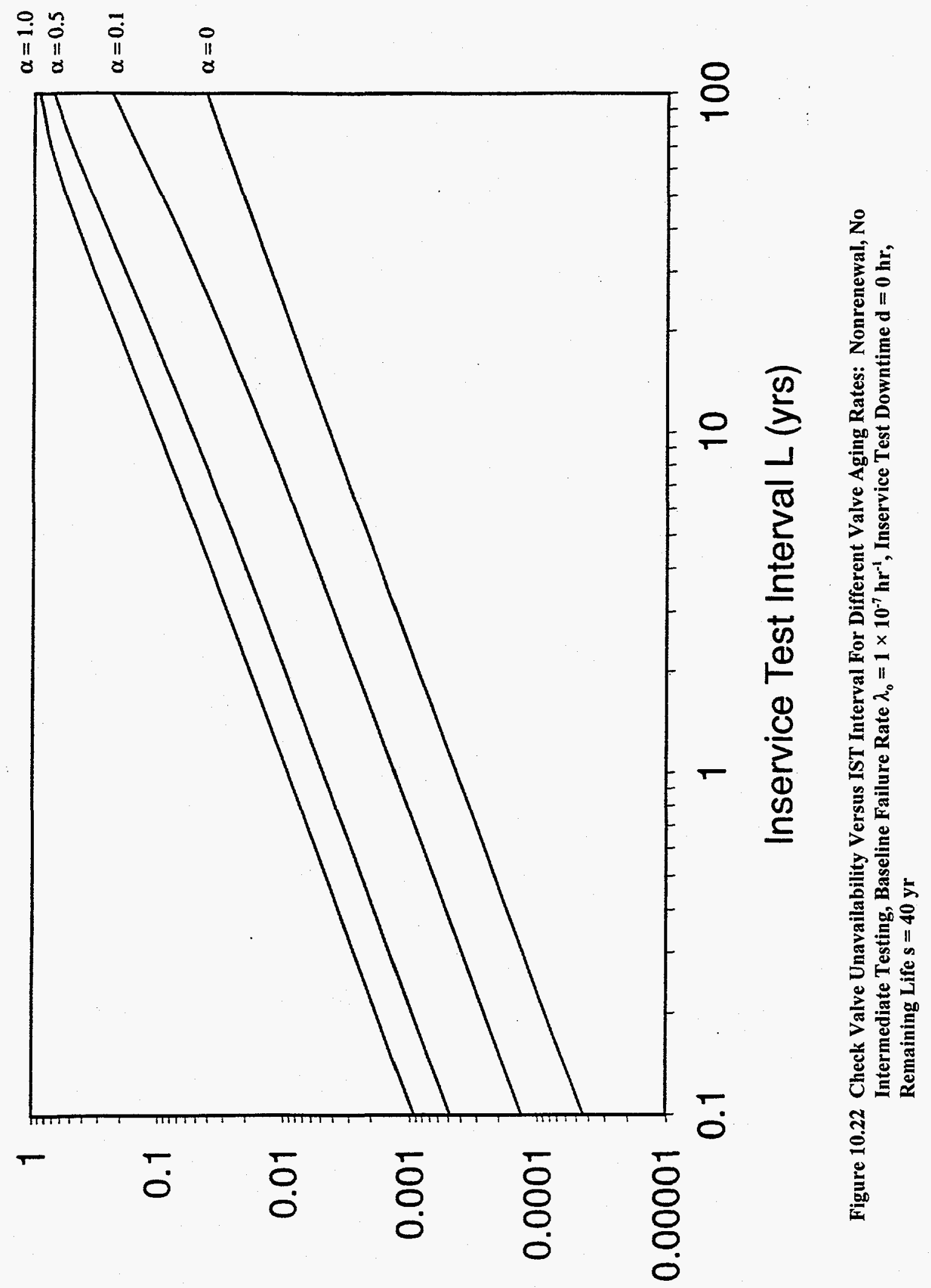

b א4!!!qe|!eлeuก 


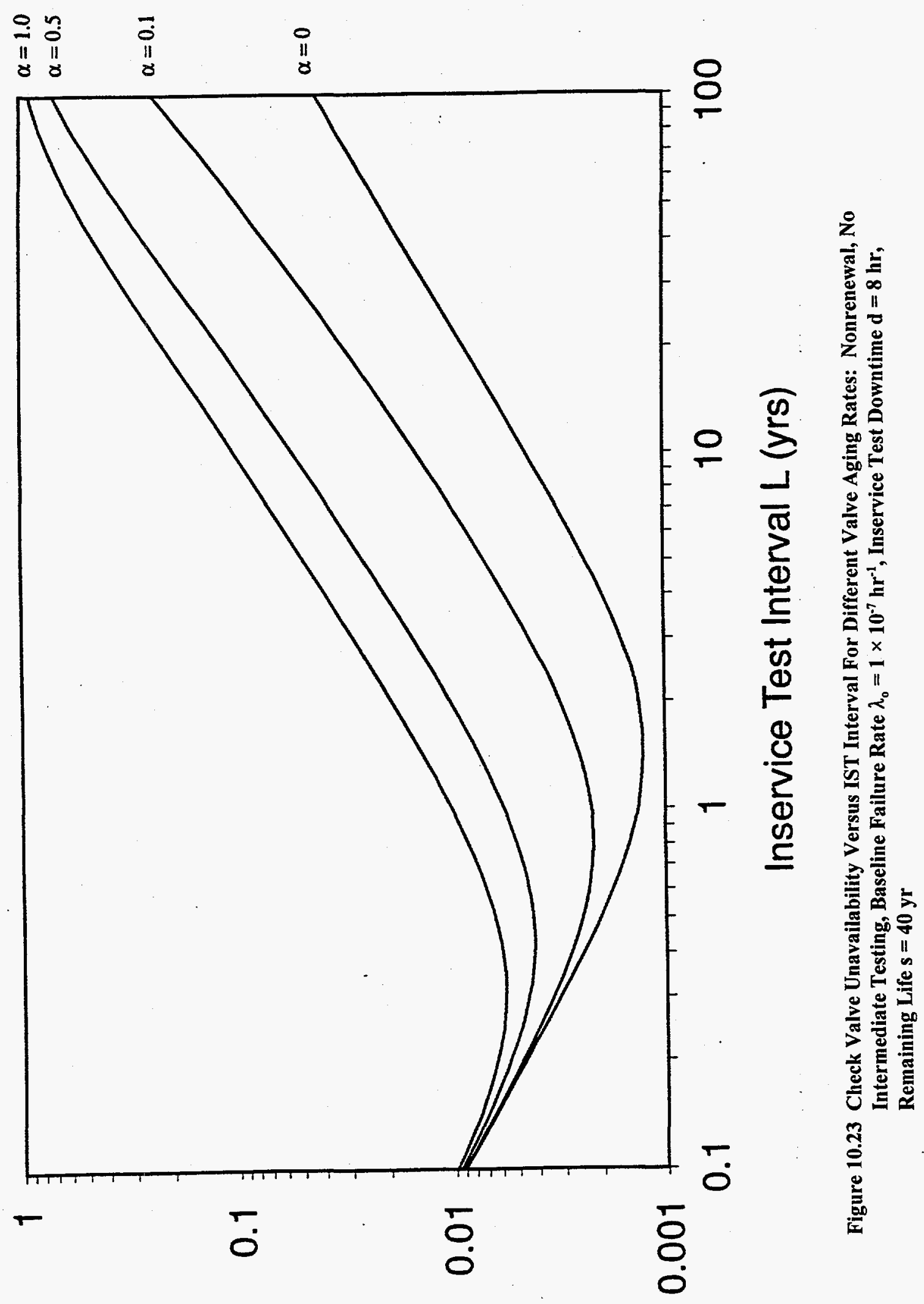

b イł!!!qe|!eıeuก 


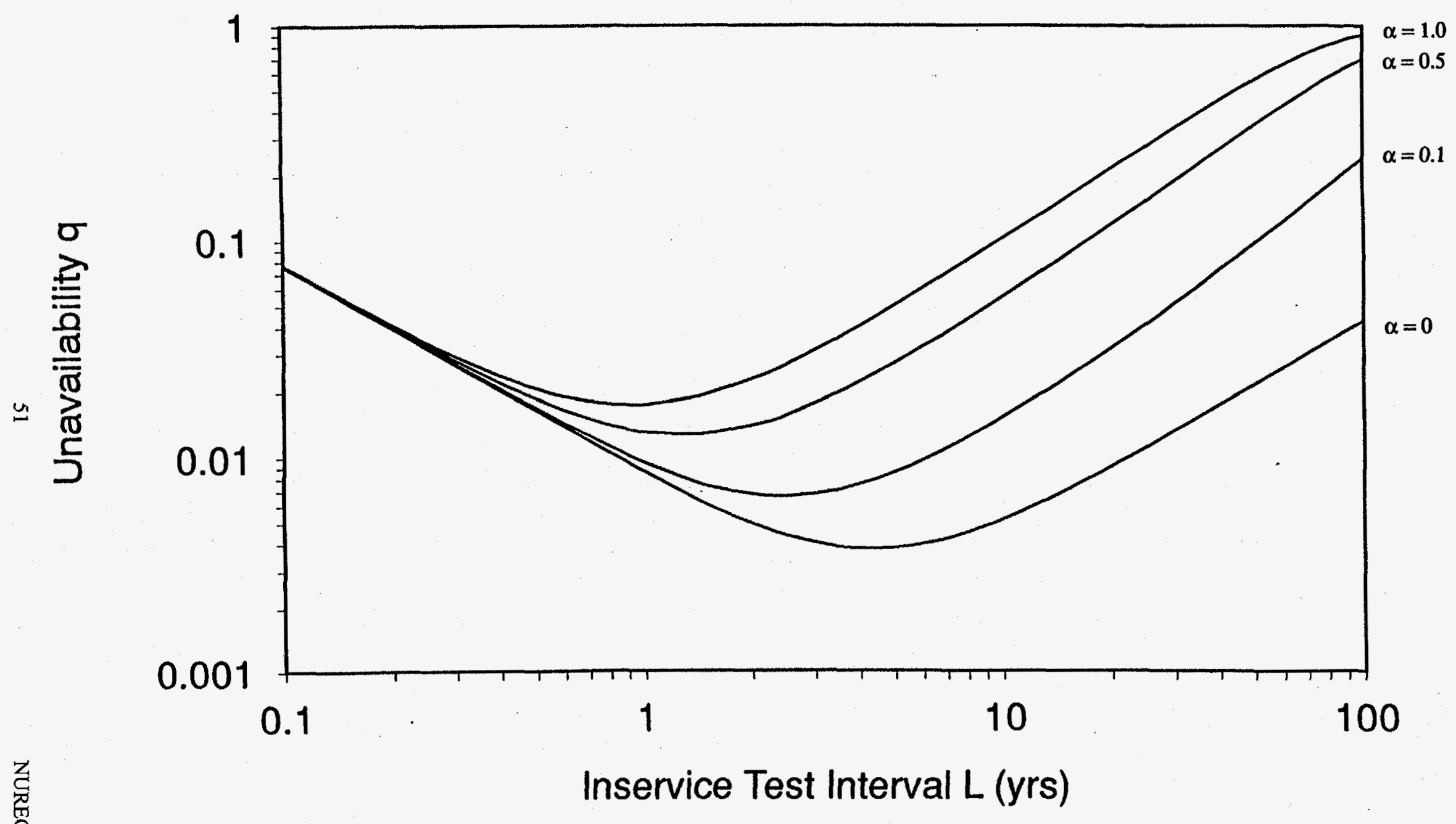

Figure 10.24 Check Valve Unavailability Versus IST Interval For Different Valve Aging Rates: Nonrenewal, No Intermediate Testing, Baseline Failure Rate $\lambda_{0}=1 \times 10^{-7} \mathrm{hr}^{-1}$, Inservice Test Downtime d $=72 \mathrm{hr}$, Remaining Life $s=40$ yr 
BLOCK 3. CURVES OF CHECK VALVE UNAVAILABILITY VERSUS IST INTERVAL FOR LINEAR AGING AND PARTIAL RENEWAL AFTER THE IST

Partial Renewal Following the IST

Renewal Fraction of 0.1 or 0.5

No Additional Operational Testing

Linear Aging Rates of $0 \%, 10 \%, 50 \%, 100 \%$ per year

Baseline Check Valve Failure Rate of $1 \times 10^{-6} \mathrm{hr}^{-1}$ or $1 \times 10^{-7} \mathrm{hr}^{-1}$

IST Associated Downtime of $0 \mathrm{hrs}, 8 \mathrm{hrs}, 72 \mathrm{hrs}$ 


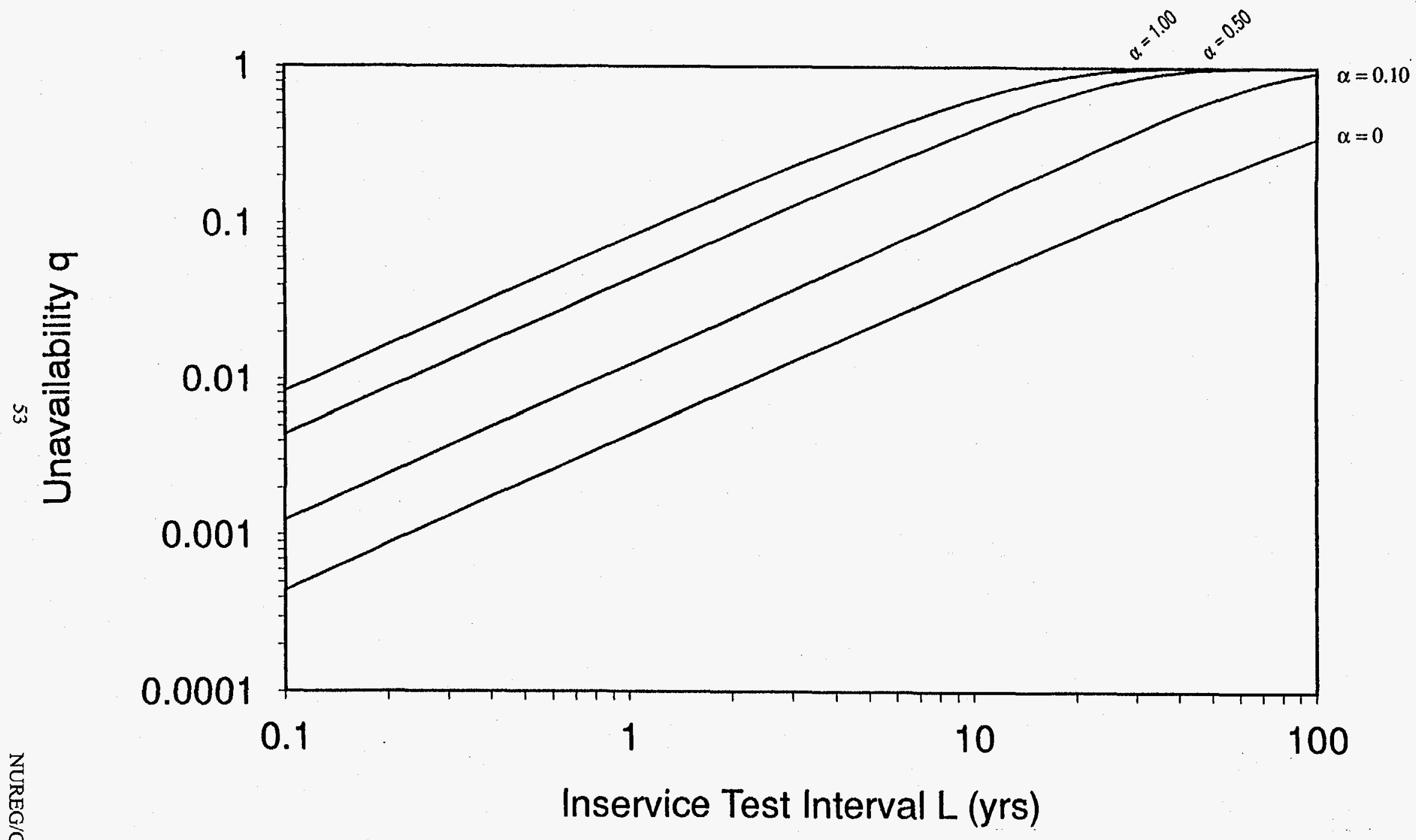

Figure 10.25 Check Valve Unavailability Versus IST Interval For Different Valve Aging Rates: Partial Renewal, No Intermediate Testing, Baseline Failure Rate $\lambda_{0}=1 \times 10^{-6} \mathrm{hr}^{-1}$, Inservice Test Downtime d $=0 \mathrm{hr}$, Partial Renewal Fraction $f=0.1$, Valve Lifetime $s=40$ yrs 


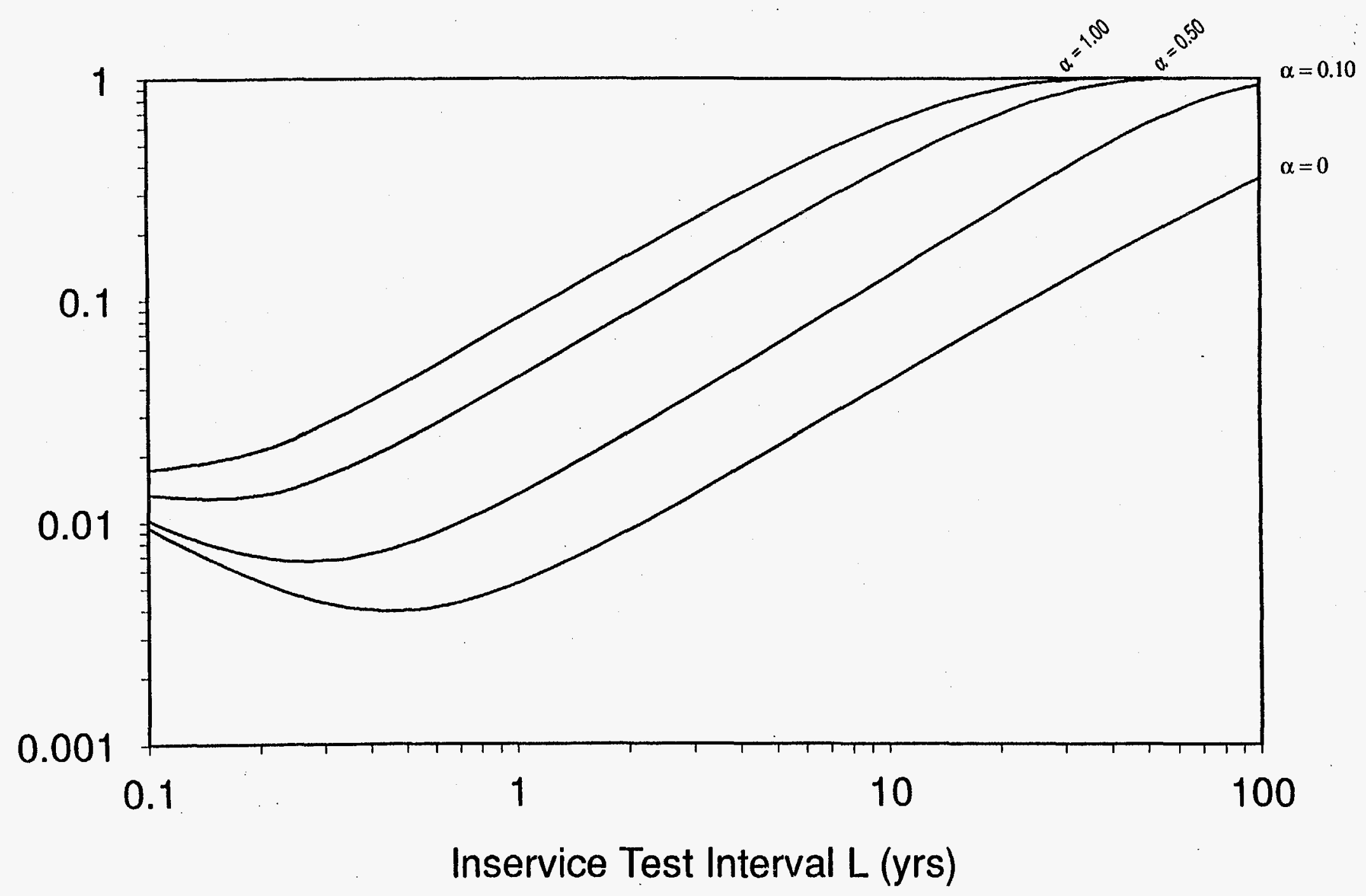

Figure 10.26 Check Valve Unavailability Versus IST Interval For Different Valve Aging Rates: Partial Renewal, No Intermediate Testing, Baseline Failure Rate $\lambda_{o}=1 \times 10^{-6} \mathrm{hr}^{-1}$, Inservice Test Downtime $\mathrm{d}=8 \mathrm{hr}$, Partial Renewal Fraction $f=0.1$, Valve Lifetime $s=40$ yrs 


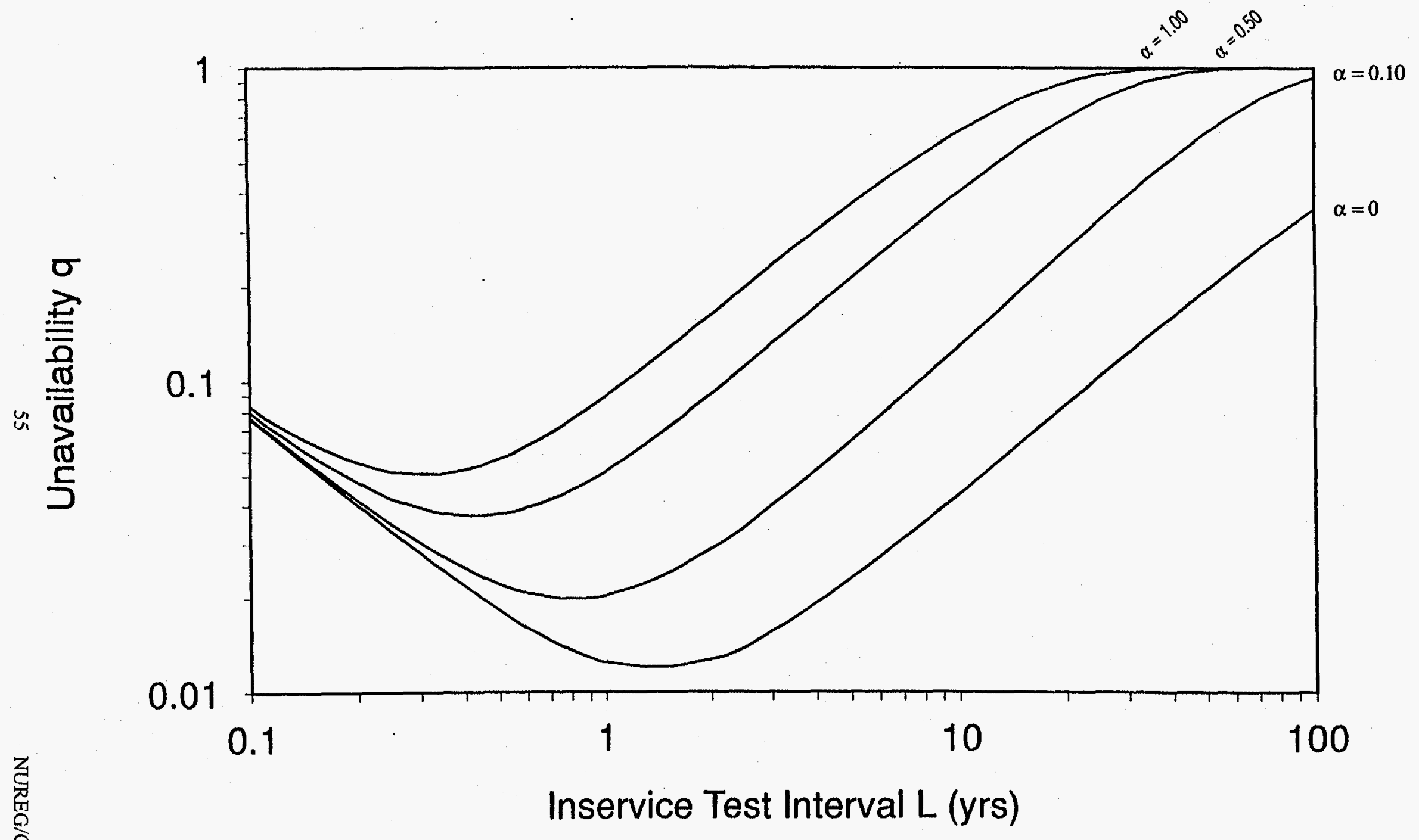

Figure 10.27 Check Valve Unavailability Versus IST Interval For Different Valve Aging Rates: Partial Renewal, No Intermediate Testing, Baseline Failure Rate $\lambda_{0}=1 \times 10^{-6} \mathrm{hr}^{-1}$, Inservice Test Downtime $\mathrm{d}=72 \mathrm{hr}$, Partial Renewal Fraction $f=0.1$, Valve Lifetime $s=40$ yrs 


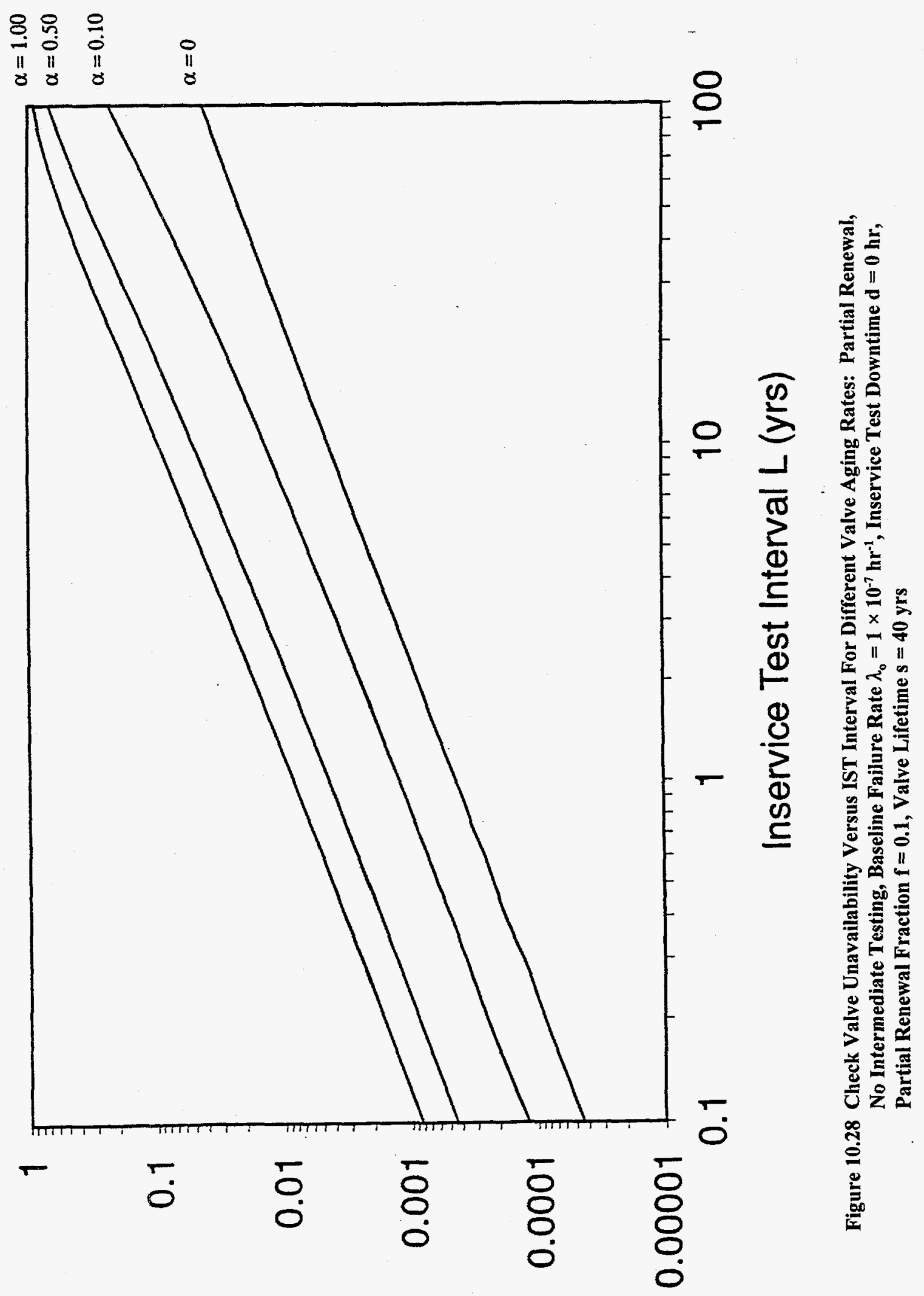

b K1!!!qe|!eseuก 


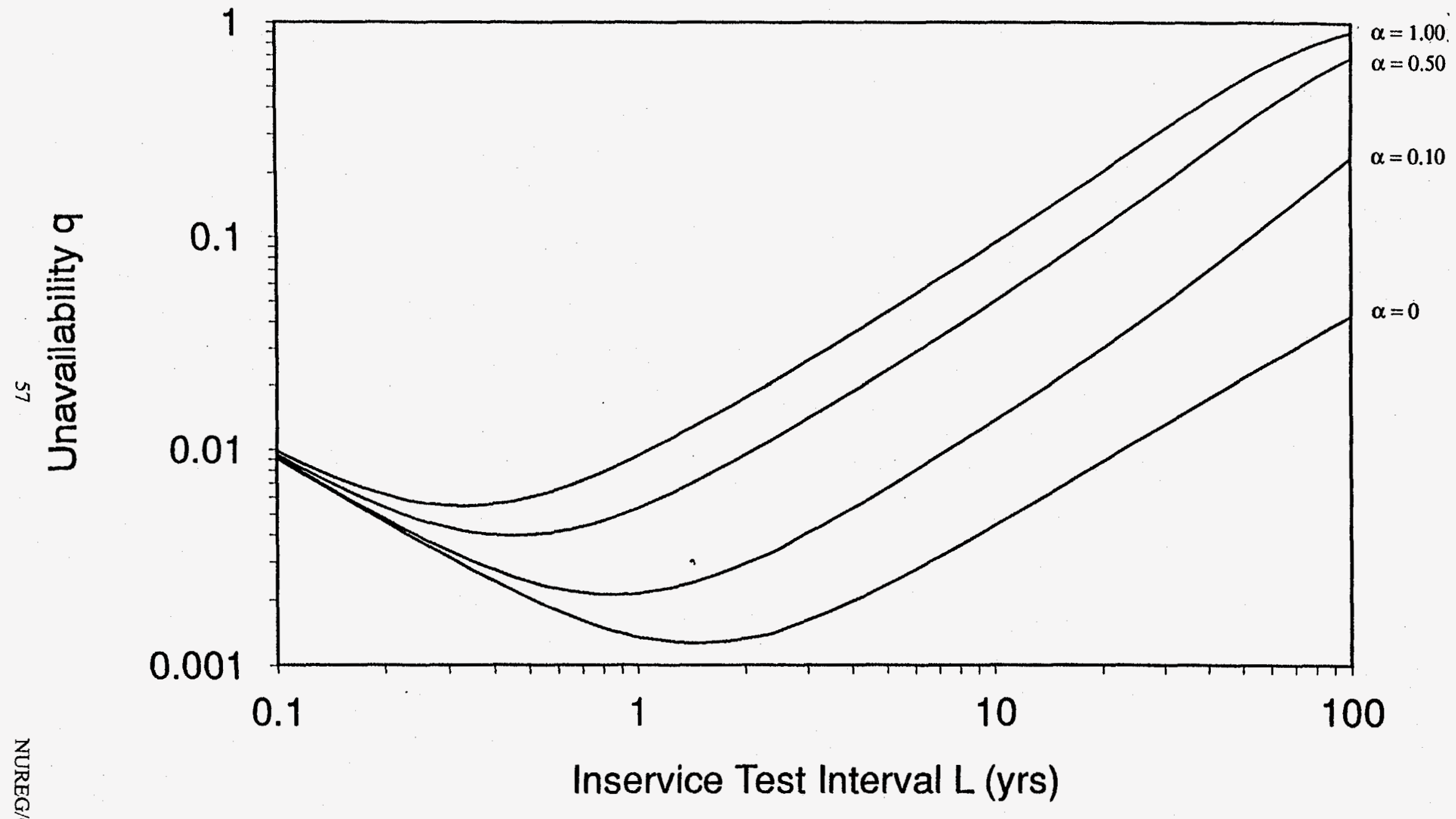

Figure 10.29 Check Valve Unavailability Versus IST Interval For Different Valve Aging Rates: Partial Renewal, No Intermediate Testing, Baseline Failure Rate $\lambda_{0}=1 \times 10^{-7} \mathrm{hr}^{-1}$, Inservice Test Downtime $\mathrm{d}=8 \mathrm{hr}$, Partial Renewal Fraction $f=0.1$, Valve Lifetime $s=40$ yrs 


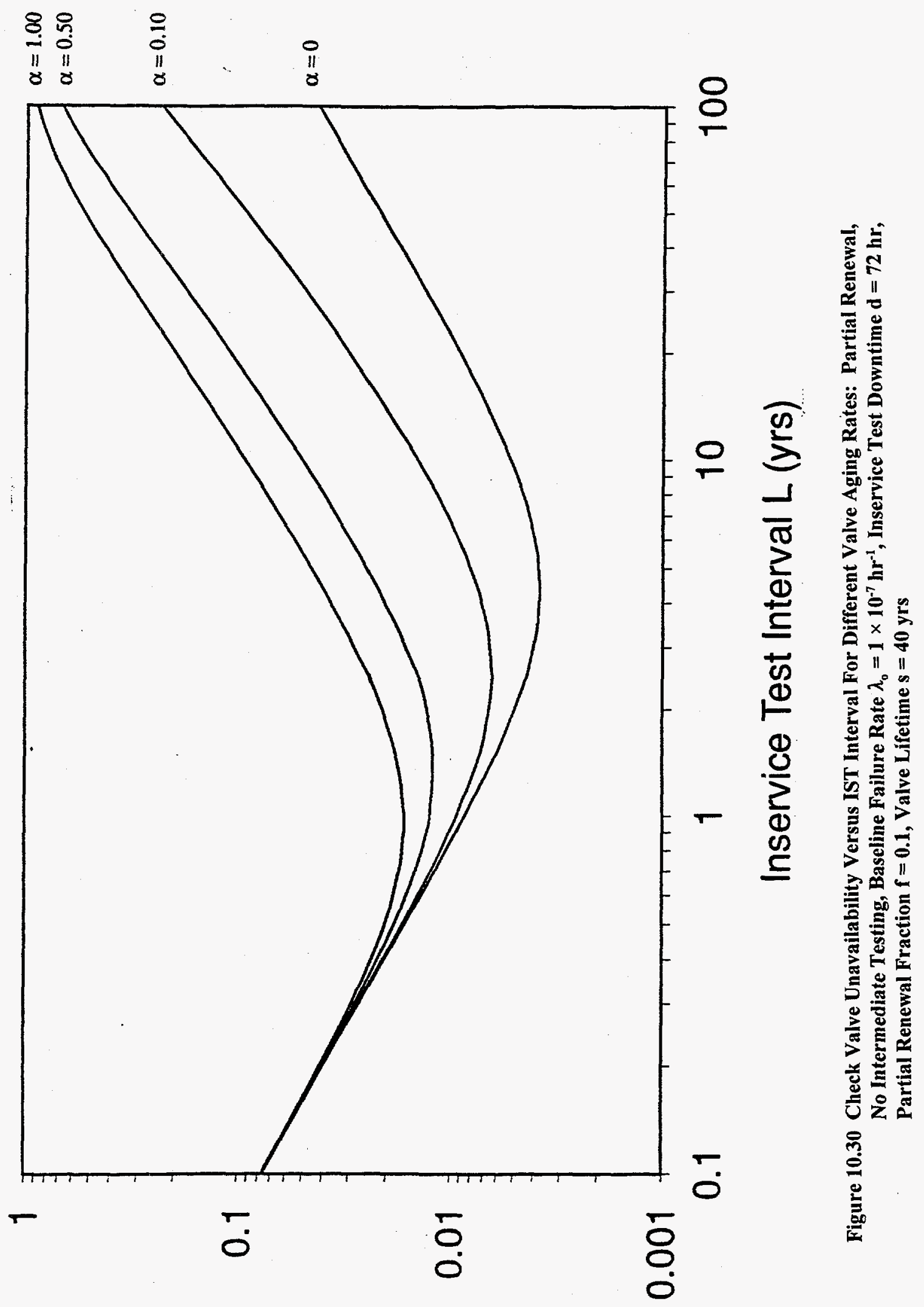

b K1!!!qe|!eneuก 


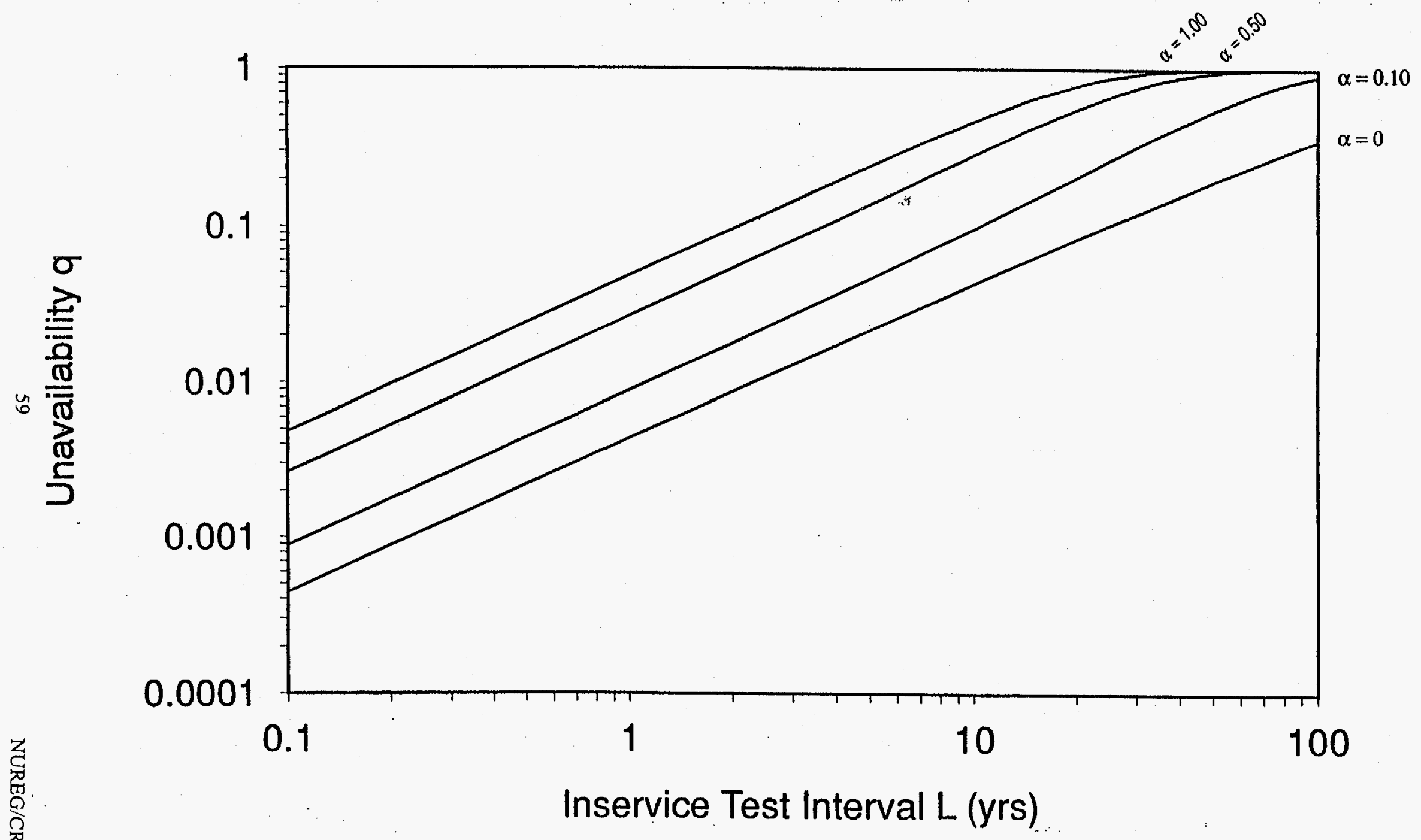

Figure 10.31 Check Valve Unavailability Versus IST Interval For Different Valve Aging Rates: Partial Renewal, No Intermediate Testing, Baseline Failure Rate $\lambda_{0}=1 \times 10^{-6} \mathrm{hr}^{-1}$, Inservice Test Downtime $\mathrm{d}=0 \mathrm{hr}$, Partial Renewal Fraction $f=0.5$, Valve Lifetime $s=40 \mathrm{yrs}$ 


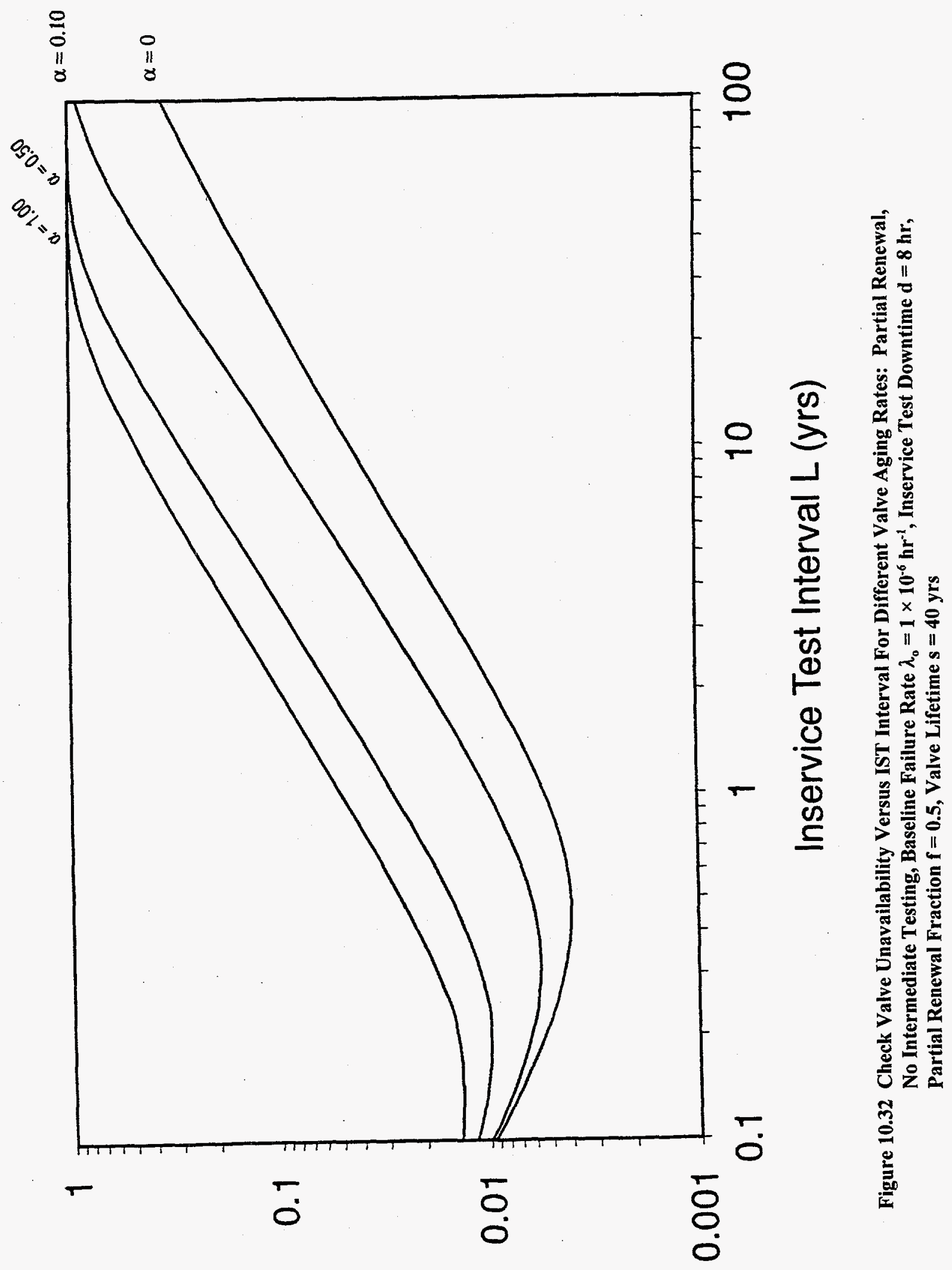

b א1!!!qe|!eseun 


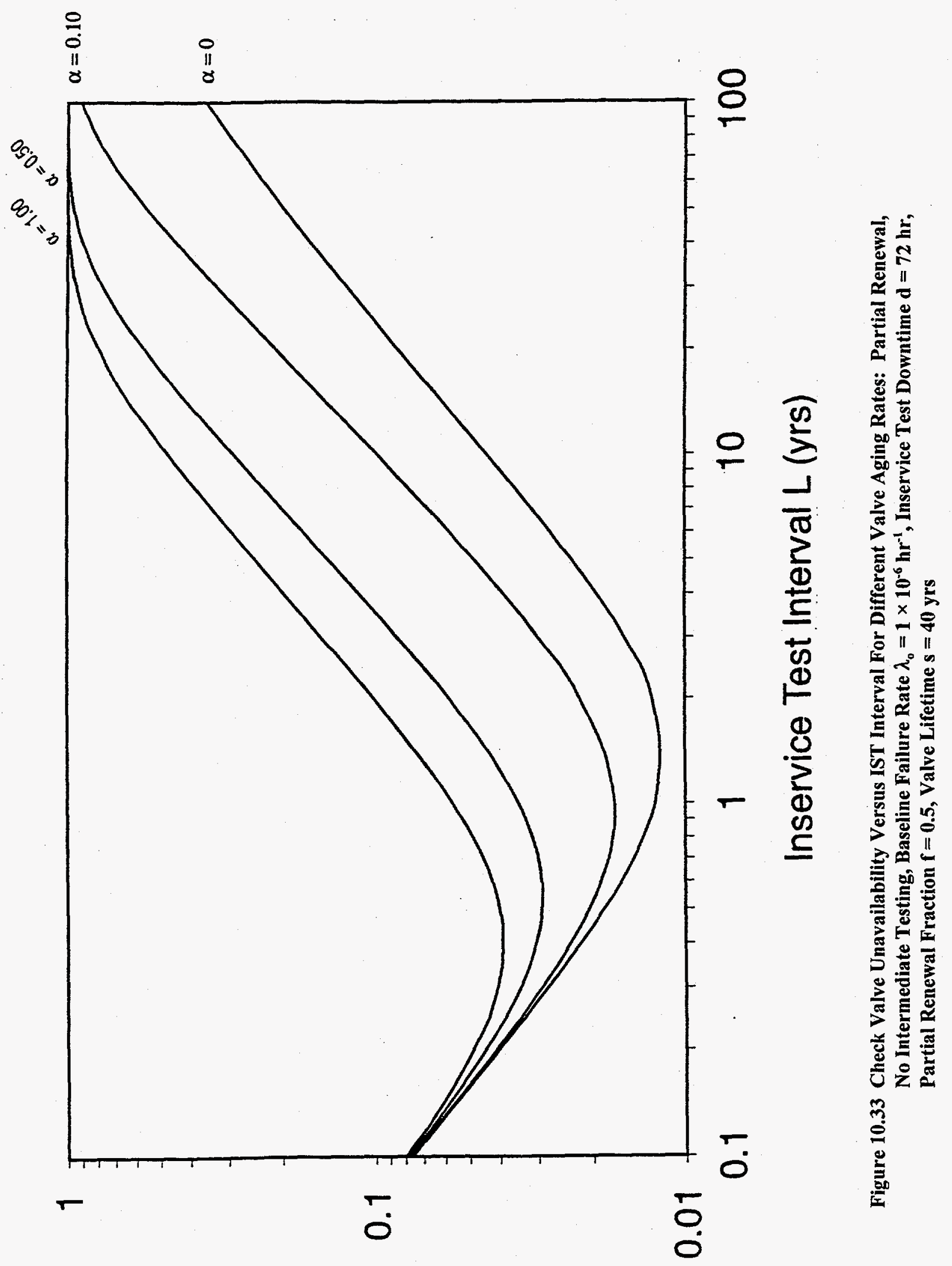

b אł!!!qe|!e^euก 


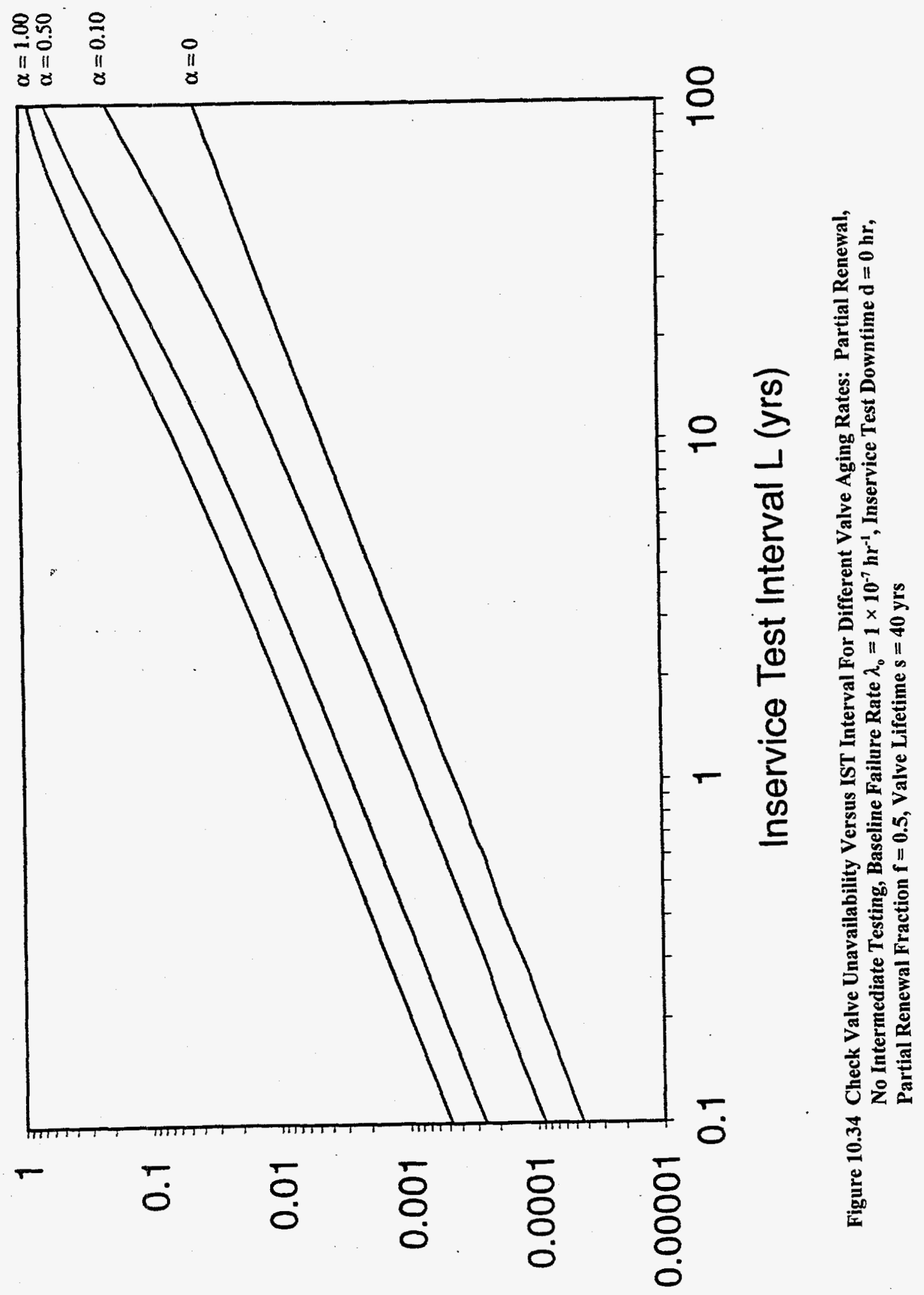

b אi!!!qe|!eseun 


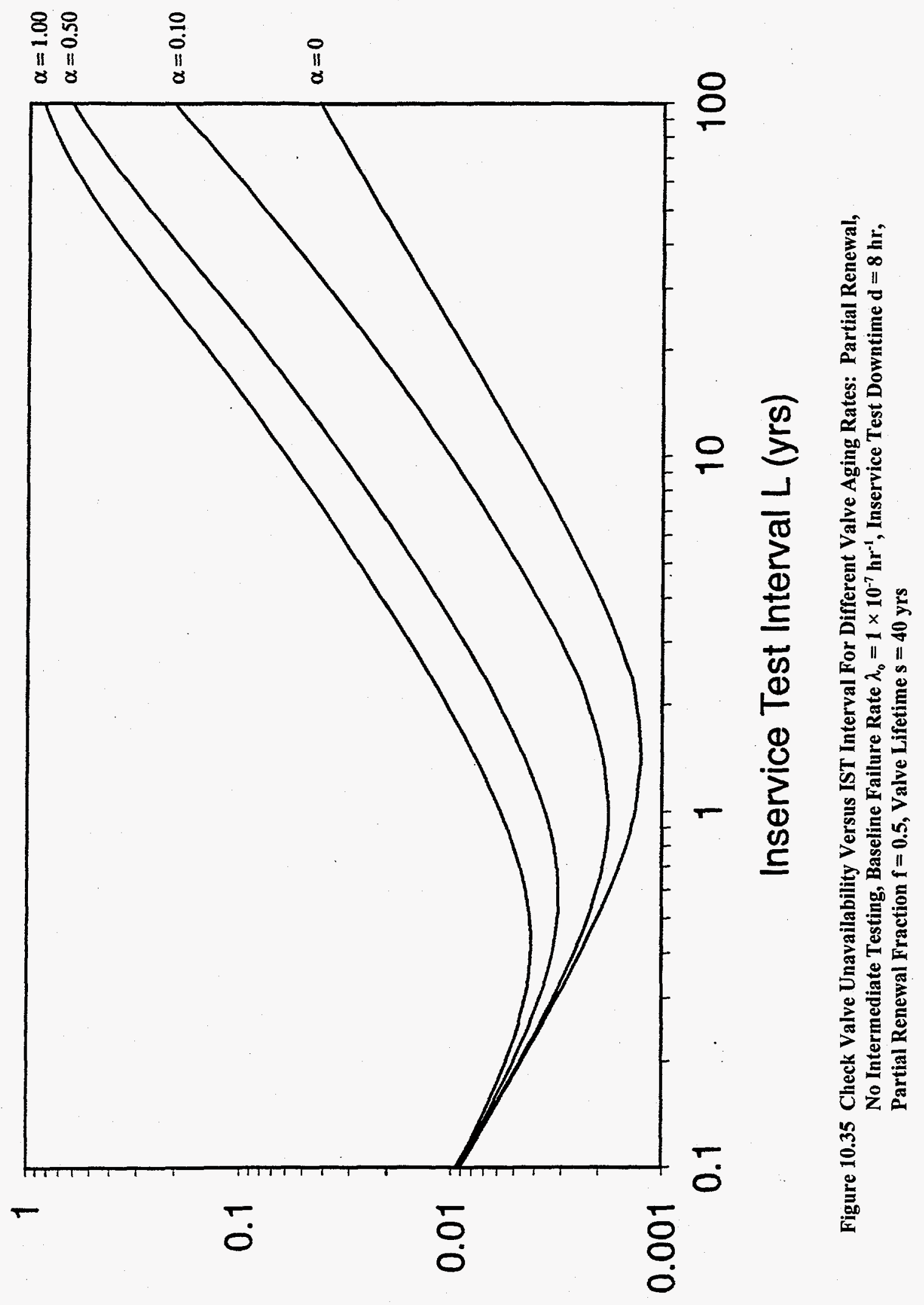

b Rł!!!qe|!eneuก 


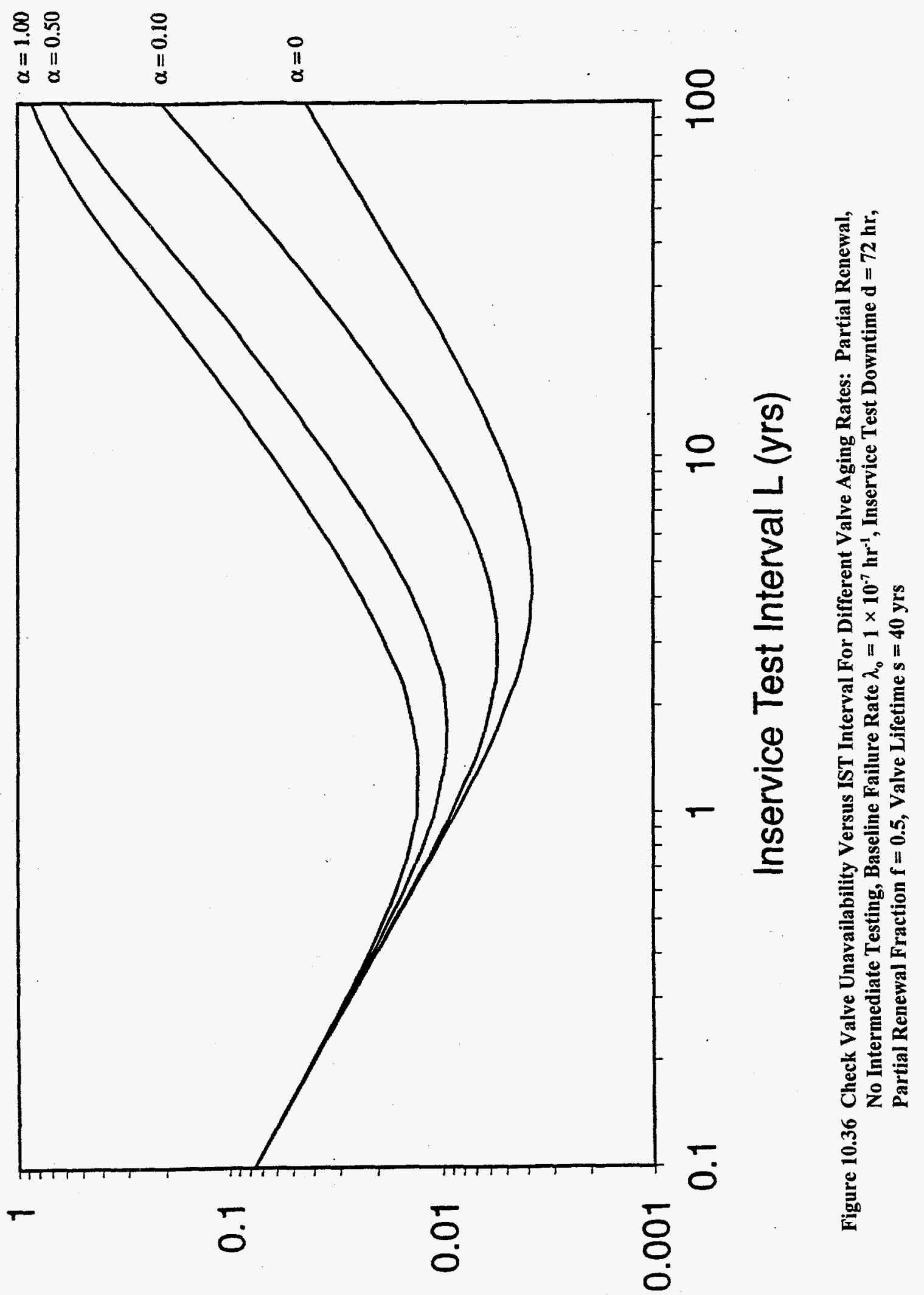

b אł!!!qe|!eлеUก 


\section{Evaluations of Component Unavailability Versus IST Interval for Check Valves with Nonlinear Aging}

This section presents evaluations of check valve unavailability versus IST interval for cases of check valve nonlinear aging behavior. The nonlinear aging behavior is modeled by the Weibull trend factor (power aging factor) $c$. Values of $c=2$ and $c=3$ are evaluated, which represent quadratic and cubic aging trends, respectively. Comparisons with $c=1$, which represents linear aging, are made. Ranges of aging rates and different IST characteristics are evaluated to cover different cases. The figures are given in this section and the corresponding tables are given in Appendix $\mathrm{C}$. The figures again are organized into blocks covering IST with total renewal, IST with nonrenewal, and IST with partial renewal:

Block 1: Total Renewal Following the IST

No Additional Testing or Additional Testing at $1 \mathrm{mo}$ or $12 \mathrm{mo}$

Nonlinear Aging Rates $(\mathrm{c}=2)$ of $0 \%, 3 \%, 5 \%, 10 \%, 30 \%$,

$50 \%, 100 \%$ per year

Baseline Check Valve Failure Rate of $1 \times 10^{-6} \mathrm{hr}^{-1}$ or $1 \times 10^{-7} \mathrm{hr}^{-1}$

IST Associated Downtime of $0 \mathrm{hrs}, 8 \mathrm{hrs}, 72 \mathrm{hrs}$

Block 2: No Renewal Following the IST

No Additional Operational Testing

Nonlinear Aging Rates ( $c=2$ or $c=3$ ) of $0 \%, 10 \%, 50 \%, 100 \%$ per year

Baseline Check Valve Failure Rate of $1 \times 10^{-6} \mathrm{hr}^{-1}$ or $1 \times 10^{-7} \mathrm{hr}^{-1}$

IST Associated Downtime of $0 \mathrm{hrs}, 8 \mathrm{hrs}, 72 \mathrm{hrs}$

Block 3: Partial Renewal Following the IST

Renewal Fraction of 0.1 or 0.5

No Additional Operational Testing

Nonlinear Aging Rates ( $c=2$ or $c=3$ ) of $0 \%, 10 \%, 50 \%, 100 \%$ per year

Baseline Check Valve Failure Rate of $1 \times 10^{-6} \mathrm{hr}^{-1}$ or $1 \times 10^{-7} \mathrm{hr}^{-1}$

IST Associated Downtime of $0 \mathrm{hrs}, 8 \mathrm{hrs}, 72 \mathrm{hrs}$ 


\section{BLOCK 1. CURVES OF CHECK VALVE UNAVAILABILITY VERSUS IST INTERVAL FOR NONLINEAR AGING AND TOTAL RENEWAL AFTER THE IST}

Total Renewal Following the IST

No Additional Testing or Additional Testing at 1 mo or 12 mo

Nonlinear Aging Rates $(\mathrm{c}=2)$ of $0 \%, 3 \%, 5 \%, 10 \%, 30 \%, 50 \%, 100 \%$ per year

Baseline Check Valve Failure Rate of $1 \times 10^{-6} \mathrm{hr}^{-1}$ or $1 \times 10^{-7} \mathrm{hr}^{-1}$

IST Associated Downtime of $0 \mathrm{hrs}, 8 \mathrm{hrs}, 72 \mathrm{hrs}$ 


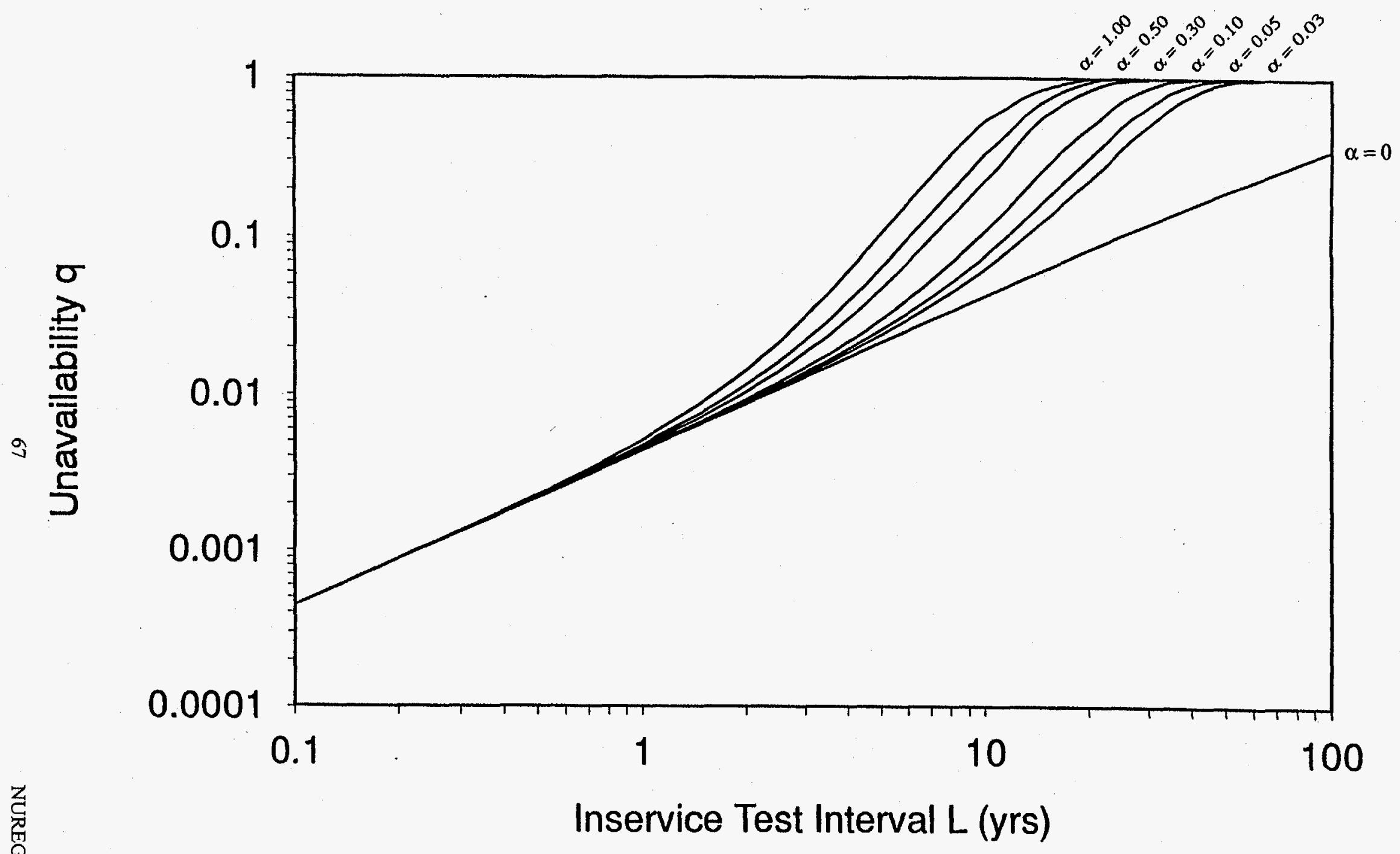

Figure 10.37 Check Valve Unavailability Versus IST Interval For Different Valve Aging Rates: Total Renewal, Weibull Aging Model c $=2$, No Intermediate Testing, Baseline Failure Rate $\lambda_{0}=1 \times 10^{-6} \mathrm{hr}^{-1}$, Inservice Test Downtime $\mathrm{d}=\mathbf{0} \mathrm{hr}$ 


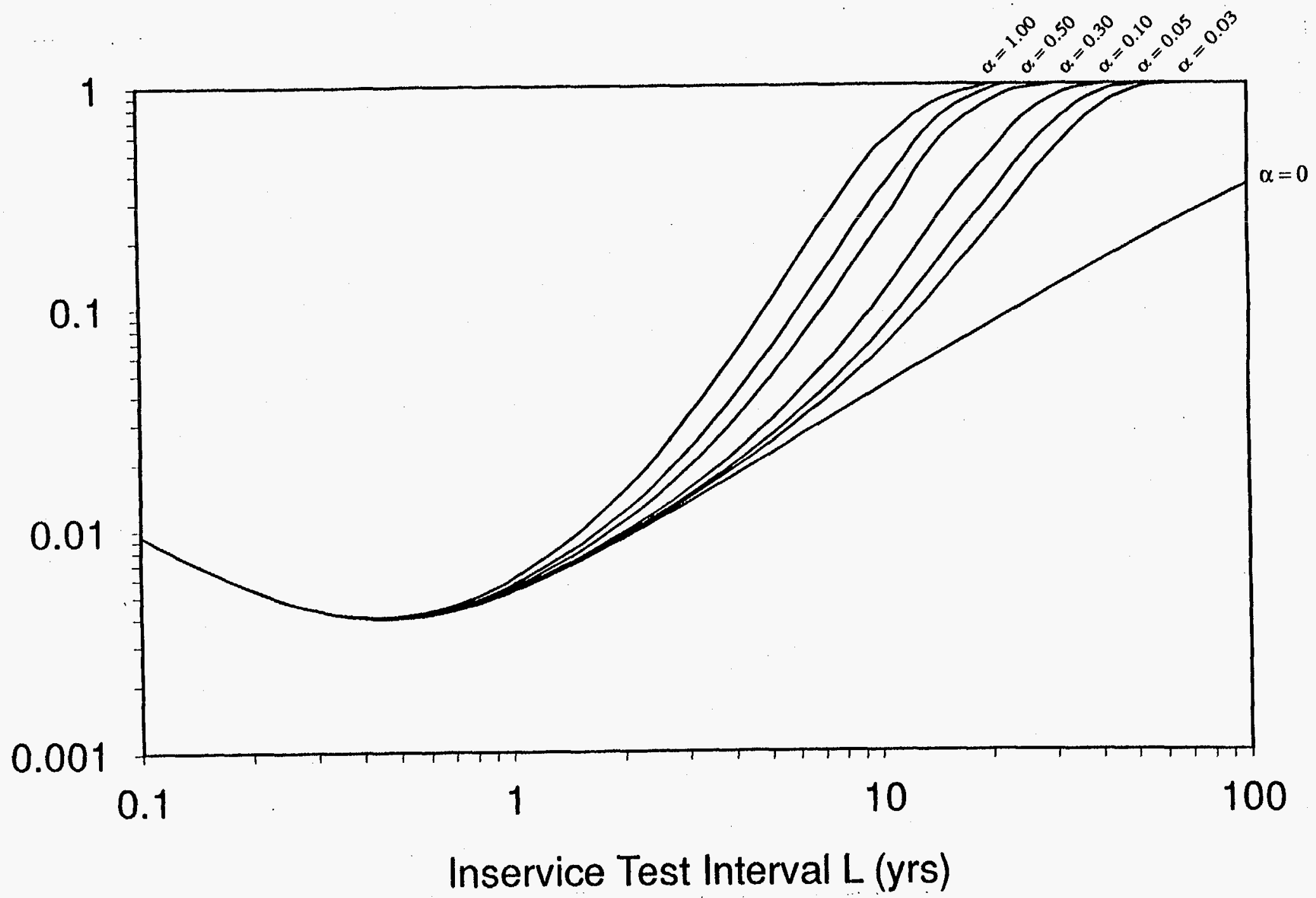

Figure 10.38 Check Valve Unavailability Versus IST Interval For Different Valve Aging Rates: Total Renewal, Weibull Aging Model c $=2$, No Intermediate Testing, Baseline Failure Rate $\lambda_{0}=1 \times 10^{-6} \mathrm{hr}^{-1}$,

Inservice Test Downtime $\mathrm{d}=8 \mathrm{hr}$ 


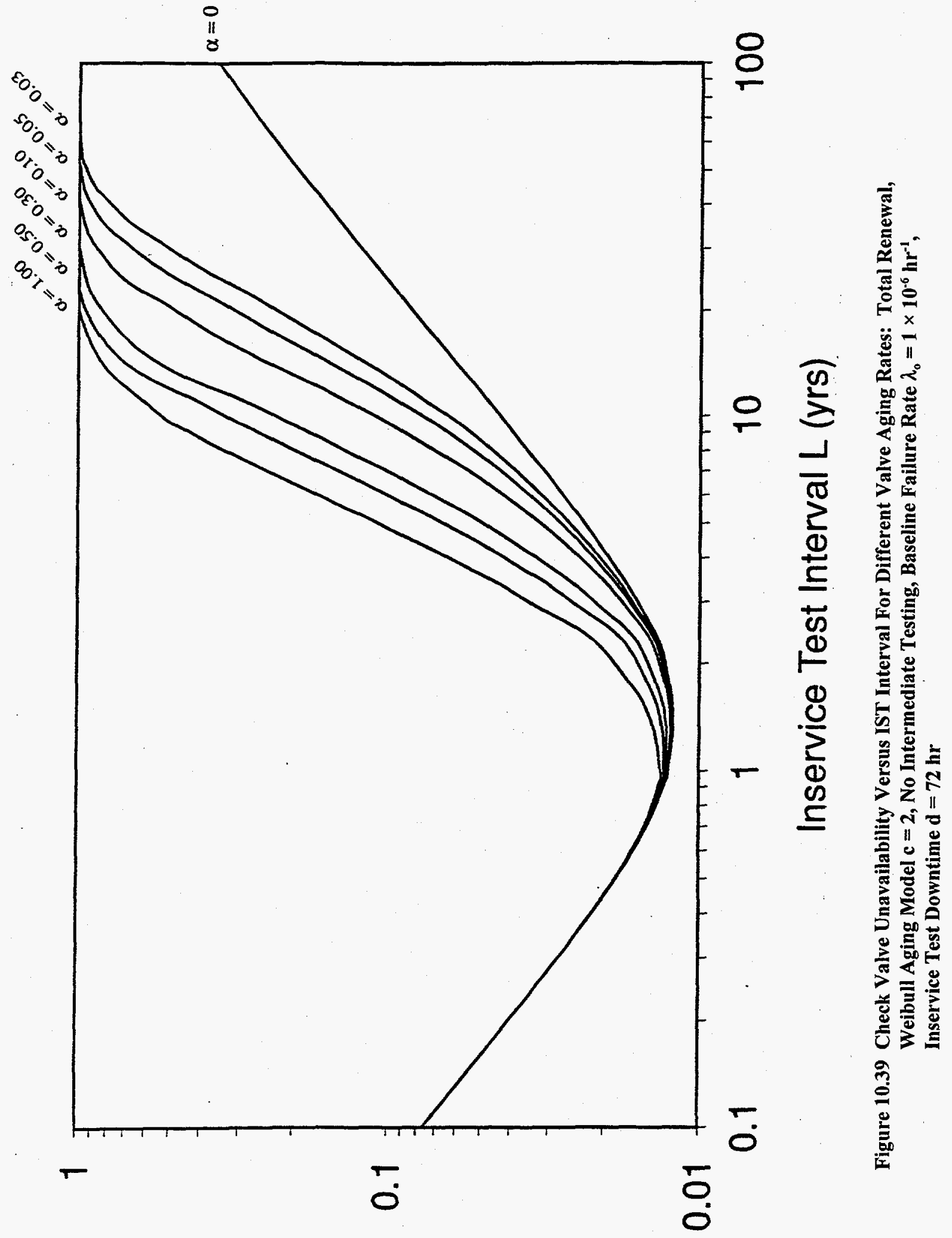

b אł!!!qe|!eseuก 


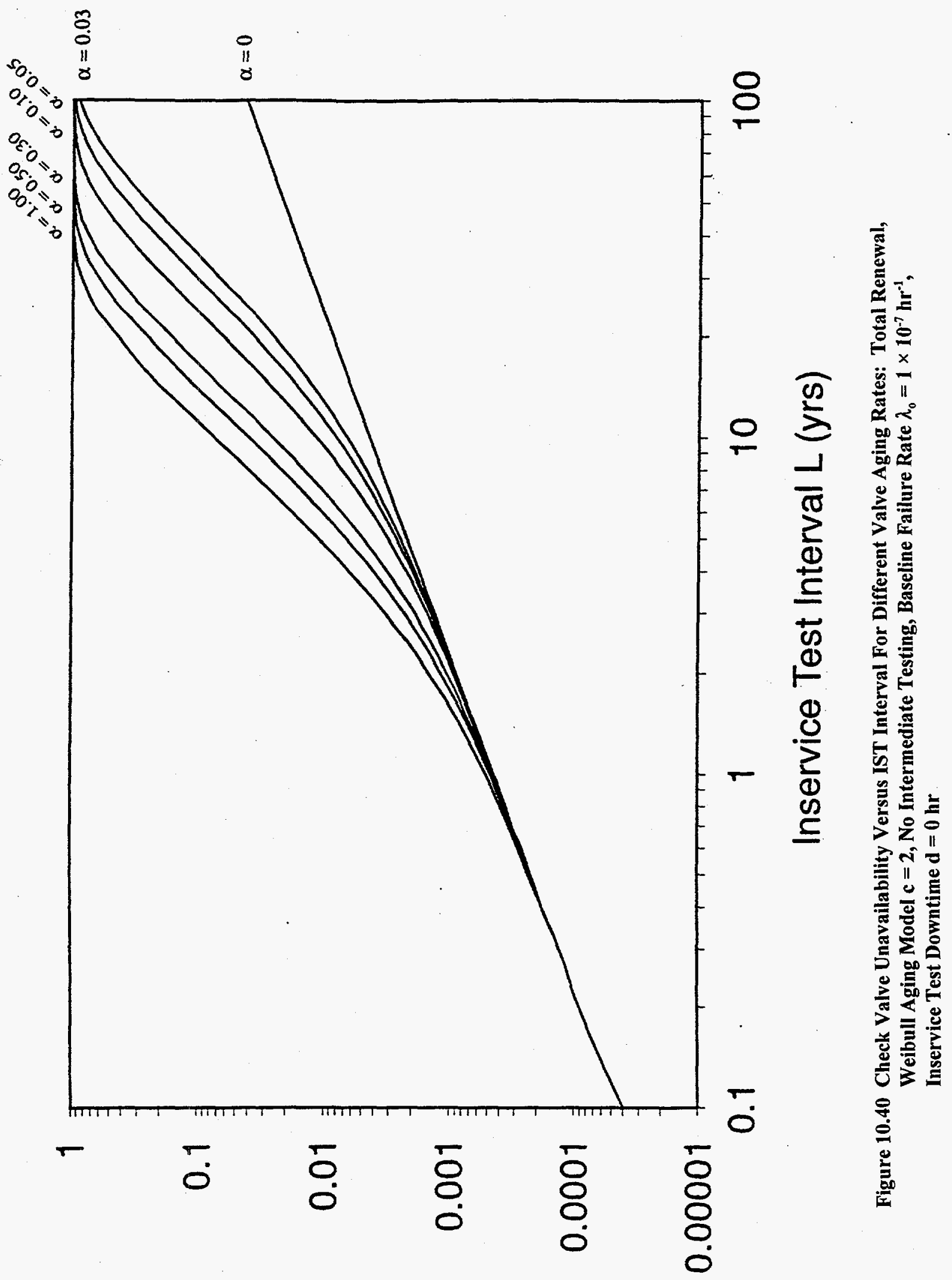




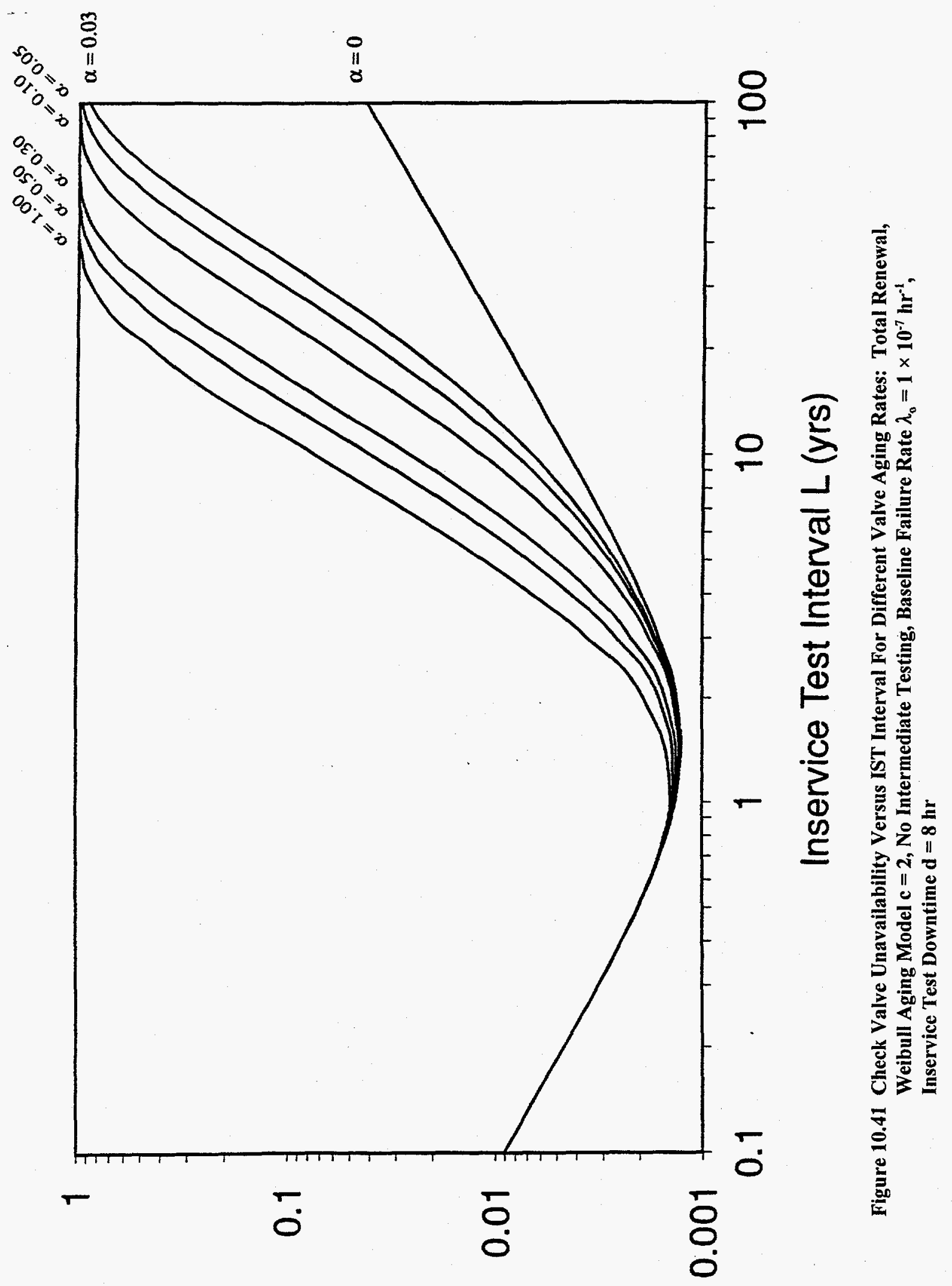

b אł!!!qe|!eлeuก 


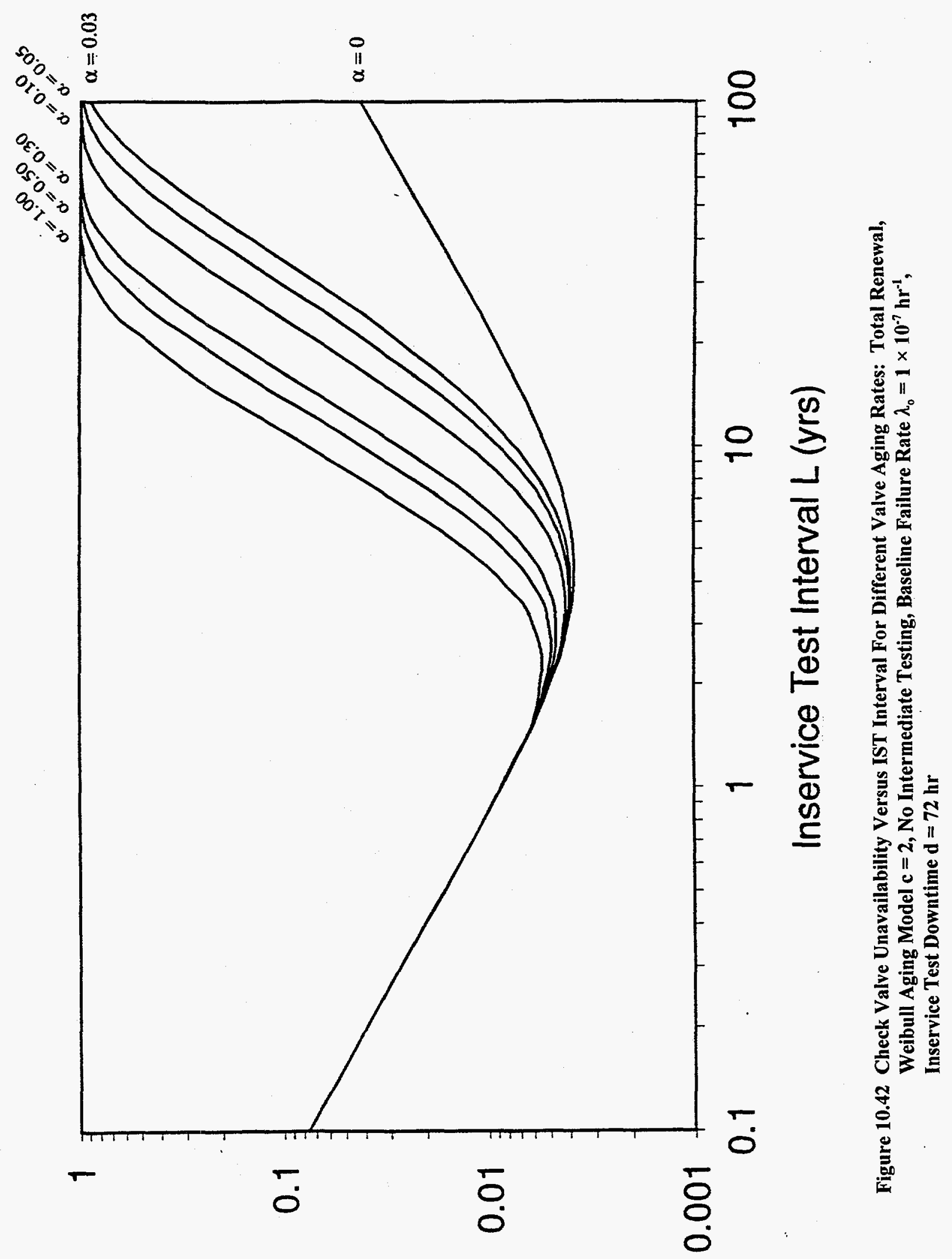

b K4!!!qe|!eseuก 


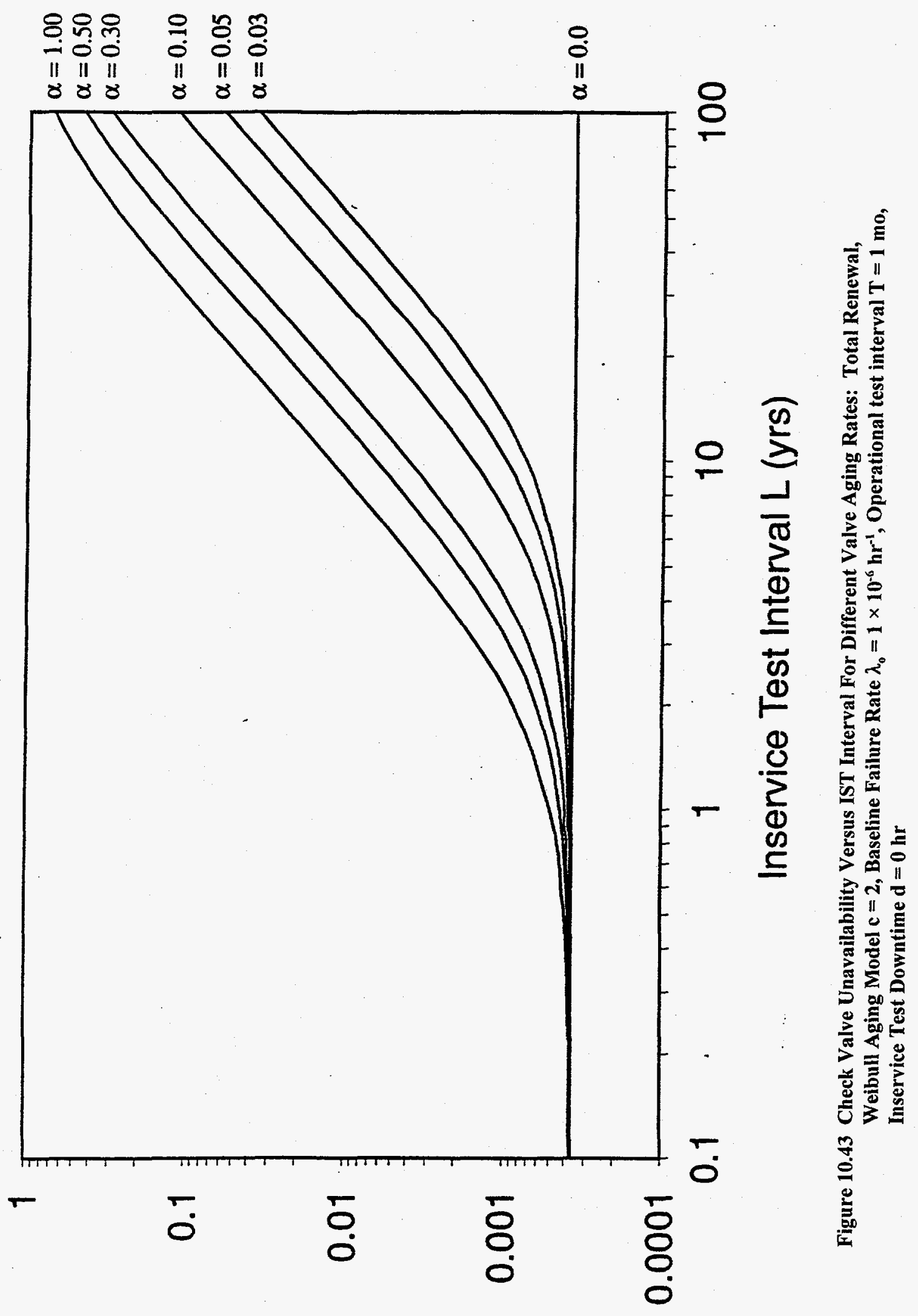

b К‼!qe|!e^euก 


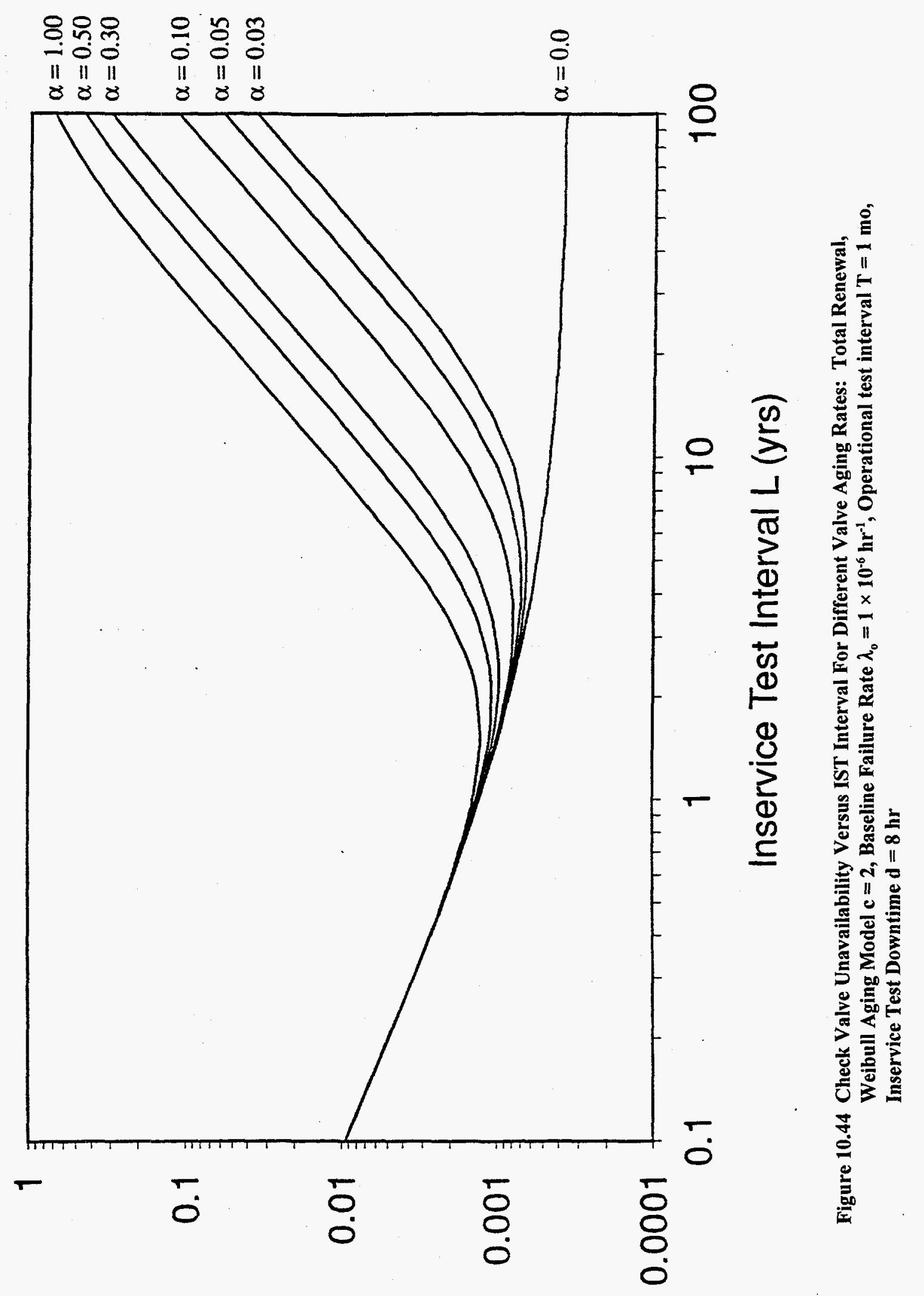

b אł!!!qe|!eлeun 


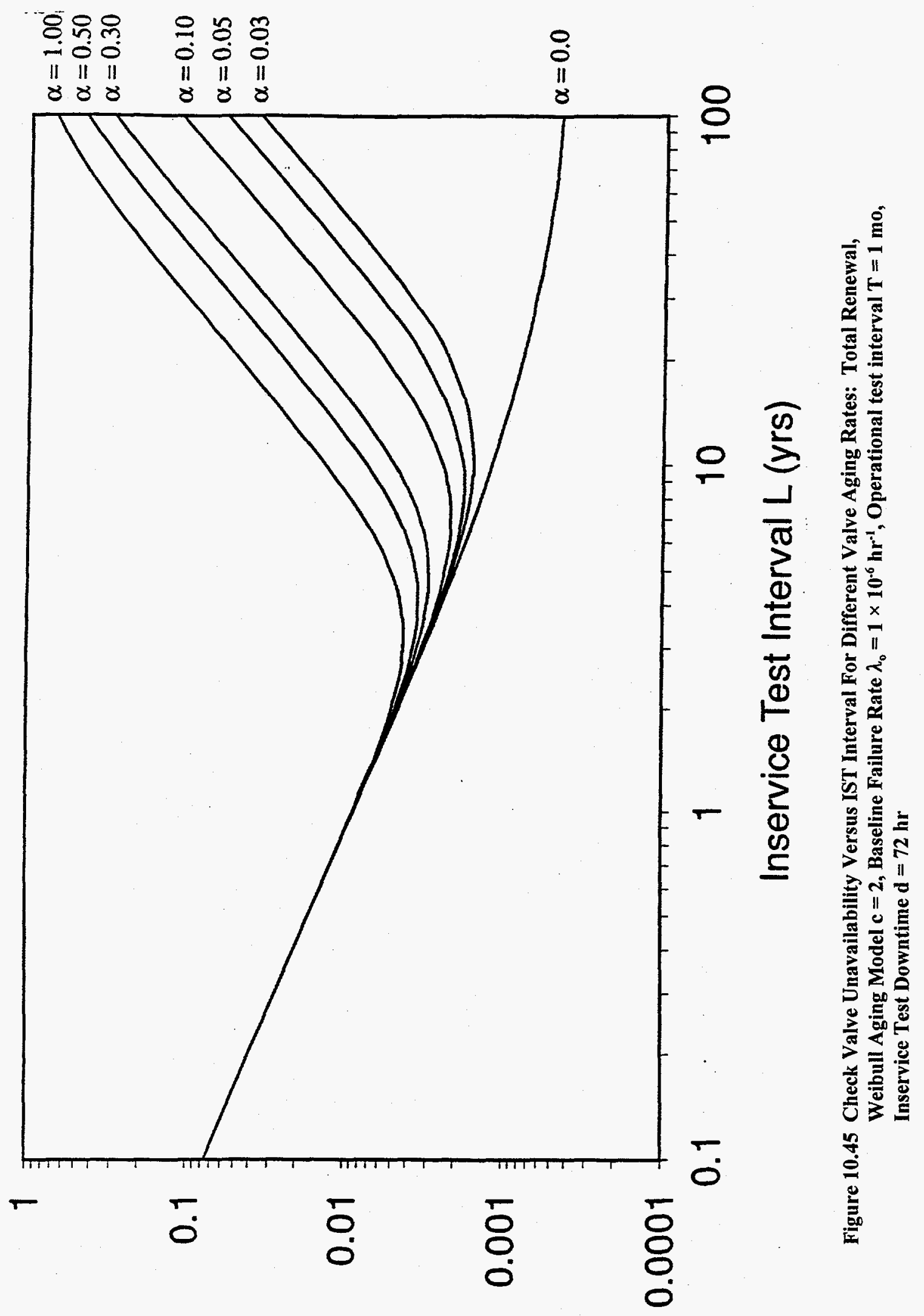

b אł!!!qe|!eseuก 


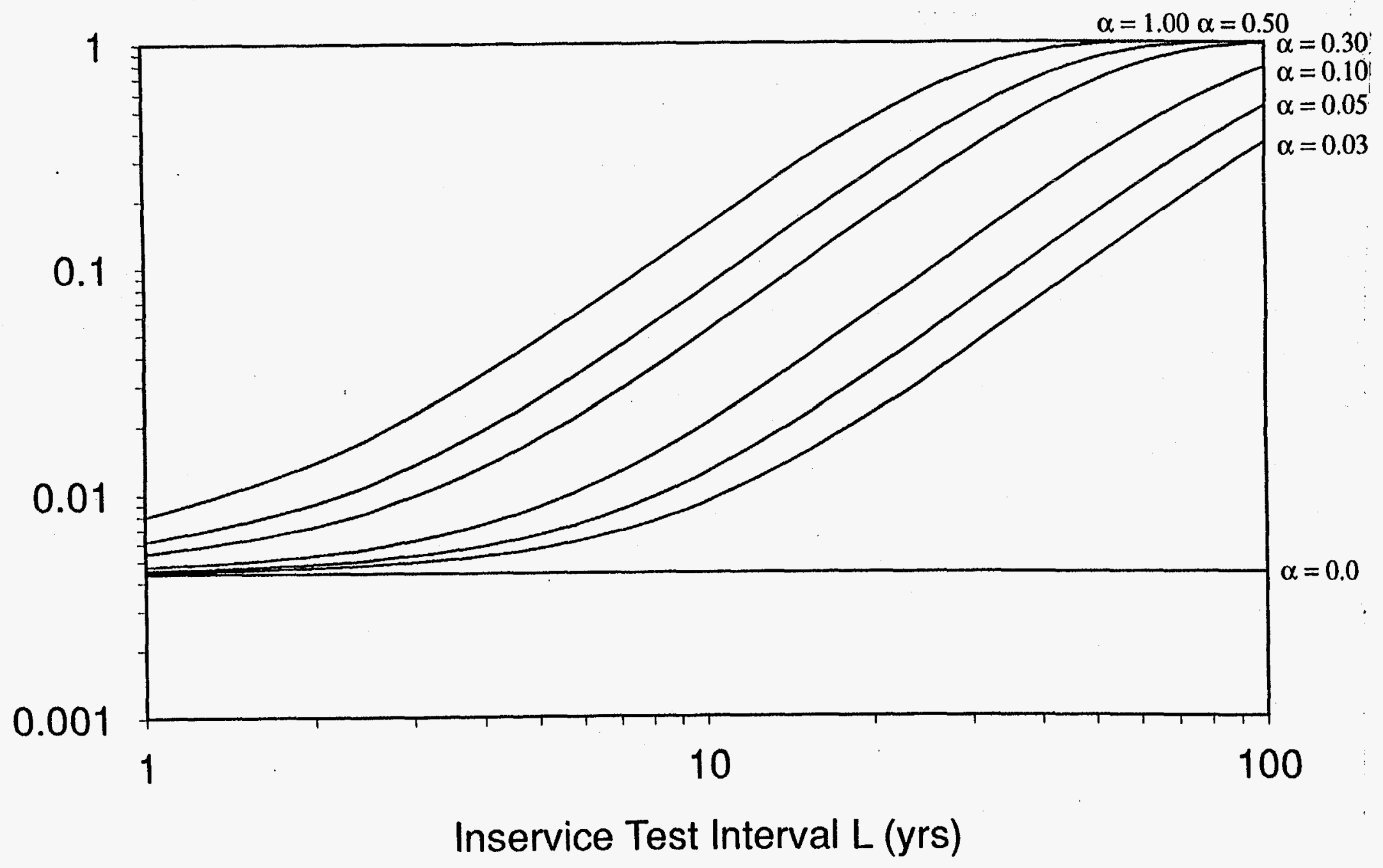

Figure 10.46 Check Valve Unavailability Versus IST Interval For Different Valve Aging Rates: Total Renewal, Weibull Aging Model $\mathrm{c}=2$, Baseline Failure Rate $\lambda_{0}=1 \times 10^{-6} \mathrm{hr}^{-1}$, Operational test interval $\mathrm{T}=12 \mathrm{mo}$, Inservice Test Downtime $\mathrm{d}=0 \mathrm{hr}$ 


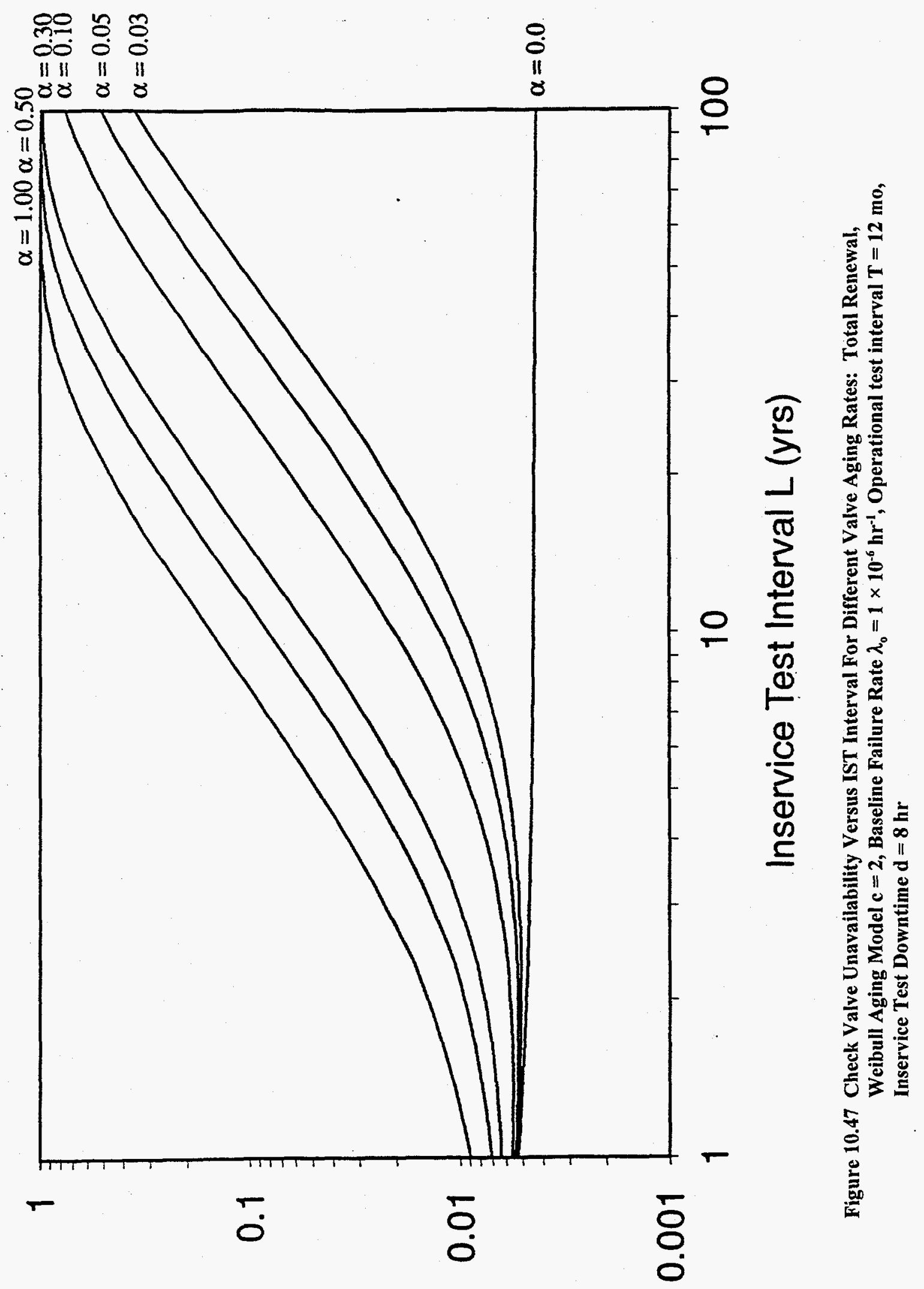

b אł!!!qe|!eлеuก 


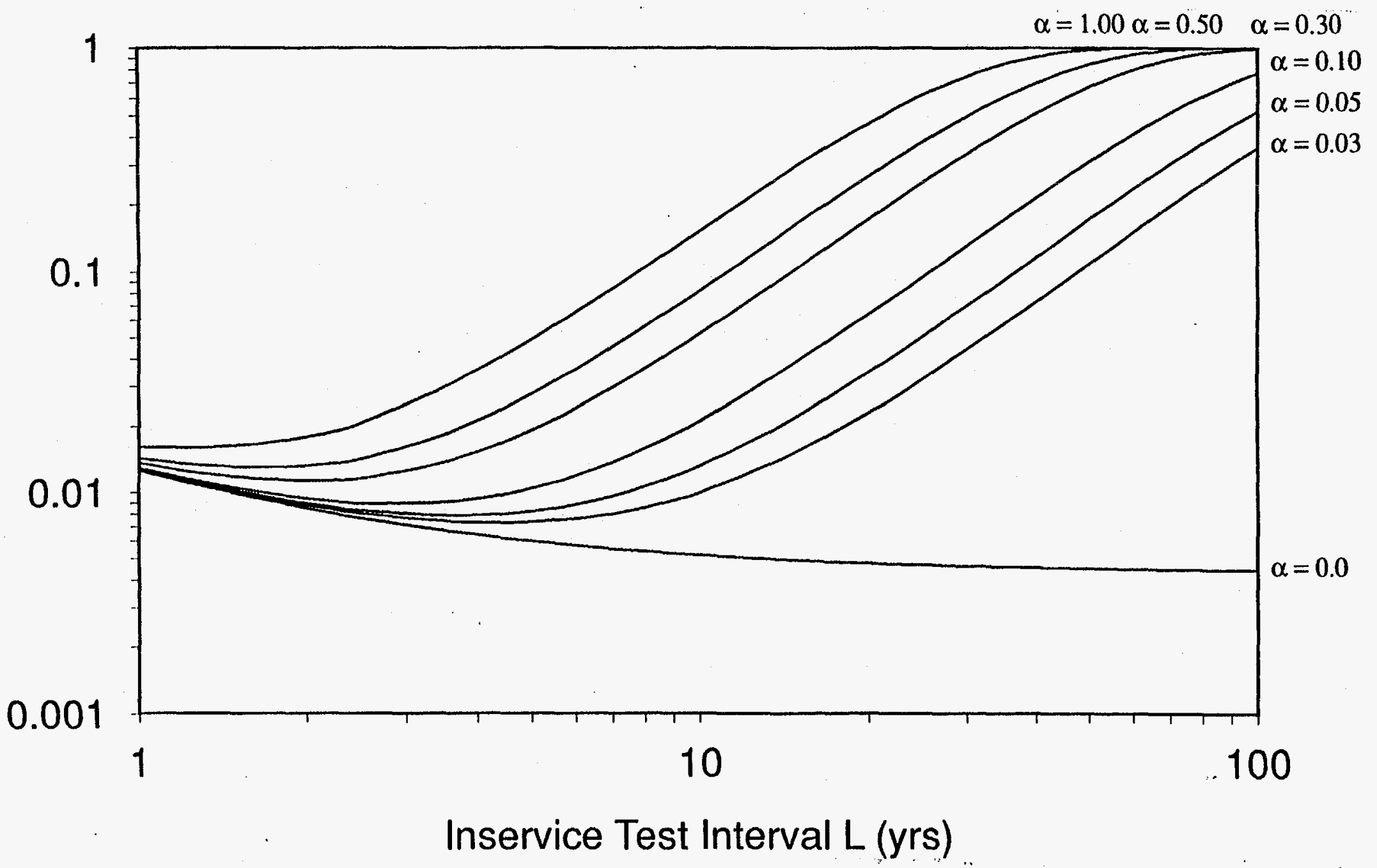

Figure 10.48 Check Valve Unavailability Versus IST Interval For Different Valve Aging Rates: Total Renewal, Weibull Aging Model $\mathrm{c}=2$, Baseline Failure Rate $\lambda_{\mathrm{o}}=1 \times 10^{-6} \mathrm{hr}^{-1}$, Operational test interval $\mathrm{T}=12 \mathrm{mo}$, Inservice Test Downtime $\mathrm{d}=\mathbf{7 2} \mathrm{hr}$ 


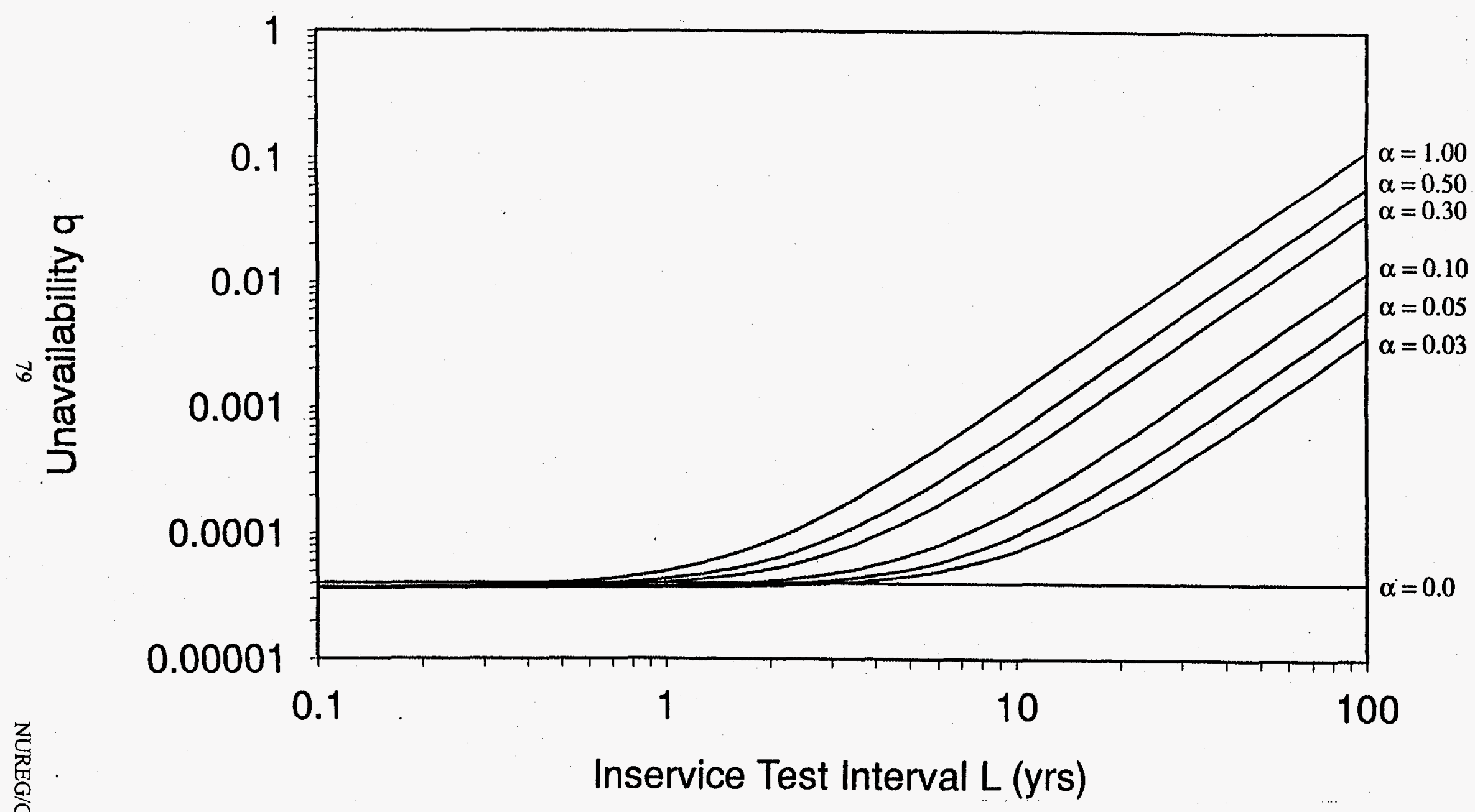

Figure 10.49 Check Valve Unavailability Versus IST Interval For Different Valve Aging Rates: Total Renewal, Weibull Aging Model c $=2$, Baseline Failure Rate $\lambda_{0}=1 \times 10^{-7} \mathrm{hr}^{-1}$, Operational test interval $\mathrm{T}=1 \mathrm{mo}$, Inservice Test Downtime $\mathrm{d}=0 \mathrm{hr}$ 


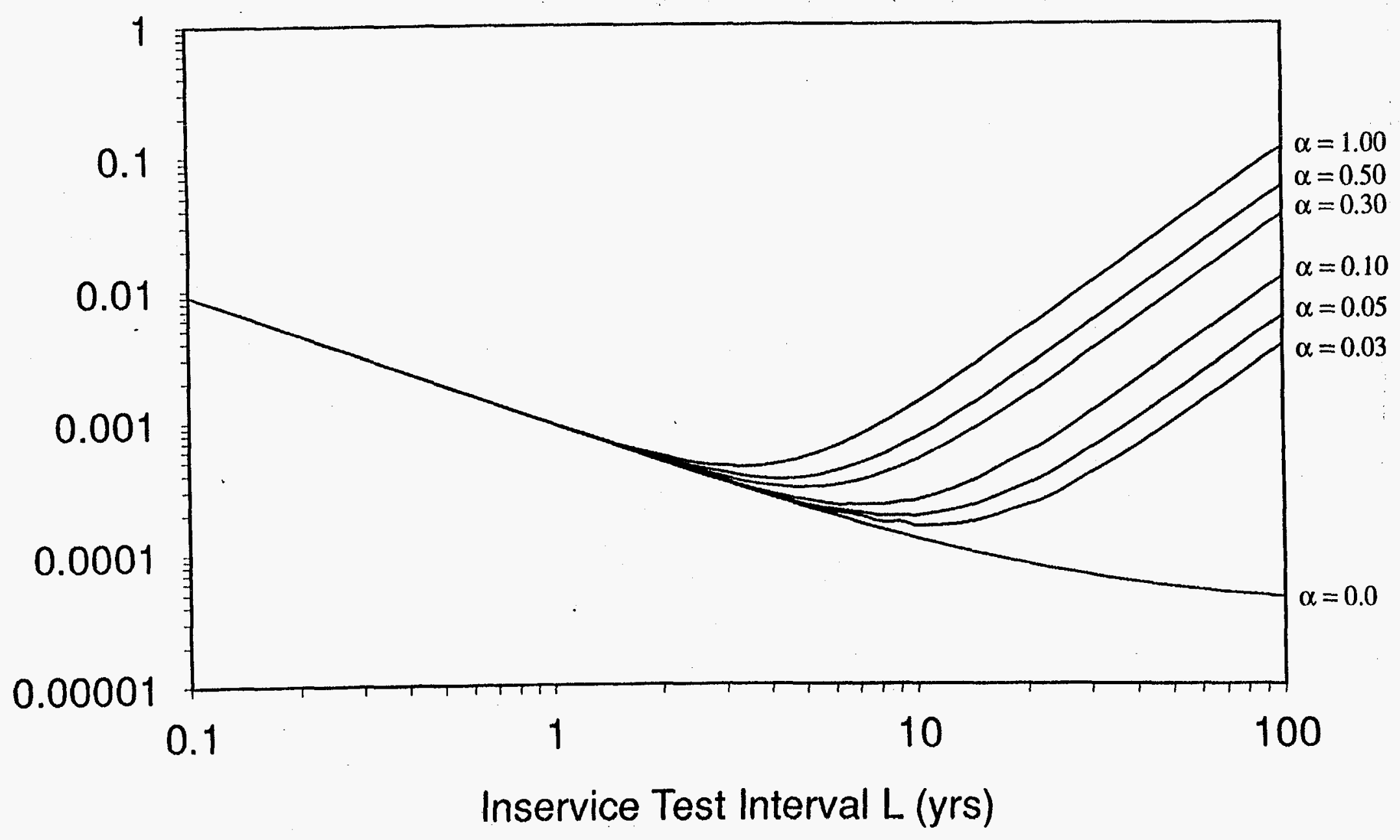

Figure 10.50 Check Valve Unavailability Versus IST Interval For Different Valve Aging Rates: Total Renewal, Weibull Aging Model $\mathrm{c}=2$, Baseline Failure Rate $\lambda_{0}=1 \times 10^{-7} \mathrm{hr}^{-1}$, Operational test interval $\mathrm{T}=1 \mathrm{mo}$, Inservice Test Downtime $\mathbf{d}=\mathbf{8} \mathrm{hr}$ 


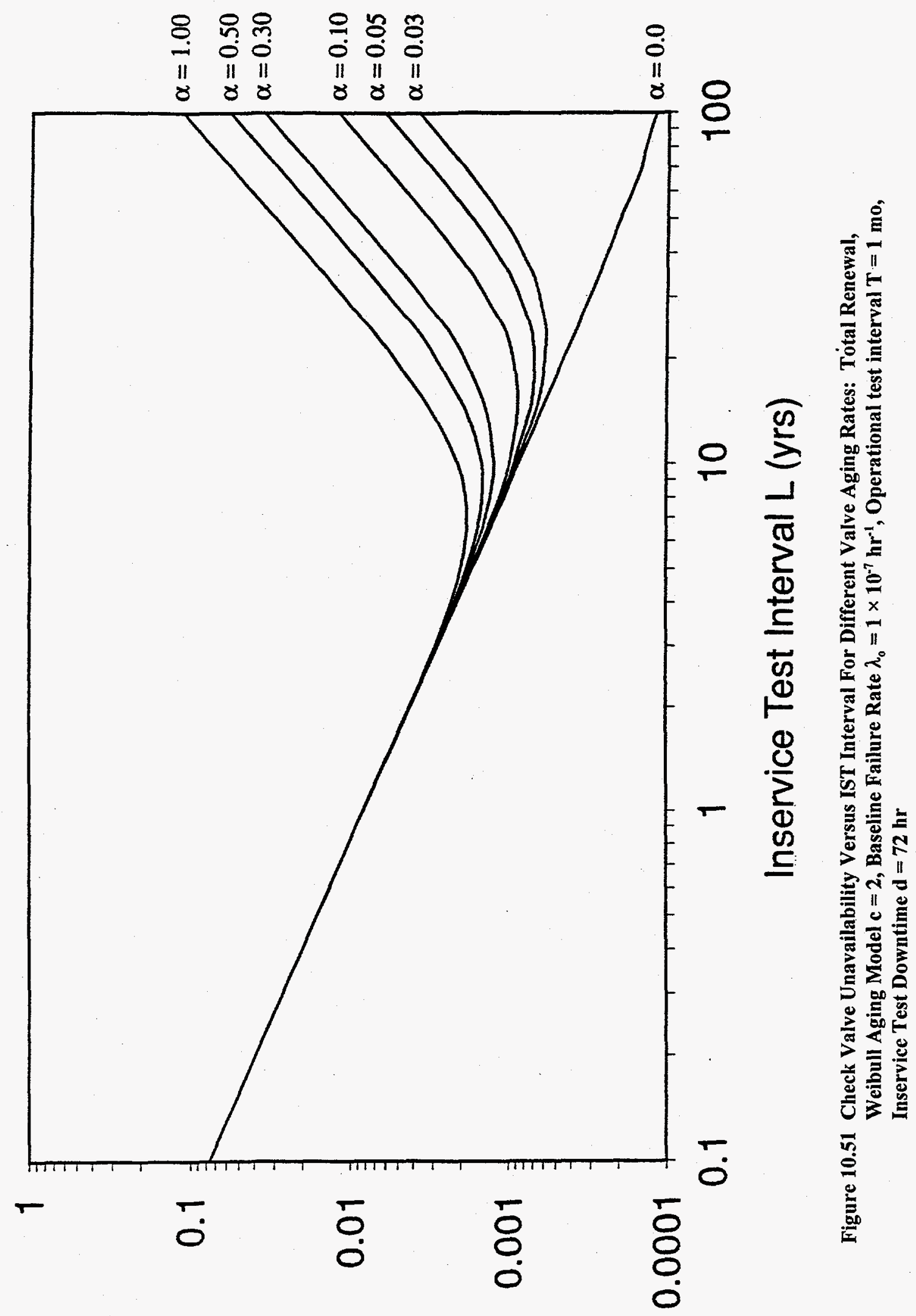

b אł!!!qe|!eıеuก 


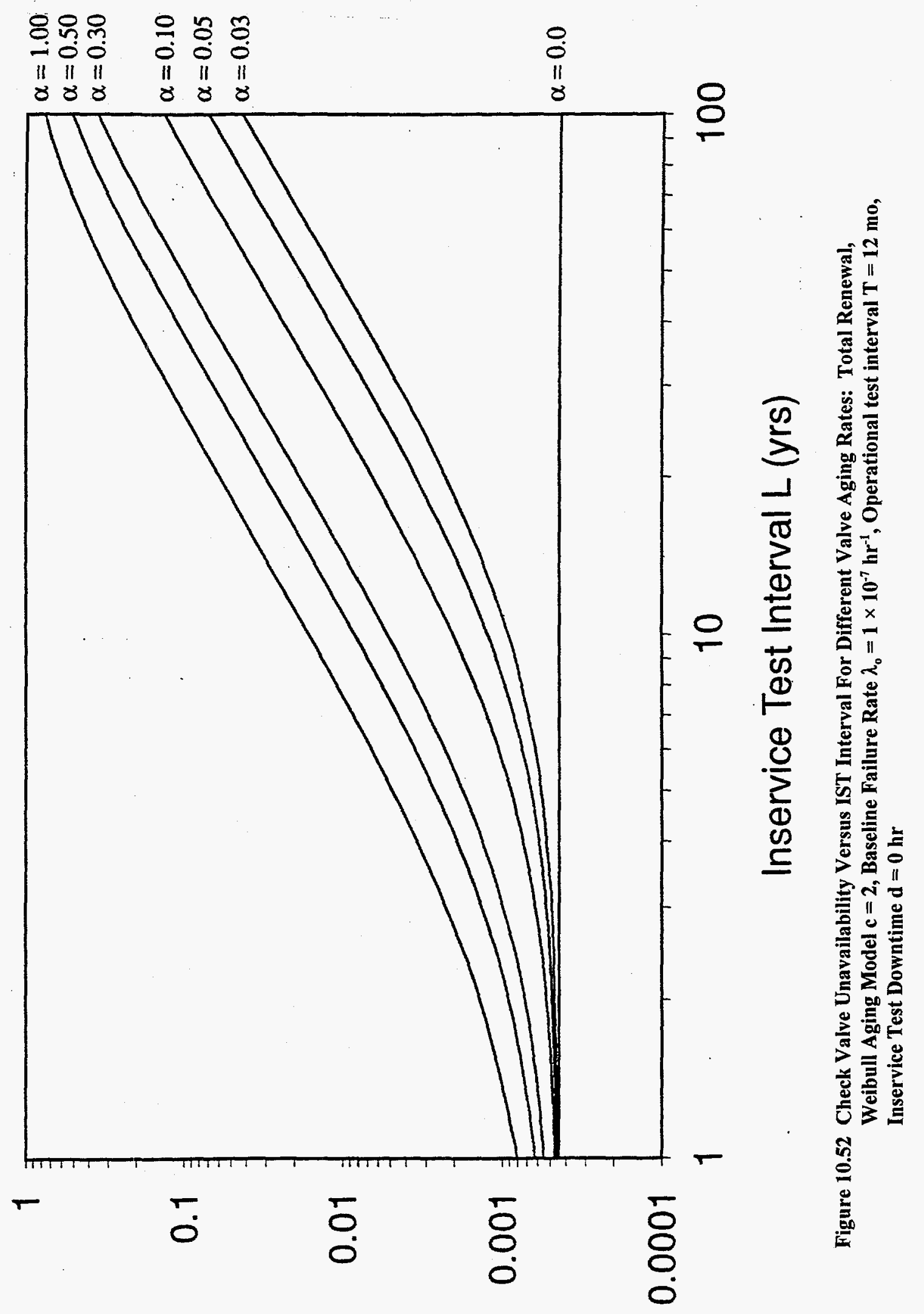

b Kł!!!qe|!eneuก 


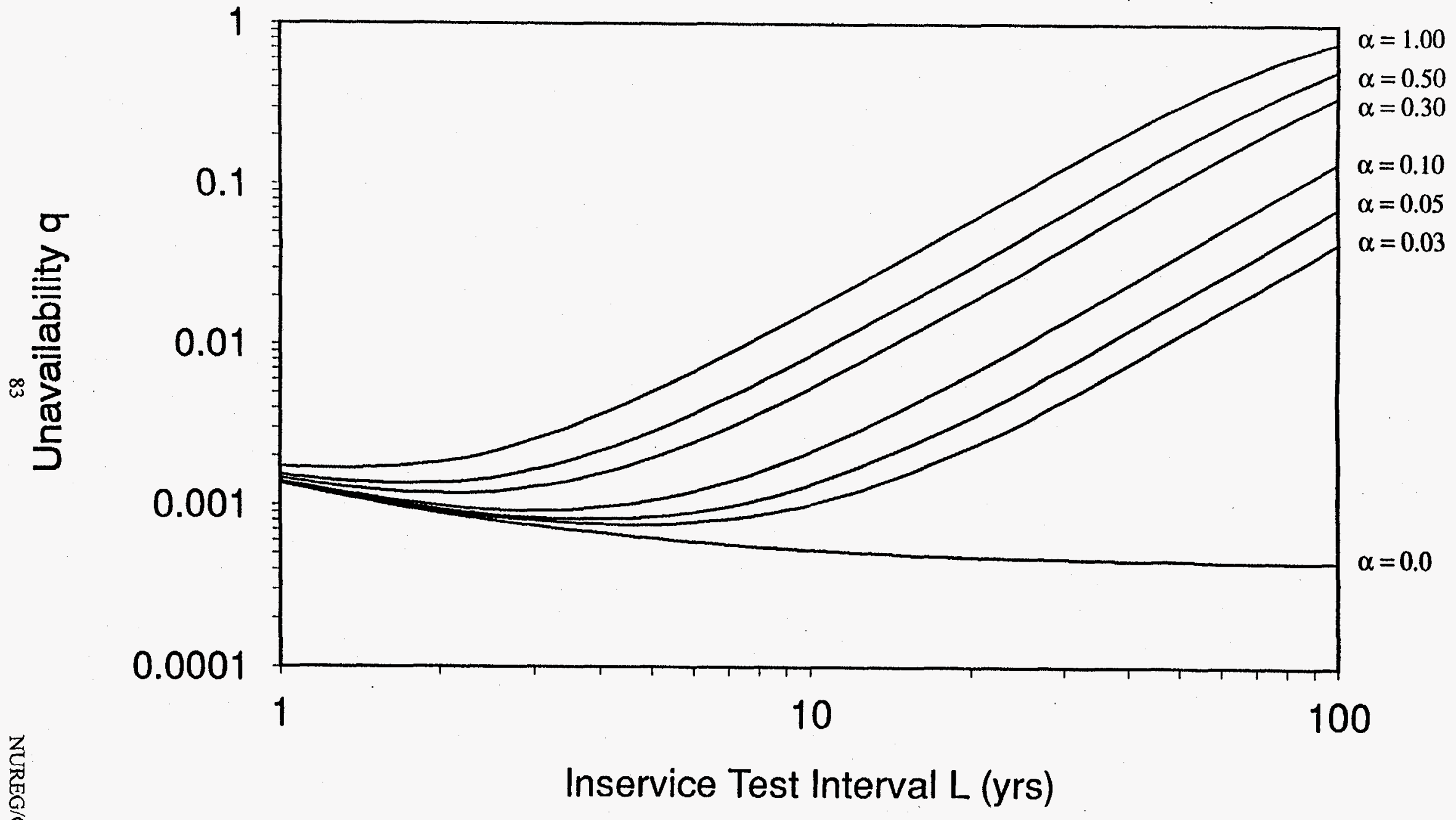

Figure 10.53 Check Valve Unavailability Versus IST Interval For Different Valve Aging Rates: Total Renewal, Weibull Aging Model c $=2$, Baseline Failure Rate $\lambda_{0}=1 \times 10^{-7} \mathrm{hr}^{-1}$, Operational test interval T $=12 \mathrm{mo}$, Inservice Test Downtime $\mathrm{d}=\mathbf{8} \mathrm{hr}$ 


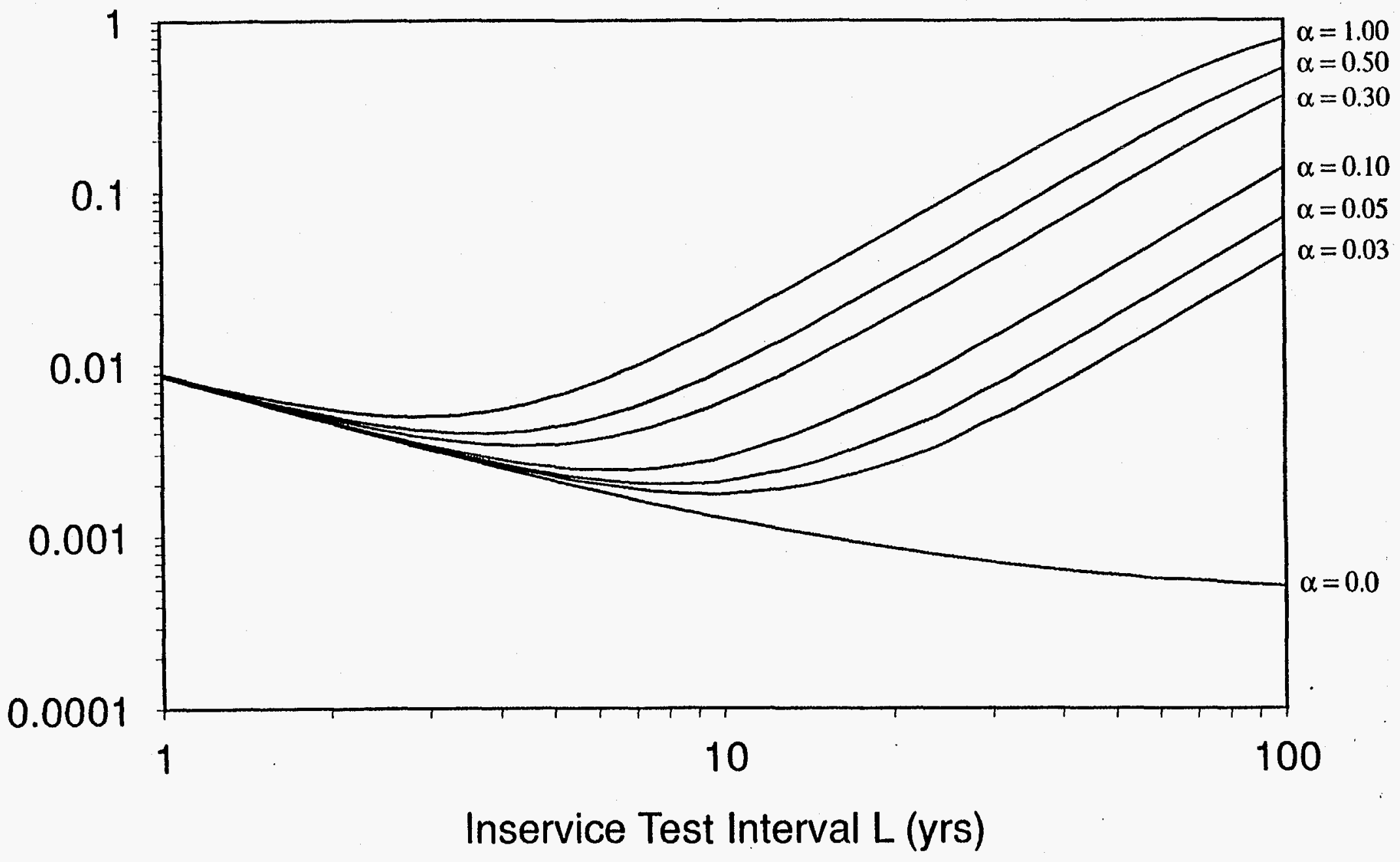

Figure 10.54 Check Valve Unavailability Versus IST Interval For Different Valve Aging Rates: Total Renewal, Weibull Aging Model $\mathrm{c}=2$, Baseline Failure Rate $\lambda_{\mathrm{o}}=1 \times 10^{-7} \mathrm{hr}^{-1}$, Operational test interval T $=12 \mathrm{mo}$, Inservice Test Downtime d $=\mathbf{7 2} \mathrm{hr}$ 


\section{BLOCK 2. CURVES OF CHECK VALVE UNAVAILABILITY VERSUS IST INTERVAL FOR NONLINEAR AGING AND NO RENEWAL AFTER THE IST}

No Renewal Following the IST

No Additional Operational Testing

Nonlinear Aging Rates ( $c=2$ or $\mathrm{c}=3$ ) of $0 \%, 10 \%, 50 \%, 100 \%$ per year

Baseline Check Valve Failure Rate of $1 \times 10^{-6} \mathrm{hr}^{-1}$ or $1 \times 10^{-7} \mathrm{hr}^{-1}$

IST Associated Downtime of $0 \mathrm{hrs}, 8 \mathrm{hrs}, 72 \mathrm{hrs}$ 


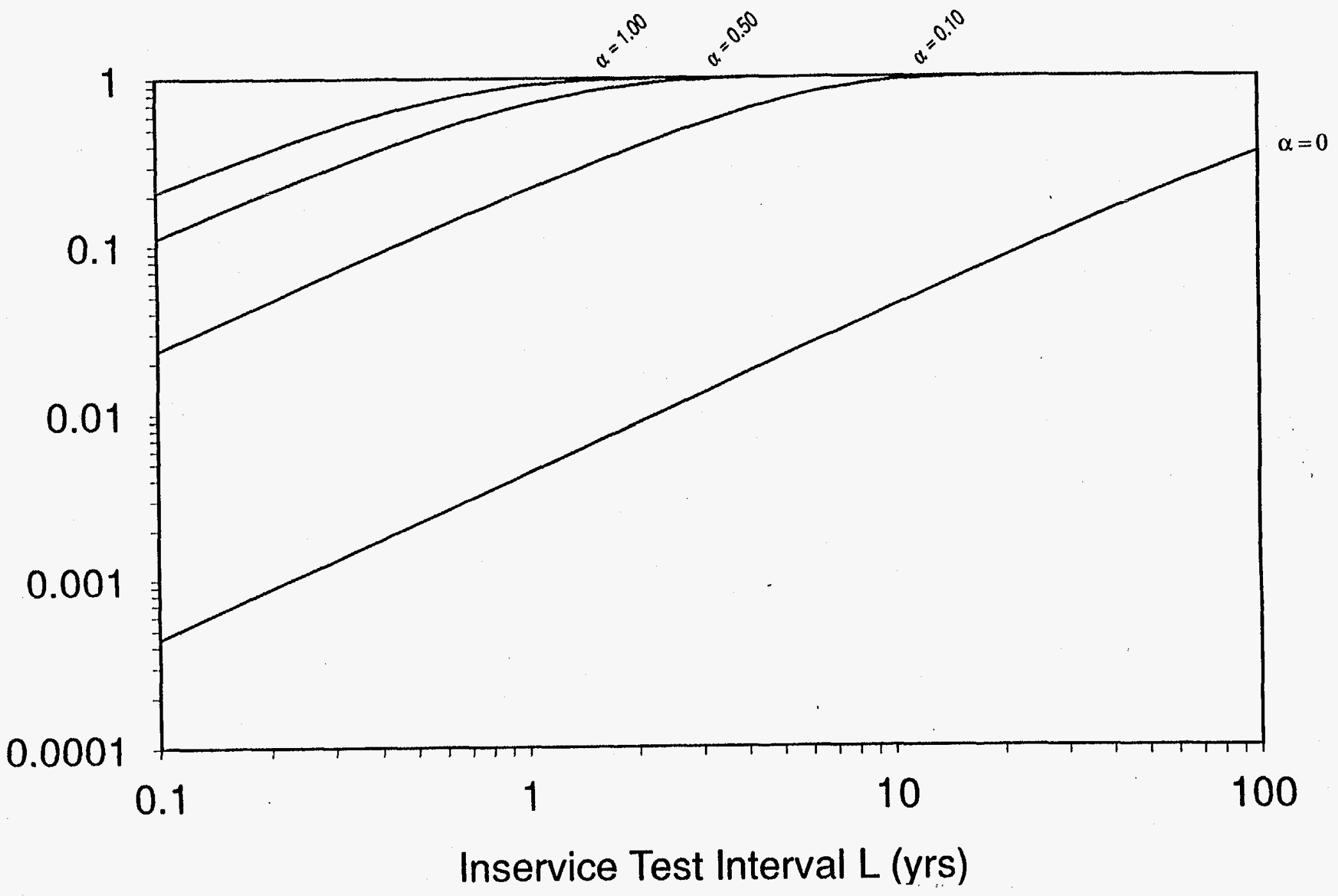

Figure 10.55 Check Valve Unavailability Versus IST Interval For Different Valve Aging Rates: Nonrenewal, No Intermediate Testing, Baseline Failure Rate $\lambda_{0}=1 \times 10^{-6} \mathrm{hr}^{-1}$, Inservice Test Downtime d $=0 \mathrm{hr}$,

Valve Life $s=\mathbf{4 0}$ yrs, Weibull aging model $c=2$ 


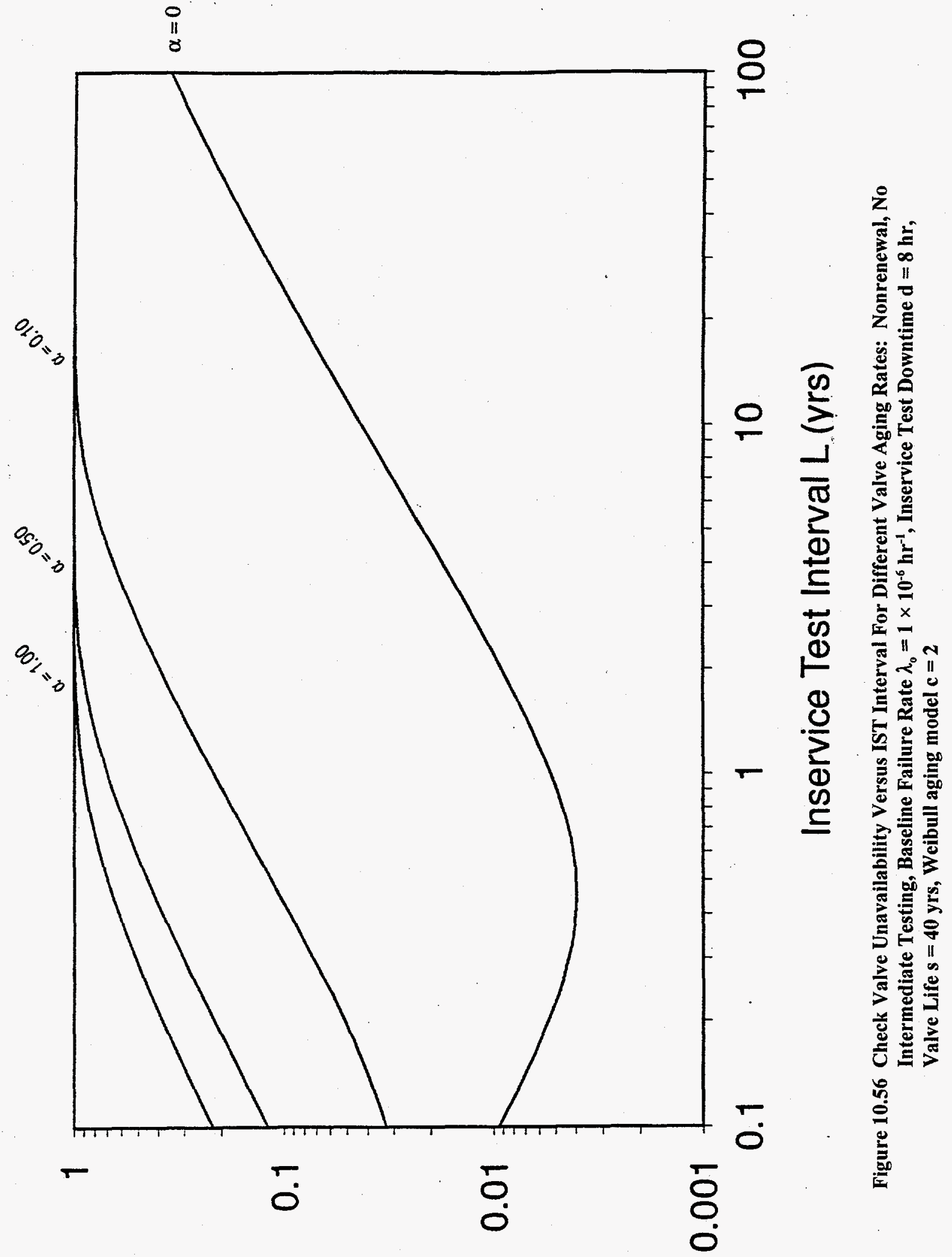

b Kt!!!qe\|!eseuก 


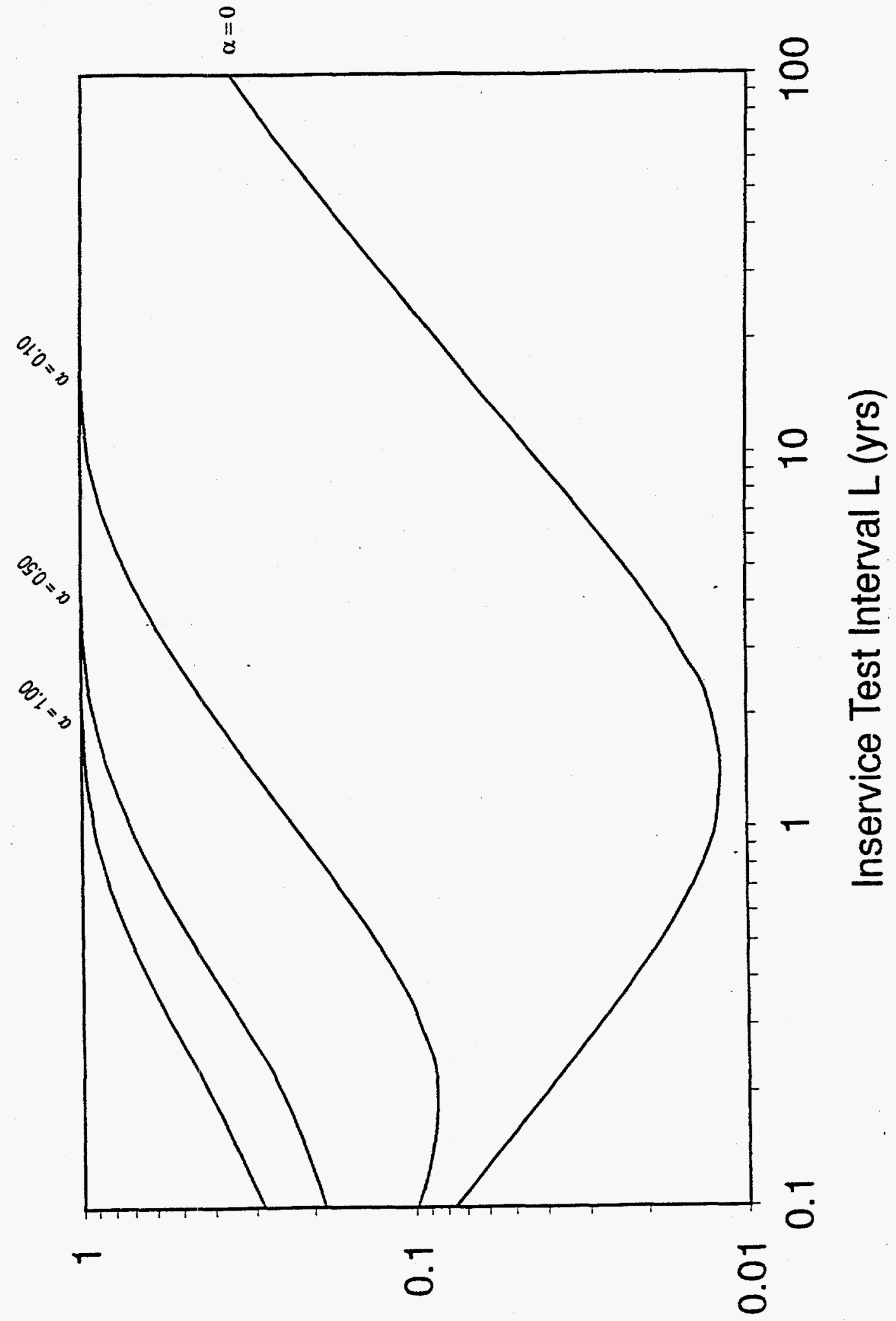

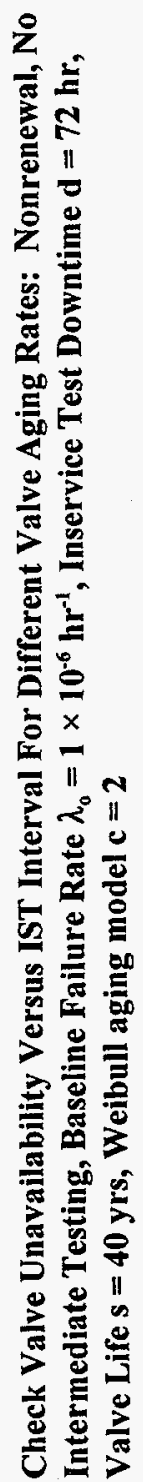

है

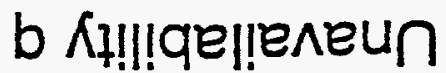




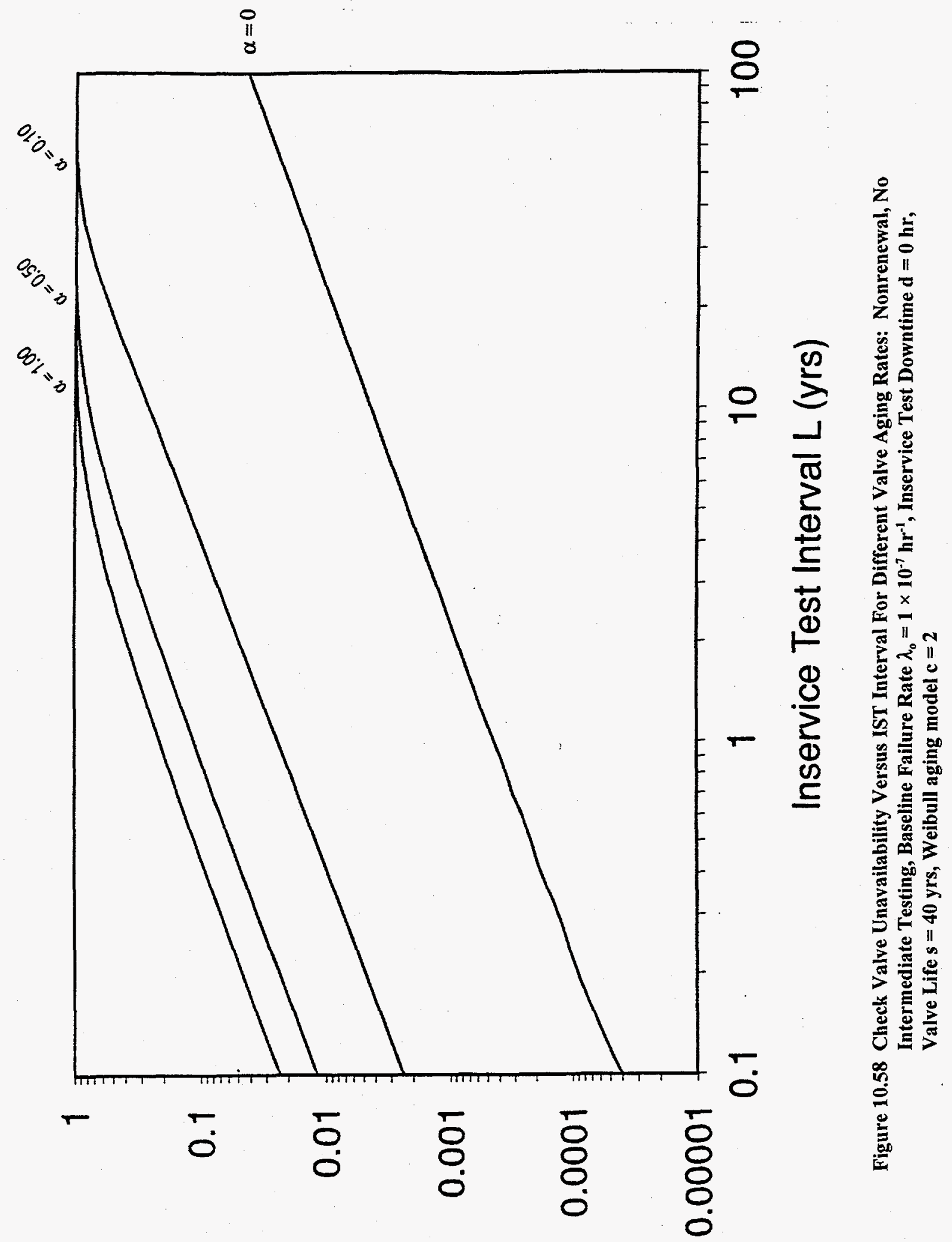

b Kł!!!qe|!eseuก 


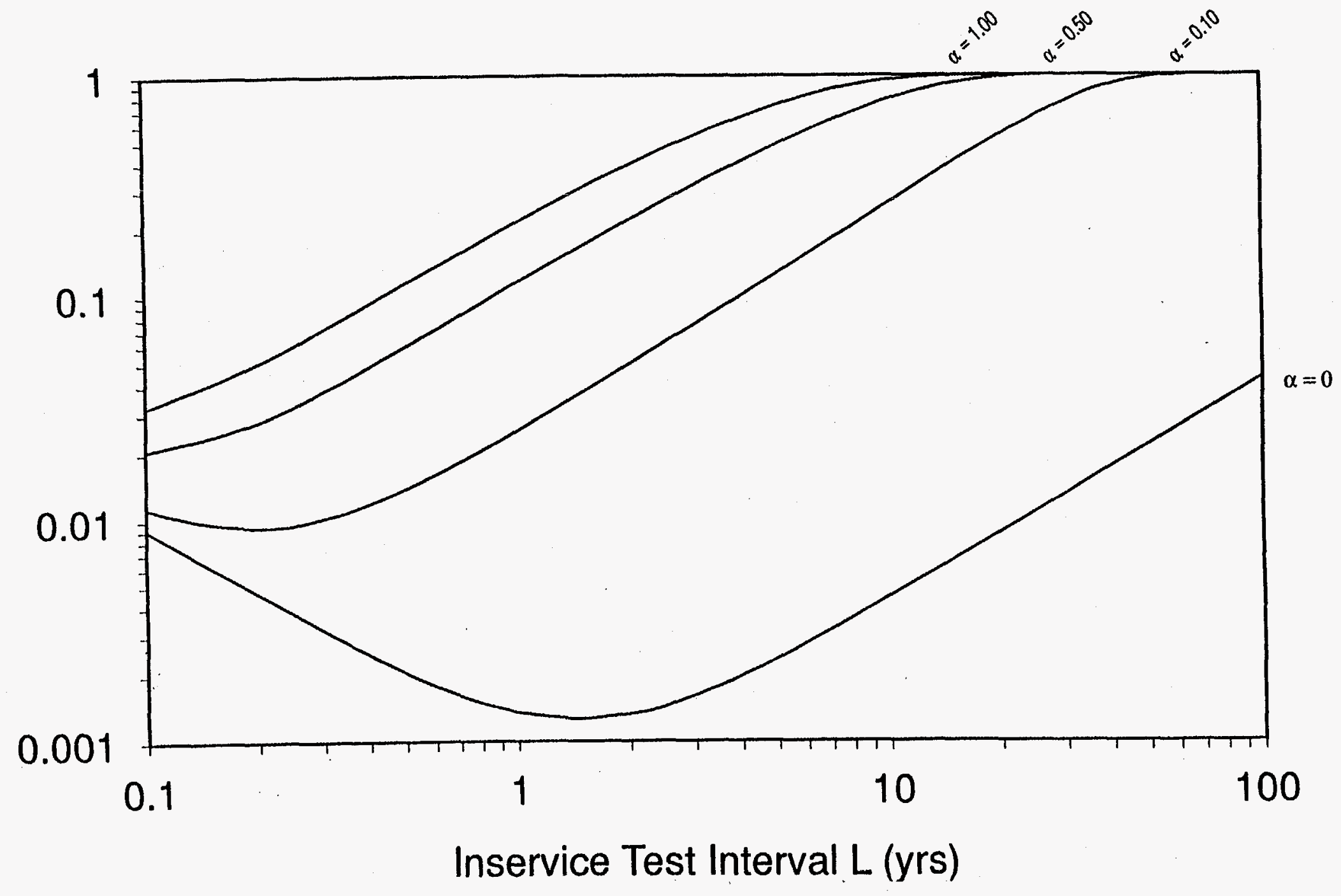

Figure 10.59 Check Valve Unavailability Versus IST Interval For Different Valve Aging Rates: Nonrenewal, No Intermediate Testing, Baseline Failure Rate $\lambda_{o}=1 \times 10^{-7} \mathrm{hr}^{-1}$, Inservice Test Downtime d $=8 \mathrm{hr}$, Valve Life $s=40 \mathrm{yrs}$, Weibull aging model $c=2$ 


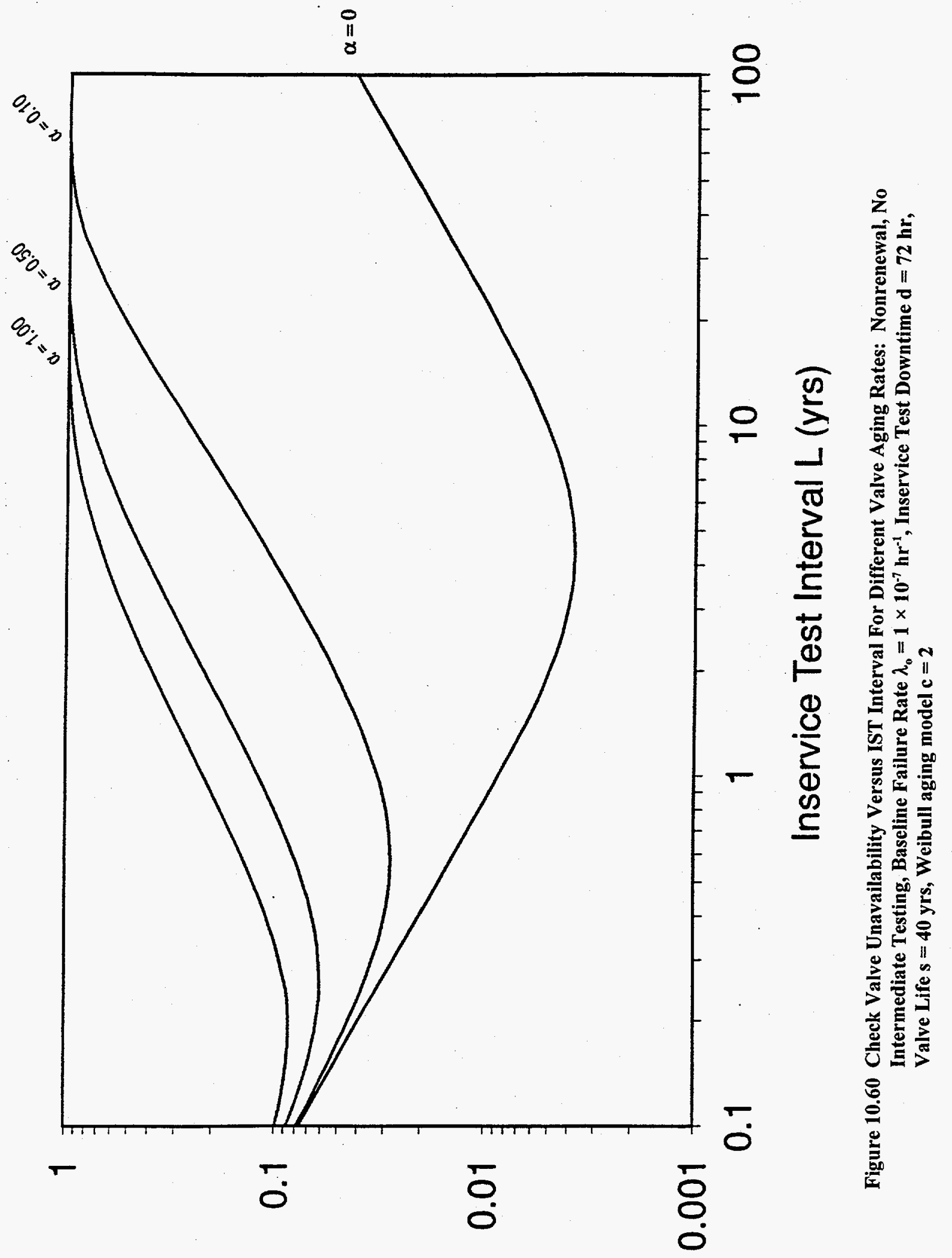

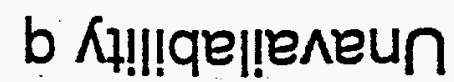




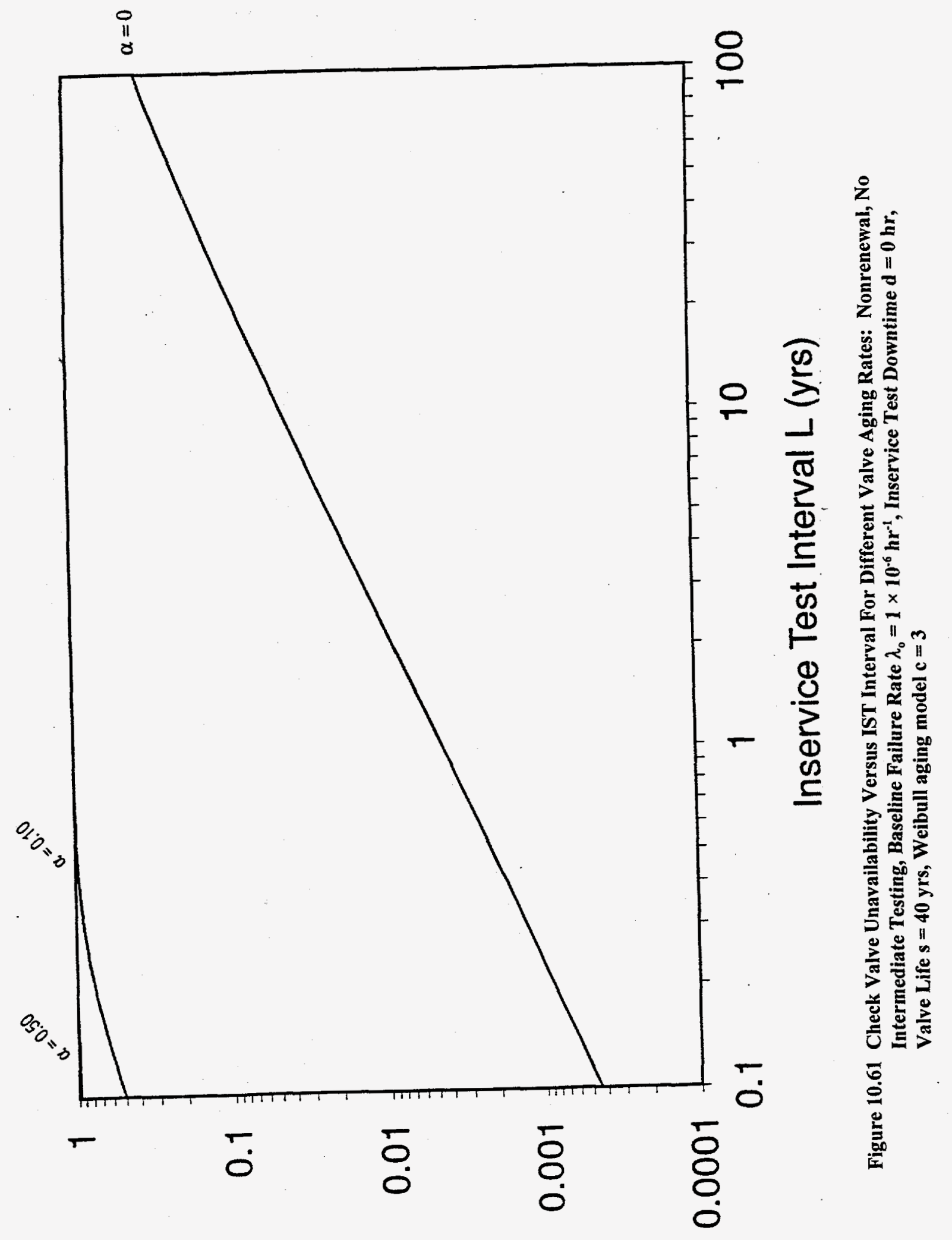

NUREG/CR-6508

b אł!!!qe!!eneuก 


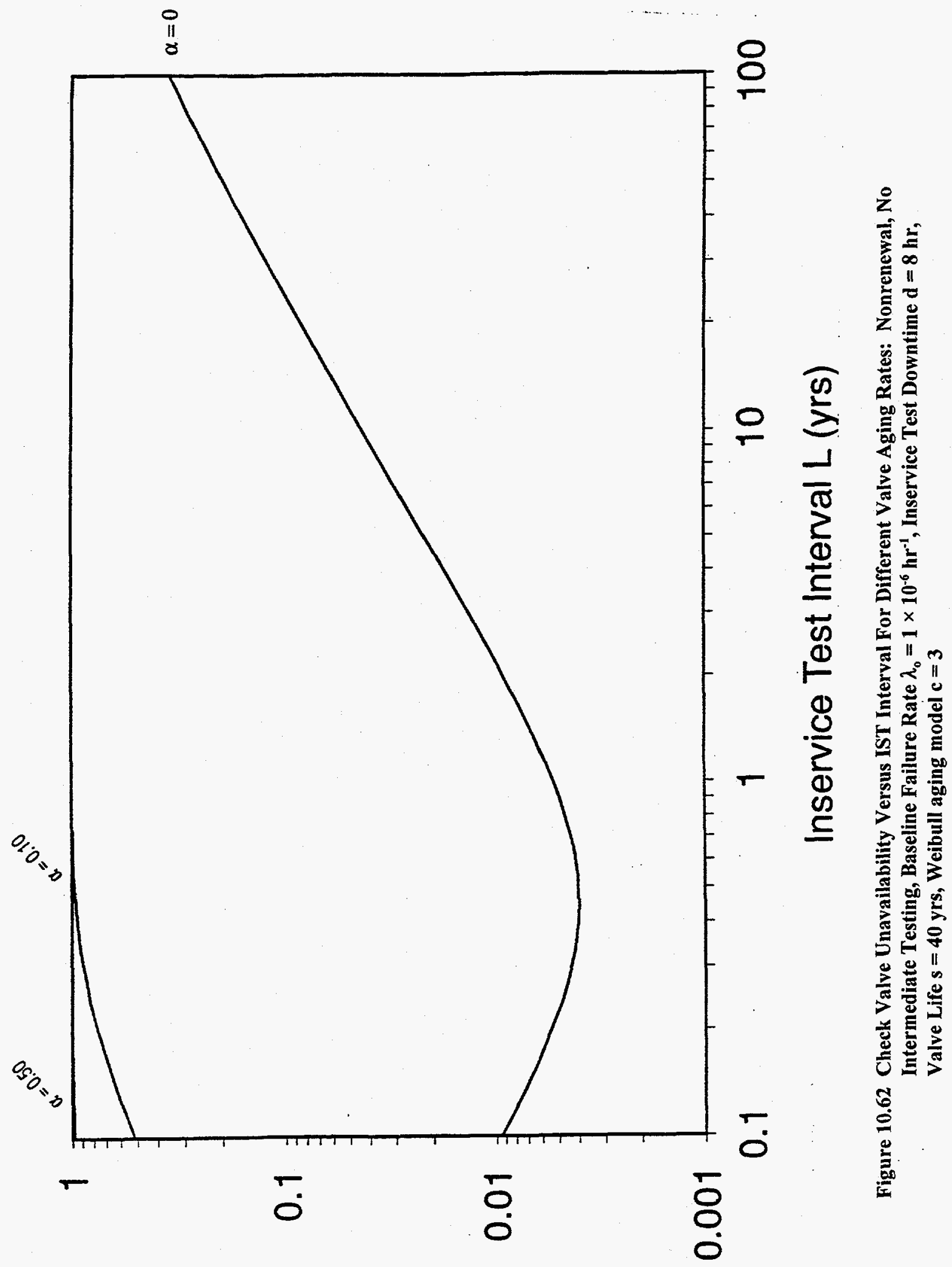

b אł!!!qe|!eıeuก 


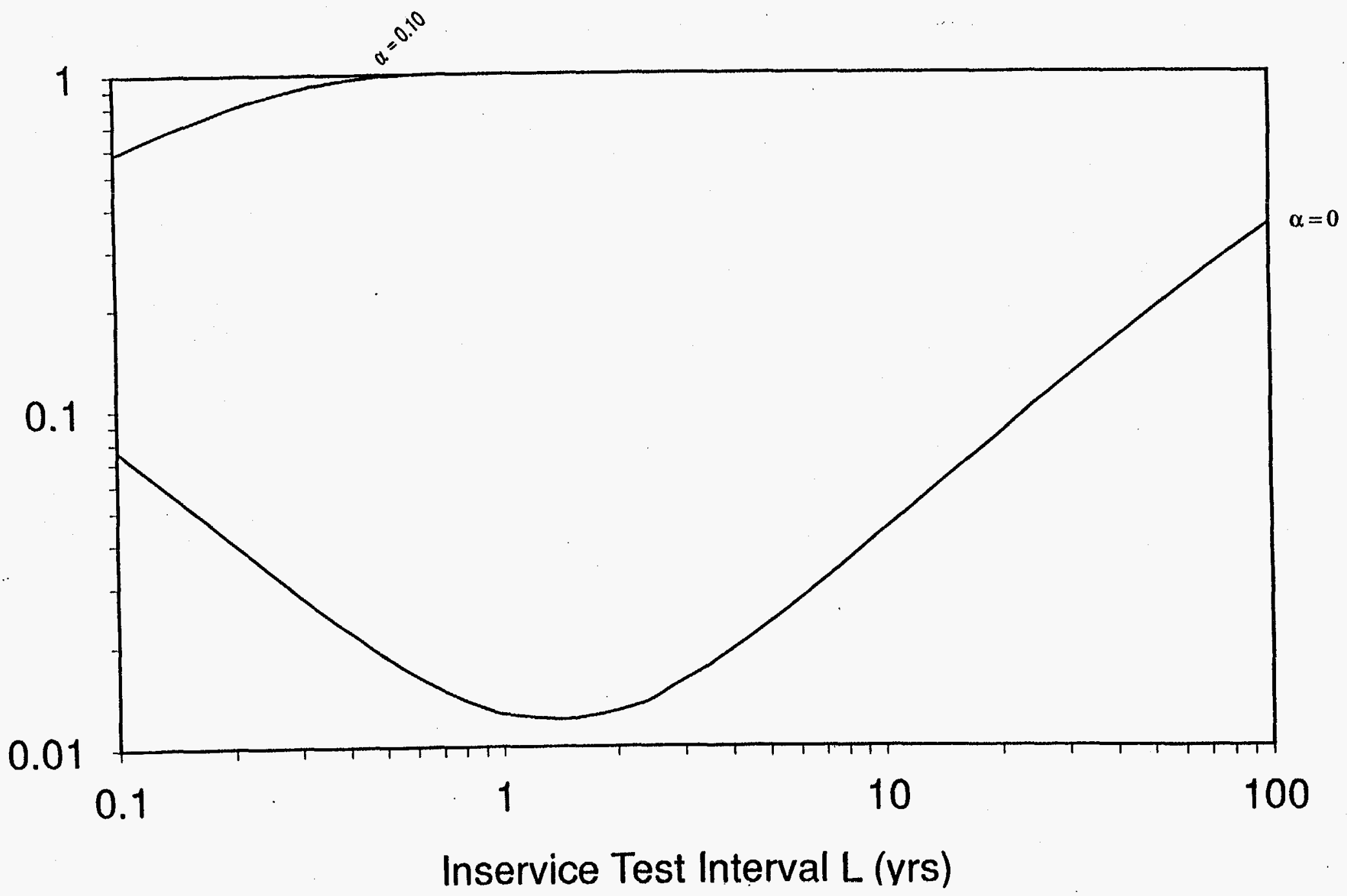

Figure 10.63 Check Valve Unavailability Versus IST Interval For Different Valve Aging Rates: Nonrenewal, No Intermediate Testing, Baseline Failure Rate $\lambda_{0}=1 \times 10^{-6} \mathrm{hr}^{-1}$, Inservice Test Downtime $\mathrm{d}=0 \mathrm{hr}$, Valve Life $s=40$ yrs, Weibull aging model $c=3$ 


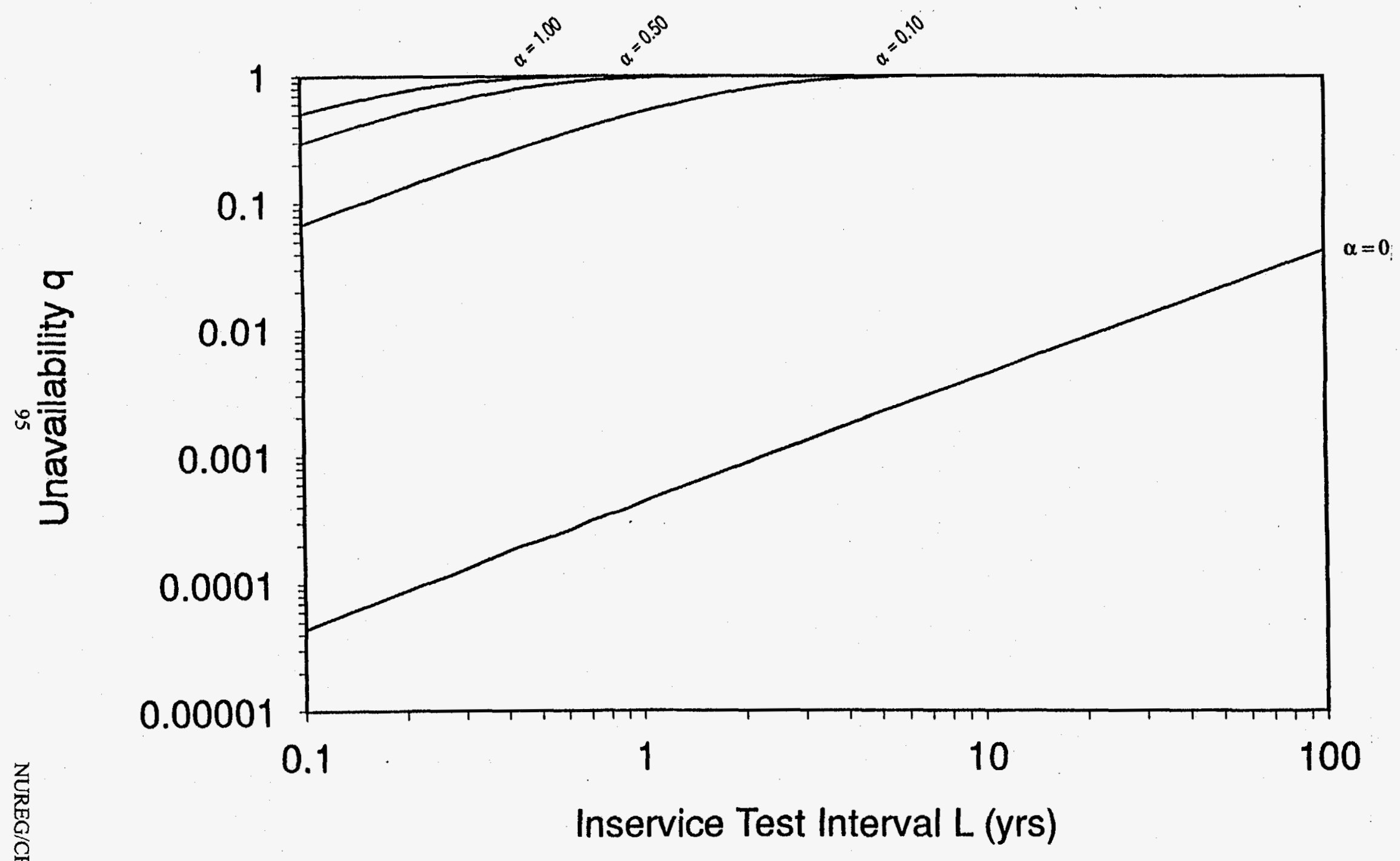

Figure 10.64 Check Valve Unavailability Versus IST Interval For Different Valve Aging Rates: NonrenewaI, No Intermediate Testing, Baseline Failure Rate $\lambda_{0}=1 \times 10^{-7} \mathrm{hr}^{-1}$, Inservice Test Downtime d $=0 \mathrm{hr}$, Valve Life $s=40$ yrs, Weibull aging model $c=3$ 


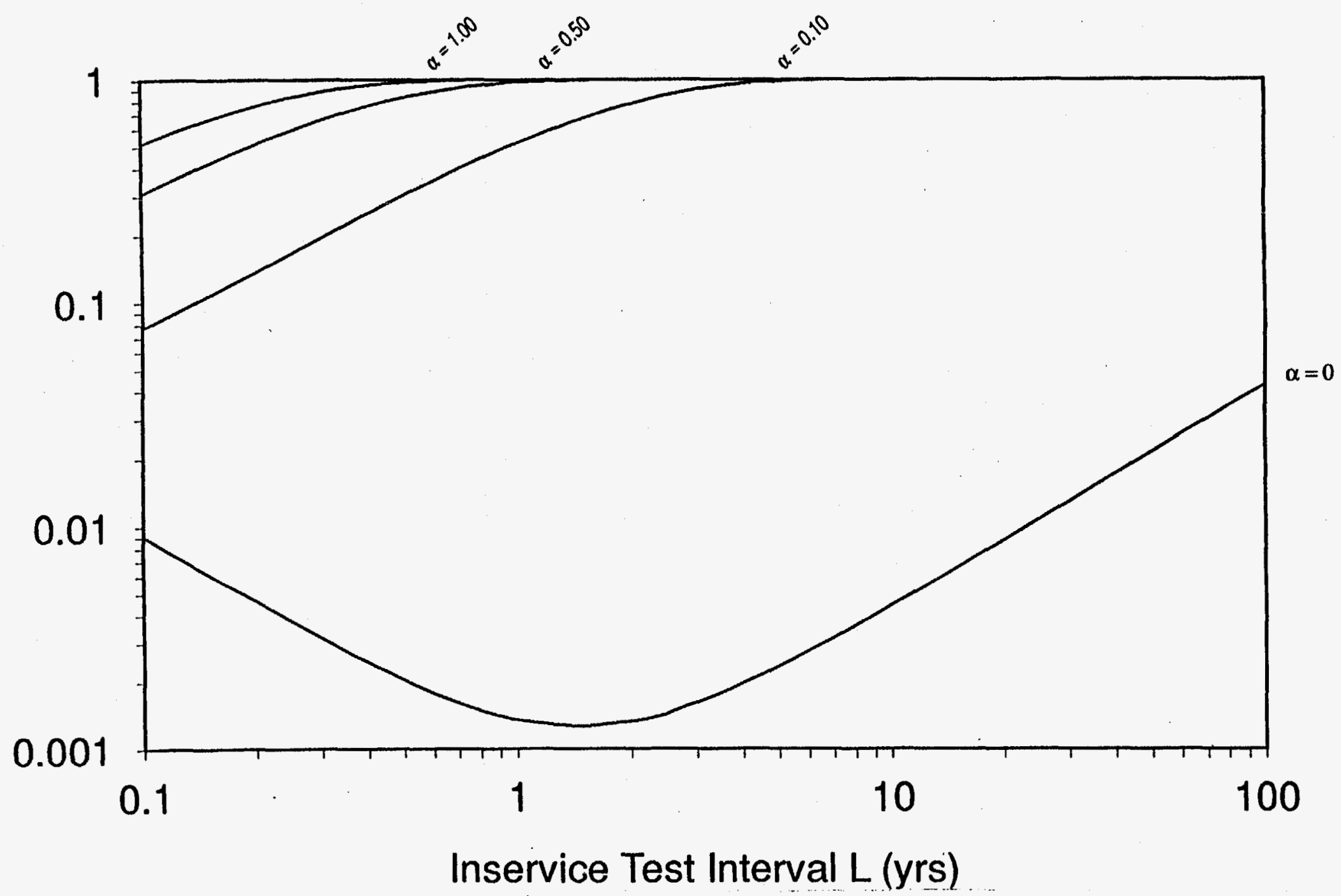

Figure 10.65 Check Valve Unavailability Versus IST Interval For Different Valve Aging Rates: Nonrenewal, No Intermediate Testing, Baseline Failure Rate $\lambda_{0}=1 \times 10^{-7} \mathrm{hr}^{-1}$, Inservice Test Downtime $\mathrm{d}=8 \mathrm{hr}$, Valve Life $s=40$ yrs, Weibull aging model $c=3$ 


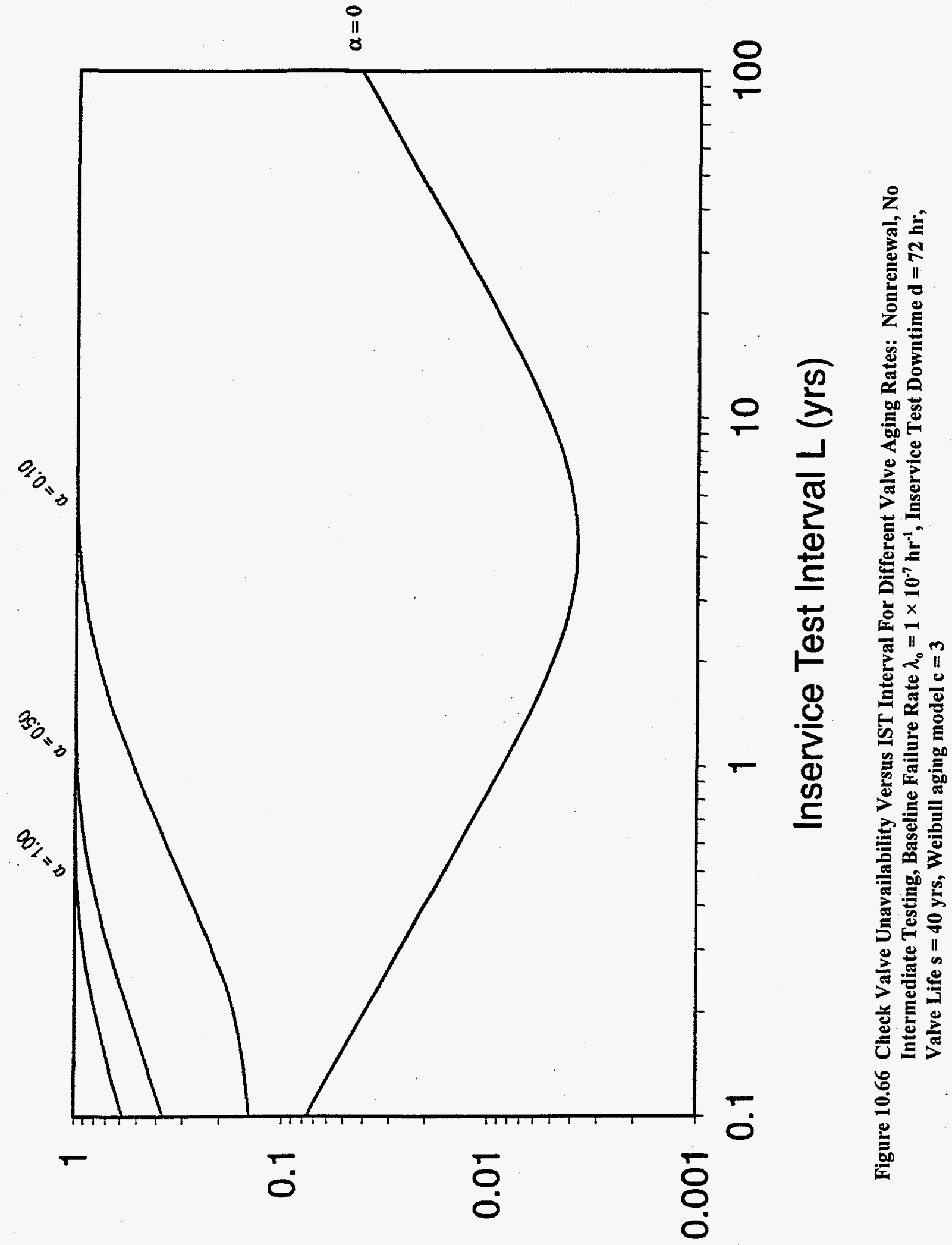

b K1!!!qe|!eneuก 


\section{BLOCK 3. CURVES OF CHECK VALVE UNAVAILABILITY VERSUS IST INTERVAL FOR NONLINEAR AGING AND PARTIAL RENEWAL AFTER THE IST}

Partial Renewal Following the IST

Renewal Fraction of 0.1 or 0.5

No Additional Operational Testing

Nonlinear Aging Rates $(\mathrm{c}=2$ or $\mathrm{c}=3$ ) of $0 \%, 10 \%, 50 \%, 100 \%$ per year

Baseline Check Valve Failure Rate of $1 \times 10^{-6} \mathrm{hr}^{-1}$ or $1 \times 10^{-7} \mathrm{hr}^{-1}$

IST Associated Downtime of $0 \mathrm{hrs}, 8 \mathrm{hrs}, 72 \mathrm{hrs}$ 


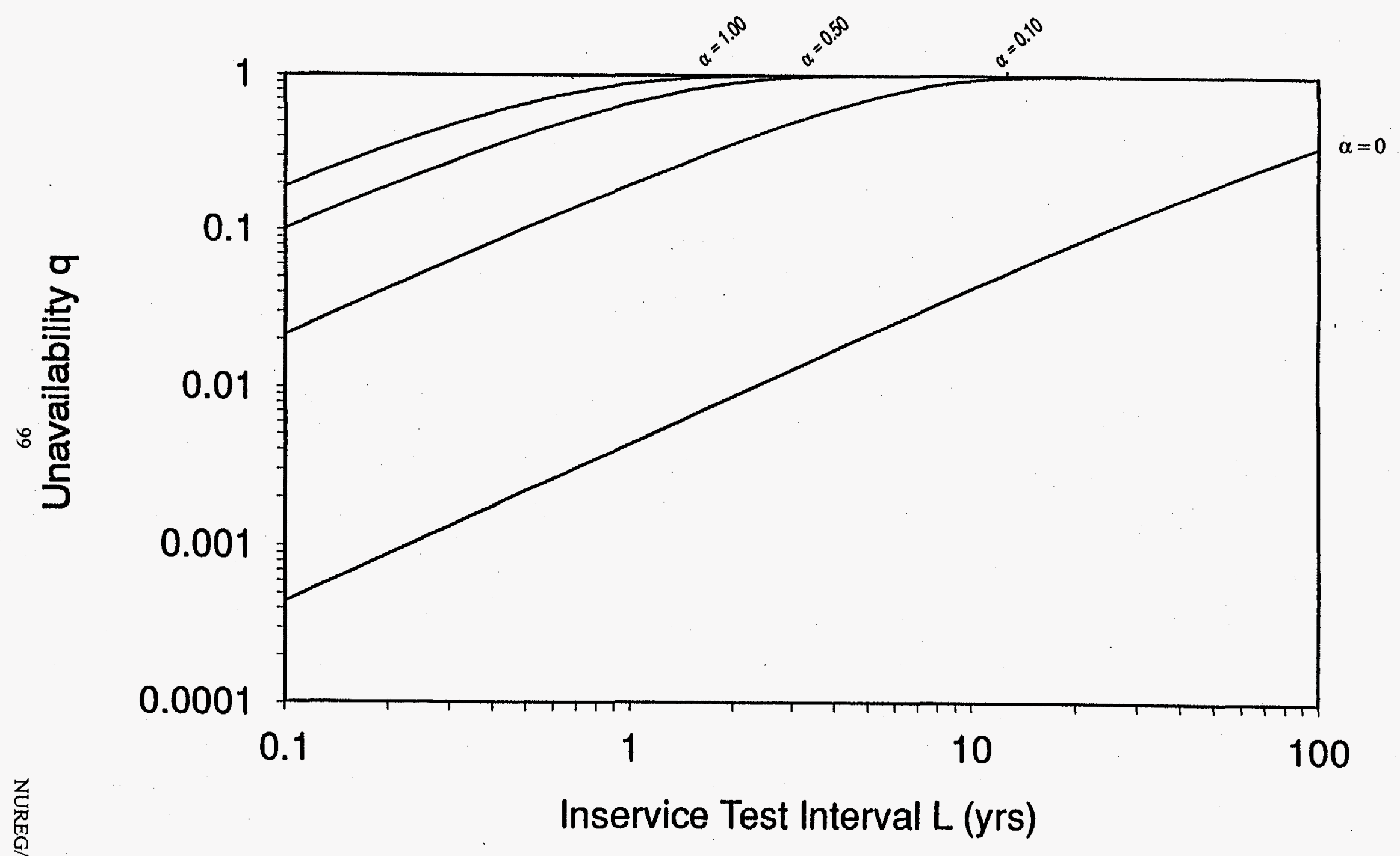

Figure 10.67 Check Valve Unavailability Versus IST Interval For Different Valve Aging Rates: Partial Renewal, No Intermediate Testing, Baseline Failure Rate $\lambda_{0}=1 \times 10^{-6} \mathrm{hr}^{-1}$, Inservice Test Downtime d $=0 \mathrm{hr}$, Partial Renewal Fraction $f=0.1$, Valve Life $s=40 \mathrm{yrs}$, Weibull aging model $c=2$ 


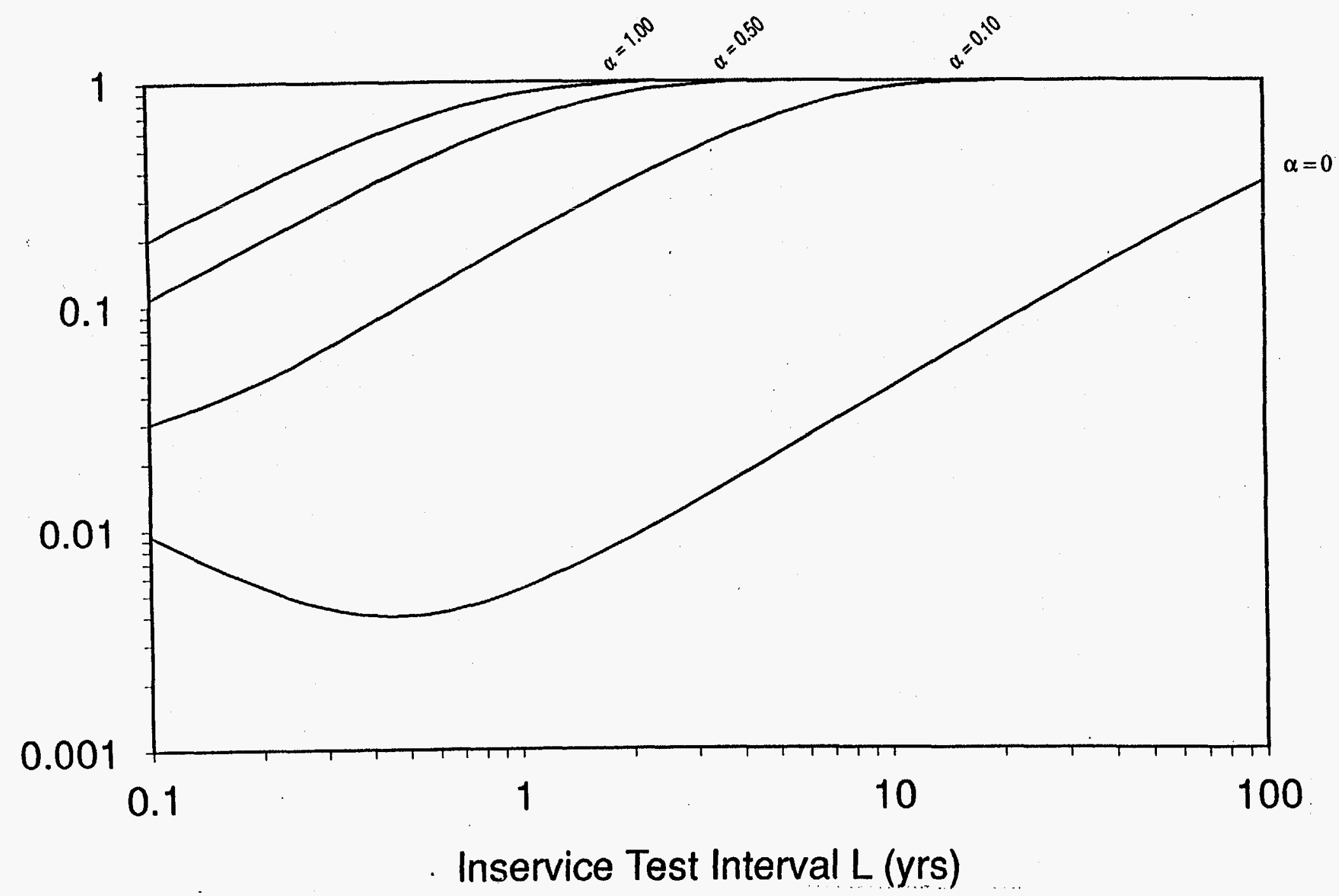

Figure 10.68 Check Valve Unavailability Versus IST Interval For Different Valve Aging Rates: Partial Renewal, No Intermediate Testing, Baseline Failure Rate $\lambda_{0}=1 \times 10^{-6} \mathrm{hr}^{-1}$, Inservice Test Downtime d $=8 \mathrm{hr}$,

Partial Renewal Fraction $f=0.1$, Valve Life $s=40 \mathrm{yrs}$, Weibull aging model $\mathrm{c}=2$ 


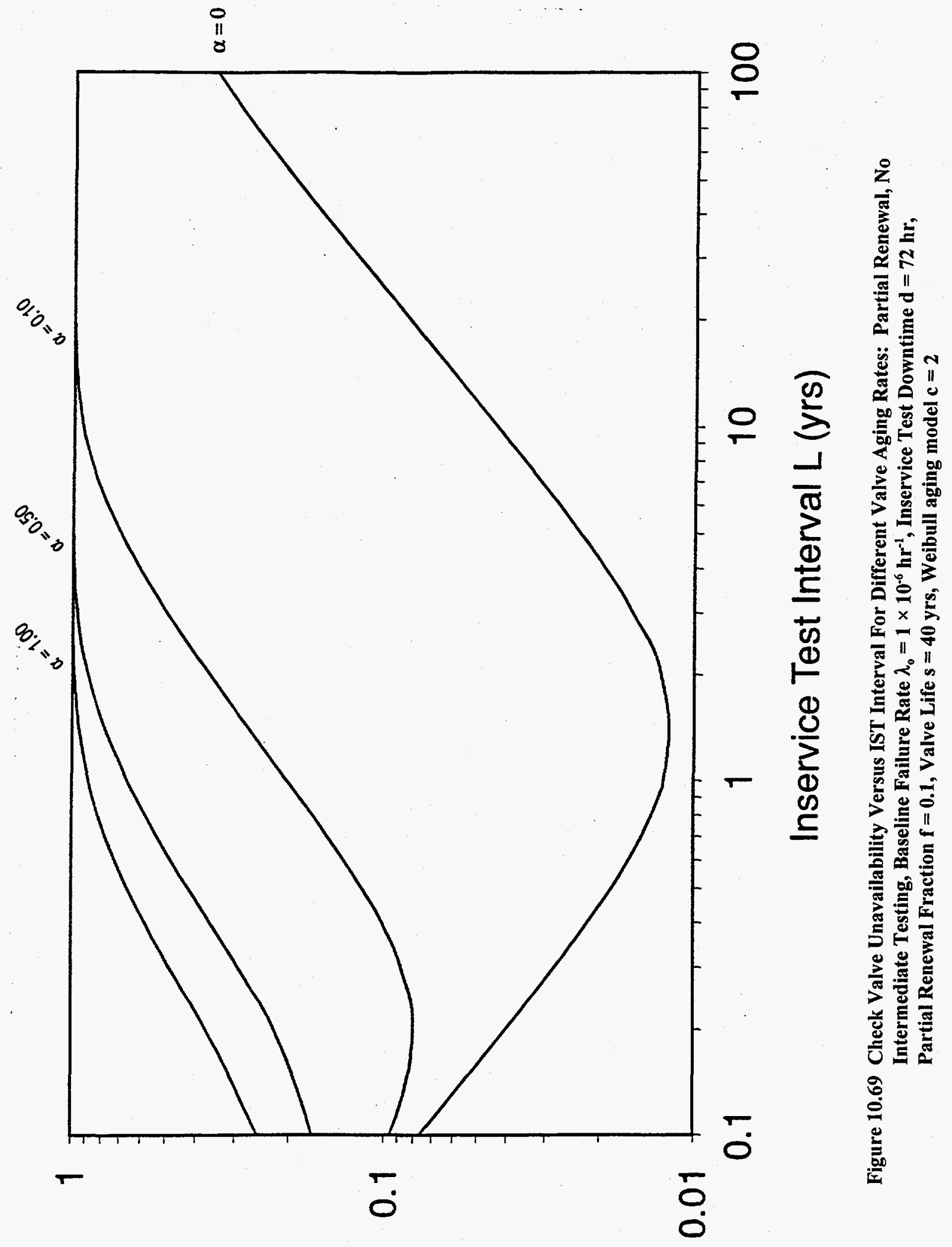

b אł!!!qe|!eseun 


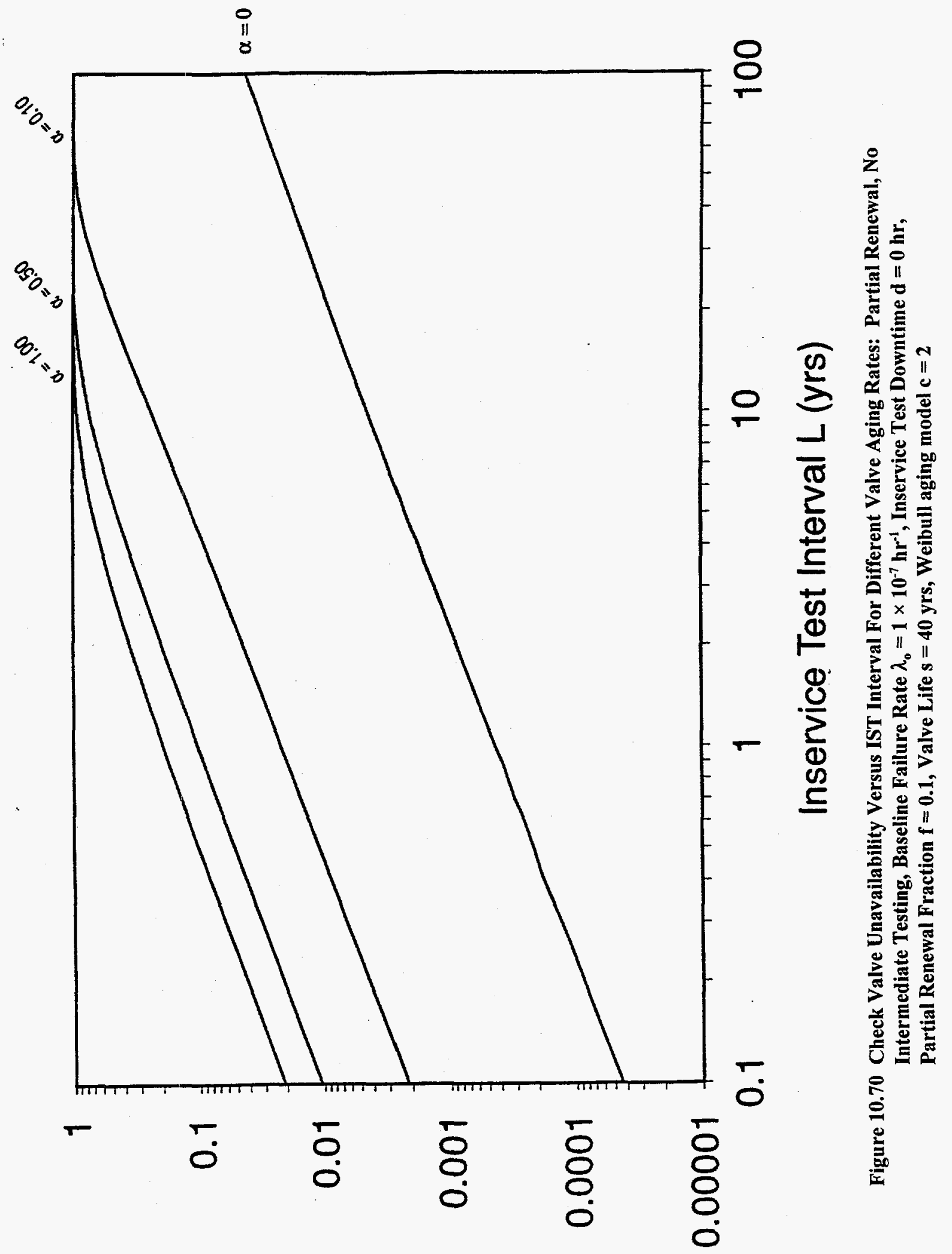

b א1!!!qe|!eseun 


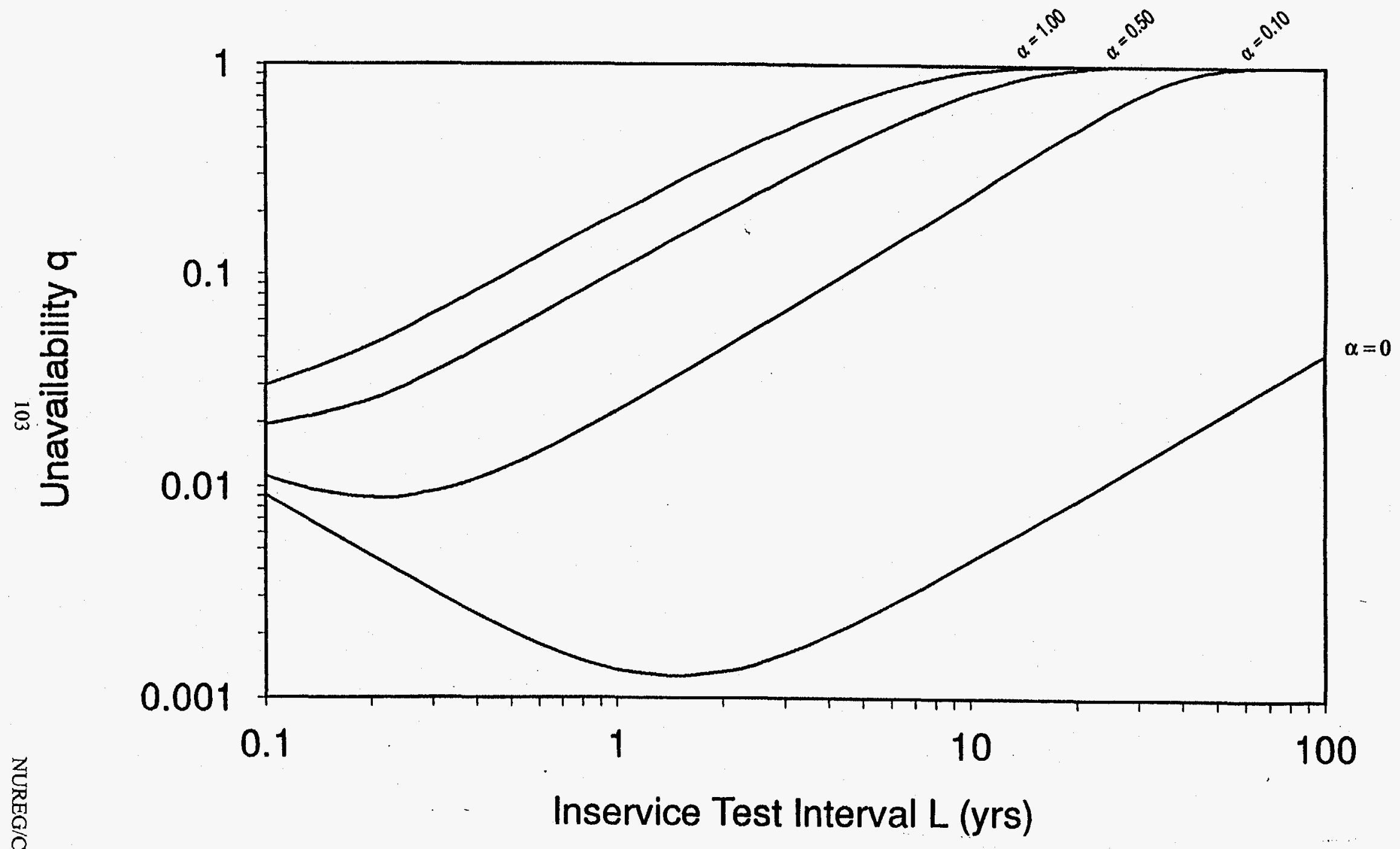

Figure 10.71 Check Valve Unavailability Versus IST Interval For Different Valve Aging Rates: Partial Renewal, No Intermediate Testing, Baseline Failure Rate $\lambda_{0}=1 \times 10^{-7} \mathrm{hr}^{-1}$, Inservice Test Downtime d $=8 \mathrm{hr}$, Partial Renewal Fraction $f=0.1$, Valve Life $s=40 \mathrm{yrs}$, Weibull aging model $c=2$ 


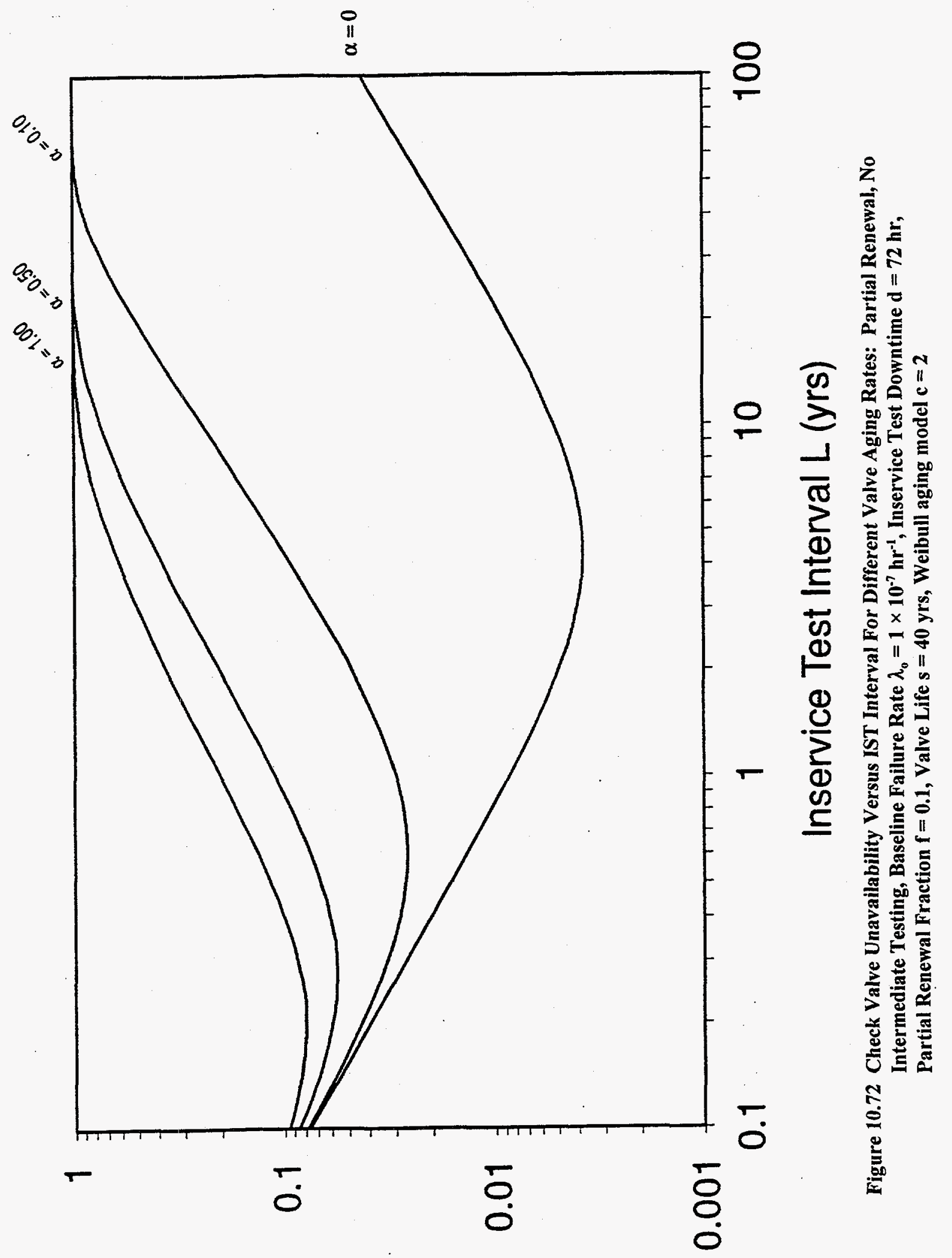

b אł!!!qe|!eseuก 


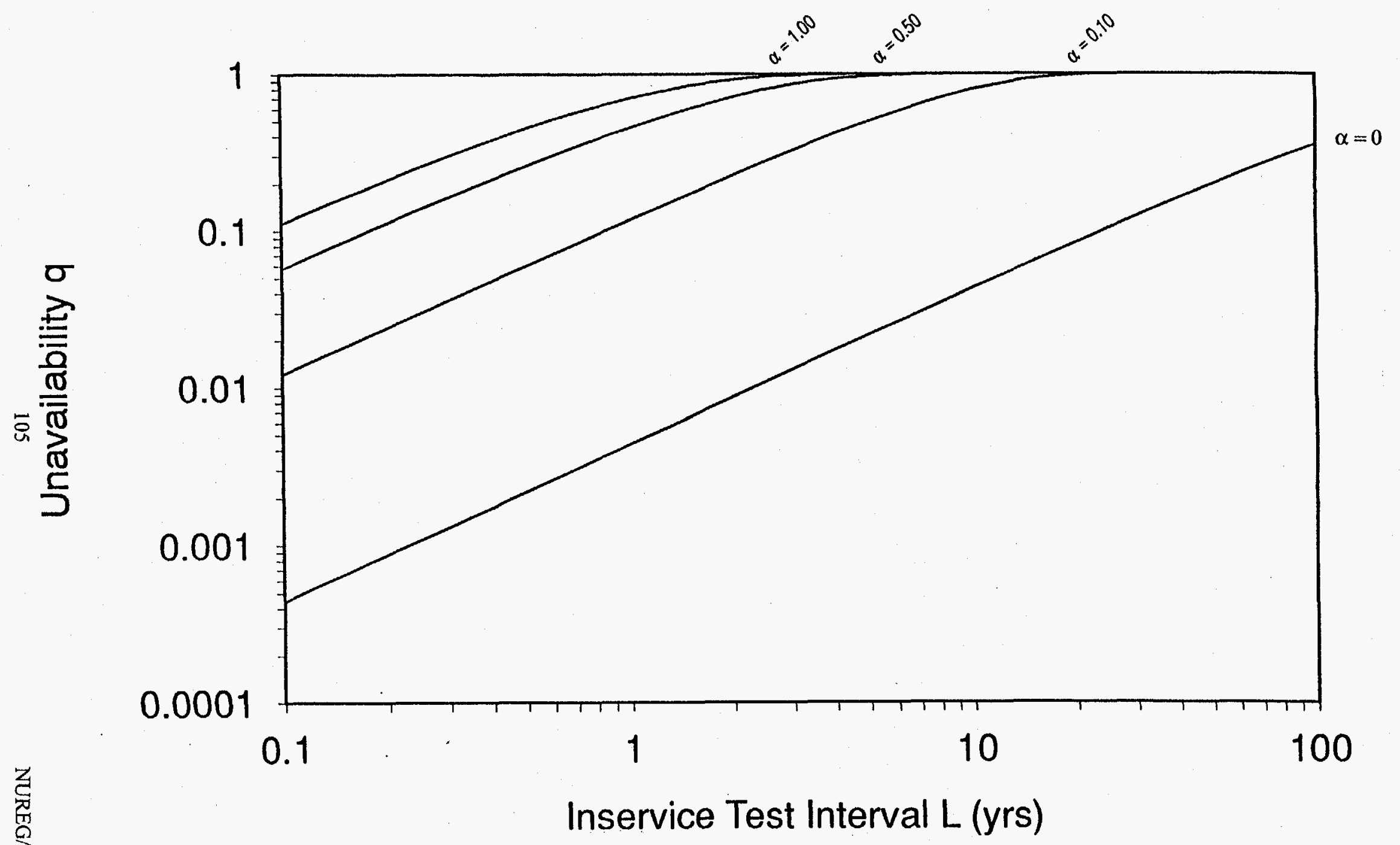

Figure 10.73 Check Valve Unavailability Versus IST Interval For Different Valve Aging Rates: Partial Renewal, No Intermediate Testing, Baseline Failure Rate $\lambda_{0}=1 \times 10^{-6} \mathrm{hr}^{-1}$, Inservice Test Downtime $\mathrm{d}=0 \mathrm{hr}$,

Partial Renewal Fraction $f=0.5$, Valve Life $s=40$ yrs, Weibull aging model $c=2$ 


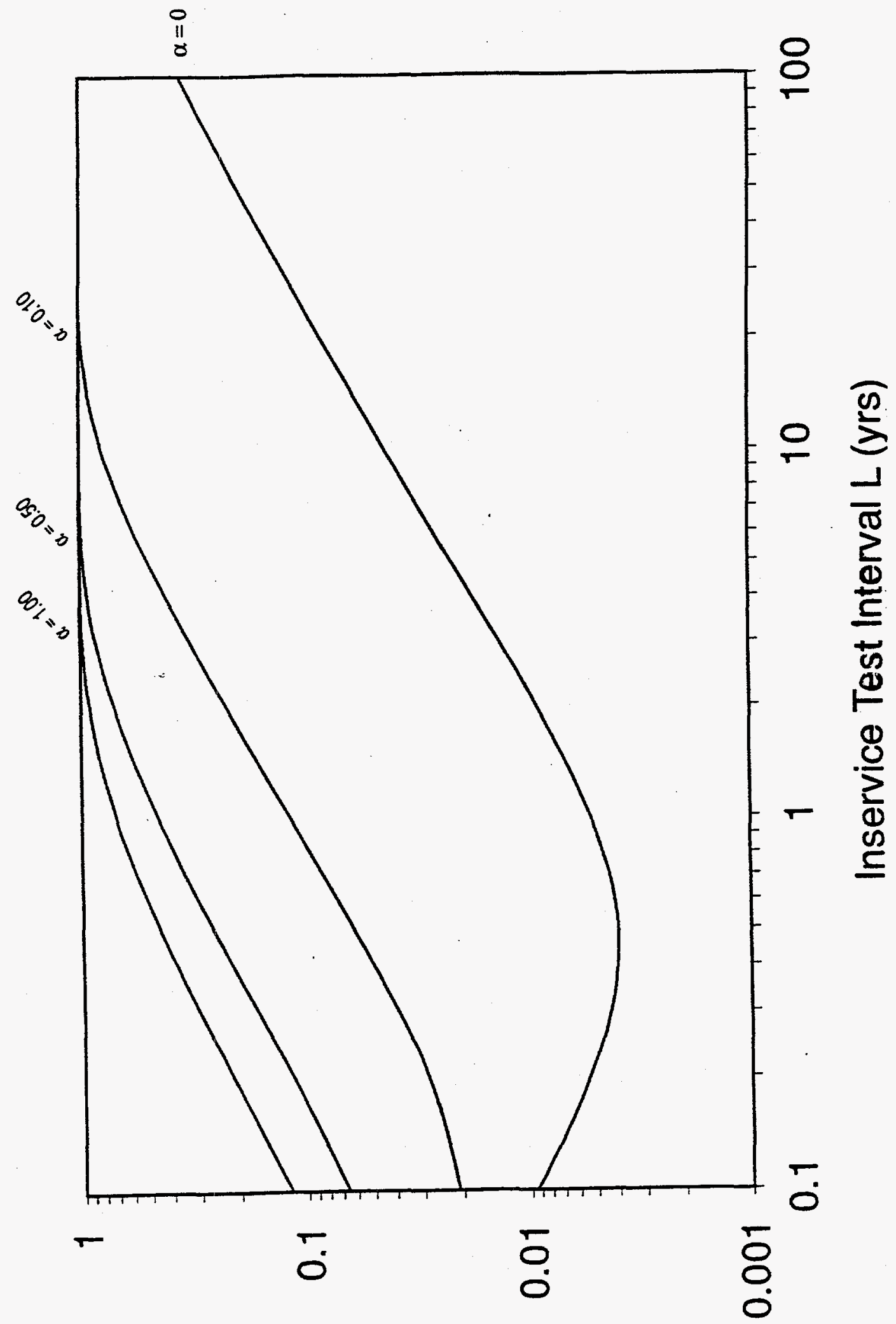

定

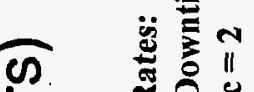

$\geq \quad$

]

递曷

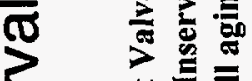

(1)

递文

章家京

웅

त्)

(1) 焉苛

$\underline{5}$

昰

矛宁

$>$

큼

흘

올

政

蛋

\%

출

톨

导

판.

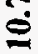

总

b אł!!!qe||елeuก 


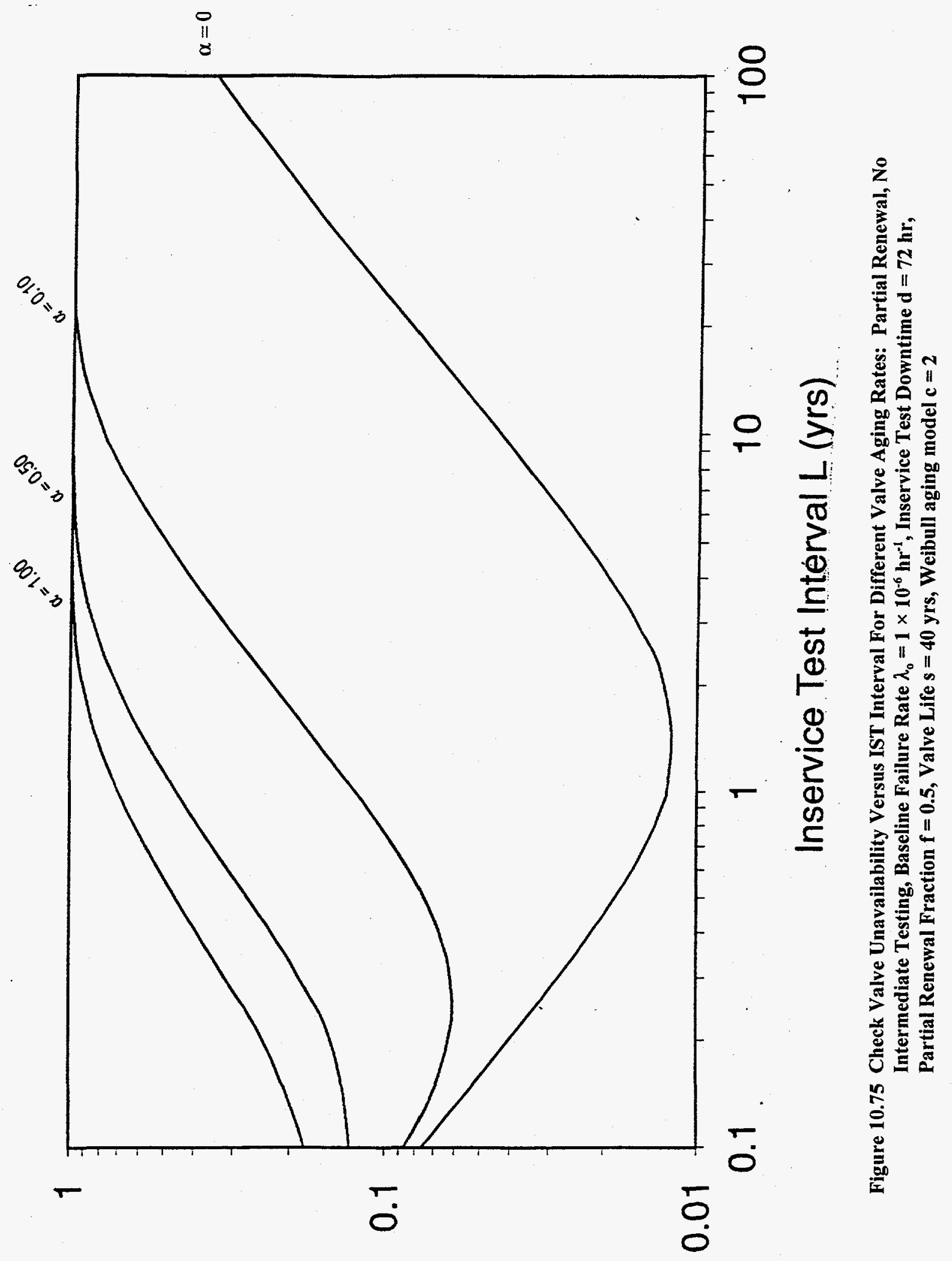

b Kt!!!qe|!eseun 


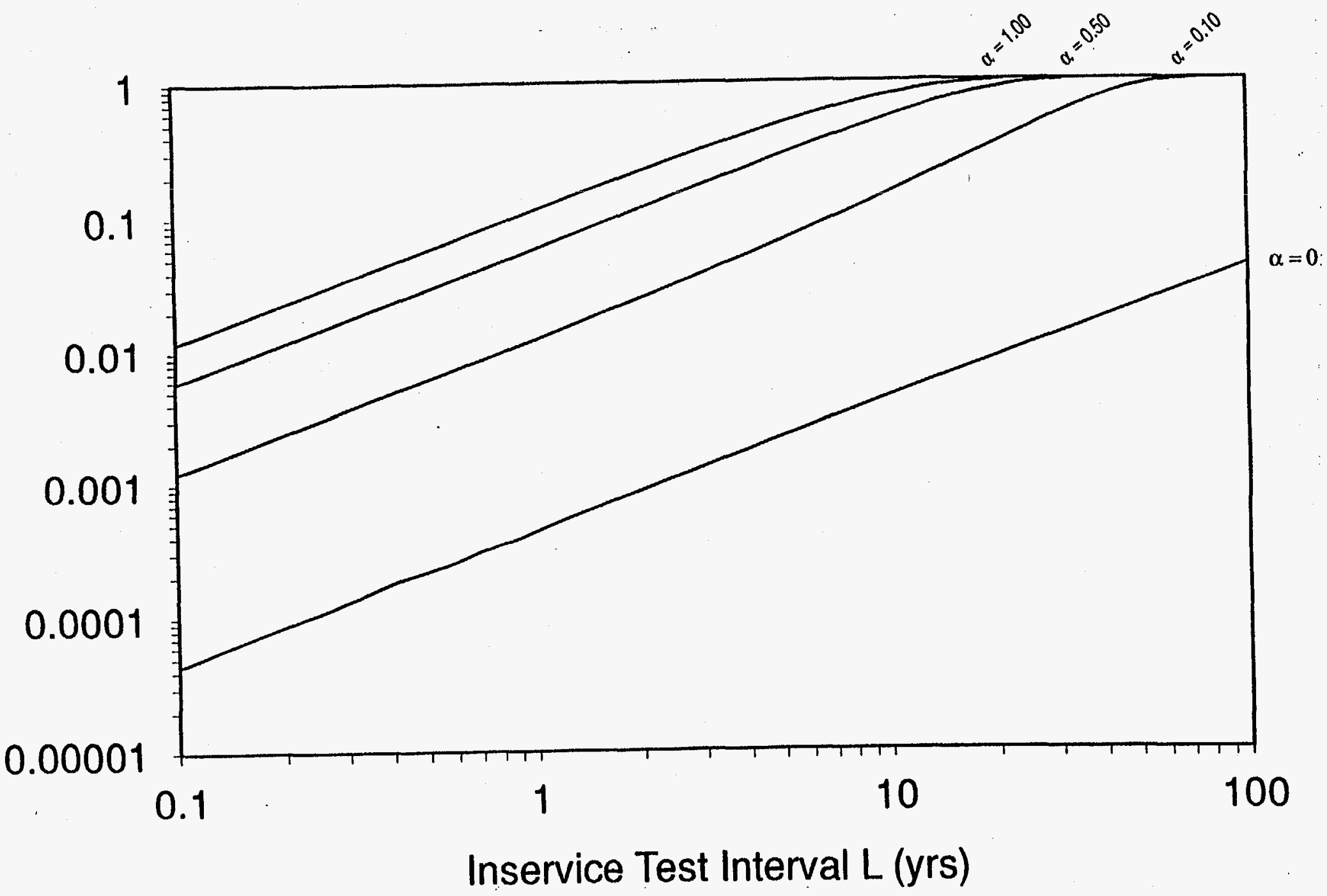

Figure 10.76 Check Valve Unavailability Versus IST Interval For Different Valve Aging Rates: Partial Renewal, No Intermediate Testing, Baseline Failure Rate $\lambda_{0}=1 \times 10^{-7} \mathrm{hr}^{-1}$, Inservice Test Downtime d $=0 \mathrm{hr}$,

Partial Renewal Fraction $\mathrm{f}=0.5$, Valve Life $s=40 \mathrm{yrs}$, Weibull aging $\operatorname{model} \mathrm{c}=\mathbf{2}$ 


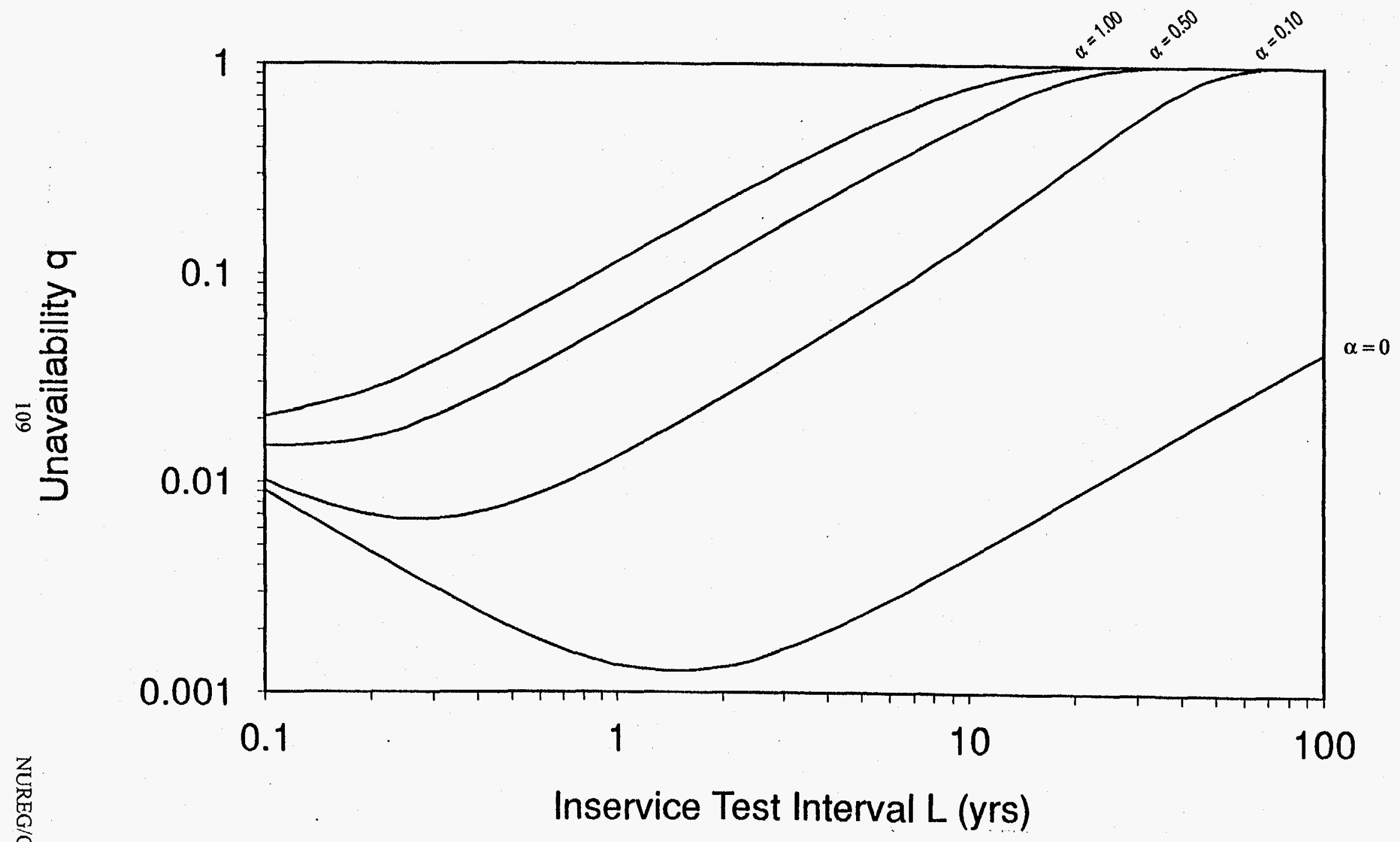

Figure 10.77 Check Valve Unavailability Versus IST Interval For Different Valve Aging Rates: Partial Renewal, No Intermediate Testing, Baseline Failure Rate $\lambda_{0}=1 \times 10^{-7} \mathrm{hr}^{-1}$, Inservice Test Downtime $\mathrm{d}=8 \mathrm{hr}$, Partial Renewal Fraction $f=0.5$, Valve Life $s=40$ yrs, Weibull aging model $c=2$ 


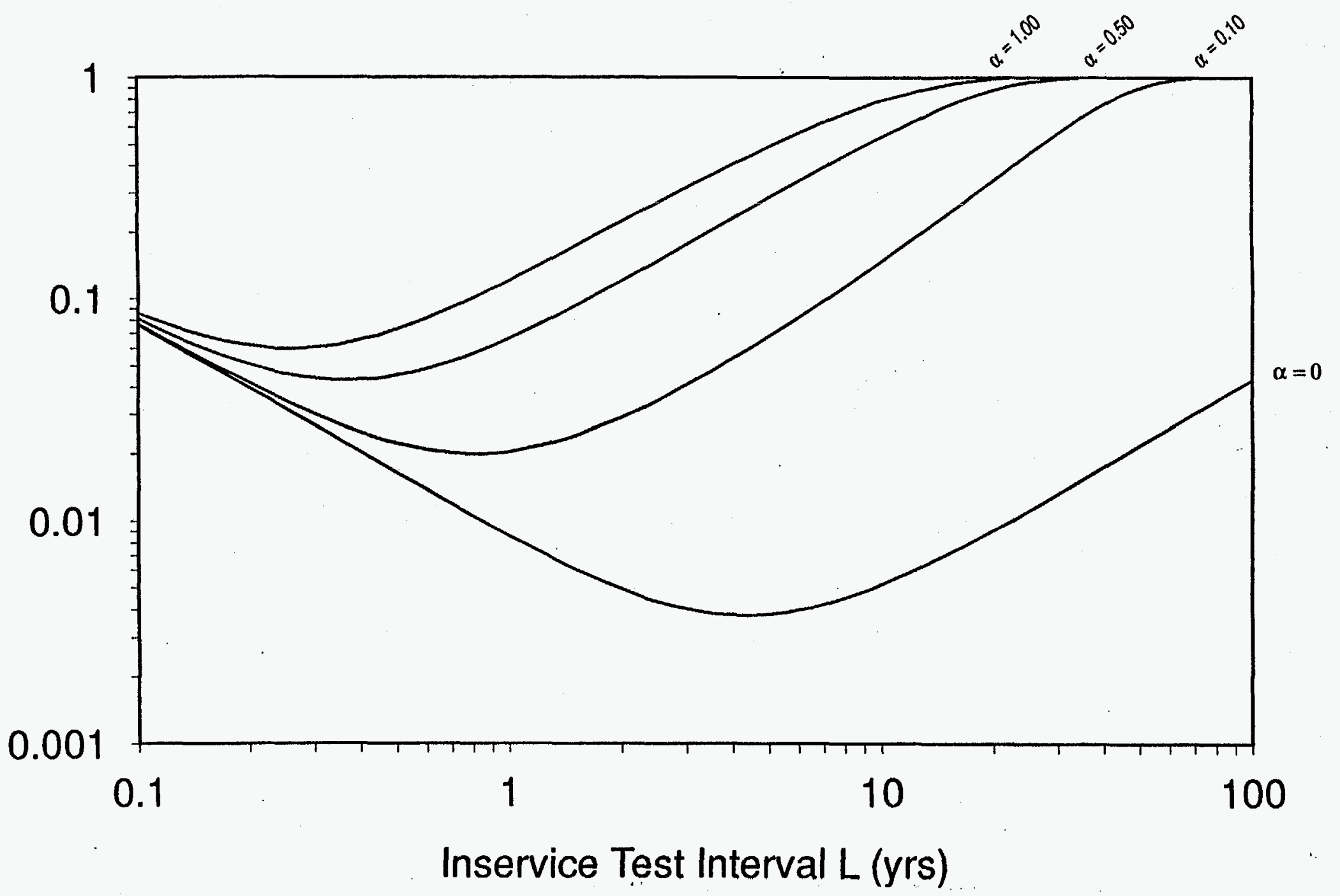

Figure 10.78 Check Valve Unavailability Versus IST Interval For Different Valve Aging Rates: Partial Renewal, No Intermediate Testing, Baseline Failure Rate $\lambda_{0}=1 \times 10^{-7} \mathrm{hr}^{-1}$, Inservice Test Downtime d $=72 \mathrm{hr}$,

Partial Renewal Fraction $f=0.5$, Valve Life $s=40$ yrs, Weibull aging model $c=2$ 


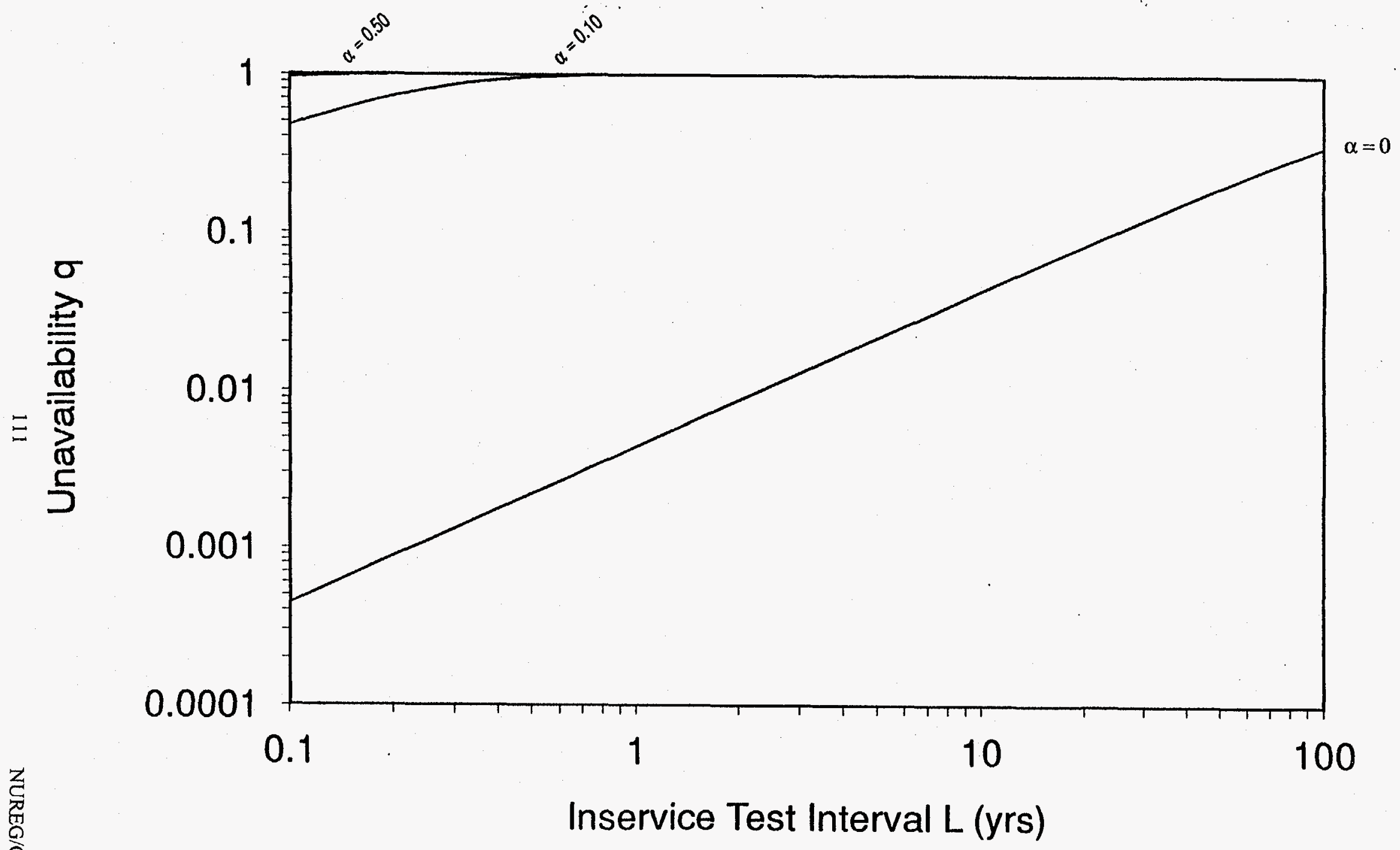

Figure 10.79 Check Valve Unavailability Versus IST Interval For Different Valve Aging Rates: Partial Renewal, No Intermediate Testing, Baseline Failure Rate $\lambda_{0}=1 \times 10^{-6} \mathrm{hr}^{-1}$, Inservice Test Downtime d $=0 \mathrm{hr}$, Partial Renewal Fraction $f=0.1$, Valve Life $s=40 \mathrm{yrs}$, Weibull aging model $c=3$ 


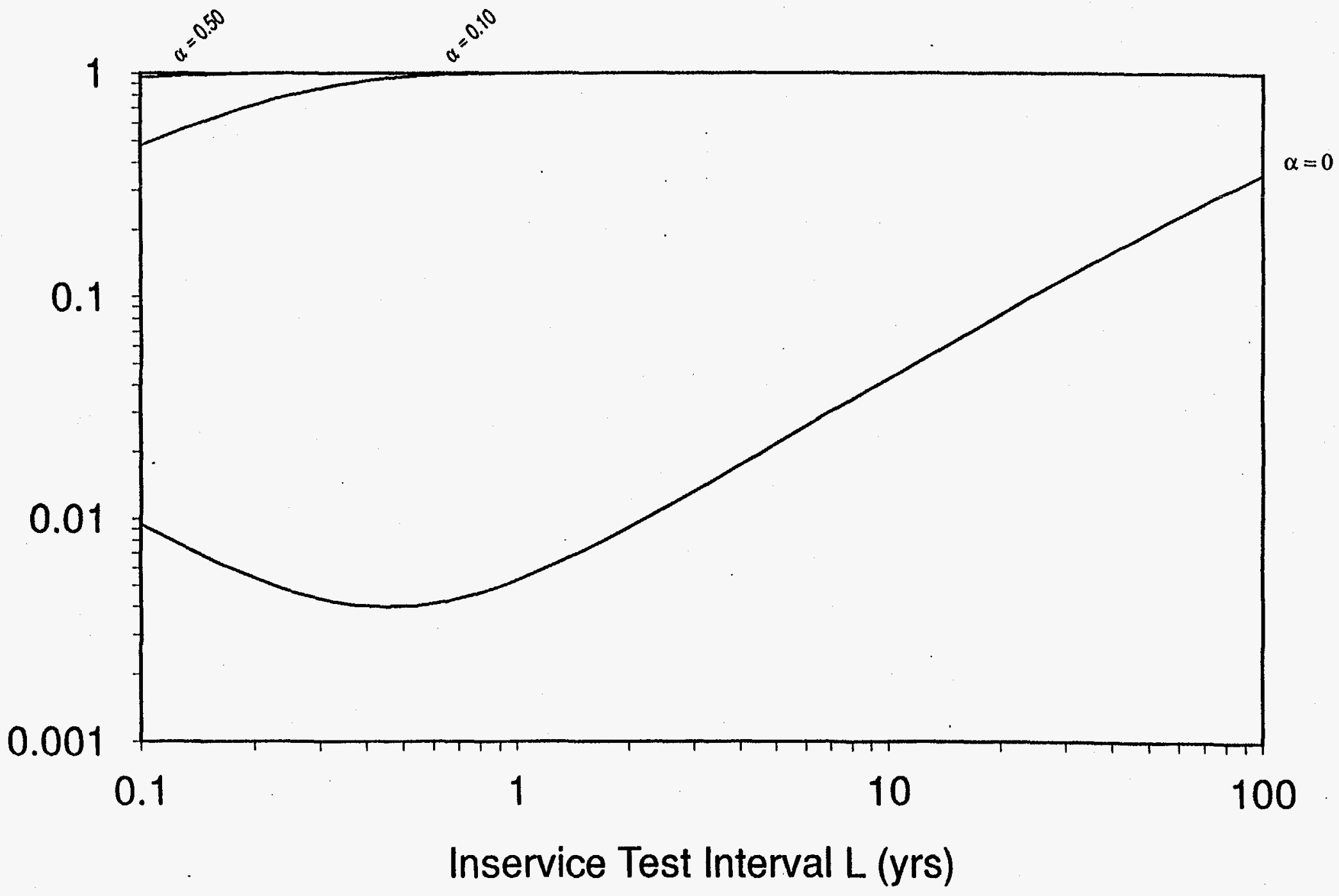

Figure 10.80 Check Valve Unavailability Versus IST Interval For Different Valve Aging Rates: Partial Renewal, No Intermediate Testing, Baseline Failure Rate $\lambda_{0}=1 \times 10^{-6} \mathrm{hr}^{-1}$, Inservice Test Downtime $\mathrm{d}=8 \mathrm{hr}$,

Partial Renewal Fraction $f=0.1$, Valve Life $s=40$ yrs, Weibull aging model $c=3$ 


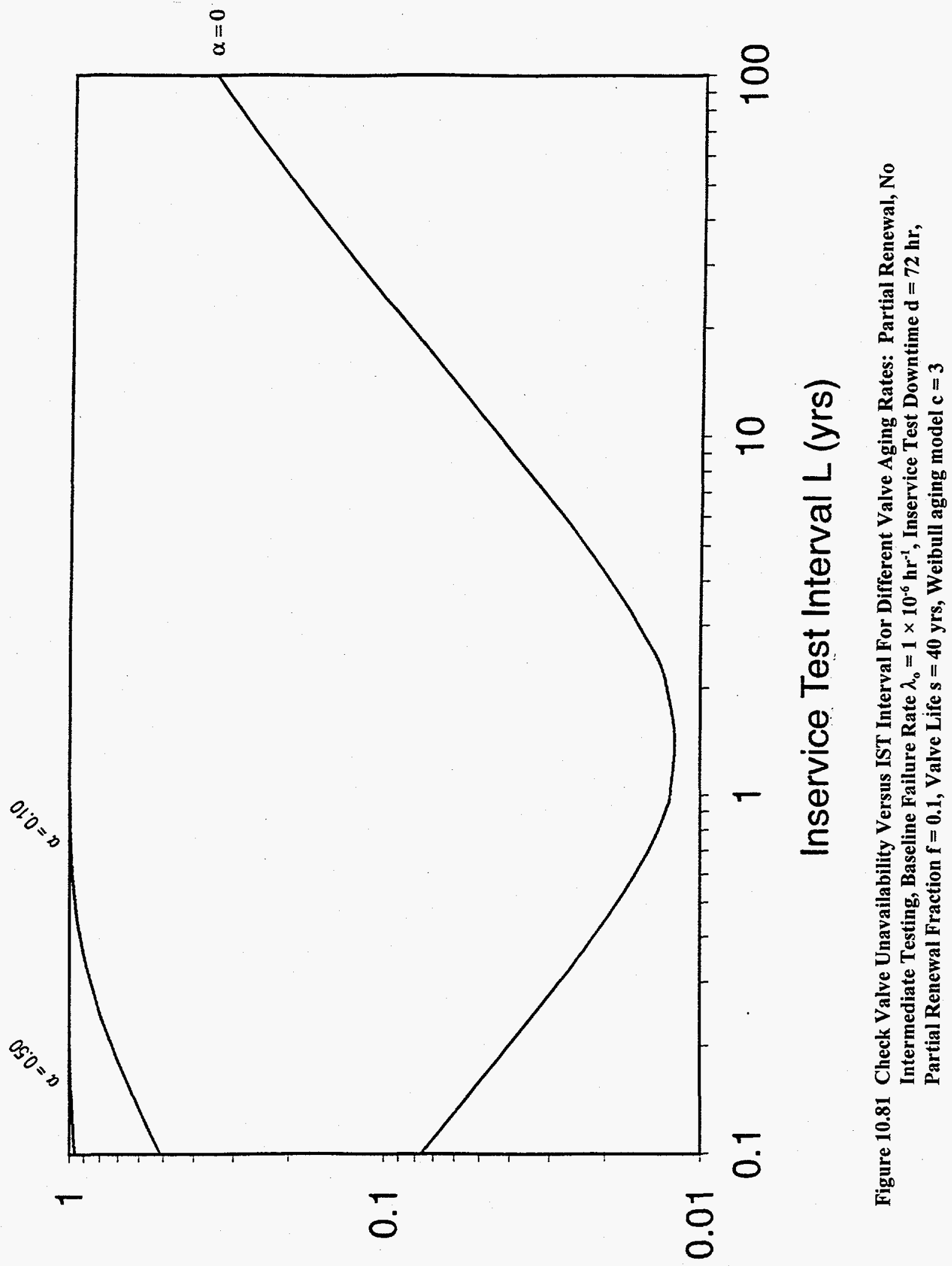

b Kt!!!ge|!eseun 


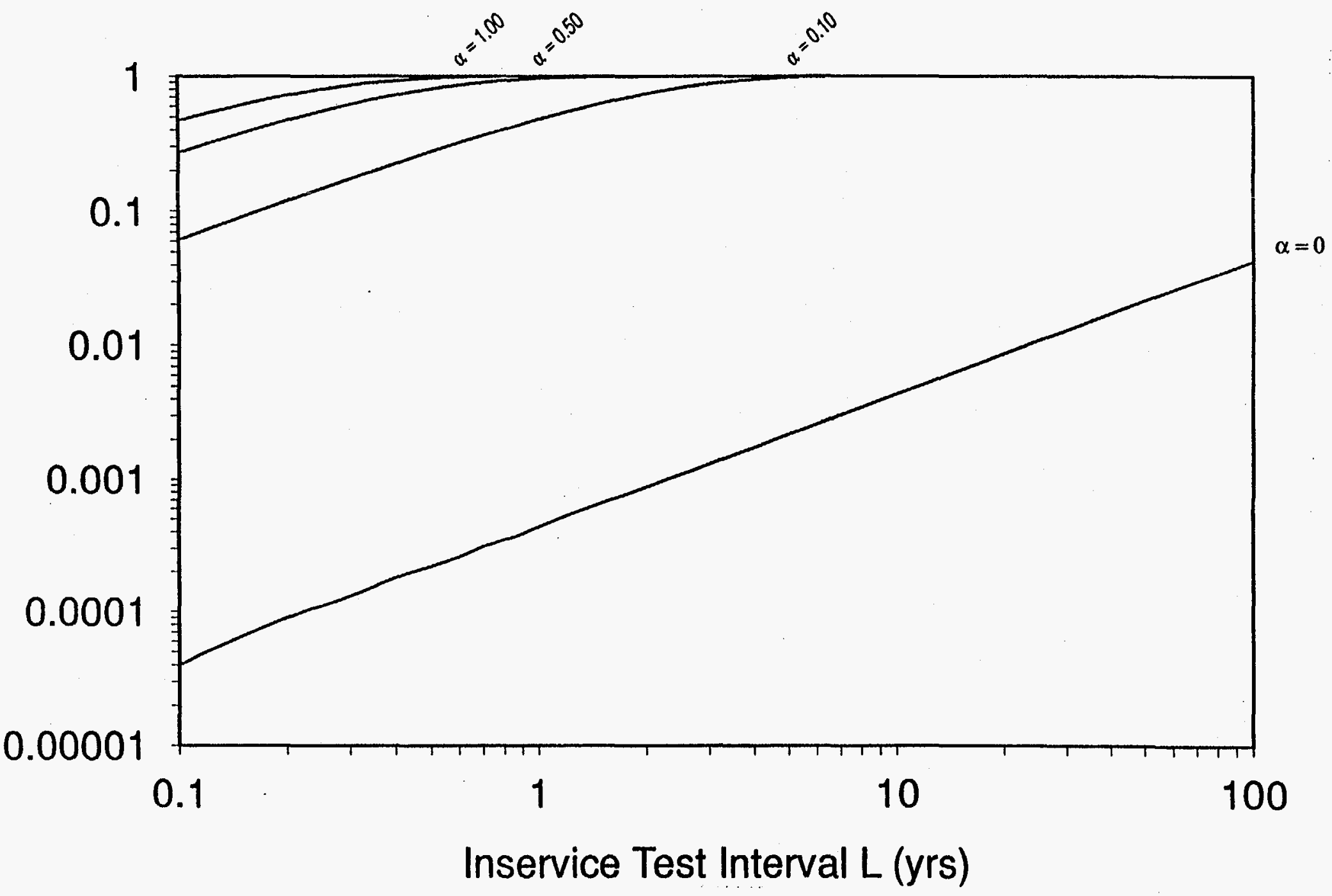

Figure 10.82 Check Valve Unavailability Versus IST Interval For Different Valve Aging Rates: Partial Renewal, No Intermediate Testing, Baseline Failure Rate $\lambda_{0}=1 \times 10^{-7} \mathrm{hr}^{-1}$, Inservice Test Downtime d $=0 \mathrm{hr}$,

Partial Renewal Fraction $f=0.1$, Valve Life $s=40$ yrs, Weibull aging model $c=3$ 


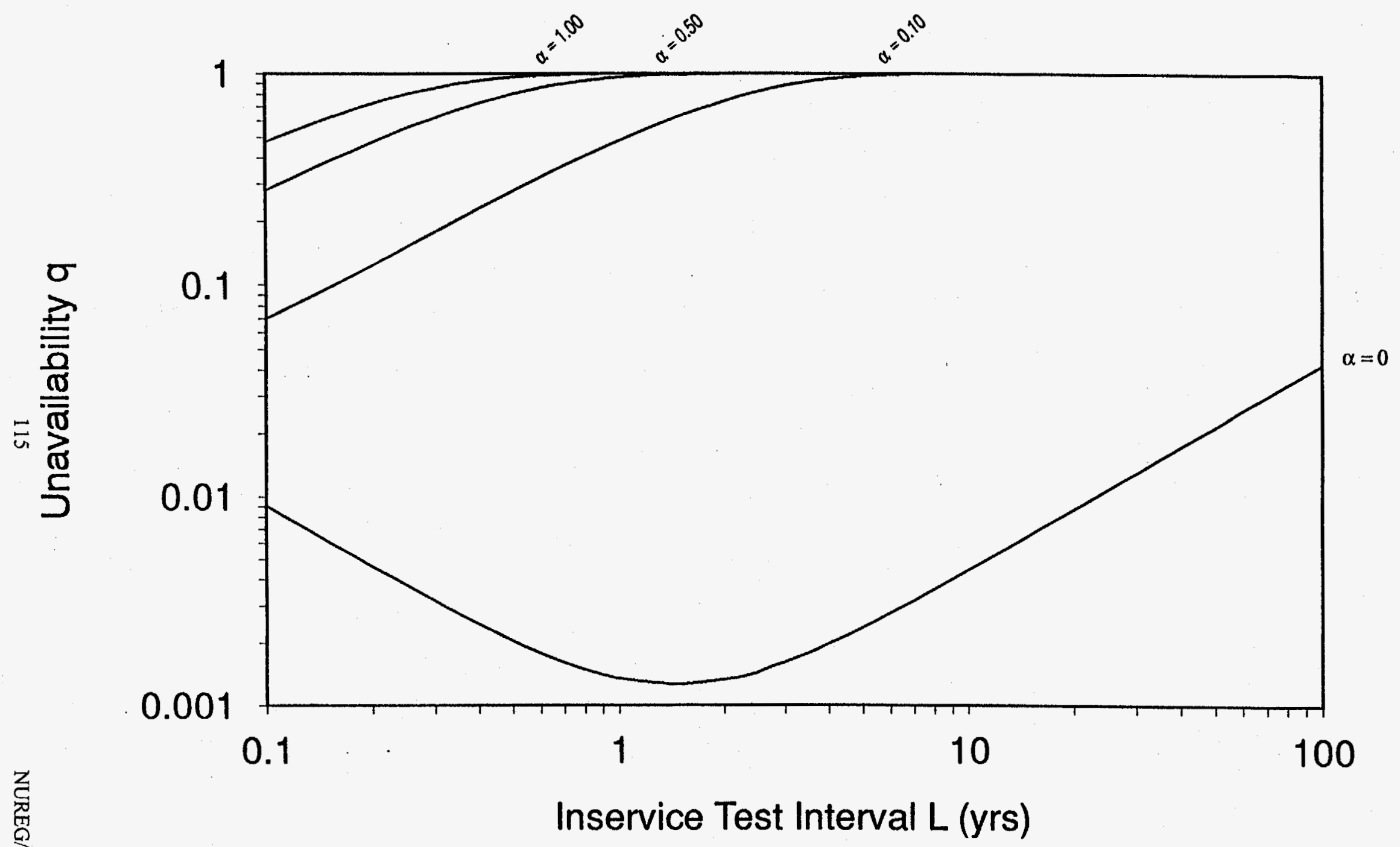

Figure 10.83 Check Valve Unavailability Versus IST Interval For Different Valve Aging Rates: Partial Renewal, No Intermediate Testing, Baseline Failure Rate $\lambda_{\mathrm{o}}=1 \times 10^{-7} \mathrm{hr}^{-1}$, Inservice Test Downtime $\mathrm{d}=8 \mathrm{hr}$, Partial Renewal Fraction $f=0.1$, Valve Life $s=40$ yrs, Weibull aging model $c=3$ 


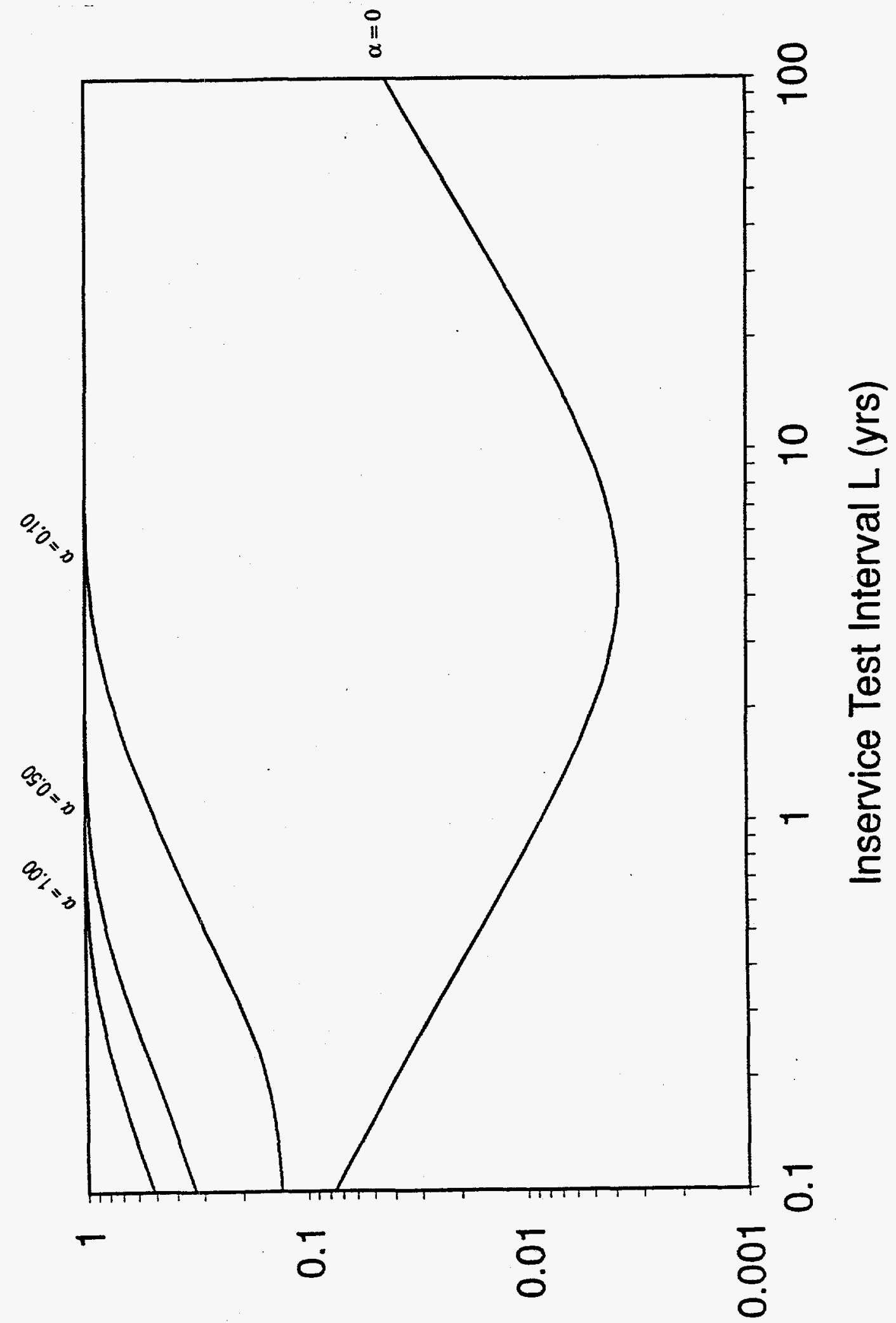

莡

$\ddot{0} m$

ت

正

댕

\&

를

总

政

递定

응

ํํㅊ

इ

눙

(1) 吾造

50

突

承?

$>\stackrel{0}{\circ}$

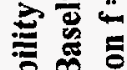

ज里

需

密

$5 \mathrm{~F}$

퐁

ส

늘 흘

递苋

$\stackrel{\infty}{\varrho}$

竞

b Kt!!!qe\|!eıeun 


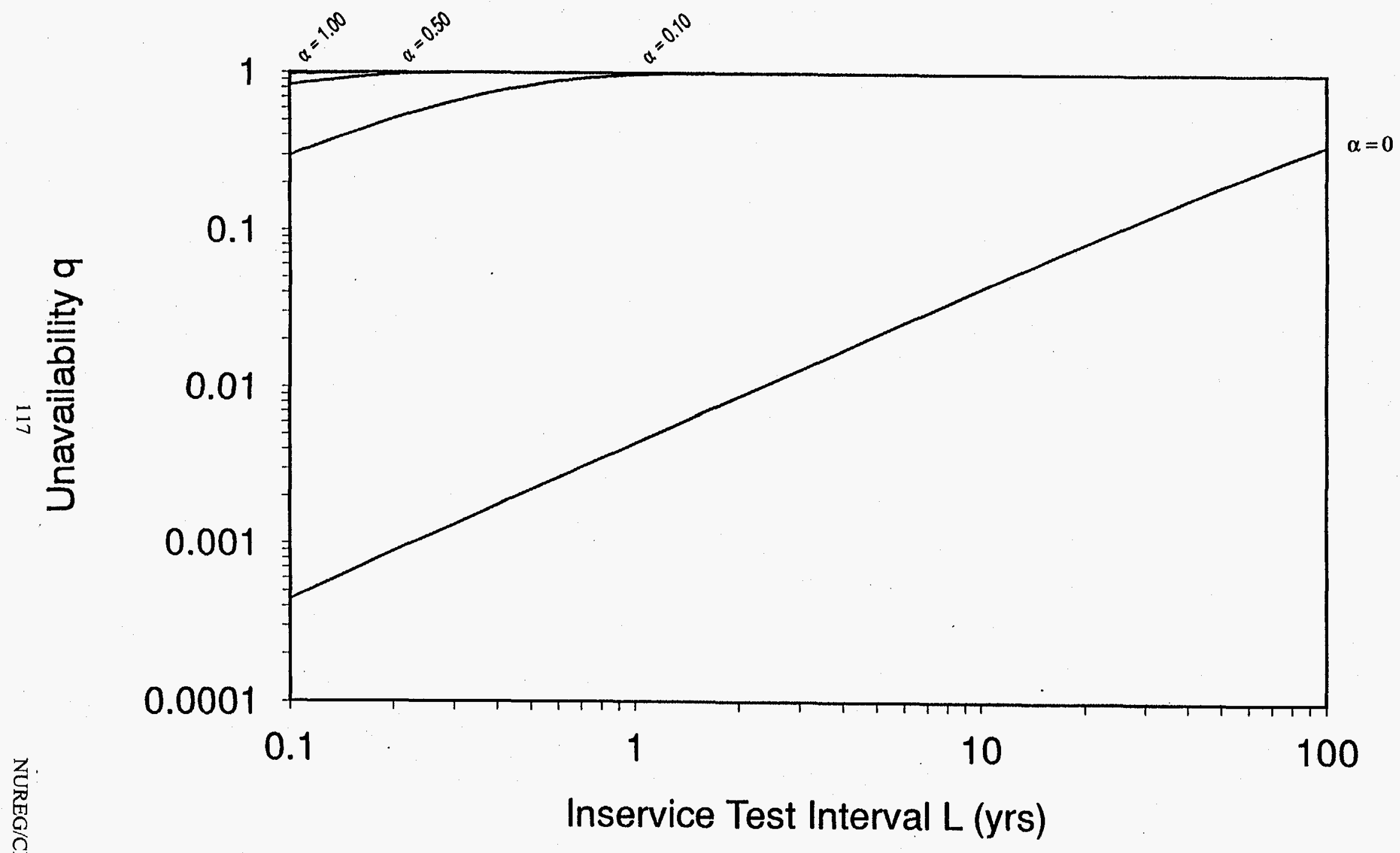

Figure 10.85 Check Valve Unavailability Versus IST Interval For Different Valve Aging Rates: Partial Renewal, No Intermediate Testing, Baseline Failure Rate $\lambda_{0}=1 \times 10^{-6} \mathrm{hr}^{-1}$, Inservice Test Downtime d $=0 \mathrm{hr}$, Partial Renewal Fraction $f=0.5$, Valve Life $s=40$ yrs, Weibull aging model $c=3$ 


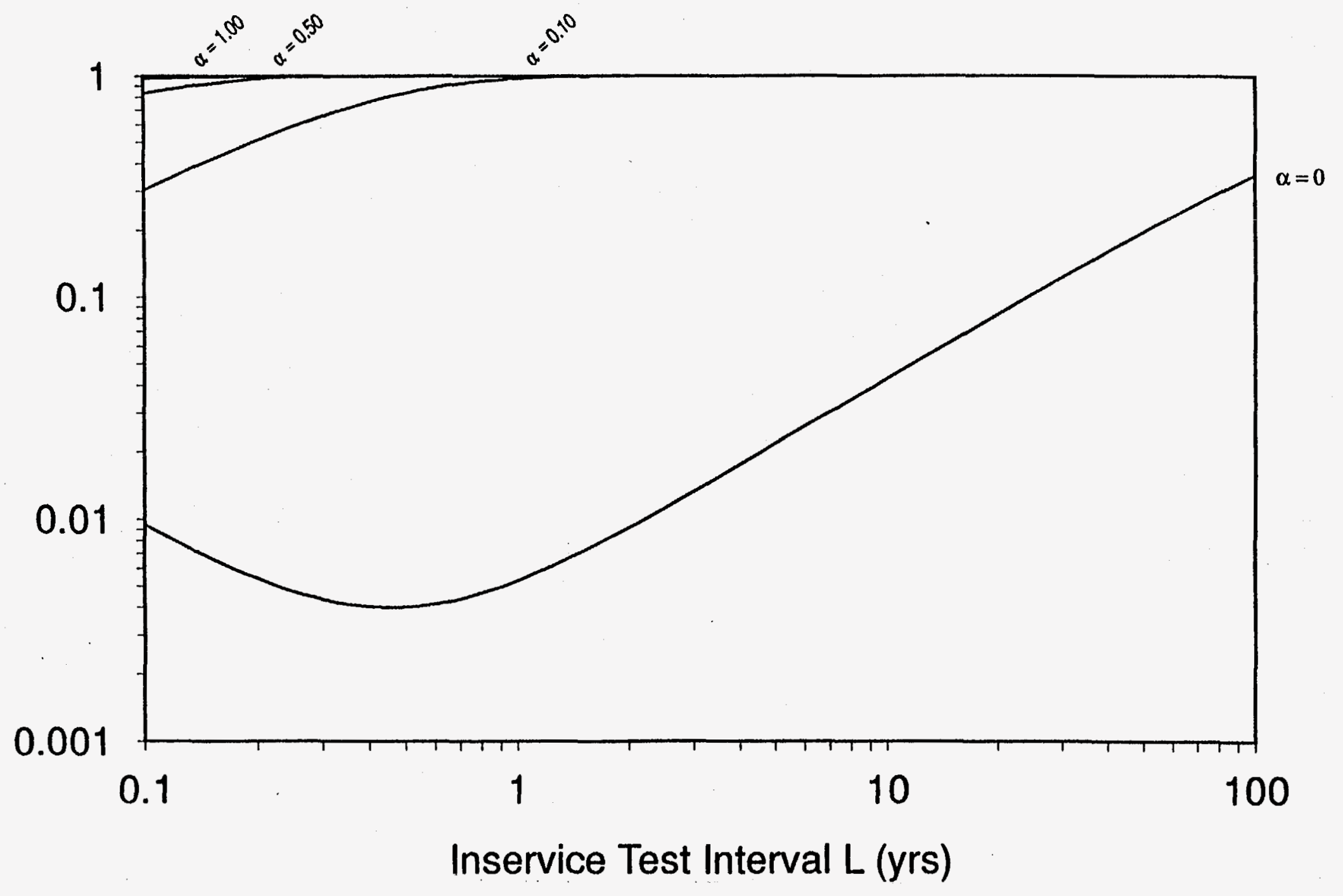

Figure 10.86 Check Valve Unavailability Versus IST Interval For Different Valve Aging Rates: Partial Renewal, No Intermediate Testing, Baseline Failure Rate $\lambda_{\circ}=1 \times 10^{-6} \mathrm{hr}^{-1}$, Inservice Test Downtime $\mathrm{d}=8 \mathrm{hr}$,

Partial Renewal Fraction $f=0.5$, Valve Life $s=40$ yrs, Weibull aging model $c=3$ 


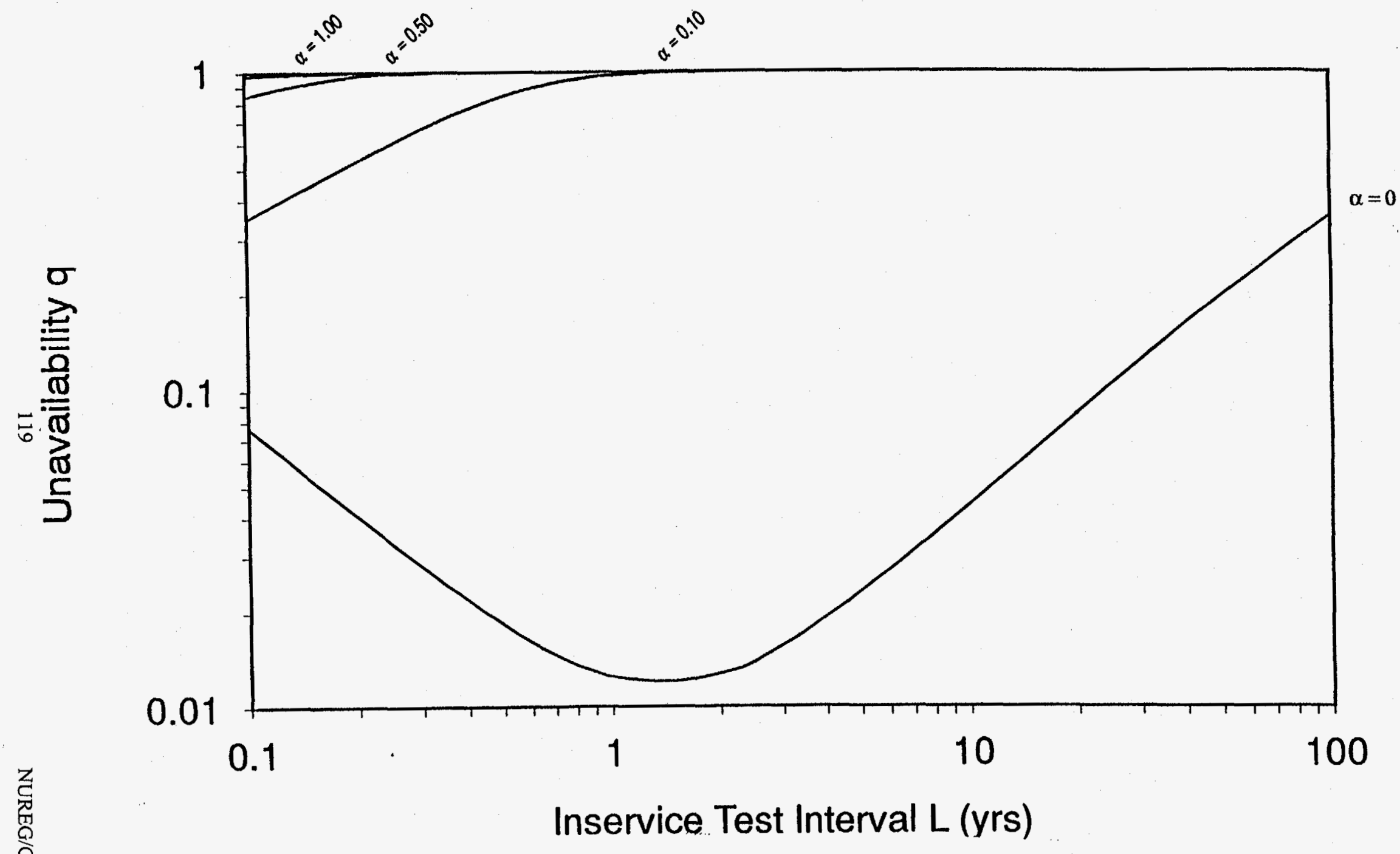

Figure 10.87 Check Valve Unavailability Versus IST Interval For Different Valve Aging Rates: Partial Renewal, No Intermediate Testing, Baseline Failure Rate $\lambda_{o}=1 \times 10^{-6} \mathrm{hr}^{-1}$, Inservice Test Downtime d $=72 \mathrm{hr}$, Partial Renewal Fraction $f=0.5$, Valve Life $s=40$ yrs, Weibull aging model $c=3$ 


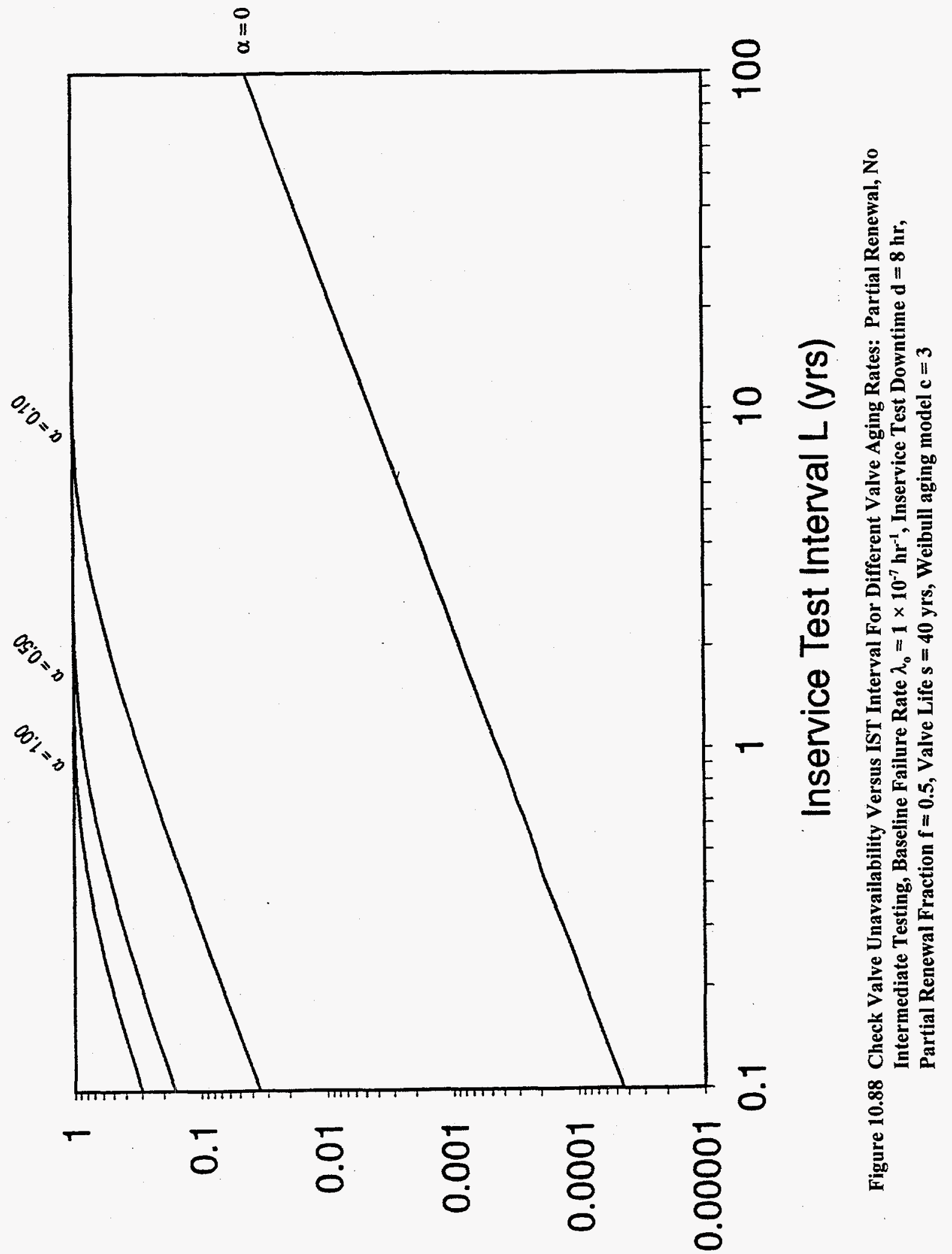

b אł!!!qe|!eseuก 


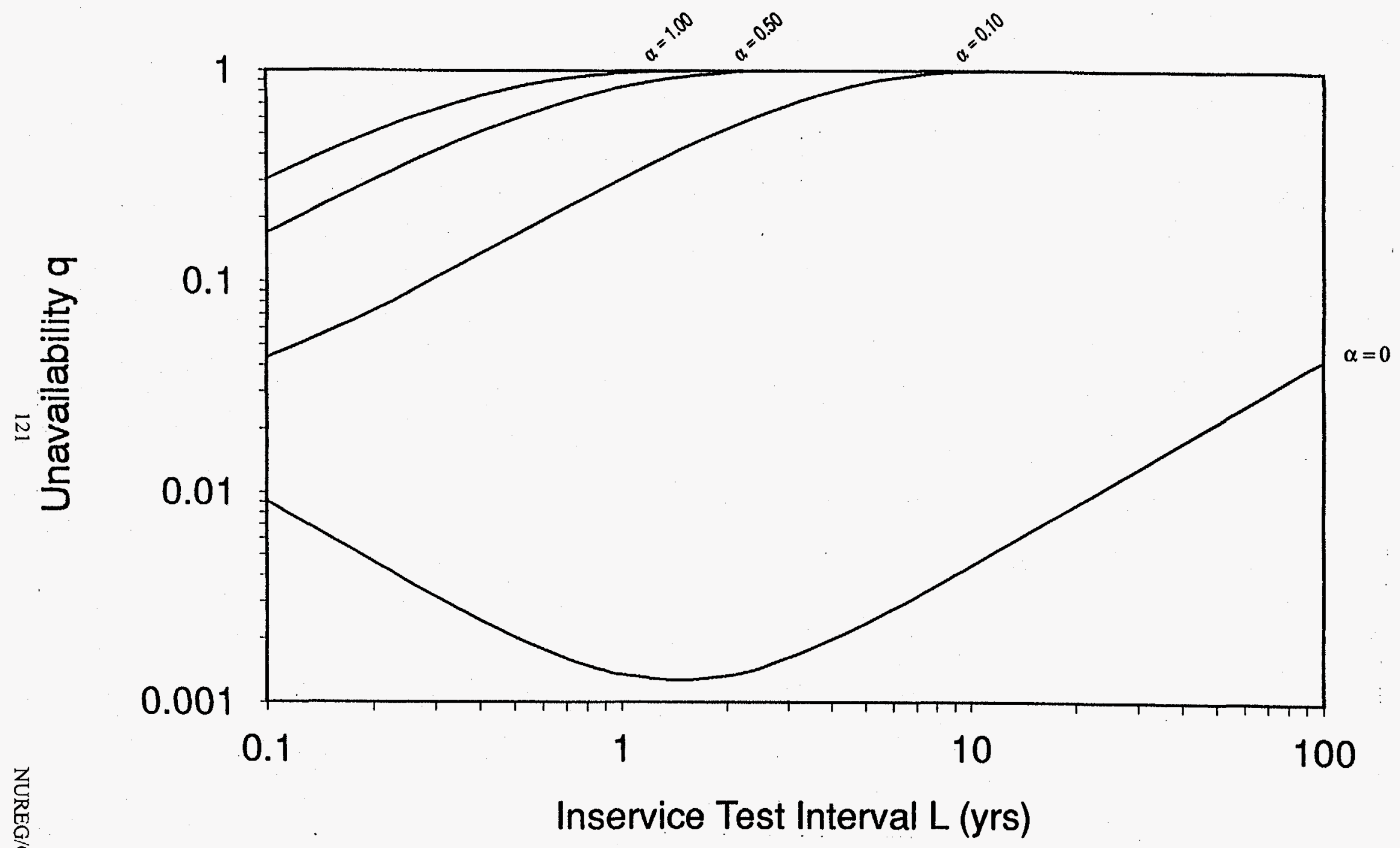

Figure 10.89 Check Valve Unavailability Versus IST Interval For Different Valve Aging Rates: Partial Renewal, No Intermediate Testing, Baseline Failure Rate $\lambda_{0}=1 \times 10^{-7} \mathrm{hr}^{-1}$, Inservice Test Downtime $\mathrm{d}=8 \mathrm{hr}$, Partial Renewal Fraction $f=0.5$, Valve Life $s=40$ yrs, Weibull aging model $c=3$ 


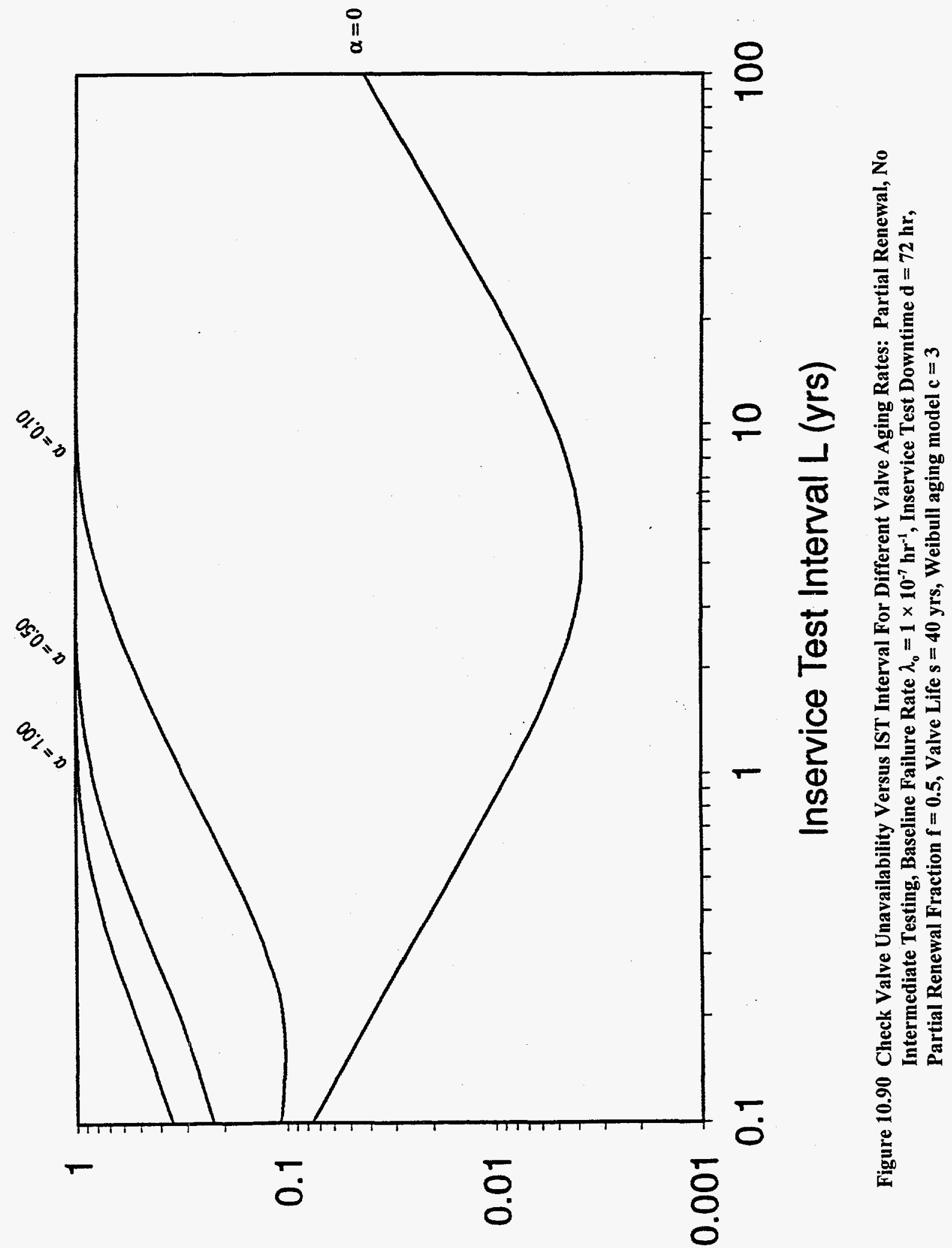

b אł!!!qe|!eлeuก 


\section{Conclusions from the Check Valve Sensitivity Studies on Optimal IST Interval Regions and Effects of Aging}

The following sections present observations and conclusions from the sensitivity studies on optimal IST interval regions and the effects of aging on check valve unavailabilities. The conclusions are based on the sensitivity results obtained for linear aging behaviors, including zero aging. As previously stated, the linear behaviors are used in the study to represent most practical examples of nuclear plant check valves. Nonlinear aging behaviors, which for example might occur under very harsh environments, need to be treated on a case-by-case basis. The conclusions which are presented are based on the evaluations which were performed and should be checked for specific applicability to a given plant utilization based on plant specific considerations and data.

\subsection{Conclusions on IST Intervals When the IST is Followed by Total Renewal}

Table 12.1 presents extracted results from the check valve evaluations when the IST is followed by corrective maintenance that results in total renewal and there is no additional testing performed. Table 12.2 presents extracted results when the IST is followed by total renewal with additional operational testing performed. The extracted results in Tables 12.1 and 12.2 are general and are used to identify general behaviors.

In Tables 12.1 and 12.2 the following symbols are used

$\widetilde{\mathrm{L}}_{\text {opt }}$ the approximate, optimal IST interval for the range of low to moderate relative
aging rates $\alpha\left(\alpha<0.5 \mathrm{yr}^{-1}\right)$

$\tilde{\mathrm{q}}_{\mathrm{opt}}$ the corresponding, approximate optimal component unavailability for this

and aging rate range

$\widetilde{R}_{2}$ the approximate optimal IST interval range in which the unavailability is within
a factor of 2 of the optimal value.

The symbols in Tables 12.1 and 12.2 which have been defined previously are $\lambda_{0}=$ baseline (good as new) failure rate; $d=$ IST associated downtime, $T=$ intermediate test interval, $L=I S T$ interval, and $q=$ the component unavailability corresponding to $\mathrm{L}$. 
Table 12.1 Results For Optimal Check Valve IST Intervals:

Total Renewal, Low to Moderate Linear Aging*

no additional testing

IST optimal values

\begin{tabular}{|c|c|c|c|c|}
\hline $\begin{array}{c}\text { baseline } \\
\text { failure } \\
\text { rate } \\
\lambda_{0}\left(\mathbf{h r} \mathbf{r}^{-1}\right)\end{array}$ & $\begin{array}{c}\text { IST } \\
\text { downtime } \\
\text { d } \\
(\mathbf{h r s})\end{array}$ & $\begin{array}{c}\text { IST } \\
\text { interval } \\
\widetilde{\mathrm{L}}_{\text {opt }} \\
\text { (yrs) }\end{array}$ & $\begin{array}{c}\text { component } \\
\text { unavilability } \\
\widetilde{\mathrm{q}}_{\text {opt }}\end{array}$ & $\begin{array}{l}\text { optimal interval } \\
\text { range } \\
\widetilde{\mathrm{R}}_{2} \\
\text { (yrs) }\end{array}$ \\
\hline $\begin{array}{l}1 \times 10^{-6} \\
1 \times 10^{-7}\end{array}$ & $\begin{array}{l}0 \\
0\end{array}$ & \multicolumn{3}{|c|}{$\begin{array}{l}\text { No Optimum. Component aging causes significantly unavailability } \\
\text { increases (e.g., greater than a factor of } 2 \text { ) for } L>5 \text { yrs. }\end{array}$} \\
\hline $\begin{array}{l}1 \times 10^{-6} \\
1 \times 10^{-7}\end{array}$ & $\begin{array}{l}8 \\
8\end{array}$ & $\begin{array}{l}0.5 \\
1.5\end{array}$ & $\begin{array}{l}4 \times 10^{-3} \\
1 \times 10^{-3}\end{array}$ & $\begin{array}{l}(0.1,2) \\
(0.3,5)\end{array}$ \\
\hline $\begin{array}{l}1 \times 10^{-6} \\
1 \times 10^{-6}\end{array}$ & $\begin{array}{l}72 \\
72\end{array}$ & $\begin{array}{c}1.5 \\
4\end{array}$ & $\begin{array}{l}1 \times 10^{-2} \\
4 \times 10^{-3}\end{array}$ & $\begin{array}{l}(0.3,5) \\
(1,15)\end{array}$ \\
\hline
\end{tabular}

Table 12.2 Results For Optimal Check Valve IST Intervals:

Total Renewal, Low to Moderate Linear Aging"

\begin{tabular}{|c|c|c|c|c|}
\hline $\begin{array}{c}\lambda^{0} \\
\left(\mathbf{h r}^{-1}\right)\end{array}$ & $\begin{array}{c}\text { d } \\
(\mathbf{h r s})\end{array}$ & $\begin{array}{l}\widetilde{\mathrm{L}}_{\text {opt }} \\
\text { (yrs) }\end{array}$ & $\widetilde{\mathrm{q}}_{\mathrm{opt}}$ & $\begin{array}{r}\widetilde{R}_{2} \\
(\mathbf{y r s})\end{array}$ \\
\hline $\begin{array}{l}1 \times 10^{-6} \\
1 \times 10^{-7}\end{array}$ & $\begin{array}{l}0 \\
0\end{array}$ & \multicolumn{3}{|c|}{$\begin{array}{l}\text { No Optimum. Component aging causes significant unavailability } \\
\text { increases (e.g., greater than a factor of } 2 \text { ) for } L>5 \text { yrs }\end{array}$} \\
\hline $\begin{array}{l}1 \times 10^{-6} \\
1 \times 10_{-7}^{-7}\end{array}$ & $\begin{array}{l}8 \\
8\end{array}$ & $\begin{array}{l}3 \\
6\end{array}$ & $\begin{array}{l}1 \times 10^{-3} \\
3 \times 10^{-4}\end{array}$ & $\begin{array}{l}(0.1,8) \\
(2,15)\end{array}$ \\
\hline $\begin{array}{l}1 \times 10^{-6} \\
1 \times 10^{-7}\end{array}$ & $\begin{array}{l}72 \\
72\end{array}$ & $\begin{array}{c}8 \\
20\end{array}$ & $\begin{array}{l}3 \times 10^{-3} \\
6 \times 10^{-4}\end{array}$ & $\begin{array}{l}(3,20) \\
(6,40)\end{array}$ \\
\hline \multicolumn{5}{|c|}{ additional test interval $T=12$ mo } \\
\hline $\begin{array}{l}1 \times 10^{-6} \\
1 \times 10^{-7}\end{array}$ & $\begin{array}{l}0 \\
0\end{array}$ & \multicolumn{3}{|c|}{$\begin{array}{l}\text { No Optimum. Component aging causes significant unavailability } \\
\text { increases (e.g., greater than a factor of } 2 \text { ) for } L>5 \text { yrs }\end{array}$} \\
\hline $\begin{array}{l}1 \times 10^{-6} \\
1 \times 10^{-7}\end{array}$ & $\begin{array}{l}8 \\
8\end{array}$ & $\begin{array}{l}3 \\
2\end{array}$ & $\begin{array}{l}1 \times 10^{-2} \\
2 \times 10^{-3}\end{array}$ & $\begin{array}{l}(1,7) \\
(1,5)\end{array}$ \\
\hline $\begin{array}{l}1 \times 10^{-6} \\
1 \times 10_{-7}\end{array}$ & $\begin{array}{l}72 \\
72\end{array}$ & $\begin{array}{l}4 \\
8\end{array}$ & $\begin{array}{l}2 \times 10^{-2} \\
3 \times 10^{-3}\end{array}$ & $\begin{array}{c}(1,9) \\
(3,20)\end{array}$ \\
\hline
\end{tabular}

"Low to moderate aging is associated with a relative aging rate of $0<\alpha<0.5 \mathrm{yr}^{1}$ with a midpoint value of $\alpha=0.2 \mathrm{yr}^{-1}$ 
From Tables 12.1 and 12.2 the following general conclusions are obtained:

For total renewal, when the IST downtime is negligible, then for IST intervals greater than $\sim 5$ years, valve aging effects will cause significant valve unavailability increases above PRA calculated values (greater than a factor of 2).

For total renewal, for nonnegligible IST downtimes of 8 or 72 hours, the optimal IST interval decreases as the downtime decreases or the failure rate decreases, varying from 0.5 year to 20 years. Carrying out additional testing will result in larger optimal IST intervals.

For total renewal, the optimal IST interval range, where the unavailability is within a factor of 2 of the optimal value, has endpoints which are approximately a factor of 3 smaller and larger than the optimal IST value.

\subsection{Conclusions on IST Intervals When the IST Has No Follow-up Renewal}

Tables 12.3 and 12.4 present extracted results from the check valve evaluations when the IST is followed by no renewal of the check valve. Again, the results in the tables are general and are used to identify general behaviors. From Tables 12.3 and 12.4, the following general conclusions are obtained:

For an IST with no associated resulting renewal, valve aging has significant impacts on valve unavailability for any IST interval and downtime, including optimal values. Each $10 \%$ increase in aging rate results in a factor of approximately 2 increase in unavailability as compared to the zero aging unavailability value. Thus, a $50 \%$ aging rate for the valve results in a factor of $5 \times 2=10$ increase in unavailability.

For an IST with no associated renewal, the valve unavailability is directly proportional to the IST interval. Increases in IST intervals and increases in aging rates are approximately multiplicative. Thus, an IST interval of 1 year results in a valve unavailability 4 times larger than for an IST interval of 0.25 year (quarterly) with no aging and $2 \times 4=8$ times larger if the valve has a $10 \%$ aging rate.

For an IST with no associated renewal, for nonnegligible downtimes of 8 or 72 hours, the optimal IST interval is insensitive to the aging rate and increases as the downtime increases. An IST interval of 2 to 3 years is generally within the optimal range for all cases. 
Table 12.3. Results For Check Valve IST Intervals: Nonrenewal With Zero Downtime, Linear Aging failure rate $\lambda_{o}=1 \times 10^{-6}\left(\mathrm{hr}^{-1}\right)$

\begin{tabular}{cccc}
\hline $\begin{array}{c}\text { IST interval } \\
\mathbf{L} \text { (yrs) }\end{array}$ & $\begin{array}{c}\text { relative aging rate } \\
\boldsymbol{\alpha}\left(\mathrm{yr}^{-1}\right)\end{array}$ & $\begin{array}{c}\text { unavailability } \\
\mathbf{q}\end{array}$ & $\begin{array}{c}\text { Factor Increase in q } \\
\text { (compared to } \boldsymbol{\alpha}=\mathbf{0} \text { ) }\end{array}$ \\
\hline 1 & 0 & $4 \times 10^{-3}$ & 1 \\
& 0.1 & $1 \times 10^{-2}$ & 2.5 \\
& 0.5 & $4 \times 10^{-2}$ & 10 \\
& 1 & $1 \times 10^{-1}$ & 25 \\
3 & 0 & $1 \times 10^{-2}$ & 1 \\
& 0.1 & $3 \times 10^{-2}$ & 3 \\
& 0.5 & $2 \times 10^{-1}$ & 20 \\
& 1.0 & $3 \times 10^{-3}$ & 30 \\
\hline \multirow{2}{*}{ failure rate $\lambda_{0}=\mathbf{1} \times \mathbf{1 0}^{-7}\left(\mathbf{h r}^{-1}\right)$} & & \\
1 & 0 & $3 \times 10^{-4}$ & 1 \\
& 0.1 & $1 \times 10^{-3}$ & 3 \\
& 0.5 & $5 \times 10^{-3}$ & 14 \\
& 1.0 & $1 \times 10^{-2}$ & 30 \\
3 & 0 & $8 \times 10^{-4}$ & 1 \\
& 0.1 & $3 \times 10^{-3}$ & 4 \\
& 0.5 & $1 \times 10^{-2}$ & 12 \\
& 1.0 & $2 \times 10^{-2}$ & 25 \\
\hline
\end{tabular}

Table 12.4. Results For Check Valve IST Intervals: Nonrenewal With Nonzero Downtime, Linear Aging

\begin{tabular}{|c|c|c|c|c|c|}
\hline $\begin{array}{c}\begin{array}{c}\text { baseline } \\
\text { failure rate } \\
\lambda_{0}\left(\mathbf{h r}^{-1}\right)\end{array} \\
\end{array}$ & $\begin{array}{c}\text { IST } \\
\text { downtime } \\
\text { d (hrs) }\end{array}$ & $\begin{array}{c}\text { relative } \\
\text { aging rate } \\
\alpha\left(\mathrm{yr}^{-1}\right) \\
\end{array}$ & $\begin{array}{c}\text { IST } \\
\text { interval } \\
\mathbf{L}^{*} \text { (yrs) } \\
\end{array}$ & $\begin{array}{c}\text { associated } \\
\text { component } \\
\text { unavailability } \\
\mathbf{q} \\
\end{array}$ & $\begin{array}{c}\text { factor increase } \\
\text { in q compared } \\
\text { to } \alpha=0\end{array}$ \\
\hline \multirow[t]{8}{*}{$1 \times 10^{-6}$} & 8 & 0 & 0.5 & $4 \times 10^{-3}$ & - \\
\hline & & 0.1 & $"$ & $1 \times 10^{-2}$ & 2.5 \\
\hline & & 0.5 & “ & $3 \times 10^{-2}$ & 9 \\
\hline & & 1.0 & “ & $5 \times 10^{-2}$ & 14 \\
\hline & 72 & 0 & 1.5 & $1 \times 10^{-2}$ & - \\
\hline & & 0.1 & $"$ & $3 \times 10^{-2}$ & 3 \\
\hline & & 0.5 & “ & $8 \times 10^{-2}$ & 8 \\
\hline & & 1.0 & “ & $2 \times 10^{-1}$ & 20 \\
\hline \multirow[t]{8}{*}{$1 \times 10^{-7}$} & 8 & 0 & 2 & $1 \times 10^{-3}$ & - \\
\hline & & 0.1 & " & $3 \times 10^{-3}$ & 3 \\
\hline & & 0.5 & $"$ & $1 \times 10^{-2}$ & 10 \\
\hline & & 1.0 & “ & $2 \times 10^{-2}$ & 20 \\
\hline & 72 & 0 & 5 & $4 \times 10^{-3}$ & - \\
\hline & & 0.1 & " & $9 \times 10^{-3}$ & 2.5 \\
\hline & & 0.5 & “ & $3 \times 10^{-2}$ & 9 \\
\hline & & 1.0 & “ & $6 \times 10^{-2}$ & 15 \\
\hline
\end{tabular}




\subsection{Conclusions on the IST Intervals When the IST is Followed by Partial Renewal}

No tables need to be extracted for the partial renewal results since the partial renewal curves are essentially the same as the corresponding nonrenewal curves. For a partial renewal fraction of 0.1 the curves essentially overlap with the corresponding nonrenewal curves. For a partial renewal fraction of 0.5 the unavailability is generally within a factor of 2 of the corresponding nonrenewal unavailability. These basic similarities with the nonrenewal results lead to the following general conclusion:

For partial renewal, unless a significant fraction of failure modes is renewed, e.g. the renewal fraction is $>50 \%$, the IST with partial renewal has results similar to the IST with no renewal. If a significant fraction of failure modes is renewed, e.g. $>50 \%$, then the IST with follow-up partial renewal can be treated as being equivalent to an IST with follow-up total renewal. 


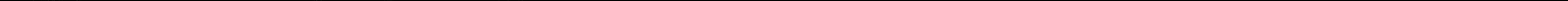




\section{Recommendations for Implementations}

Based on the methodology which has been developed and the sensitivity studies which have been carried out, the following recommendations can be made for using the results and methodology in this report:

1. ISTs should be treated as resulting in nonrenewal of the component unless there is justification that the IST is followed by corrective maintenances which significantly renew the component, i.e. refurbishes greater than $50 \%$ of the failure modes. ISTs followed by selective corrective maintenances which refurbish less than $\mathbf{5 0} \%$ of the failure modes give basically the same unavailabilities as ISTs followed by no renewal.

2. For ISTs with no follow-up renewal, aging has impacts on check valve unavailability at all IST intervals, with the unavailability increasing by a factor of approximately 2 for each $10 \%$ increase in the valve aging rate. Thus, if the usual PRA calculations are performed assuming no aging, sensitivity studies should at a minimum be carried out increasing the valve unavailability by a factor of at least 2 to evaluate aging effects. Unavailabilities of all valves susceptible to aging should be simultaneously increased by this factor to cover the simultaneous effects of aging.

3. An IST interval between 2 to 3 years is identified to be near optimal in providing minimal unavailabilities for the range of check valve aging rates and IST characteristics covered in the sensitivity studies. IST intervals which are robust to component aging are identified as being those which were less than or equal to 5 years since IST intervals greater than 5 years result in significant valve unavailability increases for even the lower valve aging rates.

4. To use the formulas in this report, component aging rates and IST downtimes are required. The discussions in Chapter 5 are useful in this regard. For initial evaluations, the IST can be treated as having no associated renewal. When the component is not subjected to harsh operating conditions, a low to moderate aging rate can be used (e.g. $\alpha=0.2$ ) to check the robustness of the IST interval to possible component aging effects.

5. If the valve is subjected to harsh operating conditions, such as being located in a sea water environment or being in a location which subjects the valve to flutter or constant operation then a higher aging rate (e.g. $a=$ 0.5 ) can be used to check the robustness of the IST interval. A nonlinear aging model can also be used to check for effects of aging nonlinearities.

6. Since plant specific considerations and plant specific data are always most valid, the results and general observations which are given in this report should be checked and be modified where warranted using plant specific considerations and data.

7. Finally, to determine the risk implications of the IST intervals, the associated component unavailabilities can be input to the PRA or the age-dependent component unavailability models can be used in place of the constant failure rate models. 


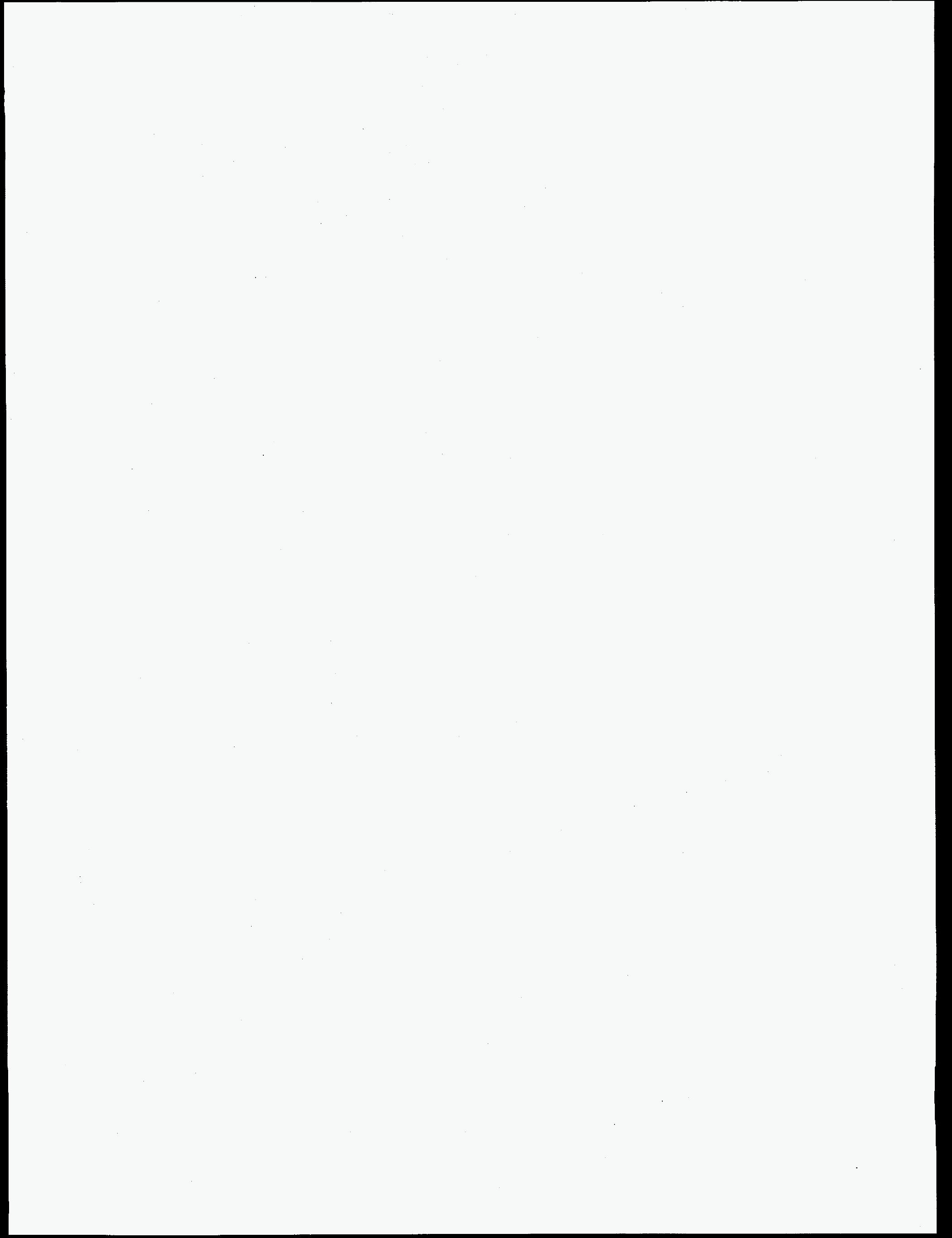




\section{References}

1. Casada, D.A. and M.D. Todd, NUREG/CR-5944, Vol. 1, "A Characterization of Check Valve Degradation and Failure Experience in the Nuclear Power Industry," September 1993.

2. McElhaney, K.L., NUREG/CR-5944, Vol. 2, "A Characterization of Check Valve Degradation and Failure Experience in the Nuclear Power Industry," July 1995.

3. W.E. Vesely, R.E. Kurth, and S.M. Scalzo, "Evaluations of Core Melt Frequency Effects Due to Component Aging and Maintenance," NUREG/CR-5510, June 1990.

4. E.N. Dialynas and D.G. Michos, "Time-Dependent Unavailability Analysis of Standby Components Incorporating Arbitrary Failure Distributions and Inspection/Maintenance Policies," Reliability Engineering and System Safety, Vol. 39, 1993, pp. 35-54.

5. G.E. Apostolakis and B.B. Chu, "The Unavailability of Systems Under Periodic Test and Maintenance," Nuclear Technology, Vol. 50, 1980, pp. 5-15. 

Appendix A. Derivation of the Component Unavailability Formulas 


\section{Appendix A. Derivation of the Component Unavailability Formulas}

This appendix derives the unavailability formulas for the linear aging model and nonlinear aging model. The derivation steps are shown in detail to provide a documentation of the bases for the formulas.

\section{Methodology for Linear Aging Rates}

If unmitigated, aging and deterioration in a component can cause the failure rate to increase with time from the point of the installation of the component or the point of the last renewal of the component, whichever occurred last. From NUREG/CR5510 , the simplest aging model is to treat the component failure rate as linearly increasing with time:

$$
\lambda(t)=\lambda_{0}+a t
$$

where

$$
\begin{aligned}
& \lambda(t)=\text { the time-dependent component failure rate } \\
& \lambda_{0}=\text { the reference failure rate of a new component }
\end{aligned}
$$

and

$$
\mathrm{a}=\text { the linear aging rate }
$$

where again $t$ is the time from installation or last renewal, whichever occurred last.

From Appendix B of NUREG/CR-5510, if successive operational tests are performed at times $\ell$ and $T+l$ where $l$ is the time since the last component-renewal, then the probability $q(t)$ of the component being down at interval $t$ from $l$ is

$$
\mathrm{q}(\mathrm{t})=1-\exp \left(-\int_{\ell}^{\ell+\mathrm{t}} \lambda\left(\mathrm{t}^{\prime}\right) \mathrm{dt^{ \prime }}\right)
$$

Using the linear failure rate,

$$
\begin{aligned}
& \mathrm{q}(\mathrm{t})=1-\exp \left(-\left.\left(\lambda_{\mathrm{o}} \mathrm{t}^{\prime}+\mathrm{a} \frac{\mathrm{t}^{\prime 2}}{2}\right)\right|_{\ell} ^{\ell+\mathrm{t}}\right) \\
& =1-\exp \left(-\left(\lambda_{0} \mathrm{t}+\mathrm{a} \frac{(\ell+\mathrm{t})^{2}}{2}-\mathrm{a} \frac{\ell^{2}}{2}\right)\right) \\
& =1-\exp \left(-\left(\lambda_{\mathrm{o}} \mathrm{t}+\mathrm{a} \frac{\mathrm{t}^{2}}{2}+\mathrm{at} \ell\right)\right)
\end{aligned}
$$


Averaging the unavailability $\mathrm{q}(\mathrm{t})$ over $\mathrm{t}$ from 0 to $\mathrm{T}$ by averaging the exponent gives*

$$
\overline{\mathrm{q}}(\ell)=1-\exp \left[-\left(\lambda_{\mathrm{o}} \frac{\mathrm{T}}{2}+\mathrm{a} \frac{\mathrm{T}^{2}}{6}+\mathrm{a} \frac{\mathrm{T}}{2} \ell\right)\right]
$$

If renewals are performed at intervals of $L$ then averaging the exponent over $l$ from 0 to $L-T$ gives

$$
\overline{\mathrm{q}}=1-\exp \left[-\left(\lambda_{0} \frac{\mathrm{T}}{2}+\mathrm{a} \frac{\mathrm{T}^{2}}{6}+\mathrm{a} \frac{\mathrm{T}}{2} \frac{(\mathrm{L}-\mathrm{T})}{2}\right)\right]
$$

The average is taken to L-T under the assumption that a renewal and operational test are not both performed at one time. If this constraint is not utilized then the term $L-T$ is replaced by $L$. The effect is insignificant for $L \gg T$.

If $d$ is the downtime associated with the renewal then the total, average unavailability $q$ is

$$
\mathrm{q}=\overline{\mathrm{q}}+\frac{\mathrm{d}}{\mathrm{L}+\mathrm{d}}
$$

or

$$
q=1-\exp \left[-\left(\lambda_{0} \frac{T}{2}+a \frac{T^{2}}{6}+a \frac{T}{2} \frac{(L-T)}{2}\right)\right]+\frac{d}{L+d}
$$

The above equation is a first order expression for $q$ in terms of $d /(L+d)$ as used in PRAs.

If no intermediate operational testing is performed then $l$ is set to zero in Equation (A-8) and $t$ averaged from 0 to $L$ giving

$$
q=1-\exp \left[-\left(\lambda_{0} \frac{L}{2}+\frac{1}{6} a L^{2}\right)\right]+\frac{d}{L+d}
$$

If we express the aging rate $a$ in terms of a relative aging rate $\alpha$ then

$$
\mathrm{a}=\alpha \lambda_{0}
$$

and then for intermediate operational testing

$$
\mathrm{q}=1-\exp \left[-\left(\lambda_{0} \frac{\mathrm{T}}{2}+\alpha \lambda_{0} \frac{\mathrm{T}^{2}}{6}+\alpha \lambda_{\mathrm{o}} \frac{\mathrm{T}}{2} \frac{(\mathrm{L}-\mathrm{T})}{2}\right)\right]+\frac{\mathrm{d}}{\mathrm{L}+\mathrm{d}}
$$

*For an unavailability less than $\mathbf{0 . 1}$, averaging over the exponent is equivalent to averaging over the first order expression for the unavailability which will give accurate values. For higher unavailabilities the exponent averaging will give slightly conservative values because of the concave nature of the function. 
where

$$
\begin{aligned}
& \lambda_{\mathrm{o}}=\text { the baseline, new component failure rate } \\
& \alpha=\text { the relative linear aging rate } \\
& \mathrm{T}=\text { the operational test interval } \\
& \mathrm{L}=\text { the renewal interval } \\
& \mathrm{d}=\text { the downtime associated with the renewal. }
\end{aligned}
$$

For no intermediate operational testing

$$
q=1-\exp \left[-\left(\lambda_{0} \frac{L}{2}+\frac{1}{6} \alpha \lambda_{o} L^{2}\right)\right]+\frac{d}{L+d}
$$

\section{Application Formulas for the Linear Aging Rate for Given Units}

For $\lambda_{o}$ in units of per hour, $\alpha$ in units of per year, $T$ in months, $d$ in hours, $L$ in years, then for an additional intermediate test carried out at intervals of $T$, the average unavailability $q$

$$
\begin{aligned}
& q=1-\exp \left[-\frac{1}{2} \lambda_{0} 8760 \frac{\mathrm{T}}{12}-\frac{1}{6} \alpha \lambda_{0} 8760\left(\frac{\mathrm{T}}{12}\right)^{2}\right. \\
& \left.-\frac{1}{4} \alpha \lambda_{0} 8760 \frac{\mathrm{T}}{12}\left(\mathrm{~L}-\frac{\mathrm{T}}{12}\right)\right]+\frac{\mathrm{d} / 8760}{\mathrm{~L}+\mathrm{d} / 8760}
\end{aligned}
$$

For no intermediate test

$$
q=1-\exp \left[-\frac{1}{2} \lambda_{o} 8760 L-\frac{1}{6} \alpha \lambda_{o} 8760 L^{2}\right]+\frac{d / 8760}{L+d / 8760}
$$

\section{Methodology for a Nonlinear Weibull Aging Rate}

For the nonlinear Weibull model which is used here the time-dependent failure rate $\lambda(t)$ is given by

$$
\lambda(t)=\lambda_{0}+b t^{c}
$$

Substituting in Equation (A-5), $q(t)$ is then given by

$$
\begin{aligned}
& q(\mathrm{t})=1-\exp \left(-\left.\left(\lambda_{0} \mathrm{t}+\frac{\mathrm{b}}{\mathrm{c}+1} \mathrm{t}^{\prime c+1}\right)\right|_{\ell} ^{\ell+\mathrm{t}}\right) \\
= & 1-\exp \left(-\left(\lambda_{0} \mathrm{t}+\frac{\mathrm{b}}{\mathrm{c}+1}(\ell+\mathrm{t})^{\mathrm{c}+1}-\frac{\mathrm{b}}{\mathrm{c}+1} \ell^{\mathrm{c}+1}\right)\right) .
\end{aligned}
$$


Averaging the exponent over $t$ from 0 to $T$ gives

$$
\bar{q}(\ell) \cong 1-\exp \left[-\lambda_{o} \frac{T}{2}-\frac{b}{c+1} \int_{0}^{T}(\ell+t)^{c+1} \frac{d t}{T}+\frac{b}{c+1} \ell^{c+1}\right]
$$

Now

$$
\begin{gathered}
\int_{0}^{\mathrm{T}}(\ell+\mathrm{t})^{\mathrm{c}+1} \frac{\mathrm{dt}}{\mathrm{T}}=\int_{\ell}^{\ell+\mathrm{T}} \mathrm{x}^{\mathrm{c}+1} \frac{\mathrm{dx}}{\mathrm{T}} \\
=\left.\frac{1}{\mathrm{~T}} \frac{\mathrm{x}^{\mathrm{c}+2}}{\mathrm{c}+2}\right|_{\ell} ^{\ell+\mathrm{T}}=\frac{1}{\mathrm{~T}(\mathrm{c}+2)}\left[(\ell+\mathrm{T})^{\mathrm{c}+2}-\ell^{\mathrm{c}+2}\right]
\end{gathered}
$$

Therefore,

$$
\bar{q}(\ell) \cong 1-\exp \left[-\lambda_{0} \frac{T}{2}-\frac{b}{c+1} \frac{(\ell+T)^{c+2}}{(c+2) T}+\frac{b}{c+1} \frac{\ell^{c+2}}{(c+2) T}+\frac{b}{c+1} \ell^{c+1}\right]
$$

Finally, averaging over $\ell$ from $\ell=0$ to $L^{*}$

$$
\begin{gathered}
\int_{0}^{L}(\ell+T)^{c+2} \frac{d \ell}{L}=\frac{1}{L} \int_{T}^{L+T} x^{c+2} d x \\
=\left.\frac{1}{L(c+3)} x^{c+3}\right|_{T} ^{L+T}=\frac{1}{L(c+3)}\left[(L+T)^{c+3}-T^{c+3}\right]
\end{gathered}
$$

Also,

$$
\begin{aligned}
& \int_{0}^{\mathrm{L}} \ell^{\mathrm{c}+2} \frac{\mathrm{d} \ell}{\mathrm{L}}=\frac{1}{\mathrm{c}+3} \mathrm{~L}^{\mathrm{c}+2} \\
& \int_{0}^{\mathrm{L}} \ell^{\mathrm{c}+1} \frac{\mathrm{d} \ell}{\mathrm{L}}=\frac{1}{\mathrm{c}+2} \mathrm{~L}^{\mathrm{c}+1} .
\end{aligned}
$$

Consequently,

*The averaging is carried out from 0 to $\mathrm{L}$ instead of 0 to L-T as for the linear aging model to obtain more tractable derivation. The above formulas can always be rescaled by using $L-T$ in the averaging. For $T<<L$ the difference is insignificant. 


$$
\begin{aligned}
& q=1-\exp \left[-\lambda_{0} \frac{T}{2}-\frac{b}{(c+1)(c+2)(c+3)} \frac{(L+T)^{c+3}}{L T}+\frac{b}{(c+1)(c+2)(c+3)} \frac{T^{c+2}}{L}\right. \\
& \left.+\frac{b}{(c+1)(c+2)(c+3)} \frac{L^{c+2}}{T}+\frac{b}{(c+1)(c+2)} L^{c+1}\right]+\frac{d}{L+d} .
\end{aligned}
$$

For no intermediate testing, $l$ is set to zero in Equation (A-26) and $t$ averaged from 0 to $\mathrm{L}$ giving

$$
q=1-\exp \left[-\lambda_{0} \frac{L}{2}-\frac{b}{(c+1)(c+2)} L^{c+1}\right]+\frac{d}{L+d}
$$

For relative aging rates, $\mathrm{b}$ is set to $\alpha \lambda_{\mathrm{o}}$ in the above formulas.

\section{Formulas for the Nonlinear Weibull Aging Rate for Given Units}

For $\lambda_{\mathrm{o}}$ in units of per hour, $\alpha$ in units of per year, $\mathrm{L}$ in years, $\mathrm{d}$ in hours, for an additional intermediate test carried out at intervals of $T$

$$
\begin{aligned}
& q=1-\exp \left[-\frac{1}{2} \lambda_{0} 8760 \frac{\mathrm{T}}{12}-\frac{\alpha \lambda_{0} 8760}{(\mathrm{c}+1)(\mathrm{c}+2)(\mathrm{c}+3)} \frac{(\mathrm{L}+\mathrm{T} / 12)^{\mathrm{c}+3}}{\mathrm{LT} / 12}\right. \\
& +\frac{\alpha \lambda_{0} 8760}{(\mathrm{c}+1)(\mathrm{c}+2)(\mathrm{c}+3)} \frac{(\mathrm{T} / 12)^{\mathrm{c}+2}}{\mathrm{~L}}+\frac{\alpha \lambda_{0} 8760}{(\mathrm{c}+1)(\mathrm{c}+2)(\mathrm{c}+3)} \frac{\mathrm{L}^{\mathrm{c}+2}}{\mathrm{~T} / 12} \\
& \left.+\frac{\alpha \lambda_{0} 8760}{(\mathrm{c}+1)(\mathrm{c}+2)} \mathrm{L}^{\mathrm{c}+1}\right]+\frac{\mathrm{d} / 8760}{\mathrm{~L}+\mathrm{d} / 8760}
\end{aligned}
$$

For no intermediate testing,

$$
q=1-\exp \left[-\frac{1}{2} \lambda_{0} 8760 L-\frac{\alpha \lambda_{0} 8760}{(c+1)(c+2)} L^{c+1}\right]+\frac{d / 8760}{L+d / 8760}
$$




\section{Appendix B. Evaluations of Component Unavailability Versus IST Interval for Check Valves with Linear Aging: Associated Tables}




\begin{tabular}{|c|c|}
\hline 8 & 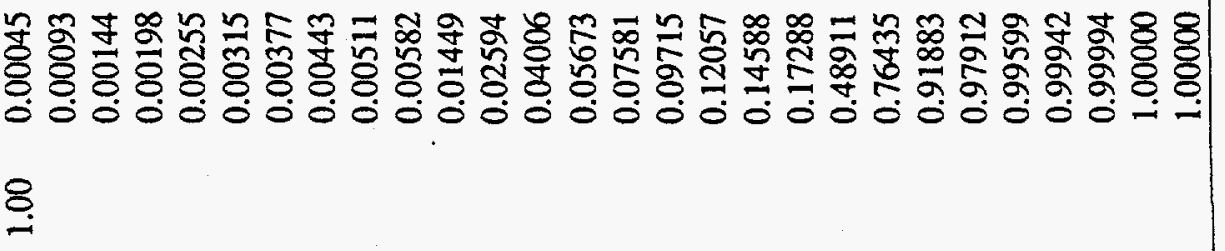 \\
\hline 8 & 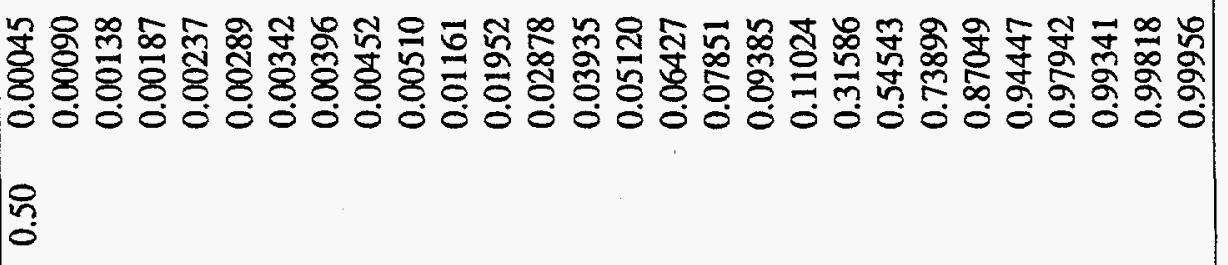 \\
\hline$x+$ & 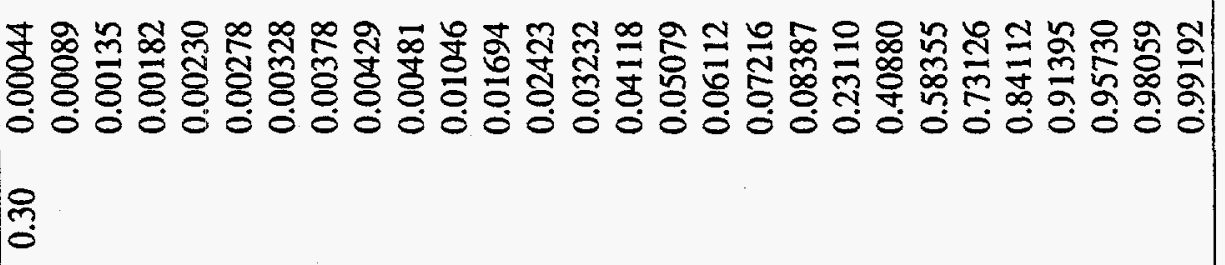 \\
\hline 8 & 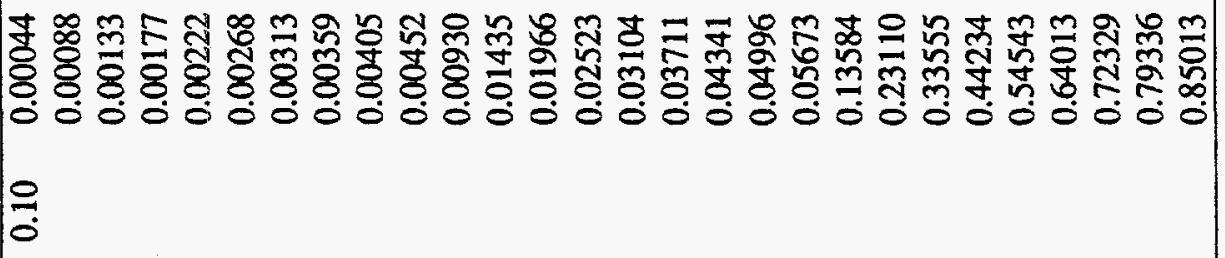 \\
\hline$\sigma$ & 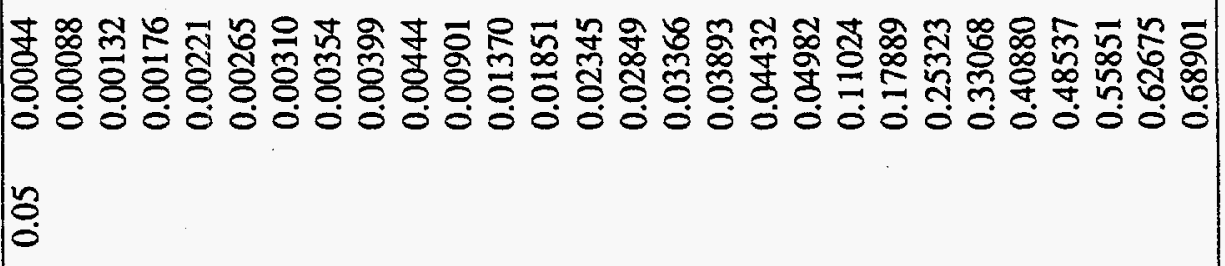 \\
\hline$\sigma$ & 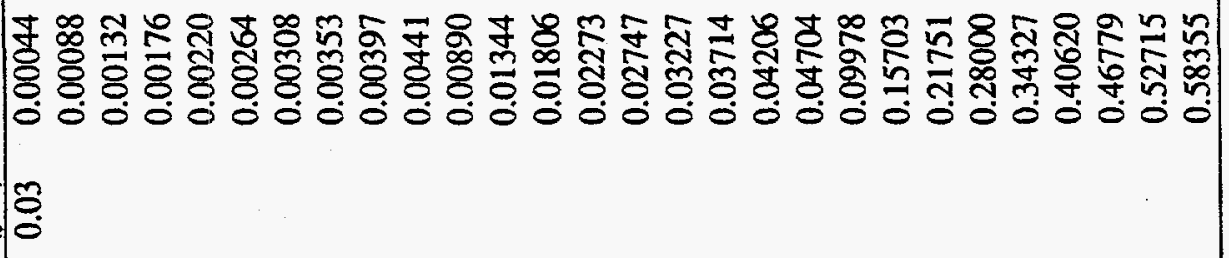 \\
\hline$\sigma$ & 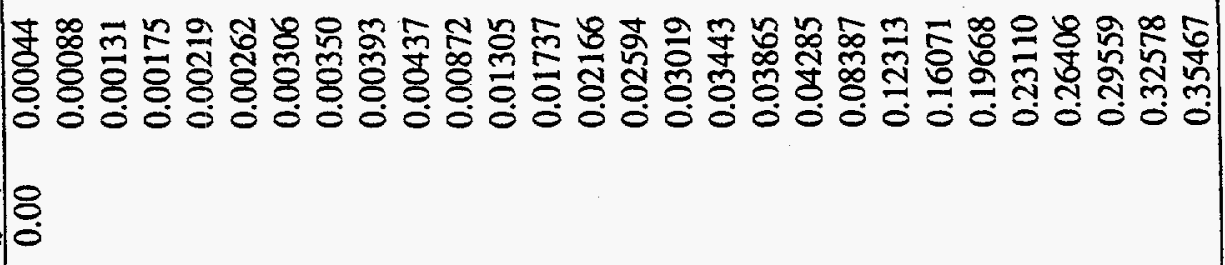 \\
\hline - & 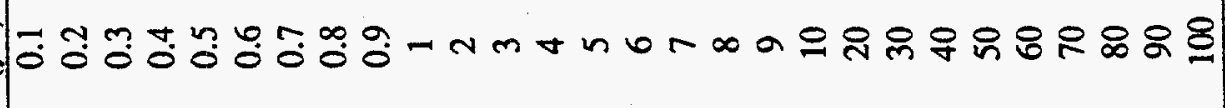 \\
\hline
\end{tabular}




\begin{tabular}{|c|c|}
\hline$\sigma$ & 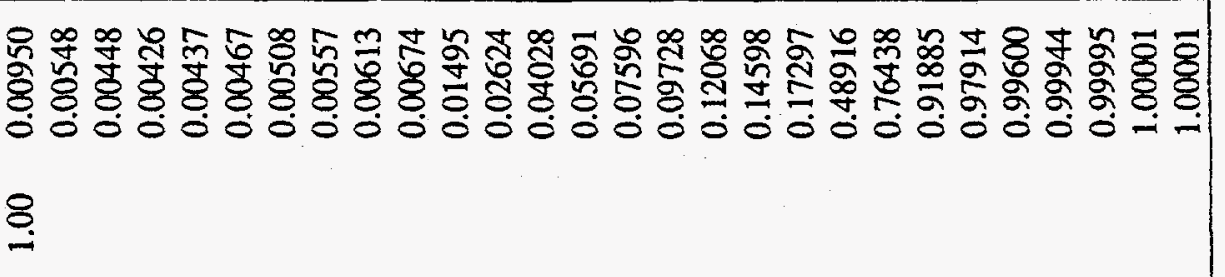 \\
\hline$\sigma$ & 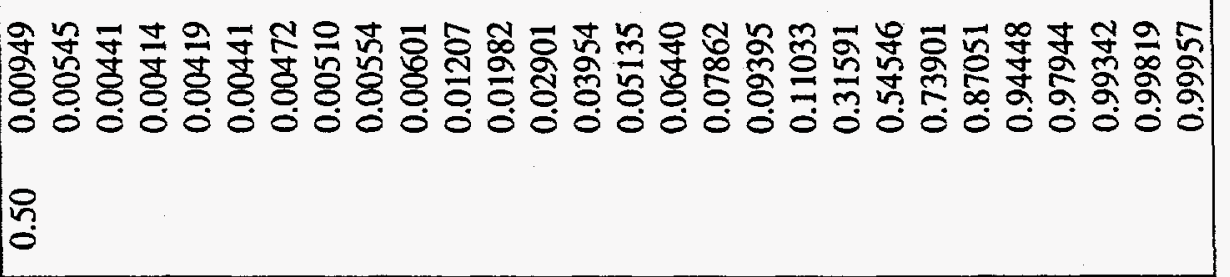 \\
\hline$\sigma$ & 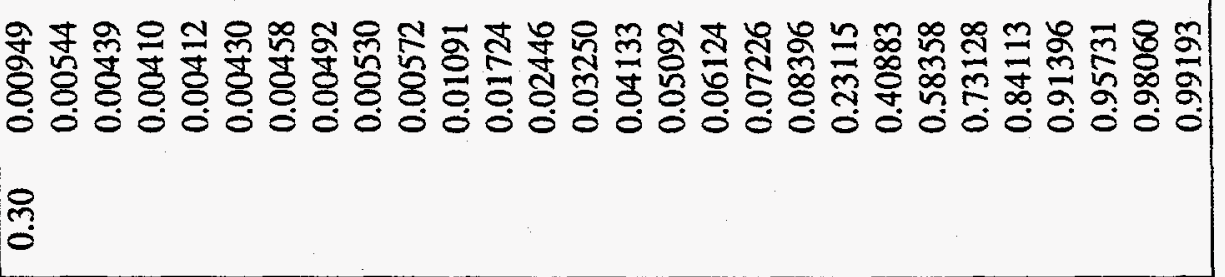 \\
\hline 8 & 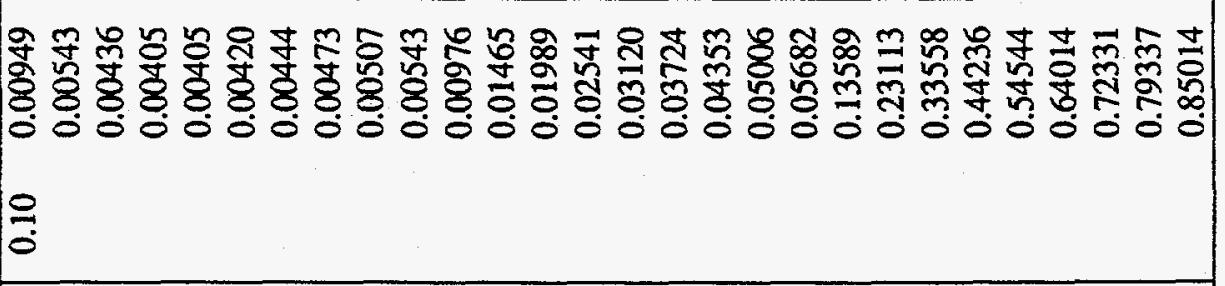 \\
\hline 8 & 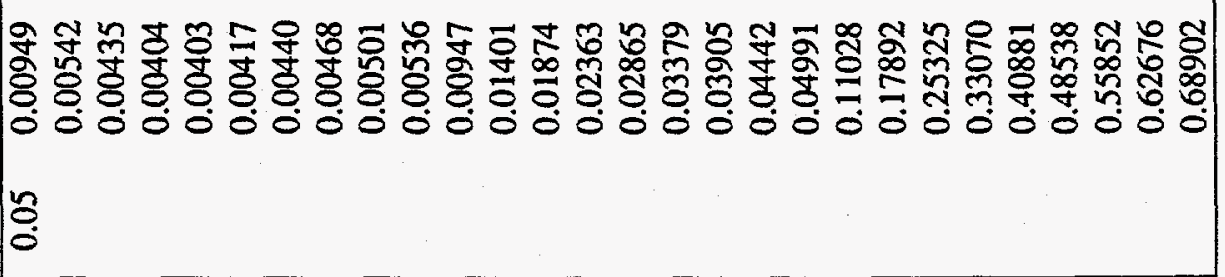 \\
\hline$\sigma$ & 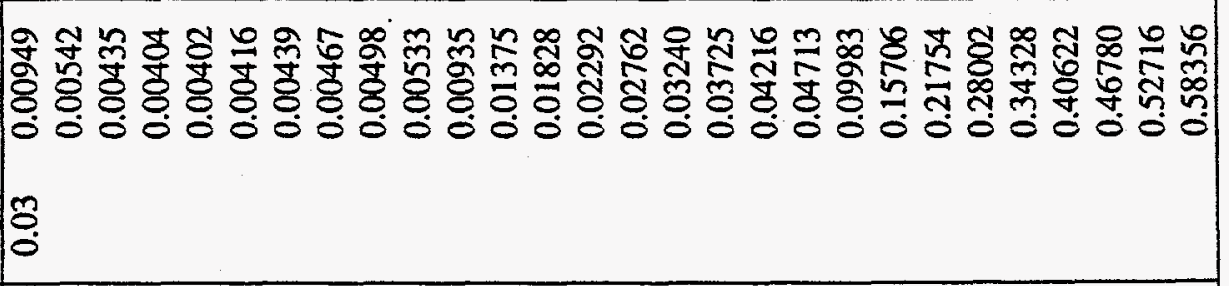 \\
\hline 8 & 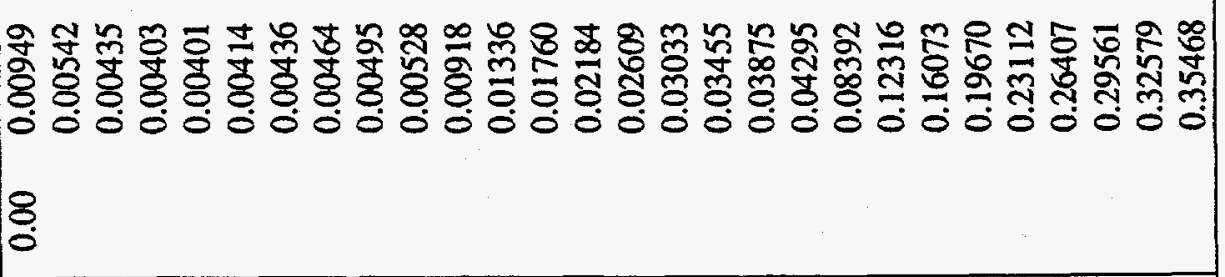 \\
\hline & 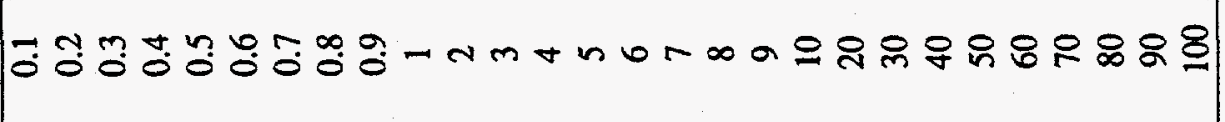 \\
\hline
\end{tabular}




\begin{tabular}{|c|c|}
\hline$\sigma$ & 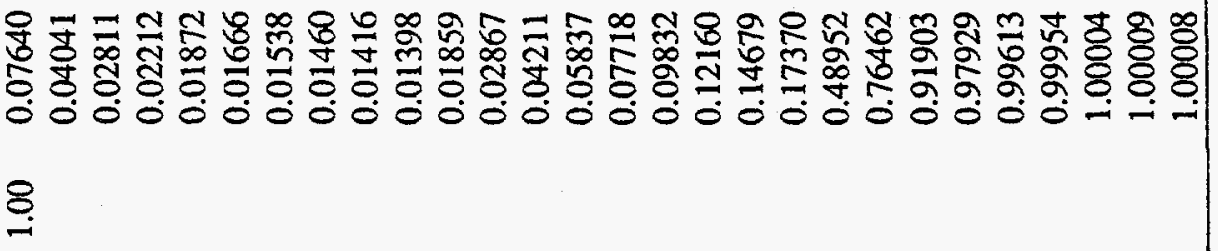 \\
\hline$\sigma$ & 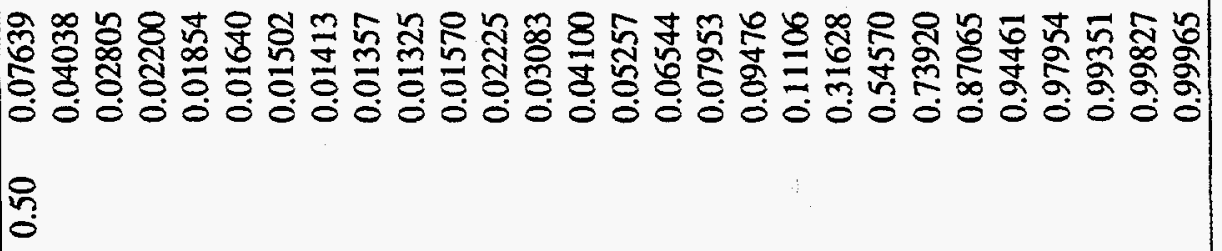 \\
\hline$\sigma$ & 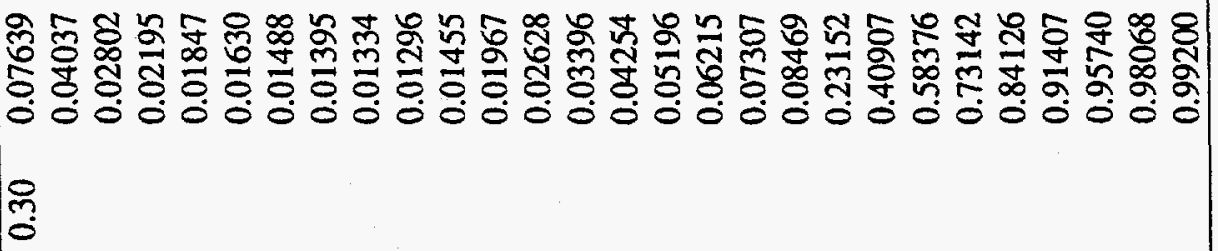 \\
\hline$\sigma$ & 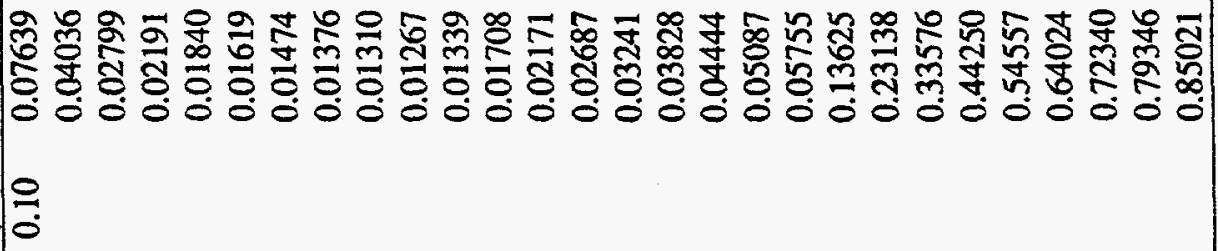 \\
\hline $8 \stackrel{7}{3}$ & 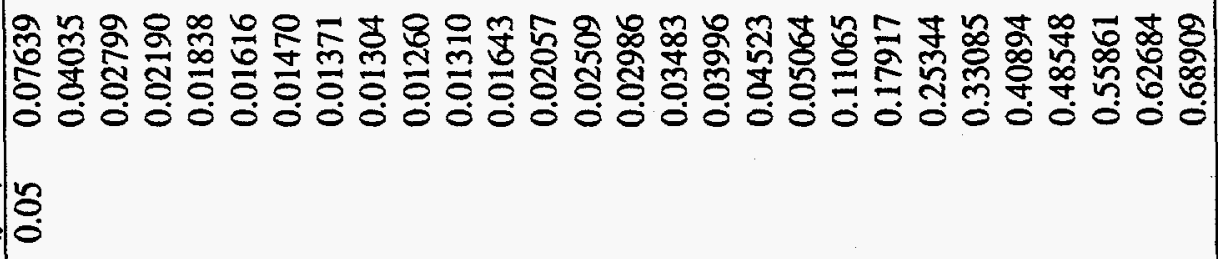 \\
\hline$\sigma$ & 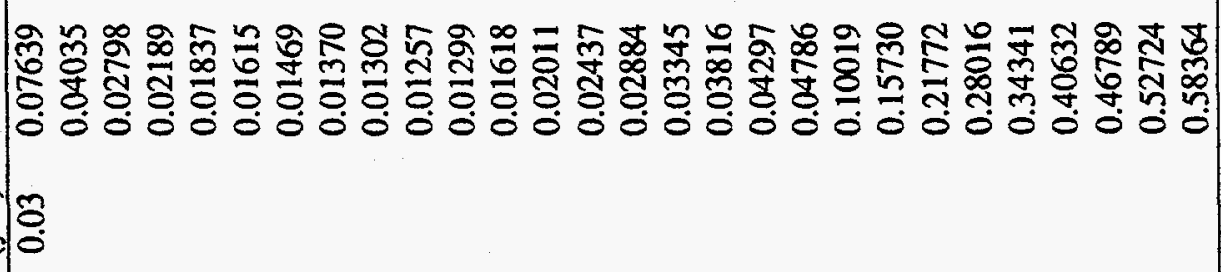 \\
\hline$\sigma$ & 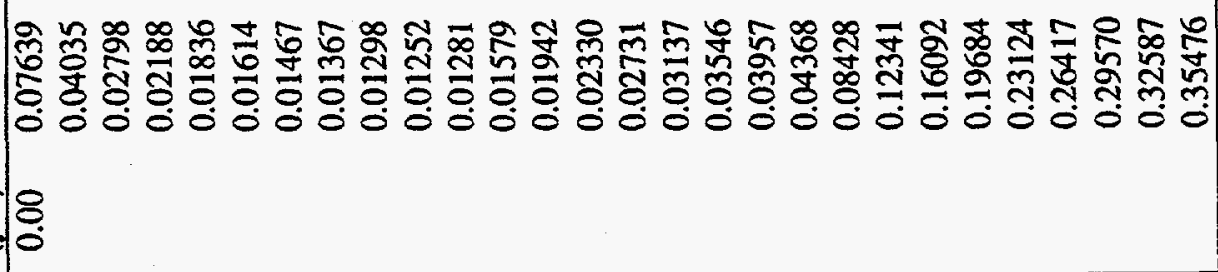 \\
\hline$\alpha$ & 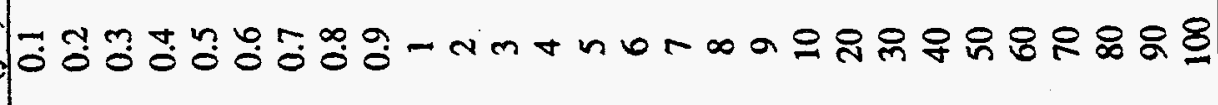 \\
\hline
\end{tabular}




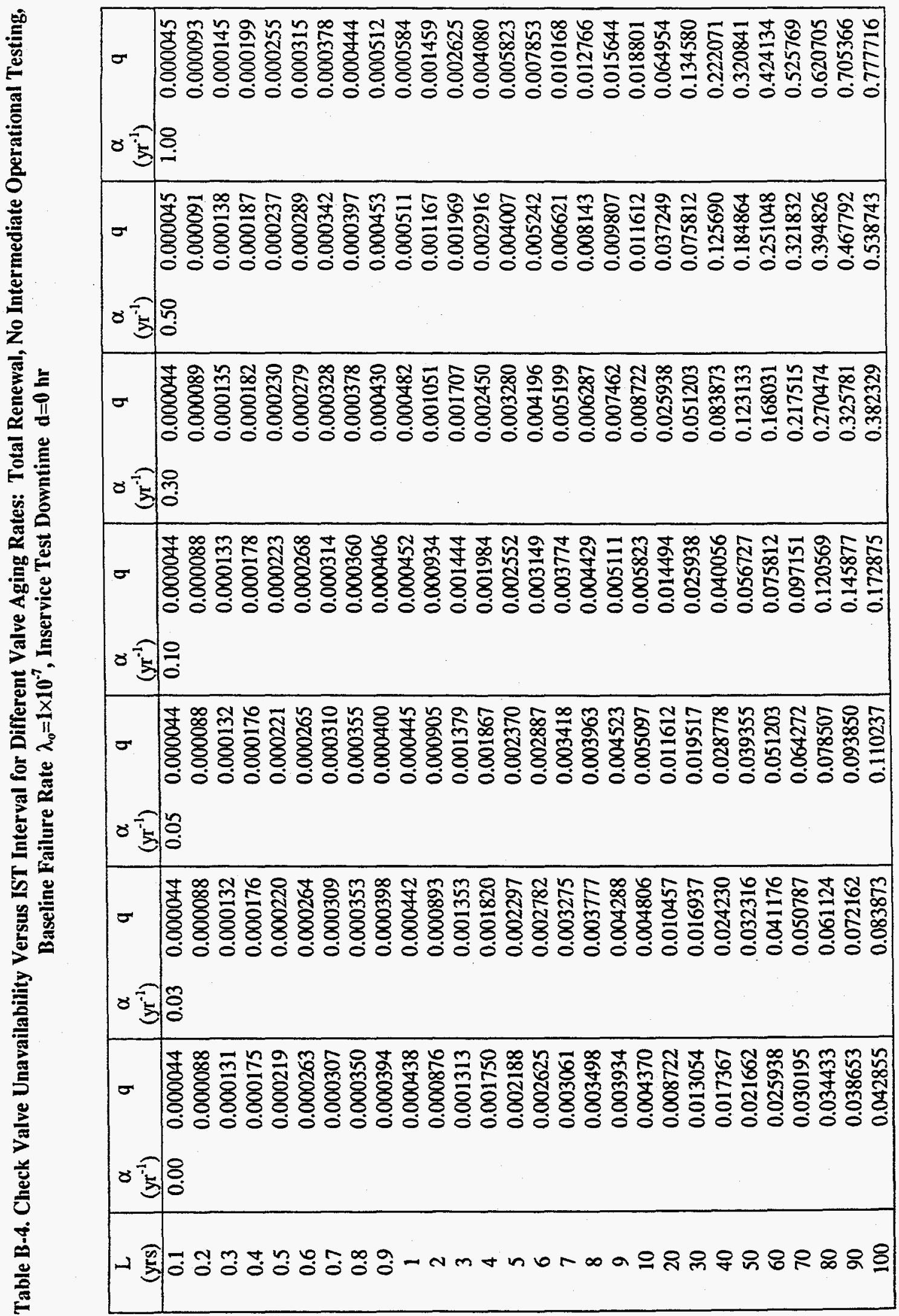




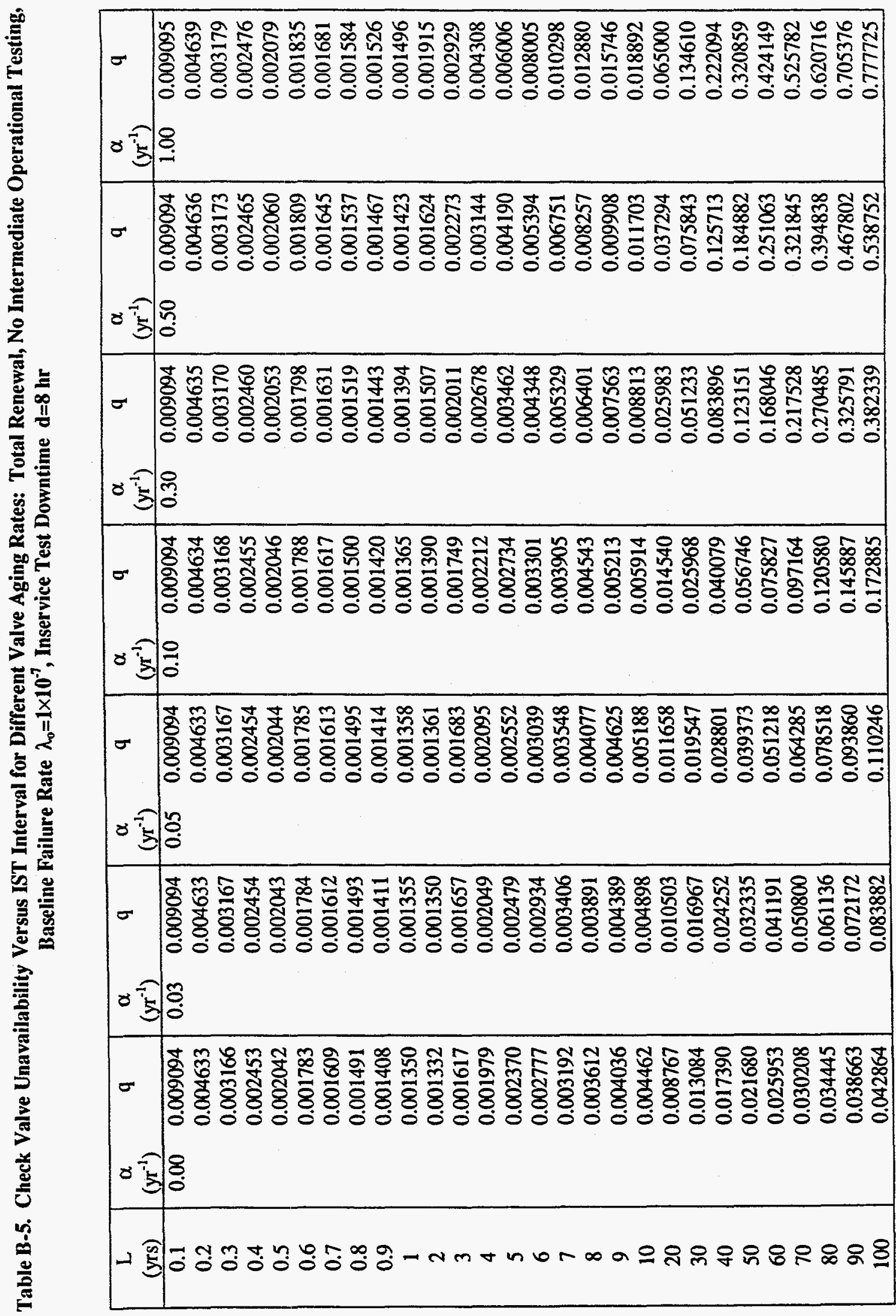


Table B-6. Check Valve Unavailability Versus IST Interval for Different Valve Aging Rates: Total Renewal, No Intermediate Operational Testing, Baseline Failure Rate $\lambda_{0}=1 \times 10^{-7}$, Inservice Test Downtime $d=72 \mathrm{hr}$

\begin{tabular}{|c|c|c|c|c|c|c|c|c|c|c|c|c|c|c|}
\hline $\begin{array}{c}\mathrm{L} \\
\text { (yrs) }\end{array}$ & $\begin{array}{c}\alpha \\
\left(\mathrm{yr}^{-1}\right)\end{array}$ & $q$ & $\begin{array}{c}\alpha \\
\left(\mathrm{yr}^{-1}\right)\end{array}$ & $q$ & $\begin{array}{c}\alpha \\
\left(\mathrm{yr}^{-1}\right)\end{array}$ & $q$ & $\begin{array}{c}\alpha \\
\left(\mathrm{yr}^{-1}\right)\end{array}$ & $q$ & $\begin{array}{c}\alpha \\
\left(\mathrm{yr}^{-1}\right) \\
\end{array}$ & $q$ & $\begin{array}{c}\alpha \\
\left(\mathrm{yr}^{-1}\right)\end{array}$ & $q$ & $\begin{array}{c}\alpha \\
\left(\mathrm{yr}^{-1}\right)\end{array}$ & $q$ \\
\hline 0.1 & 0.00 & 0.075993 & 0.03 & 0.075993 & 0.05 & 0.075993 & 0.10 & 0.075993 & 0.30 & 0.075994 & 0.50 & 0.075994 & 1.00 & 0.075995 \\
\hline 0.2 & & 0.039561 & & 0.039561 & & 0.039562 & & 0.039562 & & 0.039563 & & 0.039564 & & 0.039567 \\
\hline 0.3 & & 0.026798 & & 0.026798 & & 0.026799 & & 0.026799 & & 0.026802 & & 0.026805 & & 0.026811 \\
\hline 0.4 & & 0.020309 & & 0.020310 & & 0.020311 & & 0.020312 & & 0.020316 & & 0.020321 & & 0.020333 \\
\hline 0.5 & & 0.016391 & & 0.016393 & & 0.016393 & & 0.016395 & & 0.016402 & & 0.016410 & & 0.016428 \\
\hline 0.6 & & 0.013776 & & 0.013778 & & 0.013779 & & 0.013782 & & 0.013792 & & 0.013803 & & 0.013829 \\
\hline 0.7 & & 0.011912 & & 0.011914 & & 0.011916 & & 0.011919 & & 0.011933 & & 0.011948 & & 0.011983 \\
\hline 0.8 & & 0.010520 & & 0.010523 & & 0.010525 & & 0.010529 & & 0.010548 & & 0.010567 & & 0.010613 \\
\hline 0.9 & & 0.009444 & & 0.009447 & & 0.009450 & & 0.009456 & & 0.009479 & & 0.009503 & & 0.009562 \\
\hline 1 & & 0.008590 & & 0.008594 & & 0.008597 & & 0.008605 & & 0.008634 & & 0.008663 & & 0.008736 \\
\hline 2 & & 0.004968 & & 0.004986 & & 0.004998 & & 0.005027 & & 0.005143 & & 0.005260 & & 0.005552 \\
\hline 3 & & 0.004045 & & 0.004085 & & 0.004111 & & 0.004177 & & 0.004439 & & 0.004701 & & 0.005357 \\
\hline 4 & & 0.003801 & & 0.003871 & & 0.003918 & & 0.004034 & & 0.004500 & & 0.004966 & & 0.006130 \\
\hline 5 & & 0.003829 & & 0.003938 & & 0.004011 & & 0.004193 & & 0.004921 & & 0.005648 & & 0.007464 \\
\hline 6 & & 0.003993 & & 0.004150 & & 0.004255 & & 0.004517 & & 0.005564 & & 0.006610 & & 0.009221 \\
\hline 7 & & 0.004234 & & 0.004448 & & 0.004591 & & 0.004947 & & 0.006371 & & 0.007794 & & 0.011341 \\
\hline 8 & & 0.004524 & & 0.004804 & & 0.004990 & & 0.005455 & & 0.007314 & & 0.009169 & & 0.013792 \\
\hline 9 & & 0.004847 & & 0.005200 & & 0.005435 & & 0.006024 & & 0.008374 & & 0.010719 & & 0.016557 \\
\hline 10 & & 0.005192 & & 0.005628 & & 0.005918 & & 0.006644 & & 0.009543 & & 0.012433 & & 0.019622 \\
\hline 20 & & 0.009133 & & 0.010868 & & 0.012023 & & 0.014905 & & 0.026348 & & 0.037659 & & 0.065365 \\
\hline 30 & & 0.013328 & & 0.017211 & & 0.019791 & & 0.026212 & & 0.051477 & & 0.076086 & & 0.134854 \\
\hline 40 & & 0.017573 & & 0.024435 & & 0.028983 & & 0.040261 & & 0.084078 & & 0.125895 & & 0.222276 \\
\hline 50 & & 0.021826 & & 0.032481 & & 0.039519 & & 0.056892 & & 0.123297 & & 0.185028 & & 0.321005 \\
\hline 60 & & 0.026075 & & 0.041313 & & 0.051340 & & 0.075949 & & 0.168168 & & 0.251185 & & 0.424271 \\
\hline 70 & & 0.030312 & & 0.050904 & & 0.064389 & & 0.097268 & & 0.217632 & & 0.321949 & & 0.525886 \\
\hline 80 & & 0.034536 & & 0.061227 & & 0.078610 & & 0.120672 & & 0.270577 & & 0.394929 & & 0.620807 \\
\hline 90 & & 0.038744 & & 0.072253 & & 0.093941 & & 0.145968 & & 0.325872 & & 0.467883 & & 0.705457 \\
\hline 100 & & 0.042937 & & 0.083955 & & 0.110319 & & 0.172958 & & 0.382412 & & 0.538825 & & 0.777798 \\
\hline
\end{tabular}




\begin{tabular}{|c|c|}
\hline $8^{7}$ & 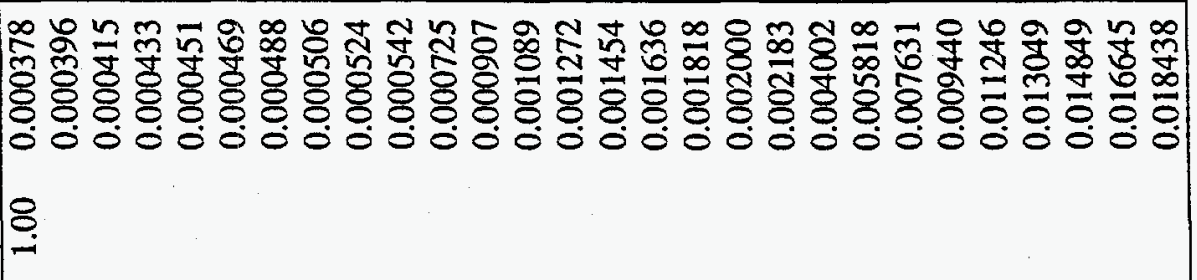 \\
\hline 8 & 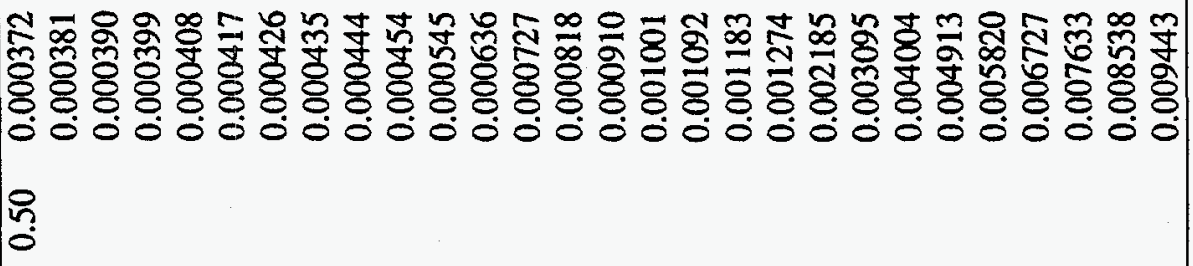 \\
\hline$\sigma$ & 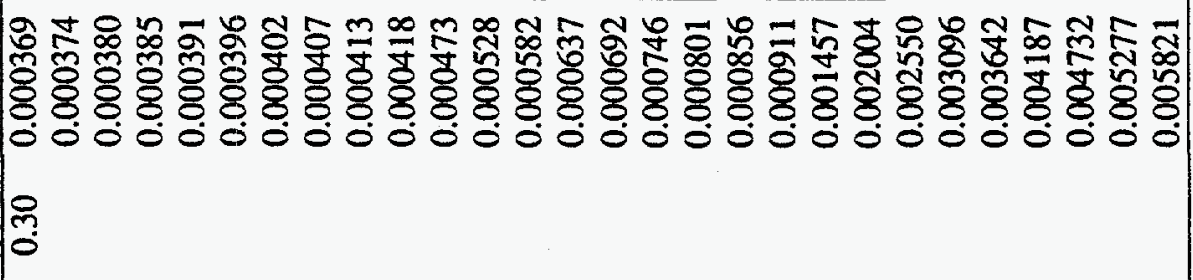 \\
\hline$\sigma$ & 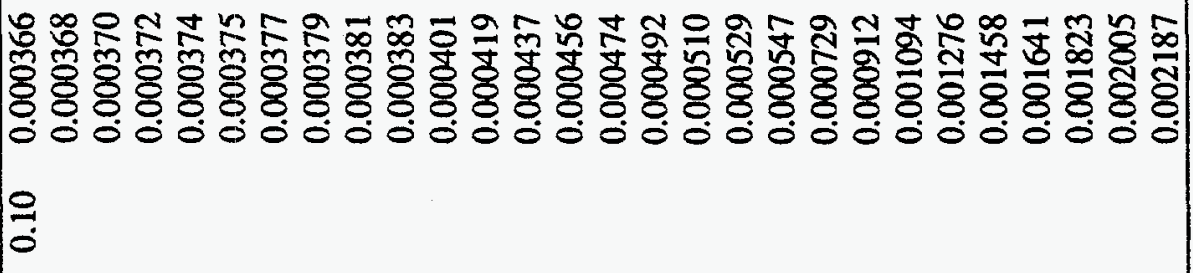 \\
\hline 8 & 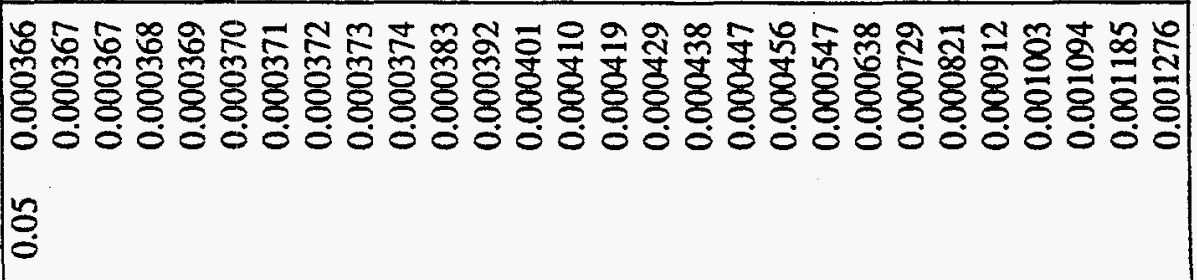 \\
\hline 8 & 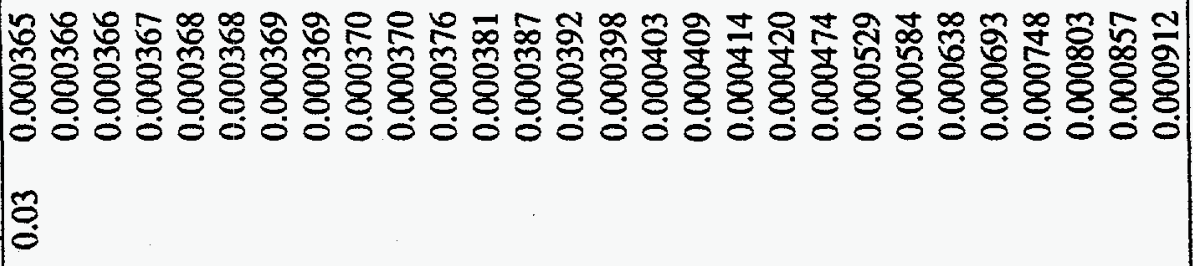 \\
\hline 8 & 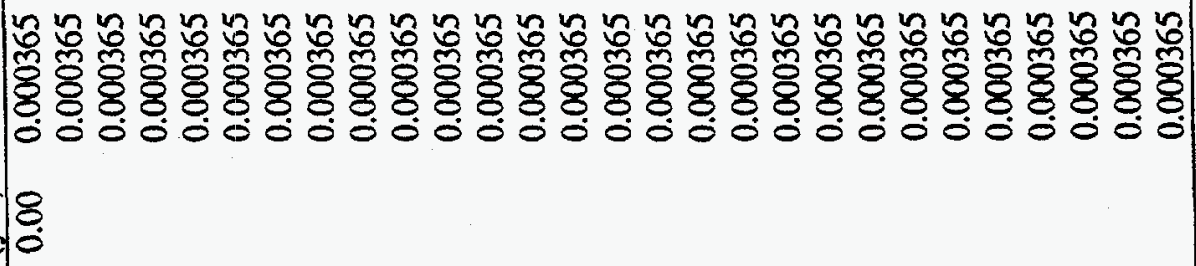 \\
\hline - & 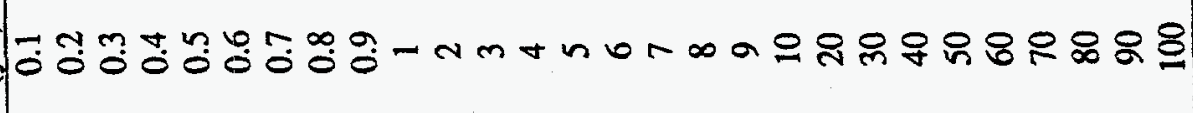 \\
\hline
\end{tabular}




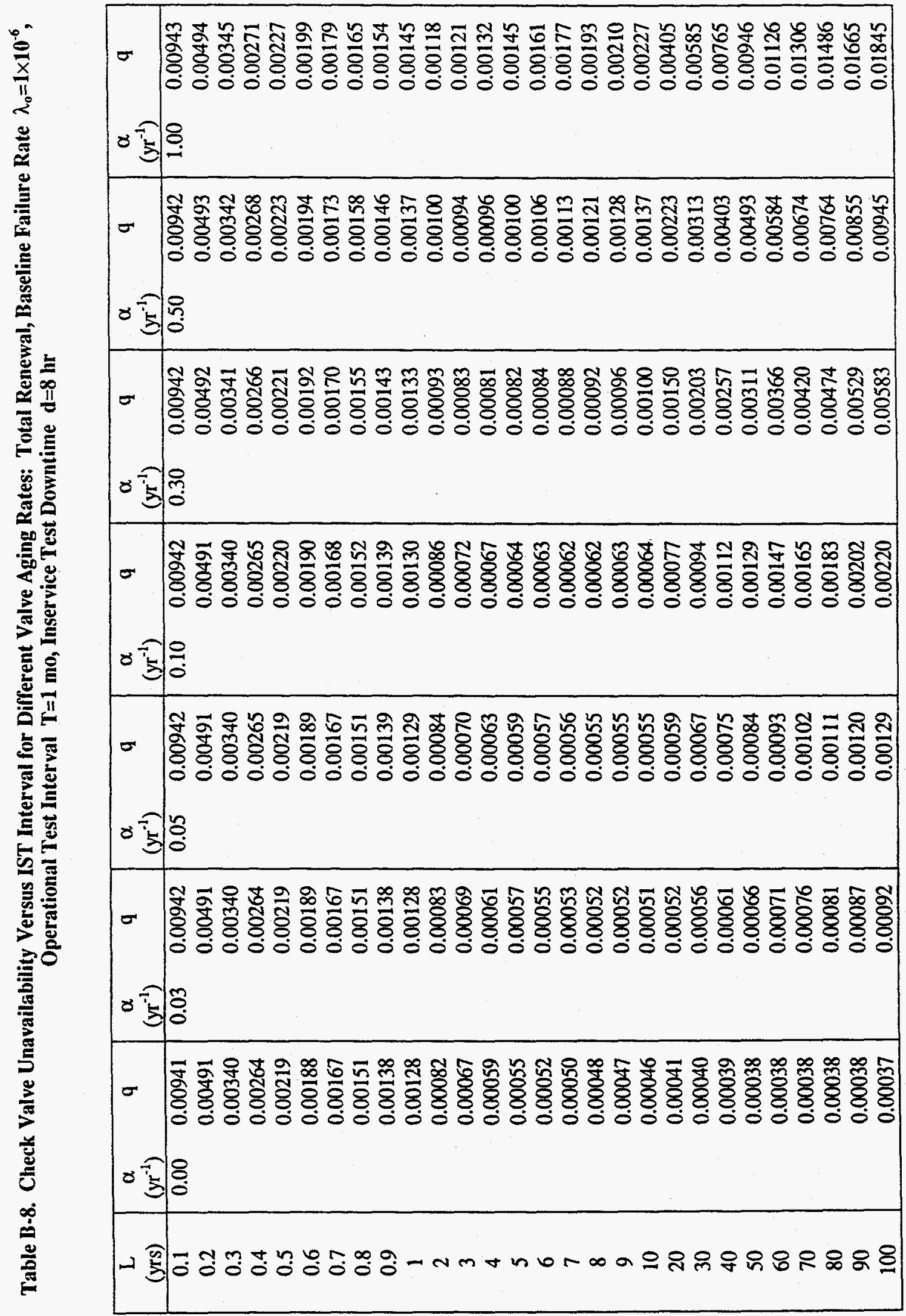




\begin{tabular}{|c|c|}
\hline 8 & 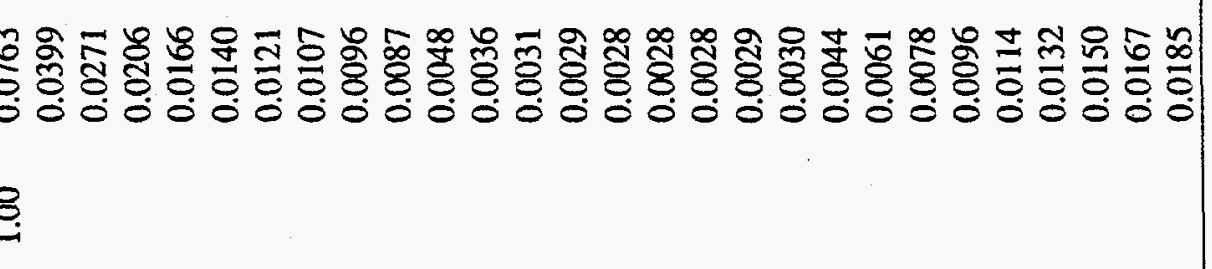 \\
\hline$\sigma$ & 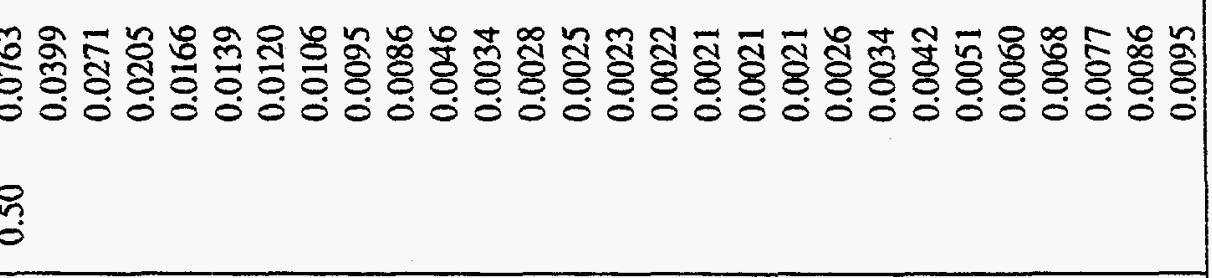 \\
\hline$\sigma$ & 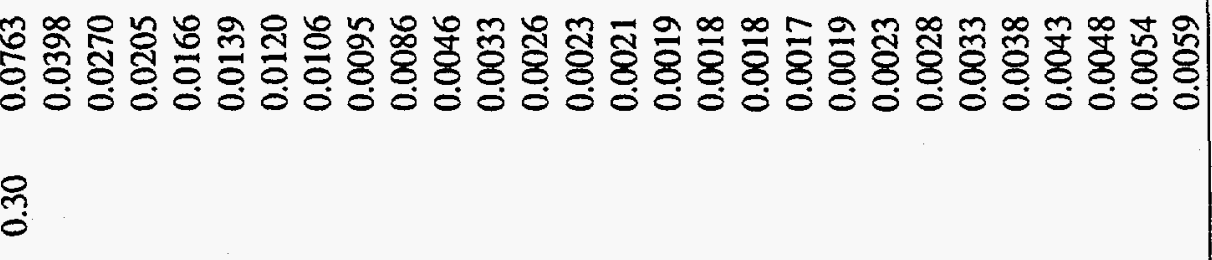 \\
\hline 8 & 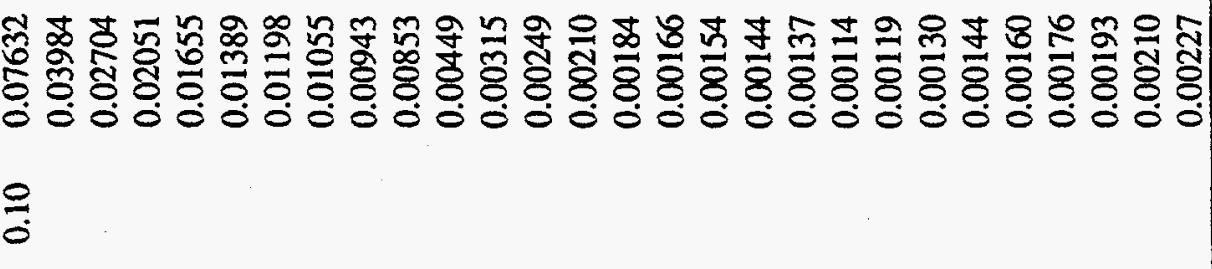 \\
\hline & 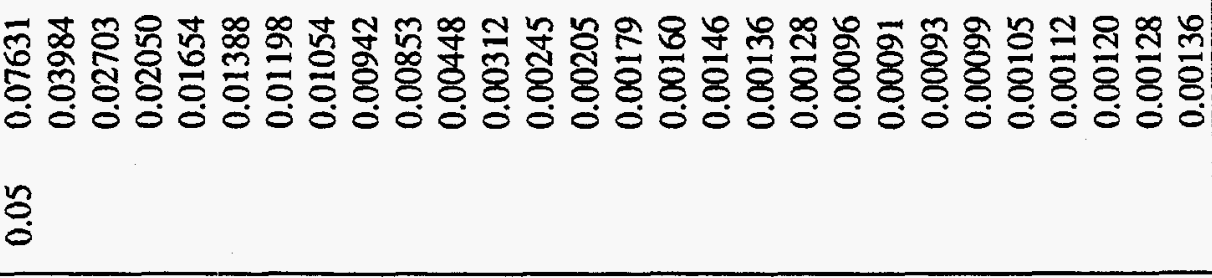 \\
\hline$\sigma$ & 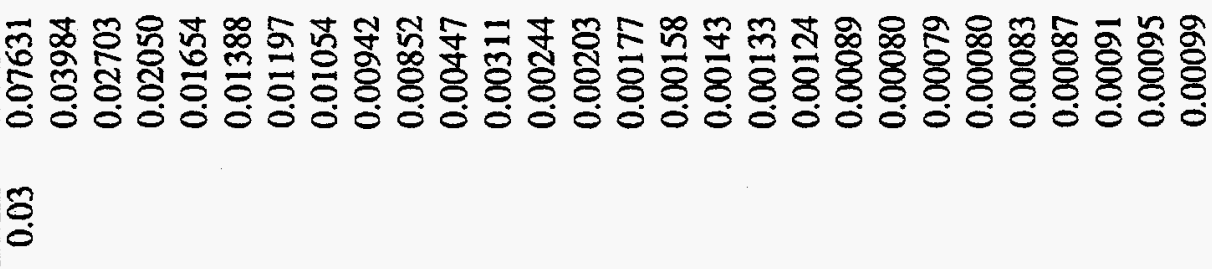 \\
\hline 8 & 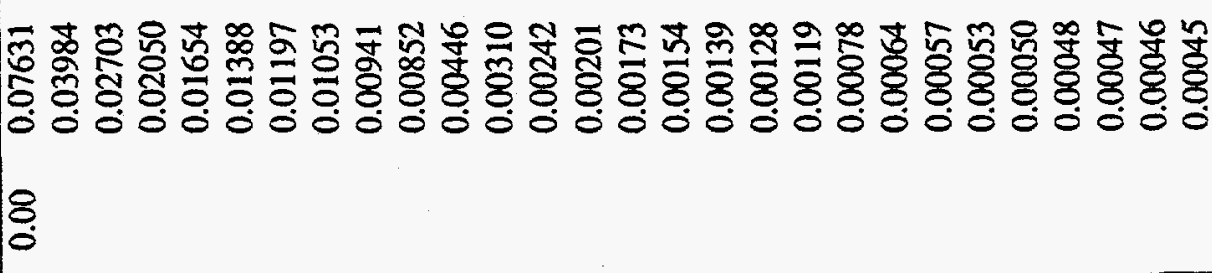 \\
\hline & $\infty \curvearrowleft \subseteq$ ๑ి \\
\hline
\end{tabular}




\begin{tabular}{|c|c|c|}
\hline 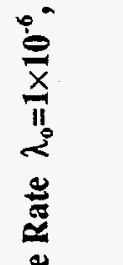 & $8\}$ & 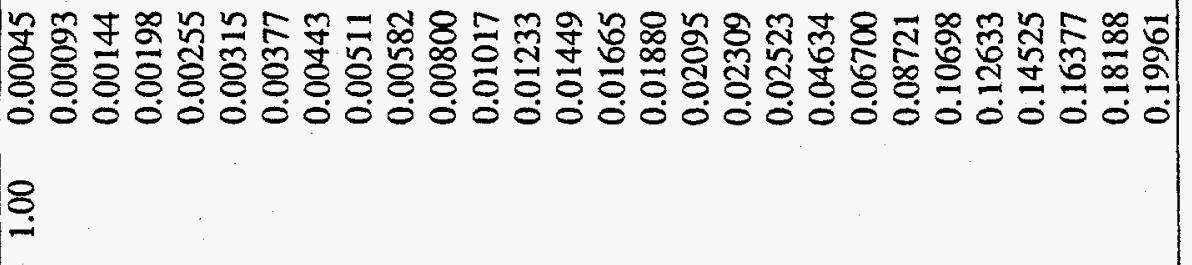 \\
\hline 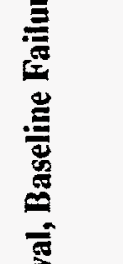 & 8 & 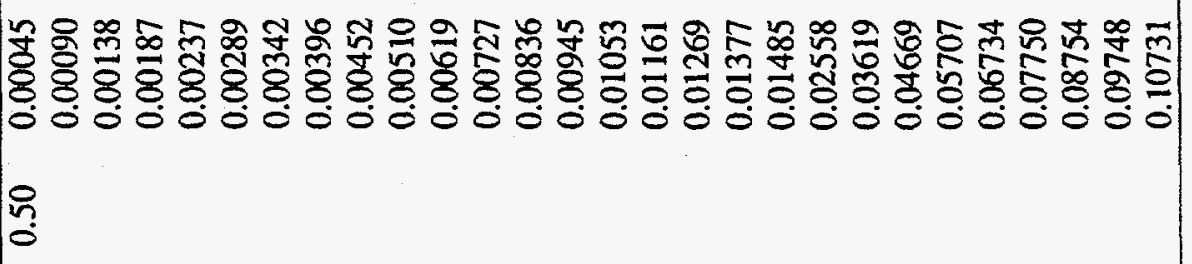 \\
\hline 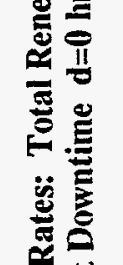 & $\sigma$ & 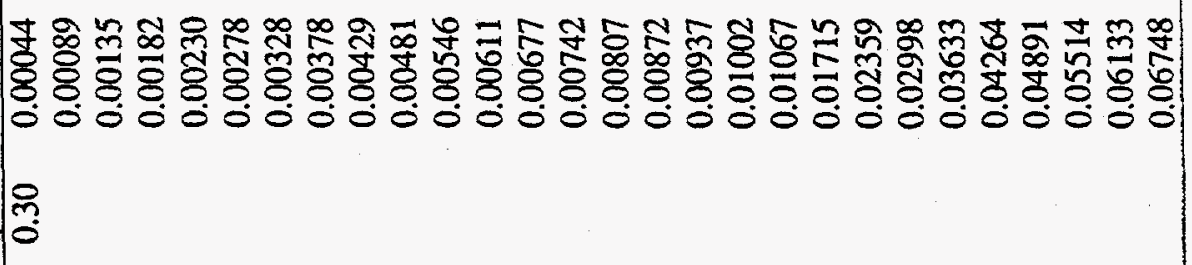 \\
\hline 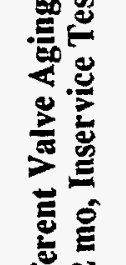 & 8 & 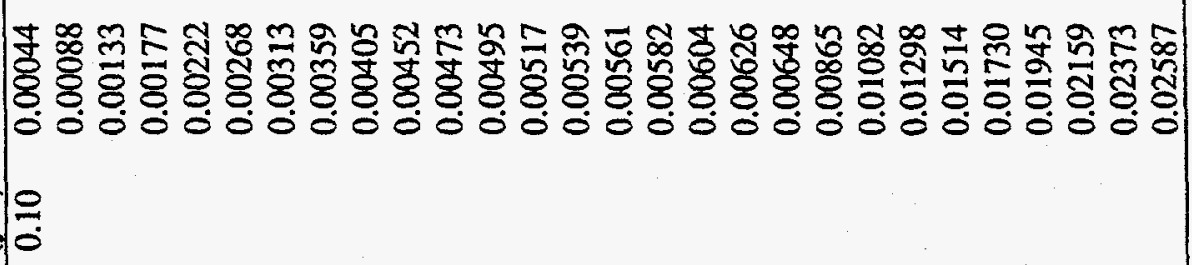 \\
\hline 焉 & 8 & 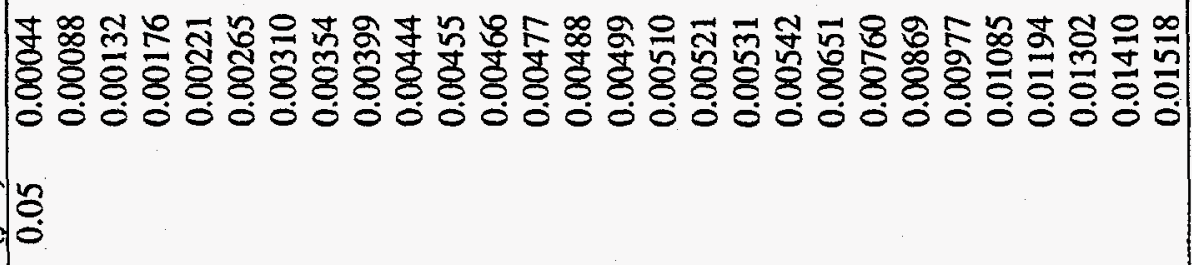 \\
\hline 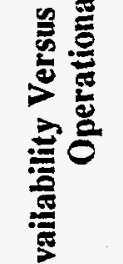 & $\sigma$ & 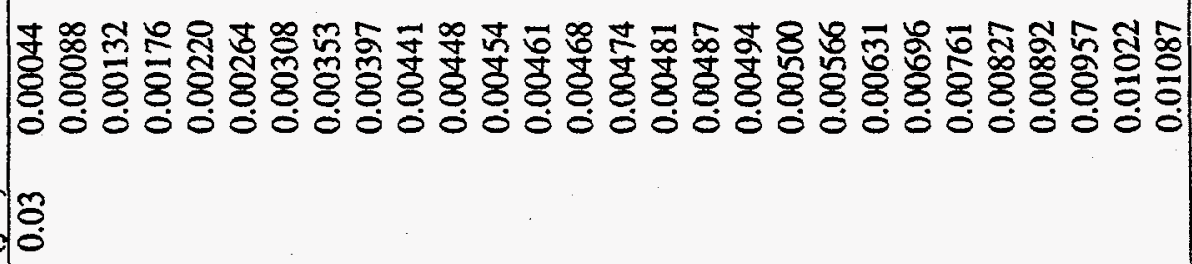 \\
\hline 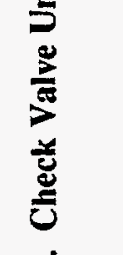 & $\sigma$ & 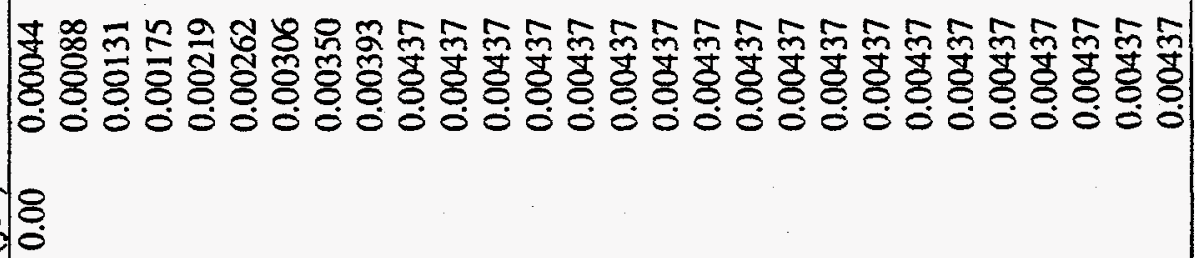 \\
\hline 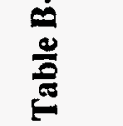 & & $=$ \\
\hline
\end{tabular}




\begin{tabular}{|c|c|}
\hline 8 & 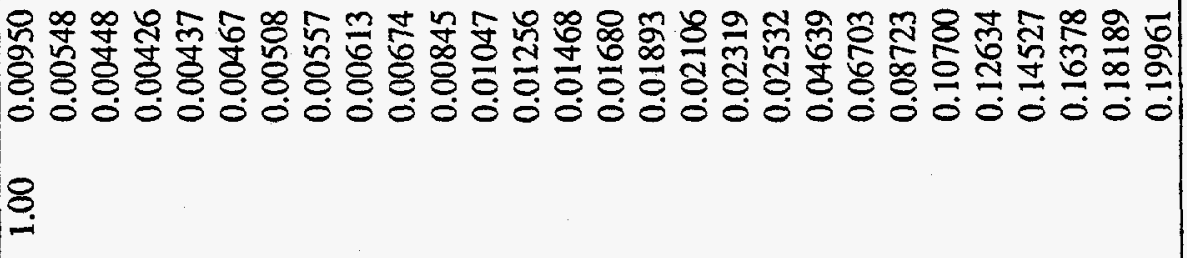 \\
\hline $8 \div$ & 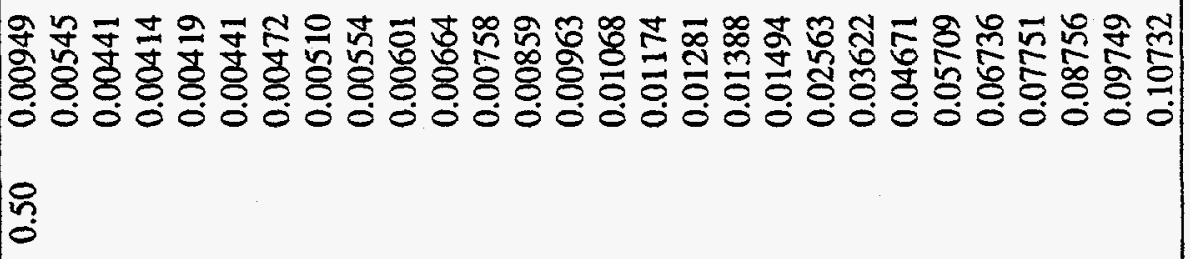 \\
\hline$\sigma$ & 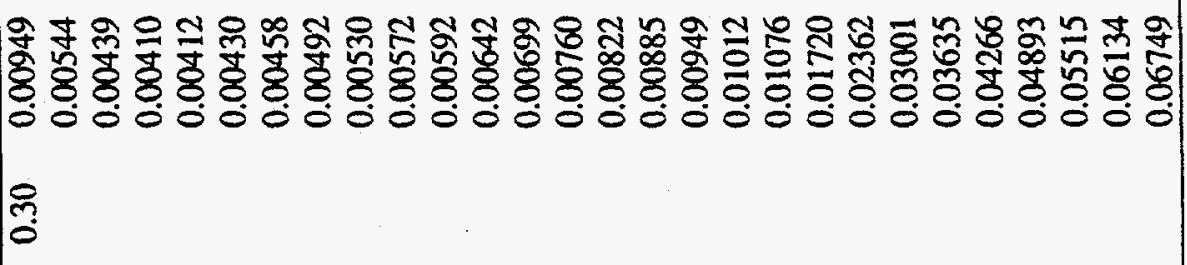 \\
\hline 8 & 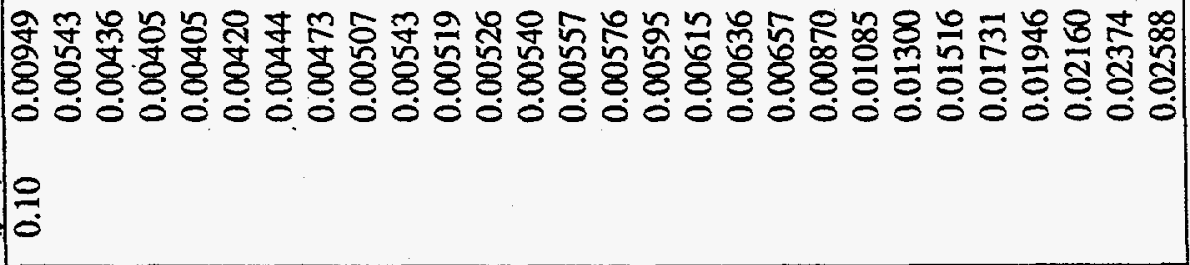 \\
\hline $\begin{array}{l}0 \\
07 \\
0\end{array}$ & 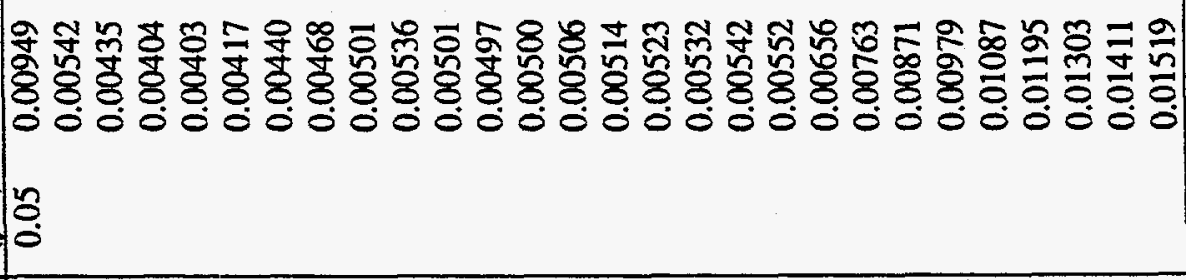 \\
\hline 8 & 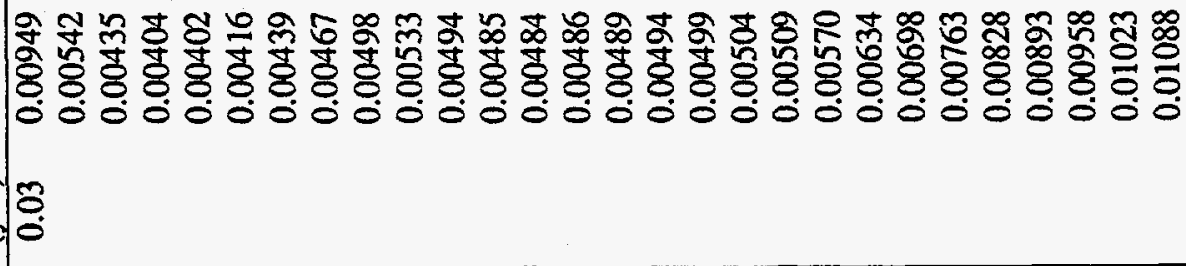 \\
\hline 8 & 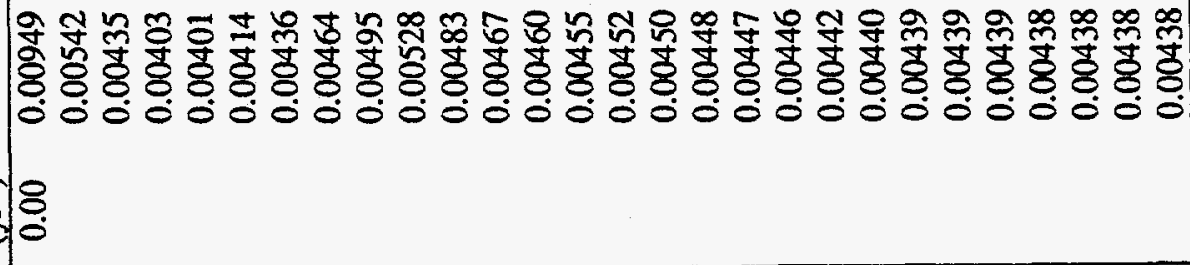 \\
\hline 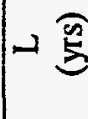 & न융 \\
\hline
\end{tabular}




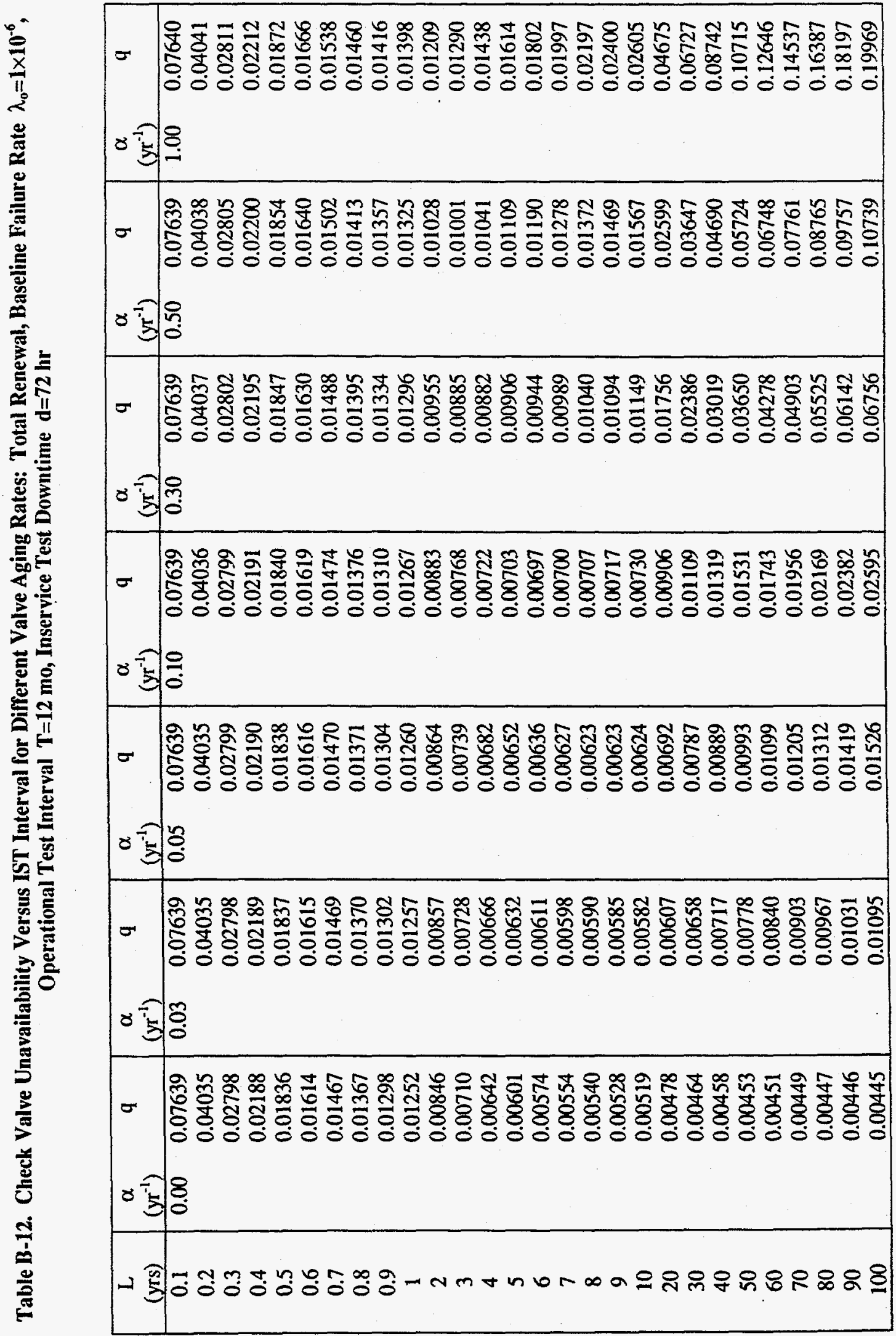




\begin{tabular}{|c|c|c|c|c|c|c|c|c|c|c|c|c|c|c|}
\hline $\begin{array}{c}\mathrm{L} \\
\text { (yrs) }\end{array}$ & $\begin{array}{c}\alpha \\
\left(\mathrm{yr}^{-1}\right)\end{array}$ & $\mathbf{q}$ & $\begin{array}{c}\alpha \\
\left(\mathrm{yr}^{-1}\right)\end{array}$ & $q$ & $\begin{array}{c}\alpha \\
\left(\mathrm{yr}^{-1}\right)\end{array}$ & $q$ & $\begin{array}{c}\alpha \\
\left(\mathrm{yr}^{-1}\right)\end{array}$ & $q$ & $\begin{array}{c}\alpha \\
\left(\mathrm{yr}^{-1}\right)\end{array}$ & $q$ & $\begin{array}{c}\alpha \\
\left(\mathrm{yr}^{-1}\right)\end{array}$ & $q$ & $\begin{array}{c}\alpha \\
\left(\mathrm{yr}^{-1}\right)\end{array}$ & $q$ \\
\hline 0.1 & 0.00 & 0.000036 & 0.03 & 0.000037 & 0.05 & 0.000037 & 0.10 & 0.000037 & 0.30 & 0.000037 & 0.50 & 0.000037 & 1.00 & 0.000038 \\
\hline 0.2 & & 0.000036 & & 0.000037 & & 0.000037 & & 0.000037 & & 0.000037 & & 0.000038 & & 0.000040 \\
\hline 0.3 & & 0.000036 & & 0.000037 & & 0.000037 & & 0.000037 & & 0.000038 & & 0.000039 & & 0.000041 \\
\hline 0.4 & & 0.000036 & & 0.000037 & & 0.000037 & & 0.000037 & & 0.000039 & & 0.000040 & & 0.000043 \\
\hline 0.5 & & 0.000036 & & 0.000037 & & 0.000037 & & 0.000037 & & 0.000039 & & 0.000041 & & 0.000045 \\
\hline 0.6 & & 0.000036 & & 0.000037 & & 0.000037 & & 0.000038 & & 0.000040 & & 0.000042 & & 0.000047 \\
\hline 0.7 & & 0.000036 & & 0.000037 & & 0.000037 & & 0.000038 & & 0.000040 & & 0.000043 & & 0.000049 \\
\hline 0.8 & & 0.000036 & & 0.000037 & & 0.000037 & & 0.000038 & & 0.000041 & & 0.000044 & & 0.000051 \\
\hline 0.9 & & 0.000036 & & 0.000037 & & 0.000037 & & 0.000038 & & 0.000041 & & 0.000044 & & 0.000052 \\
\hline 1 & & 0.000036 & & 0.000037 & & 0.000037 & & 0.000038 & & 0.000042 & & 0.000045 & & 0.000054 \\
\hline 2 & & 0.000036 & & 0.000038 & & 0.000038 & & 0.000040 & & 0.000047 & & 0.000054 & & 0.000072 \\
\hline 3 & & 0.000036 & & 0.000038 & & 0.000039 & & 0.000042 & & 0.000053 & & 0.000064 & & 0.000091 \\
\hline 4 & & 0.000036 & & 0.000039 & & 0.000040 & & 0.000044 & & 0.000058 & & 0.000073 & & 0.000109 \\
\hline 5 & & 0.000036 & & 0.000039 & & 0.000041 & & 0.000046 & & 0.000064 & & 0.000082 & & 0.000127 \\
\hline 6 & & 0.000036 & & 0.000040 & & 0.000042 & & 0.000047 & & 0.000069 & & 0.000091 & & 0.000145 \\
\hline 7 & & 0.000036 & & 0.000040 & & 0.000043 & & 0.000049 & & 0.000075 & & 0.000100 & & 0.000164 \\
\hline 8 & & 0.000036 & & 0.000041 & & 0.000044 & & 0.000051 & & 0.000080 & & 0.000109 & & 0.000182 \\
\hline 9 & & 0.000036 & & 0.000041 & & 0.000045 & & 0.000053 & & 0.000086 & & 0.000118 & & 0.000200 \\
\hline 10 & & 0.000036 & & 0.000042 & & 0.000046 & & 0.000055 & & 0.000091 & & 0.000127 & & 0.000218 \\
\hline 20 & & 0.000036 & & 0.000047 & & 0.000055 & & 0.000073 & & 0.000146 & & 0.000219 & & 0.000401 \\
\hline 30 & & 0.000036 & & 0.000053 & & 0.000064 & & 0.000091 & & 0.000201 & & 0.000310 & & 0.000583 \\
\hline 40 & & 0.000036 & & 0.000058 & & 0.000073 & & 0.000109 & & 0.000255 & & 0.000401 & & 0.000766 \\
\hline 50 & & 0.000036 & & 0.000064 & & 0.000082 & & 0.000128 & & 0.000310 & & 0.000492 & & 0.000948 \\
\hline 60 & & 0.000036 & & 0.000069 & & 0.000091 & & 0.000146 & & 0.000365 & & 0.000584 & & 0.001130 \\
\hline 70 & & 0.000036 & & 0.000075 & & 0.000100 & & 0.000164 & & 0.000420 & & 0.000675 & & 0.001313 \\
\hline 80 & & 0.000036 & & 0.000080 & & 0.000109 & & 0.000182 & & 0.000474 & & 0.000766 & & 0.001495 \\
\hline 90 & & 0.000036 & & 0.000086 & & 0.000119 & & 0.000201 & & 0.000529 & & 0.000857 & & 0.001677 \\
\hline 100 & & 0.000036 & & 0.000091 & & 0.000128 & & 0.000219 & & 0.000584 & & 0.000948 & & 0.001859 \\
\hline
\end{tabular}


Table B-14. Check Valve Unavaiiability Versus IST Interval for Different Valve Aging Rates: Total Renewal, Baseline Failure Rate $\lambda_{0}=1 \times 10^{-7}$, Operational Test Interval $T=1 \mathrm{mo}$, Inservice Test Downtime $d=8 \mathrm{hr}$

\begin{tabular}{|c|c|c|c|c|c|c|c|c|c|c|c|c|c|c|}
\hline $\begin{array}{c}\mathrm{L} \\
(\mathrm{yrs})\end{array}$ & $\begin{array}{c}\alpha \\
\left(y r^{-1}\right)\end{array}$ & $q$ & $\begin{array}{c}\alpha \\
\left(y^{-1}\right)\end{array}$ & $q$ & $\begin{array}{c}\alpha \\
\left(\mathrm{yr}^{-1}\right)\end{array}$ & $q$ & $\begin{array}{c}\alpha \\
\left(\mathrm{yr}^{-1}\right)\end{array}$ & $q$ & $\begin{array}{c}\alpha \\
\left(\mathrm{yr}^{-1}\right)\end{array}$ & $q$ & $\begin{array}{c}\alpha \\
\left(\mathrm{yr}^{-1}\right)\end{array}$ & $\mathbf{q}$ & $\begin{array}{c}\alpha \\
\left(\mathrm{yr}^{-1}\right)\end{array}$ & $q$ \\
\hline 0.1 & 0.00 & 0.00909 & 0.03 & 0.00909 & 0.05 & 0.00909 & 0.10 & 0.00909 & 0.30 & 0.00909 & 0.50 & 0.00909 & 1.00 & 0.00909 \\
\hline 0.2 & & 0.00458 & & 0.00458 & & 0.00458 & & 0.00458 & & 0.00458 & & 0.00458 & & 0.00459 \\
\hline 0.3 & & 0.00307 & & 0.00307 & & 0.00307 & & 0.00307 & & 0.00307 & & 0.00307 & & 0.00308 \\
\hline 0.4 & & 0.00231 & & 0.00231 & & 0.00231 & & 0.00232 & & 0.00232 & & 0.00232 & & 0.00232 \\
\hline 0.5 & & 0.00186 & & 0.00186 & & 0.00186 & & 0.00186 & & 0.00186 & & 0.00186 & & 0.00187 \\
\hline 0.6 & & 0.00156 & & 0.00156 & & 0.00156 & & 0.00156 & & 0.00156 & & 0.00156 & & 0.00157 \\
\hline 0.7 & & 0.00134 & & 0.00134 & & 0.00134 & & 0.00134 & & 0.00134 & & 0.00135 & & 0.00135 \\
\hline 0.8 & & 0.00118 & & 0.00118 & & 0.00118 & & 0.00118 & & 0.00118 & & 0.00118 & & 0.00119 \\
\hline 0.9 & & 0.00105 & & 0.00105 & & 0.00105 & & 0.00105 & & 0.00105 & & 0.00106 & & 0.00107 \\
\hline 1 & & 0.00095 & & 0.00095 & & 0.00095 & & 0.00095 & & 0.00095 & & 0.00096 & & 0.00097 \\
\hline 2 & & 0.00049 & & 0.00049 & & 0.00049 & & 0.00050 & & 0.00050 & & 0.00051 & & 0.00053 \\
\hline 3 & & 0.00034 & & 0.00034 & & 0.00034 & & 0.00035 & & 0.00036 & & 0.00037 & & 0.00040 \\
\hline 4 & & 0.00026 & & 0.00027 & & 0.00027 & & 0.00027 & & 0.00029 & & 0.00030 & & 0.00034 \\
\hline 5 & & 0.00022 & & 0.00022 & & 0.00022 & & 0.00023 & & 0.00025 & & 0.00026 & & 0.00031 \\
\hline 6 & & 0.00019 & & 0.00019 & & 0.00019 & & 0.00020 & & 0.00022 & & 0.00024 & & 0.00030 \\
\hline 7 & & 0.00017 & & 0.00017 & & 0.00017 & & 0.00018 & & 0.00021 & & 0.00023 & & 0.00029 \\
\hline 8 & & 0.00015 & & 0.00016 & & 0.00016 & & 0.00017 & & 0.00019 & & 0.00022 & & 0.00030 \\
\hline 9 & & 0.00014 & & 0.00014 & & 0.00015 & & 0.00015 & & 0.00019 & & 0.00022 & & 0.00030 \\
\hline 10 & & 0.00013 & & 0.00013 & & 0.00014 & & 0.00015 & & 0.00018 & & 0.00022 & & 0.00031 \\
\hline 20 & & 0.00008 & & 0.00009 & & 0.00010 & & 0.00012 & & 0.00019 & & 0.00026 & & 0.00045 \\
\hline 30 & & 0.00007 & & 0.00008 & & 0.00009 & & 0.00012 & & 0.00023 & & 0.00034 & & 0.00061 \\
\hline 40 & & 0.00006 & & 0.00008 & & 0.00010 & & 0.00013 & & 0.00028 & & 0.00042 & & 0.00079 \\
\hline 50 & & 0.00005 & & 0.00008 & & 0.00010 & & 0.00015 & & 0.00033 & & 0.00051 & & 0.00097 \\
\hline 60 & & 0.00005 & & 0.00008 & & 0.00011 & & 0.00016 & & 0.00038 & & 0.00060 & & 0.00115 \\
\hline 70 & & 0.00005 & & 0.00009 & & 0.00011 & & 0.00018 & & 0.00043 & & 0.00069 & & 0.00133 \\
\hline 80 & & 0.00005 & & 0.00009 & & 0.00012 & & 0.00019 & & 0.00049 & & 0.00078 & & 0.00151 \\
\hline 90 & & 0.00005 & & 0.00010 & & 0.00013 & & 0.00021 & & 0.00054 & & 0.00087 & & 0.00169 \\
\hline 100 & & 0.00005 & & 0.00010 & & 0.00014 & & 0.00023 & & 0.00059 & & 0.00096 & & 0.00187 \\
\hline
\end{tabular}




\begin{tabular}{|c|c|}
\hline$\sigma$ & 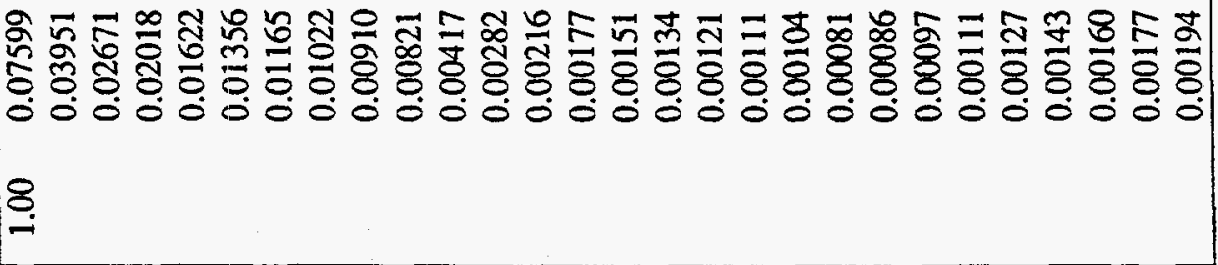 \\
\hline$\sigma$ & 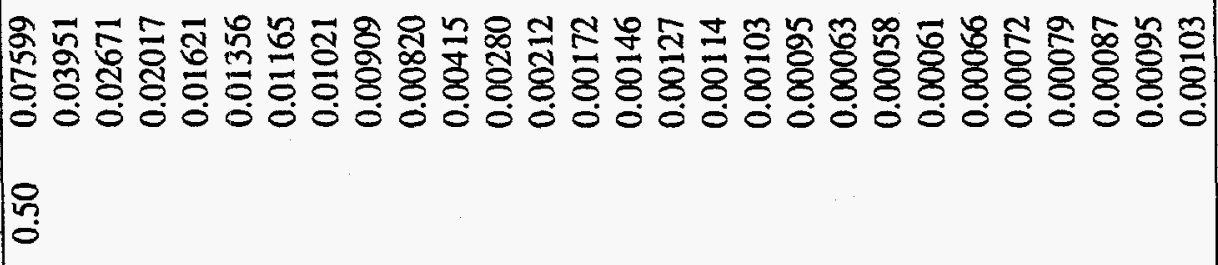 \\
\hline$\sigma$ & 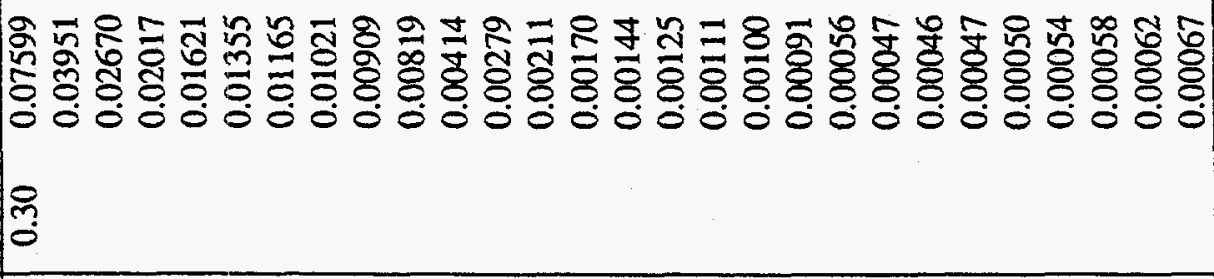 \\
\hline $0^{\circ}$ & 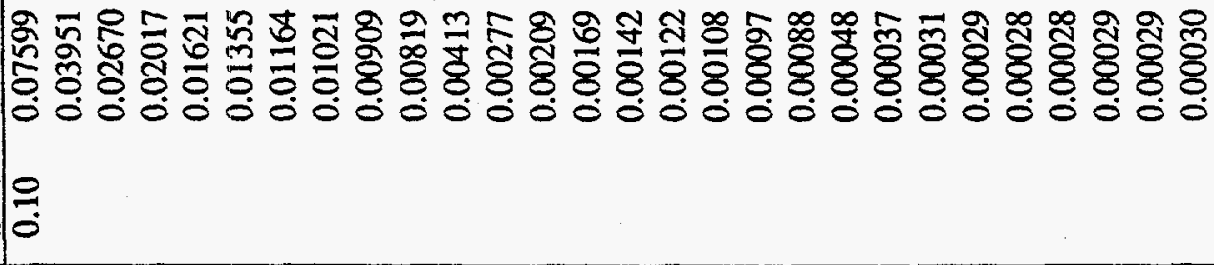 \\
\hline 8 & 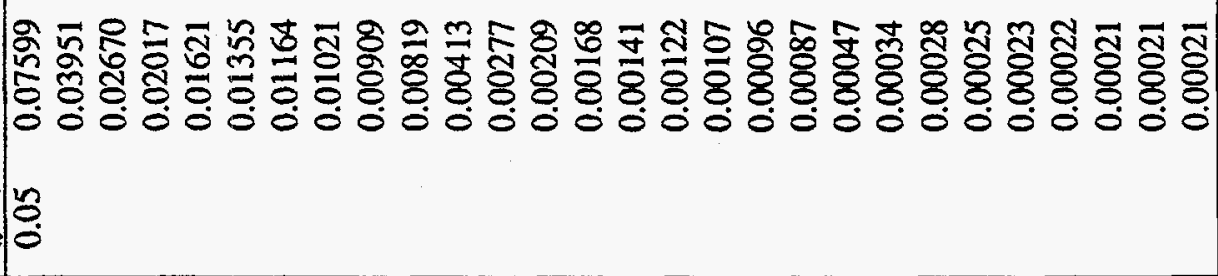 \\
\hline$\left(\begin{array}{cc}0 \\
0 \\
0\end{array}\right.$ & 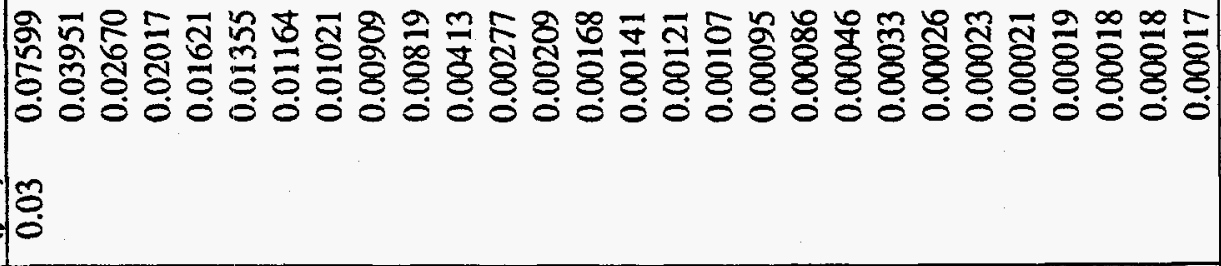 \\
\hline 8 & 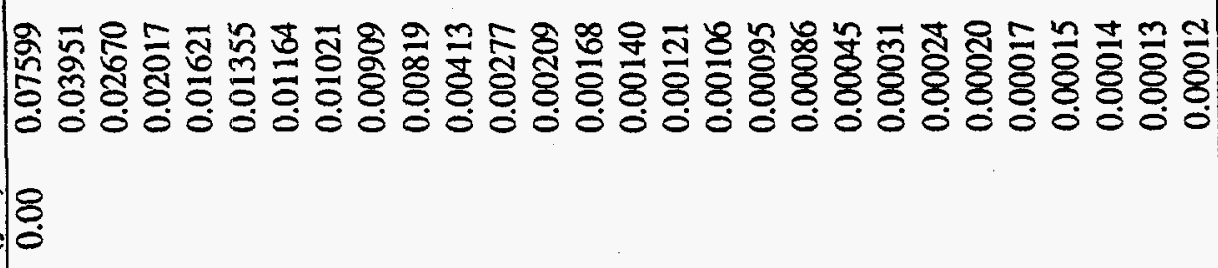 \\
\hline$\omega$ & 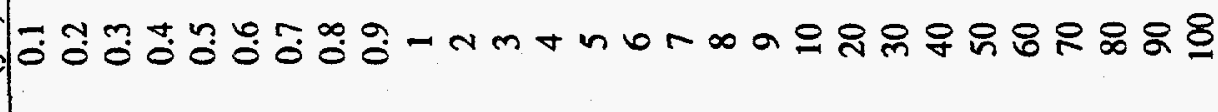 \\
\hline
\end{tabular}




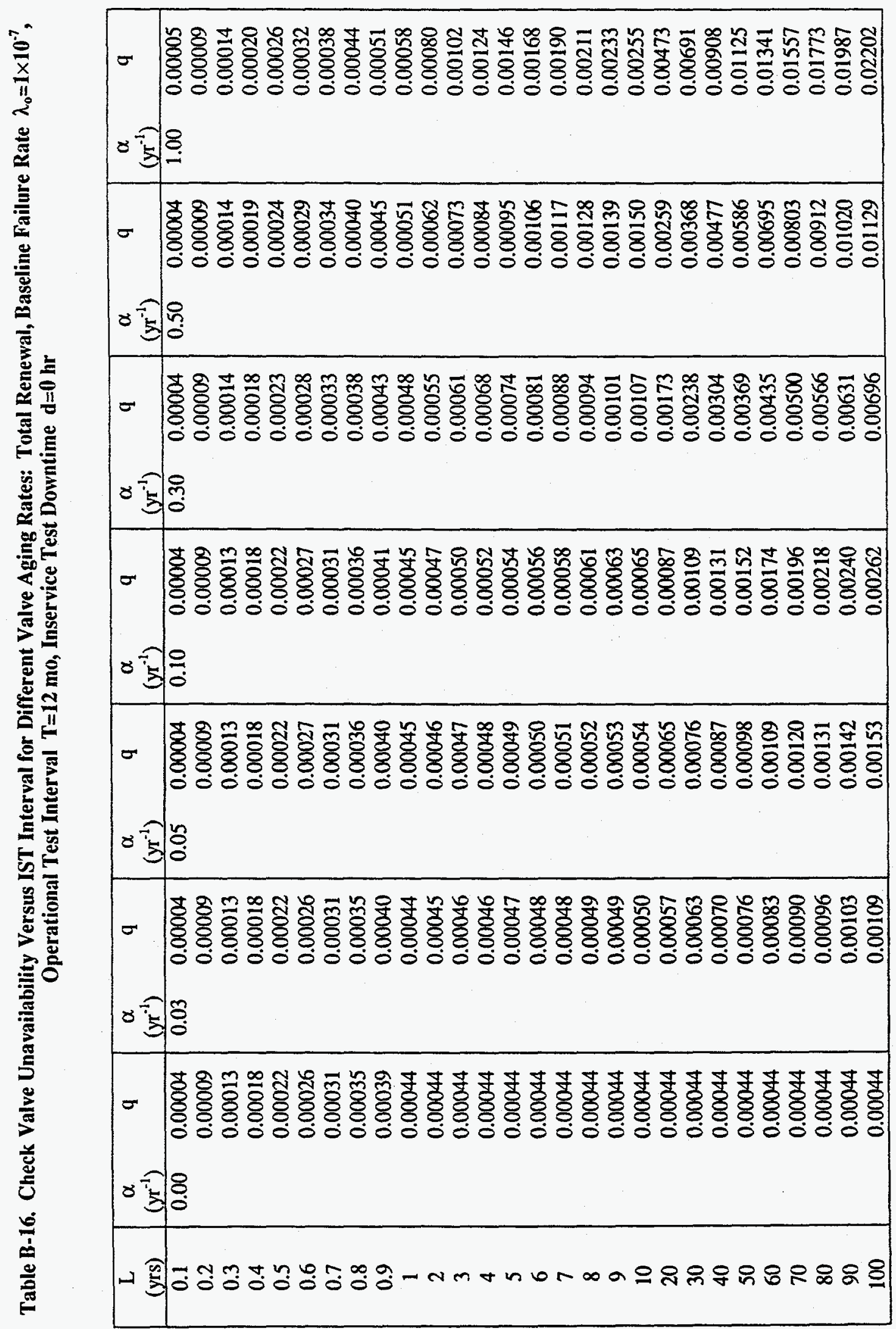


Table B-17. Check Valve Unavailability Versus IST Interval for Different Valve Aging Rates: Total Renewal, Baseline Failure Rate $\lambda_{0}=1 \times 10^{-7}$,

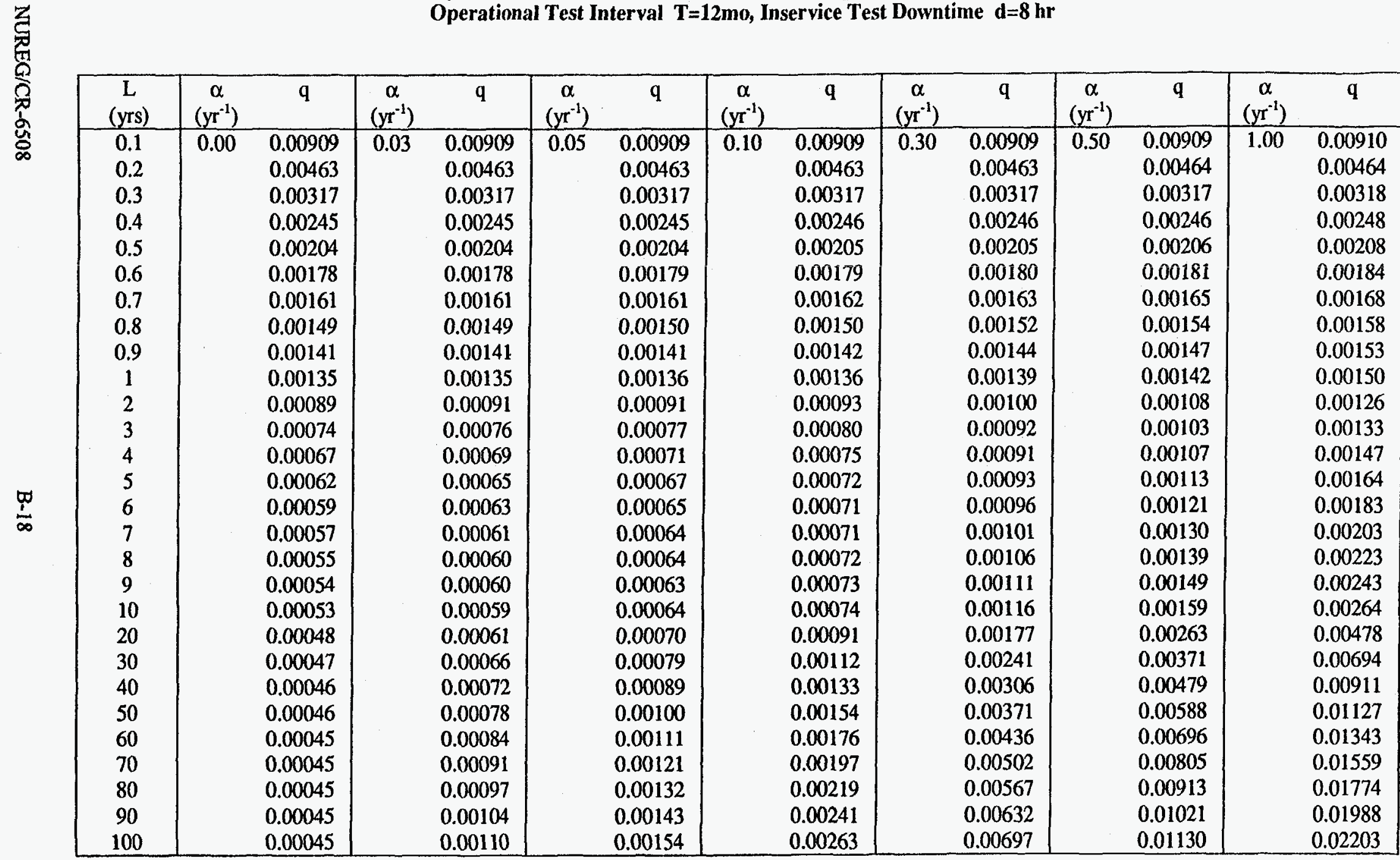


Table B-18. Check Valve Unavailability Versus IST Interval for Different Valve Aging Rates: Total Renewal, Baseline Failure Rate $\lambda_{0}=1 \times 10^{-7}$, Operational Test Interval $T=\mathbf{1 2} \mathbf{~ m o}$, Inservice Test Downtime $d=\mathbf{7 2} \mathrm{hr}$

\begin{tabular}{|c|c|c|c|c|c|c|c|c|c|c|c|c|c|c|}
\hline $\begin{array}{c}\mathrm{L} \\
(\mathrm{yrs})\end{array}$ & $\begin{array}{c}\alpha \\
\left(\mathrm{yr}^{-1}\right)\end{array}$ & $\mathbf{q}$ & $\begin{array}{c}\alpha \\
\left(y^{-1}\right)\end{array}$ & q & $\begin{array}{c}\alpha \\
\left(\mathrm{yr}^{-1}\right)\end{array}$ & $q$ & $\begin{array}{c}\alpha \\
\left(\mathrm{yr}^{-1}\right)\end{array}$ & $q$ & $\begin{array}{c}\alpha \\
\left(y^{-1}\right)\end{array}$ & $q$ & $\begin{array}{c}\alpha \\
\left(\mathrm{yr}^{-1}\right)\end{array}$ & $q$ & $\begin{array}{c}\alpha \\
\left(\mathrm{yr}^{-1}\right)\end{array}$ & $q$ \\
\hline 0.1 & 0.00 & 0.07599 & 0.03 & 0.07599 & 0.05 & 0.07599 & 0.10 & 0.07599 & 0.30 & 0.07599 & 0.50 & 0.07599 & 1.00 & 0.07599 \\
\hline 0.2 & & 0.03956 & & 0.03956 & & 0.03956 & & 0.03956 & & 0.03956 & & 0.03956 & & 0.03957 \\
\hline 0.3 & & 0.02680 & & 0.02680 & & 0.02680 & & 0.02680 & & 0.02680 & & 0.02680 & & 0.02681 \\
\hline 0.4 & & 0.02031 & & 0.02031 & & 0.02031 & & 0.02031 & & 0.02032 & & 0.02032 & & 0.02033 \\
\hline 0.5 & & 0.01639 & & 0.01639 & & 0.01639 & & 0.01640 & & 0.01640 & & 0.01641 & & 0.01643 \\
\hline 0.6 & & 0.01378 & & 0.01378 & & 0.01378 & & 0.01378 & & 0.01379 & & 0.01380 & & 0.01383 \\
\hline 0.7 & & 0.01191 & & 0.01191 & & 0.01192 & & 0.01192 & & 0.01193 & & 0.01195 & & 0.01198 \\
\hline 0.8 & & 0.01052 & & 0.01052 & & 0.01052 & & 0.01053 & & 0.01055 & & 0.01057 & & 0.01061 \\
\hline 0.9 & & 0.00944 & & 0.00945 & & 0.00945 & & 0.00946 & & 0.00948 & & 0.00950 & & 0.00956 \\
\hline 1 & & 0.00859 & & 0.00859 & & 0.00860 & & 0.00860 & & 0.00863 & & 0.00866 & & 0.00874 \\
\hline 2 & & 0.00453 & & 0.00454 & & 0.00455 & & 0.00457 & & 0.00464 & & 0.00471 & & 0.00490 \\
\hline 3 & & 0.00317 & & 0.00319 & & 0.00320 & & 0.00323 & & 0.00335 & & 0.00346 & & 0.00375 \\
\hline 4 & & 0.00249 & & 0.00251 & & 0.00253 & & 0.00257 & & 0.00273 & & 0.00289 & & 0.00329 \\
\hline 5 & & 0.00208 & & 0.00211 & & 0.00213 & & 0.00218 & & 0.00239 & & 0.00259 & & 0.00310 \\
\hline 6 & & 0.00181 & & 0.00184 & & 0.00187 & & 0.00193 & & 0.00218 & & 0.00243 & & 0.00305 \\
\hline 7 & & 0.00161 & & 0.00165 & & 0.00168 & & 0.00176 & & 0.00205 & & 0.00234 & & 0.00307 \\
\hline 8 & & 0,00146 & & 0.00151 & & 0.00155 & & 0.00163 & & 0.00197 & & 0.00230 & & 0.00314 \\
\hline 9 & & 0.00135 & & 0.00141 & & 0.00145 & & 0.00154 & & 0.00192 & & 0.00230 & & 0.00325 \\
\hline 10 & & 0.00126 & & 0.00132 & & 0.00136 & & 0.00147 & & 0.00189 & & 0.00232 & & 0.00337 \\
\hline 20 & & 0.00085 & & 0.00098 & & 0.00106 & & 0.00128 & & 0.00214 & & 0.00300 & & 0.00514 \\
\hline 30 & & 0.00071 & & 0.00091 & & 0.00104 & & 0.00136 & & 0.00266 & & 0.00395 & & 0.00718 \\
\hline 40 & & 0.00064 & & 0.00090 & & 0.00108 & & 0.00151 & & 0.00324 & & 0.00498 & & 0.00929 \\
\hline 50 & & 0.00060 & & 0.00093 & & 0.00115 & & 0.00169 & & 0.00386 & & 0.00602 & & 0.01142 \\
\hline 60 & & 0.00057 & & 0.00097 & & 0.00123 & & 0.00188 & & 0.00449 & & 0.00708 & & 0.01355 \\
\hline 70 & & 0.00056 & & 0.00101 & & 0.00132 & & 0.00208 & & 0.00512 & & 0.00815 & & 0.01569 \\
\hline 80 & & 0.00054 & & 0.00106 & & 0.00141 & & 0.00228 & & 0.00576 & & 0.00922 & & 0.01783 \\
\hline 90 & & 0.00053 & & 0.00112 & & 0.00151 & & 0.00249 & & 0.00640 & & 0.01030 & & 0.01997 \\
\hline 100 & & 0.00052 & & 0.00117 & & 0.00161 & & 0.00270 & & 0.00704 & & 0.01137 & & 0.02210 \\
\hline
\end{tabular}

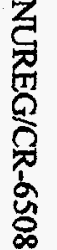


Table B-19. Check Valve Unavailability Versus IST Interval for Different Valve Aging Rates: Nonrenewal, No Intermediate Testing, Baseline Failure Rate $\lambda_{0}=1 \times 10^{-6}$, Inservice Test Downtime $\mathrm{d}=0 \mathrm{hr}$, Remaining Life $s=40 \mathrm{yr}$

\begin{tabular}{|c|c|c|c|c|c|c|c|c|}
\hline $\begin{array}{c}\mathbf{L} \\
\text { (yrs) }\end{array}$ & $\begin{array}{c}\alpha \\
\left(\mathrm{yr}^{-1}\right)\end{array}$ & $\mathbf{q}$ & $\begin{array}{c}\alpha \\
\left(\mathrm{yr}^{-1}\right) \\
\end{array}$ & $\mathbf{q}$ & $\begin{array}{c}\alpha \\
\left(\mathrm{yr}^{-1}\right)\end{array}$ & $\mathbf{q}$ & $\begin{array}{c}\alpha \\
\left(\mathrm{yr}^{-1}\right)\end{array}$ & $\mathbf{q}$ \\
\hline 0.1 & 0.00 & 0.000438 & 0.10 & 0.001315 & 0.50 & 0.004814 & 1.00 & 0.009170 \\
\hline 0.2 & & 0.000876 & & 0.002630 & & 0.009619 & & 0.018285 \\
\hline 0.3 & & 0.001313 & & 0.003947 & & 0.014415 & & 0.027345 \\
\hline 0.4 & & 0.001750 & & 0.005265 & & 0.019202 & & 0.036349 \\
\hline 0.5 & & 0.002188 & & 0.006585 & & 0.023980 & & 0.045297 \\
\hline 0.6 & & 0.002625 & & 0.007905 & & 0.028749 & & 0.054190 \\
\hline 0.7 & & 0.003061 & & 0.009227 & & 0.033509 & & 0.063028 \\
\hline 0.8 & & 0.003498 & & 0.010549 & & 0.038260 & & 0.071810 \\
\hline 0.9 & & 0.003934 & & 0.011873 & & 0.043001 & & 0.080536 \\
\hline 1 & & 0.004370 & & 0.013198 & & 0.047733 & & 0.089207 \\
\hline 2 & & 0.008722 & & 0.026506 & & 0.094511 & & 0.172875 \\
\hline 3 & & 0.013054 & & 0.039916 & & 0.140247 & & 0.251048 \\
\hline 4 & & 0.017367 & & 0.053416 & & 0.184864 & & 0.323809 \\
\hline 5 & & 0.021662 & & 0.067000 & & 0.228293 & & 0.391282 \\
\hline 6 & & 0.025938 & & 0.080657 & & 0.270474 & & 0.453620 \\
\hline 7 & & 0.030195 & & 0.094379 & & 0.311355 & & 0.511004 \\
\hline 8 & & 0.034433 & & 0.108156 & & 0.350894 & & 0.563637 \\
\hline 9 & & 0.038653 & & 0.121980 & & 0.389056 & & 0.611740 \\
\hline 10 & & 0.042855 & & 0.135842 & & 0.425813 & & 0.655548 \\
\hline 20 & & 0.083873 & & 0.274722 & & 0.715095 & & 0.911398 \\
\hline 30 & & 0.123133 & & 0.408799 & & 0.877837 & & 0.982981 \\
\hline 40 & & 0.160711 & & 0.531959 & & 0.954734 & & 0.997559 \\
\hline 50 & & 0.196678 & & 0.640126 & & 0.985506 & & 0.999738 \\
\hline 60 & & 0.231104 & & 0.731257 & & 0.995989 & & 0.999979 \\
\hline 70 & & 0.264055 & & 0.805087 & & 0.999041 & & 0.999999 \\
\hline 80 & & 0.295594 & & 0.862702 & & 0.999802 & & 1.000000 \\
\hline 90 & & 0.325781 & & 0.906069 & & 0.999965 & & 1.000000 \\
\hline 100 & & 0.354674 & & 0.937588 & & 0.999995 & & 1.000000 \\
\hline
\end{tabular}


Table B-20. Check Valve Unavailability Versus IST Interval for Different Valve Aging Rates: Nonrenewal, No Intermediate Testing, Baseline Failure Rate $\lambda_{0}=1 \times 10^{-6}$, Inservice Test Downtime $d=8 \mathrm{hr}$, Remaining Life $\mathrm{s}=40 \mathrm{yr}$

\begin{tabular}{|c|c|c|c|c|c|c|c|c|}
\hline$\underset{\text { (yrs) }}{\mathrm{L}}$ & $\begin{array}{c}\alpha \\
\left(\mathrm{yr}^{-1}\right)\end{array}$ & $q$ & $\begin{array}{c}\alpha \\
\left(\mathrm{yr}^{-1}\right)\end{array}$ & $\mathbf{q}$ & $\begin{array}{c}\alpha \\
\left(\mathrm{yr}^{-1}\right)\end{array}$ & $q$ & $\begin{array}{c}\alpha \\
\left(\mathrm{yr}^{-1}\right) \\
\end{array}$ & $\mathbf{q}$ \\
\hline 0.1 & 0.00 & 0.009488 & 0.10 & 0.010364 & 0.50 & 0.013863 & 1.00 & 0.018220 \\
\hline 0.2 & & 0.005421 & & 0.007176 & & 0.014164 & & 0.022831 \\
\hline 0.3 & & 0.004348 & & 0.006982 & & 0.017450 & & 0.030379 \\
\hline 0.4 & & 0.004028 & & 0.007543 & & 0.021480 & & 0.038626 \\
\hline 0.5 & & 0.004011 & & 0.008408 & & 0.025803 & & 0.047120 \\
\hline 0.6 & & 0.004144 & & 0.009425 & & 0.030269 & & 0.055710 \\
\hline 0.7 & & 0.004364 & & 0.010530 & & 0.034812 & & 0.064330 \\
\hline 0.8 & & 0.004638 & & 0.011690 & & 0.039400 & & 0.072950 \\
\hline 0.9 & & 0.004948 & & 0.012887 & & 0.044015 & & 0.081550 \\
\hline 1 & & 0.005283 & & 0.014111 & & 0.048646 & & 0.090120 \\
\hline 2 & & 0.009178 & & 0.026963 & & 0.094967 & & 0.173332 \\
\hline 3 & & 0.013358 & & 0.040220 & & 0.140551 & & 0.251352 \\
\hline 4 & & 0.017596 & & 0.053645 & & 0.185092 & & 0.324037 \\
\hline 5 & & 0.021845 & & 0.067183 & & 0.228475 & & 0.391465 \\
\hline 6 & & 0.026090 & & 0.080809 & & 0.270626 & & 0.453772 \\
\hline 7 & & 0.030325 & & 0.094509 & & 0.311486 & & 0.511134 \\
\hline 8 & & 0.034547 & & 0.108270 & & 0.351009 & & 0.563751 \\
\hline 9 & & 0.038755 & & 0.122082 & & 0.389157 & & 0.611841 \\
\hline 10 & & 0.042946 & & 0.135934 & & 0.425904 & & 0.655639 \\
\hline 20 & & 0.083918 & & 0.274767 & & 0.715141 & & 0.911444 \\
\hline 30 & & 0.123163 & & 0.408830 & & 0.877868 & & 0.983011 \\
\hline 40 & & 0.160734 & & 0.531982 & & 0.954757 & & 0.997581 \\
\hline 50 & & 0.196697 & & 0.640144 & & 0.985524 & & 0.999757 \\
\hline 60 & & 0.231120 & & 0.731272 & & 0.996005 & & 0.999994 \\
\hline 70 & & 0.264068 & & 0.805100 & & 0.999054 & & 1.000012 \\
\hline 80 & & 0.295605 & & 0.862713 & & 0.999813 & & 1.000011 \\
\hline 90 & & 0.325791 & & 0.906080 & & 0.999975 & & 1.000010 \\
\hline 100 & & 0.354683 & & 0.937597 & & 1.000004 & & 1.000009 \\
\hline
\end{tabular}


Table B-21. Check Valve Unavailability Versus IST Interval for Different Valve Aging Rates: Nonrenewal, No Intermediate Testing, Baseline Failure Rate $\lambda_{0}=1 \times 10^{-6}$, Inservice Test Downtime $d=72 \mathrm{hr}$, Remaining Life $s=40 \mathrm{yr}$

\begin{tabular}{|c|c|c|c|c|c|c|c|c|}
\hline $\begin{array}{c}\mathrm{L} \\
\text { (yrs) }\end{array}$ & $\begin{array}{c}\alpha \\
\left(\mathrm{yr}^{-1}\right)\end{array}$ & $\mathbf{q}$ & $\underset{\left(y r^{-1}\right)}{\alpha}$ & $q$ & $\begin{array}{c}\alpha \\
\left(\mathrm{yr}^{-1}\right)\end{array}$ & $\mathbf{q}$ & $\begin{array}{c}\alpha \\
\left(\mathrm{yr}^{-1}\right)\end{array}$ & $q$ \\
\hline 0.1 & 0.00 & 0.076387 & 0.10 & 0.077264 & 0.50 & 0.080763 & 1.00 & 0.085120 \\
\hline 0.2 & & 0.040349 & & 0.042104 & & 0.049092 & & 0.057759 \\
\hline 0.3 & & 0.027980 & & 0.030614 & & 0.041081 & & 0.054011 \\
\hline 0.4 & & 0.021885 & & 0.025400 & & 0.039336 & & 0.056483 \\
\hline 0.5 & & 0.018360 & & 0.022757 & & 0.040153 & & 0.061470 \\
\hline 0.6 & & 0.016138 & & 0.021419 & & 0.042263 & & 0.067704 \\
\hline 0.7 & & 0.014667 & & 0.020832 & & 0.045115 & & 0.074633 \\
\hline 0.8 & & 0.013667 & & 0.020719 & & 0.048430 & & 0.081979 \\
\hline 0.9 & & 0.012984 & & 0.020923 & & 0.052051 & & 0.089586 \\
\hline 1 & & 0.012523 & & 0.021350 & & 0.055885 & & 0.097360 \\
\hline 2 & & 0.012815 & & 0.030599 & & 0.098604 & & 0.176968 \\
\hline 3 & & 0.015786 & & 0.042648 & & 0.142979 & & 0.253780 \\
\hline 4 & & 0.019418 & & 0.055467 & & 0.186914 & & 0.325860 \\
\hline 5 & & 0.023303 & & 0.068641 & & 0.229934 & & 0.392923 \\
\hline 6 & & 0.027306 & & 0.082025 & & 0.271842 & & 0.454988 \\
\hline 7 & & 0.031368 & & 0.095551 & & 0.312528 & & 0.51217 \\
\hline 8 & & 0.035460 & & 0.109182 & & 0.351921 & & 0.564663 \\
\hline 9 & & 0.039566 & & 0.122892 & & 0.389968 & & 0.612652 \\
\hline 10 & & 0.043676 & & 0.136664 & & 0.426634 & & 0.656365 \\
\hline 20 & & 0.084284 & & 0.275133 & & 0.715506 & & 0.911809 \\
\hline 30 & & 0.123407 & & 0.409073 & & 0.878111 & & 0.98325 \\
\hline 40 & & 0.160916 & & 0.532165 & & 0.954939 & & 0.997764 \\
\hline 50 & & 0.196843 & & 0.640290 & & 0.985670 & & 0.999903 \\
\hline 60 & & 0.231241 & & 0.731394 & & 0.996126 & & 1.000116 \\
\hline 70 & & 0.264172 & & 0.805204 & & 0.999158 & & 1.00011 \\
\hline 80 & & 0.295696 & & 0.862805 & & 0.999905 & & 1.000103 \\
\hline 90 & & 0.325872 & & 0.906161 & & 1.000056 & & 1.000091 \\
\hline 100 & & 0.354756 & & 0.937670 & & 1.000077 & & 1.000082 \\
\hline
\end{tabular}


Table B-22. Check Valve Unavailability Versus IST Interval for Different Valve Aging Rates: Nonrenewal, No Intermediate Testing, Baseline Failure Rate $\lambda_{0}=1 \times 10^{-7}$, Inservice Test Downtime $d=0 \mathrm{hr}$, Remaining Life $s=40 \mathrm{gr}$

\begin{tabular}{|c|c|c|c|c|c|c|c|c|}
\hline $\begin{array}{c}\mathrm{L} \\
(\mathrm{yrs})\end{array}$ & $\begin{array}{c}\alpha \\
\left(\mathrm{yr}^{-1}\right)\end{array}$ & q & $\underset{\left(\mathrm{yr}^{-1}\right)}{\alpha}$ & q & $\underset{\left(\mathrm{yr}^{-1}\right)}{\alpha}$ & $\mathbf{q}$ & $\begin{array}{c}\alpha \\
\left(\mathrm{yr}^{-1}\right)\end{array}$ & $q$ \\
\hline 0.1 & 0.00 & 0.000044 & 0.10 & 0.000132 & 0.50 & 0.000482 & 1.00 & 0.000921 \\
\hline 0.2 & & 0.000088 & & 0.000263 & & 0.000966 & & 0.001844 \\
\hline 0.3 & & 0.000131 & & 0.000395 & & 0.001451 & & 0.002769 \\
\hline 0.4 & & 0.000175 & & 0.000528 & & 0.001937 & & 0.003696 \\
\hline 0.5 & & 0.000219 & & 0.000660 & & 0.002424 & & 0.004625 \\
\hline 0.6 & & 0.000263 & & 0.000793 & & 0.002913 & & 0.005556 \\
\hline 0.7 & & 0.000307 & & 0.000927 & & 0.003403 & & 0.006489 \\
\hline 0.8 & & 0.000350 & & 0.001060 & & 0.003894 & & 0.007424 \\
\hline 0.9 & & 0.000394 & & 0.001194 & & 0.004386 & & 0.008361 \\
\hline 1 & & 0.000438 & & 0.001328 & & 0.004879 & & 0.009300 \\
\hline 2 & & 0.000876 & & 0.002683 & & 0.009879 & & 0.018801 \\
\hline 3 & & 0.001313 & & 0.004065 & & 0.014997 & & 0.028494 \\
\hline 4 & & 0.001750 & & 0.005475 & & 0.020233 & & 0.038372 \\
\hline 5 & & 0.002188 & & 0.006911 & & 0.025582 & & 0.04842 \\
\hline 6 & & 0.002625 & & 0.008374 & & 0.031044 & & 0.058654 \\
\hline 7 & & 0.003061 & & 0.009864 & & 0.036616 & & 0.069041 \\
\hline 8 & & 0.003498 & & 0.011381 & & 0.042295 & & 0.079583 \\
\hline 9 & & 0.003934 & & 0.012924 & & 0.048081 & & 0.090271 \\
\hline 10 & & 0.004370 & & 0.014494 & & 0.053969 & & 0.101097 \\
\hline 20 & & 0.008722 & & 0.031610 & & 0.117997 & & 0.215226 \\
\hline 30 & & 0.013054 & & 0.051203 & & 0.189610 & & 0.334582 \\
\hline 40 & & 0.017367 & & 0.073110 & & 0.266201 & & 0.452022 \\
\hline 50 & & 0.021662 & & 0.097151 & & 0.345183 & & 0.561721 \\
\hline 60 & & 0.025938 & & 0.123133 & & 0.424134 & & 0.659548 \\
\hline 70 & & 0.030195 & & 0.150850 & & 0.500906 & & 0.743149 \\
\hline 80 & & 0.034433 & & 0.180089 & & 0.573712 & & 0.811798 \\
\hline 90 & & 0.038653 & & 0.210630 & & 0.641175 & & 0.866068 \\
\hline 100 & & 0.042855 & & 0.242249 & & 0.702339 & & 0.90743 \\
\hline
\end{tabular}


Table B-23. Check Valve Unavailability Versus IST Interval for Different Valve Aging Rates: Nonrenewal, No Intermediate Testing, Baseline Failure Rate $\lambda_{0}=1 \times 10^{-7}$, Inservice Test Downtime $\mathrm{d}=\mathbf{8} \mathrm{hr}$, Remaining Life $\mathrm{s}=40 \mathrm{yr}$

\begin{tabular}{|c|c|c|c|c|c|c|c|c|}
\hline $\begin{array}{c}\mathrm{L} \\
\text { (yrs) }\end{array}$ & $\begin{array}{c}\alpha \\
\left(\mathrm{yr}^{-1}\right)\end{array}$ & $q$ & $\begin{array}{c}\alpha \\
\left(\mathrm{yr}^{-1}\right)\end{array}$ & $\mathbf{q}$ & $\begin{array}{c}\alpha \\
\left(y^{-1}\right) \\
\end{array}$ & $\mathbf{q}$ & $\begin{array}{c}\alpha \\
\left(y r^{-1}\right)\end{array}$ & $q$ \\
\hline 0.1 & 0.00 & 0.009094 & 0.10 & 0.009181 & 0.50 & 0.009532 & 1.00 & 0.009971 \\
\hline 0.2 & & 0.004633 & & 0.004809 & & 0.005512 & & 0.006389 \\
\hline 0.3 & & 0.003166 & & 0.003430 & & 0.004486 & & 0.005804 \\
\hline 0.4 & & 0.002453 & & 0.002806 & & 0.004215 & & 0.005974 \\
\hline 0.5 & & 0.002042 & & 0.002484 & & 0.004247 & & 0.006448 \\
\hline 0.6 & & 0.001783 & & 0.002313 & & 0.004433 & & 0.007076 \\
\hline 0.7 & & 0.001609 & & 0.002229 & & 0.004705 & & 0.007792 \\
\hline 0.8 & & 0.001491 & & 0.002200 & & 0.005034 & & 0.008564 \\
\hline 0.9 & & 0.001408 & & 0.002207 & & 0.005399 & & 0.009375 \\
\hline 1 & & 0.001350 & & 0.002240 & & 0.005791 & & 0.010213 \\
\hline 2 & & 0.001332 & & 0.003139 & & 0.010335 & & 0.019257 \\
\hline 3 & & 0.001617 & & 0.004369 & & 0.015302 & & 0.028798 \\
\hline 4 & & 0.001979 & & 0.005703 & & 0.020461 & & 0.038601 \\
\hline 5 & & 0.002370 & & 0.007094 & & 0.025765 & & 0.048611 \\
\hline 6 & & 0.002777 & & 0.008527 & & 0.031196 & & 0.058806 \\
\hline 7 & & 0.003192 & & 0.009995 & & 0.036746 & & 0.069171 \\
\hline 8 & & 0.003612 & & 0.011495 & & 0.042410 & & 0.079697 \\
\hline 9 & & 0.004036 & & 0.013026 & & 0.048182 & & 0.090372 \\
\hline 10 & & 0.004462 & & 0.014585 & & 0.054060 & & 0.101188 \\
\hline 20 & & 0.008767 & & 0.031655 & & 0.118043 & & 0.215272 \\
\hline 30 & & 0.013084 & & 0.051233 & & 0.189641 & & 0.334613 \\
\hline 40 & & 0.017390 & & 0.073132 & & 0.266224 & & 0.452045 \\
\hline 50 & & 0.021680 & & 0.097169 & & 0.345202 & & 0.561739 \\
\hline 60 & & 0.025953 & & 0.123148 & & 0.424149 & & 0.659563 \\
\hline 70 & & 0.030208 & & 0.150864 & & 0.500919 & & 0.743162 \\
\hline 80 & & 0.034445 & & 0.180101 & & 0.573723 & & 0.811810 \\
\hline 90 & & 0.038663 & & 0.210640 & & 0.641185 & & 0.866078 \\
\hline 100 & & 0.042864 & & 0.242258 & & 0.702348 & & 0.907440 \\
\hline
\end{tabular}


Table B-24. Check Valve Unavailability Versus IST Interval for Different Valve Aging Rates: Nonrenewal, No Intermediate Testing, Baseline Failure Rate $\lambda_{0}=1 \times 10^{-7}$, Inservice Test Downtime $d=72 \mathrm{hr}$, Remaining Life $s=40 \mathrm{yr}$

\begin{tabular}{|c|c|c|c|c|c|c|c|c|}
\hline $\begin{array}{c}\mathrm{L} \\
\text { (yrs) }\end{array}$ & $\begin{array}{c}\alpha \\
\left(\mathrm{yr}^{-1}\right)\end{array}$ & $\mathbf{q}$ & $\begin{array}{c}\alpha \\
\left(\mathrm{yr}^{-1}\right)\end{array}$ & $q$ & $\begin{array}{c}\alpha \\
\left(y^{-1}\right)\end{array}$ & $q$ & $\begin{array}{c}\alpha \\
\left(\mathrm{yr}^{-1}\right)\end{array}$ & $q$ \\
\hline 0.1 & 0.00 & 0.075993 & 0.10 & 0.076081 & 0.50 & 0.076432 & 1.00 & 0.076870 \\
\hline 0.2 & & 0.039561 & & 0.039737 & & 0.040440 & & 0.041317 \\
\hline 0.3 & & 0.026798 & & 0.027062 & & 0.028118 & & 0.029435 \\
\hline 0.4 & & 0.020309 & & 0.020662 & & 0.022071 & & 0.023830 \\
\hline 0.5 & & 0.016391 & & 0.016833 & & 0.018597 & & 0.020797 \\
\hline 0.6 & & 0.013776 & & 0.014307 & & 0.016426 & & 0.019069 \\
\hline 0.7 & & 0.011912 & & 0.012532 & & 0.015008 & & 0.018094 \\
\hline 0.8 & & 0.010520 & & 0.011229 & & 0.014063 & & 0.017594 \\
\hline 0.9 & & 0.009444 & & 0.010243 & & 0.013435 & & 0.017411 \\
\hline 1 & & 0.008590 & & 0.009480 & & 0.013031 & & 0.017453 \\
\hline 2 & & 0.004968 & & 0.006776 & & 0.013972 & & 0.022894 \\
\hline 3 & & 0.004045 & & 0.006797 & & 0.017730 & & 0.031226 \\
\hline 4 & & 0.003801 & & 0.007525 & & 0.022283 & & 0.040423 \\
\hline 5 & & 0.003829 & & 0.008552 & & 0.027223 & & 0.050069 \\
\hline 6 & & 0.003993 & & 0.009742 & & 0.032412 & & 0.060022 \\
\hline 7 & & 0.004234 & & 0.011037 & & 0.037789 & & 0.070214 \\
\hline 8 & & 0.004524 & & 0.012407 & & 0.043322 & & 0.080609 \\
\hline 9 & & 0.004847 & & 0.013837 & & 0.048993 & & 0.091183 \\
\hline 10 & & 0.005192 & & 0.015315 & & 0.054790 & & 0.101918 \\
\hline 20 & & 0.009133 & & 0.032020 & & 0.118408 & & 0.215637 \\
\hline 30 & & 0.013328 & & 0.051477 & & 0.189884 & & 0.334856 \\
\hline 40 & & 0.017573 & & 0.073315 & & 0.266406 & & 0.452227 \\
\hline 50 & & 0.021826 & & 0.097315 & & 0.345348 & & 0.561886 \\
\hline 60 & & 0.026075 & & 0.123270 & & 0.424271 & & 0.659685 \\
\hline 70 & & 0.030312 & & 0.150968 & & 0.501023 & & 0.743267 \\
\hline 80 & & 0.034536 & & 0.180192 & & 0.573815 & & 0.811901 \\
\hline 90 & & 0.038744 & & 0.210721 & & 0.641266 & & 0.866159 \\
\hline 100 & & 0.042937 & & 0.242331 & & 0.702421 & & 0.907513 \\
\hline
\end{tabular}




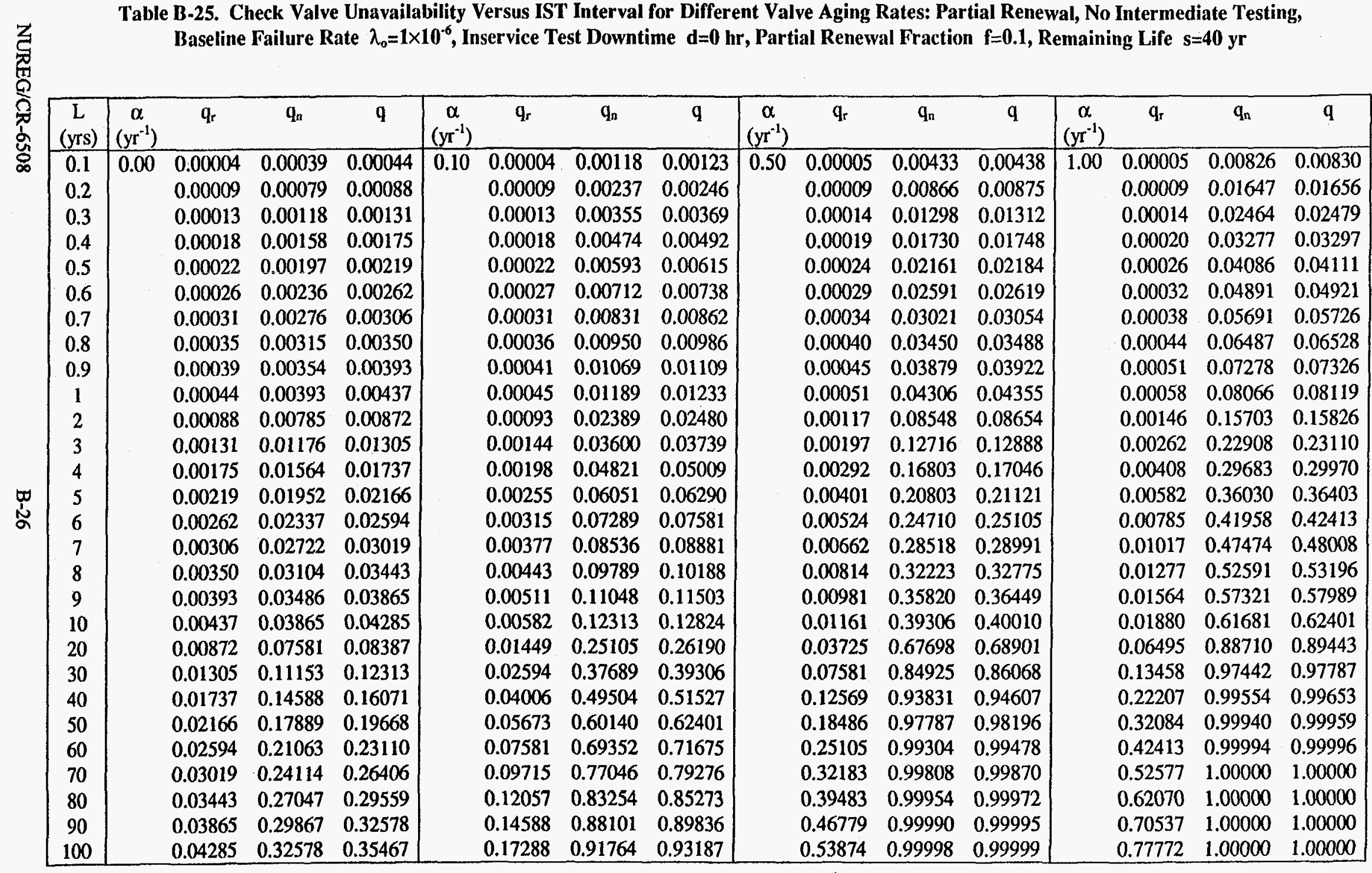


Table B-26. Check Valve Unavailability Versus IST Interval for Different Valve Aging Rates: Partial Renewal, No Intermediate Testing, Baseline Failure Rate $\lambda_{0}=1 \times 10^{-6}$, Inservice Test Downtime $d=8 \mathrm{hr}$, Partial Renewal Fraction $f=0.1$, Remaining Life $s=40 \mathrm{yr}$

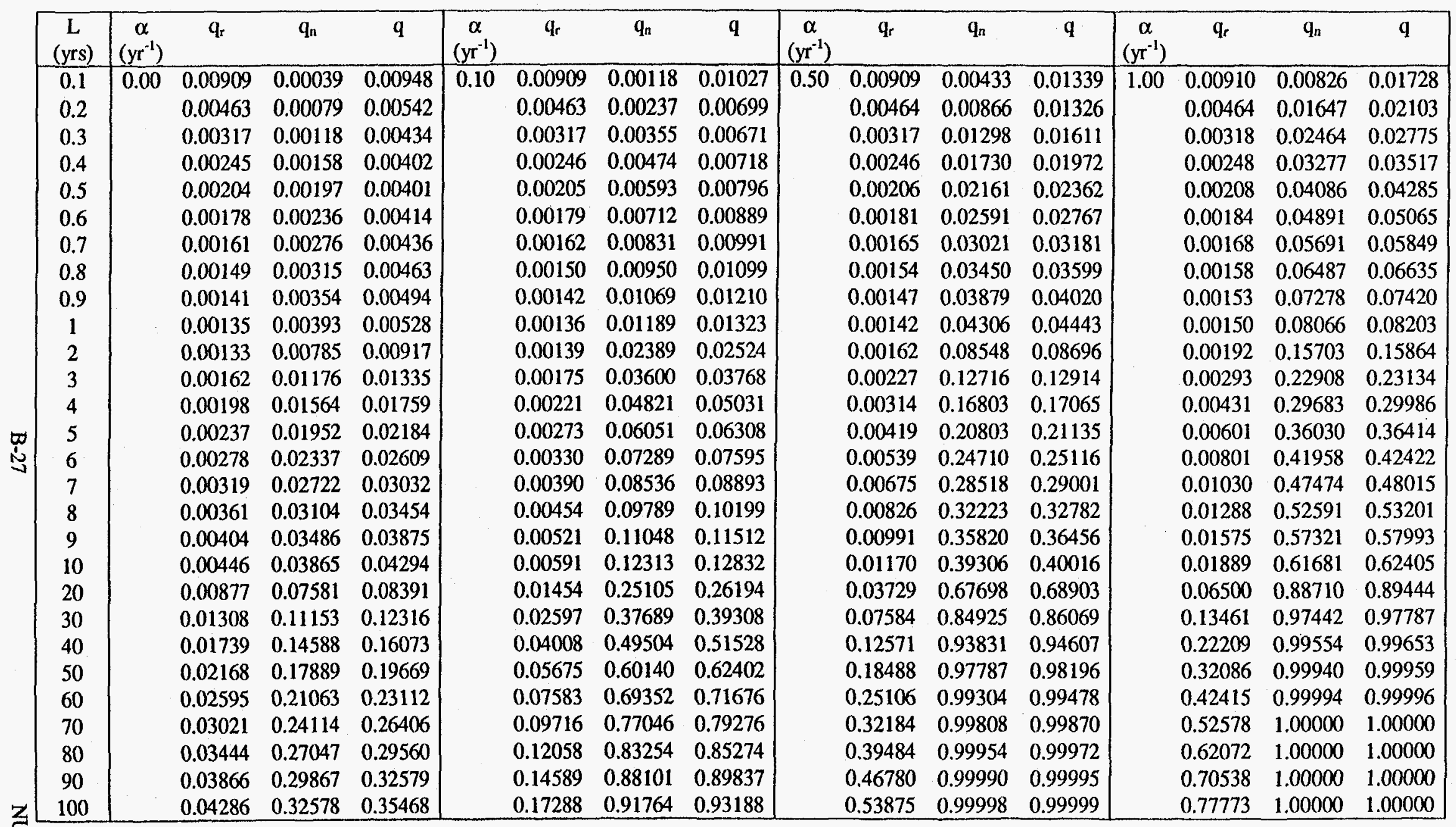




\begin{tabular}{|c|c|c|c|c|c|c|c|c|c|c|c|c|c|c|c|c|}
\hline $\begin{array}{c}\mathrm{L} \\
\text { (yrs) } \\
\end{array}$ & $\begin{array}{c}\alpha \\
\left(y r^{-1}\right) \\
\end{array}$ & $q_{r}$ & $q_{n}$ & $q$ & $\begin{array}{c}\alpha \\
\left(\mathrm{yr}^{-1}\right) \\
\end{array}$ & $q_{r}$ & $q_{n}$ & $q$ & $\left(\begin{array}{c}\alpha \\
\left(\mathrm{yr}^{-1}\right)\end{array}\right.$ & $q_{r}$ & $q_{n}$ & $q$ & {$\left[\begin{array}{c}\alpha \\
\left(\mathrm{yr}^{-1}\right)\end{array}\right.$} & $\mathbf{q}_{\mathbf{r}}$ & $\mathbf{q}_{\mathbf{n}}$ & q \\
\hline 0.1 & 0.00 & 0.07599 & 0.00039 & 0.07636 & 0.10 & 0.07599 & 0.00118 & 0.07709 & 0.50 & 0.07599 & 0.00433 & 0.08000 & 1.00 & 0.07599 & 0.00826 & 0.08362 \\
\hline 0.2 & & 0.03956 & 0.00079 & 0.04032 & & 0.03956 & 0.00237 & 0.04184 & & 0.03956 & 0.00866 & 0.04788 & & 0.03957 & 0.01647 & 0.05539 \\
\hline 0.3 & & 0.02680 & 0.00118 & 0.02795 & & 0.02680 & 0.00355 & 0.03026 & & 0.02680 & 0.01298 & 0.03944 & & 0.02681 & 0.02464 & 0.05079 \\
\hline 0.4 & & 0.02031 & 0.00158 & 0.02185 & & 0.02031 & 0.00474 & 0.02496 & & 0.02032 & 0.01730 & 0.03727 & & 0.02033 & 0.03277 & 0.05244 \\
\hline 0.5 & & 0.01639 & 0.00197 & 0.01833 & & 0.01640 & 0.00593 & 0.02223 & & 0.01641 & 0.02161 & 0.03766 & & 0.01643 & 0.04086 & 0.05662 \\
\hline 0.6 & & 0.01378 & 0.00236 & 0.01611 & & 0.01378 & 0.00712 & 0.02080 & & 0.01380 & 0.02591 & 0.03936 & & 0.01383 & 0.04891 & 0.06206 \\
\hline 0.7 & & 0.01191 & 0.00276 & 0.01463 & & 0.01192 & 0.00831 & 0.02013 & & 0.01195 & 0.03021 & 0.04180 & & 0.01198 & 0.05691 & 0.06821 \\
\hline 0.8 & & 0.01052 & 0.00315 & 0.01364 & & 0.01053 & 0.00950 & 0.01993 & & 0.01057 & 0.03450 & 0.04470 & & 0.01061 & 0.06487 & 0.07479 \\
\hline 0.9 & & 0.00944 & 0.00354 & 0.01295 & & 0.00946 & 0.01069 & 0.02005 & & 0.00950 & 0.03879 & 0.04792 & & 0.00956 & 0.07278 & 0.08165 \\
\hline 1 & & 0.00859 & 0.00393 & 0.01249 & & 0.00860 & 0.01189 & 0.02039 & & 0.00866 & 0.04306 & 0.05135 & & 0.00874 & 0.08066 & 0.08869 \\
\hline 2 & & 0.00497 & 0.00785 & 0.01278 & & 0.00503 & 0.02389 & 0.02879 & & 0.00526 & 0.08548 & 0.09029 & & 0.00555 & 0.15703 & 0.16171 \\
\hline 3 & & 0.00405 & 0.01176 & 0.01575 & & 0.00418 & 0.03600 & 0.04002 & & 0.00470 & 0.12716 & 0.13126 & & 0.00536 & 0.22908 & 0.23321 \\
\hline 4 & & 0.00380 & 0.01564 & 0.01939 & & 0.00403 & 0.04821 & 0.05205 & & 0.00497 & 0.16803 & 0.17216 & & 0.00613 & 0.29683 & 0.30114 \\
\hline 5 & & 0.00383 & 0.01952 & 0.02327 & & 0.00419 & 0.06051 & 0.06445 & & 0.00565 & 0.20803 & 0.21251 & & 0.00746 & 0.36030 & 0.36508 \\
\hline 6 & & 0.00399 & 0.02337 & 0.02727 & & 0.00452 & 0.07289 & 0.07708 & & 0.00661 & 0.24710 & 0.25208 & & 0.00922 & 0.41958 & 0.42493 \\
\hline 7 & & 0.00423 & 0.02722 & 0.03134 & & 0.00495 & 0.08536 & 0.08988 & & 0.00779 & 0.28518 & 0.29075 & & 0.01134 & 0.47474 & 0.48070 \\
\hline 8 & & 0.00452 & 0.03104 & 0.03543 & & 0.00545 & 0.09789 & 0.10281 & & 0.00917 & 0.32223 & 0.32844 & & 379 & 0.52591 & 0.53245 \\
\hline 9 & & 0.00485 & 0.03486 & 0.03953 & & 0.00602 & 0.11048 & 0.11584 & & 0.01072 & 0.35820 & 0.36508 & & 656 & 0.57321 & 0.58028 \\
\hline 10 & & 0.00519 & 0.03865 & 0.04364 & & 54 & 0.12313 & 0.12896 & & 0.01243 & 0.39306 & 0.40060 & & 0.0 & 681 & 0.62433 \\
\hline 20 & & 0.00913 & 0.07581 & 0.08425 & & 0.01490 & & 0.2 & & 0.03766 & 0.67698 & 0.68914 & & 0.0 & 0.88710 & 0.89448 \\
\hline 30 & & 0.01333 & 0.11153 & 0.12338 & & 0.02621 & 0.37689 & 0.39323 & & 0.07609 & 0.84925 & 0.86072 & & 0.13485 & 0.97442 & 0.97787 \\
\hline 40 & & 0.01757 & 0.14588 & 0.16089 & & 0.04026 & 0.49504 & 0.51537 & & 0.12590 & 0.93831 & 0.94608 & & 0.22228 & 0.99554 & 0.99654 \\
\hline 50 & & 0.02183 & 0.17889 & 0.19681 & & 0.05689 & 0.60140 & 0.62408 & & 0.18503 & 0.97787 & 0.98196 & & 0.32101 & 0.99940 & 0.99959 \\
\hline 60 & & 0.02607 & 0.21063 & 0.23121 & & 0.07595 & 0.69352 & 0.71680 & & 0.25118 & 0.99304 & 0.99478 & & 0.42427 & 0.99994 & 0.99996 \\
\hline 70 & & 0.03031 & 0.24114 & 0.26414 & & 0.09727 & 0.77046 & 0.79279 & & 0.32195 & 0.99808 & 0.99870 & & 0.52589 & 1.00000 & 1.00000 \\
\hline 80 & & 0.03454 & 0.27047 & 0.29567 & & 0.12067 & 0.83254 & 0.85275 & & 0.39493 & 0.99954 & 0.99972 & & 0.62081 & 1.00000 & 1.00000 \\
\hline 90 & & 0.03874 & 0.29867 & 0.32584 & & 0.14597 & 0.88101 & 0.89838 & & 0.46788 & 0.99990 & 0.99995 & & 0.70546 & 1.00000 & 1.00000 \\
\hline 100 & & 0.04294 & 0.32578 & 0.35473 & & 0.17296 & 0.91764 & 0.93188 & & 0.53883 & 0.99998 & 0.99999 & & 0.77780 & 1.00000 & 1.00000 \\
\hline
\end{tabular}


Table B-28. Check Valve Unavailability Versus IST Interval for Different Valve Aging Rates: Partial Renewal, No Intermediate Testing, Baseline Failure Rate $\lambda_{0}=1 \times 10^{-7}$, Inservice Test Downtime $d=0 \mathrm{hr}$, Partial Renewal Fraction $f=0.1$, Remaining Life $s=40 \mathrm{yr}$

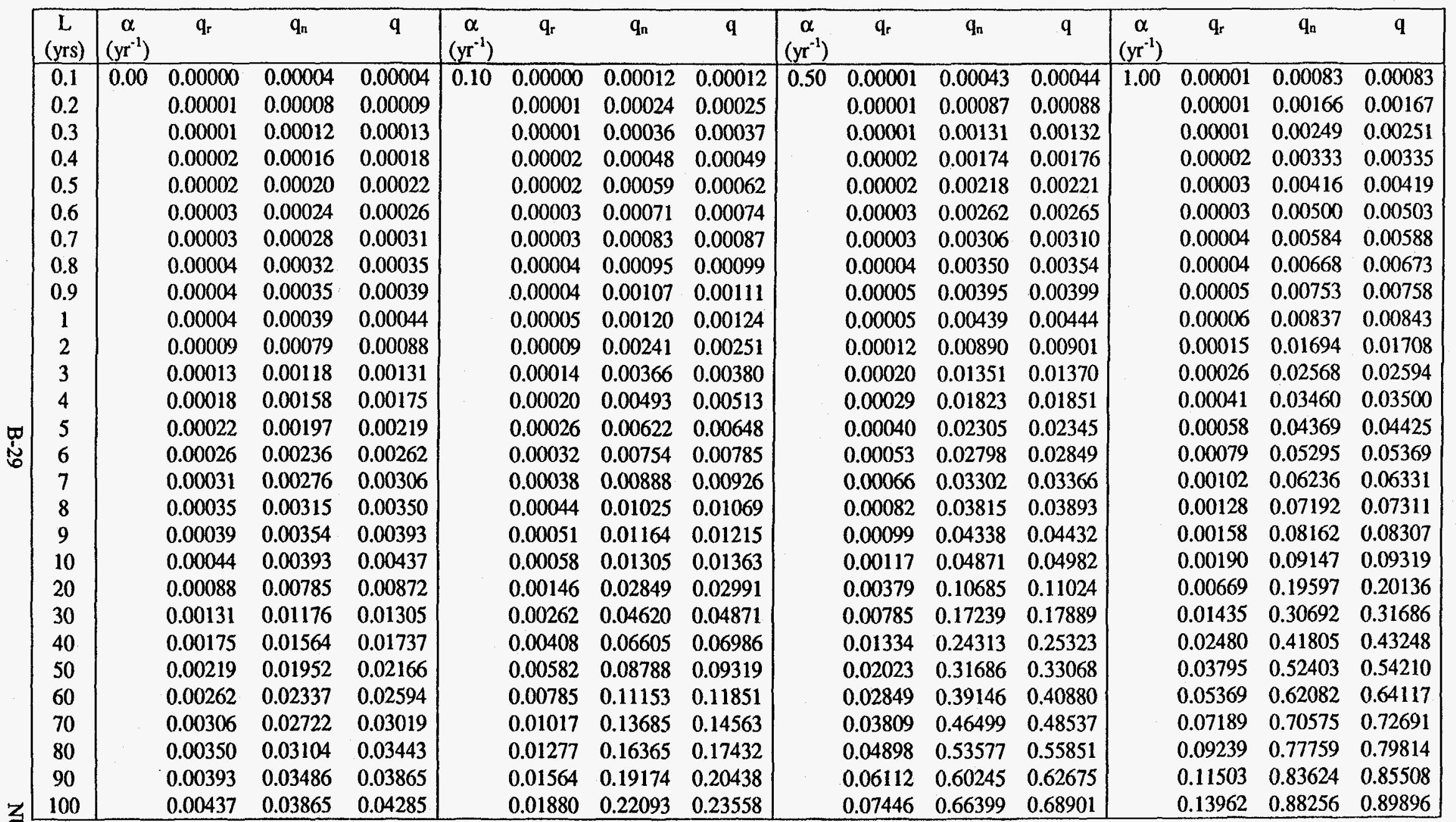


Table B-29. Check Valve Unavailability Versus IST Interval for Different Valve Aging Rates: Partial Renewal, No Intermediate Testing,

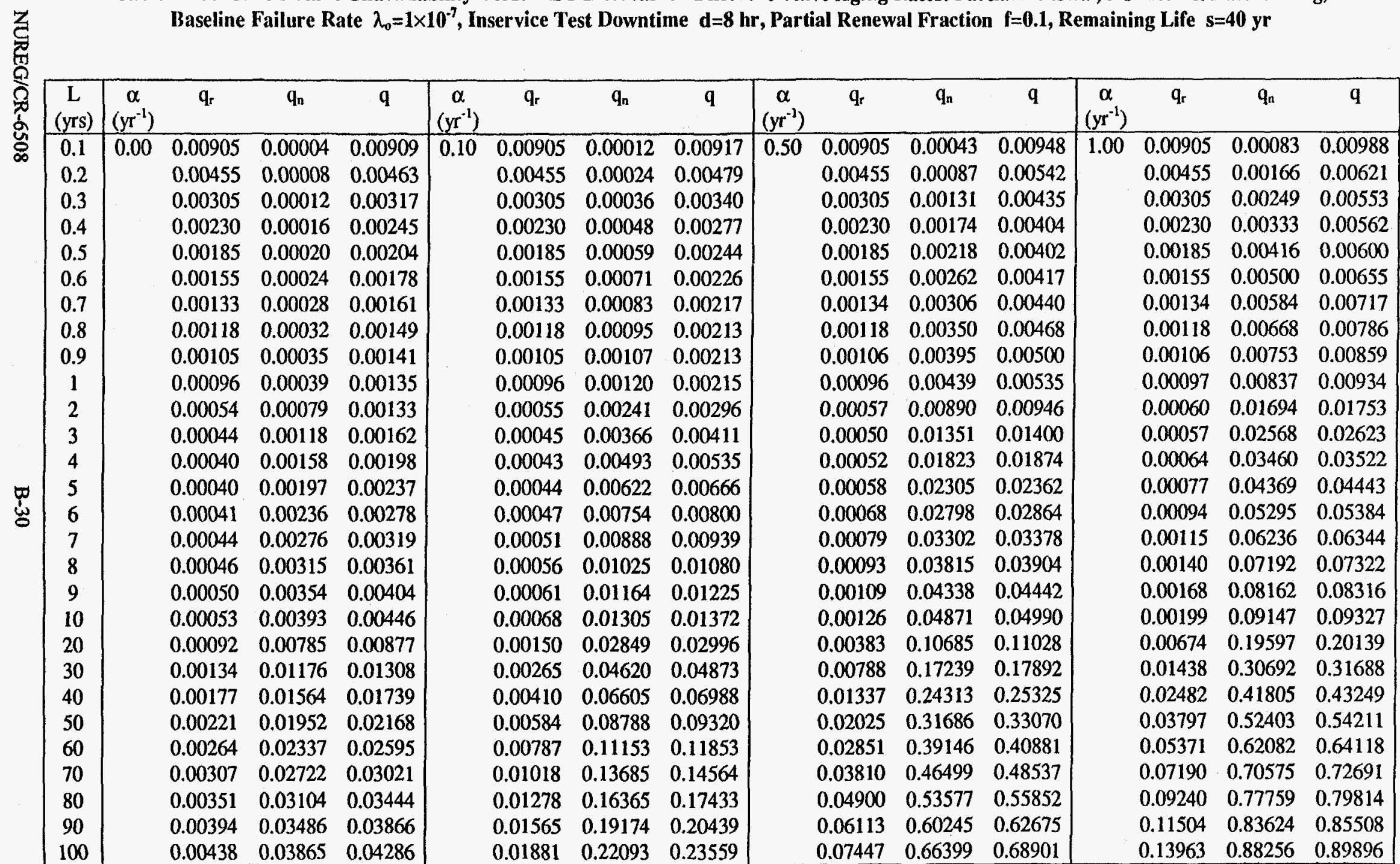


Table B-30. Check Valve Unavailability Versus IST Interval for Different Valve Aging Rates: Partial Renewal, No Intermediate Testing, Baseline Failure Rate $\lambda_{0}=1 \times 10^{-7}$, Inservice Test Downtime $d=72 \mathrm{hr}$, Partial Renewal Fraction $f=0.1$, Remaining Life $s=40 \mathrm{yr}$

\begin{tabular}{|c|c|c|c|c|c|c|c|c|c|c|c|c|c|c|c|c|}
\hline $\begin{array}{c}\mathrm{L} \\
(\mathrm{yrs})\end{array}$ & $\begin{array}{c}\alpha \\
\left(\mathrm{yr}^{-1}\right)\end{array}$ & $\mathbf{q}_{\mathbf{r}}$ & $\mathrm{q}_{\mathrm{n}}$ & $\mathbf{q}$ & $\begin{array}{c}\alpha \\
\left(\mathrm{yr}^{-1}\right)\end{array}$ & $q_{r}$ & $\mathbf{q}_{\mathbf{n}}$ & $\mathbf{q}$ & $\begin{array}{c}\alpha \\
\left(\mathrm{yr}^{-1}\right)\end{array}$ & $q_{r}$ & $q_{n}$ & $q$ & $\begin{array}{c}\alpha \\
\left(\mathrm{yr}^{-1}\right)\end{array}$ & $q_{r}$ & $\mathrm{q}_{\mathrm{n}}$ & $q$ \\
\hline 0.1 & 0.00 & 0.07595 & 0.00004 & 0.07599 & 0.10 & 0.07595 & 0.00012 & 0.07606 & 0.50 & 0.07595 & 0.00043 & 0.07636 & 1.00 & 0.07595 & 0.00083 & 0.07672 \\
\hline 0.2 & & 0.03948 & 0.00008 & 0.03956 & & 0.03948 & 0.00024 & 0.03971 & & 0.03948 & 0.00087 & 0.04032 & & 0.03948 & 0.00166 & 0.04108 \\
\hline 0.3 & & 0.02668 & 0.00012 & 0.02679 & & 0.02668 & 0.00036 & 0.02703 & & 0.02668 & 0.00131 & 0.02795 & & 0.02668 & 0.00249 & 0.02911 \\
\hline 0.4 & & 0.02015 & 0.00016 & 0.02031 & & 0.02015 & 0.00048 & 0.02062 & & 0.02015 & 0.0 & 0.02186 & & 1.02015 & 33 & 0.02341 \\
\hline 0.5 & & 0.01619 & 0.00020 & 0.01639 & & 0.01619 & 0.00059 & 0.01678 & & 0. & 0.0 & 0.01834 & & 20 & 16 & 0.02029 \\
\hline 0.6 & & 0.01354 & 0.00024 & 0.01377 & & 0.01354 & 0.00071 & 0.01424 & & & 262 & 0.01613 & & 55 & & 848 \\
\hline 0.7 & & 0.0 & 0.00028 & 0. & & 164 & 0. & 0.01246 & & 64 & 306 & 0.01467 & & 64 & 84 & 742 \\
\hline 0.8 & & $0 .($ & 0.0 & & & & & 15 & & 21 & 0.00350 & 0.01368 & & 21 & 0.0 & 83 \\
\hline 0.9 & & 0. & 0. & 0. & & & 0 & 1016 & & 0.0 & 0.0 & 0.01301 & & 10 & 0. & 656 \\
\hline 1 & & 0. & 0. & 0. & & & 0 & 0.00938 & & 0.0 & 0.0 & 0.01256 & & 21 & 37 & 652 \\
\hline 2 & & 0. & 0. & 0. & & & 1 & 0.00659 & & 0.0 & 0.0 & 0.01307 & & 0.00424 & 594 & 0.02110 \\
\hline 3 & & 86 & 0.0 & 0. & & 8 & 66 & 0.00653 & & 0.00293 & 0.01351 & 0.01640 & & 0.00300 & 0.02568 & 0.02860 \\
\hline 4 & & 23 & 0.0 & $0 .($ & & 5 & 493 & 0.00717 & & 0.00234 & 0.01823 & 0.02053 & & 0.00246 & 0.03460 & 0.03698 \\
\hline 5 & & 0.0 & 0.0 & 3 & & 0 & 622 & 0.00811 & & 0.00204 & 0.02305 & 0.02505 & & 0.00222 & 0.04369 & 0.04582 \\
\hline 6 & & 63 & 36 & 9 & & 88 & 754 & 0.00921 & & 0.00189 & 0.02798 & 0.02982 & & 0.00216 & 0.05295 & 0.05499 \\
\hline 7 & & 48 & 76 & 123 & & 55 & 0.00888 & 0.01042 & & 0.00184 & 0.03302 & 0.03479 & & 0.00219 & 0.06236 & 0.06441 \\
\hline 8 & & 38 & 0.00 & 52 & & 47 & 0.01025 & 0.01170 & & 0.00184 & 0.03815 & 0.03992 & & 0.00231 & 0.07192 & 0.07406 \\
\hline 9 & & 31 & 0.00 & 84 & & 42 & 164 & 0.01305 & & 0.00190 & 0.04338 & 0.04519 & & 0.00249 & 0.08162 & 0.08391 \\
\hline 10 & & 26 & 0.0 & 19 & & 41 & 305 & 0.01444 & & 0.00199 & 0.04871 & 0.05060 & & 0.00272 & 0.09147 & 0.09393 \\
\hline 20 & & 29 & 0.00785 & 0.00913 & & 87 & 0.02849 & 0.03031 & & 0.00420 & 0.10685 & 0.11060 & & 0.00710 & 0.19597 & 0.20169 \\
\hline 30 & & 159 & 0.01176 & 0.01332 & & 290 & 0.04620 & 0.04897 & & 0.00813 & 0.17239 & 0.17912 & & 0.01462 & 0.30692 & 0.31705 \\
\hline 40 & & 0.00196 & 0.01564 & 0.01757 & & 29 & 0.06605 & 0.07005 & & 0.01355 & 0.24313 & 0.25339 & & 0.02500 & 0.41805 & 0.43260 \\
\hline 50 & & 0235 & 0.01952 & 0.02182 & & & 0.08788 & 0.09334 & & 0.02040 & 0.31686 & 0.33080 & & 0.03812 & 0.52403 & 0.54218 \\
\hline 60 & & 0.00276 & 0.02337 & 0.02607 & & 0.00799 & 0.11153 & 0.11863 & & 0.02863 & 0.39146 & 0.40888 & & 0.05383 & 0.62082 & 0.64123 \\
\hline 70 & & & 0.02722 & 0.03031 & & 0.01029 & & 0.14573 & & 0.03821 & 0.46499 & 0.48543 & & 0.07201 & 0.70575 & 0.72694 \\
\hline 80 & & & & 0.03453 & & & & 0.17441 & & 0.04909 & 0.53577 & 0.55856 & & 0.09250 & 0.77759 & 0.79816 \\
\hline 90 & & & 0.03486 & 0.03874 & & & & 0.20446 & & 0.06122 & 0.60245 & 0.62678 & & 0.11512 & 0.83624 & 0.85510 \\
\hline 100 & & 0.00445 & 0.03865 & 0.04293 & & 0.01888 & 0.22093 & 0.23565 & & 0.07454 & 0.66399 & 0.68904 & & 0.13970 & 0.88256 & 0.89897 \\
\hline
\end{tabular}




\begin{tabular}{|c|c|c|c|c|c|c|c|c|c|c|c|c|c|c|c|c|}
\hline $\begin{array}{c}\mathrm{L} \\
(\mathrm{yrs})\end{array}$ & $\begin{array}{c}\alpha \\
\left(\mathrm{yr}^{-1}\right)\end{array}$ & $q_{r}$ & $q_{n}$ & q & $\begin{array}{c}\alpha \\
\left(\mathrm{yr}^{-1}\right) \\
\end{array}$ & $q_{s}$ & $q_{n}$ & $q$ & $\begin{array}{c}\alpha \\
\left(\mathrm{yr}^{-1}\right)\end{array}$ & $\mathrm{qr}_{\mathrm{r}}$ & $q_{n}$ & $q$ & $\begin{array}{c}\alpha \\
\left(\mathrm{yr}^{-1}\right) \\
\end{array}$ & $\mathrm{q}_{\mathrm{r}}$ & $q_{n}$ & $q$ \\
\hline 0.1 & 0.00 & 0.00022 & 0.00022 & 0.00044 & 0.10 & 0.00022 & 0.00066 & 0.00088 & 0.50 & 0.00022 & 0.00241 & 0.00263 & 1.00 & 0.00023 & 0.00460 & 0.00482 \\
\hline 0.2 & & 0.00044 & 0.00044 & 0.00088 & & 0.00044 & 0.00132 & 0.00176 & & 0.00045 & 0.00482 & 0.00527 & & 0.00047 & 0.00918 & 0.00965 \\
\hline 0.3 & & 0.00066 & 0.00066 & 0.00131 & & 0.00066 & 0.00198 & 0.00264 & & 0.00069 & 0.00723 & 0.00792 & & 0.00072 & 0.01377 & 0.01448 \\
\hline 0.4 & & 0.00088 & 0.00088 & 0.00175 & & 0.00089 & 0.00264 & 0.00352 & & 0.00093 & 0.00965 & 0.01057 & & 0.00099 & 0.01834 & 0.01932 \\
\hline 0.5 & & 0.00109 & 0.00109 & 0.00219 & & 0.00111 & 0.00330 & 0.00441 & & 0.00119 & 0.01206 & 0.01323 & & 0.00128 & 0.02291 & 0.02416 \\
\hline 0.6 & & 0.00131 & 0.00131 & 0.00262 & & 0.00134 & 0.00396 & 0.00529 & & 0.00144 & 0.01448 & 0.01590 & & 0.00158 & 0.02747 & 0.02900 \\
\hline 0.7 & & 0.00153 & 0.00153 & 0.00306 & & 0.00157 & 0.00462 & 0.00618 & & 0.00171 & 0.01690 & 0.01858 & & 0.00189 & 0.03203 & 0.03386 \\
\hline 0.8 & & 0.00175 & 0.00175 & 0.00350 & & 0.00180 & 0.00529 & 0.00708 & & 0.00198 & 0.01932 & 0.02126 & & 0.00222 & 0.03657 & 0.03871 \\
\hline 0.9 & & 0.00197 & 0.00197 & 0.00393 & & 0.00203 & 0.00595 & 0.00797 & & 0.00226 & 0.02174 & 0.02395 & & 0.00256 & 0.04111 & 0.04357 \\
\hline 1 & & 0.00219 & 0.00219 & 0.00437 & & 0.00226 & 0.00662 & 0.00887 & & 0.00255 & 0.02416 & 0.02665 & & 0.00292 & 0.04565 & 0.04843 \\
\hline 2 & & 0.00437 & 0.00437 & 0.00872 & & 0.00466 & 0.01334 & 0.01794 & & 0.00582 & 0.04843 & 0.05397 & & 0.00727 & 0.09054 & 0.09715 \\
\hline 3 & & 0.00655 & 0.00655 & 0.01305 & & 0.00720 & 0.02016 & 0.02722 & & 0.00981 & 0.07277 & 0.08186 & & 0.01305 & 0.13458 & 0.14588 \\
\hline 4 & & 0.00872 & 0.00872 & 0.01737 & & 0.00988 & 0.02707 & 0.03669 & & 0.01449 & 0.09715 & 0.11024 & & 0.02023 & 0.17769 & 0.19433 \\
\hline 5 & & 0.01089 & 0.01089 & 0.02166 & & 0.01269 & 0.03408 & 0.04634 & & 0.01987 & 0.12153 & 0.13899 & & 0.02878 & 0.21980 & 0.24225 \\
\hline 6 & & 0.01305 & 0.01305 & 0.02594 & & 0.01564 & 0.04118 & 0.05618 & & 0.02594 & 0.14588 & 0.16803 & & 0.03865 & 0.26082 & 0.28940 \\
\hline 7 & & 0.01521 & 0.01521 & 0.03019 & & 0.01873 & 0.04836 & 0.06618 & & 0.03267 & 0.17015 & 0.19726 & & 0.04982 & 0.30072 & 0.33555 \\
\hline 8 & & 0.01737 & 0.01737 & 0.03443 & & 0.02195 & 0.05563 & 0.07635 & & 0.04006 & 0.19433 & 0.22660 & & 0.06222 & 0.33942 & 0.38052 \\
\hline 9 & & 0.01952 & 0.01952 & 0.03865 & & 0.02530 & 0.06297 & 0.08668 & & 0.04808 & 0.21837 & 0.25595 & & 0.07581 & 0.37689 & 0.42413 \\
\hline 10 & & 0.02166 & 0.02166 & 0.04285 & & 0.02878 & 0.07040 & 0.09715 & & 0.05673 & 0.24225 & 0.28523 & & 0.09054 & 0.41310 & 0.46624 \\
\hline 20 & & 0.04285 & 0.04285 & 0.08387 & & 0.07040 & 0.14837 & 0.20832 & & 0.17288 & 0.46624 & 0.55851 & & 0.28523 & 0.70234 & 0.78724 \\
\hline 30 & & 0.06359 & 0.06359 & 0.12313 & & 0.12313 & 0.23110 & 0.32578 & & 0.32578 & 0.65048 & 0.76435 & & 0.51456 & 0.86954 & 0.93667 \\
\hline 40 & & 0.08387 & 0.08387 & 0.16071 & & 0.18486 & 0.31586 & 0.44234 & & 0.48911 & 0.78724 & 0.89130 & & 0.71510 & 0.95059 & 0.98592 \\
\hline 50 & & 0.10372 & 0.10372 & 0.19668 & & 0.25323 & 0.40010 & 0.55202 & & 0.64013 & 0.87961 & 0.95667 & & 0.85550 & 0.98383 & 0.99766 \\
\hline 60 & & 0.12313 & 0.12313 & 0.23110 & & 0.32578 & 0.48160 & 0.65048 & & 0.76435 & 0.93667 & 0.98508 & & 0.93667 & 0.99543 & 0.99971 \\
\hline 70 & & 0.14213 & 0.14213 & 0.26406 & & 0.40010 & 0.55851 & 0.73515 & & 0.85655 & 0.96903 & 0.99556 & & 0.97601 & 0.99888 & 0.99997 \\
\hline 80 & & 0.16071 & 0.16071 & 0.29559 & & 0.47397 & 0.62946 & 0.80509 & & 0.91883 & 0.98592 & 0.99886 & & 0.99215 & 0.99976 & 1.00000 \\
\hline 90 & & 0.17889 & 0.17889 & 0.32578 & & 0.54543 & 0.69352 & 0.86068 & & 0.95730 & 0.99405 & 0.99975 & & 0.99778 & 0.99996 & 1.00000 \\
\hline 100 & & 0.19668 & 0.19668 & 0.35467 & & 0.61287 & 0.75018 & 0.90329 & & 0.97912 & 0.99766 & 0.99995 & & 0.99946 & 0.99999 & 1.00000 \\
\hline
\end{tabular}


Table B-32. Check Valve Unavailability Versus IST Interval for Different Valve Aging Rates: Partial Renewal, No Intermediate Testing, Baseline Failure Rate $\lambda_{0}=1 \times 10^{-6}$, Inservice Test Downtime $d=8 \mathrm{hr}$, Partial Renewal Fraction $f=0.5$, Remaining Life $s=40 \mathrm{yr}$

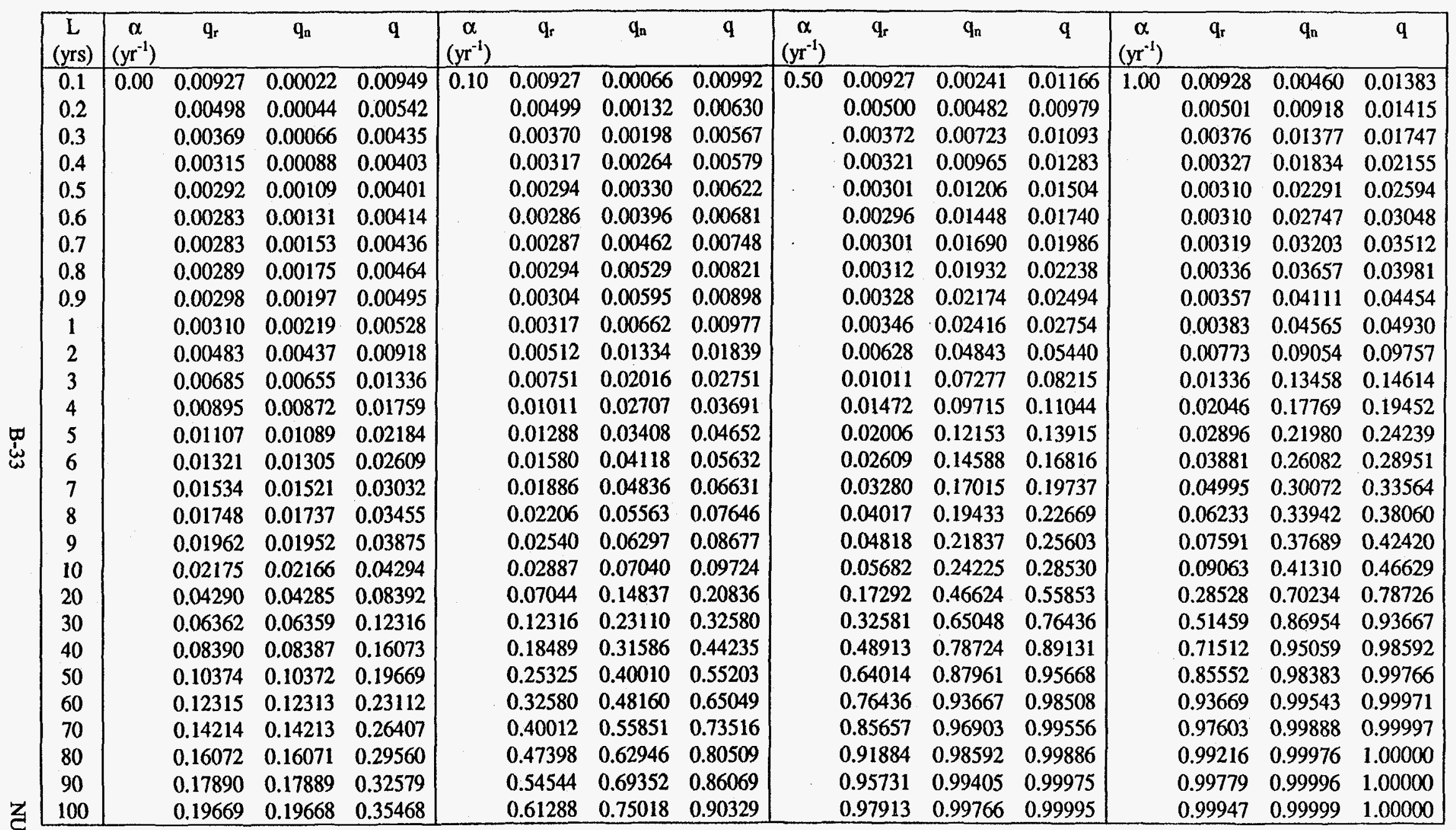

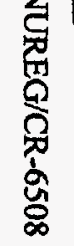




\begin{tabular}{|c|c|c|c|c|c|c|c|c|c|c|c|c|c|c|c|c|}
\hline $\begin{array}{c} \\
\text { (yrs) }\end{array}$ & $\begin{array}{c}\alpha \\
\left(\mathrm{yr}^{-1}\right)\end{array}$ & $\mathbf{q}_{\mathrm{r}}$ & $q_{n}$ & $q$ & {$\left[\begin{array}{c}\alpha \\
\left(y^{-1}\right)\end{array}\right.$} & $q_{r}$ & $q_{n}$ & $q$ & $\begin{array}{c}\alpha \\
\left(\mathrm{yr}^{-1}\right)\end{array}$ & $q_{r}$ & $q_{n}$ & $q$ & $\begin{array}{c}\alpha \\
\left(\mathrm{yr}^{-1}\right)\end{array}$ & $q_{r}$ & $q_{n}$ & $q$ \\
\hline 0.1 & 0.00 & 0.07617 & 0.00022 & 0.07637 & 0.10 & 0.07617 & 0.00066 & 0.07678 & 0.50 & 0.07617 & 0.00241 & 0.07840 & 1.00 & 0.07618 & 0.00460 & 0.08042 \\
\hline 0.2 & & 0.03991 & 0.00044 & 0.04033 & & 0.03991 & 0.00132 & 0.04118 & & 0.03993 & 0.00482 & 0.04455 & & 0.03994 & 0.00918 & 0.04876 \\
\hline 0.3 & & 0.02732 & 0.00066 & 0.02796 & & 0.02733 & 0.00198 & 0.02925 & & 0.02736 & 0.00723 & 0.03439 & & 0.02739 & 0.01377 & 0.04078 \\
\hline 0.4 & & 0.02101 & 0.00088 & 0.02187 & & 0.02102 & 0.00264 & 0.02360 & & 0.02107 & 0.00965 & 0.03051 & & 0.02113 & 0.01834 & 0.03908 \\
\hline 0.5 & & 0.01727 & 0.00109 & 0.01834 & & 0.01729 & 0.00330 & 0.02053 & & 0.01736 & 0.01206 & 0.02921 & & 0.01745 & 0.02291 & 0.03996 \\
\hline 0.6 & & 0.01483 & 0.00131 & 0.01612 & & 0.01485 & 0.00396 & 0.01875 & & 0.01496 & 0.01448 & 0.02922 & & 0.01509 & 0.02747 & 0.04215 \\
\hline 0.7 & & 0.01314 & 0.00153 & 0.01465 & & 0.01317 & 0.00462 & 0.01774 & & 0.01332 & 0.01690 & 0.02999 & & 0.01349 & 0.03203 & 0.04509 \\
\hline 0.8 & & 0.01192 & 0.00175 & 0.01365 & & 0.01197 & 0.00529 & 0.01719 & & 0.01215 & 0.01932 & 0.03123 & & 0.01239 & 0.03657 & 0.04851 \\
\hline 0.9 & & 0.01102 & 0.00197 & 0.01297 & & 0.01108 & 0.00595 & 0.01697 & & 0.01131 & 0.02174 & 0.03280 & & 0.01161 & 0.04111 & 0.05224 \\
\hline 1 & & 0.01034 & 0.00219 & 0.01250 & & 0.01041 & 0.00662 & 0.01696 & & 0.01070 & 0.02416 & 0.03460 & & 0.01107 & 0.04565 & 0.05621 \\
\hline 2 & & 0.00846 & 0.00437 & 0.01280 & & 0.00875 & 0.01334 & 0.02198 & & 0.00992 & 0.04843 & 0.05786 & & 0.01137 & 0.09054 & 0.10087 \\
\hline 3 & & 0.00928 & 0.00655 & 0.01577 & & 0.00993 & 0.02016 & 0.02989 & & 0.01254 & 0.07277 & 0.08440 & & 0.01579 & 0.13458 & 0.14824 \\
\hline 4 & & 0.01077 & 0.00872 & 0.01940 & & 0.01193 & 0.02707 & 0.03868 & & 0.01654 & 0.09715 & 0.11209 & & 0.02228 & 0.17769 & 0.19602 \\
\hline 5 & & 0.01253 & 0.01089 & 0.02329 & & 0.01433 & 0.03408 & 0.04793 & & 0.02152 & 0.12153 & 0.14043 & & 0.03042 & 0.21980 & 0.24353 \\
\hline 6 & & 0.01442 & 0.01305 & 0.02729 & & 0.01701 & 0.04118 & 0.05749 & & 0.02731 & 0.14588 & 0.16920 & & 0.04002 & 0.26082 & 0.29041 \\
\hline 7 & & 0.01639 & 0.01521 & 0.03135 & & 0.01990 & 0.04836 & 0.06730 & & 0.03384 & 0.17015 & 0.19824 & & 0.05099 & 0.30072 & 0.33637 \\
\hline 8 & & 0.01839 & 0.01737 & 0.03544 & & 0.02297 & 0.05563 & 0.07732 & & 0.04108 & 0.19433 & 0.22743 & & 0.06325 & 0.33942 & 0.38120 \\
\hline 9 & & 0.02043 & 0.01952 & 0.03955 & & 0.02621 & 0.06297 & 0.08753 & & 0.04899 & 0.21837 & 0.25667 & & 0.07672 & 0.37689 & 0.42470 \\
\hline 10 & & 0.02248 & 0.02166 & 0.04366 & & 0.02960 & 0.07040 & 0.09791 & & 0.05755 & 0.24225 & 0.28586 & & 0.09136 & 0.41310 & 0.46672 \\
\hline 20 & & 0.04327 & 0.04285 & 0.08427 & & 0.07081 & 0.14837 & 0.20867 & & 0.17329 & 0.46624 & 0.55873 & & 0.28564 & 0.70234 & 0.78736 \\
\hline 30 & & 0.06386 & 0.06359 & 0.12339 & & 0.12341 & 0.23110 & 0.32599 & & 0.32605 & 0.65048 & 0.76444 & & 0.51483 & 0.86954 & 0.93671 \\
\hline 40 & & 0.08408 & 0.08387 & 0.16090 & & 0.18507 & 0.31586 & 0.44248 & & 0.48931 & 0.78724 & 0.89135 & & 0.71530 & 0.95059 & 0.98593 \\
\hline 50 & & 0.10388 & 0.10372 & 0.19683 & & 0.25340 & 0.40010 & 0.55212 & & 0.64029 & 0.87961 & 0.95669 & & 0.85567 & 0.98383 & 0.99767 \\
\hline 60 & & 0.12327 & 0.12313 & 0.23122 & & 0.32592 & 0.48160 & 0.65055 & & 0.76449 & 0.93667 & 0.98508 & & 0.93681 & 0.99543 & 0.99971 \\
\hline 70 & & 0.14225 & 0.14213 & 0.26416 & & 0.40022 & 0.55851 & 0.73520 & & 0.85667 & 0.96903 & 0.99556 & & 0.97613 & 0.99888 & 0.99997 \\
\hline 80 & & 0.16081 & 0.16071 & 0.29568 & & 0.47407 & 0.62946 & 0.80512 & & 0.91893 & 0.98592 & 0.99886 & & 0.99225 & 0.99976 & 1.00000 \\
\hline 90 & & 0.17898 & 0.17889 & 0.32586 & & 0.54552 & 0.69352 & 0.86071 & & 0.95739 & 0.99405 & 0.99975 & & 0.99787 & 0.99996 & 1.00000 \\
\hline 100 & & 0.19676 & 0.19668 & 0.35474 & & 0.61295 & 0.75018 & 0.90331 & & 0.97920 & 0.99766 & 0.99995 & & 0.99954 & 0.99999 & 1.00000 \\
\hline
\end{tabular}


Table B-34. Check Valve Unavailability Versus IST Interval for Different Valve Aging Rates: Partial Renewal, No Intermediate Testing, Baseline Failure Rate $\lambda_{0}=1 \times 10^{-7}$, Inservice Test Downtime $d=0 \mathrm{hr}$, Partial Renewal Fraction $f=0.5$, Remaining Life $\mathrm{s}=40 \mathrm{yr}$

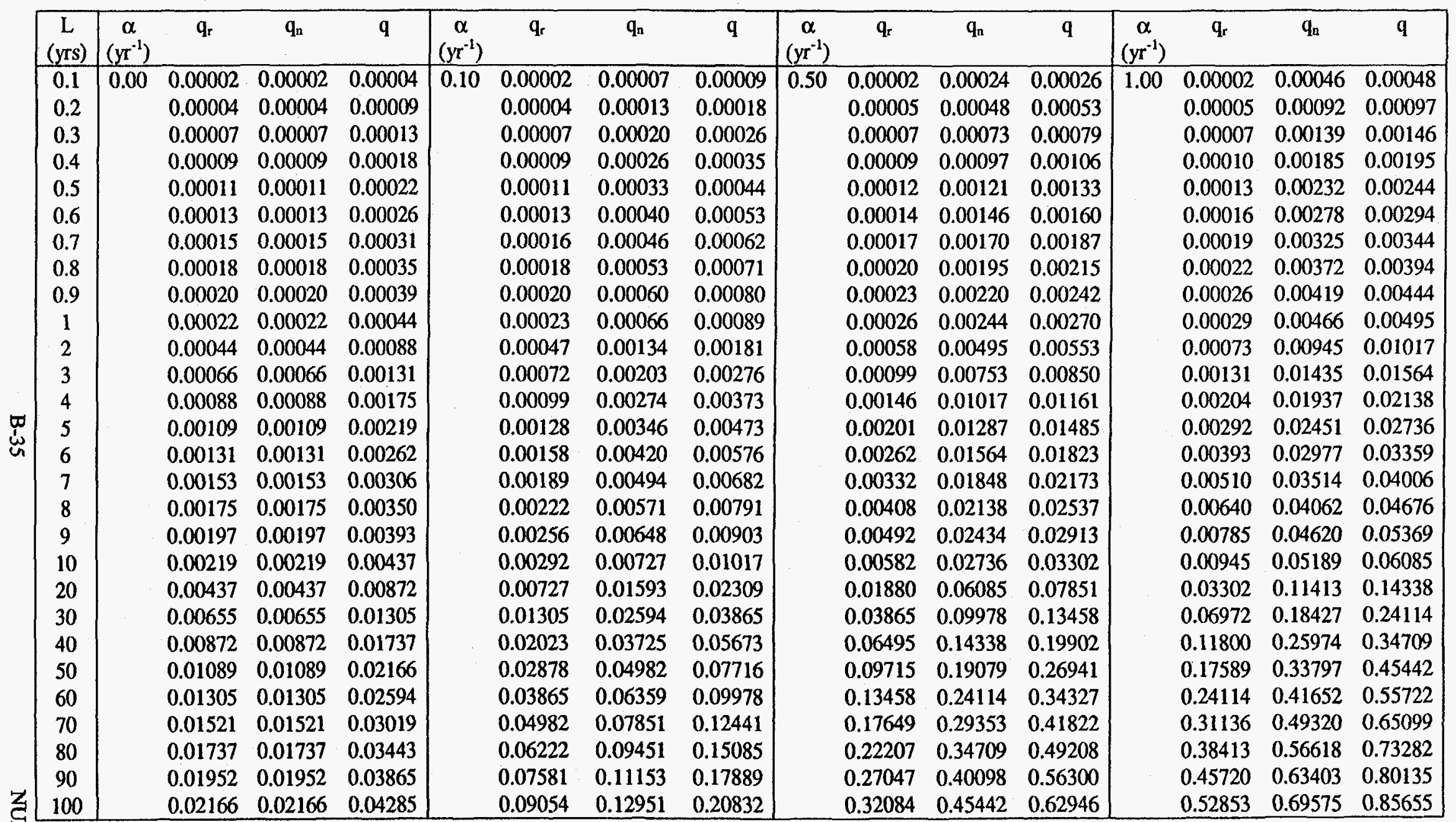

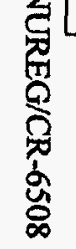




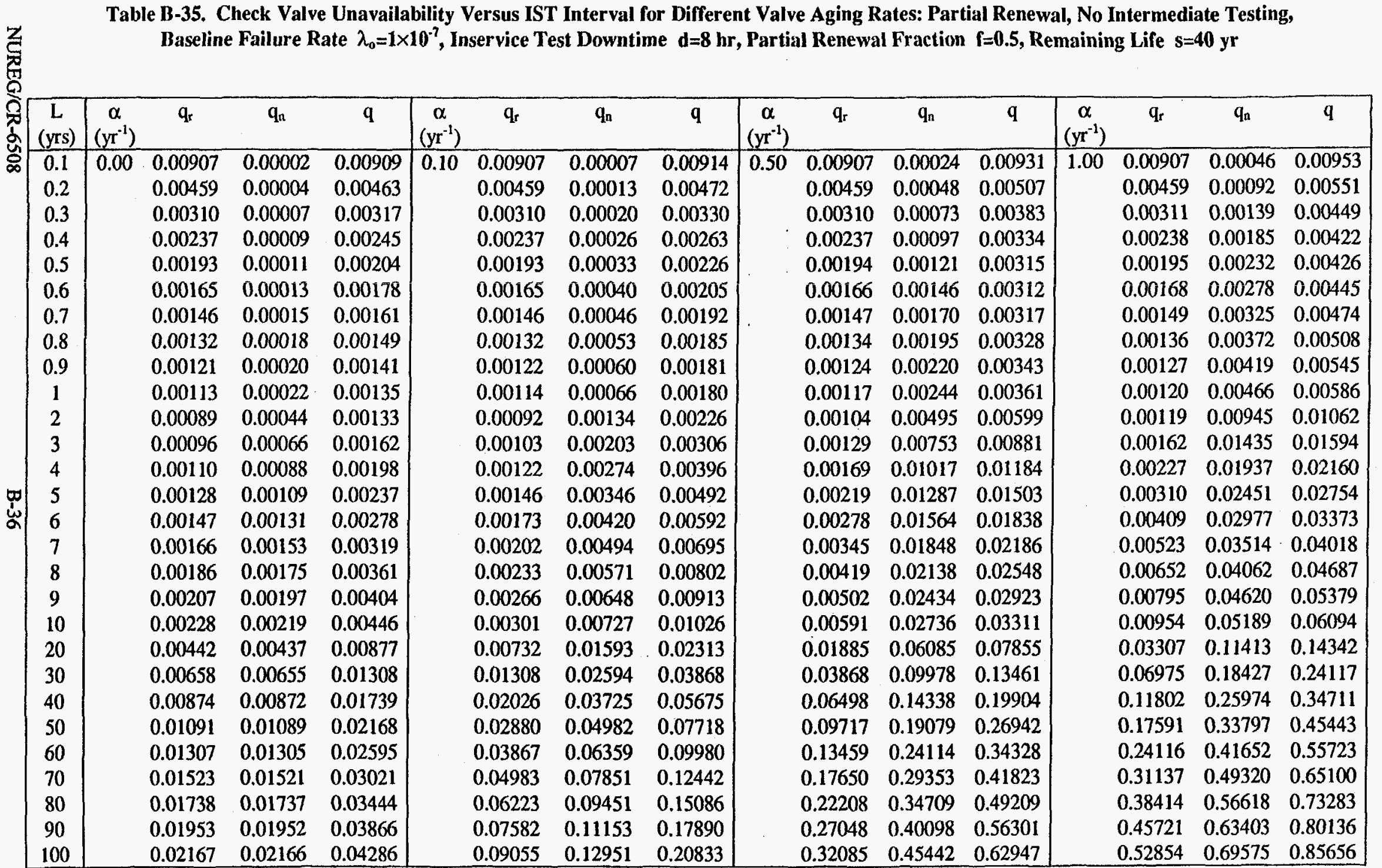


Table B-36. Check Valve Unavailability Versus IST Interval for Different Valve Aging Rates: Partial Renewal, No Intermediate Testing, Baseline Failure Rate $\lambda_{0}=1 \times 10^{-7}$, Inservice Test Downtime $d=72 \mathrm{hr}$, Partial Renewal Fraction $f=0.5$, Remaining Life $s=40 \mathrm{gr}$

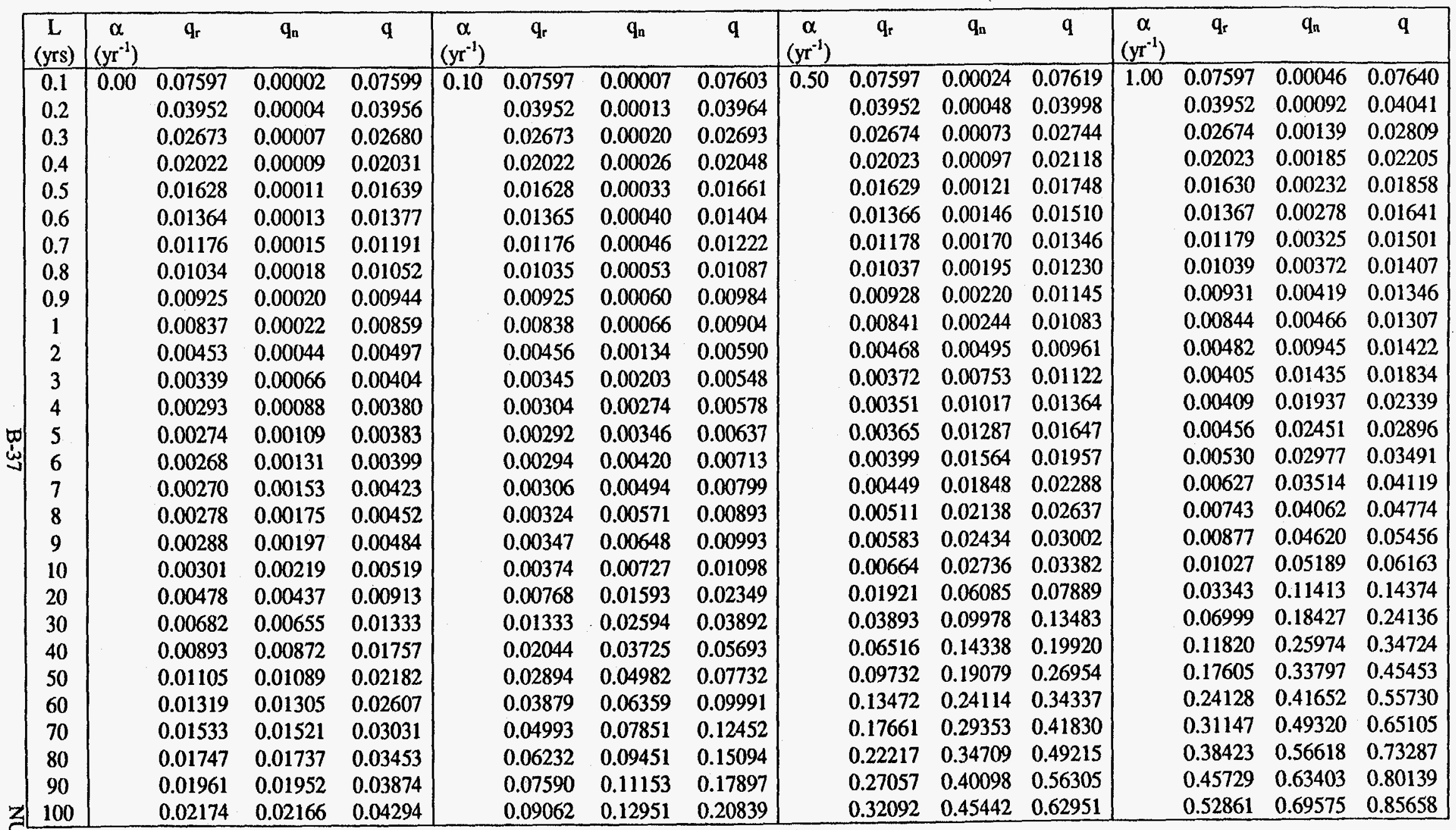



Appendix C. Evaluations of Component Unavailability

Versus IST Interval for Check Valves with

Nonlinear Aging: Associated Tables 


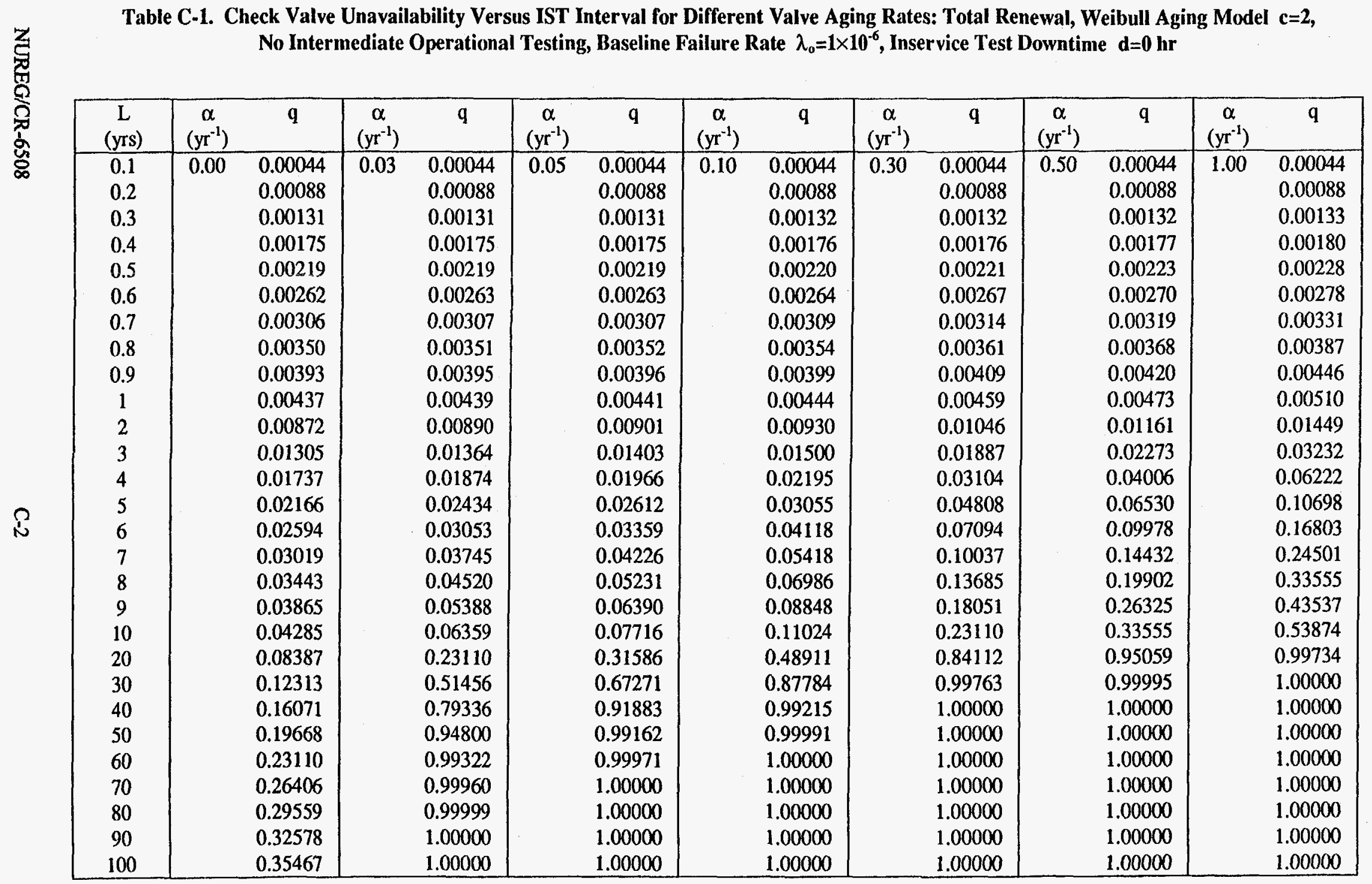


Table C-2. Check Valve Unavailability Versus IST Interval for Different Valve Aging Rates: Total Renewal, Weibull Aging Model c=2, No Intermediate Operational Testing, Baseline Failure Rate $\lambda_{0}=1 \times 10^{-6}$, Inservice Test Downtime $d=8 \mathrm{hr}$

\begin{tabular}{|c|c|c|c|c|c|c|c|c|c|c|c|c|c|c|}
\hline $\begin{array}{c}\mathrm{L} \\
\text { (yrs) }\end{array}$ & $\begin{array}{c}\alpha \\
\left(\mathrm{yr}^{-1}\right)\end{array}$ & $q$ & $\begin{array}{c}\alpha \\
\left(y \mathrm{r}^{-1}\right)\end{array}$ & $q$ & $\begin{array}{c}\alpha \\
\left(\mathrm{yr}^{-1}\right)\end{array}$ & $q$ & $\begin{array}{c}\alpha \\
\left(\mathrm{yr}^{-1}\right)\end{array}$ & $q$ & $\begin{array}{c}\alpha \\
\left(\mathrm{yr}^{-1}\right)\end{array}$ & $\mathbf{q}$ & $\begin{array}{c}\alpha \\
\left(\mathrm{yr}^{-1}\right)\end{array}$ & $q$ & $\begin{array}{c}\alpha \\
\left(\mathrm{yr}^{-1}\right)\end{array}$ & $q$ \\
\hline 0.1 & 0.00 & 0.00949 & 0.03 & 0.00949 & 0.05 & 0.00949 & 0.10 & 0.00949 & 0.30 & 0.00949 & 0.50 & 0.00949 & 1.00 & 0.00949 \\
\hline 0.2 & & 0.00542 & & 0.00542 & & 0.00542 & & 0.00542 & & 0.00542 & & 0.00542 & & 0.00543 \\
\hline 0.3 & & 0.00435 & & 0.00435 & & 0.00435 & & 0.00435 & & 0.00435 & & 0.00436 & & 0.00437 \\
\hline 0.4 & & 0.00403 & & 0.00403 & & 0.00403 & & 0.00403 & & 0.00404 & & 0.00405 & & 0.00408 \\
\hline 0.5 & & 0.00401 & & 0.00401 & & 0.00402 & & 0.00402 & & 0.00404 & & 0.00406 & & 0.00410 \\
\hline 0.6 & & 0.00414 & & 0.00415 & & 0.00415 & & 0.00416 & & 0.00419 & & 0.00422 & & 0.00430 \\
\hline 0.7 & & 0.00436 & & 0.00437 & & 0.00438 & & 0.00439 & & 0.00444 & & 0.00449 & & 0.00461 \\
\hline 0.8 & & 0.00464 & & 0.00465 & & 0.00466 & & 0.00468 & & 0.00475 & & 0.00482 & & 0.00501 \\
\hline 0.9 & & 0.00495 & & 0.00496 & & 0.00497 & & 0.00500 & & 0.00511 & & 0.00521 & & 0.00548 \\
\hline 1 & & 0.00528 & & 0.00530 & & 0.00532 & & 0.00536 & & 0.00550 & & 0.00565 & & 0.00601 \\
\hline 2 & & 0.00918 & & 0.00935 & & 0.00947 & & 0.00976 & & 0.01091 & & 0.01207 & & 0.01495 \\
\hline 3 & & 0.01336 & & 0.01394 & & 0.01433 & & 0.01530 & & 0.01918 & & 0.02304 & & 0.03262 \\
\hline 4 & & 0.01760 & & 0.01897 & & 0.01989 & & 0.02218 & & 0.03127 & & 0.04028 & & 0.06245 \\
\hline 5 & & 0.02184 & & 0.02452 & & 0.02630 & & 0.03073 & & 0.04826 & & 0.06548 & & 0.10717 \\
\hline 6 & & 0.02609 & & 0.03069 & & 0.03374 & & 0.04133 & & 0.07109 & & 0.09994 & & 0.16818 \\
\hline 7 & & 0.03033 & & 0.03758 & & 0.04239 & & 0.05431 & & 0.10051 & & 0.14445 & & 0.24514 \\
\hline 8 & & 0.03455 & & 0.04531 & & 0.05242 & & 0.06997 & & 0.13697 & & 0.19913 & & 0.33567 \\
\hline 9 & & 0.03875 & & 0.05398 & & 0.06400 & & 0.08858 & & 0.18061 & & 0.26335 & & 0.43547 \\
\hline 10 & & 0.04295 & & 0.06368 & & 0.07725 & & 0.11033 & & 0.23120 & & 0.33564 & & 0.53883 \\
\hline 20 & & 0.08392 & & 0.23115 & & 0.31591 & & 0.48916 & & 0.84116 & & 0.95064 & & 0.99738 \\
\hline 30 & & 0.12316 & & 0.51459 & & 0.67274 & & 0.87787 & & 0.99766 & & 0.99998 & & 1.00003 \\
\hline 40 & & 0.16073 & & 0.79339 & & 0.91885 & & 0.99217 & & 1.00002 & & 1.00002 & & 1.00002 \\
\hline 50 & & 0.19670 & & 0.94802 & & 0.99163 & & 0.99993 & & 1.00002 & & 1.00002 & & 1.00002 \\
\hline 60 & & 0.23112 & & 0.99323 & & 0.99973 & & 1.00002 & & 1.00002 & & 1.00002 & & 1.00002 \\
\hline 70 & & 0.26407 & & 0.99961 & & 1.00001 & & 1.00001 & & 1.00001 & & 1.00001 & & 1.00001 \\
\hline 80 & & 0.29561 & & 1.00000 & & 1.00001 & & 1.00001 & & 1.00001 & & 1.00001 & & 1.00001 \\
\hline 90 & & 0.32579 & & 1.00001 & & 1.00001 & & 1.00001 & & 1.00001 & & 1.00001 & & 1.00001 \\
\hline 100 & & 0.35468 & & 1.00001 & & 1.00001 & & 1.00001 & & 1.00001 & & 1.00001 & & 1.00001 \\
\hline
\end{tabular}




\begin{tabular}{|c|c|c|c|c|c|c|c|c|c|c|c|c|c|c|}
\hline $\begin{array}{c}\mathrm{L} \\
(\mathrm{yrs})\end{array}$ & $\begin{array}{c}\alpha \\
\left(\mathrm{yr}^{-1}\right)\end{array}$ & $q$ & $\begin{array}{c}\alpha \\
\left(\mathrm{yr}^{-1}\right)\end{array}$ & $q$ & $\begin{array}{c}\alpha \\
\left(\mathrm{yr}^{-1}\right)\end{array}$ & $q$ & $\begin{array}{c}\alpha \\
\left(y^{-1}\right)\end{array}$ & $q$ & $\begin{array}{c}\alpha \\
\left(\mathrm{yr}^{-1}\right)\end{array}$ & $q$ & $\begin{array}{c}\alpha \\
\left(\mathrm{yr}^{-1}\right)\end{array}$ & $q$ & $\begin{array}{c}\alpha \\
\left(\mathrm{yr}^{-1}\right)\end{array}$ & $q$ \\
\hline 0.1 & 0.00 & 0.07639 & 0.03 & 0.07639 & 0.05 & 0.07639 & 0.10 & 0.07639 & 0.30 & 0.07639 & 0.50 & 0.07639 & 1.00 & 0.07639 \\
\hline 0.2 & & 0.04035 & & 0.04035 & & 0.04035 & & 0.04035 & & 0.04035 & & 0.04035 & & 0.04036 \\
\hline 0.3 & & 0.02798 & & 0.02798 & & 0.02798 & & 0.02798 & & 0.02799 & & 0.02799 & & 0.02800 \\
\hline 0.4 & & 0.02188 & & 0.02189 & & 0.02189 & & 0.02189 & & 0.02190 & & 0.02191 & & 0.02193 \\
\hline 0.5 & & 0.01836 & & 0.01836 & & 0.01836 & & 0.01837 & & 0.01839 & & 0.01841 & & 0.01845 \\
\hline 0.6 & & 0.01614 & & 0.01614 & & 0.01615 & & 0.01615 & & 0.01619 & & 0.01622 & & 0.01630 \\
\hline 0.7 & & 0.01467 & & 0.01467 & & 0.01468 & & 0.01469 & & 0.01474 & & 0.01479 & & 0.01492 \\
\hline 0.8 & & 0.01367 & & 0.01368 & & 0.01369 & & 0.01370 & & 0.01378 & & 0.01385 & & 0.01404 \\
\hline 0.9 & & 0.01298 & & 0.01300 & & 0.01301 & & 0.01304 & & 0.01314 & & 0.01325 & & 0.01351 \\
\hline 1 & & 0.01252 & & 0.01254 & & 0.01256 & & 0.01260 & & 0.01274 & & 0.01289 & & 0.01325 \\
\hline 2 & & 0.01281 & & 0.01299 & & 0.01310 & & 0.01339 & & 0.01455 & & 0.01570 & & 0.01859 \\
\hline 3 & & 0.01579 & & 0.01637 & & 0.01676 & & 0.01773 & & 0.02160 & & 0.02546 & & 0.03505 \\
\hline 4 & & 0.01942 & & 0.02079 & & 0.02171 & & 0.02400 & & 0.03309 & & 0.04211 & & 0.06427 \\
\hline 5 & & 0.02330 & & 0.02598 & & 0.02776 & & 0.03219 & & 0.04972 & & 0.06694 & & 0.10862 \\
\hline 6 & & 0.02731 & & 0.03190 & & 0.03495 & & 0.04254 & & 0.07231 & & 0.10115 & & 0.16940 \\
\hline 7 & & 0.03137 & & 0.03863 & & 0.04343 & & 0.05535 & & 0.10155 & & 0.14549 & & 0.24618 \\
\hline 8 & & 0.03546 & & 0.04623 & & 0.05334 & & 0.07088 & & 0.13788 & & 0.20005 & & 0.33658 \\
\hline 9 & & 0.03957 & & 0.05479 & & 0.06481 & & 0.08939 & & 0.18142 & & 0.26416 & & 0.43629 \\
\hline 10 & & 0.04368 & & 0.06441 & & 0.07798 & & 0.11106 & & 0.23193 & & 0.33637 & & 0.53956 \\
\hline 20 & & 0.08428 & & 0.23152 & & 0.31628 & & 0.48952 & & 0.84153 & & 0.95100 & & 0.99775 \\
\hline 30 & & 0.12341 & & 0.51483 & & 0.67298 & & 0.87811 & & 0.99790 & & 1.00023 & & 1.00027 \\
\hline 40 & & 0.16092 & & 0.79357 & & 0.91903 & & 0.99236 & & 1.00020 & & 1.00021 & & 1.00021 \\
\hline 50 & & 0.19684 & & 0.94816 & & 0.99178 & & 1.00008 & & 1.00016 & & 1.00016 & & 1.00016 \\
\hline 60 & & 0.23124 & & 0.99335 & & 0.99985 & & 1.00014 & & 1.00014 & & 1.00014 & & 1.00014 \\
\hline 70 & & 0.26417 & & 0.99972 & & 1.00011 & & 1.00012 & & 1.00012 & & 1.00012 & & 1.00012 \\
\hline 80 & & 0.29570 & & 1.00009 & & 1.00010 & & 1.00010 & & 1.00010 & & 1.00010 & & 1.00010 \\
\hline 90 & & 0.32587 & & 1.00009 & & 1.00009 & & 1.00009 & & 1.00009 & & 1.00009 & & 1.00009 \\
\hline 100 & & 0.35476 & & 1.00008 & & 1.00008 & & 1.00008 & & 1.00008 & & 1.00008 & & 1.00008 \\
\hline
\end{tabular}




\begin{tabular}{|c|c|c|c|c|c|c|c|c|}
\hline $00000^{\circ} \mathrm{I}$ & & $00000^{\circ} \mathrm{I}$ & $00000^{\circ} 1$ & $S E 666^{\circ} 0$ & ZISL6 0 & $88268^{\circ} 0$ & $58260^{\circ} 0$ & $00 \mathrm{I}$ \\
\hline $00000^{\circ} \mathrm{I}$ & & $00000^{\circ} \mathrm{I}$ & $00000^{\circ} \mathrm{I}$ & $0 E S 66^{\circ} 0$ & $\operatorname{I8ZE} 6^{\circ} 0$ & $\varepsilon Z \mathrm{CS}_{0} 8^{\circ} 0$ & S98E $0^{\circ} 0$ & 06 \\
\hline $00000^{\circ} \mathrm{I}$ & & $00000^{\circ} \mathrm{I}$ & $66666^{\circ} 0$ & $10 \angle L 6^{\circ} 0$ & $00 I S 8^{\circ} 0$ & $98 S 89^{\circ} 0$ & $\varepsilon t D E 0^{\circ} 0$ & 08 \\
\hline $00000^{\circ} \mathrm{I}$ & & $00000^{\circ} \mathrm{I}$ & $L \hbar 666^{\circ} 0$ & $0 \angle 026^{\circ} 0$ & $6972 L O 0$ & $\varepsilon \nabla \tau t \varsigma^{\circ} 0$ & $6 \mathrm{IOEO} 0$ & $0 L$ \\
\hline $00000^{\circ} \mathrm{I}$ & & $\varepsilon 9666^{\circ} 0$ & ItI $66^{\circ} 0$ & ZL86LOO & ZZLSSO 0 & $90 \varepsilon 6 \varepsilon^{\circ} 0$ & $\nabla 6 \subseteq Z 0^{\circ} 0$ & 09 \\
\hline $68666^{\circ} 0$ & & $6 \angle 686^{\circ} 0$ & $\angle 99 \& 6^{\circ} 0$ & $81 \angle 09^{\circ} 0$ & $\angle 008 \varepsilon^{\circ} 0$ & S6SSZ:0 & $99120^{\circ} 0$ & $0 S$ \\
\hline I $8066^{\circ} 0$ & & $\angle 6+06^{\circ} 0$ & LO8SLO & $\mathcal{E I} \rightarrow 8 \mathcal{E}^{\prime} 0$ & LOZZZ'0 & $88 \mathrm{Stl} 0$ & $\angle E L I 0^{\circ} 0$ & $0 t$ \\
\hline $0 \$ 298^{\circ} 0$ & & Z9I\&9०0 & Z9ESt 0 & $19681^{\circ} 0$ & $89501^{\circ} 0$ & $\tau \angle 690^{\circ} 0$ & SOEIO'O & $O \varepsilon$ \\
\hline $0 Z \angle D D^{\circ} 0$ & & $\nabla \angle 6 S Z 0$ & $\varepsilon 0891^{\circ} 0$ & $56+90^{\circ} 0$ & SZLEO० 0 & $\$ 6 S Z 0^{\circ} 0$ & $Z \angle 800^{\circ} 0$ & $0 z$ \\
\hline $9 \nabla t \angle 0^{\circ} 0$ & & $900+0^{\circ} 0$ & $16 S 20^{\circ} 0$ & $19110^{\circ} 0$ & $00800^{\circ} 0$ & $\$ \$ 900^{\circ} 0$ & $\angle E \not 00^{\circ} 0$ & 01 \\
\hline $9 \$ \$ S 0^{\circ} 0$ & & $60080^{\circ} 0$ & $1 \angle 610^{\circ} 0$ & $2 Z 600^{\circ} 0$ & $85900^{\circ} 0$ & $\tau \varsigma S_{00}^{\circ} 0$ & $\varepsilon 6 \varepsilon 00^{\circ} 0$ & 6 \\
\hline $900+00^{\circ}$ & & $56120^{\circ} 0$ & $19+10^{\circ} 0$ & $Z Z \angle 00^{\circ} 0$ & $9 \varepsilon \varsigma 00^{\circ} 0$ & {$\left[9+00^{\circ} 0\right.$} & $0 S \mathcal{E} 00^{\circ} 0$ & 8 \\
\hline$I \angle L Z Z 0^{\circ} 0$ & & $9+S I 0^{\circ} 0$ & Z\$OI0 0 & $S S S 00^{\circ} 0$ & IEt $00^{\circ} 0$ & I8E00 0 & $90 \varepsilon 00^{\circ} 0$ & $L$ \\
\hline EZ810 0 & & $96010^{\circ} 0$ & $\mathcal{E E} \angle 00^{\circ} 0$ & $0 z+00^{\circ} 0$ & It\&O0'0 & OI $\varepsilon 00^{\circ} 0$ & $29 z 00^{\circ} 0$ & 9 \\
\hline SZILOO & & $\varepsilon \angle 900^{\circ} 0$ & $26+00^{\circ} 0$ & $0 I \varepsilon 00^{\circ} 0$ & $\$ 9200^{\circ} 0$ & $9 \not 200^{\circ} 0$ & $6 \mathrm{I} 200^{\circ} 0$ & $\mathcal{S}$ \\
\hline $0+900^{\circ} 0$ & & $80 t 00^{\circ} 0$ & SIEO0 0 & $2 z 200^{\circ} 0$ & $86100^{\circ} 0$ & $68100^{\circ} 0$ & SLI00'0 & $\downarrow$ \\
\hline $8 Z \varepsilon 00^{\circ} 0$ & & $0 \varepsilon z 00^{\circ} 0$ & 06100.0 & ISI00 0 & $I t 100^{\circ} 0$ & $\angle \varepsilon 100^{\circ} 0$ & IEI00 0 & $\varepsilon$ \\
\hline $9+100^{\circ} 0$ & & $\angle I 1000$ & soro0 0 & $\varepsilon 6000^{\circ} 0$ & $06000^{\circ} 0$ & $68000^{\circ} 0$ & $88000^{\circ} 0$ & $\tau$ \\
\hline ISO000 0 & & $\angle t 000^{\circ} 0$ & $9 t 000^{\circ} 0$ & $S+000^{\circ} 0$ & $t+000^{\circ} 0$ & $t+000^{\circ} 0$ & $t+000^{\circ} 0$ & I \\
\hline$S+000^{\circ} 0$ & & $\tau+000^{\circ} 0$ & It $0000^{\circ} 0$ & $0+000^{\circ} 0$ & $0 t 000^{\circ} 0$ & $0+000^{\circ} 0$ & $6 £ 000^{\circ} 0$ & 60 \\
\hline $68000^{\circ} 0$ & & $\angle \varepsilon 000^{\circ} 0$ & $9 \varepsilon 000^{\circ} 0$ & SE000 0 & $\$ £ 000^{\circ} 0$ & SEE000 0 & $\$ \varepsilon 000^{\circ} 0$ & $8^{\circ} 0$ \\
\hline $\mathcal{E E} 000^{\circ} 0$ & & $\tau \varepsilon 000^{\circ} 0$ & $1 \mathcal{E} 000^{\circ} 0$ & IEO00 0 & IE000\% 0 & $I \varepsilon 000^{\circ} 0$ & I $18000^{\circ} 0$ & $\angle 0$ \\
\hline $82000^{\circ} 0$ & & $\angle Z 000^{\circ} 0$ & $\angle Z 000^{\circ} 0$ & $92000^{\circ} 0$ & $92000^{\circ} 0$ & $92000^{\circ} 0$ & $92000^{\circ} 0$ & 90 \\
\hline$\varepsilon Z 000^{\circ} 0$ & & $22000^{\circ} 0$ & $\tau z 000^{\circ} 0$ & $22000^{\circ} 0$ & $22000^{\circ} 0$ & $2 z 000^{\circ} 0$ & $2 z 000^{\circ} 0$ & $S^{\circ} 0$ \\
\hline $81000^{\circ} 0$ & & $81000^{\circ} 0$ & $81000^{\circ} 0$ & $81000^{\circ} 0$ & $81000^{\circ} 0$ & $81000^{\circ} 0$ & $81000^{\circ} 0$ & to \\
\hline$\varepsilon 1000^{\circ} 0$ & & $\varepsilon 1000^{\circ} 0$ & $\varepsilon I 000^{\circ} 0$ & $\varepsilon 1000^{\circ} 0$ & $\mathcal{E L} 000^{\circ} 0$ & $\varepsilon\left[000^{\circ} 0\right.$ & $\varepsilon I 000^{\circ} 0$ & $\mathcal{E}^{\prime} 0$ \\
\hline $60000^{\circ} 0$ & & $60000^{\circ} 0$ & $60000^{\circ} 0$ & $60000^{\circ} 0$ & $60000^{\circ} 0$ & $60000^{\circ} 0$ & $60000^{\circ} 0$ & $z^{\prime} 0$ \\
\hline$+0000^{\circ} 0$ & $00^{\circ} I$ & $t 0000^{\circ} 0 \quad 05^{\circ} 0$ & $10000^{\circ} 0$ & $t 0000^{\circ} 0 \quad 01^{\circ} 0$ & $50000^{\circ} 0 \quad s 0^{\circ} 0$ & t0000\% & $+0000^{\circ} 0$ & I.0 \\
\hline & $(\mathrm{I} . \triangle \mathrm{L})$ & $\left({ }^{T-X} X\right)$ & $\left({ }^{I} \cdot \mathrm{I} K\right)$ & $\left({ }_{\mathrm{T}} \mathrm{I} X\right)$ & $(1,-1 K)$ & $(\mathrm{I}-\mathrm{I} K)$ & $(1-1 S)$ & $(\mathrm{s}, K)$ \\
\hline b & 0 & 10 & Do & 0 & 0 & $x$ & 20 & $\mathrm{~T}$ \\
\hline
\end{tabular}

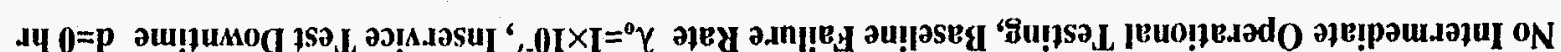

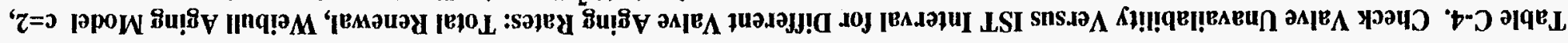




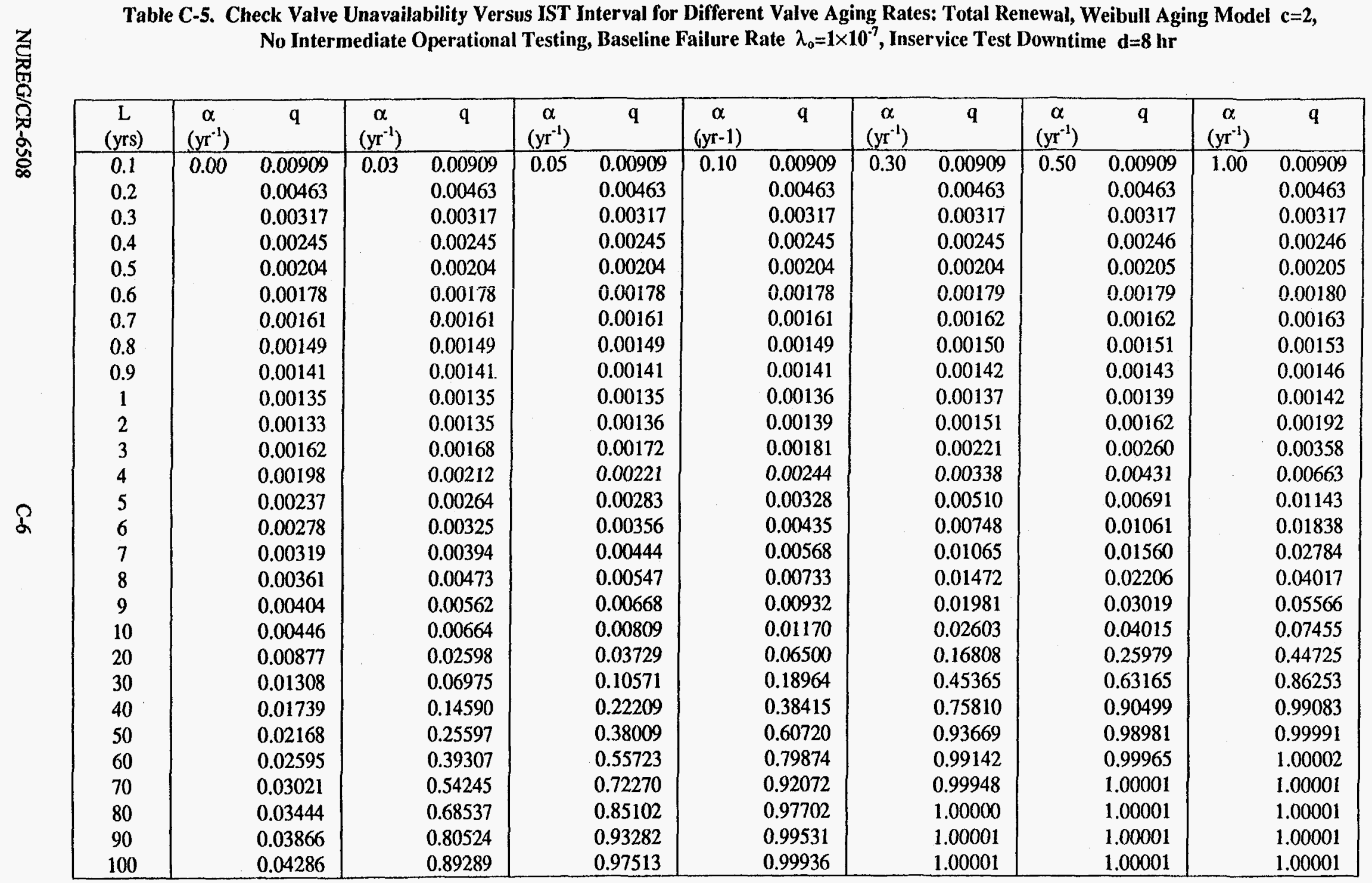


Table C-6. Check Valve Unavailability Versus IST Interval for Different Valve Aging Rates: Total Renewal, Weibull Aging Model $c=2$, No Intermediate Operational Testing, Baseline Failure Rate $\lambda_{0}=1 \times 10^{-7}$, Inservice Test Downtime $d=72 \mathrm{hr}$

\begin{tabular}{|c|c|c|c|c|c|c|c|c|c|c|c|c|c|c|}
\hline $\begin{array}{c}\mathrm{L} \\
\text { (yrs) }\end{array}$ & $\begin{array}{c}\alpha \\
\left(\mathrm{yr}^{-1}\right)\end{array}$ & $q$ & $\begin{array}{c}\alpha \\
\left(\mathrm{yr}^{-1}\right)\end{array}$ & $q$ & $\begin{array}{c}\alpha \\
\left(\mathrm{yr}^{-1}\right)\end{array}$ & $q$ & $\begin{array}{c}\alpha \\
\left(y r^{-1}\right)\end{array}$ & $q$ & $\begin{array}{c}\alpha \\
\left(\mathrm{yr}^{-1}\right)\end{array}$ & $q$ & $\begin{array}{c}\alpha \\
\left(\mathrm{yr}^{-1}\right)\end{array}$ & $\bar{q}$ & $\begin{array}{c}\alpha \\
\left(\mathrm{yr}^{-1}\right)\end{array}$ & $\mathbf{q}$ \\
\hline 0.1 & 0.00 & 0.07599 & 0.03 & 0.07599 & 0.05 & 0.07599 & 0.10 & 0.07599 & 0.30 & 0.07599 & 0.50 & 0.07599 & 1.00 & 0.07599 \\
\hline 0.2 & & 0.03956 & & 0.03956 & & 0.03956 & & 0.03956 & & 0.03956 & & 0.03956 & & 0.03956 \\
\hline 0.3 & & 0.02680 & & 0.02680 & & 0.02680 & & 0.02680 & & 0.02680 & & 0.02680 & & 0.02680 \\
\hline 0.4 & & 0.02031 & & 0.02031 & & 0.02031 & & 0.02031 & & 0.02031 & & 0.02031 & & 0.02031 \\
\hline 0.5 & & 0.01639 & & 0.01639 & & 0.01639 & & 0.01639 & & 0.01639 & & 0.01640 & & 0.01640 \\
\hline 0.6 & & 0.01378 & & 0.01378 & & 0.01378 & & 0.01378 & & 0.01378 & & 0.01378 & & 0.01379 \\
\hline 0.7 & & 0.01191 & & 0.01191 & & 0.01191 & & 0.01191 & & 0.01192 & & 0.01192 & & 0.01194 \\
\hline 0.8 & & 0.01052 & & 0.01052 & & 0.01052 & & 0.01052 & & 0.01053 & & 0.01054 & & 0.01056 \\
\hline 0.9 & & 0.00944 & & 0.00945 & & 0.00945 & & 0.00945 & & 0.00946 & & 0.00947 & & 0.00950 \\
\hline 1 & & 0.00859 & & 0.00859 & & 0.00859 & & 0.00860 & & 0.00861 & & 0.00863 & & 0.00866 \\
\hline 2 & & 0.00497 & & 0.00499 & & 0.00500 & & 0.00503 & & 0.00514 & & 0.00526 & & 0.00555 \\
\hline 3 & & 0.00405 & & 0.00410 & & 0.00414 & & 0.00424 & & 0.00464 & & 0.00503 & & 0.00601 \\
\hline 4 & & 0.00380 & & 0.00394 & & 0.00403 & & 0.00427 & & 0.00520 & & 0.00613 & & 0.00845 \\
\hline 5 & & 0.00383 & & 0.00410 & & 0.00428 & & 0.00474 & & 0.00656 & & 0.00837 & & 0.01289 \\
\hline 6 & & 0.00399 & & 0.00446 & & 0.00478 & & 0.00556 & & 0.00870 & & 0.01182 & & 0.01960 \\
\hline 7 & & 0.00423 & & 0.00498 & & 0.00548 & & 0.00673 & & 0.01169 & & 0.01664 & & 0.02889 \\
\hline 8 & & 0.00452 & & 0.00564 & & 0.00638 & & 0.00824 & & 0.01564 & & 0.02297 & & 0.04108 \\
\hline 9 & & 0.00485 & & 0.00644 & & 0.00749 & & 0.01013 & & 0.02062 & & 0.03100 & & 0.05647 \\
\hline 10 & & 0.00519 & & 0.00737 & & 0.00882 & & 0.01243 & & 0.02676 & & 0.04088 & & 0.07528 \\
\hline 20 & & 0.00913 & & 0.02635 & & 0.03766 & & 0.06537 & & 0.16844 & & 0.26016 & & 0.44761 \\
\hline 30 & & 0.01333 & & 0.06999 & & 0.10595 & & 0.18988 & & 0.45389 & & 0.63189 & & 0.86278 \\
\hline 40 & & 0.01757 & & 0.14608 & & 0.22228 & & 0.38434 & & 0.75828 & & 0.90517 & & 0.99101 \\
\hline 50 & & 0.02183 & & 0.25612 & & 0.38024 & & 0.60734 & & 0.93683 & & 0.98995 & & 1.00006 \\
\hline 60 & & 0.02607 & & 0.39319 & & 0.55736 & & 0.79886 & & 0.99154 & & 0.99977 & & 1.00014 \\
\hline 70 & & 0.03031 & & 0.54255 & & 0.72280 & & 0.92082 & & 0.99959 & & 1.00011 & & 1.00012 \\
\hline 80 & & 0.03454 & & 0.68546 & & 0.85111 & & 0.97711 & & 1.00009 & & 1.00010 & & 1.00010 \\
\hline 90 & & 0.03874 & & 0.80532 & & 0.93290 & & 0.99540 & & 1.00009 & & 1.00009 & & 1.00009 \\
\hline 100 & & 0.04294 & & 0.89296 & & 0.97520 & & 0.99944 & & 1.00008 & & 1.00008 & & 1.00008 \\
\hline
\end{tabular}




\begin{tabular}{|c|c|c|c|c|c|c|c|c|c|c|c|c|c|c|}
\hline $\begin{array}{c}\mathrm{L} \\
\text { (yrs) }\end{array}$ & $\begin{array}{c}\alpha \\
\left(\mathrm{yr}^{-1}\right)\end{array}$ & $q$ & $\begin{array}{c}\alpha \\
\left(y r^{-1}\right)\end{array}$ & $q$ & $\begin{array}{c}\alpha \\
\left(\mathrm{yr}^{-1}\right)\end{array}$ & $q$ & $\begin{array}{c}\alpha \\
\left(\mathrm{yr}^{-1}\right) \\
\end{array}$ & $q$ & $\begin{array}{c}\alpha \\
\left(y^{-1}\right)\end{array}$ & $q$ & $\begin{array}{c}\alpha \\
\left(y^{-1}\right)\end{array}$ & $q$ & $\begin{array}{c}\alpha \\
(y r-1)\end{array}$ & $q$ \\
\hline 0.1 & 0.00 & 0.00036 & 0.03 & 0.00037 & 0.05 & 0.00037 & 0.10 & 0.00037 & 0.30 & 0.00037 & 0.50 & 0.00037 & 1.00 & 0.00037 \\
\hline 0.2 & & 0.00036 & & 0.00037 & & 0.00037 & & 0.00037 & & 0.00037 & & 0.00037 & & 0.00037 \\
\hline 0.3 & & 0.00036 & & 0.00037 & & 0.00037 & & 0.00037 & & 0.00037 & & 0.00037 & & 0.00038 \\
\hline 0.4 & & 0.00036 & & 0.00037 & & 0.00037 & & 0.00037 & & 0.00037 & & 0.00038 & & 0.00039 \\
\hline 0.5 & & 0.00036 & & 0.00037 & & 0.00037 & & 0.00037 & & 0.00038 & & 0.00038 & & 0.00040 \\
\hline 0.6 & & 0.00036 & & 0.00037 & & 0.00037 & & 0.00037 & & 0.00038 & & 0.00039 & & 0.00042 \\
\hline 0.7 & & 0.00036 & & 0.00037 & & 0.00037 & & 0.00037 & & 0.00039 & & 0.00040 & & 0.00043 \\
\hline 0.8 & & 0.00036 & & 0.00037 & & 0.00037 & & 0.00037 & & 0.00039 & & 0.00041 & & 0.00045 \\
\hline 0.9 & & 0.00036 & & 0.00037 & & 0.00037 & & 0.00038 & & 0.00040 & & 0.00042 & & 0.00047 \\
\hline 1 & & 0.00036 & & 0.00037 & & 0.00037 & & 0.00038 & & 0.00040 & & 0.00043 & & 0.00050 \\
\hline 2 & & 0.00036 & & 0.00038 & & 0.00039 & & 0.00042 & & 0.00052 & & 0.00062 & & 0.00087 \\
\hline 3 & & 0.00036 & & 0.00040 & & 0.00042 & & 0.00048 & & 0.00070 & & 0.00093 & & 0.00149 \\
\hline 4 & & 0.00036 & & 0.00042 & & 0.00046 & & 0.00056 & & 0.00096 & & 0.00136 & & 0.00235 \\
\hline 5 & & 0.00036 & & 0.00046 & & 0.00052 & & 0.00067 & & 0.00129 & & 0.00191 & & 0.00345 \\
\hline 6 & & 0.00036 & & 0.00050 & & 0.00059 & & 0.00081 & & 0.00170 & & 0.00258 & & 0.00479 \\
\hline 7 & & 0.00036 & & 0.00055 & & 0.00067 & & 0.00097 & & 0.00217 & & 0.00338 & & 0.00638 \\
\hline 8 & & 0.00036 & & 0.00060 & & 0.00076 & & 0.00115 & & 0.00272 & & 0.00429 & & 0.00820 \\
\hline 9 & & 0.00036 & & 0.00066 & & 0.00086 & & 0.00136 & & 0.00334 & & 0.00532 & & 0.01026 \\
\hline 10 & & 0.00036 & & 0.00073 & & 0.00098 & & 0.00159 & & 0.00404 & & 0.00648 & & 0.01255 \\
\hline 20 & & 0.00036 & & 0.00183 & & 0.00280 & & 0.00524 & & 0.01491 & & 0.02449 & & 0.04804 \\
\hline 30 & & 0.00036 & & 0.00365 & & 0.00584 & & 0.01128 & & 0.03276 & & 0.05377 & & 0.10432 \\
\hline 40 & & 0.00036 & & 0.00620 & & 0.01007 & & 0.01968 & & 0.05719 & & 0.09326 & & 0.17753 \\
\hline 50 & & 0.00036 & & 0.00946 & & 0.01548 & & 0.03036 & & 0.08768 & & 0.14161 & & 0.26291 \\
\hline 60 & & 0.00036 & & 0.01343 & & 0.02205 & & 0.04326 & & 0.12361 & & 0.19722 & & 0.35530 \\
\hline 70 & & 0.00036 & & 0.01811 & & 0.02976 & & 0.05829 & & 0.16425 & & 0.25829 & & 0.44967 \\
\hline 80 & & 0.00036 & & 0.02347 & & 0.03858 & & 0.07532 & & 0.20880 & & 0.32301 & & 0.54152 \\
\hline 90 & & 0.00036 & & 0.02951 & & 0.04847 & & 0.09426 & & 0.25643 & & 0.38956 & & 0.62722 \\
\hline 100 & & 0.00036 & & 0.03622 & & 0.05941 & & 0.11497 & & 0.30627 & & 0.45622 & & 0.70419 \\
\hline
\end{tabular}




\begin{tabular}{|c|c|}
\hline 8 & 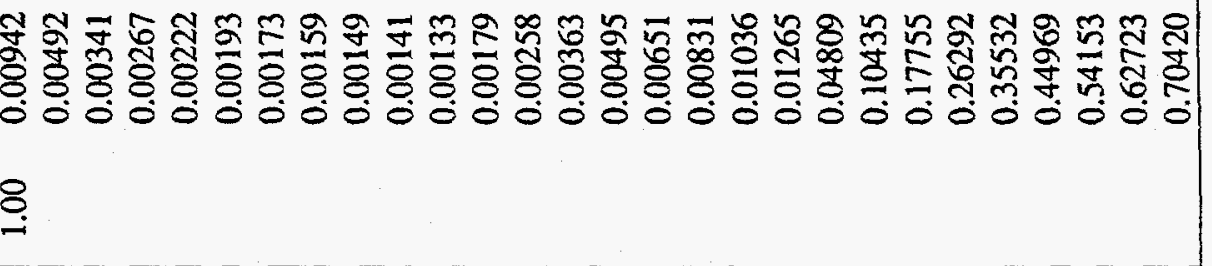 \\
\hline$\sigma$ & 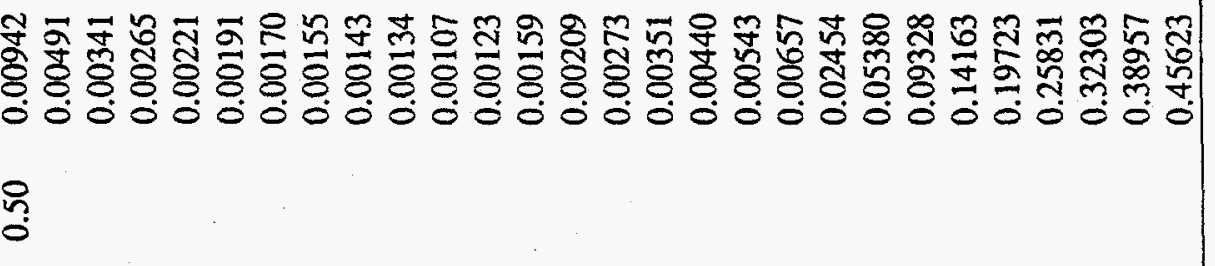 \\
\hline $\begin{array}{l}\sigma \\
8 \%\end{array}$ & 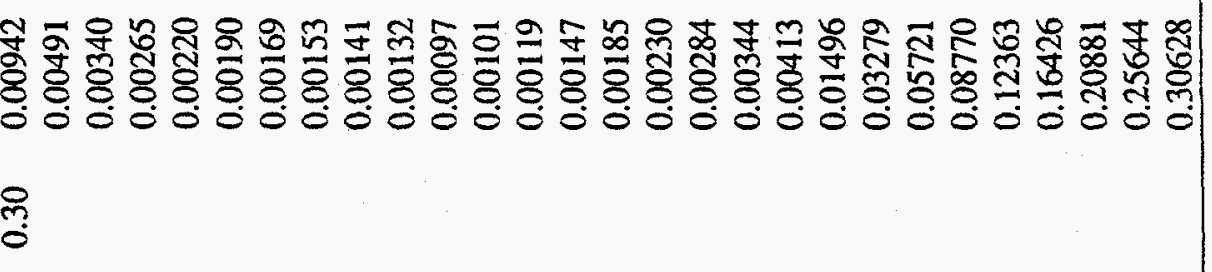 \\
\hline$\sigma$ & 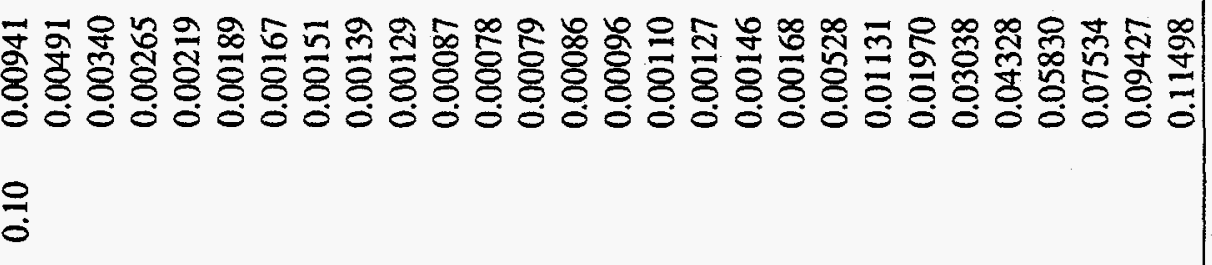 \\
\hline$\sigma$ & 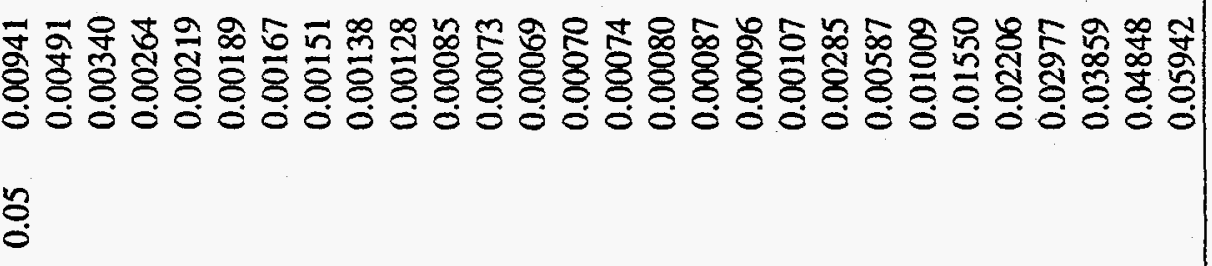 \\
\hline$\sigma$ & 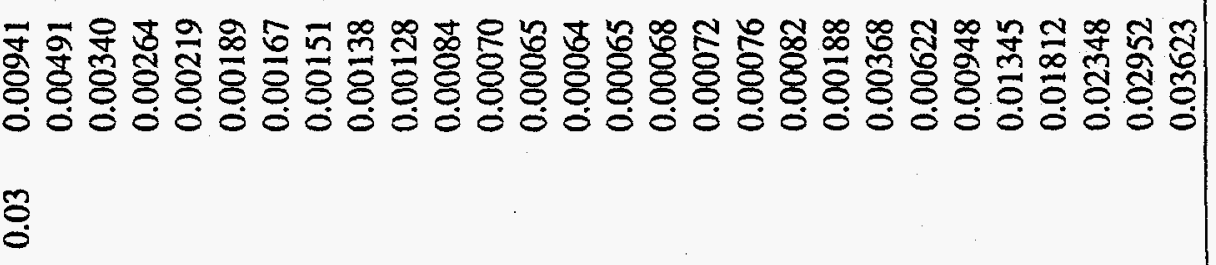 \\
\hline$\sigma$ & 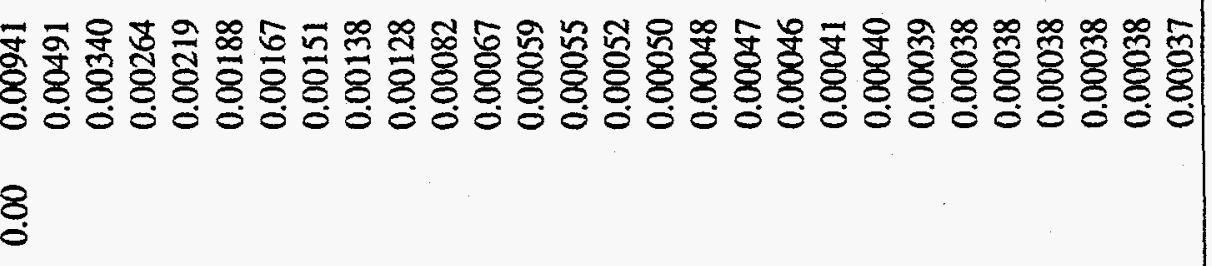 \\
\hline-2 & I-nm+nor-na: \\
\hline
\end{tabular}




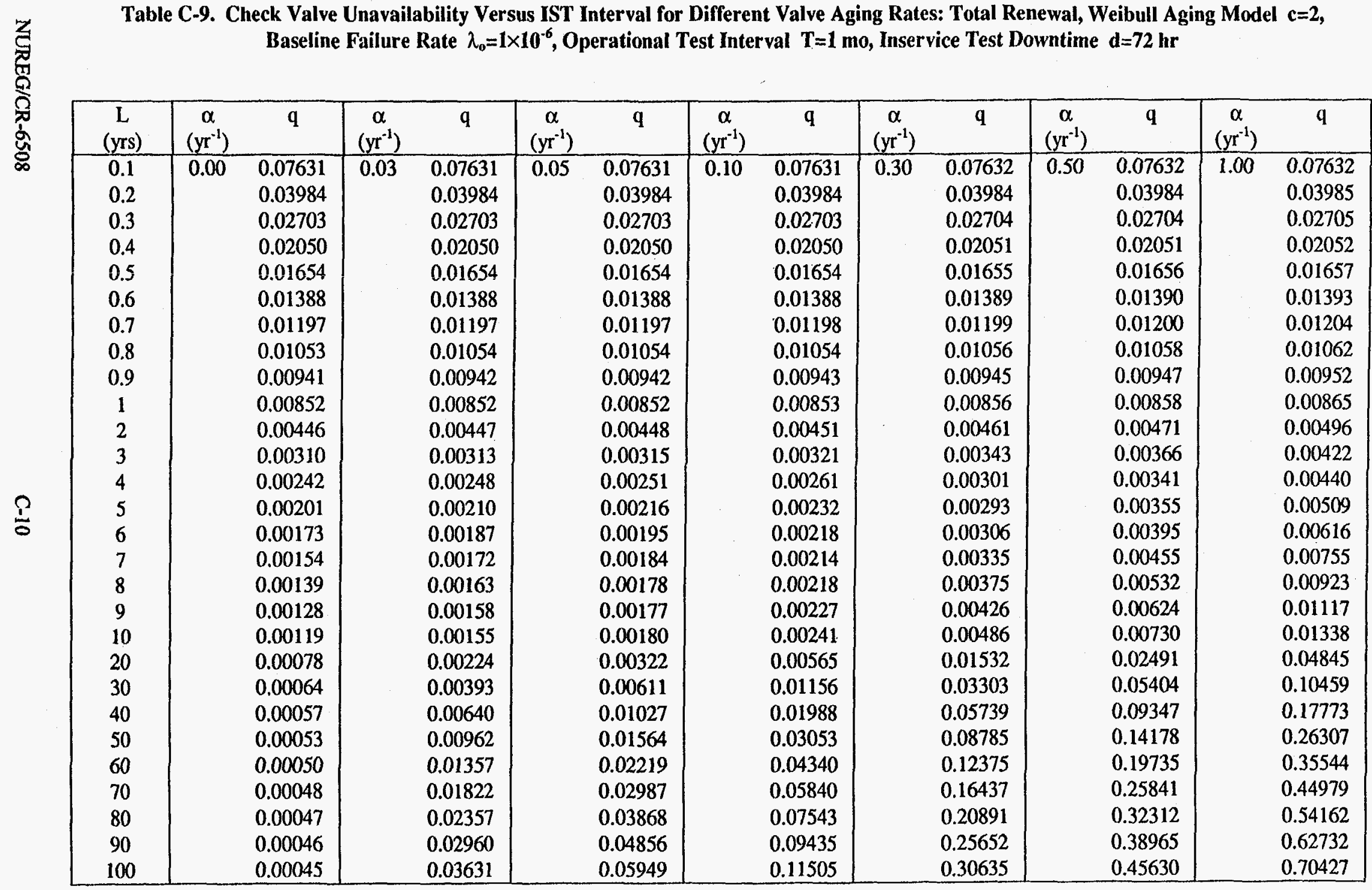


Table C-10. Check Valve Unavailability Versus IST Interval for Different Valve Aging Rates: Total Renewal, Weibull Aging Model $c=2$, Baseline Failure Rate $\lambda_{0}=1 \times 10^{-6}$, Operational Test Interval $T=12 \mathrm{mo}$, Inservice Test Downtime $d=0 \mathrm{hr}$

\begin{tabular}{|c|c|c|c|c|c|c|c|c|c|c|c|c|c|c|}
\hline $\begin{array}{c}\mathrm{L} \\
\text { (yrs) }\end{array}$ & $\begin{array}{c}\alpha \\
(\mathrm{yr}-1)\end{array}$ & q & $\underset{(\mathrm{yr}-1)}{\alpha}$ & $q$ & $\underset{(\mathrm{yr}-1)}{\alpha}$ & $\mathbf{q}$ & $\underset{(\mathrm{yr}-1)}{\alpha}$ & $q$ & $\begin{array}{c}\alpha \\
(\mathrm{yr}-1)\end{array}$ & $\mathbf{q}$ & $\begin{array}{c}\alpha \\
(\mathrm{yr}-1)\end{array}$ & $q$ & $\begin{array}{c}\alpha \\
(\mathrm{yr}-1)\end{array}$ & $q$ \\
\hline 1 & 0.00 & 0.00437 & 0.03 & 0.00448 & 0.05 & 0.00455 & 0.10 & 0.00473 & 0.30 & 0.00546 & 0.50 & 0.00619 & 1.00 & 0.00800 \\
\hline 2 & & 0.00437 & & 0.00465 & & 0.00484 & & 0.00531 & & 0.00720 & & 0.00908 & & 0.01377 \\
\hline 3 & & 0.00437 & & 0.00492 & & 0.00528 & & 0.00619 & & 0.00981 & & 0.01341 & & 0.02238 \\
\hline 4 & & 0.00437 & & 0.00526 & & 0.00586 & & 0.00735 & & 0.01327 & & 0.01916 & & 0.03373 \\
\hline 5 & & 0.00437 & & 0.00570 & & 0.00658 & & 0.00879 & & 0.01758 & & 0.02629 & & 0.04773 \\
\hline 6 & & 0.00437 & & 0.00622 & & 0.00745 & & 0.01053 & & 0.02273 & & 0.03479 & & 0.06427 \\
\hline 7 & & 0.00437 & & 0.00683 & & 0.00847 & & 0.01255 & & 0.02871 & & 0.04460 & & 0.08320 \\
\hline 8 & & 0.00437 & & 0.00753 & & 0.00963 & & 0.01485 & & 0.03549 & & 0.05569 & & 0.10437 \\
\hline 9 & & 0.00437 & & 0.00831 & & 0.01093 & & 0.01744 & & 0.04306 & & 0.06802 & & 0.12760 \\
\hline 10 & & 0.00437 & & 0.00918 & & 0.01237 & & 0.02030 & & 0.05141 & & 0.08153 & & 0.15271 \\
\hline 20 & & 0.00437 & & 0.02254 & & 0.03447 & & 0.06366 & & 0.17185 & & 0.26754 & & 0.46115 \\
\hline 30 & & 0.00437 & & 0.04413 & & 0.06975 & & 0.13084 & & 0.33764 & & 0.49523 & & 0.74409 \\
\hline 40 & & 0.00437 & & 0.07340 & & 0.11674 & & 0.21643 & & 0.51467 & & 0.69939 & & 0.90924 \\
\hline 50 & & 0.00437 & & 0.10961 & & 0.17351 & & 0.31391 & & 0.67421 & & 0.84530 & & 0.97596 \\
\hline 60 & & 0.00437 & & 0.15186 & & 0.23784 & & 0.41656 & & 0.79965 & & 0.93120 & & 0.99525 \\
\hline 70 & & 0.00437 & & 0.19916 & & 0.30735 & & 0.51813 & & 0.88712 & & 0.97356 & & 0.99930 \\
\hline 80 & & 0.00437 & & 0.25041 & & 0.37964 & & 0.61347 & & 0.94174 & & 0.99122 & & 0.99992 \\
\hline 90 & & 0.00437 & & 0.30450 & & 0.45244 & & 0.69886 & & 0.97245 & & 0.99748 & & 0.99999 \\
\hline 100 & & 0.00437 & & 0.36032 & & 0.52370 & & 0.77215 & & 0.98807 & & 0.99937 & & 1.00000 \\
\hline
\end{tabular}




\begin{tabular}{|c|c|c|c|c|c|c|c|c|c|c|c|c|c|c|}
\hline $\begin{array}{c}\mathrm{L} \\
\text { (yrs) }\end{array}$ & $\begin{array}{c}\alpha \\
\left(\mathrm{yr}^{-1}\right)\end{array}$ & $q$ & $\begin{array}{c}\alpha \\
\left(\mathrm{yr}^{-1}\right)\end{array}$ & $q$ & $\begin{array}{c}\alpha \\
\left(\mathrm{yr}^{-1}\right) \\
\end{array}$ & $q$ & $\begin{array}{c}\alpha \\
\left(\mathrm{yr}^{-1}\right)\end{array}$ & $q$ & $\begin{array}{c}\alpha \\
\left(\mathrm{yr}^{-1}\right)\end{array}$ & $q$ & $\begin{array}{c}\alpha \\
\left(\mathrm{yr}^{-1}\right)\end{array}$ & q & $\begin{array}{c}\alpha \\
\left(\mathrm{yr}^{-1}\right)\end{array}$ & $q$ \\
\hline 1 & 0.00 & 0.00528 & 0.03 & 0.00539 & 0.05 & 0.00546 & 0.10 & 0.00565 & 0.30 & 0.00637 & 0.50 & 0.00710 & 1.00 & 0.00891 \\
\hline 2 & & 0.00483 & & 0.00511 & & 0.00530 & & 0.00577 & & 0.00766 & & 0.00954 & & 0.01423 \\
\hline 3 & & 0.00467 & & 0.00522 & & 0.00558 & & 0.00649 & & 0.01011 & & 0.01372 & & 0.02268 \\
\hline 4 & & 0.00460 & & 0.00549 & & 0.00609 & & 0.00757 & & 0.01350 & & 0.01939 & & 0.03396 \\
\hline 5 & & 0.00455 & & 0.00588 & & 0.00677 & & 0.00898 & & 0.01777 & & 0.02648 & & 0.04792 \\
\hline 6 & & 0.00452 & & 0.00637 & & 0.00761 & & 0.01068 & & 0.02288 & & 0.03494 & & 0.06442 \\
\hline 7 & & 0.00450 & & 0.00696 & & 0.00860 & & 0.01268 & & 0.02884 & & 0.04473 & & 0.08333 \\
\hline 8 & & 0.00448 & & 0.00764 & & 0.00974 & & 0.01497 & & 0.03560 & & 0.05581 & & 0.10449 \\
\hline 9 & & 0.00447 & & 0.00841 & & 0.01103 & & 0.01754 & & 0.04317 & & 0.06812 & & 0.12770 \\
\hline 10 & & 0.00446 & & 0.00927 & & 0.01246 & & 0.02040 & & 0.05150 & & 0.08162 & & 0.15280 \\
\hline 20 & & 0.00442 & & 0.02259 & & 0.03451 & & 0.06370 & & 0.17189 & & 0.26758 & & 0.46119 \\
\hline 30 & & 0.00440 & & 0.04416 & & 0.06978 & & 0.13087 & & 0.33767 & & 0.49526 & & 0.74412 \\
\hline 40 & & 0.00439 & & 0.07342 & & 0.11676 & & 0.21645 & & 0.51469 & & 0.69941 & & 0.90926 \\
\hline 50 & & 0.00439 & & 0.10962 & & 0.17353 & & 0.31393 & & 0.67423 & & 0.84531 & & 0.97598 \\
\hline 60 & & 0.00439 & & 0.15188 & & 0.23785 & & 0.41657 & & 0.79966 & & 0.93121 & & 0.99526 \\
\hline 70 & & 0.00438 & & 0.19917 & & 0.30736 & & 0.51814 & & 0.88714 & & 0.97357 & & 0.99931 \\
\hline 80 & & 0.00438 & & 0.25042 & & 0.37965 & & 0.61348 & & 0.94175 & & 0.99123 & & 0.99993 \\
\hline 90 & & 0.00438 & & 0.30451 & & 0.45245 & & 0.69887 & & 0.97246 & & 0.99749 & & 1.00000 \\
\hline 100 & & 0.00438 & & 0.36033 & & 0.52371 & & 0.77216 & & 0.98808 & & 0.99938 & & 1.00001 \\
\hline
\end{tabular}


Table C-12. Check Valve Unavailability Versus IST Interval for Different Valve Aging Rates: Total Renewal, Weibull Aging Model $c=2$, Baseline Failure Rate $\lambda_{0}=1 \times 10^{-6}$, Operational Test Interval $T=12$ mo, Inservice Test Downtime $d=72 \mathrm{hr}$

\begin{tabular}{|c|c|c|c|c|c|c|c|c|c|c|c|c|c|c|}
\hline $\begin{array}{c}\mathrm{L} \\
(\mathrm{yrs})\end{array}$ & $\begin{array}{c}\alpha \\
\left(\mathrm{yr}^{-1}\right)\end{array}$ & $\mathbf{q}$ & $\begin{array}{c}\alpha \\
\left(\mathrm{yr}^{-1}\right)\end{array}$ & $q$ & $\begin{array}{c}\alpha \\
\left(\mathrm{yr}^{-1}\right)\end{array}$ & $q$ & $\begin{array}{c}\alpha \\
\left(\mathrm{yr}^{-1}\right)\end{array}$ & $q$ & $\underset{\left(\mathrm{yr}^{-1}\right)}{\alpha}$ & $q$ & $\begin{array}{c}\alpha \\
\left(\mathrm{yr}^{-1}\right)\end{array}$ & $q$ & $\underset{\left({y r^{-1}}^{-1}\right)}{\alpha}$ & $q$ \\
\hline 1 & 0.00 & 0.01252 & 0.03 & 0.01263 & 0.05 & 0.01270 & 0.10 & 0.01289 & 0.30 & 0.01361 & 0.50 & 0.01434 & 1.00 & 0.01615 \\
\hline 2 & & 0.00846 & & 0.00875 & & 0.00894 & & 0.00941 & & 0.01129 & & 0.01318 & & 0.01787 \\
\hline 3 & & 0.00710 & & 0.00765 & & 0.00801 & & 0.00892 & & 0.01254 & & 0.01615 & & 0.02511 \\
\hline 4 & & 0.00642 & & 0.00731 & & 0.00791 & & 0.00940 & & 0.01532 & & 0.02121 & & 0.03578 \\
\hline 5 & & 0.00601 & & 0.00734 & & 0.00823 & & 0.01044 & & 0.01922 & & 0.02793 & & 0.04937 \\
\hline 6 & & 0.00574 & & 0.00759 & & 0.00882 & & 0.01190 & & 0.02410 & & 0.03615 & & 0.06564 \\
\hline 7 & & 0.00554 & & 0.00800 & & 0.00964 & & 0.01372 & & 0.02988 & & 0.04577 & & 0.08438 \\
\hline 8 & & 0.00540 & & 0.00855 & & 0.01065 & & 0.01588 & & 0.03652 & & 0.05672 & & 0.10540 \\
\hline 9 & & 0.00528 & & 0.00922 & & 0.01184 & & 0.01835 & & 0.04398 & & 0.06893 & & 0.12851 \\
\hline 10 & & 0.00519 & & 0.01000 & & 0.01319 & & 0.02113 & & 0.05223 & & 0.08235 & & 0.15353 \\
\hline 20 & & 0.00478 & & 0.02295 & & 0.03488 & & 0.06407 & & 0.17226 & & 0.26795 & & 0.46156 \\
\hline 30 & & 0.00464 & & 0.04441 & & 0.07003 & & 0.13112 & & 0.33791 & & 0.49550 & & 0.74436 \\
\hline 40 & & 0.00458 & & 0.07361 & & 0.11695 & & 0.21663 & & 0.51487 & & 0.69960 & & 0.90944 \\
\hline 50 & & 0.00453 & & 0.10977 & & 0.17367 & & 0.31408 & & 0.67437 & & 0.84546 & & 0.97613 \\
\hline 60 & & 0.00451 & & 0.15200 & & 0.23798 & & 0.41670 & & 0.79978 & & 0.93134 & & 0.99538 \\
\hline 70 & & 0.00449 & & 0.19927 & & 0.30746 & & 0.51824 & & 0.88724 & & 0.97368 & & 0.99942 \\
\hline 80 & & 0.00447 & & 0.25051 & & 0.37974 & & 0.61357 & & 0.94184 & & 0.99132 & & 1.00003 \\
\hline 90 & & 0.00446 & & 0.30459 & & 0.45253 & & 0.69896 & & 0.97254 & & 0.99757 & & 1.00008 \\
\hline 100 & & 0.00445 & & 0.36040 & & 0.52379 & & 0.77223 & & 0.98815 & & 0.99946 & & 1.00008 \\
\hline
\end{tabular}




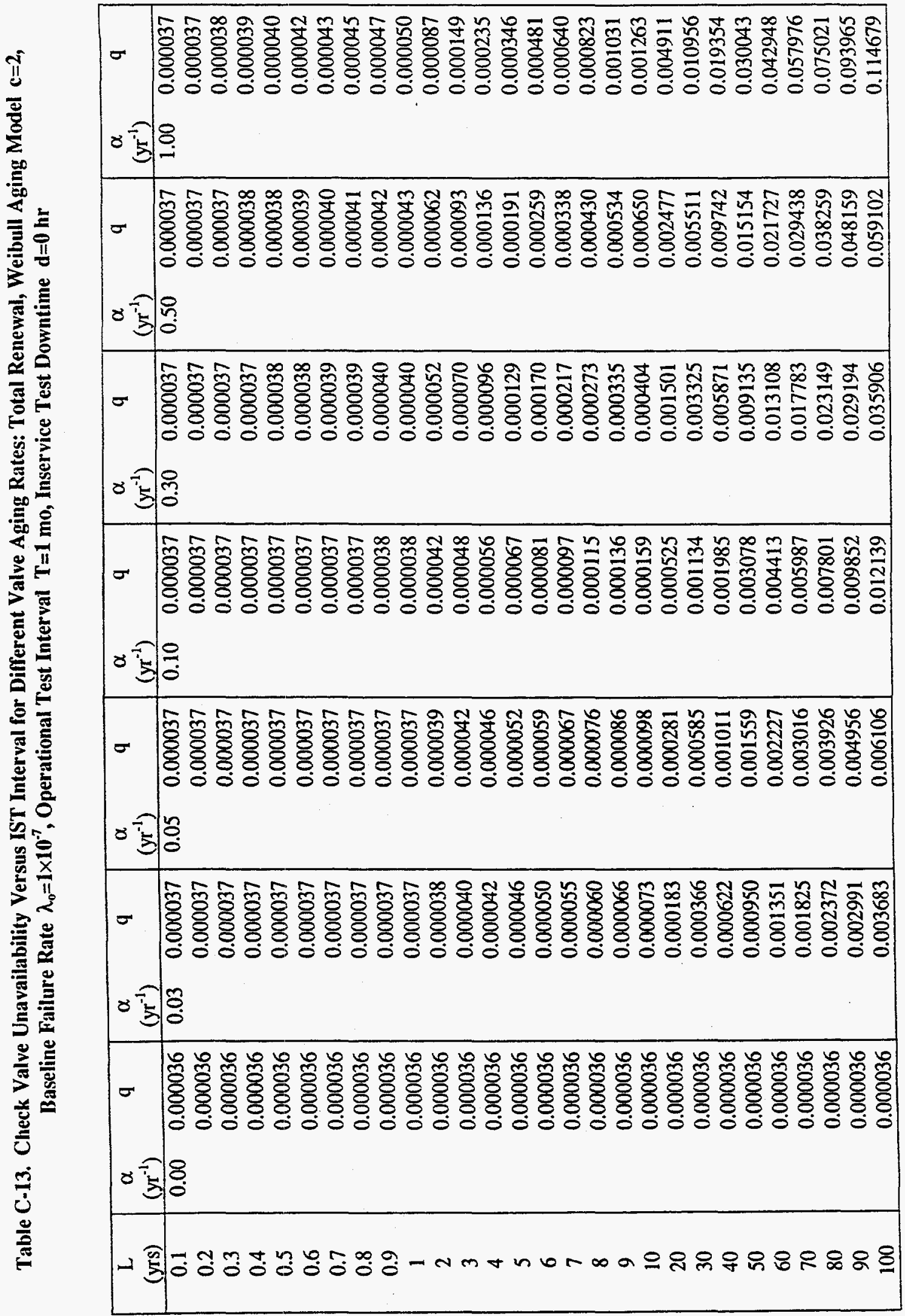


Table C-14. Check Valve Unavailability Versus IST Interval for Different Valve Aging Rates: Total Renewal, Weibull Aging Model $c=2$, Baseline Failure Rate $\lambda_{0}=1 \times 10^{-7}$, Operational Test Interval $T=1$ mo, Inservice Test Downtime $d=8 \mathrm{hr}$

\begin{tabular}{|c|c|c|c|c|c|c|c|c|c|c|c|c|c|c|}
\hline $\begin{array}{c}\mathrm{L} \\
\text { (yrs) }\end{array}$ & $\begin{array}{c}\alpha \\
\left(\mathrm{yr}^{-1}\right)\end{array}$ & $q$ & $\begin{array}{c}\alpha \\
\left(\mathrm{yr}^{-1}\right)\end{array}$ & $q$ & $\begin{array}{c}\alpha \\
\left(\mathrm{yr}^{-1}\right)\end{array}$ & $\mathbf{q}$ & $\begin{array}{c}\alpha \\
\left(\mathrm{yr}^{-1}\right)\end{array}$ & $q$ & $\begin{array}{c}\alpha \\
\left(\mathrm{yr}^{-1}\right)\end{array}$ & $q$ & $\begin{array}{c}\alpha \\
\left(\mathrm{yr}^{-1}\right)\end{array}$ & $q$ & $\begin{array}{c}\alpha \\
\left(\mathrm{yr}^{-1}\right)\end{array}$ & $q$ \\
\hline 0.1 & 0.00 & 0.00909 & 0.03 & 0.00909 & 0.05 & 0.00909 & 0.10 & 0.00909 & 0.30 & 0.00909 & 0.50 & 0.00909 & 1.00 & 0.00909 \\
\hline 0.2 & & 0.00458 & & 0.00458 & & 0.00458 & & 0.00458 & & 0.00458 & & 0.00458 & & 0.00458 \\
\hline 0.3 & & 0.00307 & & 0.00307 & & 0.00307 & & 0.00307 & & 0.00307 & & 0.00307 & & 0.00307 \\
\hline 0.4 & & 0.00231 & & 0.00231 & & 0.00231 & & 0.00231 & & 0.00232 & & 0.00232 & & 0.00232 \\
\hline 0.5 & & 0.00186 & & 0.00186 & & 0.00186 & & 0.00186 & & 0.00186 & & 0.00186 & & 0.00186 \\
\hline 0.6 & & 0.00156 & & 0.00156 & & 0.00156 & & 0.00156 & & 0.00156 & & 0.00156 & & 0.00156 \\
\hline 0.7 & & 0.00134 & & 0.00134 & & 0.00134 & & 0.00134 & & 0.00134 & & 0.00134 & & 0.00135 \\
\hline 0.8 & & 0.00118 & & 0.00118 & & 0.00118 & & 0.00118 & & 0.00118 & & 0.00118 & & 0.00119 \\
\hline 0.9 & & 0.00105 & & 0.00105 & & 0.00105 & & 0.00105 & & 0.00105 & & 0.00106 & & 0.00106 \\
\hline 1 & & 0.00095 & & 0.00095 & & 0.00095 & & 0.00095 & & 0.00095 & & 0.00096 & & 0.00096 \\
\hline 2 & & 0.00049 & & 0.00049 & & 0.00050 & & 0.00050 & & 0.00051 & & 0.00052 & & 0.00054 \\
\hline 3 & & 0.00034 & & 0.00034 & & 0.00035 & & 0.00035 & & 0.00037 & & 0.00040 & & 0.00045 \\
\hline 4 & & 0.00026 & & 0.00027 & & 0.00027 & & 0.00028 & & 0.00032 & & 0.00036 & & 0.00046 \\
\hline 5 & & 0.00022 & & 0.00023 & & 0.00023 & & 0.00025 & & 0.00031 & & 0.00037 & & 0.00053 \\
\hline 6 & & 0.00019 & & 0.00020 & & 0.00021 & & 0.00023 & & 0.00032 & & 0.00041 & & 0.00063 \\
\hline 7 & & 0.00017 & & 0.00019 & & 0.00020 & & 0.00023 & & 0.00035 & & 0.00047 & & 0.00077 \\
\hline 8 & & 0.00015 & & 0.00017 & & 0.00019 & & 0.00023 & & 0.00039 & & 0.00054 & & 0.00094 \\
\hline 9 & & 0.00014 & & 0.00017 & & 0.00019 & & 0.00024 & & 0.00044 & & 0.00064 & & 0.00113 \\
\hline 10 & & 0.00013 & & 0.00016 & & 0.00019 & & 0.00025 & & 0.00050 & & 0.00074 & & 0.00135 \\
\hline 20 & & 0.00008 & & 0.00023 & & 0.00033 & & 0.00057 & & 0.00155 & & 0.00252 & & 0.00496 \\
\hline 30 & & 0.00007 & & 0.00040 & & 0.00062 & & 0.00116 & & 0.00336 & & 0.00554 & & 0.01099 \\
\hline 40 & & 0.00006 & & 0.00064 & & 0.00103 & & 0.00201 & & 0.00589 & & 0.00977 & & 0.01938 \\
\hline 50 & & 0.00005 & & 0.00097 & & 0.00158 & & 0.00310 & & 0.00915 & & 0.01517 & & 0.03006 \\
\hline 60 & & 0.00005 & & 0.00137 & & 0.00224 & & 0.00443 & & 0.01312 & & 0.02174 & & 0.04296 \\
\hline 70 & & 0.00005 & & 0.00184 & & 0.00303 & & 0.00600 & & 0.01780 & & 0.02945 & & 0.05799 \\
\hline 80 & & 0.00005 & & 0.00238 & & 0.00394 & & 0.00781 & & 0.02316 & & 0.03827 & & 0.07503 \\
\hline 90 & & 0.00005 & & 0.00300 & & 0.00497 & & 0.00986 & & 0.02920 & & 0.04817 & & 0.09398 \\
\hline 100 & & 0.00005 & & 0.00369 & & 0.00612 & & 0.01215 & & 0.03592 & & 0.05911 & & 0.11469 \\
\hline
\end{tabular}




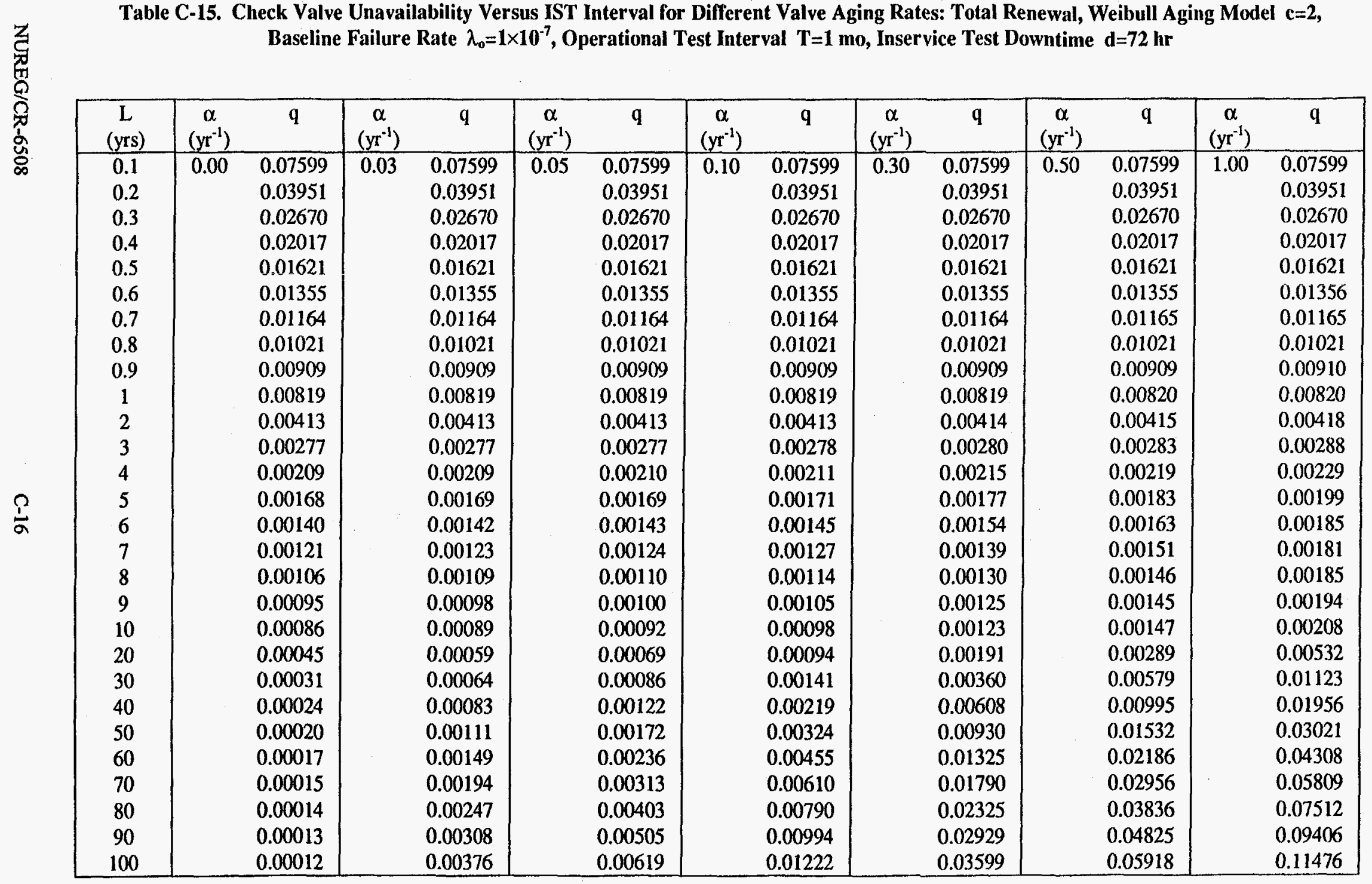




\begin{tabular}{|c|c|c|}
\hline $\begin{array}{l}\text { in } \\
\bar{\Xi} \\
\frac{\pi}{\Sigma}\end{array}$ & 8 & 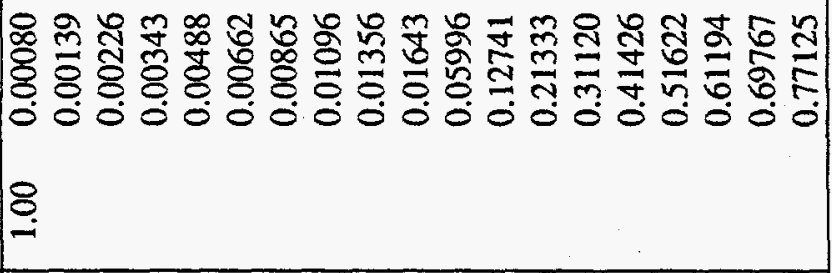 \\
\hline 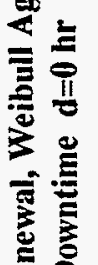 & 87 & 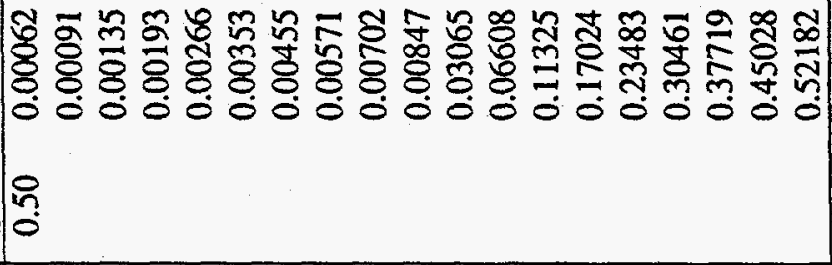 \\
\hline 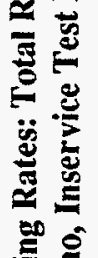 & 8 & 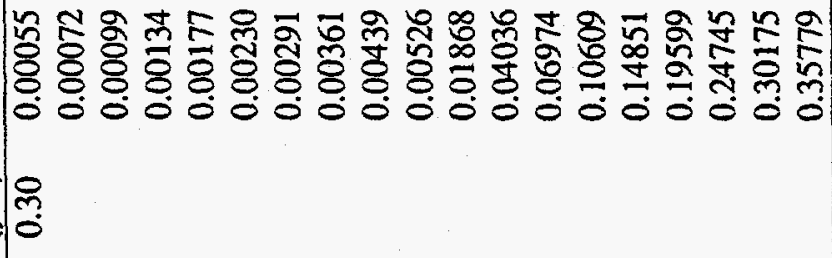 \\
\hline 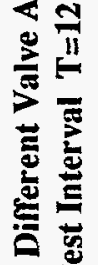 & $8 \div$ & 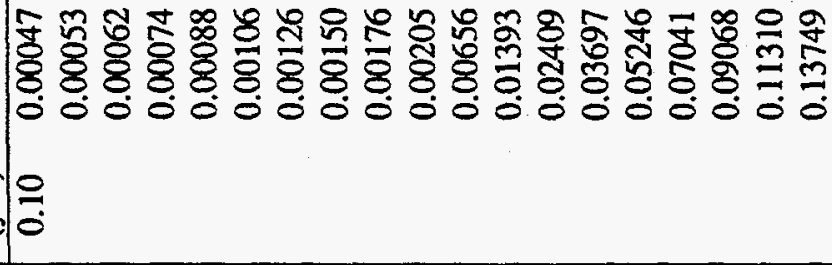 \\
\hline 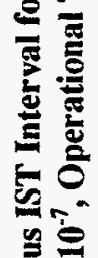 & 8 & 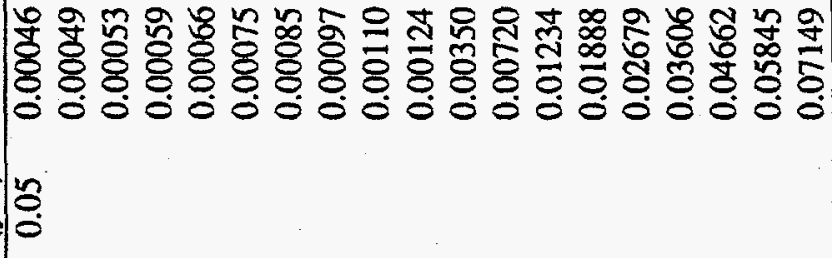 \\
\hline 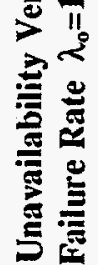 & 87 & 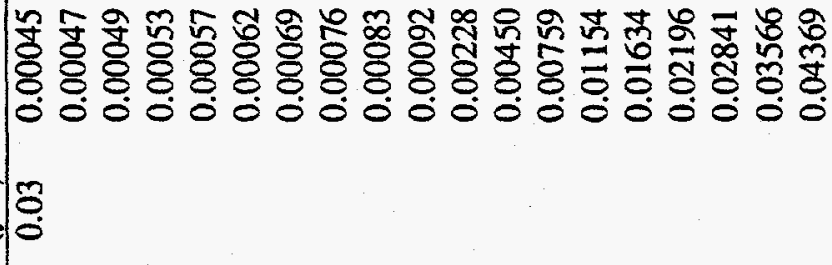 \\
\hline 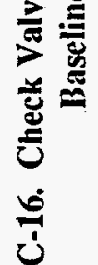 & 85 & 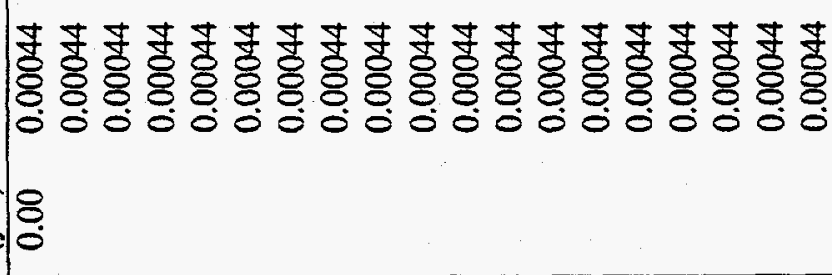 \\
\hline & -2 & 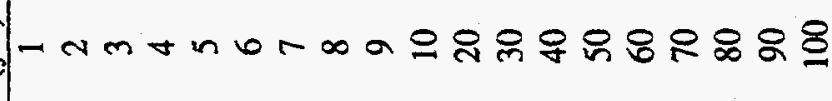 \\
\hline
\end{tabular}




\begin{tabular}{|c|c|c|c|c|c|c|c|}
\hline $9 Z \mathrm{I} \angle L O 0$ & E8IZS 0 & $08 \angle S E^{\circ} 0$ & OSLEIO & OSI $\angle 0^{\circ} 0$ & $0 \angle \varepsilon+0^{\circ} 0$ & $s+000^{\circ} 0$ & $00 \mathrm{I}$ \\
\hline $89 \angle 69^{\circ} 0$ & $6205+0$ & 9LIOEO & IIEII'0 & $9 \$ 8 \mathrm{SO}^{\circ} 0$ & $\angle 9 S E 0^{\circ} 0$ & $\$ t 000^{\circ} 0$ & 06 \\
\hline $56119^{\circ} 0$ & OZLLEO & $9 \triangleright \angle \downarrow \tau 0$ & $69060^{\circ} 0$ & $\$ 99 t 0^{\circ} 0$ & $2 \downarrow 820^{\circ} 0$ & $s t 000^{\circ} 0$ & 08 \\
\hline troIs 0 & $29+0 \varepsilon 0$ & $0096 I^{\circ} 0$ & $\tau \succcurlyeq 0 \angle 0^{\circ} 0$ & $\angle 0980^{\circ} 0$ & $86120^{\circ} 0$ & $S t 000^{\circ} 0$ & $0 L$ \\
\hline LてヤIヤ0 & $+8+\varepsilon z^{\circ} 0$ & $\varepsilon S 8+I^{\circ} 0$ & $\angle t Z S 0^{\circ} 0$ & $18920^{\circ} 0$ & SE910'0 & $S t 000^{\circ} 0$ & 09 \\
\hline ZZIIEO & $9 Z 0 \angle I^{\circ} 0$ & II $90 I^{\circ} 0$ & $669 \varepsilon 0^{\circ} 0$ & $68810^{\circ} 0$ & $9 S \operatorname{II} 0^{\circ} 0$ & $9 t 000^{\circ} 0$ & $0 S$ \\
\hline 9EEIZ 0 & LZEIIO & $9 \angle 690^{\circ} 0$ & $z I \forall Z 0^{\circ} 0$ & $9 E Z\left[0^{\circ} 0\right.$ & $29 \angle 00^{\circ} 0$ & $9+000^{\circ} 0$ & $0 t$ \\
\hline$\varpi t \angle Z I^{\circ} 0$ & I $\left[990^{\circ} 0\right.$ & $6 \varepsilon 0+0^{\circ} 0$ & $96 \varepsilon 10^{\circ} 0$ & $\nabla C \angle 00^{\circ} 0$ & $\varepsilon S t 00^{\circ} 0$ & $\angle D 000^{\circ} 0$ & $O E$ \\
\hline $00090^{\circ} 0$ & $0 \angle O E 0^{\circ} 0$ & ZL810 0 & $09900^{\circ} 0$ & SSE $00^{\circ} 0$ & $z \varepsilon Z 00^{\circ} 0$ & $8+000^{\circ} 0$ & $0 z$ \\
\hline ¿S9I00 & $95800^{\circ} 0$ & $9 \varepsilon S 00^{\circ} 0$ & $t I Z 00^{\circ} 0$ & $\downarrow E I 00^{\circ} 0$ & $10100^{\circ} 0$ & $\varepsilon S 000^{\circ} 0$ & OI \\
\hline $99 \varepsilon 10^{\circ} 0$ & $\tau I \angle 00^{\circ} 0$ & $6 t+00^{\circ} 0$ & $98100^{\circ} 0$ & $0 Z 100^{\circ} 0$ & $t 6000^{\circ} 0$ & $t S 000^{\circ} 0$ & 6 \\
\hline $80110^{\circ} 0$ & $\mathrm{ESSO0}^{\circ} 0$ & ZLEO0 0 & I9L00 0 & $80100^{\circ} 0$ & $\angle 8000^{\circ} 0$ & $\$ \$ 000^{\circ} 0$ & 8 \\
\hline $8 \angle 800^{\circ} 0$ & $89+00^{\circ} 0$ & t0E00 0 & $6 E 100^{\circ} 0$ & $86000^{\circ} 0$ & $28000^{\circ} 0$ & $\angle S 000^{\circ} 0$ & $L$ \\
\hline$\angle L 900^{\circ} 0$ & $69 \varepsilon 00^{\circ} 0$ & $s+200^{\circ} 0$ & $\operatorname{IZI00^{\circ }0}$ & $06000^{\circ} 0$ & $8 \angle 000^{\circ} 0$ & 650000 & 9 \\
\hline $90500^{\circ} 0$ & $\$ 8 z 00^{\circ} 0$ & $\$ 6 \mathrm{~L} 00^{\circ} 0$ & $\angle 01000$ & $\dot{18000} 0$ & $S \angle 000^{\circ} 0$ & $z 90000$ & 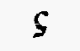 \\
\hline$\$ 9 \varepsilon 000^{\circ}$ & $91200^{\circ} 0$ & $9 S 100^{\circ} 0$ & $\angle 6000^{\circ} 0$ & $28000^{\circ} 0$ & $9 \angle 000^{\circ} 0$ & $\angle 9000^{\circ} 0$ & $\downarrow$ \\
\hline $9 S 200^{\circ} 0$ & $\$ 9100^{\circ} 0$ & $6 \mathrm{Z} 100^{\circ} 0$ & $26000^{\circ} 0$ & $\varepsilon 8000^{\circ} 0$ & $08000^{\circ} 0$ & $\nabla L 000^{\circ} 0$ & $\mathcal{\varepsilon}$ \\
\hline $18100^{\circ} 0$ & $\angle E I 00^{\circ} 0$ & $81100^{\circ} 0$ & $66000^{\circ} 0$ & $t 6000^{\circ} 0$ & $26000^{\circ} 0$ & $68000^{\circ} 0$ & $\tau$ \\
\hline$Z \angle I 00^{\circ} 0 \quad 00^{\circ} \mathrm{I}$ & $\mathcal{E S I 0 0 ^ { \circ } 0}$ & $90 \mathrm{I} 00^{\circ} 0 \quad O E^{\circ} 0$ & $6 \varepsilon 100^{\circ} 0$ & $\angle E I 00^{\circ} 0 \quad S 0^{\circ} 0$ & $9 \varepsilon 100^{\circ} 0$ & SEIO0 0 & I \\
\hline $\begin{array}{lc} & (\mathrm{I} K) \\
\text { b } & 0\end{array}$ & 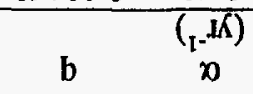 & 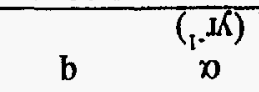 & $\begin{array}{ll}\text { b } & (\mathrm{IK}) \\
\mathrm{I}\end{array}$ & b $\quad \begin{array}{c}(\mathrm{I}-\mathrm{IK}) \\
\boldsymbol{n}\end{array}$ & $\left(\begin{array}{c}t-1 K) \\
0\end{array}\right.$ & $\left(\begin{array}{c}1 . \cdot K) \\
0\end{array}\right.$ & $\begin{array}{c}(\mathbf{S I K}) \\
\mathrm{T}\end{array}$ \\
\hline
\end{tabular}

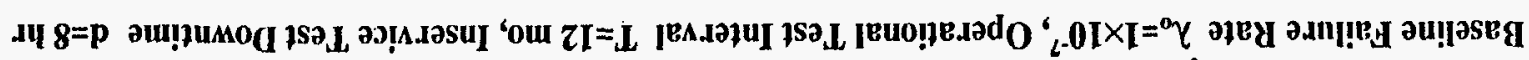


Table C-18. Check Valve Unavailability Versus IST Interval for Different Valve Aging Rates: Total Renewal, Weibull Aging Model $\mathrm{c}=2$, Baseline Failure Rate $\lambda_{0}=1 \times 10^{-7}$, Operational Test Interval $T=12 \mathrm{mo}$, Inservice Test Downtime $d=72 \mathrm{hr}$

\begin{tabular}{|c|c|c|c|c|c|c|c|c|c|c|c|c|c|c|}
\hline $\begin{array}{c}\mathrm{L} \\
(\mathrm{yrs})\end{array}$ & $\begin{array}{c}\alpha \\
\left(\mathrm{yr}^{-1}\right)\end{array}$ & $q$ & $\begin{array}{c}\alpha \\
\left(\mathrm{yr}^{-1}\right)\end{array}$ & $q$ & $\begin{array}{c}\alpha \\
\left(\mathrm{yr}^{-1}\right)\end{array}$ & $q$ & $\begin{array}{c}\alpha \\
\left(\mathrm{yr}^{-1}\right)\end{array}$ & $q$ & $\underset{\left(\mathrm{yr}^{-1}\right)}{\alpha}$ & $q$ & $\begin{array}{c}\alpha \\
\left(\mathrm{yr}^{-1}\right)\end{array}$ & $q$ & $\begin{array}{c}\alpha \\
\left(\mathrm{yr}^{-1}\right)\end{array}$ & $q$ \\
\hline 1 & 0.00 & 0.00859 & 0.03 & 0.00860 & 0.05 & 0.00861 & 0.10 & 0.00863 & 0.30 & 0.00870 & 0.50 & 0.00877 & 1.00 & 0.00895 \\
\hline 2 & & 0.00453 & & 0.00456 & & 0.00458 & & 0.00463 & & 0.00482 & & 0.00500 & & 0.00548 \\
\hline 3 & & 0.00317 & & 0.00322 & & 0.00326 & & 0.00335 & & 0.00372 & & 0.00408 & & 0.00499 \\
\hline 4 & & 0.00249 & & 0.00258 & & 0.00264 & & 0.00279 & & 0.00339 & & 0.00398 & & 0.00548 \\
\hline 5 & & 0.00208 & & 0.00221 & & 0.00230 & & 0.00252 & & 0.00341 & & 0,00430 & & 0.00652 \\
\hline 6 & & 0.00181 & & 0.00199 & & 0.00212 & & 0.00243 & & 0.00366 & & 0.00490 & & 0.00799 \\
\hline 7 & & 0.00161 & & 0.00186 & & 0.00202 & & 0.00243 & & 0.00408 & & 0.00572 & & 0.00982 \\
\hline 8 & & 0.00146 & & 0.00178 & & 0.00199 & & 0.00252 & & 0.00463 & & 0.00674 & & 0.01199 \\
\hline 9 & & 0.00135 & & 0.00175 & & 0.00201 & & 0.00267 & & 0.00530 & & 0.00793 & & 0.01447 \\
\hline 10 & & 0.00126 & & 0.00174 & & 0.00207 & & 0.00287 & & 0.00609 & & 0.00929 & & 0.01726 \\
\hline 20 & & 0.00085 & & 0.00269 & & 0.00391 & & 0.00697 & & 0.01909 & & 0.03107 & & 0.06037 \\
\hline 30 & & 0.00071 & & 0.00478 & & 0.00748 & & 0.01420 & & 0.04063 & & 0.06635 & & 0.12769 \\
\hline 40 & & 0.00064 & & 0.00780 & & 0.01254 & & 0.02430 & & 0.06995 & & 0.11346 & & 0.21354 \\
\hline 50 & & 0.00060 & & 0.01171 & & 0.01904 & & 0.03714 & & 0.10625 & & 0.17041 & & 0.31137 \\
\hline 60 & & 0.00057 & & 0.01647 & & 0.02693 & & 0.05259 & & 0.14865 & & 0.23496 & & 0.41439 \\
\hline 70 & & 0.00056 & & 0.02208 & & 0.03617 & & 0.07052 & & 0.19611 & & 0.30473 & & 0.51634 \\
\hline 80 & & 0.00054 & & 0.02851 & & 0.04673 & & 0.09078 & & 0.24755 & & 0.37729 & & 0.61204 \\
\hline 90 & & 0.00053 & & 0.03575 & & 0.05854 & & 0.11319 & & 0.30184 & & 0.45037 & & 0.69777 \\
\hline 100 & & 0.00052 & & 0.04378 & & 0.07157 & & 0.13757 & & 0.35787 & & 0.52191 & & 0.77133 \\
\hline
\end{tabular}


Table C-19. Check Valve Unavailability Versus IST Interval for Different Valve Aging Rates: Nonrenewal, No Intermediate Testing, Baseline Failure Rate $\lambda_{0}=1 \times 10^{-6}$, Inservice Test Downtime $d=0 \mathrm{hr}$, Valve Life $s=40 \mathrm{yrs}$, Weibull Aging Model $c=2$

\begin{tabular}{|c|cc|cc|cc|cc|}
\hline $\begin{array}{c}\mathrm{L} \\
(\mathrm{yrs})\end{array}$ & $\begin{array}{c}\alpha \\
\left(\mathrm{yr}^{-1}\right)\end{array}$ & $\mathrm{q}$ & $\begin{array}{c}\alpha \\
\left(\mathrm{yr}^{-1}\right)\end{array}$ & $\mathrm{q}$ & $\begin{array}{c}\alpha \\
\left(\mathrm{yr}^{-1}\right)\end{array}$ & $\mathrm{q}$ & $\begin{array}{c}\alpha \\
\left(\mathrm{yr}^{-1}\right)\end{array}$ \\
\hline 0.1 & 0.00 & 0.00044 & 0.10 & 0.02357 & 0.50 & 0.11089 & 1.00 & 0.20913 \\
0.2 & & 0.00088 & & 0.04670 & & 0.20994 & & 0.37526 \\
0.3 & & 0.00131 & & 0.06940 & 0.29837 & 0.50707 \\
0.4 & & 0.00175 & & 0.09166 & & 0.37727 & 0.61153 \\
0.5 & & 0.00219 & & 0.11349 & 0.44763 & 0.69422 \\
0.6 & & 0.00262 & & 0.13490 & 0.51033 & 0.75959 \\
0.7 & & 0.00306 & & 0.15589 & 0.56617 & 0.81121 \\
0.8 & & 0.00350 & & 0.17647 & 0.61587 & 0.85193 \\
0.9 & & 0.00393 & & 0.19665 & 0.66009 & 0.88400 \\
1 & & 0.00437 & & 0.21643 & 0.69939 & 0.90924 \\
2 & & 0.00872 & & 0.39341 & 0.91495 & 0.99270 \\
3 & & 0.01305 & & 0.53628 & 0.97740 & 0.99948 \\
4 & & 0.01737 & & 0.65007 & 0.99437 & 0.99997 \\
5 & 0.02166 & & 0.73947 & 0.99869 & 1.00000 \\
6 & 0.02594 & 0.80870 & 0.99972 & 1.00000 \\
7 & 0.03019 & 0.86152 & 0.99994 & 1.00000 \\
8 & & 0.03443 & & 0.90123 & 0.99999 & 1.00000 \\
9 & & 0.03865 & & 0.93061 & 1.00000 & 1.00000 \\
10 & 0.04285 & & 0.95201 & 1.00000 & 1.00000 \\
20 & 0.08387 & 0.99954 & 1.00000 & 1.00000 \\
30 & 0.12313 & 1.00000 & 1.00000 & 1.00000 \\
40 & 0.16071 & 1.00000 & 1.00000 & 1.00000 \\
50 & 0.19668 & 1.00000 & 1.00000 & 1.00000 \\
60 & 0.23110 & 1.00000 & 1.00000 & 1.00000 \\
70 & 0.26406 & 1.00000 & 1.00000 & 1.00000 \\
80 & 0.2959 & 1.00000 & 1.00000 & 1.00000 \\
90 & 0.32578 & 1.00000 & 1.00000 & 1.00000 \\
100 & 0.35467 & 1.00000 & 1.00000 & 1.00000 \\
\hline
\end{tabular}




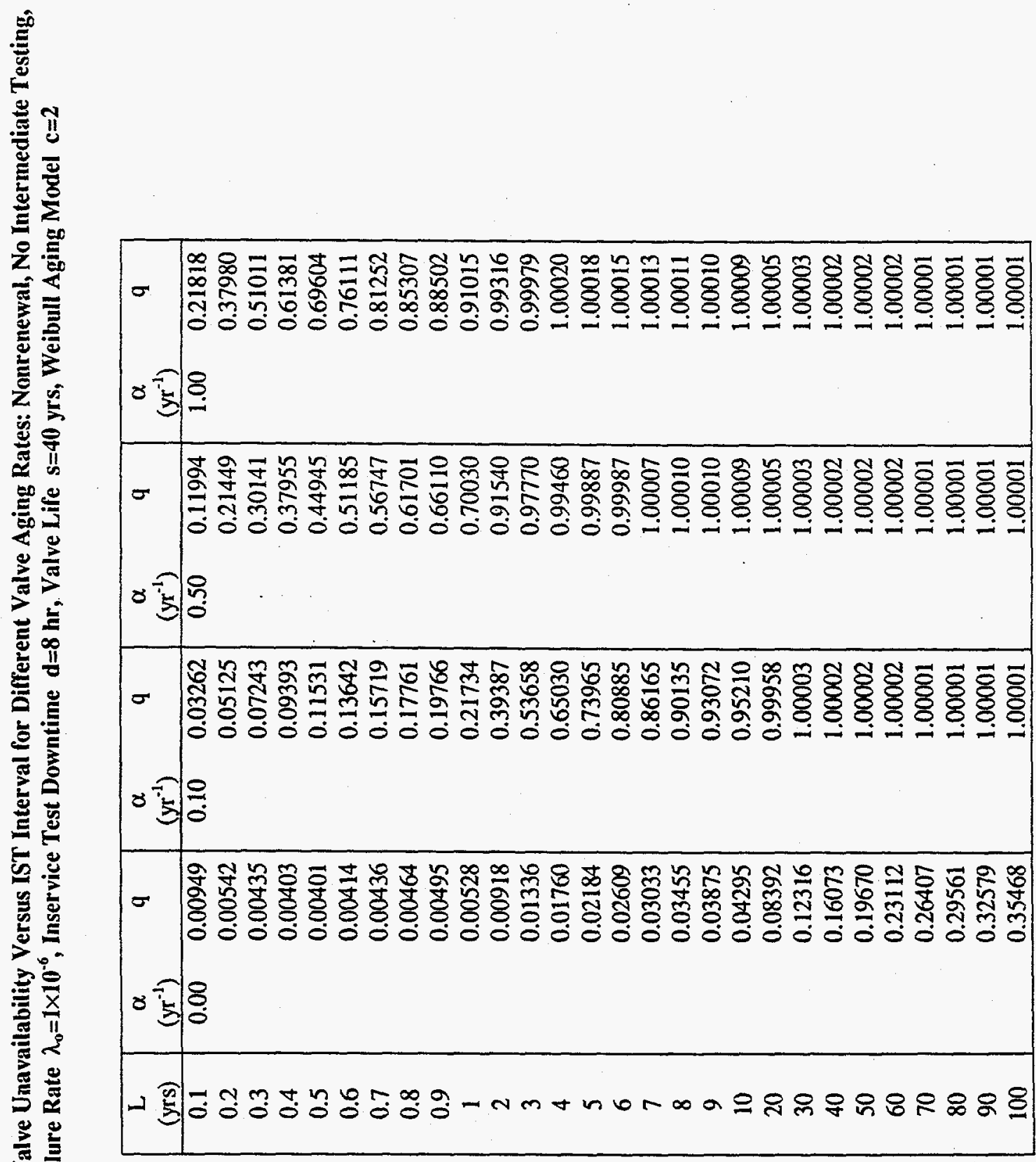


噶

\begin{tabular}{|c|c|}
\hline$\sigma$ & 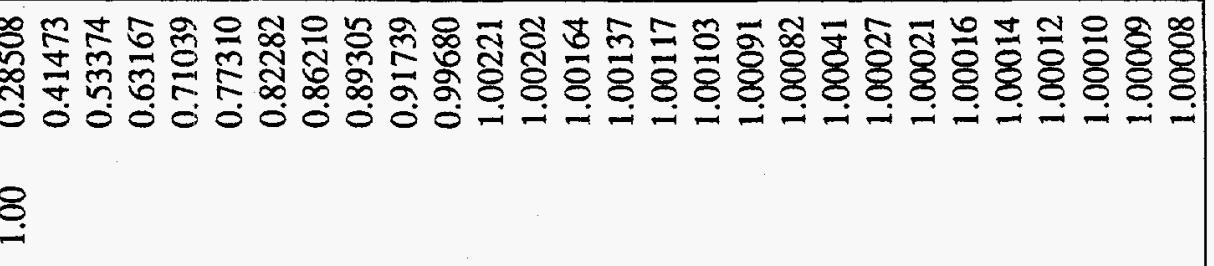 \\
\hline$\sigma$ & 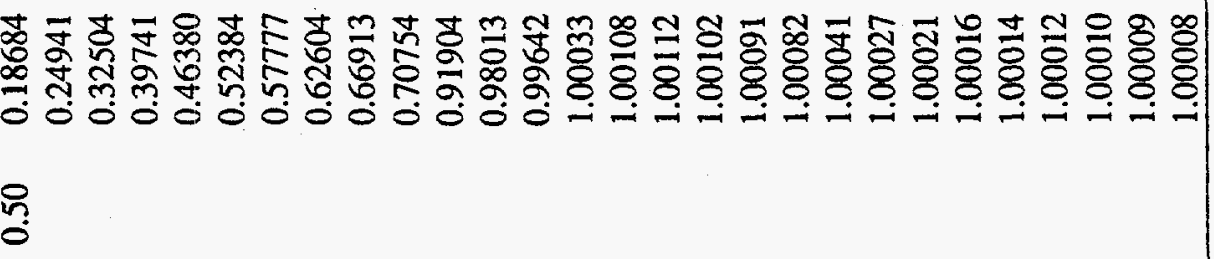 \\
\hline$\sigma$ & 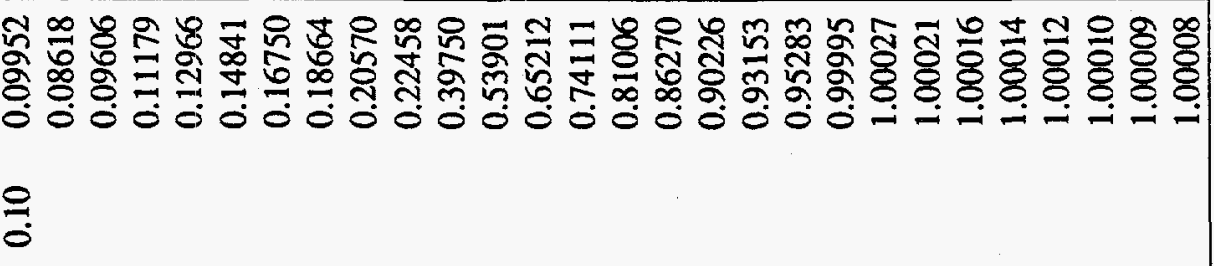 \\
\hline$\sigma$ & 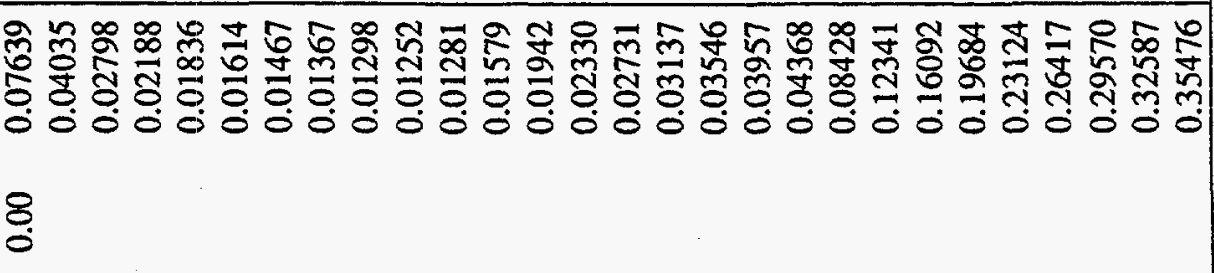 \\
\hline & $x-a m+i$ \\
\hline
\end{tabular}


:

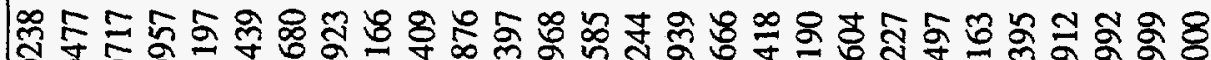
- 施 $\int_{0}$

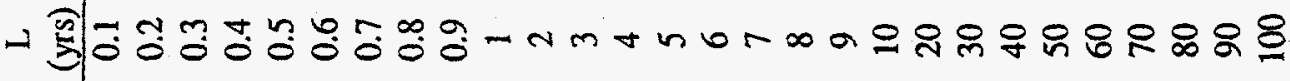


Table C-23. Check Valve Unavailability Versus IST Interval for Different Valve Aging Rates: Nonrenewal, No Intermediate Testing, Baseline Failure Rate $\lambda_{v}=1 \times 10^{-7}$, Inservice Test Downtime $d=8 \mathrm{hr}$; Valve Life $s=40 \mathrm{yrs}$, Weibull Aging Model $c=2$

\begin{tabular}{|c|c|c|c|c|c|c|c|c|}
\hline $\begin{array}{c}\mathrm{L} \\
\text { (yrs) }\end{array}$ & $\begin{array}{c}\alpha \\
\left(y \pi^{-1}\right)\end{array}$ & $q$ & $\begin{array}{c}\alpha \\
\left(y r^{-1}\right)\end{array}$ & $q$ & $\underset{\left(y r^{-1}\right)}{\alpha}$ & $q$ & $\begin{array}{c}\alpha \\
\left(\mathrm{yr}^{-1}\right)\end{array}$ & $q$ \\
\hline 0.1 & 0.00 & 0.00909 & 0.10 & 0.01143 & 0.50 & 0.02073 & 1.00 & 0.03224 \\
\hline 0.2 & & 0.00463 & & 0.00932 & & 0.02783 & & 0.05050 \\
\hline 0.3 & & 0.00317 & & 0.01020 & & 0.03785 & & 0.07133 \\
\hline 0.4 & & 0.00245 & & 0.01184 & & 0.04854 & & 0.09250 \\
\hline 0.5 & & 0.00204 & & 0.01380 & & 0.05945 & & 0.11356 \\
\hline 0.6 & & 0.00178 & & 0.01591 & & 0.07043 & & 0.13437 \\
\hline 0.7 & & 0.00161 & & 0.01811 & & 0.08142 & & 0.15486 \\
\hline 0.8 & & 0.00149 & & 0.02037 & & 0.09238 & & 0.17501 \\
\hline 0.9 & & 0.00141 & & 0.02267 & & 0.10330 & & 0.19481 \\
\hline 1 & & 0.00135 & & 0.02501 & & 0.11416 & & 0.21425 \\
\hline 2 & & 0.00133 & & 0.04922 & & 0.21888 & & 0.38907 \\
\hline 3 & & 0.00162 & & 0.07427 & & 0.31574 & & 0.53107 \\
\hline 4 & & 0.00198 & & 0.09991 & & 0.40452 & & 0.64474 \\
\hline 5 & & 0.00237 & & 0.12603 & & 0.48527 & & 0.73446 \\
\hline 6 & & 0.00278 & & 0.15259 & & 0.55815 & & 0.80427 \\
\hline 7 & & 0.00319 & & 0.17952 & & 0.62342 & & 0.85778 \\
\hline 8 & & 0.00361 & & 0.20677 & & 0.68140 & & 0.89818 \\
\hline 9 & & 0.00404 & & 0.23428 & & 0.73250 & & 0.92821 \\
\hline 10 & & 0.00446 & & 0.26199 & & 0.77716 & & 0.95017 \\
\hline 20 & & 0.00877 & & 0.53609 & & 0.97778 & & 0.99955 \\
\hline 30 & & 0.01308 & & 0.76231 & & 0.99923 & & 1.00003 \\
\hline 40 & & 0.01739 & & 0.90499 & & 1.00001 & & 1.00002 \\
\hline 50 & & 0.02168 & & 0.97165 & & 1.00002 & & 1.00002 \\
\hline 60 & & 0.02595 & & 0.99396 & & 1.00002 & & 1.00002 \\
\hline 70 & & 0.03021 & & 0.99913 & & 1.00001 & & 1.00001 \\
\hline 80 & & 0.03444 & & 0.99993 & & 1.00001 & & 1.00001 \\
\hline 90 & & 0.03866 & & 1.00001 & & 1.00001 & & 1.00001 \\
\hline 100 & & 0.04286 & & 1.00001 & & 1.00001 & & 1.00001 \\
\hline
\end{tabular}


Table C-24. Check Valve Unavailability Versus IST Interval for Different Valve Aging Rates: Nonrenewal, No Intermediate Testing, Baseline Failure Rate $\lambda_{0}=1 \times 10^{-7}$, Inservice Test Downtime $d=72 \mathrm{hr}$, Valve Life $s=40 \mathrm{yrs}$, Weibull Aging Model $c=2$

\begin{tabular}{|c|c|c|c|c|c|c|c|c|}
\hline $\begin{array}{c}\mathrm{L} \\
\text { (yrs) }\end{array}$ & $\begin{array}{c}\alpha \\
\left(\mathrm{yr}^{-1}\right)\end{array}$ & $q$ & $\begin{array}{c}\alpha \\
\left(y r^{-1}\right)\end{array}$ & $q$ & $\begin{array}{c}\alpha \\
\left(\mathrm{yr}^{-1}\right)\end{array}$ & $q$ & $\begin{array}{c}\alpha \\
\left(\mathrm{yr}^{-1}\right)\end{array}$ & $q$ \\
\hline 0.1 & 0.00 & 0.07599 & 0.10 & 0.07833 & 0.50 & 0.08763 & 1.00 & 0.09914 \\
\hline 0.2 & & 0.03956 & & 0.04425 & & 0.06276 & & 0.08543 \\
\hline 0.3 & & 0.02680 & & 0.03383 & & 0.06148 & & 0.09496 \\
\hline 0.4 & & 0.02031 & & 0.02970 & & 0.06639 & & 0.11036 \\
\hline 0.5 & & 0.01639 & & 0.02815 & & 0.07380 & & 0.12791 \\
\hline 0.6 & & 0.01378 & & 0.02790 & & 0.08243 & & 0.14636 \\
\hline 0.7 & & 0.01191 & & 0.02841 & & 0.09172 & & 0.16516 \\
\hline 0.8 & & 0.01052 & & 0.02940 & & 0.10141 & & 0.18404 \\
\hline 0.9 & & 0.00944 & & 0.03071 & & 0.11134 & & 0.20285 \\
\hline 1 & & 0.00859 & & 0.03225 & & 0.12140 & & 0.22149 \\
\hline 2 & & 0.00497 & & 0.05285 & & 0.22252 & & 0.39270 \\
\hline 3 & & 0.00405 & & 0.07670 & & 0.31817 & & 0.53349 \\
\hline 4 & & 0.00380 & & 0.10173 & & 0.40634 & & 0.64656 \\
\hline 5 & & 0.00383 & & 0.12749 & & 0.48673 & & 0.73592 \\
\hline 6 & & 0.00399 & & 0.15380 & & 0.55936 & & 0.80548 \\
\hline 7 & & 0.00423 & & 0.18056 & & 0.62446 & & 0.85882 \\
\hline 8 & & 0.00452 & & 0.20768 & & 0.68232 & & 0.89909 \\
\hline 9 & & 0.00485 & & 0.23509 & & 0.73331 & & 0.92902 \\
\hline 10 & & 0.00519 & & 0.26272 & & 0.77789 & & 0.95090 \\
\hline 20 & & 0.00913 & & 0.53645 & & 0.97815 & & 0.99991 \\
\hline 30 & & 0.01333 & & 0.76255 & & 0.99947 & & 1.00027 \\
\hline 40 & & 0.01757 & & 0.90517 & & 1.00020 & & 1.00021 \\
\hline 50 & & 0.02183 & & 0.97179 & & 1.00016 & & 1.00016 \\
\hline 60 & & 0.02607 & & 0.99408 & & 1.00014 & & 1.00014 \\
\hline 70 & & 0.03031 & & 0.99923 & & 1,00012 & & 1.00012 \\
\hline 80 & & 0.03454 & & 1.00002 & & 1.00010 & & 1.00010 \\
\hline 90 & & 0.03874 & & 1.00009 & & 1.00009 & & 1.00009 \\
\hline 100 & & 0.04294 & & 1.00008 & & 1.00008 & & 1.00008 \\
\hline
\end{tabular}


Table C-25. Check Valve Unavailability Versus IST Interval for Different Valve Aging Rates: Nonrenewal, No Intermediate Testing, Baseline Failure Rate $\lambda_{0}=1 \times 10^{-6}$, Inservice Test Downtime $d=0 \mathrm{hr}$, Valve Life $s=40 \mathrm{yrs}$, Weibull Aging Model $c=3$

\begin{tabular}{|c|c|c|c|c|c|c|c|c|}
\hline $\begin{array}{c}\mathrm{L} \\
\text { (yrs) }\end{array}$ & $\begin{array}{c}\alpha \\
\left(\mathrm{yr}^{-1}\right)\end{array}$ & $q$ & $\begin{array}{c}\alpha \\
\left(\mathrm{yr}^{-1}\right)\end{array}$ & $q$ & $\begin{array}{c}\alpha \\
\left(\mathrm{yr}^{-1}\right)\end{array}$ & $\mathbf{q}$ & $\underset{\left(\mathrm{yr}^{-1}\right)}{\alpha}$ & $q$ \\
\hline 0.1 & 0.00 & 0.00044 & 0.10 & 0.50519 & 0.50 & 0.97029 & 1.00 & 0.99912 \\
\hline 0.2 & & 0.00088 & & 0.75631 & & 0.99914 & & 1.00000 \\
\hline 0.3 & & 0.00131 & & 0.88055 & & 0.99998 & & 1.00000 \\
\hline 0.4 & & 0.00175 & & 0.94173 & & 1.00000 & & 1.00000 \\
\hline 0.5 & & 0.00219 & & 0.97171 & & 1.00000 & & 1.00000 \\
\hline 0.6 & & 0.00262 & & 0.98633 & & 1.00000 & & 1.00000 \\
\hline 0.7 & & 0.00306 & & 0.99343 & & 1.00000 & & 1.00000 \\
\hline 0.8 & & 0.00350 & & 0.99685 & & 1.00000 & & 1.00000 \\
\hline 0.9 & & 0.00393 & & 0.99850 & & 1.00000 & & 1.00000 \\
\hline 1 & & 0.00437 & & 0.99929 & & 1.00000 & & 1.00000 \\
\hline 2 & & 0.00872 & & 1.00000 & & 1.00000 & & 1.00000 \\
\hline 3 & & 0.01305 & & 1.00000 & & 1.00000 & & 1.00000 \\
\hline 4 & & 0.01737 & & 1.00000 & & 1.00000 & & 1.00000 \\
\hline 5 & & 0.02166 & & 1.00000 & & 1.00000 & & 1.00000 \\
\hline 6 & & 0.02594 & & 1.00000 & & 1.00000 & & 1.00000 \\
\hline 7 & & 0.03019 & & 1.00000 & & 1.00000 & & 1.00000 \\
\hline 8 & & 0.03443 & & 1.00000 & & 1.00000 & & 1.00000 \\
\hline 9 & & 0.03865 & & 1.00000 & & 1.00000 & & 1.00000 \\
\hline 10 & & 0.04285 & & 1.00000 & & 1.00000 & & 1.00000 \\
\hline 20 & & 0.08387 & & 1.00000 & & 1.00000 & & 1.00000 \\
\hline 30 & & 0.12313 & & 1.00000 & & 1.00000 & & 1.00000 \\
\hline 40 & & 0.16071 & & 1.00000 & & 1.00000 & & 1.00000 \\
\hline 50 & & 0.19668 & & 1.00000 & & 1.00000 & & 1.00000 \\
\hline 60 & & 0.23110 & & 1.00000 & & 1.00000 & & 1.00000 \\
\hline 70 & & 0.26406 & & 1.00000 & & 1.00000 & & 1.00000 \\
\hline 80 & & 0.29559 & & 1.00000 & & 1.00000 & & 1.00000 \\
\hline 90 & & 0.32578 & & 1.00000 & & 1.00000 & & 1.00000 \\
\hline 100 & & 0.35467 & & 1.00000 & & 1.00000 & & 1.00000 \\
\hline
\end{tabular}


Table C-26. Check Valve Unavailability Versus IST Interval for Different Valve Aging Rates: Nonrenewal, No Intermediate Testing, Baseline Failure Rate $\lambda_{0}=1 \times 10^{-6}$, Inservice Test Downtime $d=8 \mathrm{hr}$, Valve Life $s=40 \mathrm{yrs}$, Weibull Aging Model $c=3$

\begin{tabular}{|c|cc|cc|cc|cc|}
\hline $\begin{array}{c}\mathrm{L} \\
\text { (yrs) }\end{array}$ & $\begin{array}{c}\alpha \\
\left(\mathrm{yr}^{-1}\right)\end{array}$ & $\mathrm{q}$ & $\begin{array}{c}\alpha \\
\left(\mathrm{yr}^{-1}\right)\end{array}$ & $\mathrm{q}$ & $\begin{array}{c}\alpha \\
\left(\mathrm{yr}^{-1}\right)\end{array}$ & $\mathrm{q}$ & $\begin{array}{c}\alpha \\
\left(\mathrm{yr}^{-1}\right)\end{array}$ \\
\hline 0.1 & 0.00 & 0.00949 & 0.10 & 0.51424 & 0.50 & 0.97934 & 1.00 & 1.00817 \\
0.2 & & 0.00542 & & 0.76085 & & 1.00368 & & 1.00454 \\
0.3 & & 0.00435 & & 0.88358 & & 1.00301 & 1.00303 \\
0.4 & & 0.00403 & & 0.94400 & & 1.00228 & 1.00228 \\
0.5 & & 0.00401 & & 0.97353 & & 1.00182 & 1.00182 \\
0.6 & & 0.00414 & & 0.98785 & 1.00152 & 1.00152 \\
0.7 & & 0.00436 & & 0.99473 & 1.00130 & 1.00130 \\
0.8 & & 0.00464 & & 0.99799 & & 1.00114 & 1.00114 \\
0.9 & & 0.00495 & & 0.99952 & & 1.00101 & 1.00101 \\
1 & & 0.00528 & & 1.00020 & 1.00091 & 1.00091 \\
2 & & 0.00918 & & 1.00046 & 1.00046 & 1.00046 \\
3 & & 0.01336 & & 1.00030 & 1.00030 & 1.00030 \\
4 & & 0.01760 & & 1.00023 & & 1.00023 & 1.00023 \\
5 & & 0.02184 & & 1.00018 & 1.00018 & 1.00018 \\
6 & & 0.02609 & & 1.00015 & 1.00015 & 1.00015 \\
7 & & 0.03033 & & 1.00013 & & 1.00013 & 1.00013 \\
8 & & 0.03455 & & 1.00011 & 1.00011 & 1.00011 \\
9 & & 0.03875 & & 1.00010 & 1.00010 & 1.00010 \\
10 & & 0.04295 & & 1.00009 & 1.00009 & 1.00009 \\
20 & & 0.08392 & 1.00005 & 1.00005 & 1.00005 \\
30 & 0.12316 & 1.00003 & 1.00003 & 1.00003 \\
40 & 0.16073 & 1.00002 & 1.00002 & 1.00002 \\
50 & 0.19670 & 1.00002 & 1.00002 & 1.00002 \\
60 & 0.23112 & 1.00002 & 1.00002 & 1.00002 \\
70 & 0.26407 & 1.00001 & 1.00001 & 1.00001 \\
80 & 0.29561 & 1.00001 & 1.00001 & 1.00001 \\
90 & 0.32579 & 1.00001 & 1.00001 & 1.00001 \\
100 & 0.35468 & 1.00001 & 1.00001 & 1.00001 \\
\hline
\end{tabular}


Table C-27. Check Valve Unavailability Versus IST Interval for Different Valve Aging Rates: Nonrenewal, No Intermediate Testing, Baseline Failure Rate $\lambda_{0}=1 \times 10^{-6}$, Inservice Test Downtime $d=72 \mathrm{hr}$, Valve Life $s=40$ yrs, Weibull Aging Model $c=3$

\begin{tabular}{|c|c|c|c|c|c|c|c|c|}
\hline $\begin{array}{c}\mathrm{L} \\
(\mathrm{yrs})\end{array}$ & $\begin{array}{c}\alpha \\
\left(\mathrm{yr}^{-1}\right)\end{array}$ & $q$ & $\begin{array}{c}\alpha \\
\left(y r^{-1}\right)\end{array}$ & $q$ & $\begin{array}{c}\alpha \\
\left(\mathrm{yr}^{-1}\right)\end{array}$ & $q$ & $\begin{array}{c}\alpha \\
\left(\mathrm{yr}^{-1}\right)\end{array}$ & $q$ \\
\hline 0.1 & 0.00 & 0.07639 & 0.10 & 0.58114 & 0.50 & 1.04624 & 1.00 & 1.07507 \\
\hline 0.2 & & 0.04035 & & 0.79578 & & 1.03861 & & 1.03947 \\
\hline 0.3 & & 0.02798 & & 0.90722 & & 1.02664 & & 1.02667 \\
\hline 0.4 & & 0.02188 & & 0.96186 & & 1.02013 & & 1.02013 \\
\hline 0.5 & & 0.01836 & & 0.98788 & & 1.01617 & & 1.01617 \\
\hline 0.6 & & 0.01614 & & 0.99984 & & 1.01351 & & 1.01351 \\
\hline 0.7 & & 0.01467 & & 1.00503 & & 1.01161 & & 1.01161 \\
\hline 0.8 & & 0.01367 & & 1.00702 & & 1.01017 & & 1.01017 \\
\hline 0.9 & & 0.01298 & & 1.00755 & & 1.00905 & & 1.00905 \\
\hline 1 & & 0.01252 & & 1.00744 & & 1.00815 & & 1.00815 \\
\hline 2 & & 0.01281 & & 1.00409 & & 1.00409 & & 1.00409 \\
\hline 3 & & 0.01579 & & 1.00273 & & 1.00273 & & 1.00273 \\
\hline 4 & & 0.01942 & & 1.00205 & & 1.00205 & & 1.00205 \\
\hline 5 & & 0.02330 & & 1.00164 & & 1.00164 & & 1.00164 \\
\hline 6 & & 0.02731 & & 1.00137 & & 1.00137 & & 1.00137 \\
\hline 7 & & 0.03137 & & 1.00117 & & 1.00117 & & 1.00117 \\
\hline 8 & & 0.03546 & & 1.00103 & & 1.00103 & & 1.00103 \\
\hline 9 & & 0.03957 & & 1.00091 & & 1.00091 & & 1.00091 \\
\hline 10 & & 0.04368 & & 1.00082 & & 1.00082 & & 1.00082 \\
\hline 20 & & 0.08428 & & 1.00041 & & 1.00041 & & 1.00041 \\
\hline 30 & & 0.12341 & & 1.00027 & & 1.00027 & & 1.00027 \\
\hline 40 & & 0.16092 & & 1.00021 & & 1.00021 & & 1.00021 \\
\hline 50 & & 0.19684 & & 1.00016 & & 1.00016 & & 1.00016 \\
\hline 60 & & 0.23124 & & 1.00014 & & 1.00014 & & 1.00014 \\
\hline 70 & & 0.26417 & & 1.00012 & & 1.00012 & & 1.00012 \\
\hline 80 & & 0.29570 & & 1.00010 & & 1.00010 & & 1.00010 \\
\hline 90 & & 0.32587 & & 1.00009 & & 1.00009 & & 1.00009 \\
\hline 100 & & 0.35476 & & 1.00008 & & 1.00008 & & 1.00008 \\
\hline
\end{tabular}


Table C-28. Check Valve Unavailability Versus IST Interval for Different Valve Aging Rates: Nonrenewal, No Intermediate Testing, Baseline Failure Rate $\lambda_{0}=1 \times 10^{-7}$, Inservice Test Downtime $d=0 \mathrm{hr}$, Valve Life $s=40 \mathrm{yrs}$, Weibull Aging Model $c=3$

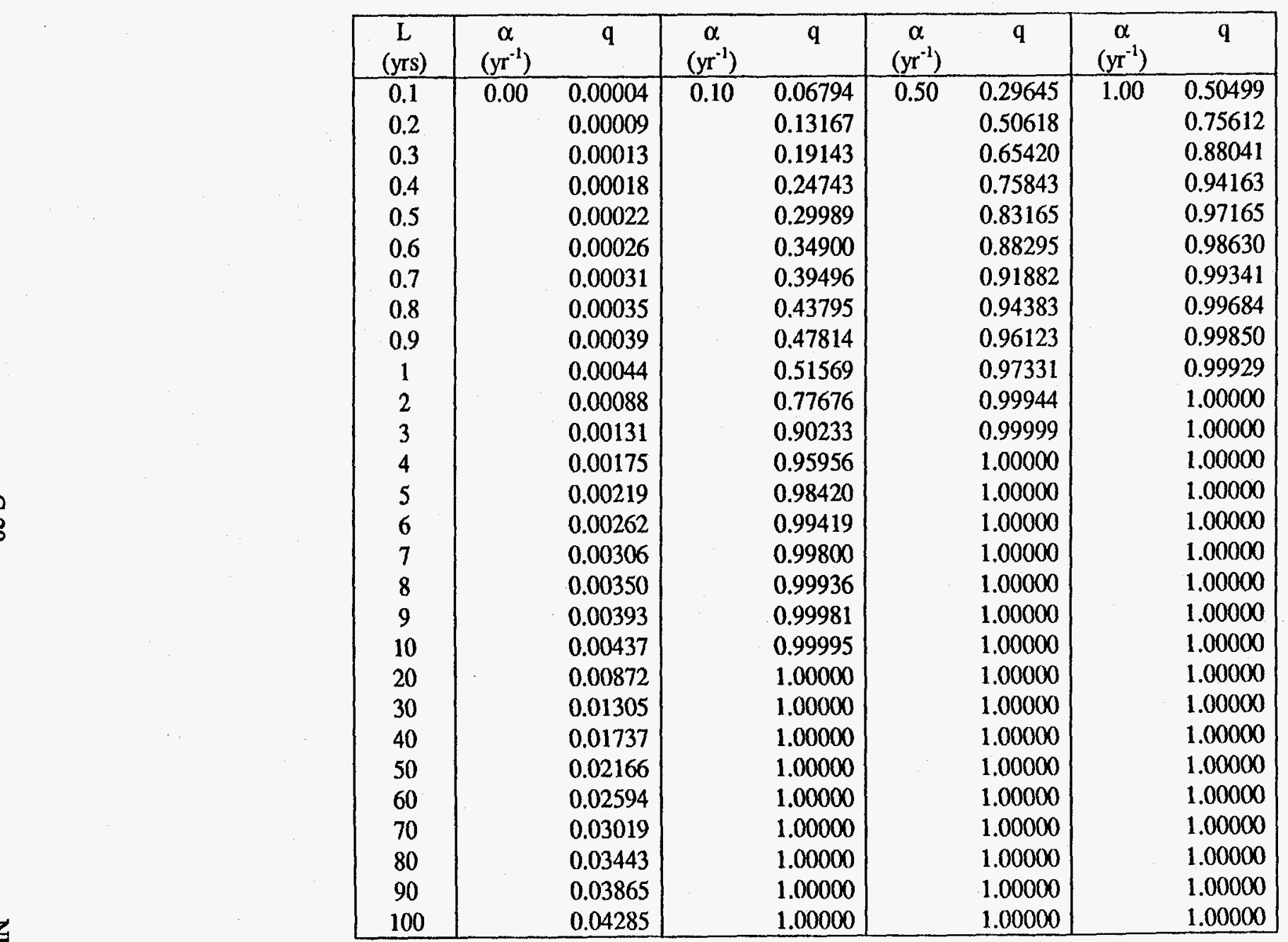


Table C-29. Check Valve Unavailability Versus IST Interval for Different Valve Aging Rates: Nonrenewal, No Intermediate Testing, Baseline Failure Rate $\lambda_{0}=1 \times 10^{-7}$, Inservice Test Downtime $d=8 \mathrm{hr}$, Valve Life $s=40$ yrs, Weibull Aging Model $c=3$

\begin{tabular}{|c|c|c|c|c|c|c|c|c|}
\hline $\begin{array}{c}\mathrm{L} \\
\text { (yrs) }\end{array}$ & $\begin{array}{c}\alpha \\
\left(\mathrm{yr}^{-1}\right)\end{array}$ & $q$ & $\begin{array}{c}\alpha \\
\left(\mathrm{yr}^{-1}\right)\end{array}$ & $q$ & $\begin{array}{c}\alpha \\
\left(\mathrm{yr}^{-1}\right)\end{array}$ & $q$ & $\begin{array}{c}\alpha \\
\left(\mathrm{yr}^{-1}\right)\end{array}$ & $q$ \\
\hline 0.1 & 0.00 & 0.00909 & 0.10 & 0.07699 & 0.50 & 0.30550 & 1.00 & 0.51404 \\
\hline 0.2 & & 0.00463 & & 0.13622 & & 0.51072 & & 0.76066 \\
\hline 0.3 & & 0.00317 & & 0.19446 & & 0.65724 & & 0.88344 \\
\hline 0.4 & & 0.00245 & & 0.24971 & & 0.76071 & & 0.94391 \\
\hline 0.5 & & 0.00204 & & 0.30171 & & 0.83347 & & 0.97347 \\
\hline 0.6 & & 0.00178 & & 0.35052 & & 0.88447 & & 0.98782 \\
\hline 0.7 & & 0.00161 & & 0.39627 & & 0.92012 & & 0.99471 \\
\hline 0.8 & & 0.00149 & & 0.43909 & & 0.94497 & & 0.99798 \\
\hline 0.9 & & 0.00141 & & 0.47915 & & 0.96225 & & 0.99951 \\
\hline 1 & & 0.00135 & & 0.51661 & & 0.97422 & & 1.00020 \\
\hline 2 & & 0.00133 & & 0.77721 & & 0.99990 & & 1.00046 \\
\hline 3 & & 0.00162 & & 0.90263 & & 1.00030 & & 1.00030 \\
\hline 4 & & 0.00198 & & 0.95979 & & 1.00023 & & 1.00023 \\
\hline 5 & & 0.00237 & & 0.98438 & & 1.00018 & & 1.00018 \\
\hline 6 & & 0.00278 & & 0.99435 & & 1.00015 & & 1.00015 \\
\hline 7 & & 0.00319 & & 0.99813 & & 1.00013 & & 1.00013 \\
\hline 8 & & 0.00361 & & 0.99947 & & 1.00011 & & 1.00011 \\
\hline 9 & & 0.00404 & & 0.99991 & & 1.00010 & & 1.00010 \\
\hline 10 & & 0.00446 & & 1.00004 & & 1.00009 & & 1.00009 \\
\hline 20 & & 0.00877 & & 1.00005 & & 1.00005 & & 1.00005 \\
\hline 30 & & 0.01308 & & 1.00003 & & 1.00003 & & 1.00003 \\
\hline 40 & & 0.01739 & & 1.00002 & & 1.00002 & & 1.00002 \\
\hline 50 & & 0.02168 & & 1.00002 & & 1.00002 & & 1.00002 \\
\hline 60 & & 0.02595 & & 1.00002 & & 1.00002 & & 1.00002 \\
\hline 70 & & 0.03021 & & 1.00001 & & 1.00001 & & 1.00001 \\
\hline 80 & & 0.03444 & & 1.00001 & & 1.00001 & & 1.00001 \\
\hline 90 & & 0.03866 & & 1.00001 & & 1.00001 & & 1.00001 \\
\hline 100 & & 0.04286 & & 1.00001 & & 1.00001 & & 1.00001 \\
\hline
\end{tabular}


Table C-30. Check Valve Unavailability Versus IST Interval for Different Valve Aging Rates: Nonrenewal, No Intermediate Testing, Baseline Failure Rate $\lambda_{0}=1 \times 10^{-7}$, Inservice Test Downtime $d=72 \mathrm{hr}$, Valve Life $s=40 \mathrm{yrs}$, Weibull Aging Model $c=3$

\begin{tabular}{|c|cc|cc|cc|cc|}
\hline $\begin{array}{c}\mathrm{L} \\
(\mathrm{yrs})\end{array}$ & $\begin{array}{c}\alpha \\
\left(\mathrm{yr}^{-1}\right)\end{array}$ & $\mathrm{q}$ & $\begin{array}{c}\alpha \\
\left(\mathrm{yr}^{-1}\right)\end{array}$ & $\mathrm{q}$ & $\begin{array}{c}\alpha \\
\left(\mathrm{yr}^{-1}\right)\end{array}$ & $\mathrm{q}$ & $\begin{array}{c}\alpha \\
\left(\mathrm{yr}^{-1}\right)\end{array}$ \\
\hline 0.1 & 0.00 & 0.07599 & 0.10 & 0.14389 & 0.50 & 0.37240 & 1.00 & 0.58094 \\
0.2 & & 0.03956 & & 0.17115 & & 0.54565 & & 0.79559 \\
0.3 & & 0.02680 & & 0.21809 & 0.68087 & 0.90708 \\
0.4 & & 0.02031 & & 0.26756 & 0.77857 & 0.96177 \\
0.5 & & 0.01639 & & 0.31606 & 0.84782 & 0.98782 \\
0.6 & & 0.01378 & & 0.36251 & 0.89647 & 0.99981 \\
0.7 & & 0.01191 & & 0.40657 & 0.93043 & 1.00501 \\
0.8 & & 0.01052 & & 0.44812 & 0.95400 & 1.00701 \\
0.9 & & 0.00944 & & 0.48719 & 0.97028 & 1.00755 \\
1 & & 0.00859 & & 0.52385 & 0.98146 & 1.00744 \\
2 & & 0.00497 & & 0.78085 & 1.00354 & 1.00409 \\
3 & & 0.00405 & & 0.90506 & 1.00272 & 1.00273 \\
4 & & 0.00380 & 0.96161 & 1.00205 & 1.00205 \\
5 & & 0.00383 & 0.98584 & 1.00164 & 1.00164 \\
6 & & 0.00399 & 0.99556 & 1.00137 & 1.00137 \\
7 & & 0.00423 & 0.99917 & 1.00117 & 1.00117 \\
8 & & 0.00452 & 1.00038 & 1.00103 & 1.00103 \\
9 & & 0.00485 & 1.00072 & 1.00091 & 1.00091 \\
10 & 0.00519 & 1.00077 & 1.00082 & & 1.00082 \\
20 & 0.00913 & 1.00041 & 1.00041 & 1.00041 \\
30 & 0.01333 & 1.00027 & 1.00027 & 1.00027 \\
40 & 0.01757 & 1.00021 & 1.00021 & 1.00021 \\
50 & 0.02183 & 1.00016 & 1.00016 & 1.00016 \\
60 & 0.02607 & 1.00014 & 1.00014 & 1.00014 \\
70 & 0.03031 & 1.00012 & 1.00012 & 1.00012 \\
80 & 0.03454 & 1.00010 & 1.00010 & 1.00010 \\
90 & 0.03874 & 1.00009 & 1.00009 & 1.00009 \\
100 & 0.04294 & 1.00008 & 1.00008 & 1.00008 \\
\hline
\end{tabular}


Table C.31. Check Valve Unavailability Versus IST Interval for Different Valve Aging Rates: Partial Renewal, No Intermediate Testing, Baseline Failure Rate $\lambda_{0}=1 \times 10^{-6}$, Inservice Test Downtime $\mathrm{d}=0 \mathrm{hr}$, Partial Renewal Fraction $\mathrm{f}=0.1$, Valve Lifetime $\mathrm{s}=40 \mathrm{yrs}$, Weibull Aging Model $\mathrm{c}=2$

\begin{tabular}{|c|c|c|c|c|c|c|c|c|c|c|c|c|c|c|c|c|}
\hline $\begin{array}{c}\mathrm{L} \\
\text { (yrs) }\end{array}$ & $\begin{array}{c}\alpha \\
\left(\mathrm{yr}^{-1}\right)\end{array}$ & $\mathrm{q}_{\mathrm{r}}$ & $q_{n}$ & $q$ & $\begin{array}{c}\alpha \\
\left(\mathrm{yr}^{-1}\right)\end{array}$ & $q_{r}$ & $q_{n}$ & $q$ & $\begin{array}{c}\alpha \\
\left(\mathrm{yr}^{-1}\right)\end{array}$ & $q_{r}$ & $q_{n}$ & $q$ & $\begin{array}{c}\alpha \\
\left(\mathrm{yr}^{-1}\right)\end{array}$ & $q_{r}$ & $q_{n}$ & $q$ \\
\hline 0.1 & 0.00 & 0.00004 & 0.00039 & 0.00044 & 0.10 & 0.00004 & 0.02124 & 0.02128 & 0.50 & 0.00004 & 0.10038 & 0.10041 & 1.00 & 0.00004 & 0.19036 & 0.19039 \\
\hline 0.2 & & 0.00009 & 0.00079 & 0.00088 & & 0.00009 & 0.04213 & 0.04222 & & 0.00009 & 0.19110 & 0.19117 & & 0.00009 & 0.34517 & 0.34523 \\
\hline 0.3 & & 0.00013 & 0.00118 & 0.00131 & & 0.00013 & 0.06268 & 0.06280 & & 0.00013 & 0.27306 & 0.27316 & & 0.00013 & 0.47094 & 0.47101 \\
\hline 0.4 & & 0.00018 & 0.00158 & 0.00175 & & 0.00018 & 0.08288 & 0.08304 & & 0.00018 & 0.34707 & 0.34718 & & 0.00018 & 0.57301 & 0.57308 \\
\hline 0.5 & & 0.00022 & 0.00197 & 0.00219 & & 0.00022 & 0.10274 & 0.10294 & & 0.00022 & 0.41385 & 0.41398 & & 0.00023 & 0.65575 & 0.65583 \\
\hline 0.6 & & 0.00026 & 0.00236 & 0.00262 & & 0.00026 & 0.12227 & 0.12250 & & 0.00027 & 0.47409 & 0.47423 & & 0.00028 & 0.72276 & 0.72284 \\
\hline 0.7 & & 0.00031 & 0.00276 & 0.00306 & & 0.00031 & 0.14146 & 0.14173 & & 0.00032 & 0.52838 & 0.52853 & & 0.00033 & 0.77696 & 0.77704 \\
\hline 0.8 & & 0.00035 & 0.00315 & 0.00350 & & 0.00035 & 0.16033 & 0.16062 & & 0.00037 & 0.57730 & 0.57746 & & 0.00039 & 0.82076 & 0.82083 \\
\hline 0.9 & & 0.00039 & 0.00354 & 0.00393 & & 0.00040 & 0.17887 & 0.17919 & & 0.00042 & 0.62135 & 0.62151 & & 0.00045 & 0.85612 & 0.85618 \\
\hline 1 & & 0.00044 & 0.00393 & 0.00437 & & 0.00045 & 0.19708 & 0.19744 & & 0.00047 & 0.66100 & 0.66116 & & 0.00051 & 0.88462 & 0.88468 \\
\hline 2 & & 0.00088 & 0.00785 & 0.00872 & & 0.00093 & 0.36232 & 0.36291 & & 0.00117 & 0.89118 & 0.89130 & & 0.00146 & 0.98806 & 0.98808 \\
\hline 3 & & 0.00131 & 0.01176 & 0.01305 & & 0.00151 & 0.49924 & 0.49999 & & 0.00230 & 0.96699 & 0.96706 & & 0.00328 & 0.99890 & 0.99890 \\
\hline 4 & & 0.00175 & 0.01564 & 0.01737 & & 0.00222 & 0.61133 & 0.61219 & & 0.00408 & 0.99055 & 0.99059 & & 0.00640 & 0.99991 & 0.99991 \\
\hline 5 & & 0.00219 & 0.01952 & 0.02166 & & 0.00310 & 0.70196 & 0.70288 & & 0.00673 & 0.99746 & 0.99747 & & 0.01125 & 0.99999 & 0.99999 \\
\hline 6 & & 0.00262 & 0.02337 & 0.02594 & & 0.00420 & 0.77429 & 0.77524 & & 0.01046 & 0.99936 & 0.99936 & & 0.01823 & 1.00000 & 1.00000 \\
\hline 7 & & 0.00306 & 0.02722 & 0.03019 & & 0.00555 & 0.83125 & 0.83219 & & 0.01546 & 0.99985 & 0.99985 & & 0.02771 & 1.00000 & 1.00000 \\
\hline 8 & & 0.00350 & 0.03104 & 0.03443 & & 0.00722 & 0.87550 & 0.87640 & & 0.02195 & 0.99997 & 0.99997 & & 0.04006 & 1.00000 & 1.00000 \\
\hline 9 & & 0.00393 & 0.03486 & 0.03865 & & 0.00922 & 0.90940 & 0.91023 & & 0.03009 & 0.99999 & 0.99999 & & 0.05556 & 1.00000 & 1.00000 \\
\hline 10 & & 0.00437 & 0.03865 & 0.04285 & & 0.01161 & 0.93498 & 0.93574 & & 0.04006 & 1.00000 & 1.00000 & & 0.07446 & 1.00000 & 1.00000 \\
\hline 20 & & 0.00872 & 0.07581 & 0.08387 & & 0.06495 & 0.99900 & 0.99907 & & 0.25974 & 1.00000 & 1.00000 & & 0.44720 & 1.00000 & 1.00000 \\
\hline 30 & & 0.01305 & 0.11153 & 0.12313 & & 0.18961 & 1.00000 & 1.00000 & & 0.63162 & 1.00000 & 1.00000 & & 0.86250 & 1.00000 & 1.00000 \\
\hline 40 & & 0.01737 & 0.14588 & 0.16071 & & 0.38413 & 1.00000 & 1.00000 & & 0.90497 & 1.00000 & 1.00000 & & 0.99081 & 1.00000 & 1.00000 \\
\hline 50 & & 0.02166 & 0.17889 & 0.19668 & & 0.60718 & 1.00000 & 1.00000 & & 0.98979 & 1.00000 & 1.00000 & & 0.99989 & 1.00000 & 1.00000 \\
\hline 60 & & 0.02594 & 0.21063 & 0.23110 & & 0.79872 & 1.00000 & 1.00000 & & 0.99963 & 1.00000 & 1.00000 & & 1.00000 & 1.00000 & 1.00000 \\
\hline 70 & & 0.03019 & 0.24114 & 0.26406 & & 0.92070 & 1.00000 & 1.00000 & & 1.00000 & 1.00000 & 1.00000 & & 1.00000 & 1.00000 & 1.00000 \\
\hline 80 & & 0.03443 & 0.27047 & 0.29559 & & 0.97701 & 1.00000 & 1.00000 & & 1.00000 & 1.00000 & 1.00000 & & 1.00000 & 1.00000 & 1.00000 \\
\hline 90 & & 0.03865 & 0.29867 & 0.32578 & & 0.99530 & 1.00000 & 1.00000 & & 1.00000 & 1.00000 & 1.00000 & & 1.00000 & 1.00000 & 1.00000 \\
\hline 100 & & 0.04285 & 0.32578 & 0.35467 & & 0.99935 & 1.00000 & 1.00000 & & 1.00000 & 1.00000 & 1.00000 & & 1.00000 & 1.00000 & 1.00000 \\
\hline
\end{tabular}


Table C-32. Check Valve Unavailability Versus IST Interval for Different Valve Aging Rates: Partial Renewal, No Intermediate Testing, Baseline Failure Rate $\lambda_{v}=1 \times 10^{-6}$, Inservice Test Downtime $d=8 \mathrm{hr}$, Partial Renewal Fraction $f=0.1$, Valve Lifetime $s=40 \mathrm{yrs}$, Weibull Aging Model $c=2$

\begin{tabular}{|c|c|c|c|c|c|c|c|c|c|c|c|c|c|c|c|c|}
\hline $\begin{array}{c}\mathrm{L} \\
\text { (yrs) }\end{array}$ & $\begin{array}{c}\alpha \\
\left(\mathrm{yr}^{-1}\right)\end{array}$ & $\mathrm{q}_{\mathrm{r}}$ & $\mathbf{q}_{n}$ & $q$ & $\begin{array}{c}\alpha \\
\left(y r^{-1}\right)\end{array}$ & $q_{r}$ & $q_{n}$ & $q$ & $\begin{array}{c}\alpha \\
\left(\mathrm{yr}^{-1}\right) \\
\end{array}$ & $\mathrm{q}_{\mathrm{r}}$ & $q_{n}$ & $q$ & $\begin{array}{c}\alpha \\
\left(\mathrm{yr}^{-1}\right)\end{array}$ & $q_{r}$ & $\mathrm{q}_{\mathrm{n}}$ & $q$ \\
\hline 0.1 & 0.00 & 0.00909 & 00039 & .00948 & 0.10 & 0.00909 & 0.02124 & 0.03014 & 0.50 & 0.00909 & 0.10038 & 0.10856 & 1.00 & 0.00909 & 0.19036 & 0.19772 \\
\hline 0.2 & & 0.00463 & 0.00079 & 0.00542 & & 0.00463 & 0.04213 & 0.04657 & & 0.00463 & 0.19110 & 0.19485 & & 0.00463 & 0.34517 & 0.34820 \\
\hline 0.3 & & 0.00317 & 0.00118 & 0.00434 & & 0.00317 & 0.06268 & 0.06565 & & 0.00317 & 0.27306 & 0.27537 & & 0.00317 & 0.47094 & 0.47261 \\
\hline 0.4 & & 0.00245 & 0.00158 & 0.00402 & & 0.00245 & 0.08288 & 0.08513 & & 0.00246 & 0.34707 & 0.34867 & & 0.00246 & 0.57301 & 0.57406 \\
\hline 0.5 & & 0.00204 & 0.00197 & 0.00401 & & 0.00204 & 0.10274 & 0.10458 & & 0.00205 & 0.41385 & 0.41505 & & 0.00205 & 0.65575 & 0.65646 \\
\hline 0.6 & & 0.00178 & 0.00236 & 0.00414 & & 0.00178 & 0.12227 & 0.12384 & & 0.00179 & 0.47409 & 0.47503 & & 0.00180 & 0.72276 & 0.72326 \\
\hline 0.7 & & 0.00161 & 0.00276 & 0.00436 & & 0.00161 & 0.14146 & 0.14285 & & 0.00162 & 0.52838 & 0.52915 & & 0.00163 & 0.77696 & 0.77733 \\
\hline 0.8 & & 0149 & 0315 & 0.00463 & & 0.00149 & 0.16033 & 0.16158 & & 0.00151 & 0.57730 & 0.57794 & & 0.00153 & 0.82076 & 0.82104 \\
\hline 0.9 & & 0.00141 & 0354 & 0.00494 & & 0.00141 & 0.17887 & 0.18003 & & 0.00143 & 0.62135 & 0.62190 & & 0.00146 & 0.85612 & 0.85633 \\
\hline 1 & & 0.00135 & 0.00393 & 0.00528 & & 0.00136 & 0.19708 & 0.19817 & & 0.00139 & 0.66100 & 0.66147 & & 0.00142 & 0.88462 & 0.88479 \\
\hline 2 & & 0.00133 & 0.00785 & 0.00 & & 39 & 0.36232 & 0.36320 & & 0.00162 & 0.89118 & 0.89135 & & 0.00192 & 806 & 0.98809 \\
\hline 3 & & 0.00162 & 0.01176 & 0.01 & & 0.00181 & 0.49924 & 0.50015 & & 0.00260 & 699 & 707 & & 0.00358 & 890 & 0.99890 \\
\hline 4 & & 0.00198 & 64 & & & 44 & 0.61133 & 28 & & 0.00431 & 555 & 059 & & 663 & & 0.99991 \\
\hline 5 & & & 0.01952 & 0.02 & & 28 & 0.70196 & 294 & & 0.00691 & 746 & 0.99747 & & 143 & 99 & 0.99999 \\
\hline 6 & & 0.00278 & 0.02337 & & & 35 & 0.77429 & & & 0.01 & & 36 & & & 00 & 1.00000 \\
\hline 7 & & 0.00319 & 0.02722 & 0.03032 & & 0.00568 & 0.83125 & 221 & & 60 & 85 & 85 & & 784 & 000 & 1.00000 \\
\hline 8 & & 0.00361 & 0.03104 & 0.03454 & & 0.00733 & 0.87550 & 0.87642 & & 206 & 997 & 997 & & 17 & 000 & 1.00000 \\
\hline 9 & & 0.00404 & 0.03486 & 0.03875 & & 0.00932 & 0.90940 & 24 & & & 99 & 99 & & 566 & 000 & 1.00000 \\
\hline 10 & & 0.00446 & 0.03865 & 0.04294 & & 0.01170 & 0.93498 & & & & 00 & 00 & & 155 & 000 & 1.00000 \\
\hline 20 & & 0.00877 & 0.07581 & 0.08391 & & 0.06500 & 0.99900 & & & 0.2 & 00 & 000 & & 725 & 000 & 1.00000 \\
\hline 30 & & 0.01308 & 0.11153 & 0.12316 & & 0.18964 & 1.00000 & 000 & & 65 & 00 & 000 & & 53 & 000 & 1.00000 \\
\hline 40 & & 0.01739 & 0.14588 & 0.16073 & & 0.38415 & 1.00000 & 000 & & & & 000 & & 83 & 000 & 1.00000 \\
\hline 50 & & 0.02168 & 0.17889 & 0.19669 & & 0.60720 & 1.00000 & 1.00000 & & 0.98981 & 000 & & & 991 & 000 & 1.00000 \\
\hline 60 & & 0.02595 & 0.21063 & 0.23112 & & 0.79874 & 1.00000 & 1.00000 & & 0.99965 & 1.00000 & 000 & & 302 & 1.00000 & 1.00000 \\
\hline 70 & & 0.03021 & 0.24114 & 0.26406 & & 0.92072 & 1.00000 & 1.00000 & & 1.00001 & 1.00000 & 1.00000 & & 1.00001 & 1.00000 & 1.00000 \\
\hline 80 & & 0.03444 & 0.27047 & 0.29560 & & 0.97702 & 1.00000 & 1.00000 & & 1.00001 & 1.00000 & 1.00000 & & 1.00001 & 1.00000 & 1.00000 \\
\hline 90 & & 0.03866 & 0.29867 & 0.32579 & & 0.99531 & 1.00000 & 1.00000 & & 1.00001 & 1.00000 & 1.00000 & & 1.00001 & 1.00000 & 1.00000 \\
\hline 100 & & 0.04286 & 0.32578 & 0.35468 & & 0.99936 & 1.00000 & 1.00000 & & 1.00001 & 1.00000 & 1.00000 & & 1.00001 & 1.00000 & 1.00000 \\
\hline
\end{tabular}


Table C-33. Check Valve Unavailability Versus IST Interval for Different Valve Aging Rates: Partial Renewal, No Intermediate Testing, Z Baseline Failure Rate $\lambda_{0}=1 \times 10^{-6}$, Inservice Test Downtime $d=72 \mathrm{hr}$, Partial Renewal Fraction $f=0.1$, Valve Lifetime $s=40$ yrs, Weibull Aging Model $c=2$

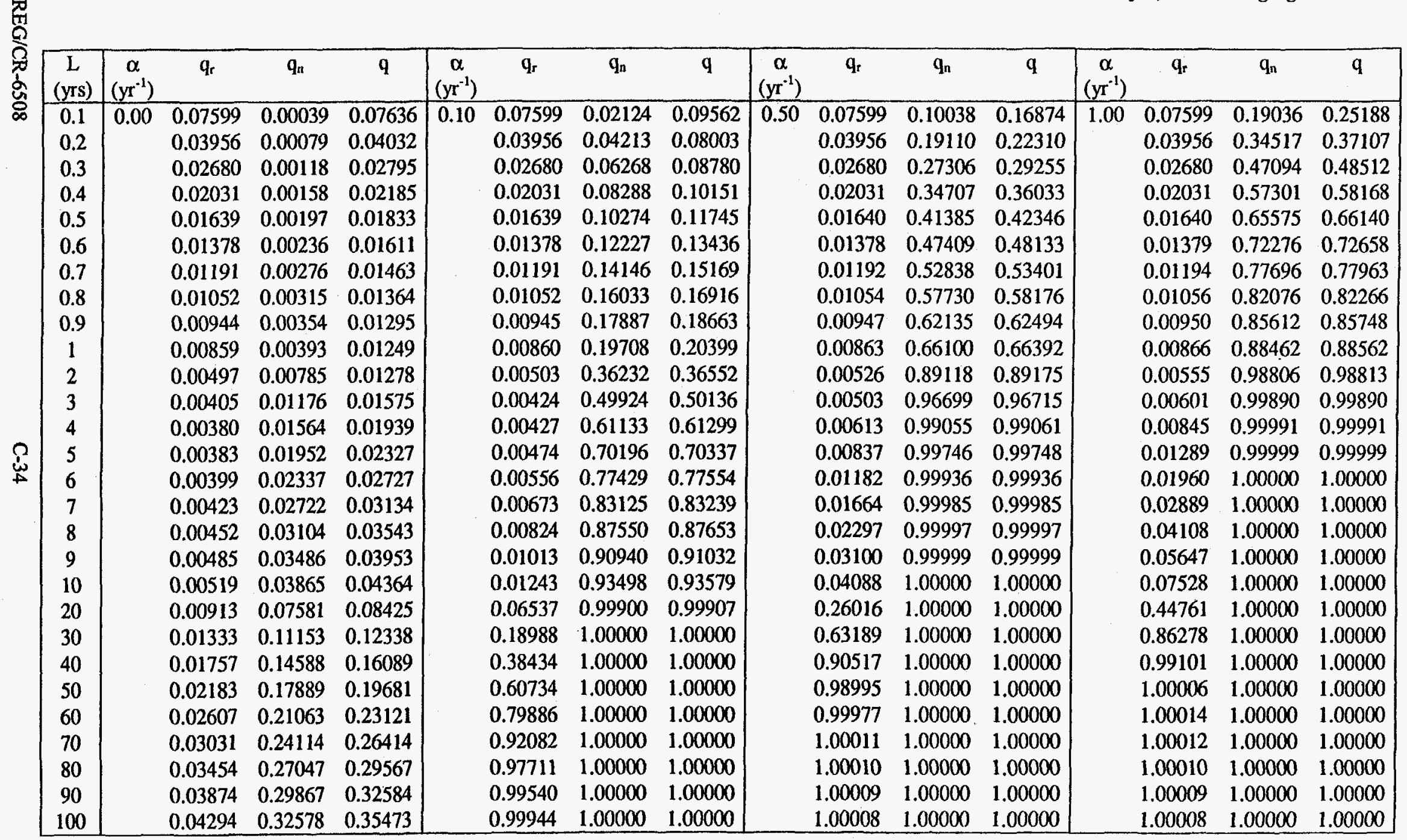


Table C-34. Check Valve Unavailability Versus IST Interval for Different Valve Aging Rates: Partial Renewal, No Intermediate Testing, Baseline Failure Rate $\lambda_{0}=1 \times 10^{-7}$, Inservice Test Downtime $d=0 \mathrm{hr}$, Partial Renewal Fraction $f=0.1$, Valve Lifetime $s=40$ yrs, Weibull Aging Model $c=2$

\begin{tabular}{|c|c|c|c|c|c|c|c|c|c|c|c|c|c|c|c|c|}
\hline $\begin{array}{c}\mathrm{L} \\
\text { (yrs) }\end{array}$ & $\begin{array}{c}\alpha \\
\left(y r^{-1}\right)\end{array}$ & $\mathrm{q}_{\mathrm{r}}$ & $\mathrm{q}_{\mathrm{n}}$ & $q$ & $\begin{array}{c}\alpha \\
\left(\mathrm{yr}^{-1}\right)\end{array}$ & $\mathbf{q}_{\mathbf{r}}$ & $q_{n}$ & $q$ & $\begin{array}{c}\alpha \\
\left(\mathrm{yr}^{-1}\right)\end{array}$ & $\mathrm{q}_{\mathrm{r}}$ & $q_{n}$ & $q$ & $\begin{array}{c}\alpha \\
\left(\mathrm{yr}^{-1}\right)\end{array}$ & $\mathbf{q}_{\mathbf{r}}$ & $q_{n}$ & $q$ \\
\hline 0.2 & & 0.00001 & 0.00008 & 0.00009 & & 0.00001 & 0.00430 & 0.00430 & & 0.00001 & 0.02098 & 0.02099 & & 0.00001 & 0.04145 & 0.04146 \\
\hline 0.4 & & 0.00002 & 0.00016 & 0.00018 & & 0.00002 & 0.00861 & 0.00863 & & 0.00002 & 0.04173 & 0.04175 & & 0.00002 & 0.08158 & 0.08160 \\
\hline 0.5 & & 0.00002 & 0.00020 & 0.00022 & & 0.00002 & 0.01078 & 0.01080 & & 0.00002 & 0.05202 & 0.05204 & & 0.00002 & 0.10115 & 0.10117 \\
\hline 0.6 & & 0.00003 & 0.00024 & 0.00026 & & 0.00003 & 0.01296 & 0.01298 & & 0.00003 & 0.06224 & 0.06227 & & 0.00003 & 0.12040 & 0.12042 \\
\hline 0.7 & & 0.00003 & 0.00028 & 0.00031 & & 0.00003 & 0.01514 & 0.01517 & & 0.00003 & 0.07240 & 0.07243 & & 0.00003 & 0.13933 & 0.13936 \\
\hline 1 & & 0.00004 & 0.00039 & 0.00044 & & 0.00004 & 0.02171 & 0.02175 & & 0.00005 & 0.10253 & 0.10257 & & 0.00005 & 0.19423 & 0.19427 \\
\hline 2 & & 0.00009 & 0.00079 & 0.00088 & & 0.00009 & 0.04399 & 0.04408 & & 0.00012 & 0.19893 & 0.19902 & & 0.00015 & 0.35778 & 0.35787 \\
\hline 3 & & 0.00013 & 0.00118 & 0.00131 & & 0.00015 & 0.06682 & 0.06697 & & 0.00023 & 0.28900 & 0.28916 & & 0.00033 & 0.49388 & 0.49405 \\
\hline 4 & & 0.00018 & 0.00158 & 0.00175 & & 0.00022 & 0.09017 & 0.09038 & & 0.00041 & 0.37262 & 0.37288 & & 0.00064 & 0.60578 & 0.60603 \\
\hline 5 & & 0.00022 & 0.00197 & 0.00219 & & 0.00031 & 0.11401 & 0.11429 & & 0.00068 & 0.44975 & 0.45012 & & 0.00113 & 0.69662 & 0.69697 \\
\hline 6 & & 0.00026 & 0.00236 & 0.00262 & & 0.00042 & 0.13830 & 0.13866 & & 0.00105 & 0.52039 & 0.52090 & & 0.00184 & 0.76943 & 0.76986 \\
\hline 20 & & 0.00088 & 0.00785 & 0.00872 & & 0.00669 & 0.49901 & 0.50236 & & 0.02963 & 0.96743 & 0.96839 & & 0.05755 & 0.99893 & 0.99899 \\
\hline 30 & & 0.00131 & 0.01176 & 0.01305 & & 0.02080 & 0.72555 & 0.73126 & & 0.09504 & 0.99837 & 0.99852 & & 0.17997 & 1.00000 & 1.00000 \\
\hline 40 & & 0.00175 & 0.01564 & 0.01737 & & 0.04732 & 0.87975 & 0.88544 & & 0.20971 & 0.99997 & 0.99998 & & 0.37434 & 1.00000 & 1.00000 \\
\hline 50 & & 0.00219 & 0.01952 & 0.02166 & & 0.08921 & 0.95949 & 0.96310 & & 0.36773 & 1.00000 & 1.00000 & & 0.59936 & 1.00000 & 1.00000 \\
\hline 60 & & 0.00262 & 0.02337 & 0.02594 & & 0.14812 & 0.98991 & 0.99141 & & 0.54662 & 1.00000 & 1.00000 & & 0.79391 & 1.00000 & 1.00000 \\
\hline 70 & & 0.00306 & 0.02722 & 0.03019 & & 0.22389 & 0.99821 & 0.99861 & & 0.71493 & 1.00000 & 1.00000 & & 0.91848 & 1.00000 & 1.00000 \\
\hline 80 & & 0.00350 & 0.03104 & 0.03443 & & 0.31426 & 0.99978 & 0.99985 & & 0.84623 & 1.00000 & 1.00000 & & 0.97627 & 1.00000 & 1.00000 \\
\hline 90 & & 0.00393 & 0.03486 & 0.03865 & & 0.41498 & 0.99998 & 0.99999 & & 0.93039 & 1.00000 & 1.00000 & & 0.99513 & 1.00000 & 1.00000 \\
\hline 100 & & 0.00437 & 0.03865 & 0.04285 & & 0.52020 & 1.00000 & 1.00000 & & 0.97412 & 1.00000 & 1.00000 & & 0.99933 & 1.00000 & 1.00000 \\
\hline
\end{tabular}


Table C-35. Check Valve Unavailability Versus IST Interval for Different Valve Aging Rates: Partial Renewal, No Intermediate Testing,

\begin{tabular}{|c|c|c|c|c|c|c|c|c|c|c|c|c|c|c|c|c|}
\hline $\begin{array}{c}\mathrm{L} \\
\text { (yrs) }\end{array}$ & $\begin{array}{c}\alpha \\
\left(\mathrm{yr}^{-1}\right)\end{array}$ & $q_{r}$ & $q_{n}$ & $q$ & $\begin{array}{c}\alpha \\
\left(\mathrm{yr}^{-1}\right)\end{array}$ & $q_{r}$ & $q_{n}$ & $q$ & $\begin{array}{c}\alpha \\
\left(\mathrm{yr}^{-1}\right)\end{array}$ & $\mathrm{q}_{\mathrm{r}}$ & $q_{n}$ & $\mathbf{q}$ & $\begin{array}{c}\alpha \\
\left(\mathrm{yr}^{-1}\right)\end{array}$ & $\mathbf{q}_{\mathbf{r}}$ & $q_{n}$ & $q$ \\
\hline 0.1 & 0.00 & 0.00905 & 0.00004 & 0.00909 & 0.10 & 0.00905 & 0.00214 & 0.01118 & 0.50 & 0.00905 & 0.01052 & 0.01948 & 1.00 & 0.00905 & 0.02089 & 0.02976 \\
\hline 0.2 & & 0.00455 & 0.00008 & 0.00463 & & 0.00455 & 0.00430 & 0.00883 & & 0.00455 & 0.02098 & 0.02544 & & 0.00455 & 0.04145 & 0.04582 \\
\hline 0.3 & & 0.00305 & 0.00012 & 0.00317 & & 0.00305 & 0.00645 & 0.00948 & & 0.00305 & 0.03139 & 0.03434 & & 0.00305 & 0.06168 & 0.06454 \\
\hline 0.4 & & 0.00230 & 0.00016 & 0.00245 & & 0.00230 & 0.00861 & 0.01089 & & 0.00230 & 0.04173 & 0.04393 & & 0.00230 & 0.08158 & 0.08369 \\
\hline 0.5 & & 0.00185 & 0.00020 & 0.00204 & & 0.00185 & 0.01078 & 0.01261 & & 0.00185 & 0.05202 & 0.05377 & & 0.00185 & 0.10115 & 0.10281 \\
\hline 0.6 & & 0.00155 & 0.00024 & 0.00178 & & 0.00155 & 0.01296 & 0.01448 & & 0.00155 & 0.06224 & 0.06369 & & 0.00155 & 0.12040 & 0.12176 \\
\hline 0.7 & & 0.00133 & 0.00028 & 0.00161 & & 0.00133 & 0.01514 & 0.01645 & & 0.00133 & 0.07240 & 0.07364 & & 0.00134 & 0.13933 & 0.14048 \\
\hline 0.8 & & 0.00118 & 0.00032 & 0.00149 & & 0.00118 & 0.01732 & 0.01848 & & 0.00118 & 0.08251 & 0.08359 & & 0.00118 & 0.15794 & 0.15893 \\
\hline 0.9 & & 0.00105 & 0.00035 & 0.00141 & & 0.00105 & 0.01951 & 0.02055 & & 0.00106 & 0.09255 & 0.09351 & & 0.00106 & 0.17624 & 0.17711 \\
\hline 1 & & 0.00096 & 0.00039 & 0.00135 & & 0.00096 & 0.02171 & 0.02265 & & 0.00096 & 0.10253 & 0.10339 & & 0.00096 & 0.19423 & 0.19501 \\
\hline 2 & & 0.00054 & 0.00079 & 0.00133 & & 0.00055 & 0.04399 & 0.04452 & & 0.00057 & 0.19893 & 0.19939 & & 0.00060 & 0.35778 & 0.35816 \\
\hline 3 & & 0.00044 & 0.00118 & 0.00162 & & 0.00046 & 0.06682 & 0.06725 & & 0.00053 & 0.28900 & 0.28938 & & 0.00063 & 0.49388 & 0.49420 \\
\hline 4 & & 0.00040 & 0.00158 & 0.00198 & & 0.00045 & 0.09017 & 0.09058 & & 0.00064 & 0.37262 & 0.37302 & & 0.00087 & 0.60578 & 0.60612 \\
\hline 5 & & 0.00040 & 0.00197 & 0.00237 & & 0.00049 & 0.11401 & 0.11445 & & 0.00086 & 0.44975 & 0.45022 & & 0.00131 & 0.69662 & 0.69702 \\
\hline 6 & & 0.00041 & 0.00236 & 0.00278 & & 0.00057 & 0.13830 & 0.13879 & & 0.00120 & 0.52039 & 0.52097 & & 0.00199 & 0.76943 & 0.76989 \\
\hline 7 & & 0.00044 & 0.00276 & 0.00319 & & 0.00069 & 0.16300 & 0.16358 & & 0.00169 & 0.58465 & 0.58535 & & 0.00294 & 0.82701 & 0.82752 \\
\hline 8 & & 0.00046 & 0.00315 & 0.00361 & & 0.00084 & 0.18808 & 0.18876 & & 0.00233 & 0.64268 & 0.64351 & & 0.00419 & 0.87192 & 0.87246 \\
\hline 9 & & 0.00050 & 0.00354 & 0.00404 & & 0.00103 & 0.21347 & 0.21428 & & 0.00315 & 0.69469 & 0.69566 & & 0.00580 & 0.90646 & 0.90700 \\
\hline 10 & & 0.00053 & 0.00393 & 0.00446 & & 0.00126 & 0.23914 & 0.24010 & & 0.00417 & 0.74096 & 0.74205 & & 0.00780 & 0.93264 & 0.93316 \\
\hline 20 & & 0.00092 & 0.00785 & 0.00877 & & 0.00674 & 0.49901 & 0.50238 & & 0.02967 & 0.96743 & 0.96839 & & 0.05760 & 0.99893 & 0.99899 \\
\hline 30 & & 0.00134 & 0.01176 & 0.01308 & & 0.02083 & 0.72555 & 0.73127 & & 0.09507 & 0.99837 & 0.99852 & & 0.18000 & 1.00000 & 1.00000 \\
\hline 40 & & 0.00177 & 0.01564 & 0.01739 & & 0.04734 & 0.87975 & 0.88544 & & 0.20973 & 0.99997 & 0.99998 & & 0.37437 & 1.00000 & 1.00000 \\
\hline 50 & & 0.00221 & 0.01952 & 0.02168 & & 0.08923 & 0.95949 & 0.96310 & & 0.36775 & 1.00000 & 1.00000 & & 0.59938 & 1.00000 & 1.00000 \\
\hline 60 & & 0.00264 & 0.02337 & 0.02595 & & 0.14813 & 0.98991 & 0.99141 & & 0.54664 & 1.00000 & 1.00000 & & 0.79392 & 1.00000 & 1.00000 \\
\hline 70 & & 0.00307 & 0.02722 & 0.03021 & & 0.22390 & 0.99821 & 0.99861 & & 0.71494 & 1.00000 & 1.00000 & & 0.91850 & 1.00000 & 1.00000 \\
\hline 80 & & 0.00351 & 0.03104 & 0.03444 & & 0.31428 & 0.99978 & 0.99985 & & 0.84624 & 1.00000 & 1.00000 & & 0.97628 & 1.00000 & 1.00000 \\
\hline 90 & & 0.00394 & 0.03486 & 0.03866 & & 0.41499 & 0.99998 & 0.99999 & & 0.93040 & 1.00000 & 1.00000 & & 0.99514 & 1.00000 & 1.00000 \\
\hline 100 & & 0.00438 & 0.03865 & 0.04286 & & 0.52021 & 1.00000 & 1.00000 & & 0.97413 & 1.00000 & 1.00000 & & 0.99934 & 1.00000 & 1.00000 \\
\hline
\end{tabular}


Table C-36. Check Valve Unavailability Versus IST Interval for Different Valve Aging Rates: Partial Renewal, No Intermediate Testing, Baseline Failure Rate $\lambda_{0}=1 \times 10^{-7}$, Inservice Test Downtime $d=72 \mathrm{hr}$, Partial Renewal Fraction $f=0.1$, Valve Lifetime $s=40$ yrs, Weibull Aging Model $c=2$

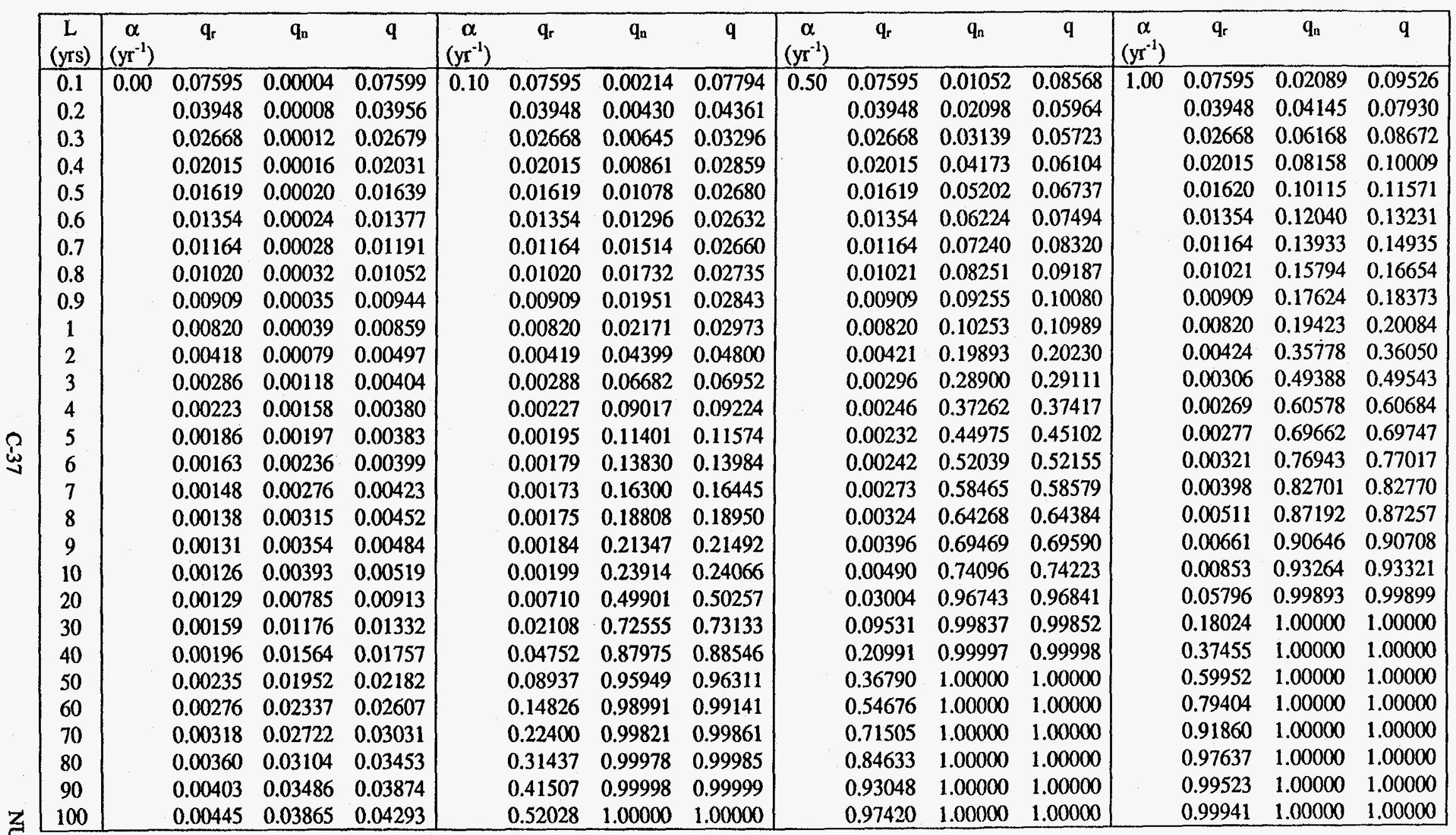


Table C-37. Check Valve Unavailability Versus IST Interval for Different Valve Aging Rates: Partial Renewal, No Intermediate Testing,

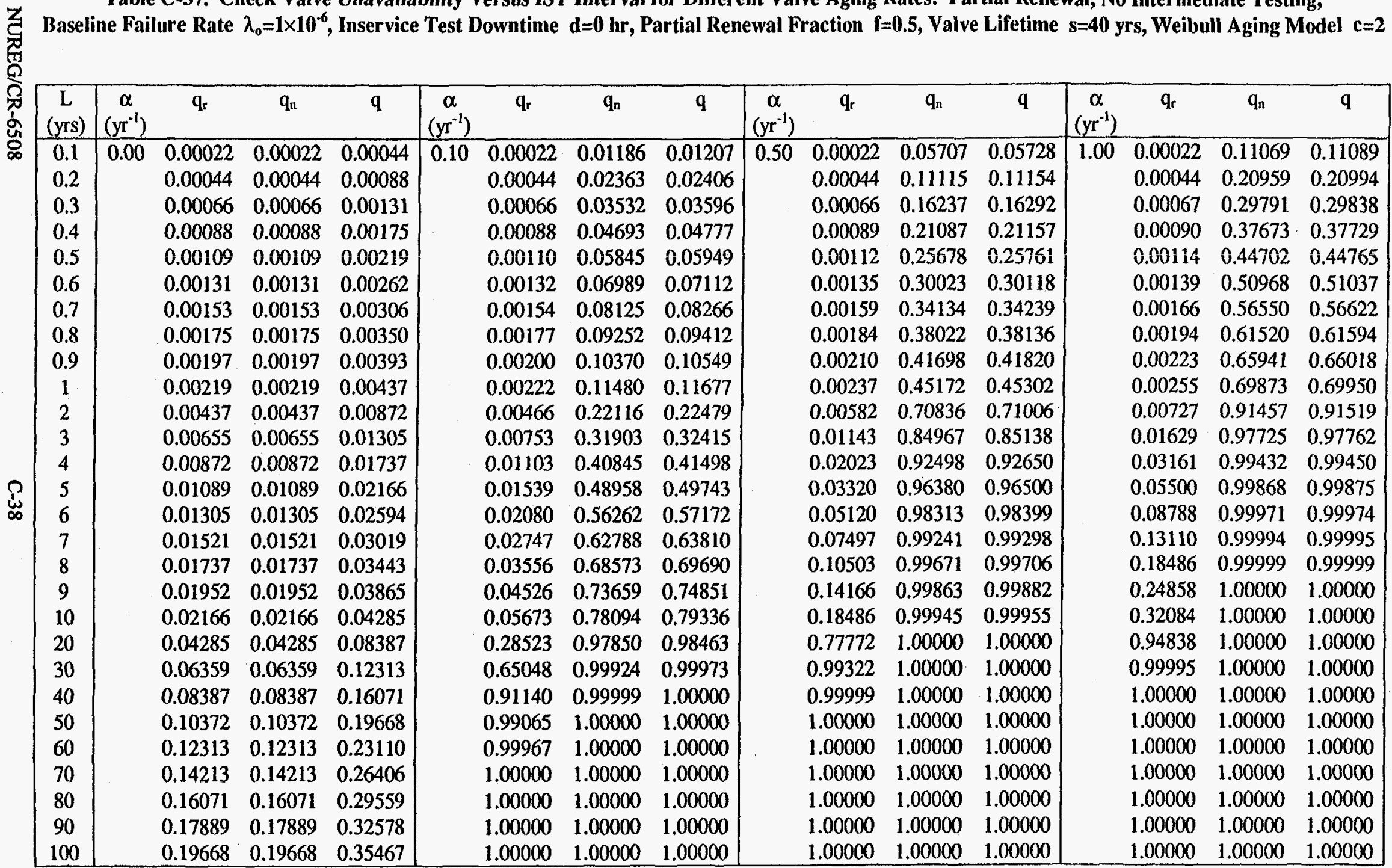


Table C-38. Check Valve Unavailability Versus IST Interval for Different Valve Aging Rates: Partial Renewal, No Intermediate Testing, Baseline Failure Rate $\lambda_{0}=1 \times 10^{-6}$, Inservice Test Downtime $d=8 \mathrm{hr}$, Partial Renewal Fraction $f=0.5$, Valve Lifetime $s=40$ yrs, Weibull Aging Model $c=2$

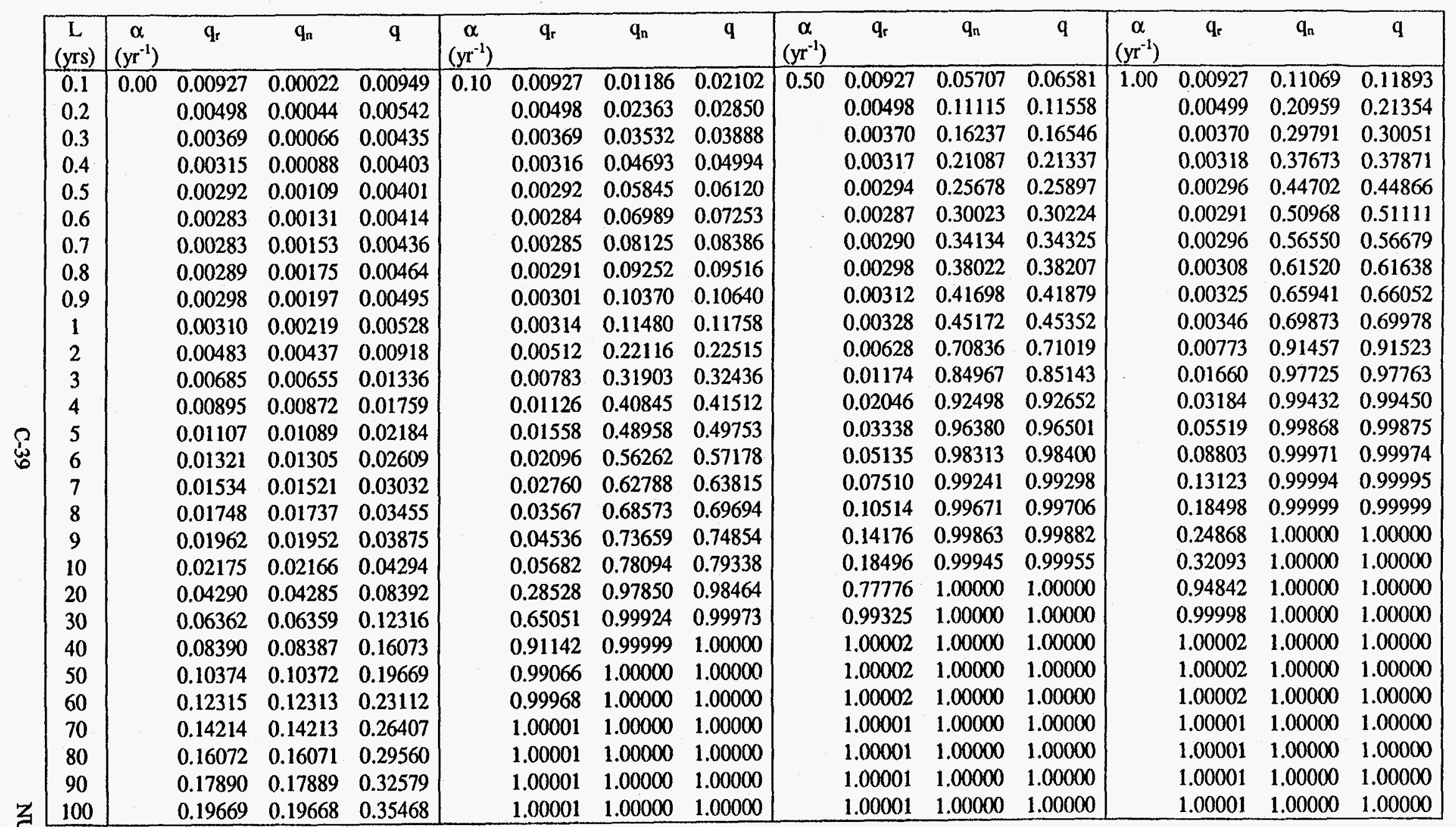

$$
\text { 苛 }
$$


Table C-39. Check Valve Unavailability Versus IST Interval for Different Valve Aging Rates: Partial Renewal, No Intermediate Testing, Baseline Failure Rate $\lambda_{0}=1 \times 10^{-6}$, Inservice Test Downtime $d=72 \mathrm{hr}$, Partial Renewal Fraction $f=0.5$, Valve Lifetime $s=40$ yrs, Weibull Aging Model $c=2$

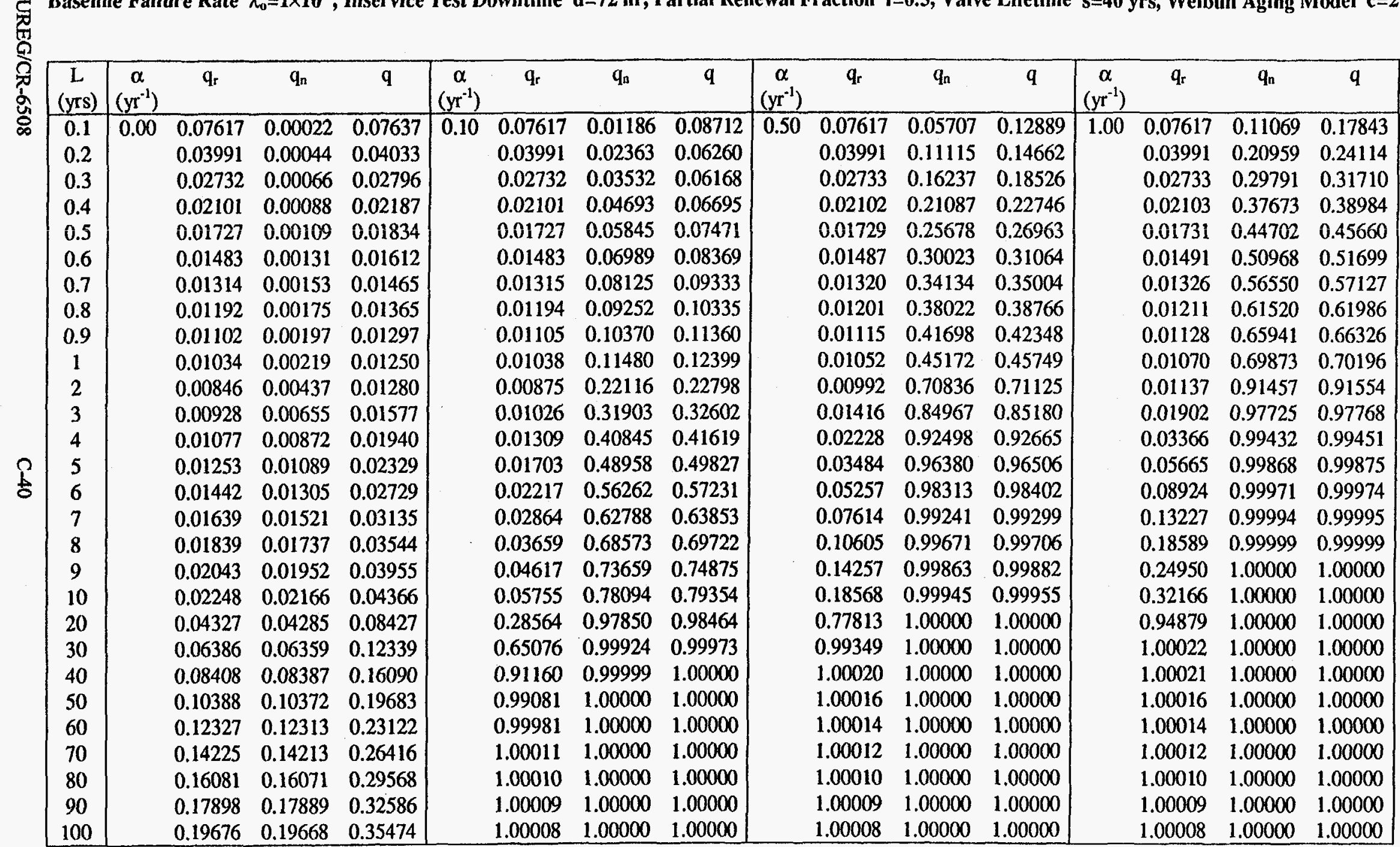


Table C-40. Check Valve Unavailability Versus IST Interval for Different Valve Aging Rates: Partial Renewal, No Intermediate Testing, Baseline Failure Rate $\lambda_{0}=1 \times 10^{-7}$, Inservice Test Downtime $d=0 \mathrm{hr}$, Partial Renewal Fraction $f=0.5$, Valve Lifetime $s=40$ yrs, Weibull Aging Model $c=2$

\begin{tabular}{|c|c|c|c|c|c|c|c|c|c|c|c|c|c|c|c|c|}
\hline $\begin{array}{c} \\
(\mathrm{yrs}) \\
\end{array}$ & $\begin{array}{c}\alpha \\
\left(\mathrm{yr}^{-1}\right)\end{array}$ & $\overline{q_{r}}$ & $\mathrm{q}_{\mathrm{n}}$ & $q$ & $\begin{array}{c}\alpha \\
\left(\mathrm{yr}^{-1}\right)\end{array}$ & $\mathrm{q}_{\mathrm{r}}$ & $\mathbf{q}_{\mathrm{n}}$ & $q$ & $\begin{array}{c}\alpha \\
\left(\mathrm{yr}^{-1}\right)\end{array}$ & $\mathrm{q}_{\mathrm{r}}$ & $q_{n}$ & $q$ & $\left(\begin{array}{c}\alpha \\
\left(\mathrm{yr}^{-1}\right)\end{array}\right.$ & $\mathrm{q}_{\mathrm{r}}$ & $q_{n}$ & $q$ \\
\hline 0.1 & 0.00 & 0.00002 & 0.00002 & 0.00004 & 0.10 & 0.00002 & 0.00119 & 0.00121 & 0.50 & 0.00002 & 0.00586 & 0.00588 & 1.00 & 0.00002 & 0.01166 & 0.01168 \\
\hline 0.2 & & 0.00004 & 0.00004 & 0.00009 & & 0.00004 & 0.00239 & 0.00243 & & 0.00004 & 0.01171 & 0.01176 & & 0.00004 & 0.02325 & 0.02329 \\
\hline 0.3 & & 0.00007 & 0.00007 & 0.00013 & & 0.00007 & 0.00359 & 0.00366 & & 0.00007 & 0.01756 & 0.01763 & & 0.00007 & 0.03475 & 0.03482 \\
\hline 0.4 & & 0.00009 & 0.00009 & 0.00018 & & 0.00009 & 0.00480 & 0.00488 & & 0.00009 & 0.02340 & 0.02349 & & 0.00009 & 0.04618 & 0.04626 \\
\hline 0.5 & & 0.00011 & 0.00011 & 0.00022 & & 0.00011 & 0.00600 & 0.00611 & & 0.00011 & 0.02924 & 0.02935 & & 0.00011 & 0.05752 & 0.05763 \\
\hline 0.6 & & 0.00013 & 0.00013 & 0.00026 & & 0.00013 & 0.00722 & 0.00735 & & 0.00014 & 0.03507 & 0.03520 & & 0.00014 & 0.06879 & 0.06892 \\
\hline 0.7 & & 0.00015 & 0.00015 & 0.00031 & & 0.00015 & 0.00844 & 0.00859 & & 0.00016 & 0.04090 & 0.04105 & & 0.00017 & 0.07998 & 0.08013 \\
\hline 0.8 & & 0.00018 & 0.00018 & 0.00035 & & 0.00018 & 0.00966 & 0.00984 & & 0.00018 & 0.04671 & 0.04689 & & 0.00019 & 0.09108 & 0.09126 \\
\hline 0.9 & & 0.00020 & 0.00020 & 0.00039 & & 0.00020 & 0.01089 & 0.01109 & & 0.00021 & 0.05252 & 0.05272 & & 0.00022 & 0.10211 & 0.10231 \\
\hline 1 & & 0.00022 & 0.00022 & 0.00044 & & 0.00022 & 0.01212 & 0.01234 & & 0.00024 & 0.05833 & 0.05855 & & 0.00026 & 0.11306 & 0.11328 \\
\hline 2 & & 0.00044 & 0.00044 & 0.00088 & & 0.00047 & 0.02469 & 0.02514 & & 0.00058 & 0.11593 & & & 0.00073 & 0.21809 & 0.21866 \\
\hline 3 & & 0.00066 & 0.00066 & 0.00131 & & 0.00076 & 0.03769 & 0.03842 & & 0.00115 & 0.17262 & & & 0.00164 & 0.31499 & 0.31611 \\
\hline 4 & & 0.00088 & 0.00088 & 0.00175 & & 0.00111 & 0.05115 & 0.05220 & & 0.00204 & 0.22818 & 0.22976 & & 0.00321 & 377 & 0.40568 \\
\hline 5 & & 0.00109 & 0.00109 & 0.00219 & & 0.00155 & 0.06504 & 0.06649 & & 0.00337 & 0.28242 & 0.28484 & & 0.00564 & 452 & 0.48743 \\
\hline 6 & & 0.00131 & 0.00131 & 0.00262 & & 210 & $0.0^{\circ}$ & 30 & & 0.00524 & 16 & 65 & & 916 & 741 & 0.56147 \\
\hline 7 & & 0.00153 & 0.00153 & 0.00306 & & 278 & 0.05 & 0.0 & & 0.00776 & & & & & 0.6 & 0.62797 \\
\hline 8 & & 0.00175 & 0.00175 & 50 & & 361 & 0.1 & 0.11 & & 0.01103 & 0.4 & 69 & & 0.02023 & 073 & 0.68719 \\
\hline 9 & & 0.00197 & 0.00197 & 0.00 & & 62 & 0.12 & 0.1 & & 516 & 0.4 & 54 & & 0.02817 & 187 & 0.73943 \\
\hline 10 & & 0.00219 & 0.00219 & 0.00 & & 82 & 0.1 & 0.1 & & & & & & 795 & 658 & 0.78506 \\
\hline 20 & & 0.00437 & 0.00437 & 2 & & 02 & 85 & 35 & & & & & & 50 & & 337 \\
\hline 30 & & 0.00655 & 0.00655 & 05 & & 978 & 0.51243 & 08 & & 06 & 71 & & & 0.6 & 919 & 970 \\
\hline 40 & & 0.00872 & 0.00872 & & & 0.21523 & 0.69172 & 307 & & 172 & 712 & 111 & & 0.9 & 999 & 1.00000 \\
\hline 50 & & 0.01089 & 0.01089 & 0.02166 & & 325 & 0.83156 & 0.8 & & 0.89896 & & & & & 000 & 1.00000 \\
\hline 60 & & 0.01305 & 0.01305 & & & 0.55136 & 0.92219 & 0.96509 & & 0.98084 & & & & 0.99963 & & 1.00000 \\
\hline 70 & & 0.01521 & 0.01521 & 0.03019 & & 0.71840 & 0.97027 & & & 0.99812 & & & & 1.00000 & & 1.00000 \\
\hline 80 & & 0.01737 & 0.01737 & 0.03443 & & 0.84837 & 0.99081 & 0.99861 & & 0.99991 & 1.00000 & & & 1.00000 & 1.00000 & 1.00000 \\
\hline 90 & & 0.01952 & 0.01952 & 0.03865 & & 0.93148 & 0.99775 & 0.99985 & & 1.00000 & 1.00000 & & & 1.00000 & 1.00000 & 1.00000 \\
\hline 100 & & 0.02166 & 0.02166 & 0.04285 & & 0.97457 & 0.99957 & 0.99999 & & 1.00000 & 1.00000 & 1.00000 & & 1.00000 & 1.00000 & 1.00000 \\
\hline
\end{tabular}


Table C-41. Check Valve Unavailability Versus IST Interval for Different Valve Aging Rates: Partial Renewal, No Intermediate Testing,

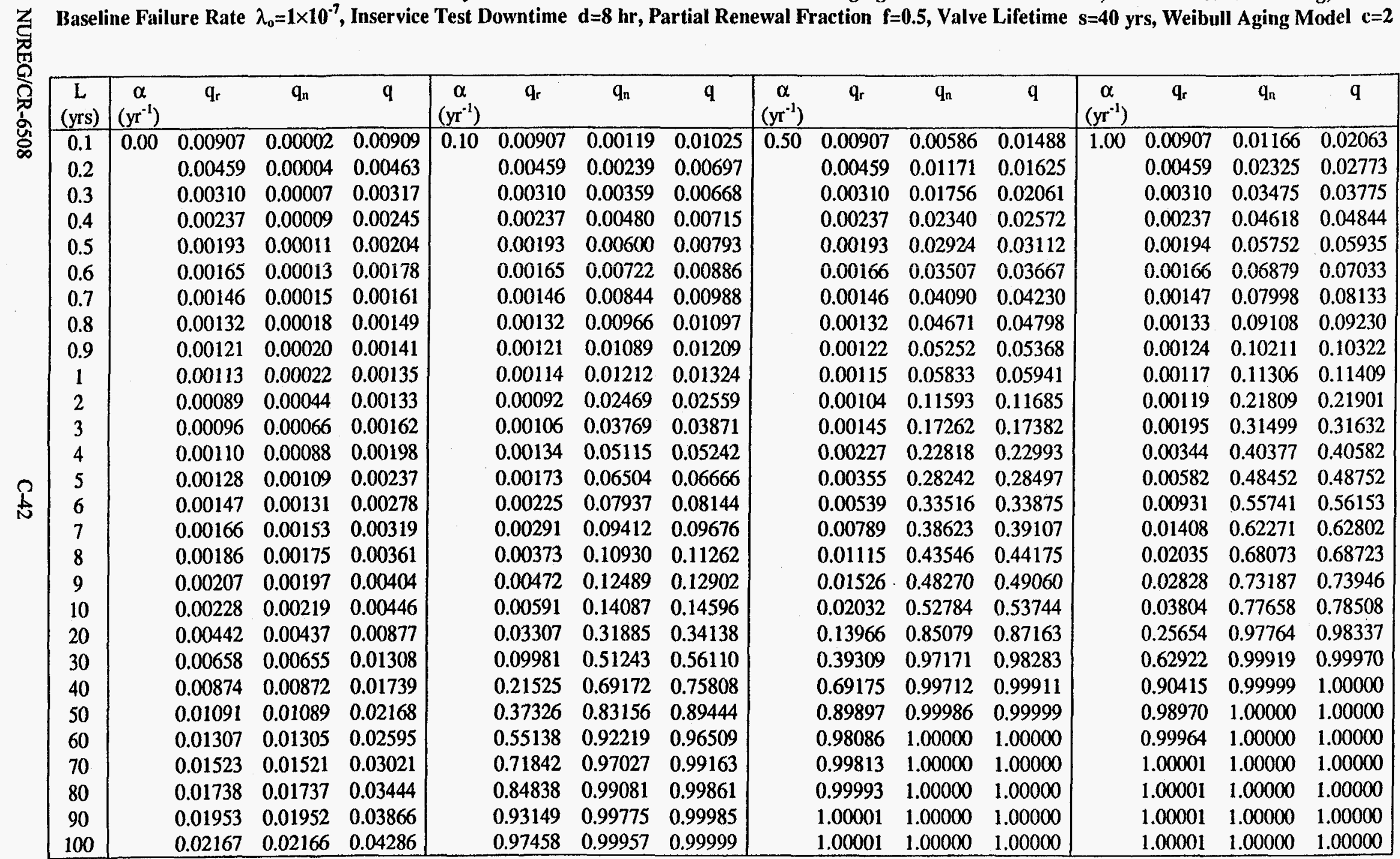


Table C-42. Check Valve Unavailability Versus IST Interval for Different Valve Aging Rates: Partial Renewal, No Intermediate Testing, Baseline Failure Rate $\lambda_{0}=1 \times 10^{-7}$, Inservice Test Downtime $d=72 \mathrm{hr}$, Partial Renewal Fraction $f=0.5$, Valve Lifetime $s=40$ yrs, Weibull Aging Model $c=2$

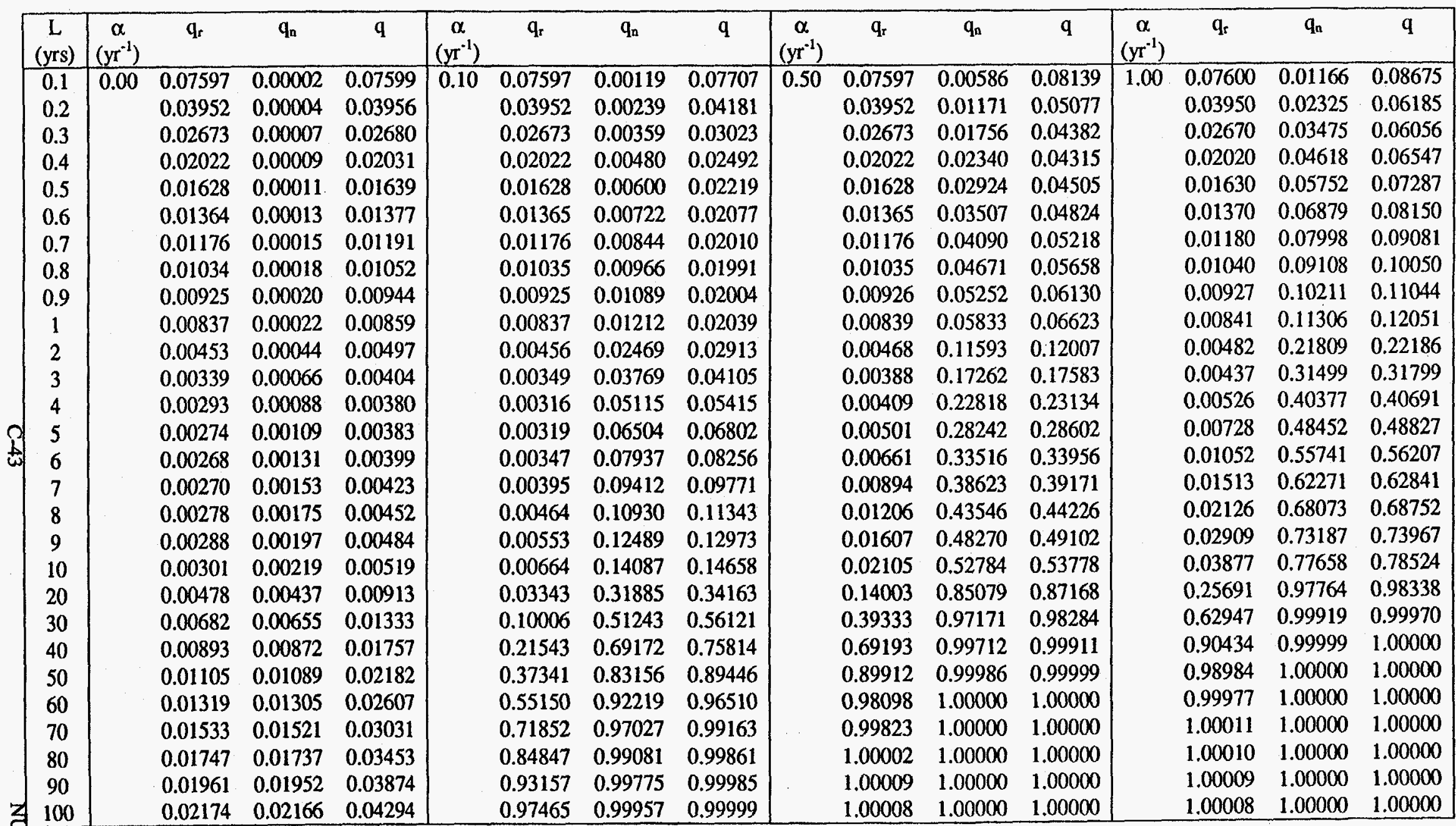


Table C-43. Check Valve Unavailability Versus IST Interval for Different Valve Aging Rates: Partial Renewal, No Intermediate Testing,

\begin{tabular}{|c|c|c|c|c|c|c|c|c|c|c|c|c|c|c|c|c|}
\hline $\begin{array}{c}\mathrm{L} \\
\text { (yrs) }\end{array}$ & $\begin{array}{c}\alpha \\
\left(\mathrm{yr}^{-1}\right)\end{array}$ & $\mathrm{q}_{\mathrm{r}}$ & $\mathrm{q}_{\mathrm{n}}$ & $q$ & $\begin{array}{c}\alpha \\
\left(\mathrm{yr}^{-1}\right)\end{array}$ & $q_{r}$ & $\mathrm{q}_{\mathrm{n}}$ & $q$ & $\begin{array}{c}\alpha \\
\left(\mathrm{yr}^{-1}\right)\end{array}$ & $q_{r}$ & $q_{n}$ & $q$ & $\begin{array}{c}\alpha \\
\left(\mathrm{yr}^{-1}\right)\end{array}$ & $\mathbf{q}_{\mathrm{r}}$ & $q_{n}$ & $q$ \\
\hline 0.1 & 0.00 & 0.00004 & 0.00039 & 0.00044 & 0.10 & 0.00004 & 0.46912 & 0.46914 & 0.50 & 0.00004 & 0.95777 & 0.95777 & 1.00 & 0.00004 & 0.99822 & 0.99822 \\
\hline 0.2 & & 0.00009 & 0.00079 & 0.00088 & & 0.00009 & 0.71936 & 0.71938 & & 0.00009 & 0.99825 & 0.99825 & & 0.00009 & 1.00000 & 1.00000 \\
\hline 0.3 & & 0.00013 & 0.00118 & 0.00131 & & 0.00013 & 0.85227 & 0.85229 & & 0.00013 & 0.99993 & 0.99993 & & 0.00013 & 1.00000 & 1.00000 \\
\hline 0.4 & & 0.00018 & 0.00158 & 0.00175 & & 0.00018 & 0.92257 & 0.92258 & & 0.00018 & 1.00000 & 1.00000 & & 0.00018 & 1.00000 & 1.00000 \\
\hline 0.5 & & 0.00022 & 0.00197 & 0.00219 & & 0.00022 & 0.95959 & 0.95960 & & 0.00022 & 1.00000 & 1.00000 & & 0.00022 & 1.00000 & 1.00000 \\
\hline 0.6 & & 0.00026 & 0.00236 & 0.00262 & & 0.00026 & 0.97900 & 0.97901 & & 0.00027 & 1.00000 & 1.00000 & & 0.00027 & 1.00000 & 1.00000 \\
\hline 0.7 & & 0.00031 & 0.00276 & 0.00306 & & 0.00031 & 0.98913 & 0.98914 & & 0.00031 & 1.00000 & 1.00000 & & 0.00032 & 1.00000 & 1.00000 \\
\hline 0.8 & & 0.00035 & 0.00315 & 0.00350 & & 0.00035 & 0.99440 & 0.99440 & & 0.00036 & 1.00000 & 1.00000 & & 0.00037 & 1.00000 & 1.00000 \\
\hline 0.9 & & 0.00039 & 0.00354 & 0.00393 & & 0.00040 & 0.99713 & 0.99713 & & 0.00041 & 1.00000 & 1.00000 & & 0.00042 & 1.00000 & 1.00000 \\
\hline 1 & & 0.00044 & 0.00393 & 0.00437 & & 0.00044 & 0.99853 & 0.99853 & & 0.00046 & 1.00000 & 1.00000 & & 0.00048 & 1.00000 & 1.00000 \\
\hline 2 & & 0.00088 & 0.00785 & 0.00872 & & 0.00095 & 1.00000 & 1.00000 & & 0.00123 & 1.00000 & 1.00000 & & 0.00158 & 1.00000 & 1.00000 \\
\hline 3 & & 0.00131 & 0.01176 & 0.01305 & & 0.00167 & 1.00000 & 1.00000 & & 0.00308 & 1.00000 & 1.00 & & 0.00485 & 1.00000 & 1.00000 \\
\hline 4 & & 0.00175 & 0.01564 & 0.01737 & & 0.00287 & 1.00000 & 1.00000 & & 0.00733 & 1.00000 & 1.00 & & 0.01288 & 1.00000 & 1.00000 \\
\hline 5 & & 0.00219 & 0.01952 & 0.02166 & & 0.00492 & 1.00000 & 1.00000 & & 0.01575 & 1.00000 & 1.00000 & & 0.02913 & 1.00000 & 1.00000 \\
\hline 6 & & 0.00262 & 0.02337 & 0.02594 & & 0.00827 & 1.00000 & 1.00000 & & 0.03053 & 1.00000 & 1.00000 & & 0.05766 & 1.00000 & 1.00000 \\
\hline 7 & & 0.00306 & 0.02722 & 0.03019 & & 0.01349 & 1.00000 & 1.00000 & & 0.05413 & 1.00000 & 1.00000 & & 0.10258 & 1.00000 & 1.00000 \\
\hline 8 & & 0.00350 & 0.03104 & 0.03443 & & 0.02122 & 1.00000 & 1.00000 & & 0.08899 & 1.00000 & 1.00000 & & 0.16716 & 1.00000 & 1.00000 \\
\hline 9 & & 0.00393 & 0.03486 & 0.03865 & & 0.03215 & 1.00000 & 1.00000 & & 0.13725 & 1.00000 & 1.00000 & & 272 & 1.00000 & 1.00000 \\
\hline 10 & & 0.00437 & 0.03865 & 0.04285 & & 0.04704 & 1.00000 & 1.00000 & & 0.20019 & 1.00000 & 1.00000 & & 0.3 & 00 & 1.00000 \\
\hline 20 & & 0.00872 & 0.07581 & 0.08387 & & 0.50814 & 1.00000 & 1.00000 & & 0.97019 & 1.00000 & 1.0 & & & $1 .($ & 00 \\
\hline 30 & & 0.01305 & 0.11153 & 0.12313 & & 0.97159 & 1.00000 & 1.00000 & & 1.00000 & 1.00000 & 1.0 & & & 1. & 00 \\
\hline 40 & & 0.01737 & 0.14588 & 0.16071 & & 0.99999 & 1.00000 & 1.00000 & & 1.00000 & 1.00000 & $1 .($ & & & 1. & 00 \\
\hline 50 & & 0.02166 & 0.17889 & 0.19668 & & 1.00000 & 1.00000 & 1.00000 & & 1.00000 & 1.00000 & 1.0 & & & 0 & 000 \\
\hline 60 & & 0.02594 & 0.21063 & 0.23110 & & 1.00000 & 1.00000 & 1.0 & & 100 & 1.0 & 1.0 & & & 90 & 1.00000 \\
\hline 70 & & 0.03019 & 0.24114 & 0.26406 & & 0000 & 1.00000 & 1.0 & & & 1.0 & 1. & & 1.00000 & 1.00000 & 1.00000 \\
\hline 80 & & 0.03443 & 0.27047 & 0.29559 & & 1.00000 & 1.00000 & 1.00 & & & 1.0 & & & 1.00000 & 1.00000 & 1.00000 \\
\hline 90 & & 0.03865 & 0.29867 & 0.32578 & & 1.00000 & 1.00000 & & & & 1.0 & 1.00000 & & 1.00000 & 1.00000 & 1.00000 \\
\hline 100 & & 0.04285 & 0.32578 & 0.35467 & & 1.00000 & 1.00000 & 1.00000 & & 1.00000 & 1.00000 & 1.00000 & & 1.00000 & 1.00000 & 1.00000 \\
\hline
\end{tabular}


Table C-44. Check Valve Unavailability Versus IST Interval for Different Valve Aging Rates: Partial Renewal, No Intermediate Testing, Baseline Failure Rate $\lambda_{0}=1 \times 10^{-6}$, Inservice Test Downtime $d=8 \mathrm{hr}$, Partial Renewal Fraction $f=0.1$, Valve Lifetime $s=40$ yrs, Weibull Aging Model $c=3$

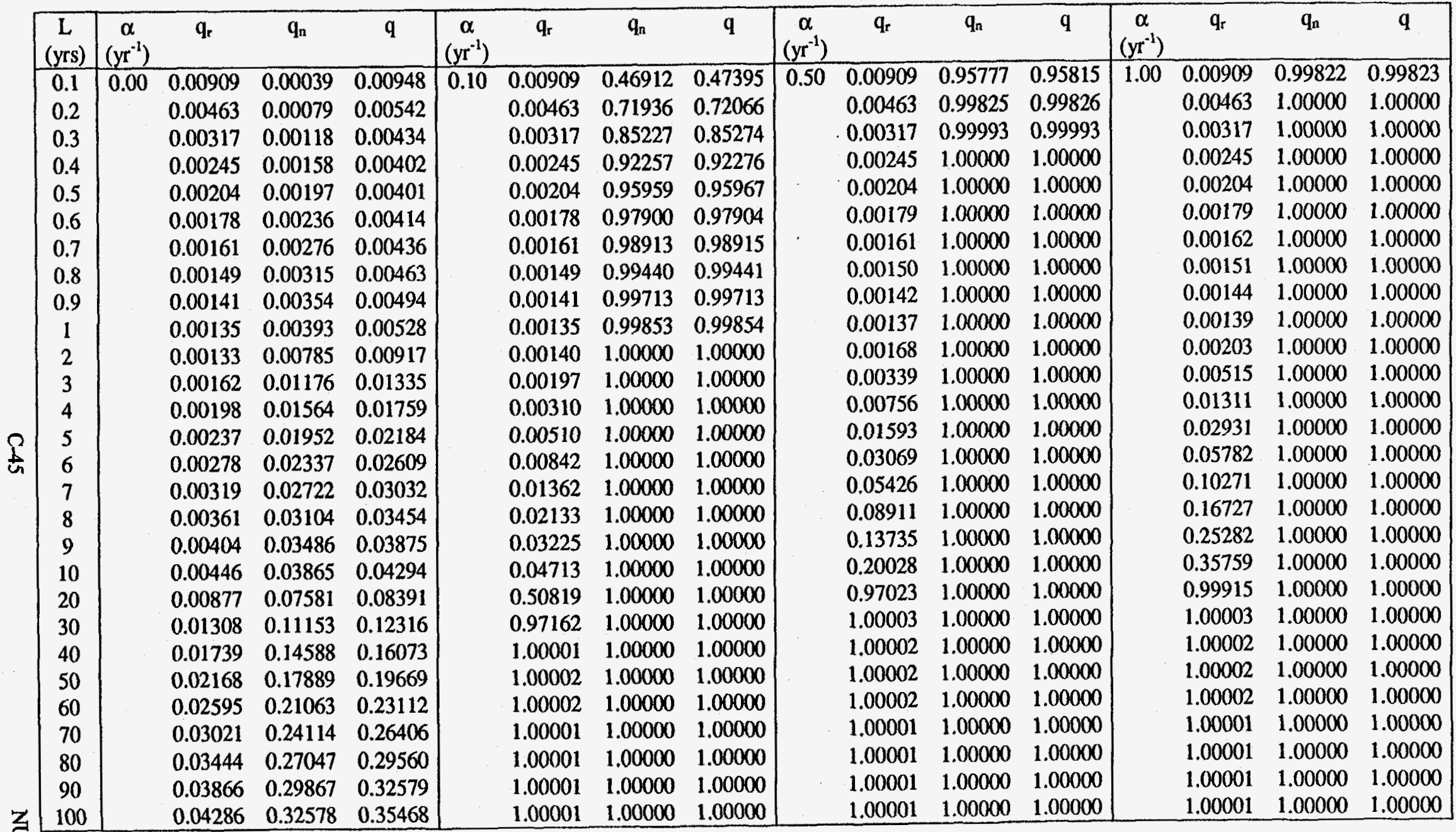


Table C-45. Check Valve Unavailability Versus IST Interval for Different Valve Aging Rates: Partial Renewal, No Intermediate Testing,

Baseline Failure Rate $\lambda_{0}=1 \times 10^{-6}$, Inservice Test Downtime $d=72$ hr, Partial Renewal Fraction $f=0.1$, Valve Lifetime $s=40$ yrs, Weibull Aging Model $c=3$

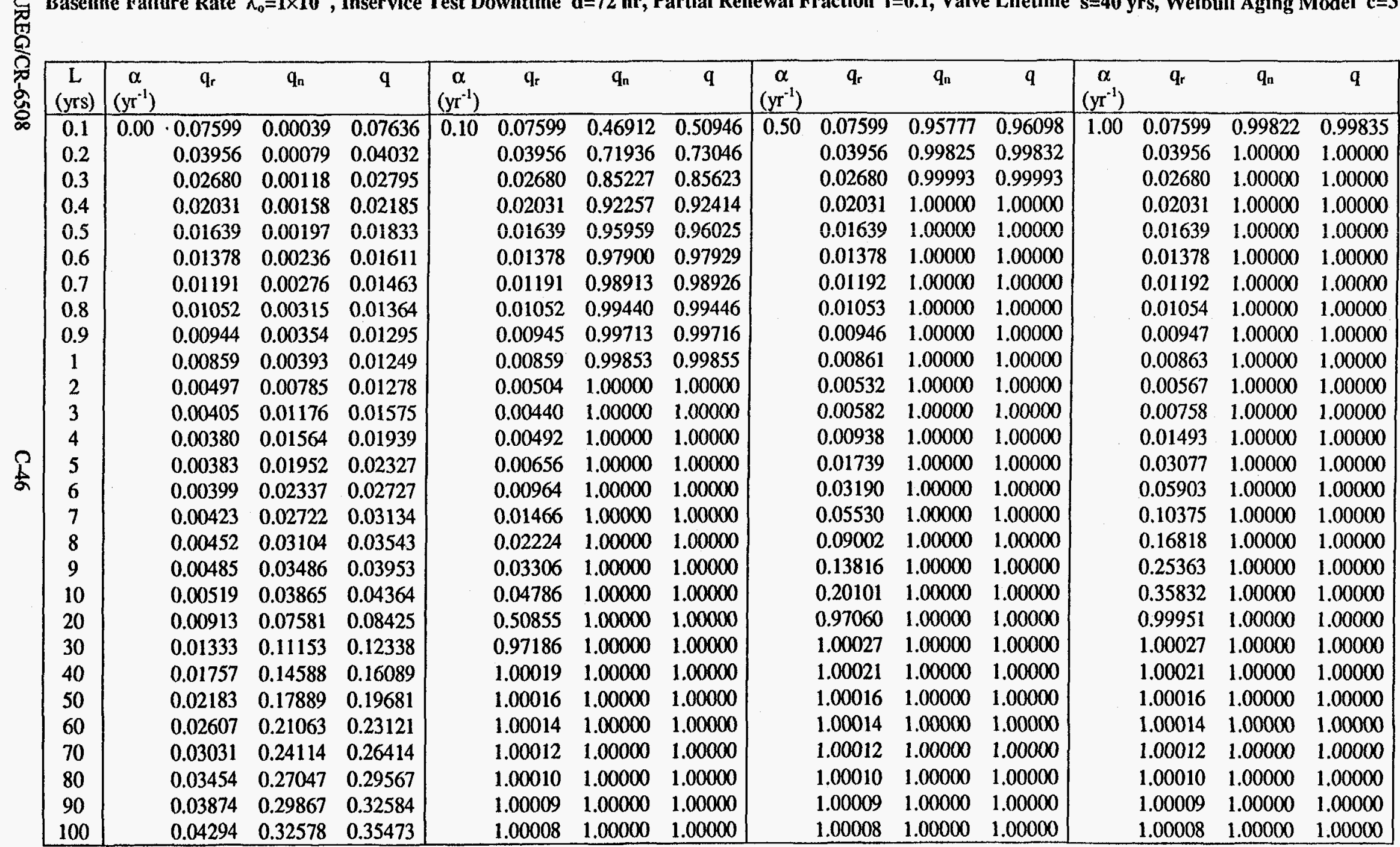


Table C-46. Check Valve Unavailability Versus IST Interval for Different Valve Aging Rates: Partial Renewal, No Intermediate Testing, Baseline Failure Rate $\lambda_{0}=1 \times 10^{-7}$, Inservice Test Downtime $d=0 \mathrm{hr}$, Partial Renewal Fraction $f=0.1$, Valve Lifetime $s=40$ yrs, Weibull Aging Model $c=3$

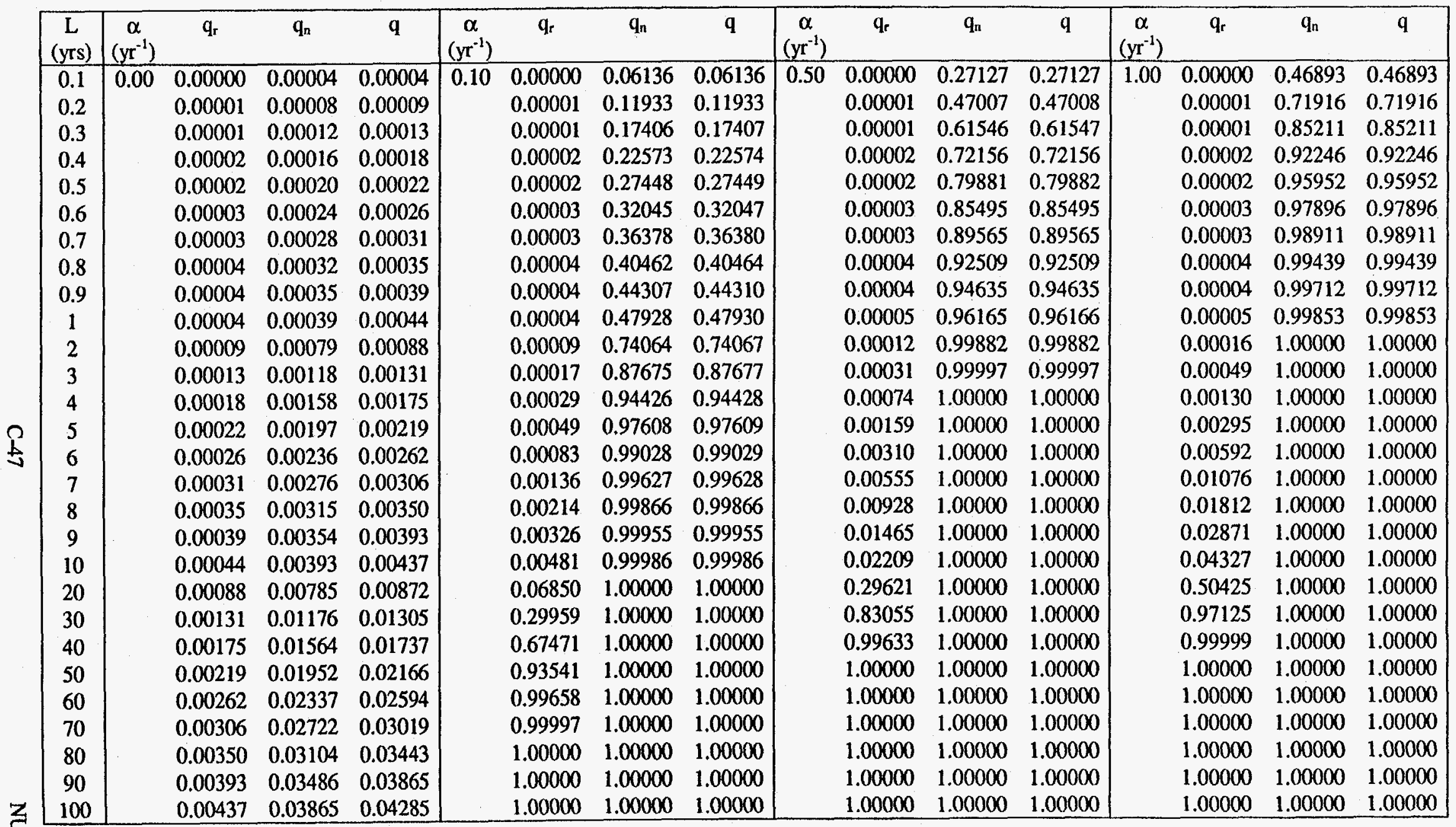


Table C-47. Check Valve Unavailability Versus IST Interval for Different Valve Aging Rates: Partial Renewal, No Intermediate Testing,

\begin{tabular}{|c|c|c|c|c|c|c|c|c|c|c|c|c|c|c|c|c|}
\hline $\begin{array}{c}\mathrm{L} \\
\text { (yrs) }\end{array}$ & $\begin{array}{c}\alpha \\
\left(\mathrm{yr}^{-1}\right)\end{array}$ & $q_{r}$ & $q_{n}$ & $q$ & $\begin{array}{c}\alpha \\
\left(\mathrm{yr}^{-1}\right)\end{array}$ & $q_{r}$ & $\mathrm{q}_{\mathrm{n}}$ & $q$ & $\begin{array}{c}\alpha \\
\left(\mathrm{yr}^{-1}\right)\end{array}$ & $q_{r}$ & $q_{n}$ & $q$ & {$\left[\begin{array}{c}\alpha \\
\left(\mathrm{yr}^{-1}\right)\end{array}\right.$} & $\mathbf{q}_{\mathbf{r}}$ & $q_{n}$ & $\mathbf{q}$ \\
\hline 0.1 & 0.00 & 0.00905 & 0.00004 & 0.00909 & 0.10 & 0.00905 & 0.06136 & 0.06986 & 0.50 & 0.00905 & 0.27127 & 0.27787 & 1.00 & 0.00905 & 0.46893 & 0.47374 \\
\hline 0.2 & & 0.00455 & 0.00008 & 0.00463 & & 0.00455 & 0.11933 & 0.12334 & & 0.00455 & 0.47007 & 0.47249 & & 0.00455 & 0.71916 & 0.72044 \\
\hline 0.3 & & 0.00305 & 0.00012 & 0.00 & & 0.00305 & 0.17406 & 0.17658 & & 0.00305 & 0.61546 & 0.61663 & & 0.00305 & 0.85211 & 0.85256 \\
\hline 0.4 & & 0.00230 & 0.00016 & 0.0 & & 0.00230 & 0.22573 & 0.22751 & & 0.00230 & 0.72156 & 0.72220 & & 0.00230 & 0.92246 & 0.92264 \\
\hline 0.5 & & 0.0 & 0.00 & 0.0 & & 0.00185 & 0.27448 & 0.27582 & & 0.00185 & 0.79881 & 0.79919 & & 0.00185 & 0.95952 & 0.95959 \\
\hline 0.6 & & 0.0 & 0.0 & 0. & & 0.00155 & 0.32045 & 0.32150 & & 0.00155 & 0.85495 & 0.85517 & & 0.00155 & 0.97896 & 0.97899 \\
\hline 0.7 & & 0. & 0.0 & 0. & & 0.00133 & 0.36378 & 0.36463 & & 0.00133 & 0.89565 & 0.89579 & & 0.00133 & 0.98911 & 0.98912 \\
\hline 0.8 & & 0.0 & 0.0 & 149 & & 0.00118 & 0.40462 & 0.40532 & & 0.00118 & 0.92509 & 0.92518 & & 0.00118 & 0.99439 & 0.99439 \\
\hline 0.9 & & 0.0 & 0.00 & 0.00141 & & 0.00105 & 0.44307 & 0.44366 & & 0.00105 & 0.94635 & 0.94640 & & 0.00106 & 0.99712 & 0.99712 \\
\hline 1 & & 0.00096 & 0.0 & 0.00135 & & 0.00096 & 0.47928 & 0.47977 & & 0.00096 & 0.96165 & 0.96169 & & 0.00096 & 0.99853 & 0.99853 \\
\hline 2 & & 1054 & 0.0 & 0.00133 & & 0.00055 & 0.74064 & 0.74078 & & 0.00058 & 0.99882 & 0.99882 & & 0.00061 & 1.00000 & 1.00000 \\
\hline 3 & & 1044 & 0.0 & 0.00162 & & 0.00047 & 0.87675 & 0.87681 & & 0.00061 & 0.99997 & 0.99997 & & 0.00079 & 1.00000 & 1.00000 \\
\hline 4 & & 40 & 0.00 & 0.00198 & & 0.00052 & 0.94426 & 0.94429 & & 0.00096 & 1.00000 & 1.00000 & & 0.00152 & 1.00000 & 1.00000 \\
\hline 5 & & 0.00040 & 0.0 & 0.00237 & & 0.00068 & 0.97608 & 0.97609 & & 0.00177 & 1.00000 & 1.00000 & & 0.00313 & 1.00000 & 1.00000 \\
\hline 6 & & 0.00041 & 0.00236 & 0.00278 & & 0.00098 & 0.99028 & 0.99029 & & 0.00325 & 1.00000 & 1.00000 & & 0.00607 & 1.00000 & 1.00000 \\
\hline 7 & & 0.00044 & 0.00276 & 0.00319 & & 0.00149 & 0.99627 & 0.99628 & & 0.00568 & 1.00000 & 1.00000 & & 0.01090 & 1.00000 & 1.00000 \\
\hline 8 & & 0.00046 & 0.00315 & 0.00361 & & 0.00226 & 0.99866 & 0.99866 & & 0.00939 & 1.00000 & 1.00000 & & 0.01824 & 1.00000 & 1.00000 \\
\hline 9 & & 0.00050 & 0.00354 & 0.00404 & & 0.00336 & 0.99955 & 0.99955 & & 0.01476 & 1.00000 & 1.00000 & & 0.02881 & 1.00000 & 1.00000 \\
\hline 10 & & 0.00053 & 0.00393 & 0.00446 & & 0.00490 & 0.99986 & 0.99986 & & 0.02218 & 1.00000 & 1.00000 & & 0.04337 & 1.00000 & 1.00000 \\
\hline 20 & & 0.00092 & 0.00785 & 0.00877 & & 0.06854 & 1.00000 & 1.00000 & & 0.29626 & 1.00000 & 1.00000 & & 0.50429 & 1.00000 & 1.00000 \\
\hline 30 & & 0.00134 & 0.01176 & 0.01308 & & 0.29962 & 1.00000 & 1.00000 & & 0.83058 & 1.00000 & 1.00000 & & 0.97128 & 1.00000 & 1.00000 \\
\hline 40 & & 0.00177 & 0.01564 & 0.01739 & & 0.67473 & 1.00000 & 1.00000 & & 0.99635 & 1.00000 & 1.00000 & & 1.00001 & 1.00000 & 1.00000 \\
\hline 50 & & 0.00221 & 0.01952 & 0.02168 & & 0.93543 & 1.00000 & 1.00000 & & 1.00002 & 1.00000 & 1.00000 & & 1.00002 & 1.00000 & 1.00000 \\
\hline 60 & & 0.00264 & 0.02337 & 0.02595 & & 0.99660 & 1.00000 & 1.00000 & & 1.00002 & 1.00000 & 1.00000 & & 1.00002 & 1.00000 & 1.00000 \\
\hline 70 & & 0.00307 & 0.02722 & 0.03021 & & 0.99999 & 1.00000 & 1.00000 & & 1.00001 & 1.00000 & 1.00000 & & 1.00001 & 1.00000 & 1.00000 \\
\hline 80 & & 0.00351 & 0.03104 & 0.03444 & & 1.00001 & 1.00000 & 1.00000 & & 1.00001 & 1.00000 & 1.00000 & & 1.00001 & 1.00000 & 1.00000 \\
\hline 90 & & 0.00394 & 0.03486 & 0.03866 & & 1.00001 & 1.00000 & 1.00000 & & 1.00001 & 1.00000 & 1.00000 & & 1.00001 & 1.00000 & 1.00000 \\
\hline 100 & & 0.00438 & 0.03865 & 0.04286 & & 1.00001 & 1.00000 & 1.00000 & & 1.00001 & 1.00000 & 1.00000 & & 1.00001 & 1.00000 & 1.00000 \\
\hline
\end{tabular}


Table C-48. Check Valve Unavailability Versus IST Interval for Different Valve Aging Rates: Partial Renewal, No Intermediate Testing, Baseline Failure Rate $\lambda_{0}=1 \times 10^{-7}$, Inservice Test Downtime $d=72 \mathrm{hr}$, Partial Renewal Fraction $f=0.1$, Valve Lifetime $s=40$ yrs, Weibull Aging Model $c=3$

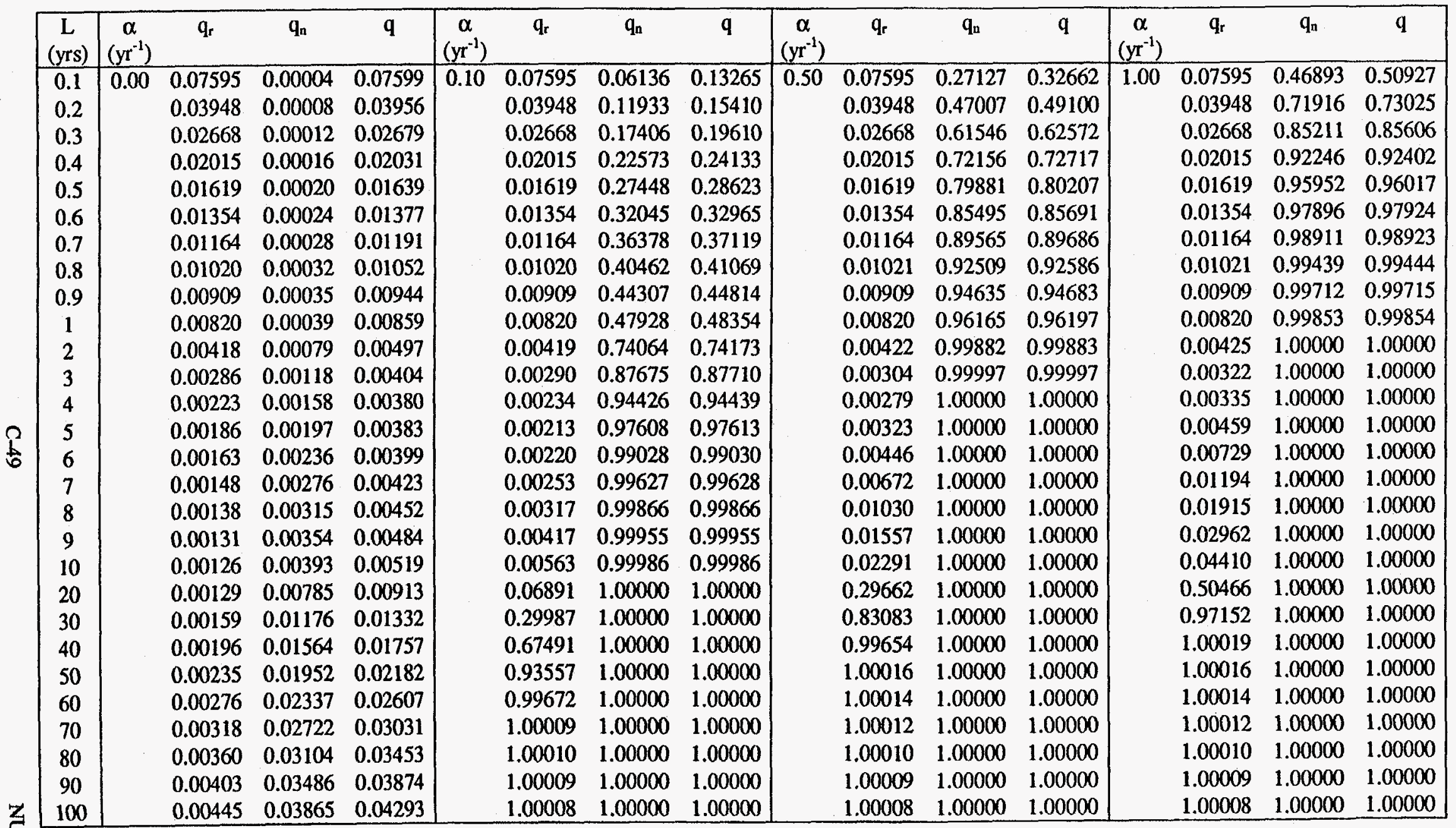




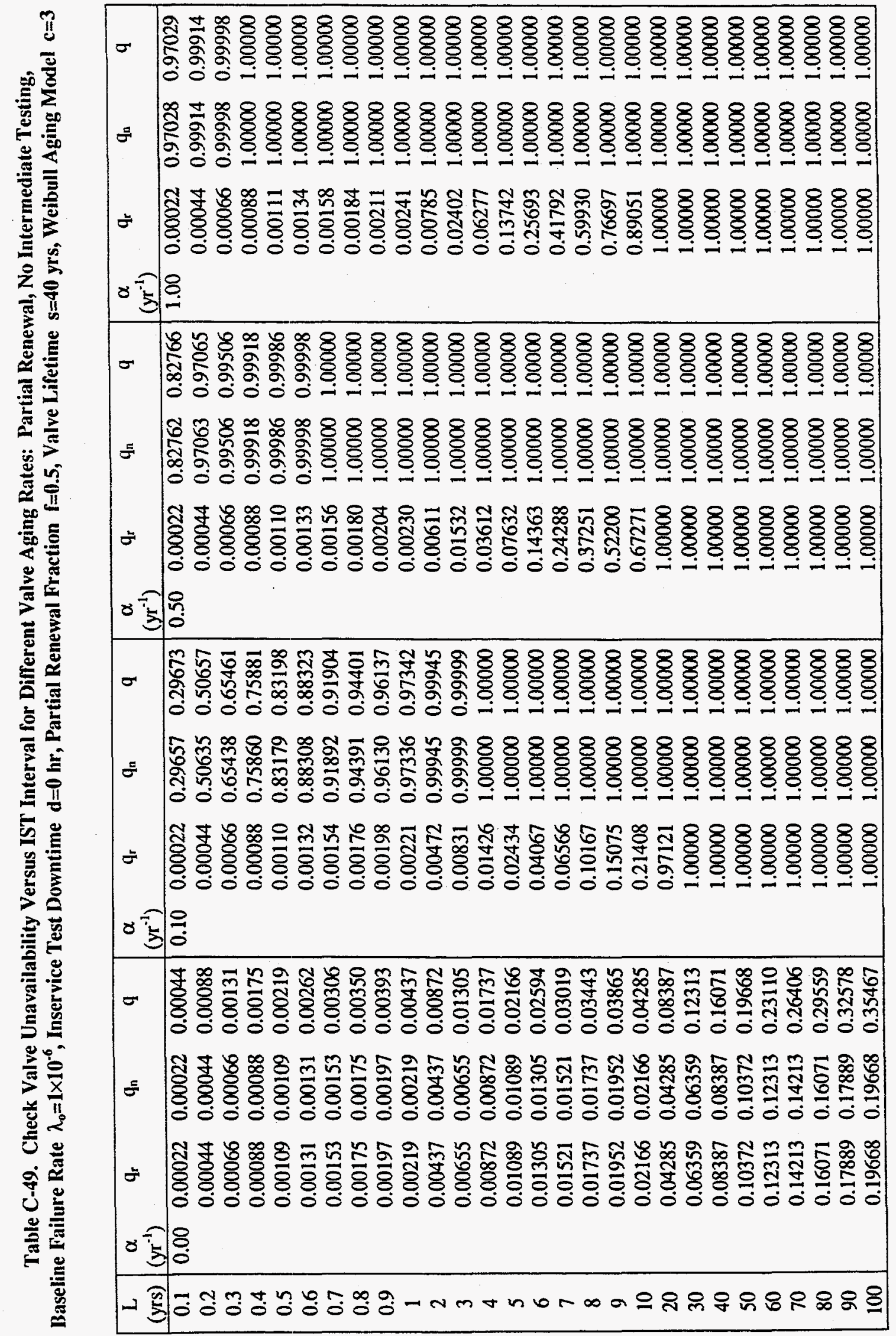


Table C-50. Check Valve Unavailability Versus IST Interval for Different Valve Aging Rates: Partial Renewal, No Intermediate Testing, Baseline Failure Rate $\lambda_{0}=1 \times 10^{-6}$, Inservice Test Downtime $d=8 \mathrm{hr}$, Partial Renewal Fraction $f=0.5$, Valve Lifetime $s=40$ yrs, Weibull Aging Model $c=3$

\begin{tabular}{|c|c|c|c|c|c|c|c|c|c|c|c|c|c|c|c|c|}
\hline $\begin{array}{c}\mathrm{L} \\
(\mathrm{yrs})\end{array}$ & $\begin{array}{c}\alpha \\
\left(\mathrm{yr}^{-1}\right)\end{array}$ & $q_{r}$ & $q_{n}$ & $q$ & $\begin{array}{c}\alpha \\
\left(\mathrm{yr}^{-1}\right)\end{array}$ & $q_{r}$ & $\mathrm{q}_{\mathrm{n}}$ & $\mathbf{q}$ & $\begin{array}{c}\alpha \\
\left(y^{-1}\right)\end{array}$ & $\overline{q_{r}}$ & $\mathrm{q}_{\mathrm{n}}$ & $q$ & {$\left[\begin{array}{c}\alpha \\
\left(\mathrm{yr}^{-1}\right)\end{array}\right.$} & $q_{r}$ & $\mathrm{q}_{\mathrm{n}}$ & $q$ \\
\hline 0.1 & 0.00 & 0.00927 & 0.00022 & 0.00949 & 0.10 & 0.00927 & 0.29657 & 0.30309 & 0.50 & 0.00927 & 0.82762 & 0.82922 & 1.00 & 0.00927 & 0.97028 & 0.970 \\
\hline 0.2 & & 0.00498 & 0.00044 & 0.00542 & & 0.00498 & 0.50635 & 0.50881 & & 0.00498 & 0.97063 & 0.97078 & & 0.00498 & 0.99914 & 0.99914 \\
\hline 0.3 & & 0.00369 & 6.57E-04 & 0.00435 & & 0.00369 & 0.65438 & 0.65566 & & 0.00369 & 0.99506 & 0.99507 & & 0.00369 & 0.99998 & 0.99998 \\
\hline 0.4 & & 0.00315 & $8.76 \mathrm{E}-04$ & 0.00403 & & 0.00315 & 0.75860 & 0.75936 & & 0.00316 & 0.99918 & 0.9 & & 16 & 1.00000 & 1.00000 \\
\hline 0.5 & & 0.00292 & 0.00109 & 0.00401 & & 0.00292 & 0.83179 & 0.83229 & & 0.00292 & 0.99986 & 0.9 & & 93 & 1.00000 & 1.00000 \\
\hline 0.6 & & 0.00283 & 0.00131 & 0.00414 & & 0.00284 & 0.88308 & 0.88341 & & 0.00285 & 0.99998 & 0.99 & & 86 & 1.00000 & 1.00000 \\
\hline 0.7 & & 0.00283 & 0.00153 & 0.00436 & & 0.00284 & 0.91892 & 0.91915 & & 0.00286 & 1.00000 & 1.0 & & & 000 & 1.00000 \\
\hline 0.8 & & 0.00289 & 0.00175 & 0.00464 & & 0.00290 & 0.94391 & 0.94407 & & 0.00294 & 1.0 & 1.0 & & & 000 & 1.00000 \\
\hline 0.9 & & 0.00298 & 0.00197 & 0.00495 & & 0.00300 & 0.96130 & 141 & & 0.00305 & 1.00000 & 1.0 & & & 000 & 1000 \\
\hline 1 & & 0.00310 & 0.00219 & 0.00528 & & 0.00312 & 0.97336 & 44 & & 0.00321 & 1.00000 & 1.0 & & & 000 & 000 \\
\hline 2 & & 0.00483 & 0.00437 & 0.00918 & & 0.00518 & 0.99945 & & & 0.00657 & 1.00000 & & & & 000 & 0000 \\
\hline 3 & & 0.00685 & 0.00655 & 0.01336 & & 0.00861 & 0.99999 & & & 0.01563 & & & & & 000 & 000 \\
\hline 4 & & 0.00895 & 0.00872 & 0.01759 & & 0.01449 & 1.00000 & 1.00000 & & 0.03635 & & 1.0 & & & 000 & .00000 \\
\hline 5 & & 0.01107 & 0.01089 & 0.02184 & & 0.02452 & 1.00000 & & & 0.07650 & & 1.0 & & & 000 & .00000 \\
\hline 6 & & 0.01321 & 0.01305 & 0.02609 & & 0.04082 & 1.00000 & 1.00000 & & 378 & 1.0 & 1.0 & & & 000 & .00000 \\
\hline 7 & & 0.01534 & 0.01521 & 0.03032 & & 0.06579 & 1.00000 & & & & 1.0 & & & 305 & 000 & .00000 \\
\hline 8 & & 0.01748 & 0.01737 & 0.03455 & & 0.10179 & 1.00000 & & & 263 & 1.0 & & & 941 & 000 & 1.00000 \\
\hline 9 & & 0.01962 & 0.01952 & 0.03875 & & 0.15085 & 1.00000 & & & 0.52210 & 1.0 & 1.0 & & 707 & 000 & 1.00000 \\
\hline 10 & & 0.02175 & 0.02166 & 0.04294 & & 0.21417 & 1.00000 & 1.00000 & & 0.67280 & 1.0 & 1.0 & & 060 & 000 & 1.00000 \\
\hline 20 & & 0.04290 & 0.04285 & 0.08392 & & 0.97126 & 1.00000 & 1.00000 & & 1.00005 & 1.0 & 1.0 & & 05 & 1.00000 & 1.00000 \\
\hline 30 & & 0.06362 & 0.06359 & 0.12316 & & 1.00003 & 1.00000 & 1.00000 & & 1.00003 & 1.00000 & 1.00000 & & 003 & 1.00000 & 1.00000 \\
\hline 40 & & 0.08390 & 0.08387 & 0.16073 & & 1.00002 & 1.00000 & 1.00000 & & 1.00002 & 1.00000 & 1.0 & & 02 & 000 & 1.00000 \\
\hline 50 & & 0.10374 & 0.10372 & 0.19669 & & 1.00002 & 1.00000 & 1.00000 & & 1.00002 & 1.00000 & 1.00000 & & 002 & 000 & 1.00000 \\
\hline 60 & & 0.12315 & 0.12313 & 0.23112 & & 1.00002 & 1.00000 & 1.00000 & & 1.00002 & 1.00000 & 1.00000 & & 002 & 000 & 1.00000 \\
\hline 70 & & 0.14214 & 0.14213 & 0.26407 & & 1.00001 & 1.00000 & 1.00000 & & 1.00001 & 1.00000 & 1.00000 & & & 000 & 1.00000 \\
\hline 80 & & 0.16072 & 0.16071 & 0.29560 & & 1.00001 & 1.00000 & 1.00000 & & 1.00001 & 1.00000 & 1.00000 & & 1.00001 & 1.00000 & 1.00000 \\
\hline 90 & & 0.17890 & 0.17889 & 0.32579 & & 1.00001 & 1.00000 & 1.00000 & & 1.00001 & 1.00000 & 1.00000 & & 1.00001 & 1.00000 & 1.00000 \\
\hline 100 & & 0.19669 & 0.19668 & 0.35468 & & 1.00001 & 1.00000 & 1.00000 & & 1.00001 & 1.00000 & 1.00000 & & 1.00001 & 1.00000 & 1.0000 \\
\hline
\end{tabular}


Table C-51. Check Valve Unavailability Versus IST Interval for Different Valve Aging Rates: Partial Renewal, No Intermediate Testing, $Z$ Baseline Failure Rate $\lambda_{0}=1 \times 10^{-6}$, Inservice Test Downtime $d=72 \mathrm{hr}$, Partial Renewal Fraction $f=0.5$, Valve Lifetime $s=40$ yrs, Weibull Aging Model $c=3$

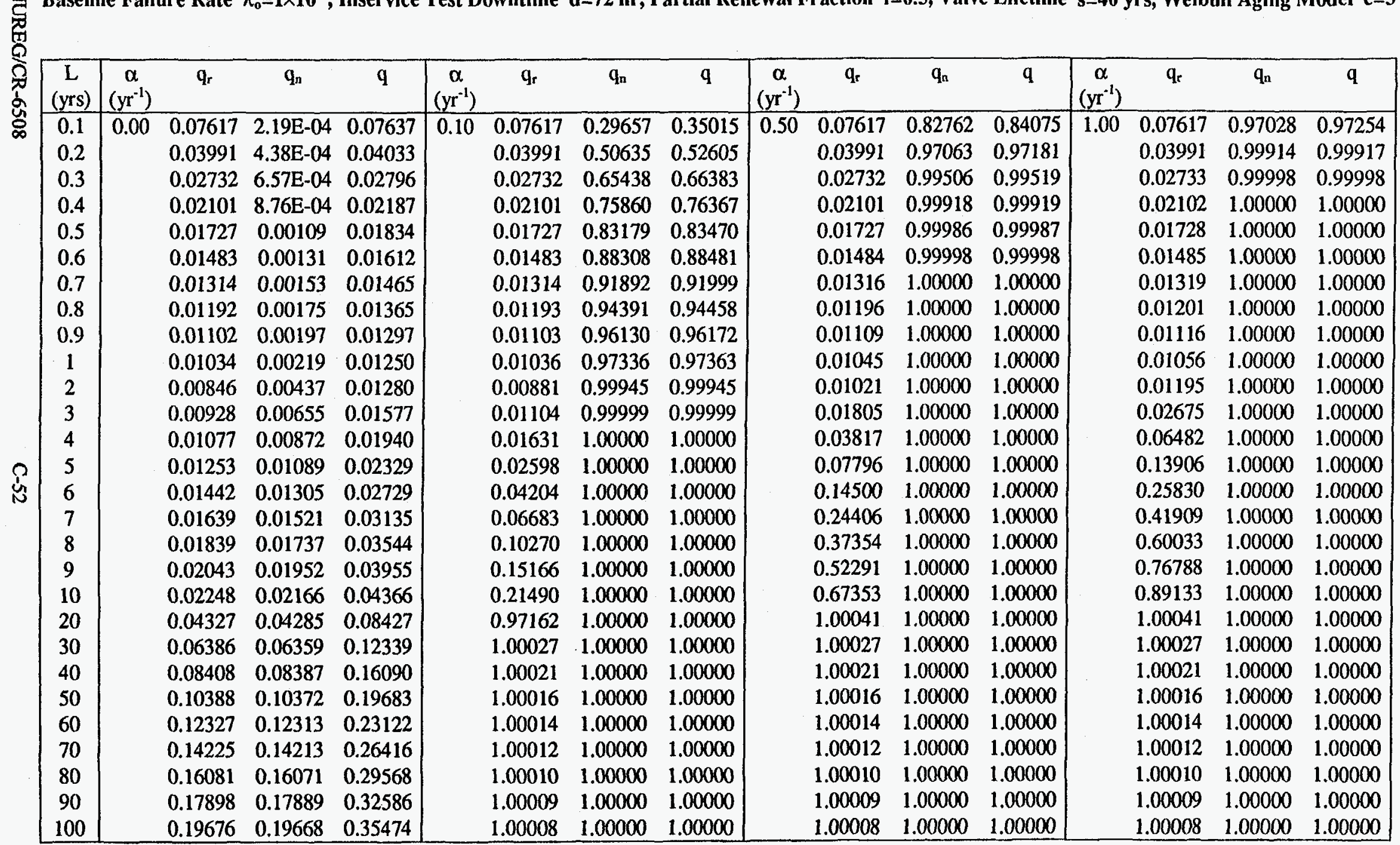


Table C-52. Check Valve Unavailability Versus IST Interval for Different Valve Aging Rates: Partial Renewal, No Intermediate Testing,

Baseline Failure Rate $\lambda_{0}=1 \times 10^{-7}$, Inservice Test Downtime $d=0 \mathrm{hr}$, Partial Renewal Fraction $f=0.5$, Valve Lifetime $s=40$ yrs, Weibull Aging Model $c=3$

\begin{tabular}{|c|c|c|c|c|c|c|c|c|c|c|c|c|c|c|c|c|}
\hline $\begin{array}{c}\mathbf{L} \\
\text { (yrs) }\end{array}$ & $\begin{array}{c}\alpha \\
\left(y^{-1}\right)\end{array}$ & $q_{r}$ & $\mathrm{q}_{\mathrm{n}}$ & $q$ & $\begin{array}{c}\alpha \\
\left(\mathrm{yr}^{-1}\right)\end{array}$ & $\mathrm{q}_{\mathrm{r}}$ & $q_{n}$ & $q$ & $\left\{\begin{array}{c}\alpha \\
\left(\mathrm{yr}^{-1}\right)\end{array}\right.$ & $\mathbf{q}_{\mathrm{r}}$ & $\mathrm{q}_{\mathrm{n}}$ & $q$ & $\begin{array}{c}\alpha \\
\left(\mathrm{yr}^{-1}\right)\end{array}$ & $\mathrm{q}_{\mathrm{r}}$ & $\mathrm{q}_{\mathrm{n}}$ & $q$ \\
\hline 0.1 & 0.00 & 0.00002 & 0.00002 & 0.00004 & 0.10 & 0.00002 & 0.03457 & 0.03459 & 0.50 & 0.00002 & 0.16122 & 0.16124 & 1.00 & 0.00002 & 0.29643 & 0.29645 \\
\hline 0.2 & & 0.00004 & 0.00004 & 0.00009 & & 0.00004 & 0.06816 & 0.06820 & & 0.00004 & 0.29727 & 0.29731 & & 0.00004 & 0.50615 & 0.50618 \\
\hline 0.3 & & 0.00007 & 0.00007 & 0.00013 & & 0.00007 & 0.10079 & 0.10085 & & 0.00007 & 0.41195 & 0.41199 & & 0.00007 & 0.65418 & 0.65420 \\
\hline 0.4 & & 0.00009 & 0.00009 & 0.00018 & & 0.00009 & 0.13249 & 0.13257 & & 0.00009 & 0.50850 & 0.50855 & & 0.00009 & 0.75841 & 0.75843 \\
\hline 0.5 & & 0.00011 & 0.00011 & 0.00022 & & 0.00011 & 0.16327 & 0.16336 & & 0.00011 & 0.58969 & 0.58974 & & 0.00011 & 0.83163 & 0.83165 \\
\hline 0.6 & & 0.00013 & 0.00013 & 0.00026 & & 0.00013 & 0.19316 & 0.19326 & & 0.00013 & 0.65788 & 0.65793 & & 0.00013 & 0.88294 & 0.88295 \\
\hline 0.7 & & 0.00015 & 0.00015 & 0.00031 & & 0.00015 & 0.22216 & 0.22228 & & 0.00016 & 0.71508 & 0.71512 & & 0.00016 & 0.91881 & 0.91882 \\
\hline 0.8 & & 0.00018 & 0.00018 & 0.00035 & & 0.00018 & 0.25030 & 0.25043 & & 0.00018 & 0.76301 & 0.76305 & & 0.00018 & & 0.94383 \\
\hline 0.9 & & 0.00020 & 0.00020 & 0.00039 & & 0.00020 & 0.27760 & 0.27775 & & 0.00020 & 0.80311 & 0.80315 & & 0.00021 & 0.96123 & 0.96123 \\
\hline 1 & & 0.00022 & 0.00022 & 0.00044 & & 0.00022 & 0.30408 & 0.30423 & & 0.00023 & 0.83663 & 0.83667 & & 0.00024 & & 0.97331 \\
\hline 2 & & 0.00044 & 0.00044 & 0.00088 & & 0.00047 & 0.52751 & 0.52774 & & 0.00061 & 0.97641 & 0.97643 & & 0.00079 & & 0.99944 \\
\hline 3 & & 0.00066 & 0.00066 & 0.00131 & & 0.00083 & 0.68 & 0.68773 & & 0.00154 & 0.99701 & 0.99702 & & 0.00243 & & 0.99999 \\
\hline 4 & & 0.00088 & 0.00088 & 0.00175 & & 0.00144 & 0.79890 & 0.79918 & & 0.00367 & 0.99967 & 0.99967 & & 0.00646 & & 1.00000 \\
\hline 5 & & 0.00109 & 0.00109 & 0.00219 & & 0.00246 & 0.87430 & 0.87461 & & 0.00791 & 0.99997 & 0.99997 & & 0.01467 & & 1.00000 \\
\hline 6 & & 0.00131 & 0.00131 & 0.00262 & & 0.00414 & 0.92380 & 0.92411 & & 0.01539 & 1.00000 & 1.00000 & & 0.02926 & 000 & 1.00000 \\
\hline 7 & & 0.00153 & 0.00153 & 0.00306 & & 0.00677 & 0.95527 & 0.95557 & & 0.02744 & 1.00000 & 1.00000 & & 0.05268 & 000 & 1.00000 \\
\hline 8 & & 0.00175 & 0.00175 & 0.00350 & & 0.01066 & 0.97461 & 0.97489 & & 0.04553 & 1.00000 & 1.00000 & & 0.08740 & 1.00000 & 1.00000 \\
\hline 9 & & 0.00197 & 0.00197 & 0.00393 & & 0.01621 & 0.98610 & 0.98632 & & 116 & 1.00000 & 000 & & 555 & 1.00000 & 1.00000 \\
\hline 10 & & 0.00219 & 0.00219 & 0.00437 & & 0.02380 & 0.99266 & 84 & & 568 & 000 & 000 & & 844 & 1.00000 & 1.00000 \\
\hline 20 & & 0.00437 & 0.00437 & 0.00872 & & 0.29867 & 1.00000 & 00 & & & 900 & & & 05 & 000 & 1.00000 \\
\hline 30 & & 0.00655 & 0.00655 & 0.01305 & & 0.83144 & 1.00000 & 1.00000 & & 986 & & & & 300 & 1.00000 & 1.00000 \\
\hline 40 & & 0.00872 & 0.00872 & 0.01737 & & 0.99636 & & 1.00000 & & 000 & & & & & 1.00000 & 1.00000 \\
\hline 50 & & 0.01089 & 0.01089 & 0.02166 & & 1.00000 & & & & 000 & & & & & 000 & 1.00000 \\
\hline 60 & & 0.01305 & 0.01305 & 0.02594 & & 1.00000 & & & & 1.00000 & & 1.00000 & & & & 1.00000 \\
\hline 70 & & 0.01521 & 0.01521 & 0.03019 & & 1.00000 & & & & & & 1.00000 & & & & 1.00000 \\
\hline 80 & & 0.01737 & 0.01737 & 0.03443 & & 1.00000 & & & & & & & & & 000 & 1.00000 \\
\hline 90 & & 0.01952 & 0.01952 & 0.03865 & & 1.00000 & & & & & & & & & 1.00000 & 1.00000 \\
\hline 100 & & 0.02166 & 0.02166 & 0.04285 & & 1.00000 & 1.00000 & 1.00000 & & 1.00000 & 1.00000 & 1.00000 & & 1.00000 & 1.00000 & 1.00000 \\
\hline
\end{tabular}


Table C-53. Check Valve Unavailability Versus IST Interval for Different Valve Aging Rates: Partial Renewal, No Intermediate Testing,

\begin{tabular}{|c|c|c|c|c|c|c|c|c|c|c|c|c|c|c|c|c|}
\hline $\begin{array}{c}\mathrm{L} \\
\text { (yrs) }\end{array}$ & $\begin{array}{c}\alpha \\
\left(\mathrm{yr}^{-1}\right)\end{array}$ & $\mathrm{q}_{\mathrm{r}}$ & $q_{n}$ & $q$ & {$\left[\begin{array}{c}\alpha \\
\left(\mathrm{yr}^{-1}\right)\end{array}\right.$} & $q_{r}$ & $\mathrm{q}_{\mathrm{n}}$ & $q$ & $\begin{array}{c}\alpha \\
\left(\mathrm{yr}^{-1}\right)\end{array}$ & $\mathrm{qr}_{\mathrm{r}}$ & $\mathrm{q}_{n}$ & $q$ & $\begin{array}{c}\alpha \\
\left(\mathrm{yr}^{-1}\right)\end{array}$ & $\mathrm{q}_{\mathrm{r}}$ & $q_{a}$ & $q$ \\
\hline 0.1 & 0.00 & 0.00907 & 0.00002 & 0.00909 & 0.10 & 0.00907 & 0.03457 & 0.04333 & 0.50 & 0.00907 & 0.16122 & 0.16883 & 1.00 & 0.00907 & 0.29643 & 0.30282 \\
\hline 0.2 & & 0.00459 & 0.00004 & 0.00463 & & 0.00459 & 0.06816 & 0.07244 & & 0.00459 & 0.29727 & 0.30050 & & 0.00459 & 0.50615 & 0.50842 \\
\hline 0.3 & & 0.00310 & 0.00007 & 0.00317 & & 0.00310 & 0.10079 & 0.10358 & & 0.00310 & 0.41195 & 0.41378 & & 0.00310 & 0.65418 & 0.65525 \\
\hline 0.4 & & 0.00237 & 0.00009 & 0.00245 & & 0.00237 & 0.13249 & 0.13454 & & 0.00237 & 0.50850 & 0.50967 & & 0.00237 & 0.75841 & 0.75898 \\
\hline 0.5 & & 0.00193 & 0.00011 & 0.00204 & & 0.00193 & 0.16327 & 0.16489 & & 0.00193 & 0.58969 & 0.59049 & & 0.00193 & 0.83163 & 0.83195 \\
\hline 0.6 & & 0.00165 & 0.00013 & 0.00178 & & 0.00165 & 0.19316 & 0.19449 & & 0.00165 & 0.65788 & 0.65845 & & 0.00165 & 0.88294 & 0.88313 \\
\hline 0.7 & & 0.00146 & 0.00015 & 0.00161 & & 0.00146 & 0.22216 & 0.22329 & & 0.00146 & 0.71508 & 0.71550 & & 146 & 0.91881 & 0.91893 \\
\hline 0.8 & & 0.00132 & 0.00018 & 0.00149 & & 0.00132 & 0.25030 & 0.25129 & & 0.00132 & 0.76301 & $0.7 \epsilon$ & & 32 & 82 & 0.94390 \\
\hline 0.9 & & 0.00121 & 0.00020 & 0.00141 & & 0.00121 & 0.27760 & 0.27848 & & 0.00122 & 0.80311 & 0.80335 & & 0.0 & 123 & 0.96127 \\
\hline 1 & & 0.00113 & 0.00022 & 0.00135 & & 0.00113 & 0.30408 & 0.30487 & & 0.00114 & 0.83663 & 0.83681 & & 15 & 330 & 0.97333 \\
\hline 2 & & 0.00089 & 0.00044 & 0.00133 & & 0.00093 & 0.52751 & 0.52795 & & 0.00107 & 0.97641 & 0.97644 & & 0.00124 & 0.99944 & 0.99944 \\
\hline 3 & & 0.00096 & 0.00066 & 0.00162 & & 0.00114 & 0.68747 & 0.68783 & & 0.00185 & 0.99701 & 0.99702 & & 0.00273 & 0.99999 & 0.99999 \\
\hline 4 & & 0.00110 & 0.00088 & 0.00198 & & 0.00166 & 0.79890 & 0.79923 & & 0.00390 & 0.99967 & 0.99967 & & 0.00669 & 1.00000 & 1.00000 \\
\hline 5 & & 0.00128 & 0.00109 & 0.00237 & & 0.00264 & 0.87430 & 0.87463 & & 0.00809 & 0.99997 & 0.99997 & & 0.01486 & 1.00000 & 1.00000 \\
\hline 6 & & 0.00147 & 0.00131 & 0.00278 & & 0.00430 & 0.92380 & 0.92412 & & 0.01554 & 1.00000 & 1.00000 & & 0.02941 & 1.00000 & 1.00000 \\
\hline 7 & & 0.00166 & 0.00153 & 0.00319 & & 0.00690 & 0.95527 & 0.95557 & & 0.02757 & 1.00000 & 1.00000 & & 0.05281 & 1.00000 & 1.00000 \\
\hline 8 & & 0.00186 & 0.00175 & 0.00361 & & 0.01078 & 0.97461 & 0.97489 & & 0.04565 & 1.00000 & 1.00000 & & 0.08751 & 1.00000 & 1.00000 \\
\hline 9 & & 0.00207 & 0.00197 & 0.00404 & & 0.01631 & 0.98610 & 0.98632 & & 0.07126 & 1.00000 & 1.00000 & & 0.13565 & 1.00000 & 1.00000 \\
\hline 10 & & 0.00228 & 0.00219 & 0.00446 & & 0.02389 & 0.99266 & 0.99284 & & 0.10577 & 1.00000 & 1.00000 & & 0.19853 & 1.00000 & 1.00000 \\
\hline 20 & & 0.00442 & 0.00437 & 0.00877 & & 0.29872 & 1.00000 & 1.00000 & & 0.82738 & 1.00000 & 1.00000 & & 0.97010 & 1.00000 & 1.00000 \\
\hline 30 & & 0.00658 & 0.00655 & 0.01308 & & 0.83147 & 1.00000 & 1.00000 & & 0.99989 & 1.00000 & 1.00000 & & 1.00003 & 1.00000 & 1.00000 \\
\hline 40 & & 0.00874 & 0.00872 & 0.01739 & & 0.99638 & 1.00000 & 1.00000 & & 1.00002 & 1.00000 & 1.00000 & & 1.00002 & 1.00000 & 1.00000 \\
\hline 50 & & 0.01091 & 0.01089 & 0.02168 & & 1.00002 & 1.00000 & 1.00000 & & 1.00002 & 1.00000 & 1.00000 & & 1.00002 & 1.00000 & 1.00000 \\
\hline 60 & & 0,01307 & 0.01305 & 0.02595 & & 1.00002 & 1.00000 & 1.00000 & & 1.00002 & 1.00000 & 1.00000 & & 1.00002 & 1.00000 & 1.00000 \\
\hline 70 & & 0.01523 & 0.01521 & 0.03021 & & 1.00001 & 1.00000 & 1.00000 & & 1.00001 & 1.00000 & 1.00000 & & 1.00001 & 1.00000 & 1.00000 \\
\hline 80 & & 0.01738 & 0.01737 & 0.03444 & & 1.00001 & 1.00000 & 1.00000 & & 1.00001 & 1.00000 & 1.00000 & & 1.00001 & 1.00000 & 1.00000 \\
\hline 90 & & 0.01953 & 0.01952 & 0.03866 & & 1.00001 & 1.00000 & 1.00000 & & 1.00001 & 1.00000 & 1.00000 & & 1.00001 & 1.00000 & 1.00000 \\
\hline 100 & & 0.02167 & 0.02166 & 0.04286 & & 1.00001 & 1.00000 & 1.00000 & & 1.00001 & 1.00000 & 1.00000 & & 1.00001 & 1.00000 & 1.00000 \\
\hline
\end{tabular}


Table C-54. Check Valve Unavailability Versus IST Interval for Different Valve Aging Rates: Partial Renewal, No Intermediate Testing, Baseline Failure Rate $\lambda_{0}=1 \times 10^{-7}$, Inservice Test Downtime $d=72 \mathrm{hr}$, Partial Renewal Fraction $f=0.5$, Valve Lifetime $s=40$ yrs, Weibull Aging Model $c=3$

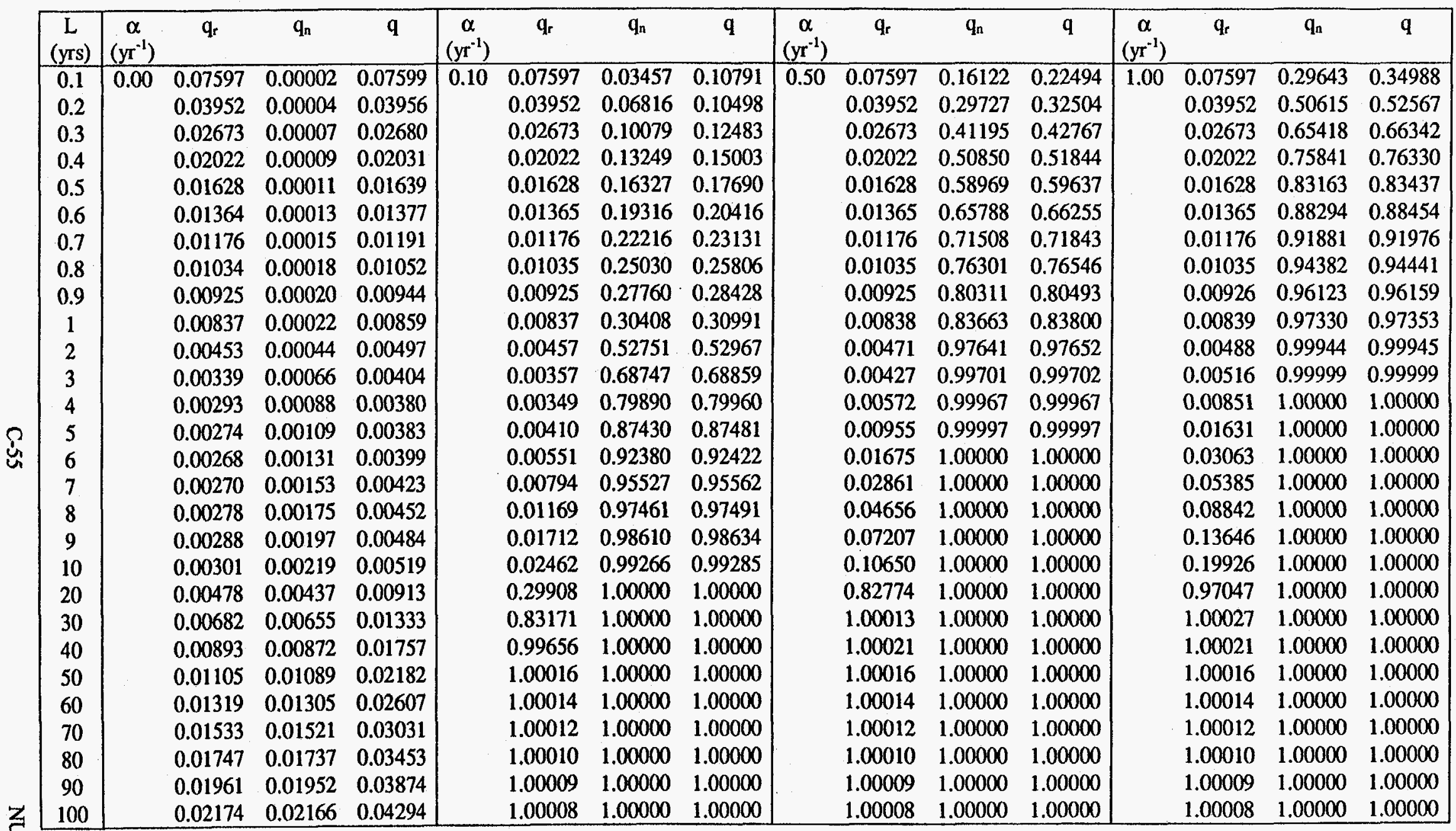




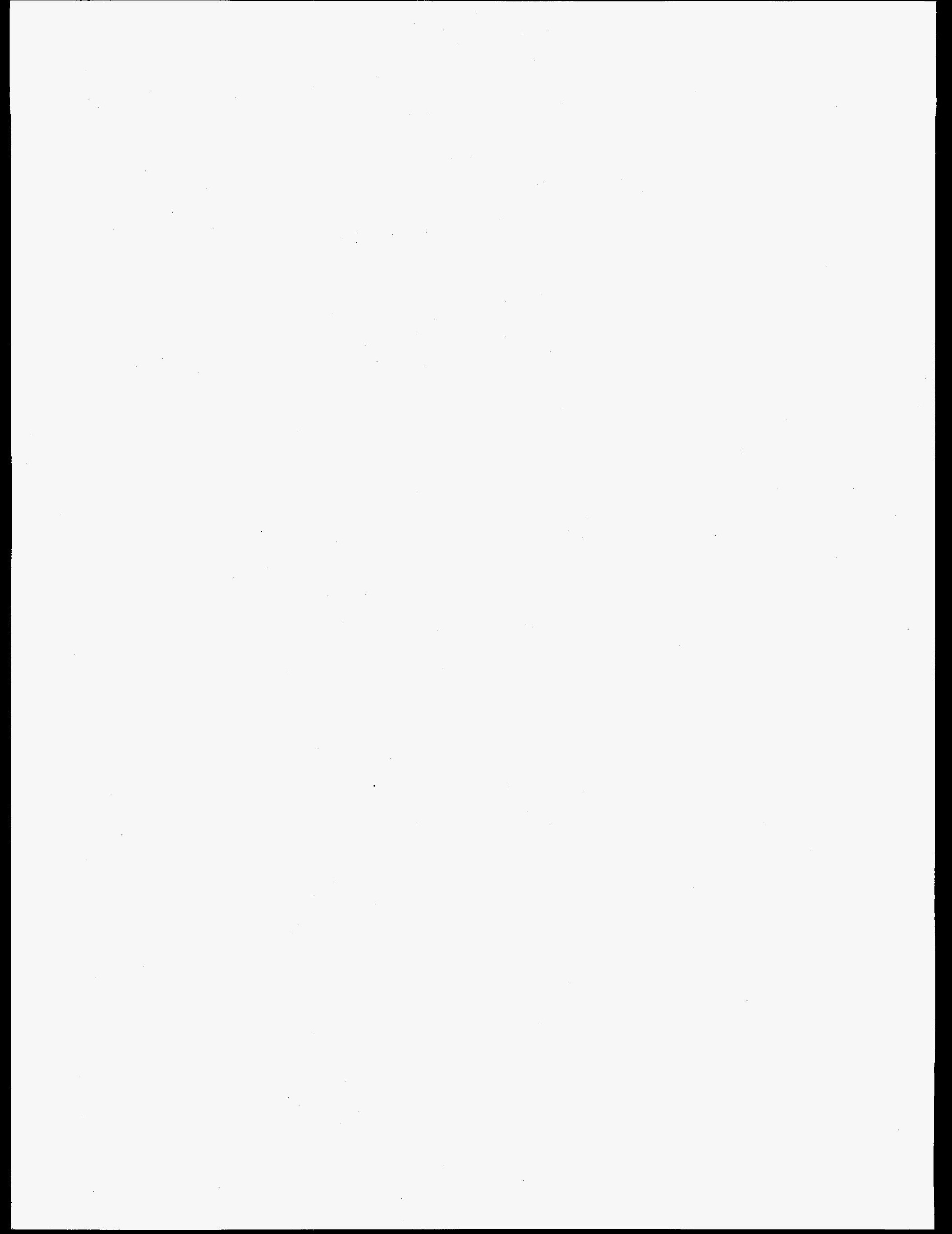


Appendix D. Check Valve Inservice Test Requirements And Implementation Results 


\section{Appendix D. Check Valve Inservice Test Requirements And Implementation Results}

All Light Water Reactor (LWR) licensees have submitted to the Nuclear Regulatory Commission (NRC) an inservice testing (IST) program for pumps and valves which meets the appropriate requirements of the Code of Federal Regulations. The IST program also identifies the applicable editions and addenda of the American Society of Mechanical Engineers (ASME) Code. All IST programs contain requests for relief from various Code requirements. The IST programs are required to be revised and updated to later code requirements at 10 year intervals. The inservice testing of ASME Code Class 1,2 and 3 pumps and valves is intended to ensure operational readiness of equipment and the intent of the testing is to detect degradation affecting operation and assess whether adequate margins are maintained.

Due to the large number of plants and various editions and addenda of the ASME Code in use, a total review of IST requirements for check valves will not be attempted. However, five basic test types and four different testing frequencies are usually combined to establish most IST programs for check valves. These basic tests and frequencies are as follows:

\section{Test Type}

FF - Full flow exercise valve for operability.

PS - Partial stroke valve.

BS - Back-Seat valve to closed position.

LT - Leak Test Valve

DS - Valve will be disassembled and visually inspected.

\section{Test Frequency}

Q - Quarterly (i.e., once per 92 days)

CS - Testing performed during cold shutdown (but no sooner than 92 days).

RS - Once per refueling outage.

$2 Y$ - Once per 2 years.

Table D.1 takes the Oak Ridge National Laboratory characterized check valve data for failures occurring during the 1984 1992 time period at BWRs and PWRs and looks at the general results of these test for systems with the highest overall failure rates. In Table D.1, the values listed are the percentages of failures found by various tests methods for these systems. The tests FF, PS, and BS are not specifically listed in NPRDS but the tests LT and DS are identified. 
Table D.1 Check Valve Testing Summary (1984-1992)

\begin{tabular}{|c|c|c|c|c|c|c|c|c|c|}
\hline \multirow[b]{2}{*}{ System } & \multicolumn{9}{|c|}{ Percentage of Failures Found By Several Detection Methods ${ }^{(1)}$} \\
\hline & $\begin{array}{l}\text { Disassembly } \\
\text { (DS) }\end{array}$ & $\begin{array}{l}\text { External } \\
\text { Leakage }\end{array}$ & $\begin{array}{l}\text { Hyd. } \\
\text { Ind. }\end{array}$ & $\begin{array}{l}\text { Leak Test } \\
\text { (LT) }\end{array}$ & $\begin{array}{l}\text { Non-Hyd. } \\
\text { Ind. }\end{array}$ & $\begin{array}{c}\text { Nonint- } \\
\text { rusive }\end{array}$ & $\begin{array}{c}\text { Not } \\
\text { Specific }\end{array}$ & $\begin{array}{l}\text { Other } \\
\text { Maint. }\end{array}$ & $\begin{array}{c}\text { Pump/Comp } \\
\text { rotation }\end{array}$ \\
\hline AFW & 19.6 & 0 & 29.7 & 9.4 & 4.3 & 4.4 & 27.5 & 5.1 & 0 \\
\hline $\mathrm{CCW}$ & 5.1 & 0 & 4.5 & 45.9 & 2.5 & 0.6 & 26.8 & 1.3 & 13.4 \\
\hline Comb. Gas Control & 0 & 0 & 0 & 66.7 & 0 & 0 & 33.3 & 0 & 0 \\
\hline Cont. Isolation & 1.7 & 0 & 6.1 & 82.6 & 1.7 & 0 & 7.8 & 0 & 0 \\
\hline Diesel Starting Air & 9.3 & 0 & 22.5 & 6.4 & 15.2 & 0.5 & 39.2 & 6.4 & 0.5 \\
\hline ESW & 19.1 & 0 & 5.8 & 11.0 & 3.5 & 4.6 & 34.5 & 5.5 & 15.9 \\
\hline Feedwater & 10.8 & 0 & 12.7 & 45.3 & 4.2 & 0 & 15.5 & 3.8 & 7.5 \\
\hline HPCI & 14.6 & 0 & 29.2 & 33.3 & 12.5 & 0 & 10.4 & 0 & 0 \\
\hline Main Steam & 25.8 & 0.5 & 4.6 & 16.1 & 27.6 & 0.9 & 23.0 & 1.4 & 0 \\
\hline RCIC & 9.1 & 0 & 14.5 & 47.3 & 7.3 & 1.8 & 18.2 & 0 & 1.8 \\
\hline RHR & 10.5 & 0 & 17.0 & 40.5 & 10.5 & 1.3 & 17.0 & 0.7 & 2.6 \\
\hline Supp. Pool Support & 10.7 & 0 & 10.7 & 44.0 & 14.7 & 0 & 20.0 & 0 & 0 \\
\hline $\begin{array}{l}\text { Average For All } \\
12 \text { Systems }\end{array}$ & 11 & 0 & 13 & 37 & 9 & 1 & 23 & 2 & 4 \\
\hline
\end{tabular}




\section{(1) Notes for Table D.1}

\section{Detection Methods}

- Disassembly and/or inspection: Degradation or failure discovered when the valve was disassembled and examined or a special inspection was performed. Includes both inspections conducted as part of a programmatic disassembly and examination effort, plus inspections performed for other reasons. Includes normal preventive maintenance.

- External leakage: Observation of external process fluid leakage or evidence of leakage.

- Hydraulic/pneumatic indication: An operator or other personnel noticed abnormal hydraulic or pneumatic indication, such as higher than normal pressure, level, or temperature upstream of a valve that should be closed, leakage from a drain'test valve, etc.

- Leak test: Degradation or failure discovered during the conduct of a local leak rate test (LLRT) or other leak test (including post-modification leak test, bench test, etc.), or failed exercise test or failed surveillance test by some mechanism other than seat leakage, such as failure to open/close, vacuum breaker valve not opening under required torque, etc.

- Nonhydraulic indication: Observation of some indication, such as unusual noise or difficulty in operation of a stop check valve, failure of a power-operated valve to stroke, relief valve lifting when compressor is running, compressor short cycling due to air leakage past check valve, etc., such that the valve was not functioning properly. Includes failures discovered by observation of alarm signals.

- Nonintrusive diagnostic test: Degradation or failure discovered by use of nonintrusive testing. Includes radiography, acoustic monitoring, magnetic flux/eddy current analysis, ultrasonic signature analysis, etc.

- Not specific: The discovery method was not identified in the narrative or was not specific, such as "...an operator noticed that the valve was not seating..." Includes incipient conditions not resulting in a significant effect on operations.

- Other or corrective maintenance: Degradation discovered when conducting maintenance on another component or when correcting an unrelated check valve problem (such as replacing a leaking bonnet gasket).

- Pump/Compressor rotation: Observation of pump or compressor rotating in reverse.

The data presented in Table D.1 compiles all data from 1984-1992. It should be noted that the percentage of check valve failures found by plant programmatic methods has in general been increasing in each study. The Leak Test type of detection has been more effective over all than other detection methods and for these 12 systems approximately $37 \%$ of the check valve failures have been found by Leak Test (LT).

Non-intrusive testing is being done at some plants and would appear to have major potential for use in condition monitoring programs for check valves. However, trending data from NPRDs does not currently identify many failures being found by non-intrusive examinations of check valves.

The Leak Test (LT) results are somewhat increased because Boiling Water Reactor (BWR) plants had a higher overall relative failure rate, and leak testing is more programmatically extensive in the BWR systems than in Pressurized Water Reactor (PWR) systems. In order to provide more detail on this point, Table D.2 shows a breakdown by system for a typical PWR plant check valve testing program and Table D.3 a similar listing for a typical BWR. On a plant basis, the number of check valves leak tested are both approximately $25 \%$. However, the BWR has $74 \%$ more check valves in the program than does the PWR. Thus for leak testing, the data is weighted more toward BWRs. Also, as discussed in Appendix E, the predominant failure mode for all check valves is seat leakage. These two facts combine so that more check valve failures are found by leak testing than the other methods. 
A review of Tables D.2 and D.3 show that for the main steam system the PWR plant has 2 check valves in the IST program with no leak testing done. However, the BWR plant has 56 check valves in the IST program with 18 being leak tested. Of these 18 check valves being leak tested, 16 are check valves $\leq 2.0$ inches in size that are leak tested as part of the air leakage test on the BWR main steam line safety-relief valve actuator air system. The Appendix $E$ analysis has shown that the main steam system had an above average number of failures in check valves $\leq 2$ inches in size. Using 1991 failure data on main steam check valves, it can be shown that $18 \%$ of the failures are for lift check valves $\leq 2$ inches in size.

A similar review of Tables D.2 and D.3 for the feedwater system show that zero (o) check valves at the PWR plant are in the IST program. The BWR plant has four (4) check valves in the IST program and all four are leak tested. This indicates that the 45.3\% listed for leak tests under feedwater in Table D.1 are primarily from BWR plants. Using all 1984-1992 failure data on feedwater check valves, it can be shown that $37.7 \%$ of all the failures are found by Leak Test (LT) at BWR plants.

For a system like essential service water (ESW), the total number of check valves for both study plants are 47 (BWR-34, PWR-13) and the number of leak tests are 2 (BWR-1, PWR-1). This explains why the leak test failure percentage, $11 \%$ for ESW, is low. In the ESW System, the primary testing methods are FF, PS, and DS with very few LTs.

Table D.2 Typical PWR Check Valve Test Program

\begin{tabular}{lcc}
\hline \multicolumn{1}{c}{ System } & $\begin{array}{c}\text { Total Number } \\
\text { of Check Valves }\end{array}$ & $\begin{array}{c}\text { Number Check } \\
\text { Valves Leak Tested }\end{array}$ \\
\hline Containment HVAC & 3 & 3 \\
Reactor Aux. Bldg. HVAC & 2 & 0 \\
Control Room HVAC & 2 & 0 \\
Fuel Bldg. HVAC & 0 & 0 \\
Switch Gear HVAC & 0 & 0 \\
Main Steam & 2 & 0 \\
Feedwater & 0 & 0 \\
Auxiliary Feedwater & 18 & 0 \\
Condensate & 3 & 0 \\
Service Water & 13 & 1 \\
Containment Spray & 8 & 2 \\
S. G. Blowdown & 0 & 0 \\
Process Sampling & 0 & 0 \\
D. G. Fuel Oil Transfer & 1 & 0 \\
H Analyzer & 4 & 0 \\
D. G. Starting Air & 0 & 0 \\
Demineralized Water & 0 & 1 \\
CTMT. Sump Drains & 1 & 0 \\
Service Air & 0 & 0 \\
\hline & 0 & 0 \\
\hline
\end{tabular}


Table D.2 Typical PWR Check Valve Test Program (Continued)

\begin{tabular}{lcc}
\hline \multicolumn{1}{c}{ System } & $\begin{array}{c}\text { Total Number } \\
\text { of Check Valves }\end{array}$ & $\begin{array}{c}\text { Number Check } \\
\text { Valves Leak Tested }\end{array}$ \\
\hline Instrument Air & 7 & 1 \\
Fuel Pool Cooling & 2 & 0 \\
Emergency Screen Wash & 2 & 0 \\
Fire Protection & 2 & 2 \\
Reactor Coolant & 1 & 1 \\
CVCS & 20 & 5 \\
Safety Injection & 35 & 15 \\
CTMT. Waste Processing & 0 & 0 \\
Component Cooling Water & 13 & 4 \\
Residual Heat Removal & 2 & 0 \\
Leak Detection & 0 & 0 \\
\hline \multicolumn{1}{c}{ Totals } & 156 & 39 \\
\hline
\end{tabular}




\begin{tabular}{|c|c|c|}
\hline System & $\begin{array}{c}\text { Total Number } \\
\text { of Check Valves }\end{array}$ & $\begin{array}{c}\text { Number Check Valves } \\
\text { Leak Tested }\end{array}$ \\
\hline Control Rod Drive- Hyd. Sys. & 4 & 2 \\
\hline Reactor Recirculation & 4 & 4 \\
\hline Condensate Makeup \& Storage & 1 & 1 \\
\hline Feedwater & 4 & 4 \\
\hline Main Steam & 56 & 18 \\
\hline Closed Cooling Water & 13 & 4 \\
\hline Service Water & 34 & 1 \\
\hline Service Air & 2 & 2 \\
\hline Instrument Air & 9 & 3 \\
\hline Standby Liquid Control & 4 & 2 \\
\hline High Pressure Core Spray & 6 & 1 \\
\hline RHR - LPCI & 21 & 4 \\
\hline Low Pressure Core Spray & 4 & 1 \\
\hline MSIV Leak Control & 2 & 0 \\
\hline Reactor Core Isolation Cooling & 9 & 2 \\
\hline Fire Protection & 1 & 1 \\
\hline Hydrogen Purge & 1 & 0 \\
\hline MSIV \& Penet. Leak Ctrl. & 28 & 0 \\
\hline Service Water/Standby & 4 & 0 \\
\hline Diesel Gen. Starting Air & 8 & 0 \\
\hline HVAC Cont. Bldg. & 0 & 0 \\
\hline HVAC Control Bldg. & 0 & 0 \\
\hline HVAC Fuel Bldg. & 0 & 0 \\
\hline HVAC Aux. Bldg. & 0 & 0 \\
\hline
\end{tabular}


Table D.3 Typical BWR Check Valve Test Program (Continued)

\begin{tabular}{lcc}
\hline \multicolumn{1}{c}{ System } & $\begin{array}{c}\text { Total Number } \\
\text { of Check Valves }\end{array}$ & $\begin{array}{c}\text { Number Check Valves } \\
\text { Leak Tested }\end{array}$ \\
\hline HVAC Chilled Water & 15 & 2 \\
Reactor Water Cleanup & 0 & 0 \\
Fuel Pool Cooling & 9 & 3 \\
Floor Drains & 25 & 12 \\
Sampling System & 2 & 0 \\
\hline \multicolumn{1}{c}{ Totals } & 271 & 69 \\
\hline
\end{tabular}


Appendix E. Check Valve Types and Failure Rates and Trends from Failure Data 


\section{Appendix E. Check Valve Types and Failure Rates and Trends From Failure Data}

\section{E.1 Introduction}

This appendix discusses the most populous (i.e., most common) of check valves installed in the U.S. nuclear power plants and failure rates evaluated for specific types of check valves using data developed in several Oak Ridge National Laboratory (ORNL) reports $[1,2,3,4,5]$. Performance data used was based on the ORNL analyses of failure reports and component engineering records from the Institute of Nuclear Power Operations Nuclear Plant Reliability Data Systems (NPRDS), data base. These failure rate trends have been evaluated relative to the specific components' age in years and, where possible, this data has been used to make some preliminary assessments per the linear aging model described in Section 3 of this report.

\section{E.2 Valve Types}

The most common nuclear plant components (based on manufacturer and model no.) were identified in Reference 5 for four major types of check valves; i.e., swing checks, lift/piston checks, tilting disc checks, and duo/double disc checks. Prior to detailed discussions of failure rates and trends, the general design and application[6] of each check valve type will be reviewed as follows:

\section{Swing Check Valves}

Swing check valves are the most common type of check valve currently in nuclear power plants ( $>26 \%$ of that portion of the 1991 NPRDS check valve population so far identified according to specific type). This is due to their simple design, low pressure drop, economy, reliable sealing, relative ease of repair, and availability in a wide range of sizes. Swing checks consists of a heavy disc suspended from a hinge pin located above the flow stream. They rely on gravity force for closure. The disc and hinge arm can be of one piece or two piece construction. Figure E.1 shows a two piece disc where the arm and disc are connected with a stud pin. The extra degree of freedom of motion produced by clearances at the stud pin provides sealing without the need for close machining tolerances. One piece styles are most stable because there is no relative motion between the disc and arm; but closer tolerances are required for sealing.

The speed of closure is controlled by the mass of the moving parts (disc and hinge arm), the distance from the center of rotation to the center of gravity of the disc, the maximum angular travel of the disc, and the force of the water if the flow reverses before the disc closes. The seat is usually set at an angle to reduce the stroke of the disc and provide a positive sealing force when the disc is closed.

Seating occurs between the flat sealing surface on the valve body and the flat sealing surface on the disc. Clearances between the hinge and hinge pin and at the stud pin (for two piece discs) allow the two sealing surfaces to self align, creating an effective seal. Significant wear to the pins and bushings can occur without reducing the effectiveness of the seal.

These valves can be designed to fully open at relatively low velocities and have a low pressure drop. The primary disadvantage of swing check valves is that they are the slowest closing of all the check valves due to the large mass of the disc and the long distance of travel from full open to full closed. They are generally not used in systems where rapid flow reversals occur. 


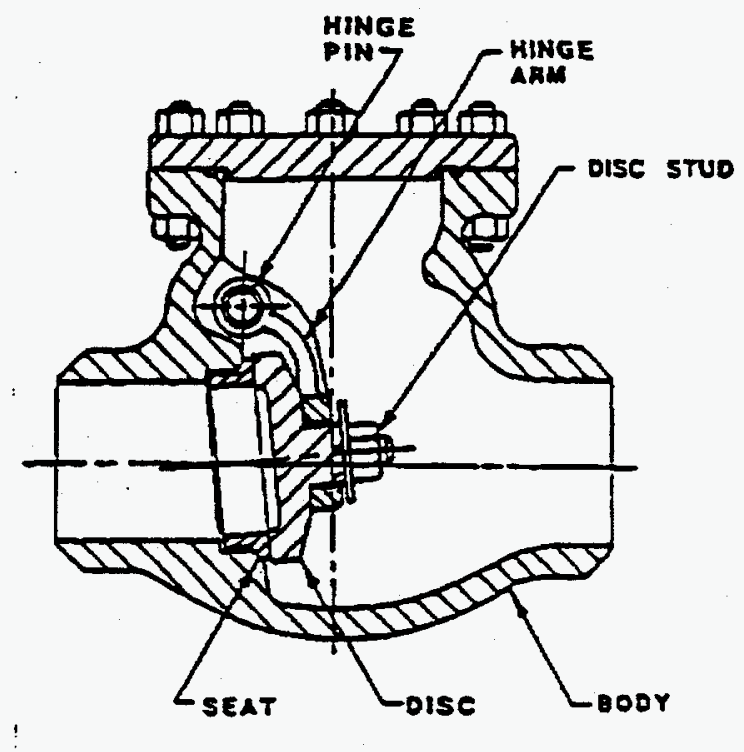

Figure E.1 Swing Check Valve

\section{Lift/Piston Check Valves}

The body and closing elements of lift/piston check valves come in a variety of configurations. They are also called by a variety of names describing either the shape of the body or disc: such as piston, ball, Y-pattern, etc. The body usually has the inlet and outlet in-line but some valves have these $90^{\circ}$ opposed. The disc (closing element) is generally piston shaped and moves in guide surfaces. Some styles have a spherical disc. The guide surface can be either vertical or inclined at an angle from vertical. Figure E.2 shows a typical design with a vertical guide design.

The configuration of this check valve makes it possible to fabricate it in a wide range of sizes (1/4-inch to 24-inch). It is a widely used choice for valves less than about 2-inch diameter. Nineteen percent of the 1991 NPRDS check valve population so far identified according to specific valve type are lift checks.

When compared at the same flow rate, lift checks (both $\mathrm{T}$ and $\mathrm{Y}$ patterns) have a larger pressure drop than swing and tilt disc valves due to the configuration of the body. The pressure drop can be reduced by inclining the guide surface (as in a Y pattern) to streamline the flow path but it is still generally larger than many of the other types of valves.

Lift/piston checks generally rely on both gravity and spring forces for closure. With the aid of the spring, the lift check can close very fast; especially in smaller sizes. The closing speed, disc position versus velocity, and the pressure drop characteristics can be changed significantly by merely changing the spring. Those valves that rely primarily on the spring for closure can be installed in almost any configuration, i.e., horizontal, vertical, or inclined. Styles without springs should not be installed in non-horizontal pipes.

One of the compromises in the design of these valves is the amount of clearance between the disc and guide surfaces. For a vertical bonnet design, the disc can self align and seat properly even with large clearances. For the angled bonnet design, closer tolerances are required to guide the disc into its seat. The guide clearance affects the amount of lateral motion (and wear) of the disc caused by flow instabilities, and the possibility of the disc binding or sticking due to foreign matter in the flow. Lift checks are more sensitive to solid contaminants than swing and tilting disc types (e.g., this type of failure has been significant in diesel starting air systems due to binding and sticking caused by rust and debris from the system).

Because the spring is always in compression, a broken spring should have only a slight effect on the safe operation of the valve. The disc should still close, but perhaps a little slower. The possibility of sticking also increases. 


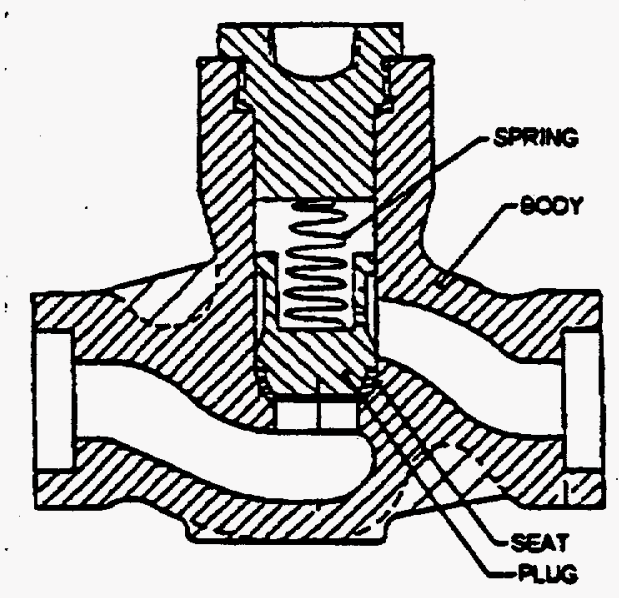

Figure E.2 Lift/Piston Check Valve

3. Tilting Disc Check Valves

Tilting disc check valves differ from the swing check valves in that the hinge pin is located in the flow stream, just above the centerline of the disc. A typical design is shown in Figure E.3. The pressure loss, the flow rate at which the disc fully opens, and the speed of closure are controlled primarily by the mass of the disc, the maximum angular rotation of disc, and the amount that the hinge pin is offset from the disc centerline. As with the swing check valves, tilting disc valves depend on gravity for closure. In the nuclear industry, this type of check valve is not used as.often as swing check valves ( $\sim 5 \%$ of identified listings from the 1991 characterized NPRDS check valve population). They close significantly faster than swing check valves because of the shorter travel distance of the center of mass of the disc. The single-piece construction of typical tilting disc check valve closure elements is an advantage from the standpoint that while hinge pins or bearings may fail as in a swing check, there can be no separation of the disc from a hinge arm.

The pressure drop at comparable flow conditions may be slightly larger than for a swing check because the disc and hinge pin are always in the flow path. The velocity required to open the tilt disc is comparable to the swing check.

Closer machining tolerances of the sealing surfaces are required than for a swing check because the disc rotates into the seat. Compared to swing check valves, smaller amounts of wear of the hinge pins or bushings can cause sealing problems in tilt disc check valves. Due to the complexity of the sealing arrangement, field repairs to the seats are more difficult. Tilting disc check valves account for slightly less than $30 \%$ of the failures due to improper installation in the failures studied by ORNL occurring during 1991 and 1992. 


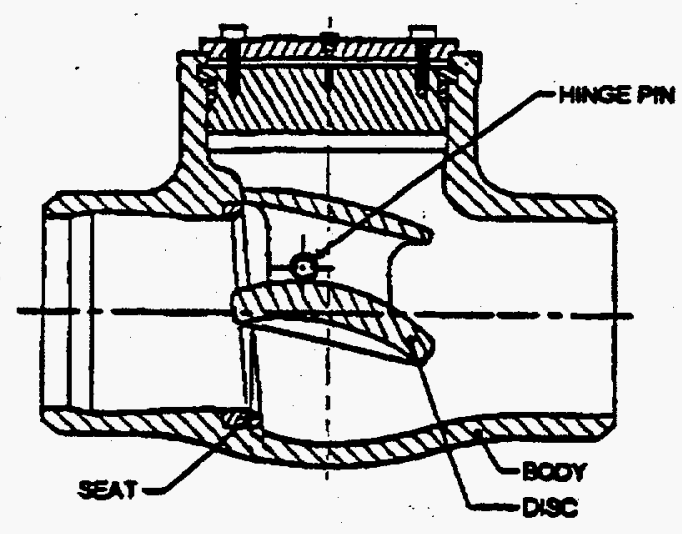

Figure E.3 Tilting Disc Check Valve

\section{Duo/Double Disc Check Valves}

In the duo/double disc check valve the flow is divided into two parallel flow passages each with a spring loaded door. Figure E.4 shows the general configuration of the valve with one door open and one closed. The flow area is less than the pipe area to allow for the seat. Even though the inlet to the valve is streamlined, the blockage caused by the seat and hinge support result in this style of valve having pressure losses larger than swing and tilt disc valves.

Sealing occurs between the flat sealing surface machined into the valve body and the seat on the discs. Due to the discontinuity of the seat at the hinge pin and clearances in the hinge pin, leak tight sealing is not possible (only about $1 \%$ of the identified listings from the 1991 NPRDS check valve population are of this type).

These valves rely primarily on the spring force for closure. (The disc can close without the spring, from back flow). Like the spring loaded lift check valves, these can be installed in almost any configuration, i.e., horizontal, vertical, or inclined. However, vertical application with flow down is undesirable, since the weight of the disc tends to lead to the weakening or failure of the closure spring. Since the closing elements for these valves have significantly less mass and usually travel shorter distances than swing and tilt disc valves, they close more rapidly when flow reversal occurs. Their closing speed is comparable to the lift check.

Since the disc does not close easily without the aid of the spring, failure of the spring creates potentially serious operational problems. Without the restraining force of the spring, disc flutter and wear may increase significantly. Without the spring to assist in disc closure, higher pressure transients can occur because the discs will not close until after the flow reverses. Significant failures in NPRDS for this type valve are approximately $1 / 3$ stuck open, 1/3 restricted motion, and $1 / 3$ disc or other part broken. 


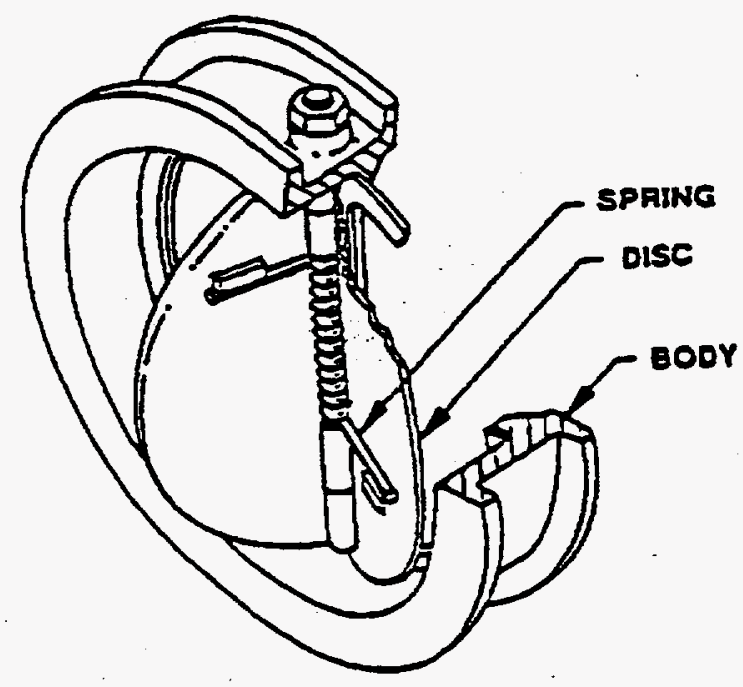

Figure E.4 Duo/Double Disc Check Valve

\section{E.3 Check Valve Failure Data}

Oak Ridge National Laboratory (ORNL) has characterized and published four reports $[1,2,3,4]$ on nuclear plant check valve failures. The purpose of this Appendix will be to evaluate this failure data in a way which can be used in unavailability studies. Reliability theory shows that component unavailability is a needed input to risk based studies. From NUREG/CR-5510, the simplest calculation of unavailability versus aging requires that component failure rates during some operating time be established. Failure rate is defined as the number of failures per unit of time. When the failure rate of a given type of component is calculated based on failure population data, the number of units in the population $(n)$ and the time of the study $(t)$ are needed along with the quantity of failures $(f)$. The average failure rate is given by $\lambda=f / n t$. When establishing an absolute failure rate, the use of the data on significant failures alone is the most valid way to approach the problem.

Thus if you have seven (7) significant failures in a total of 231 check valves during an 8 year period whère the actual valve - years was 1,894 then the average failure rate $=7 / 1,894=0.0037 /$ year. Table E.1 provides a summary of the ORNL characterized check valve study results. 
TABLE E.1 Check Valve Failures 1984-1992

\begin{tabular}{lcc}
\hline \multicolumn{1}{c}{ Study Period } & Total Valve-Years & Significant Failures $^{(5)}$ \\
\hline $1992^{(1)}$ & 20,751 & $152(0.0073 /$ Year $)$ \\
$1991^{(2)}$ & 20,751 & $143(0.0069 /$ Year $)$ \\
$1984-1990^{(3)}$ & 123,204 & $650(0.0053 /$ Year $)$ \\
$1984-1992^{(4)}$ & 1,894 & $7(0.0037 /$ Year $)$ \\
Accum. Discharge CV & & \\
\hline
\end{tabular}

Notes:

(1) ORNL Letter Report ORNL/NRC/LTR-96/11

(2) NUREG/CR-5944, Vol. 2

(3) NUREG/CR-5944, Vol. 1

(4) ORNL Letter Report ORNL/NRC/LTR-95/22

(5) Significant: Includes broken and/or detached internals, restricted motion, stuck open and stuck closed cases, and cases where relief valves failed to meet set pressure. Also includes gross internal leakage. Failures were characterized as either "moderate" or "significant" in terms of the valve's ability to perform its intended function(s), not to the resulting effects on a system or plant. This characterization was intended to be an indicator of how seriously degraded a particular valve was not to the effect on system or plant operation.

This data would indicate that a basic significant check valve failure rate for all nuclear plant systems would be 0.0057 failures/year.

If each of the specific types of check valves previously discussed are evaluated to provide their significant failure rate, then these types would be listed as shown in Table E.2.

Table E.2 Check Valve Failure Rate by Type of Check Valve for 1991 and 1992 Failures

\begin{tabular}{lccc}
\multicolumn{1}{c}{$\begin{array}{c}\text { Type of } \\
\text { Check Valve }\end{array}$} & $\begin{array}{c}\text { Significant } \\
\text { Failures }\end{array}$ & $\begin{array}{c}\text { Valve- } \\
\text { Years }\end{array}$ & $\begin{array}{c}\text { Approximate Significant } \\
\text { Failure Rate }\end{array}$ \\
\hline Tilting Disc & 33 & 1,992 & 0.0166 \\
Duo/double Disc & 9 & 457 & 0.0197 \\
Swing & 105 & 11,040 & 0.0095 \\
Lift/piston & 74 & 7,927 & 0.0093 \\
\hline
\end{tabular}

Additional information can be gained by looking at the overall failure distribution by specific valve type and size group. This evaluation shows that about $40 \%$ of the 1991 and 1992 failures evaluated by ORNL are in valves that are $\leq 2$ inches in size. And in this size classification about $72 \%$ of all the 1991 and 1992 check valve failures are in Lift/piston check valves which makes up a major portion of the population (about $45 \%$ ). Some of the fluid systems having above average relative failure rates for valves $\leq 2$ inches in size are:

- Containment Isolation

- Main Steam

- Essential Service Water

- Diesel Starting Air 
- Standby Liquid Control

- $\mathrm{HPCI}$

- Reactor Recirc.

Most of these failures are due to minor leakage through the check valve; however, in the diesel starting air system a significant percentage of the failures are due to stuck closed or stuck open check valves.

The second highest failure percentage by size group is about $26 \%$ for check valves that are $>10$ inches in size for the 1991 and 1992 failures. In this size group, about $40 \%$ of the valve failures are swing check valves and $22 \%$ are tilting disc check valves. The base population of check valves $>10$ inches in size is distributed with $28 \%$ swing and $13 \%$ tilting disc. The following systems have above average relative failure rates for valves $>10$ inches in size:

- Suppression Pool Support

- Feedwater

- Main Steam

- Essential Service Water

The third highest failure percentage for the 1991 and 1992 ORNL evaluated check valve failures is $18 \%$ for check valves that are $>4$ and $\leq 10$ inches in size. And in this size group, about $59 \%$ of all the check valve failures are in swing check valves. The base population of check valves $>4$ and $\leq 10$ inches in size is distributed with $53 \%$ swing and $6 \%$ tilting disc. The following systems having above average relative failure rates:

- Component Cooling Water

- Essential Service Water

The fourth highest failure percentage for 1991 and 1992 failures is $15 \%$ for check valves that are $>2$ and $\leq 4$ inches in size. And in this size group, approximately $53 \%$ of all the check valve failures are in swing check valves. The base population of check valves $>2$ and $\leq 4$ inches in size is distributed with $48 \%$ swing and $5 \%$ tilting disc. The following systems have above average relative failure rates:

- Main Steam

- Residual Heat Removal

- Essential Service Water

- $\mathrm{CCW}$

This above review shows that the Essential Service Water (ESW) system has a higher than average failure rate in check valves for all size categories. This higher check valve failure rate is most probably due to the lower quality of water that is generally present in ESW systems.

It can also be shown that $33 \%$ of the 1991 and 1992 analyzed check valve failures are associated with swing check valves. The next highest percentage is $32 \%$, which is associated with Lift/piston type check valves that are $\leq 2$ inches in size.

The aging rate for check valves has only been estimated over the whole check valve population and across all systems of service. The average relative linear aging rate $\alpha$ (\% increase per year) appears to be fairly small and has varied from about $2 \%$ in 1991 to about $7 \%$ in 1992 and was about $3 \%$ for the period 1984-1990. This aging rate most accurately reflects the sum of all types of check valve failures, and may not be applicable to any particular valve or valve group.

As an example of the variability in failure rates noted by a more rigorous analysis of component behavior based on a specific parameter, the total nuclear industry check valve population has been evaluated by failure rate for all check valve vendors. The major population is defined by data from 22 different vendors. These 22 vendors have been statistically evaluated using their relative failure rates and this evaluation is shown in Figure E.5. 


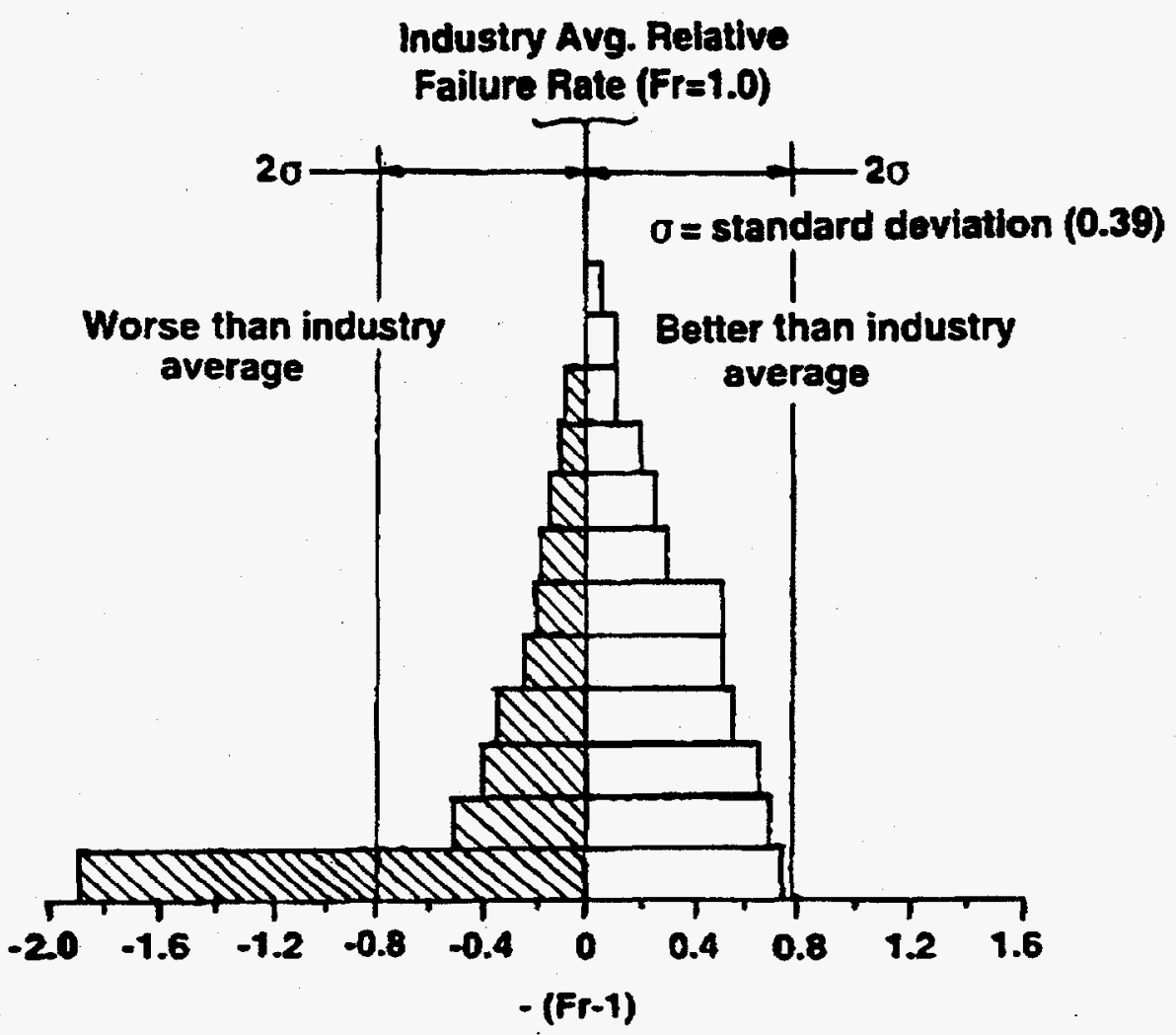

Figure E.5 Failure rate data for check valves from ORNL/NRC/LTR-96/11 (1992 data) for 22 vendors.

The Figure E. 5 data shows that all of the check valve vendors fall within 2 standard deviations $(2 \sigma)$ of the industry average except one vendor. This vendor has had failure rates above 2 standard deviations form the industry average for all of the case studies completed by ORNL and appears to be an industry outlyer. However, the total population of check valves for this vendor listed in NPRDS is only 762 . This population is only about $3.7 \%$ of the total. Therefore, this outlyer will not be included in the calculation of a standard deviation for relative failure rates. It must also be noted that service conditions were not considered in this simplified analysis, a parameter which might make a significant difference in failure rate determination (e.g., the vendor with the highest failure rate may have valves which tend to be used in harsh applications). This example shows the variability of failure rate values depending on the number of parameters considered.[7]

Using significant failure data for 1984-1992, an average significant failure rate can be estimated $(945 / 164,706)=0.0057$. With this as an average value, and $\pm 2 \sigma$ variations you can estimate a significant failure rate range as follows:

Estimated Significant Failure Rate Range (failures/year)

\begin{tabular}{ll}
\hline Maximum & 0.0101 \\
Average & 0.0057 \\
Minimum & 0.0013 \\
\hline
\end{tabular}




\section{E.4 References}

1. Casada, D. A. and M. D. Todd, NUREG/CR-5944, Vol. 1, "A Characterization of Check Valve Degradation and Failure Experience in the Nuclear Power Industry," September 1993.

2. McElhaney, K. L., NUREG/CR-5944, Vol. 2, "A Characterization of Check Valve Degradation and Failure Experience in the Nuclear Power Industry - 1991 Failures," July 1995.

3. McElhaney, K. L., ORNL Letter Report ORNL/NRC/LTR-95/22, "An Evaluation of PWR Safety Injection Accumulator Tank Discharge Check Valve Performance," August 1995.

4. McElhaney, K. L., ORNL Letter Report ORNL/NRC/LTR-96/11, "A Characterization of Check Valve Degradation and Failure Experience in the Nuclear Power Industry - 1992 Failures," June 1996.

5. McElhaney, K. L., ORNL Letter Report ORNL/NRC/LTR-96/29, "A Study of the Most Populous Check Valve Types Installed in Nuclear Power Plants," Draft, September 1996.

6. Application Guidelines for Check Valves in Nuclear Power Plants, Electric Power Research Institute Final Report NP5479 Project 2233-20, EPRI Research Reports Center, January 1988.

7. McElhaney, K. L. and R. H. Staunton, "Reliability Estimation for Check Valves and Other Components," presented at the 1996 ASME Pressure Vessels and Piping Conference, June 21-25, 1996, Montreal, Canada. 
Appendix F. Responses to Questions from Reviews of the Draft Version of the Report 


\section{Appendix F. Responses to Questions from Reviews of the Draft Version of the Report}

This appendix gives responses to questions that were generated from review of the draft version of this report. The questions are compiled from the various individual questions that were generated. Each question is first given in italics followed by the response.

The report does not address the risk implications of the IST intervals and associated component unavailabilities. Doesn't this need to be done for risk-based or risk-informed decision-making?

The unavailability models and unavailability results in the report can be input into Probabilistic Risk Assessments (PRAs) to determine the resulting risk implications. This can be done for various risk-informed decision strategies. The unavailability results which are the focus of the report in themselves provide useful information for riskinformed decision-making. If aging effects cause insignificant increases in the component unavailability then the risk effects will be insignificant. If the current or proposed IST interval is in the optimal region which gives minimal component unavallability then the component performance and resulting risk performance is optimized. Determining the risk implications of IST intervals is a decision alternative when the IST interval results in a significant component unavailability increase and the justification is that the resulting risk increase is still insignificant. Determining the risk implications is also a decision alternative when IST intervals of different components are traded off against each other with some resulting in unavailability increases and others resulting in unavailability decreases. However, even in these cases, evaluating the component unavailabilities resulting from the ISTs provides useful information for the risk-informed decision-making.

In the uncvailability equations there is no contribution to unavailability from downtime from repair performed as a result of an operational test revealing a failure. Therefore, the repair time must be assumed to be zero.

What is assumed in the report is that the repair time is small compared to the test interval, which is the usual case. If the repair time is small compared to the test interval then the unavailability contribution from repair is small and can be neglected compared to the unavailability contribution between tests. This is a simplification also often made in PRA quantifications. The relative error made in neglecting the repair time contribution is approximately equal to $\mathrm{r} /(\mathrm{T} / 2)$ where $\mathrm{r}$ is the average repair time duration and $\mathrm{T}$ is the test interval. For a repair time of 24 hours and monthly testing, the relative error made is thus less than $10 \%$. This error is small compared to data uncertainties, for example.

The small size of the relative error in neglecting the repair contribution can be seen from the following standard formulas. Let

$P_{F}=$ the probability of component failure between operational tests

$\mathrm{Q}_{\mathrm{T}}=$ the unavailability contribution between tests

$Q_{R}=$ the unavailability contribution from repair

Then

$$
\mathrm{Q}_{\mathrm{T}}=\frac{\mathrm{P}_{\mathrm{F}} \frac{1}{2} \mathrm{~T}}{\mathrm{~T}+\mathrm{r}}
$$




$$
\mathrm{Q}_{\mathrm{R}}=\frac{\mathrm{P}_{\mathrm{F}} \mathbf{r}}{\mathrm{T}+\mathrm{r}}
$$

and the relative contribution of the repair unavailability to the between test unavailability is

$$
\frac{\mathrm{Q}_{\mathrm{R}}}{\mathrm{Q}_{\mathrm{T}}}=\frac{\mathrm{r}}{\mathrm{T} / 2} .
$$

The above results are the first order results for a constant failure rate. For an aging failure, the average undetected downtime given failure (T/2) will slightly change but the relative error will be of the same order.

For each renewal test the downtime is assumed to be the same. The downtime in actuality varies.

The equations in the report give the average unavailability and hence the downtime value in the report is the average value. Thus, the equations also apply where the downtime is variable as long as the average downtime value is used. This is the same approach as used in PRA modeling where the average downtime is used.

For more detailed plant specific applications, the likelihood of the need for the corrective maintenance could be factored into the unavailability equations and could be a function of the aging rate.

If the IST is performed at an interval of $L$ and only a fraction of time $p$ a renewal corrective maintenance is performed then the results in the report are applicable using a renewal IST interval of $L / p$ and an operational test interval of $L$. This is a standard result for the time of occurrence of an event with trials performed at intervals of $L$ with each trial having a probability of success of $p$. If the renewal probability $p$ can be obtained as a function of age from data, then it can be used in the equation with an average being used or with different values being used for different age periods or to check sensitivities. These more detailed models were not used in the main body of the report since the objective was to present a general methodology and to investigate general effects due for aging. If more detailed data exists for plant specific applications, then more detailed models can provide useful additional information and resolution.

Corrective maintenances which are performed after an IST has detected deteriorating conditions, may be performed during shutdown. How is this situation handled?

When the corrective maintenances are performed during shutdown, then the IST associated downtime $d$ should only include the test time, if it is nonnegligible, since the downtime $d$ is the online downtime.

How are those situations handled where renewal of the component is only carried out when a failure occurs?

If the mean time to failure of the component is much larger than the operational test interval or IST interval than whether there is renewal or nonrenewal after a failure will have a small effect on the average unavailability. When the mean time to failure is not necessarily large and renewal is performed after a failure, then the nonrenewal equation in the report is applicable with the component lifetime $S$ set equal to the mean time to failure which is then the only renewal time.

\section{How is the situation handled where preventative maintenance is also performed and replacements are made in the preventative maintenances?}

If preventative maintenance is performed and replacements are carried out then the component lifetime $S$ in the equations is set equal to the average replacement interval. If only a fraction of the parts are replaced then the fraction replaced and fraction not replaced are treated as separate contributions as they are in the partial renewal 
equation. The aging rate can also be lowered to reflect preventative maintenances which lubricate or clean component pieceparts thereby limiting the aging rate. Sensitivity studies can be performed to determine if any of these effects are significant.

It is not clear that the models which are presented are applicable to all the different IST scenarios which can occur in plants.

The models are not intended to cover all the possible situations which can occur in a plant. The objective of the work is to present models which cover the different major cases and which can be adapted to cover variations of the cases.

Can the formulas be used when the ISTs are only operational tests and replacements are carried out in a different program, such as in a preventative maintenance program?

As indicated in the report, if the IST conducted by a plant is only an operational test then it should be treated with the nonrenewal formula. This will give no credit for any additional corrective or preventative maintenances which are performed to replace aged pieceparts. The nonrenewal formula in the report has a component lifetime parameter $\mathrm{S}$ which is the average interval at which the component is replaced or rebuilt. This parameter can be set equal to the mean time to failure of the component at which the component fails the test and is rebuilt or replaced. This will then account for renewal at failure. This parameter was set equal to 40 years in the studies representing the plant lifetime and the time period for the unavailability averaging.

If preventative maintenances which renew the component are performed at intervals of S and operational ISTs are performed at intervals of $L$ then the nonrenewal formula in the report is applicable with the component lifetime parameter $S$ set equal to the preventative maintenance interval. The component lifetime parameter $S$ is the average interval at which the component is renewed or rebuilt if this is less than the plant lifetime, otherwise it is the plant lifetime. Note, this is the same as treating the preventative maintenance as a "renewal IST" and the IST as an "operational test." The formulas in the report can be adapted to different situations.

The failure rates for check valves are not homogeneous. The report seems to assume this.

The report does not assume that check valves are homogeneous. The focus of the work is the evaluation of the relative effects of aging on the component unavailability compared to the assumption of no aging. The initial, baseline check valve failure rates which are used are reference values and are not assumed to apply to the whole check valve population. Different check valve failure rates are used to illustrate that the same relative behaviors of unavailability versus aging are obtained regardless of the initial failure rate. Different aging rates are used to evaluate the performance of a given IST interval to a range of aging rates and to draw conclusions that are not dependent on the assumption of a given failure rate or aging rate.

With the possible exception of service water systems, aging has not been discernible in cvailable failure data.

The problem with available data is that it is not able to differentiate whether aging is occurring or is not occurring. This is due to the sparseness and pooling of the data. In statistical terms, available data cannot reject the hypothesis of no aging nor can it reject the hypothesis that aging is occurring. Both hypotheses are not inconsistent with available data. The assumption of no aging, however, can lead to underestimation of the unavailability impacts and risk impacts due to extending IST intervals. This can lead to nonsafe decisions. A principle objective of the work was to evaluate the impacts from potential aging effects and to identify ISTs and IST intervals that were robust to aging effects.

The modeling of partial renewal may not be practical. The estimation of component failure rates by system, based on complete failure of the component over an adequate observation period of time, can be more useful than attempting to incorporate varying percentages of component renewal into IST calculations.

Partial renewal, involving varying percentages of component renewal, was investigated in the work to determine if 
the results are significantly different from the complete renewal case or the no renewal case. The conclusion in the report is that it is not worthwhile to attempt to treat partial renewal since the differences are not significant. The estimation of check valve failure rates by system over an adequate period of time is useful, however any aging effects tend to be averaged out. The effect of component aging still needs to be considered in evaluating the performance and robustness of given IST intervals. This was an objective of the work.

The report's inclusion of varying IST downtimes implies that the downtime varies and may be a significant factor.

The IST downtimes were varied in the report as part of the overall objective to investigate the sensitivity of different parameters. Even though IST downtimes do not presently vary, when they are nonzero, some plants may consider carrying out more effective ISTs requiring extended downtimes. The sensitivity evaluations covered these possibilities.

A review of the NPRDS database produced an estimate of the probability of check valve failure to be $8 E-4$ per demand for the RCIC and HPCI systems which appears to be about a decade lower than the report's assumptions. Also, additional reviews of check valve histories for RCIC and HPCI system indicated no failures in at least 1700 demands. If the higher unavailabilities indicated in the report were true, then several failures would have been expected.

The check valve unavailabilities in the report are consistent with the estimates that are cited. There is a wide range of unavailabilities calculated in the report for different cases and different possible changes in the IST interval. For the NPRDS and additional data cited, the applicable results need to be selected in the report based on the type of IST performed and the current IST interval. Most ISTs conducted at the present time are nonrenewal ISTs having negligible downtimes. Thus, the Figures 10.19 and 10.22 on pages 46 and 49 are most applicable. For monthly IST intervals, the figure on page 46 gives an unavailability of approximately $1 \times 10^{-3}$ for aging rates of $10 \%$ per year or less. The figure on page 49 , for a lower check valve failure rate, gives an unavailability of less than $1 \times 10^{-3}$ for aging rates up to $50 \%$ per year and monthly testing. These values are consistent with cited data. For quarterly IST intervals, the unavailabilities are proportionately higher but still are not inconsistent with the cited data. Also, because the cited data are pooled data, individual check valves could have even higher unavailabilities and higher aging rates. As stated in the report, the failure rates used are typical of those evaluated in nuclear plant PRAs. 


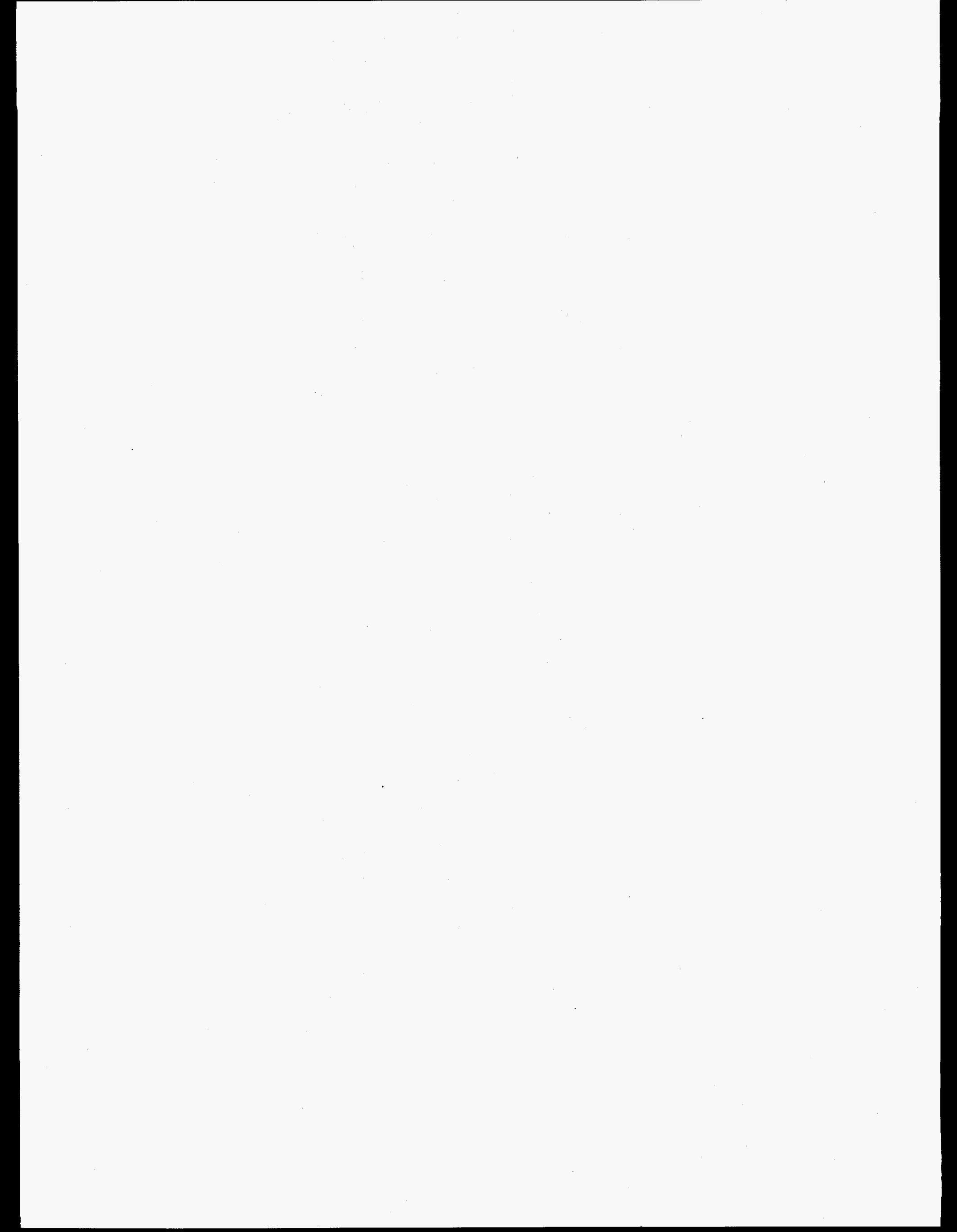




\begin{tabular}{|c|c|}
\hline $\begin{array}{l}\text { NRC FORM } 336 \\
\begin{array}{l}\text { (2-89) } \\
\text { NRCM } 1102, \\
3201,3202\end{array} \\
\text { BIBLIOGRACLEAR REGULATORY COMMISSION } \\
\text { (See instructions on the reverse) }\end{array}$ & $\begin{array}{l}\text { 1. REPORT NUMBER } \\
\text { (Aesigned by NRC, Add Vol., supp., Rev., } \\
\text { and Addendum Numbers, if any.) } \\
\text { NUREG/CR-6508 } \\
\text { ORNL-6909 }\end{array}$ \\
\hline \multirow[t]{3}{*}{$\begin{array}{l}\text { Component Unavailability Versus Inservice Test (IST) Interval: } \\
\text { Evaluations of Component Aging Effects With Applications to Check Valves }\end{array}$} & DATE REPORT PUBLUSHED \\
\hline & \begin{tabular}{|r|r|} 
MONTH & YEAR \\
July & 1997 \\
\end{tabular} \\
\hline & $\begin{array}{l}\text { 4. FIN OR GRANT NUMBER } \\
\text { W6324 }\end{array}$ \\
\hline \multirow[t]{2}{*}{ W. E. Vesely*, A. B. Poole } & $\begin{array}{l}\text { 6. TYPE OF REPORT } \\
\text { Technical }\end{array}$ \\
\hline & 7. PERIOD COVERED (nclusive Dates) \\
\hline \multicolumn{2}{|c|}{ 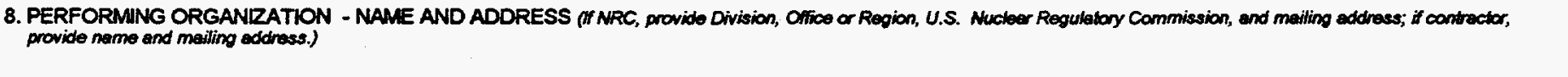 } \\
\hline $\begin{array}{l}\text { •Consultant } \\
655 \text { Metro Place South, Suite } 745 \\
\text { Dublin, OH } 43017\end{array}$ & \\
\hline
\end{tabular}

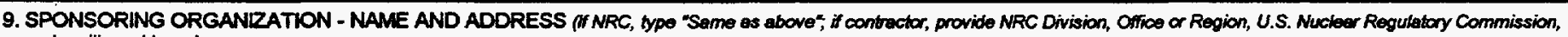
and moiling address.)

Division of Engineering Technology

Office of Nuclear Regulatory Research

U.S. Nuclear Regulatory Commission

Washington, DC 20555-0001

10. SUPPLEMENTARY NOTES

J. Jackson, NRC Project Manager

11. ABSTRACT (200 words or lass)

Methods are presented for calculating component unavailabilities when Inservice Test (IST) intervais are changed and when component aging is explicitly included. The methods extend usual approaches for calculating unavailability and risk effects of changing IST intervals which utilize Probabilistic Risk Assessment (PRA) methods that do not explicitly include component aging. Different IST characteristics are handled including ISTs which are not followed by corrective maintenances which completely renew or partially renew the component. ISTs which are not followed by maintenance activities needed to renew the component are also handled. Any downtime associated with the IST, including the test downtime and the following maintenance downtime, is included in the unavailability evaluations. A range of component aging behaviors is studied including both linear and nonlinear aging behaviors. Based upon evaluations completed to date, pooled failure data on check valves show relatively small aging (e.g., less than $7 \%$ per year). However, data from some plant systems could be evidence for larger aging rates occurring in time periods less than 5 years. The methods are utilized in this report to carry out a range of sensitivity evaluations to evaluate aging effects for different possible applications. Based on the sensitivity evaluations, summary tables are constructed showing how optimal IST interval ranges for check valves can vary relative to different aging behaviors which might exist. The evaluations are also used to identify IST intervals for check valves which are robust to component aging effects. General insights on aging effects are also extracted. These sensitivity studies and extracted results provide useful information which can be supplemented or be updated with plant specific information. The models and results can also be input to PRAs to determine associated risk implications.

12. KEY WORDSIDESCRIPTORS (List words or phreses thet witl essist researchens in loceting the report)

\begin{tabular}{|c|}
\hline $\begin{array}{l}\text { 13. AVAILABIUTY STATEMENT } \\
\text { unlimited }\end{array}$ \\
\hline 14. SECURTY CLASSIFICATION \\
\hline $\begin{array}{l}\text { (This Pege) } \\
\text { unclassified }\end{array}$ \\
\hline $\begin{array}{l}\text { (This Reporf) } \\
\text { unclassified }\end{array}$ \\
\hline 15. NUMBER OF PAGES \\
\hline 16. PRICE \\
\hline
\end{tabular}





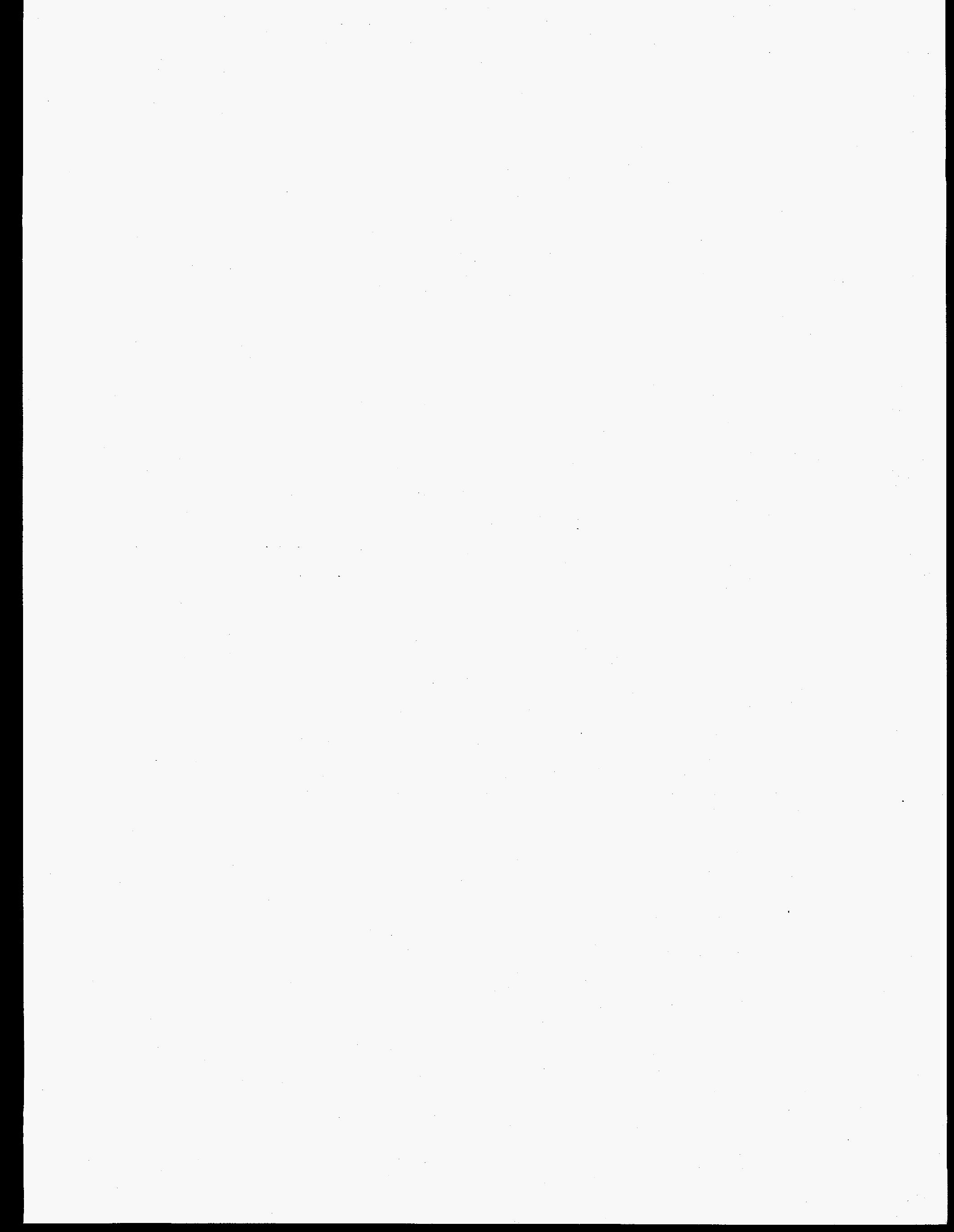




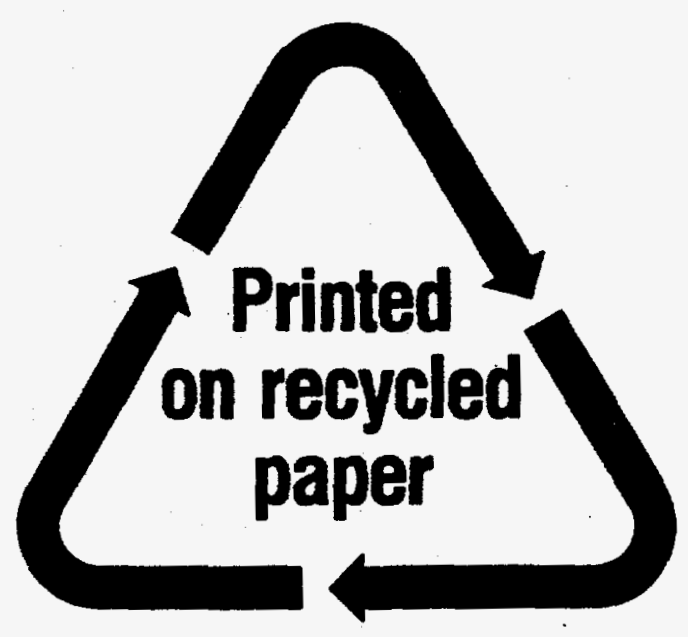

Federal Recycling Program 